$103=182 y$

Community-Baseds?

Urban Violence Prevention ? Innovative Approaches in Africa,
Latin America, Asia and the Arab Region

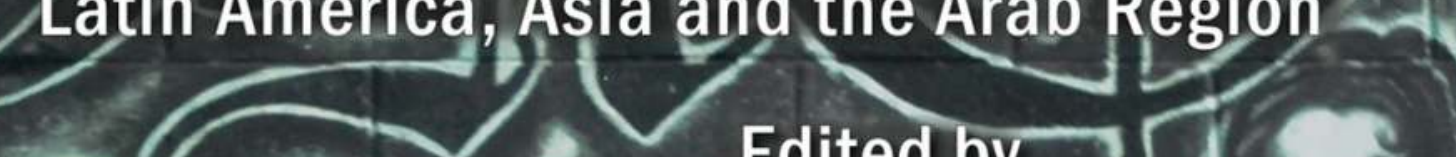

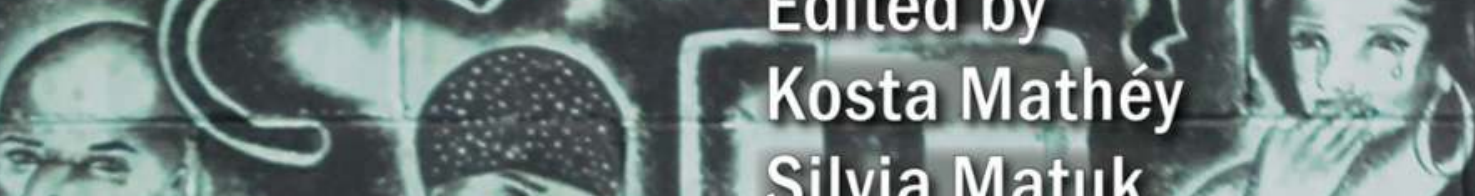

$\rightarrow 20$ Silvia Matuk
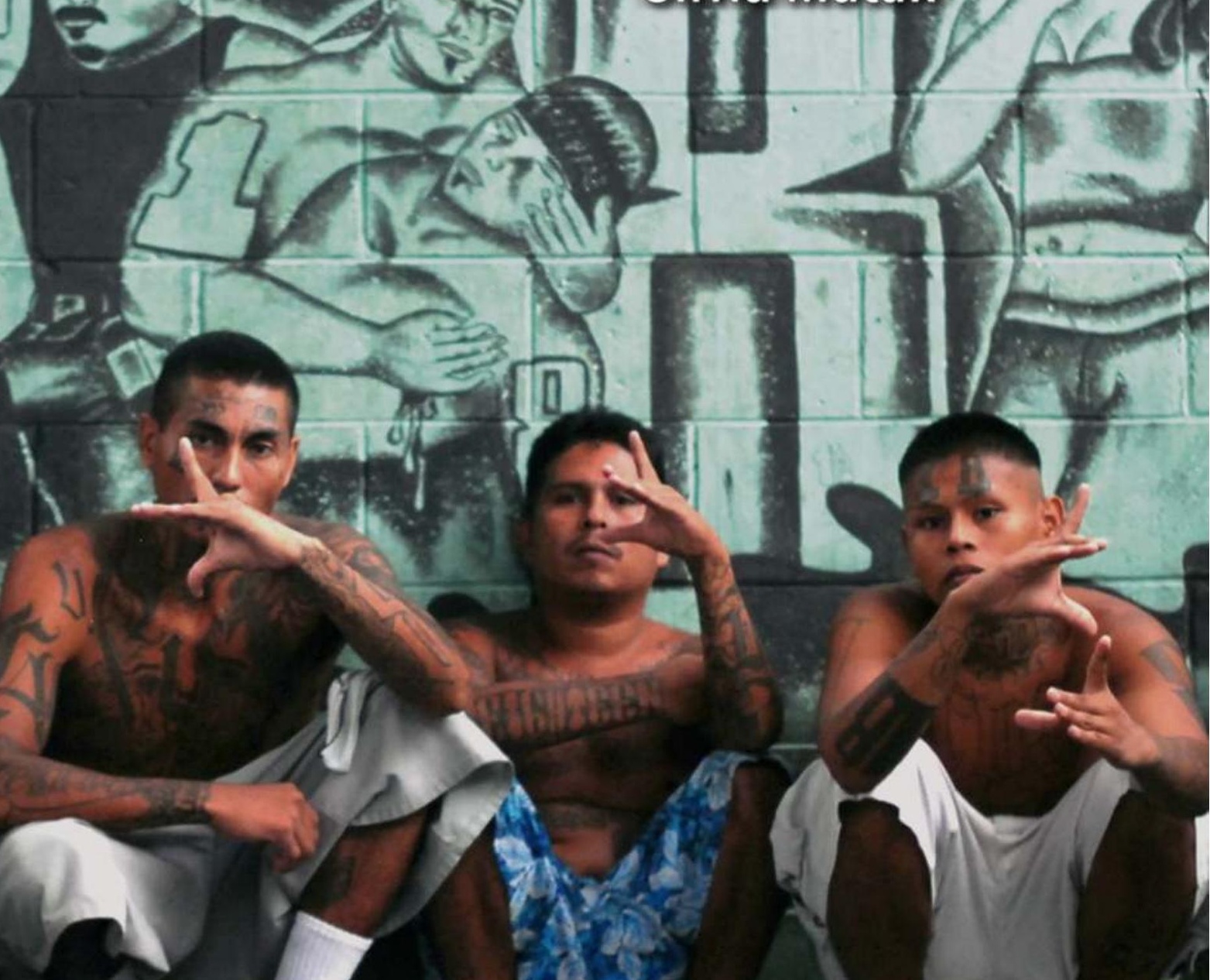

D

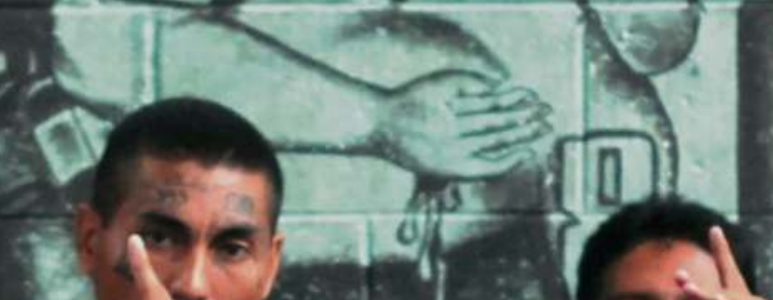

[transcripg urbapstivies 
Community-Based Violence Prevention

U r b a $\mathbf{s}$ t udi e s 
This volume was prepared by the Global Urban Studies Institute (GLOBUS) at the International Academy Berlin (INA) 


\section{Community-Based Urban Violence Prevention}

Innovative Approaches in Africa, Latin America, Asia and the Arab Region

Edited by Kosta Mathéy and Silvia Matuk

[transcript] 
This publication was co-funded by

Volkswagen Foundation

An electronic version of this book is freely available, thanks to the support of libraries working with Knowledge Unlatched. KU is a collaborative initiative designed to make high quality books Open Access for the public good. The Open Access ISBN for this book is 978-3-8394-2990-7. More information about the initiative and links to the Open Access version can be found at www.knowledgeunlatched.org.

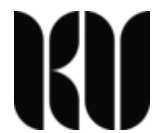

Bibliographic information published by the Deutsche Nationalbibliothek

The Deutsche Nationalbibliothek lists this publication in the Deutsche Nationalbibliografie; detailed bibliographic data are available in the Internet at http://dnb.d-nb.de

\section{(c) $)(1) \Theta(\Theta$}

This work is licensed under the Creative Commons Attribution-NonCommercial-NoDerivatives 4. 0 (BY-NC-ND) which means that the text may be used for non-commercial purposes, provided credit is given to the author. For details go to http://creativecommons.org/licenses/by-nc-nd/4.O/ To create an adaptation, translation, or derivative of the original work and for commercial use, further permission is required and can be obtained by contacting rights@transcript-verlag.de Creative Commons license terms for re-use do not apply to any content (such as graphs, figures, photos, excerpts, etc.) not original to the Open Access publication and further permission may be required from the rights holder. The obligation to research and clear permission lies solely with the party re-using the material.

\section{Bibliographic information published by the Deutsche Nationalbibliothek}

The Deutsche Nationalbibliothek lists this publication in the Deutsche Nationalbibliografie; detailed bibliographic data are available in the Internet at http://dnb.d-nb.de

\section{(C) 2015 transcript Verlag, Bielefeld}

All rights reserved. No part of this book may be reprinted or reproduced or utilized in any form or by any electronic, mechanical, or other means, now known or hereafter invented, including photocopying and recording, or in any information storage or retrieval system, without permission in writing from the publisher.

Cover Illustration: Mara Gang members at a prison in Quezaltepeque on the outskirts of San Salvador, 2012. The relentless tit-for-tat murders between El Salvador's two largest street gangs - Calle 18 and Mara Salvatrucha - made the country the most murderous in the world after neighboring Honduras. Photo: CORDIS/REUTERS/Ulises Rodriguez

Copy editing: Nicholas Kasang and Kosta Mathéy

Typesetting: Cibele Kojima de Paula

Druck: Klicks GmbH, 98693 Ilmenau

Print-ISBN 978-3-8376-2990-3

PDF-ISBN 978-3-8394-2990-7

Visit us on the internet: http://www.transcript-verlag.de

We will be pleased to send you our complete catalogue; please place your order under: info@transcript-verlag.de 


\section{Contents}

\section{Preface}

Caroline Moser | 02

\section{Setting the Context}

01. Introduction

Kosta Mathéy \& Silvia Matuk | 06

02. Conceptual Underpinning of Violence Prevention

Nicholas Kasang | 24

\section{Lessons Learnt from Africa}

03. Ethnopolitics, Fear and Safety in A Johannesburg Neighbourhood Obvious Katsaura | 42

04. Land Transformation and Criminal Violence in Dandora, Nairobi Romanus O. Opiyo | 62

05. Communities and the Prevention of Crime and Violence in Douala, Cameroon Christophe Sados Touonsi | 78

06. "There is no Justice in Guinea-Bissau" Practices in Local Dispute Settlement Anne-Kristin Borszik | 98

\section{A Lesson from China}

07. Shanghai Gone. Domicide and Defiance in A Chinese Megacity Qin Shao | 118

\section{Lessons Learnt from Latin America}

08. Local Civil Society and the Central American Puzzle of Violence Heidrun Zinecker | 128

09. Meanings and Practices of Non-Violence Luz Amparo Sánchez Medina | 150

10. Integrated Settlement Upgrading Approach to Violence Prevention in San Salvador

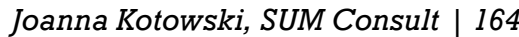

11. State and Community Responses to Drug-Related Violence in Mexico Veronica Martinez-Solares | 182 


\section{Youth and Gang Violence}

12. Youth As Key Actors in the Social Prevention of Violence

"The Experience of PROJóvenEs II in El Salvador"

María Antonieta Beltrán \& Wim Savenije | 202

13. Overcoming Invisible Frontiers in the Barrio: a Youth Initiative in Itagui Leiman Julieth Sánchez Betancur \& Carlos Andrés Restrepo Arango | 222

14. Targeting Adolescence Vandalism in A Refugee Camp in Jordan Fatima M. Al-Nammari | 234

\section{Alternative Approaches to Combat Urban Violence}

15. Religious Processions as a Means of Social Conciliation Reza Masoudi Nejad | 268

16. Violence and the Enchantment of Everyday Life in Johannesburg: Obvious Katsaura | 280

17. Building Safe Communities of Opportunities Barbara Holtmann and Emma Holtmann | 294

The Contributors | 307 


\title{
PREFACE
}

\author{
Caroline Moser
}

01.

Moser and McIlwaine 2006

02.

Sanín and Jaramillo 2004

03.

Beall at all 2013

Previous page: Several women and a girl march in protest in

Bolivar Square, demanding answers and accountability from the government concerning the thousands who were forcibly disappeared during the civil conflict here.

They are holding posters showing images of some of the disappeared. A man is also walking in front of them and

feeding a pigeon. The building in the background is the Colombian Parliament. Source: iStock/ jcarillet
The first decade of the 21st century has witnessed a dramatic increase in levels of ubiquitous violence and crime in cities across the world, 'banalized' or 'routinized' in the daily lives of urban populations ${ }^{1}$. In some contexts the politicization of crime has increased linkages between political and criminal violence ${ }^{2}$, while on others there has been a blurring of boundaries between violence and conflict, with the urbanization of warfare associated with increased attacks on civilian populations ${ }^{3}$. The close linkages between violence, inequality and exclusion, with the unequal distribution of resources intersecting with poverty, means that there are important impacts not only associated with macroeconomic development, but also in terms of the erosion of the capital assets of lowincome populations often related to growing fear and insecurity ${ }^{4}$. Both these factors mean that violence and insecurity are now a critical concern for researchers and policy makers.

In 2002, at a time when this was less recognized as a critical development constraint in cities in the Global South and often still identified as a problem of individual criminal pathology, I was commissioned by the German Bank for Reconstruction and Development (KfW) to undertake a desk appraisal of their upcoming supported project on 'Violence Prevention through Urban Upgrading' to be implemented in Khayelitsha, Cape Town ${ }^{5}$. With violence-related policy predominantly single sectorfocused $^{6}$, the project presented exciting, innovative solutions relating to a 'triangle' of violence reduction components as well as introducing a spatial approach. These linked urban renewal strategies in the public sphere for better environmental arrangements to reduce opportunities for violence, criminal justice measures to discourage potential violators and public health and conflict resolution interventions to support to victims of violence in the private space. 
In the appraisal I drew on results from participatory research in urban Colombia and Guatemala, that acknowledged the 'voices' of the poor as much as the 'wisdom' of professionals, to highlight the fact that local communities identified solutions connected with building trust and cohesion of social capital as far more important than those associated with health and education-related human capital or infrastructure-linked physical capital $^{7}$. These included the promotion of family values, and dialogue between community members as well as the formation of local organizations. In communities with limited trust in the state's ability to solve the problem-because of the absence or ineffectiveness of police, army or judicial system-local self-help solutions were favoured to deal with rapists, criminal and drug addicts.

Twelve years later, it is gratifying to acknowledge not only that the Khayelitsha project has 'been executed and become known as one of the most successful anti-violence projects in the continent', but also that it has given added importance to local community-based solutions to violence. The Khayelitsha experience then is the inspiration behind this edited collection of case studies that brings together in one volume the documentation of examples of 'good practice' community violence-related strategies from cities across three continents. Yet the focus on community solutions is not surprising considering the backgrounds of its editors; Kosta Mathéy's experience in housing and urban upgrading, along with Silvia Matuk's involvement on community construction projects, means that they translated this knowledge of 'self-help' local bottom-up solutions from housing to violence, when they turned their attention to the pressing issue of urban insecurity.

For them, as for many researchers and practitioners across the globe, community governance is key, even if not the panacea, to fundamentally addressing the multi-dimensional, endemic, context specific and interrelated complexities of urban violence and crime both 'in the street and in the home'8. This book, therefore, represents a milestone in the 'systematization of local experiences' so often invisibilized or ignored by topdown state or international agency responses. Just as the findings from Colombia and Guatemala showed that local communities did not automatically seek to resolve problems associated with violence, with avoidance rather than confrontation common strategy- remaining silent, circumventing dangerous areas, changing mobility patterns and 'don't do out at night'- so too this collection provides examples of avoidance along with prevention and reduction strategies. While individual case studies can so easily be dismissed as non-representative 'apt illustration', at the same time, the fact that there are no blue print solutions to the global challenge of urban violence, gives importance to this growing body of evidence that recognizes the plurality of actors and the specificity of local contexts. Factors such as the almost universal distrust in state's capacity to control or prevent crime, structural problems with policing and judiciary systems and the rapid expansion in non-state forms of social governance, as well as all gives added weight to the significance of the diversity of local community solutions illustration in this collection.

08.

This phrase, in Spanish 'La calle y la casa' comes from Rodríguez and Segovia. 2012 


\section{References}

Beall, Jo, Tom Goodfellow and Dennis Rodgers (2013), 'Cities and Conflict in Fragile States in the Developing World', Urban Studies, 50: page 3070

Moser, C. (2002). 'Violence Prevention through Urban Upgrading: Feasibility Study for the Support of the Khayelitsha Urbanization Renewal Programme' Desk-top study commissioned by KfW

Moser, C. 0., \& McIlwaine, C. (2006). Latin American urban violence as a development concern: towards a framework for violence reduction. World development, 34(1), 89-112.

Moser, Caroline (2004), "Urban violence and insecurity: An introductory roadmap", Urbanization and Environment, Vol 16. No 2 Oct, pages 3-16
Moser, Caroline and Cathy McIlwaine (2004) Encounters with Violence in Latin America: Urban poor perceptions from Colombia and Guatemala, London and New York, Routledge

Moser, Caroline and Cathy McIlwaine (2006) 'Latin American Urban Violence as a Development Concern: Towards a Framework for Violence Reduction', World Development, Vol. 34, No 1, pp 89-112

Rodríguez, A., M. Saborido, and O. Segovia. (2012). Understanding the Tipping Point of Urban Conflict: The Case of Santiago, Chile, Urban Tipping Point project working Paper no. 3, Manchester: University of Manchester, 85 pages.

Sanín, F. G., \& Jaramillo, A. M. (2004). Crime,(counter-) insurgency and the Privatization of Security-the Case of Medellín, Colombia. Environment and Urbanization, 16(2), 17-30. 
ailligh

ing

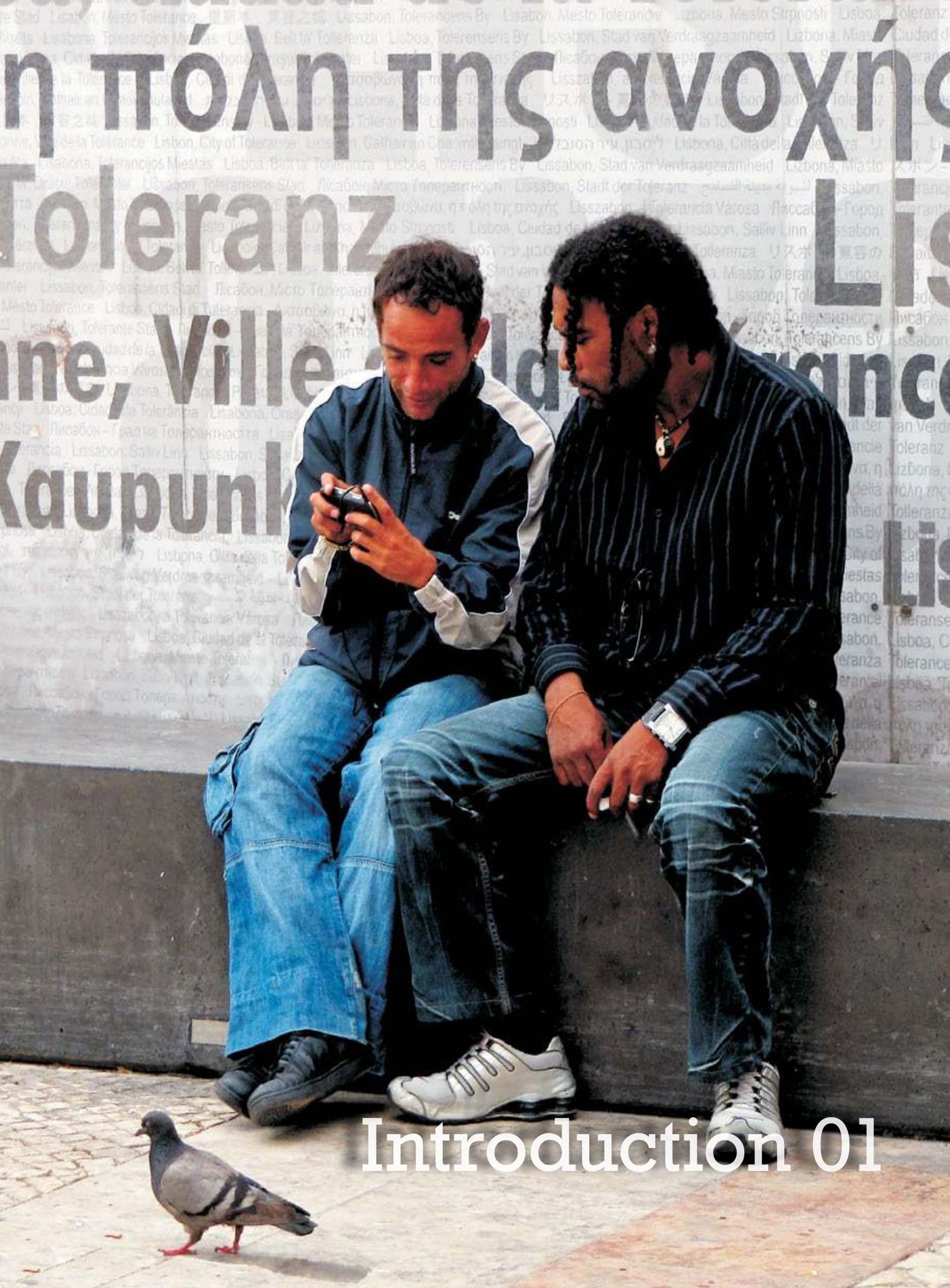




\section{Introduction}

Kosta Mathéy \& Silvia Matuk

I.

In ancient times, cities were built to provide safety to citizens against personal robberies, warlords, and wild animals. Today, with the majority of world's population living in an urban environment, the city does not provide that protection any more. Even if the city walls had not disappeared a long time ago, these walls would not provide more security, since crime and violence develop where the potential victims are to be found and in most big cities in the world their inhabitants live in constant fear of violence. We, as editors, have developed our interest, and concern in the topic primarily in working contexts in the countries of the Global South.

Previous page: In the writings of this wall, limiting a comfortable square right at the beginning of the main shopping street, the city of Lisbon identifies itself as The City of Tolerance, engraved in a large wall in several languages. Most of the time, the migrant community gathers here, experiences it as a Safe Place against xenophobic aggression. Photo: Kosta Mathéy

Silvia Matuk, while working in construction projects, with community, in highlands in Peru experienced the terror of the Sendero Luminoso and, like much of the dispersed population, had to withdraw to the capital only to see, how year after year, the threat of violence, was becoming an urban feature. In the 1990s, after the treaty to settle the civil war in El Salvador, she worked in housing construction for ex-guerilla members and displaced persons. Her conclusions from these experiences confirm the importance of housing for stabilization of peace processes, considered not only a basic need of the population but also an important element in the reconstruction of the social tissue, community cohesion and identification with a territory (Hays and Matuk, 1995:25-26).

Kosta Mathéy, with reference to his experience in urban upgrading for the poor in several countries in Asia, Africa, and Latin America had been invited to develop solutions to urban insecurity while being in charge of designing the German cooperation project "Violence Prevention through Urban Upgrading" (VPUU) in the township of Khayelitsha in South Africa. 
This township, faced with an average of one murder per day, was considered to be one of the most violent places in the whole of Africa (Mathéy, 2006). Now, ten years later, this project has been executed and became known to be one of the most successful anti-violence programs on the continent.

In all those places visited it is the poor population who suffers most from the threat of violence and wherever we met a new community to work with, the proximity of a police station was among the top "needs" listed by the residents. This was somehow paradoxical, as only a short time later they would express that the police were least likely to help them in case they got attacked (and in certain cases, the police themselves were actually the biggest threat of all) ${ }^{1}$.

The wealthy sections of the population, usually seek to protect themselves individually by turning their villas into sorts of castles with high walls and electric and barbed wire around them, hiring armed private guards, or moving into a gated community. This may be, to a certain extent, efficient in defending public violence, but not necessarily the more subtle domestic violence between family members, or more evident, violence against the employees.

The mentioned scenario includes, as one among several protective elements, the institutional security providers: the state and the private sector - which, quite frequently, cooperate by passing on information, funds, and even staff between each other. The private sector in particular, is rather a palliative approach to security provision and certainly not interested in effective prevention of violence, as this would remove the justification for their business to exist - a systemic problematic.

In cases where the state is not providing a service to the (poor section of the) population and where the private sector can not realize it's expected gains because of the economic situation of the client, the population generally resorts to self-help practices. This kind of solution is well known in other urban sectors like the provision of infrastructure or even in education and health, but also in the field of security - like for example in the form of community watches or, in the worst case, in vigilantism and mob justice.

In our rapidly globalizing world, cities are growing bigger and bigger which makes them more difficult to manage, while the governments, at local as well as central level, are losing resources. This makes the state more receptive to considering joining forces even with the poor sectors of population and assigning duties and rights that formerly were the exclusive responsibility of the state, down to the community. This kind of cooperation is commonly known as participatory governance. Concrete examples include, among other activities, neighbours going on joint patrols with a police officer or the police taking part in educational prevention exercises with youth. Recent publications and events also seem to confirm a tendency worldwide to seek closer contact between civil society and the state in an effort to reduce urban violence.

01.

At the time of writing these lines, newspapers reported of an average of 3 persons killed daily by the police in Brazil (Das Erbe der Diktatur. Exzessive Polizeigewalt prägt den brasilianischen Alltag, 9. 8. 2014.) 


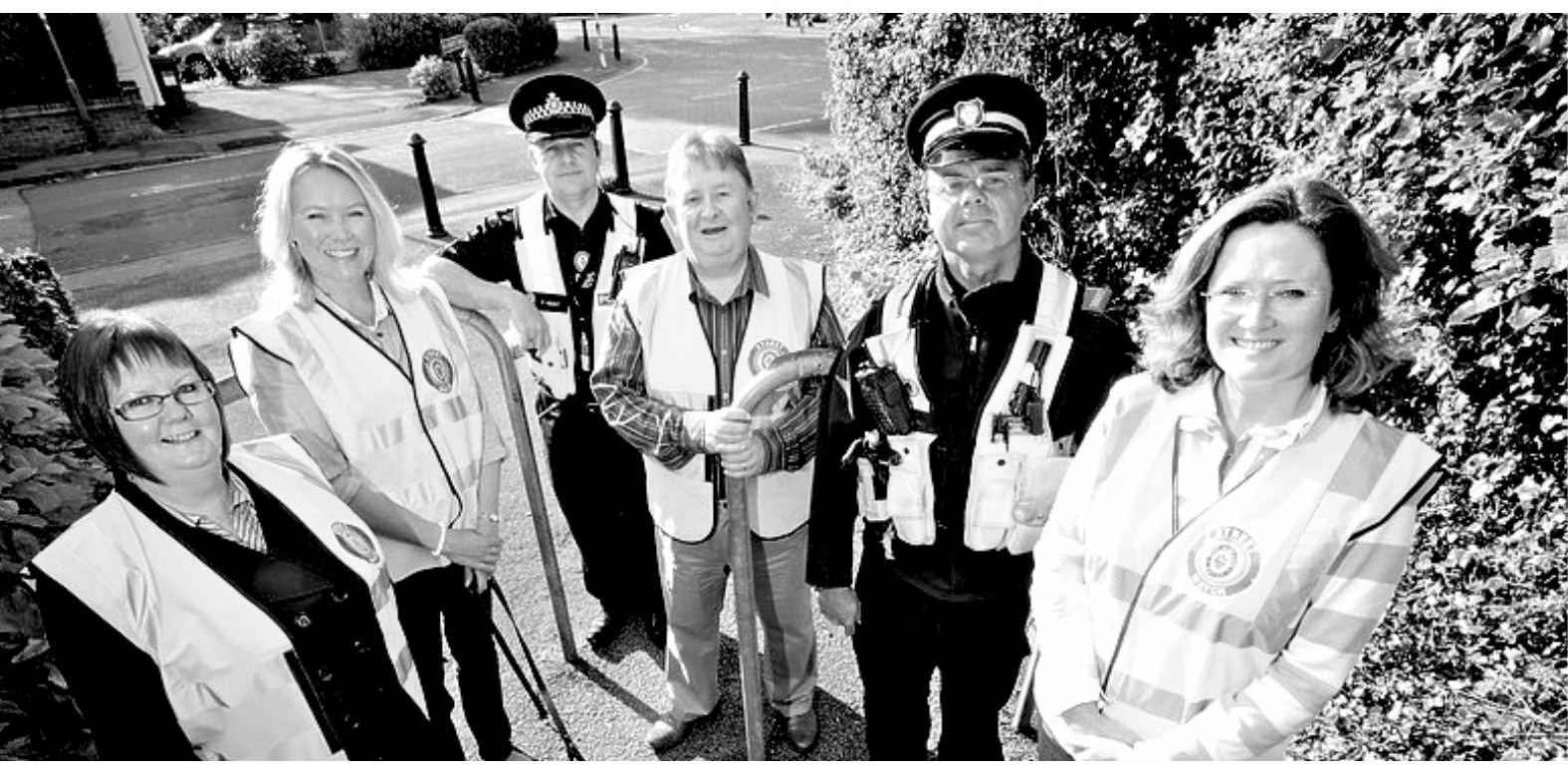

II.

02.

International symposium Community-Based Urban Violence Prevention 5 th to 7 th of June 2014 at the Senatsverwaltung Berlin, organized by GLOBUS in cooperation with the U-CARE research network, International Academy Berlin, TRI-

ALOG Association, Senate of Berlin and TRINET Global (urbanviolence. org, http://www. ina-fu.org/u-care)

03.

Urban Violence in Sub-Saharan Africa: Its Impacts, Coping Strategies, and Peace Building. University of Technology Darmstadt, project director Prof. Dr. Kosta Mathéy

04

University of Witwatersrand, Department of Urban Planning (Prof. Dr. Alan Mabin)
Those experiences, where the local community with or without state assistance, is joining to improve safety in their neighbourhood through violence prevention initiatives, represent a joint interest between the essays contained in this anthology. Many of the authors represented met for the first time 2014 at an international conference on CommunityBased Urban Violence Prevention in Berlin, ${ }^{2}$ where they discovered and discussed their common knowledge and interests in the field.

One major observation at this meeting was the large variety of community led responses, presented in the different countries and communities, which, first of all, responded to a variety of different manifestations of violence, but simultaneously depended on the social formation that regulates the division of power between state, market, and citizens in each case. Other important variables to explain the differences include the cultural background and external factors, like the world market for drugs.

A first approach, and closest to the Khayelitsha experience mentioned above, was sought in the U-CARE research project ${ }^{3}$ which responded to a call by the Volkswagen Foundation and referred to the Sub Sahara Africa region. The results of this cooperative project with three African Universities in Johannesburg, ${ }^{4}$ Nairobi $^{5}$ and Douala ${ }^{6}$ are exposed in the first three case studies in this volume. One of the very first insights obtained in this comparative work was the need to agree on very precise definitions of various forms of violence encountered. It is not an exaggeration to claim that more than $80 \%$ of the public, and also academic, discourse does not differentiate between crime and violence, and even less bother to disclose whether their argumentations refer to ordinary robbery, trafficking related violence, school violence, gang rape, domestic violence, racist or fanatic religious attacks, paramilitary interventions, state violence, or any other violent manifestation, which all have different roots and cannot be cured by one single remedy. 


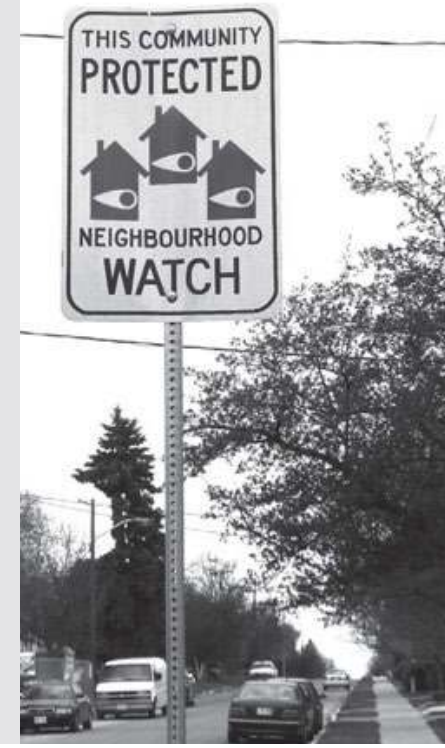

Left:

Street Watch volunteers working with police

in Olton, Solihull, West Midlands UK.

Source: Wikipedia File 7999127128.

Right:

Neighbourhood watch in Toronto.

Source: Wikimedia/ Patentattorney88

Keeping this observation in mind, Nicholas Kasang - member of the U-CARE team, begins his theoretical reflections with a useful systematization of urban violence. After that he refers to different schools of thought about the origins of violence and adequate strategies to increase urban safety. A large section of such theories, especially those relating to violence hot spots and others well known to urban planners, are "place based" and suggest improvements to the built environment in order to reduce violence. If such strategies work at all (there is not much evidence on that), the effect is most likely a displacement of the perpetrators activity to other places but not necessarily an overall reduction in volume. Hence, more recent thoughts on prevention policies rely on social and institutional aspects until they eventually join the participatory governance stream mentioned before.

The case study on Yeoville neighbourhood in Johannesburg, South Africa, conducted by Obvious Katsaura, describes a process of de-gentrification with an almost complete substitution of the former white population by a black one, including an important inner African migrant population. During the period of research, xenophobic violence exploded in Johannesburg and resulted in numerous attacks on these migrants, several of which were fatal. Different community organizations dealing with local security threats have been analyzed by Katsaura. Most of them seemed to maintain a rather conservative view on migration and tend to reproduce the xenophobic biases of the population, thus increasing the fear perceived by the foreign residents.

In his research on Dandora, an old World Bank Sites-and-Services project in Nairobi, Kenya, Romanus Opiyo links incidences of violence with different types of land uses and their change over time. Due to disinvestment in public infrastructure and rising crime levels, the original cohesive community has largely moved away and gave place to a relatively fluctuant population mixed with commercial use of plots and

05

University of Nairobi, Institute for Development Studies (Prof. Dr. Winnie Mitullah)

06.

University of Douala, Département de Géographie (Prof. Dr. Kengne Fodouop) 
have been efficient in reducing the incidences of crime and violence including violence by the community itself in the form of mob justice. Paradoxically this relief also reduces the willingness of the community members to contribute financially or in time to maintaining the community watches.

Guinea Bissau does not really have big cities: the capital has less than 500,000 inhabitants and the next biggest town only has 22,000. Nevertheless, violence levels are relatively high, on a similar rank as Kenya or Mexico on the Global Peace Index ${ }^{7}$ (Vision of Humanity, 2013). The state justice system has not developed very far, but there is a whole variety of habitual systems of conflict resolution - which are adequate in preventing conflict from turning into open violence. Anne-Kristin Borszik has investigated and compared practices of different alternative conflict mediators sought by the local people, such as the local police, religious leaders (in this case Imams), radio moderators (life broadcasting), or professional dispute settlers. Furthermore, there are also ways to involve non-impartial negotiators, like quarter heads, chiefs, influential relatives, the army - or to bribe the state institutions supposed to assume an neutral position ("pocket jurisdiction"). Finally, in certain cases, an individual involved in conflict may prefer to give in and keep quiet, considering the factual power constellations in town or the social cost of pushing for justice. The important message of the study could be that the western concept of relying on one single institution to decide on right or wrong may not necessarily be the most intelligent rule in society - especially if that institution is part of a corrupt state system.

While West African countries tend to be marked by weak states, China stands for the opposite. Civil crime may be comparatively under control in that country, but the power monopoly by the state at times creates another problem of violence. Qin Shao reports on the practice of "domicide" in Shanghai and other places, involving forceful evictions from residences in quarters earmarked for redevelopment - even in cases when the law and court rulings protect against such action. Local governments do not restrain from hiring demolition squads who beat up protesters or set remaining houses on fire. The threatened residents have developed different defensive strategies such as employing legal advice to detect loopholes in the applied legislation or its implementation; protecting their dwellings through decorating it with Chinese flags or singing the "Internationale"; publishing videos and blogs through the media and internet and likewise organizing manifestations in public spaces. So far, the success of those actions remains limited and, in most cases, can only delay but not stop the redevelopment projects for a number of years.

After extrapolating on the consequences of failing control and excesses of control by the state in the two previous chapters, Heidrun Zinecker, with reference to Charles Tittle (1997) and Peter Wallensteen (1999) presents the theory that both, excessive or defunct control by the state are decisive breeding grounds for a violent society. The importance of a similar equilibrium between too much and deficient involvement holds true as well for the civil society. She tests and endorses this theorem through a comparative study of five Central American States:
Rank 133 of

162 countries, http://www.visionofhumanity. org/\#page/indexes/global-peaceindex/2014/GNB/ OVER 


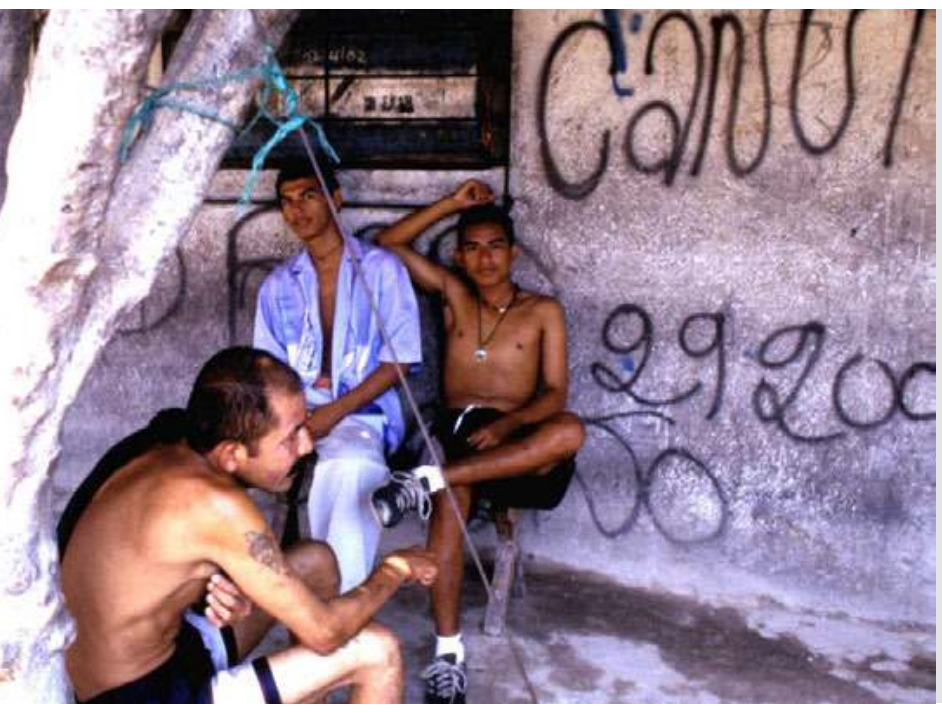

Unemployed

youth in

Manizales,

El Salvador.

Photo:

Joanna Kotowski

Guatemala, El Salvador, Honduras, Nicaragua, and Costa Rica. The comparison also reveals the positive example of a society with currently a very low presence of urban violence, in spite of wide spread poverty, represented by Nicaragua. An important factor for this result is the cooperation of a non-repressive police force cooperating closely with community representatives. The theory presented by Zinecker could be further refined and visualized by the following diagram:

Visualization of relationship between excessive and defunct controls by state and civil society for the generation of urban violence (red = violent) green $=$ peaceful Source: Kosta Mathéy
CIVIL SOCIETY

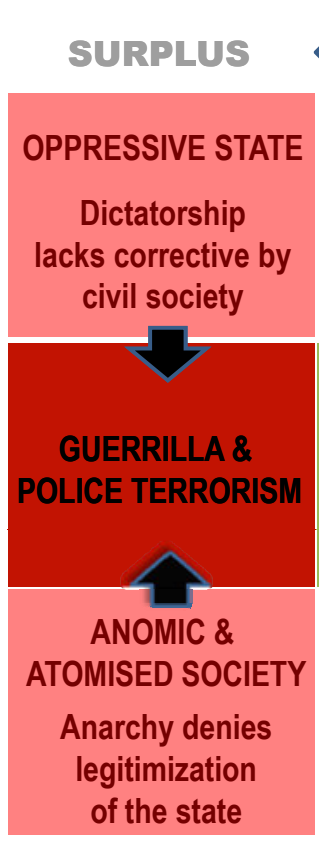

VIOLENCE

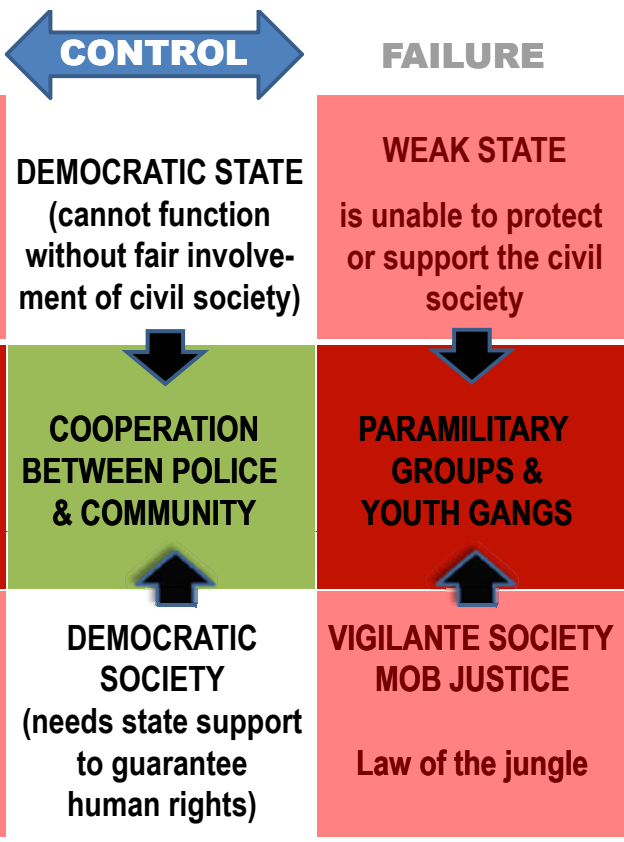

VIOLENCE 
While the Chapter by Heidrun Zinecker emphasizes the impact on state control, Luz Amparo Sánchez, in her study on District 13 in Medellin, Colombia, concentrates on civil society, which despite suffering multiple violent attacks by the army, paramilitaries, and guerillas, managed to make the situation change. Because of its strategic (and essential for controlling for drug trafficking) localization on the main road between Medellin and the coast, this district experienced much more violence than other similar neighbourhoods in the city. Many of the residents have either been extinguished, displaced from their homes by the fighting, or have left voluntarily. Remaining neighbours had no chances to enter in an arrangement with the armed groups because they lived in between the front lines. Cooperating with one group would immediately mark them as enemies for the others. From a position of "nothing left to lose" they opted for an offensive "no violence" strategy, including white handkerchief marches, massive occupation of public spaces, and the like. This movement was started by the mothers, but soon the youth joined in by organizing events that expressed their interests more closely. The activities of adolescents were also able to call the attention of the city, if not the nation, to this neighbourhood. Examples of these activities include regular hip-hop festivals, art murals and graffiti, radio programs, flashmob gatherings with percussion performances etc. A third type of peace activities were solidarity actions and associations of and with those who lost family members, their houses, their future, etc.. The common uniting element was described as "togetherness" which gave force to the community members and confused the armed groups in this district.

The - literally constructive - "Violence Prevention through Urban Upgrading" approach, referred to in the South African experience in Khayelitsha at the beginning of this introduction, also was an important aspect of a slum upgrading project in El Salvador, with funding from the same institution, ${ }^{8}$ and is being evaluated by Joanna Kotowski in one of the following chapters. Apart from physical upgrading of the urban infrastructure (which had been partially blamed for the increase in violence in Dandora in chapter 4), important social development components were also included in this program, executed by the renowned Non-Governmental Agency FUNDASAL. In line with general expert assumptions, everything was done right in this project and the evaluation confirmed that through the project general safety deficits have significantly improved for the residents - such as security of tenure, access to social and technical infrastructure, recreational facilities, and social assistance. However, the evaluation could surprisingly not identify clear evidence for a reduction of violence levels in the zone as a result of the project. The evaluation concludes: "In light of the extremely difficult and conflictive framework conditions, this aim might have been too ambitious. But the programme could have done more in this respect, if an explicit strategy for prevention of urban violence would have been designed from the very beginning."

Similar to El Salvador, Mexico has likewise suffered from the proliferation of violence in Central America, with the decision by president Calderon to launch the "war on drugs" in 2007, greatly increasing drug related violence, especially in the western part of the country. The army

08.

The German Bank for Reconstruction and Development (KfW) 
and specialized forces attempted to win control over the drug mafia who responded fiercely and also terrorized everyday life of the local population, previously not very much affected by gang violence. Veronica Martínez directed a research project on the impact of violence on victims and their families, which is the basis of her chapter. The affected and potential victims of violence are alienated by the government: generally crimes are not reported to the police, who have proved to be little help in the past, do not pass on the charges made by the population to the jurisdiction, and might even be directly linked to the criminal gangs. Neighbours only unite to defend themselves against petty crime with which, given the inefficiency of the police, they deal with in terms of vigilante justice. They do, however, recognize that organized crime is more powerful than they are themselves and hence try not to get involved at all in fighting the most serious violence. Sometimes weapons are kept at home for self defence. Since nobody knows for sure whether any of the neighbours, or their children, are connected to the gangs, the topic of violence is not discussed in detail, and not mentioned to foreigners at all. Social life came to a standstill as anyone tries not to leave the house at all, reason for fear is everywhere. Very few victims engage in collective actions like marches or the use of social media. Any public events addressing the violence are generally sustained by supporters living in other parts of the country on comparatively safe terrain.

The dominance of organized crime in the western part Mexico is an extreme problem, but organized crime, especially in the form of youth gangs, is a general phenomenon in the Americas. Joining a gang offers certain attraction to the youth in a poor neighbourhood: money, prestige, power, women, and a sense of belonging. Once having gone though the integration ritual, it is almost impossible for a gang member to return to normal life (and the tattoos with the gang's symbols are meant to inhibit it many cases). Therefore, current prevention policies concentrate on reaching youth before they can join a gang, and trying to offer them a somewhat more sustainable plan for the future. Sports facilities are quite common elements of such prevention programs, intended to foster an alternative feeling of belonging in the youth, which they may seek in a gang otherwise. Equally important are training opportunities in a professional occupation that can generate income in the long run. This situation of the youth who can become potential gang members is well analyzed in the paper authored by María Antonieta Beltrán and mented by the Instituto Nacional de la Juventud (IN-

JUVE)

10.

Funding is currently secured by a program from the European Community
Wim Savenije. They explain very clearly why, in a deprived neighbourhood, the gangs represent the final destination in an odyssey of lost or absent opportunities and that effective prevention must start in earlier in childhood and should be, above all, comprehensive by addressing all aspects of community life. A rather good example of such an approach is the city wide PROJOVENES ${ }^{9}$ program in El Salvador which the authors describe in greater detail. Program elements include the management of public spaces, vocational training, community building, and institutional development. Although the program involves a large amount of voluntary labour, it requires external funding which can affect its sustainability. ${ }^{10}$ 


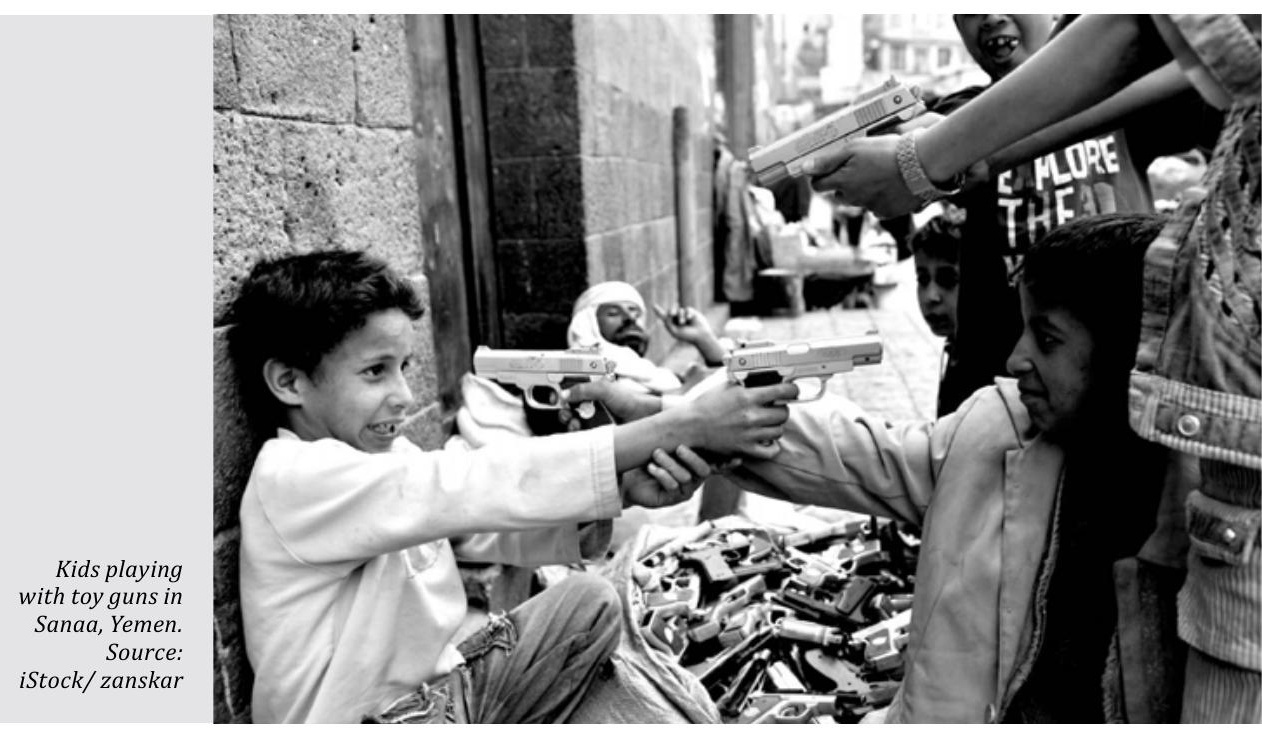

Sustainability is always a critical point in externally funded programs. The contribution on and by AEQUUS is remarkable because it presents a grass roots initiative started and maintained by a group of local youth after a friend of them was shot by a gang. They decided that they must do something to provide better alternatives for their fellow youth in their extremely violent neigbourhood and being university students themselves, they began to provide free pre-university classes and other courses to young people from the barrio (living quarter). By doing so they already facilitated access to university studies for 60 other young people from the neighbourhood and helped others to learn English or to start an artistic career. What is especially remarkable is the silent support received from many gang members who send their younger brothers to participate in the educational offers of AEQUUS since they wish that they do not to follow their own fatal destiny and join one of the gangs.

Palestinian refugee camps are a different urban situation where we find a concentration of young people growing up without realistic perspectives to find a rewarding occupation after leaving school. Fatima $\boldsymbol{M}$. Al-Nammari reports from an integral youth oriented program in Talbiyeh, the location of the oldest refugee camp in Jordan. The initiative is remarkable since it is preventive in its truest sense, as it starts before conflicts can develop into vagrant violence, as can be seen in the daily news about countries including Iraq, Syria, or Yemen. The project is particularly interesting in relation to urban development, since it's main component was an improvement-beautification element, which, as a topic of interest for all inhabitants, functioned as a common denominator and helped to bring together different sections of the camp society to work: young and old, women and men, professionals and the unemployed, all exchanging ideas about the same subject. Apart from the physical improvement results better social relations were confirmed by many sides and, in addition, numerous training activities provided better employment chances. Maybe the most important and long-lasting 
positive result was the introduction and spreading of the concept of "safe zones" where anyone entering was assured to be exempted from any kind of (physical, verbal, or other) aggression.

In the case of the refugee camps, which usually are enclosed at least in the initial period when they were established, most conflicts (can only) arise within the same community while a merger with the guest country's population is not envisaged. In other societies, where different cultures share the same space, conflict is generated more easily. As elaborated in the chapter written by Reza Masoudi Nejad, Mumbai is a case where India's Hindus and Muslims, whom for most of India's history peacefully lived side-by-side in the same neighbourhoods. However, clashes between these major fractions of Indian society exploded in

11.

There had been earlier clashes in 1893 after which a peace agreement was reached and lasted for almost 100 years.

Left:

Taboot Procession

in Bombay

100 years ago.

(Unknown artist)

Right:

The power of

belief. Man in

Johannesburg,

2005.

Photo:

Kosta Mathéy $1992,{ }^{11}$ when riots with more than 100 casualties broke out between the two religious communities. Typically, the religious differences were not the true cause of the riots, but were instrumental for political motives. After those tragic events, delegates from both sides came together to find ways to re-establish the peaceful coexistence of both religious communities and they eventually agreed to re-organize the tradition of religious processions, which had been maintained by both religions in the same district Dharavi (also referred to today as the world's biggest slum area) and in the same period of the year for centuries. These processions were to use the same route connecting both Muslim mosques and Hindu temples, showing respect for each others' beliefs. Animosities were overcome and since then no further frictions appeared between both communities in Dharavi. It seems that the act of a procession, known in many cultures and religions, causes a deeper impact in human psychology than generally realized and which is worth studying in greater detail. The processions' peace building capacities have, consciously or not, been used in certain other manifestations around the world, like in the case of gay parades or by the Carnival of Cultures in Berlin. The latter brings together different immigrant communities in this city, neutralizes remaining xenophobia, and makes even the more conservative citizens proud of the city's cosmopolitanism.
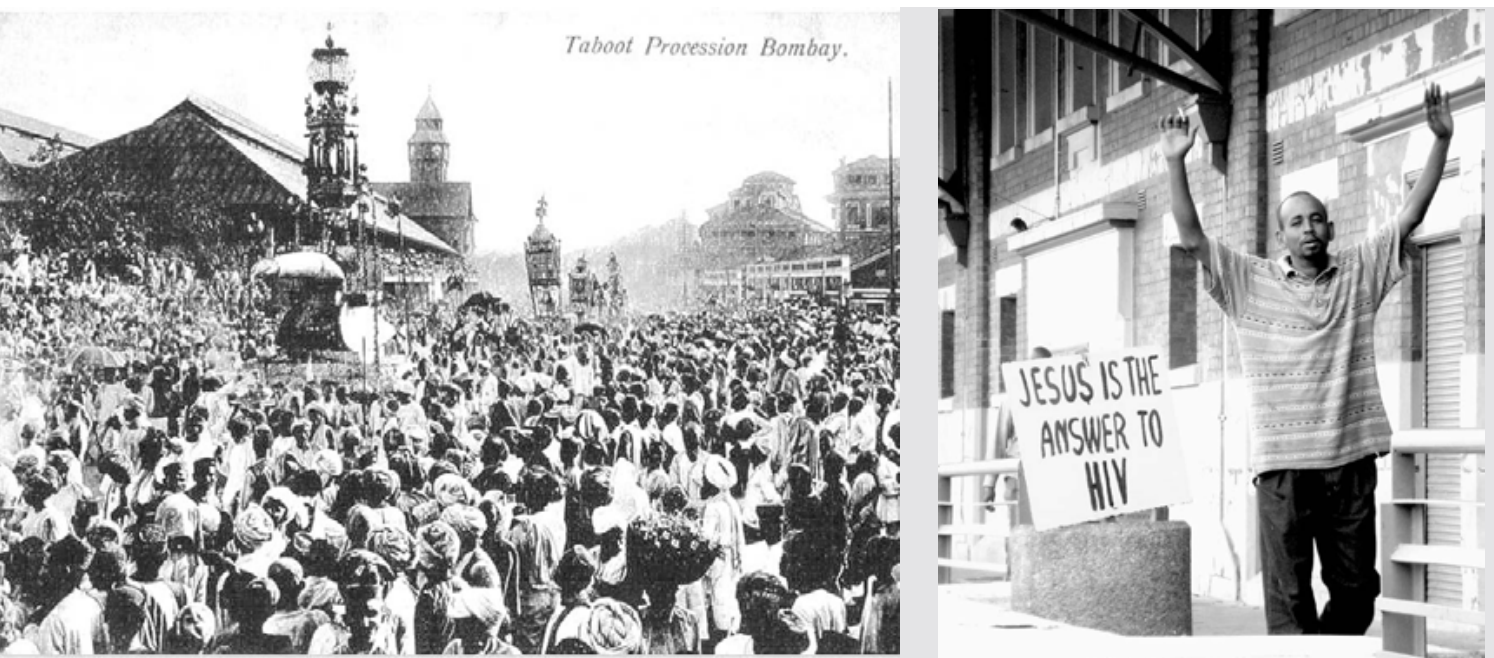
Back to South Africa, Obvious Katsaura in his second contribution to this volume, analyses the role of religion and spirituality for violence prevention in modern urban society. He argues, that

"given the institutional gap created by the inadequacies of the state, the governance of violence invites other social institutions and civic collectivities, which then fill this gap. In this case, religion is one of the social institutions that play an important role in the making of urban orders."

First of all, traditional African belief in the power of sprits is sought to protect the individual against homicides, witnessed so frequently in the big cities today - especially by black migrants who arrive from rural areas or from abroad. Equally, traditional healers play a key role in guaranteeing spiritual protection from physical attacks by criminals. A Christian equivalent can be found in Pentecostal practices in Johannesburg which promise divine protection against attacks by carrying pictures of their prophet or other dedicated items with them, including prayers. Similarly, the supposedly rational adjustment of personal behaviour, like avoiding dangerous places when choosing a movement route in town or avoiding certain hours of the day, has a lot to do with belief that renders a feeling of security. There is a tendency to automatically associate belief and myths with poor and insufficiently educated social layers. But Katsaura reminds us that also high income neighbourhoods with all their public and private security industries and their "obsession with fear" use excessive security preventions that have become ritualistic and simultaneously create psychological comfort and disturbances.

Quite a different approach to violence prevention is suggested by Barbara and Emma Holtmann, equally with reference to South Africa. As illustrated by her two case studies in Khayelitsha Township, outside Cape Town, and Joubert Park in the centre of Johannesburg, the methodology of the "Social Transformation System", developed by the two authors, allows individuals to approach the vicious cycle of crime and violence in an integrated manner and realize local resources. In the framework of community workshops, the participants usually develop a safety plan for the community and the present stakeholders can offer commitments for change. Although there is no evidence that this approach will work against intruders from outside the community, it is one of the very few strategies also to address domestic and sexual violence.

The 15 case studies presented can by no means cover the entire spectrum of possible manifestations of urban violence and even list all responses (and their combinations) tested in different settings. But they certainly illustrate the complexity of the problematic, the importance of the political and cultural context but also of external factors like the international drug mafia. The cases also endorse our starting assumption that there are better alternatives than primarily relying on police intervention or environmental-physical precautions. They represent, at best, a stone in the entire mosaic of violence-free urban and social development strategies. Nevertheless, we believe that a systematization of experiences can be helpful and have compiled a short table referring to the cases included in this anthology: 


\begin{tabular}{lll}
\hline $\begin{array}{l}\text { Country \& } \\
\text { Author }\end{array}$ & $\begin{array}{l}\text { Reported form } \\
\text { of violence }\end{array}$ & $\begin{array}{l}\text { Prevention } \\
\text { strategies } \\
\text { sought }\end{array}$ \\
\hline
\end{tabular}

3.

South Africa

Obvious Katsaura
Ethnic \& xenophobic

Integration in com-

munity policing and NGOs

Very limited effect as

prejudices are repro- Fear by the (migrant) duced inside the target group persists committees

Mostly individual:

moving to a safer

4.

Kenya

Romanus Opiyo

Primarily robberies and burglaries, also some kidnapping and rape

area, barring houses, avoiding being alone in the street at dark. some private guards

5. Cameroon Christophe Sados

Robberies, burglaries, physical assault Community watches
6. Guinea Bissau between members of Anne-Kristin Borszik the community
Conflict settlement or negotiation through intermediaries such as the police, radio moderators, imams, negotiators, influential relatives, or the army

$8 . \quad$ Latent terrorism

$\begin{array}{ll}7 . & \text { Domicide - state } \\ \text { China } & \text { violence manifest in } \\ \text { Qin Shao } & \text { home evections }\end{array}$
Central America by state and gangs Heidrun Zinecker evolving from civil society

Legal opposition, public protest, manifestations, informing the media

Control of violence through equilibrium between excessive an failing control through state and civil society

Rampant violence

9.

\section{Colombia}

Luz Amparo Sánchez caused by competing armed groups and the military. Illegal taxation of population by gangs.
Different manifestation of "non-violence" responses: marches, mass occupation of open spaces, cultural events, and festivals
Slight reduction in reported violence

Respondents perceive a decline in violence

\section{Resolution of con-}

flict if both parties agree. Alternatively the offended may decide on giving in if downgrading social status would be cost for insisting on a settlement

Often delays of the eviction process can be achieved, but rarely long term results

An example of a good Focus is put on state equilibrium is Nica- intervention and less ragua with low levels on initiatives generof violence ated by civil society

Reduction but no complete elimination of violence. Legalization of residence for informal settlement could be won in parallel.

Safe housing and General safety

Youth gangs, homi-
10.

El Salvador Joanna Kotowski threats, extortion, and other types of crimes. cide, theft, robbery,

\section{infrastructure, social} facilities, community development, recreational facilities for the youth parameters have significantly improved, but no direct impact on levels of violence could be identified
Disinvestment in public infrastructure contributes to loss of community cohesion and fluctuant population

Perceived decline in victimization reduces willingness to contribute personally

Intelligent solution where the state fails to provide a fair conflict resolution mechanism

Change of the state's role as protector of civil rights into perpetuator

Even more important is the psychological support to the population and positive perspectives in the life for the youth as an alternative to gang membership.

In spite of a strong participatory approach the project was initiated by a foreign financial cooperation agency and not really a "community initiative"

The reason for the explosion and generalization of violence was the strong arm policies introduced by president Calderon in an opportunistic election campaign 


\begin{tabular}{|c|c|c|c|c|}
\hline $\begin{array}{l}\text { Country \& } \\
\text { Author }\end{array}$ & $\begin{array}{l}\text { Reported form } \\
\text { of violence }\end{array}$ & $\begin{array}{l}\text { Prevention } \\
\text { strategies } \\
\text { sought }\end{array}$ & Results & Observations \\
\hline $\begin{array}{l}12 . \\
\text { El Salvador } \\
\text { María Antonieta } \\
\text { Beltrán and Wim } \\
\text { Savenije }\end{array}$ & $\begin{array}{l}\text { Organized crime } \\
\text { recruiting youth } \\
\text { from deprived neigh- } \\
\text { bourhoods in San } \\
\text { Salvador }\end{array}$ & $\begin{array}{l}\text { Integration of public } \\
\text { space management, } \\
\text { vocational training, } \\
\text { community devel- } \\
\text { opment, institu- } \\
\text { tional development, } \\
\text { scholarships }\end{array}$ & $\begin{array}{l}\text { By end of } 2013 \text {, four } \\
\text { thousand young } \\
\text { people participated } \\
\text { in the program, pro- } \\
\text { vision of } 400 \text { scholar- } \\
\text { ships. Impact assess- } \\
\text { ment is not (yet) } \\
\text { available }\end{array}$ & $\begin{array}{l}\text { EU-funding for PRO- } \\
\text { JOVENES ended in } \\
\text { Dec. } 2013 \text {, but more } \\
\text { generous funding has } \\
\text { been announced for a } \\
\text { follow-up program }\end{array}$ \\
\hline $\begin{array}{l}13 . \\
\text { Colombia } \\
\text { Julieth Sánchez } \\
\text { Betancourt and } \\
\text { Carlos Restrepo }\end{array}$ & $\begin{array}{l}\text { Competing youth } \\
\text { gangs establishing } \\
\text { "invisible" frontiers } \\
\text { in the territory which } \\
\text { to cross may end up } \\
\text { in being shot without } \\
\text { warning, exertion of } \\
\text { illegal taxes by the } \\
\text { gangs, recruiting of } \\
\text { children }\end{array}$ & $\begin{array}{l}\text { Provision of free } \\
\text { education to com- } \\
\text { pensate failures by } \\
\text { the state educational } \\
\text { system and giving } \\
\text { fellow youth income } \\
\text { relevant education } \\
\text { and identity through } \\
\text { cultural events by } \\
\text { the group. }\end{array}$ & $\begin{array}{l}60 \text { youth from the } \\
\text { neighbourhood suf- } \\
\text { ficiently prepared } \\
\text { to be accepted at } \\
\text { the university entry } \\
\text { exam, other edu- } \\
\text { cational programs. } \\
\text { Proving an alterna- } \\
\text { tive for adolescents } \\
\text { from joining a crimi- } \\
\text { nal gang. }\end{array}$ & $\begin{array}{l}\text { Special mention } \\
\text { because it is local } \\
\text { and self generated } \\
\text { initiative, funded by } \\
\text { voluntary work and } \\
\text { donations from the } \\
\text { neighbourhood }\end{array}$ \\
\hline $\begin{array}{l}14 . \\
\text { Jordan } \\
\text { Fátima Al-Nammari }\end{array}$ & $\begin{array}{l}\text { Petty theft, drug traf- } \\
\text { ficking, vandalism, } \\
\text { arson, child abuse, } \\
\text { rape, physical and } \\
\text { verbal assault, secu- } \\
\text { rity clashes }\end{array}$ & $\begin{array}{l}\text { Open space improve- } \\
\text { ment, participatory } \\
\text { design workshops, } \\
\text { familiarization with } \\
\text { the concept of "Safe } \\
\text { Zones", training in } \\
\text { life skills. }\end{array}$ & $\begin{array}{l}\text { Improvement of } \\
\text { self-esteem, desire } \\
\text { for volunteering, } \\
\text { respect and tolerance } \\
\text { of having different } \\
\text { ideas }\end{array}$ & $\begin{array}{l}\text { Project was stopped } \\
\text { after funding period } \\
\text { and the new genera- } \\
\text { tion regress to pat- } \\
\text { terns of behavior that } \\
\text { had been overcome } \\
\text { through the project }\end{array}$ \\
\hline $\begin{array}{l}15 . \\
\text { India } \\
\text { Reza Masoudi Nejad }\end{array}$ & $\begin{array}{l}\text { Religious clashes } \\
\text { and bombings, in } \\
\text { this particular case, } \\
\text { between Hindus and } \\
\text { Muslims }\end{array}$ & $\begin{array}{l}\text { Processions uniting } \\
\text { territories of con- } \\
\text { flicting parties }\end{array}$ & $\begin{array}{l}\text { Construction of toler- } \\
\text { ance and acceptation } \\
\text { and even pride about } \\
\text { multiculturalism }\end{array}$ & $\begin{array}{l}\text { Uniting power of pre- } \\
\text { cessions can also be } \\
\text { observed elsewhere, } \\
\text { like in the Berlin Car- } \\
\text { nival of Cultures or gay } \\
\text { parades }\end{array}$ \\
\hline
\end{tabular}

Pleasing the bad spirits, prayers, talismans, support

16.

South Africa Obvious Katsaura

Street robberies, burglaries, car-jacking, homicide

from traditional healers, avoiding places believed to be dangerous, reliance on technology and guards

Systemic transfor-
mation through col-

17.

South Africa

Barbara and Emma Holtmann
Cycle of crime. homicide, robberies, gang violence, rape, domestic violence laborative actions,

development and

implementation of safety and action plans
Psychological tranquillity to control (partly irrational) fear of violence

Research still in progress

Vision of what it looks like when it's fixed. Results are very location specific and depend on the stakeholders participating in the process.

Violence may be
reduced inside the
community, includ-
ing domestic violence,
but protection against
perpetrators from
outside the community
is limited

Table 1:

Overview over strategies in urban violence prevention as presented in the chapters of this book 


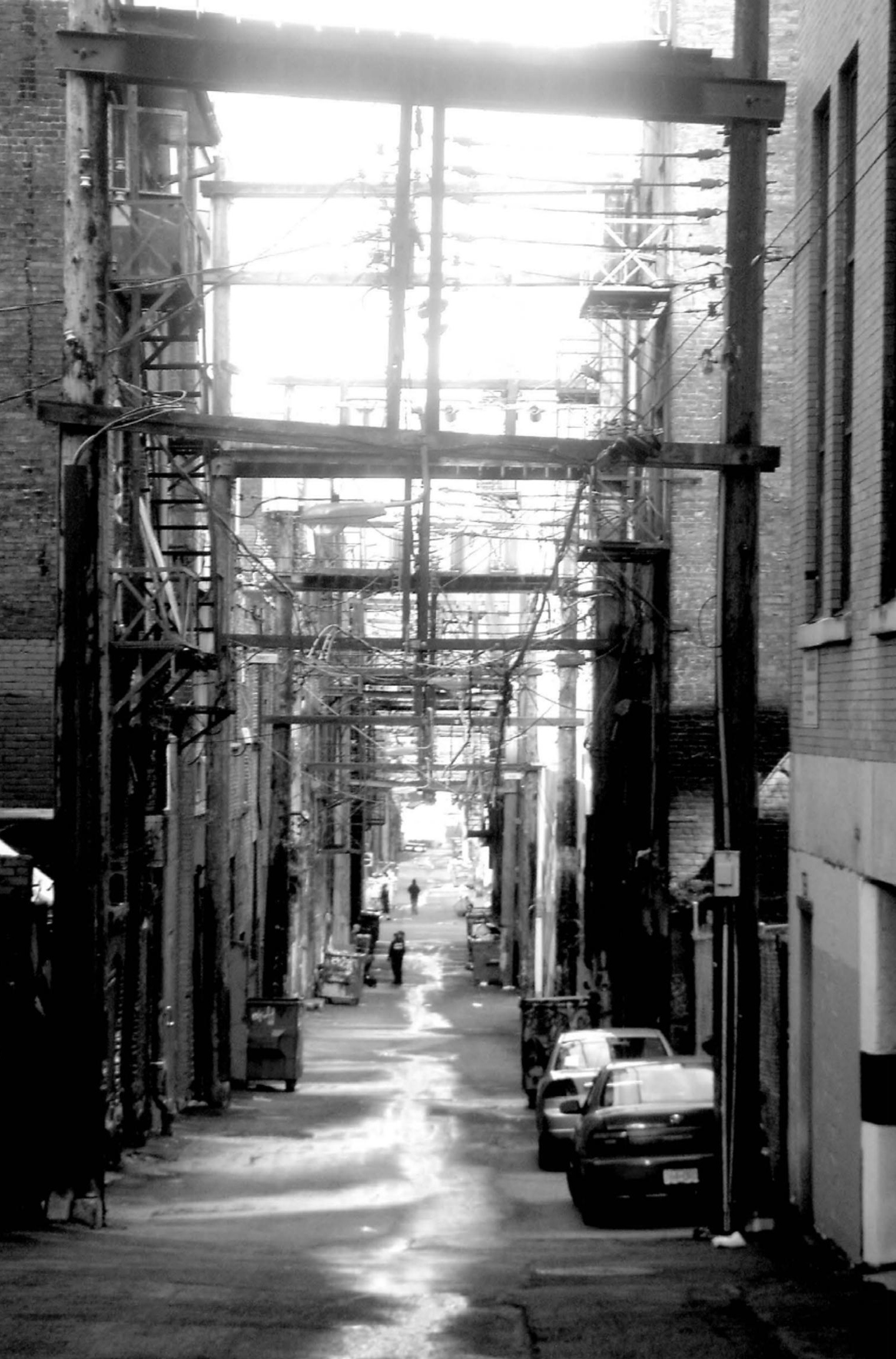




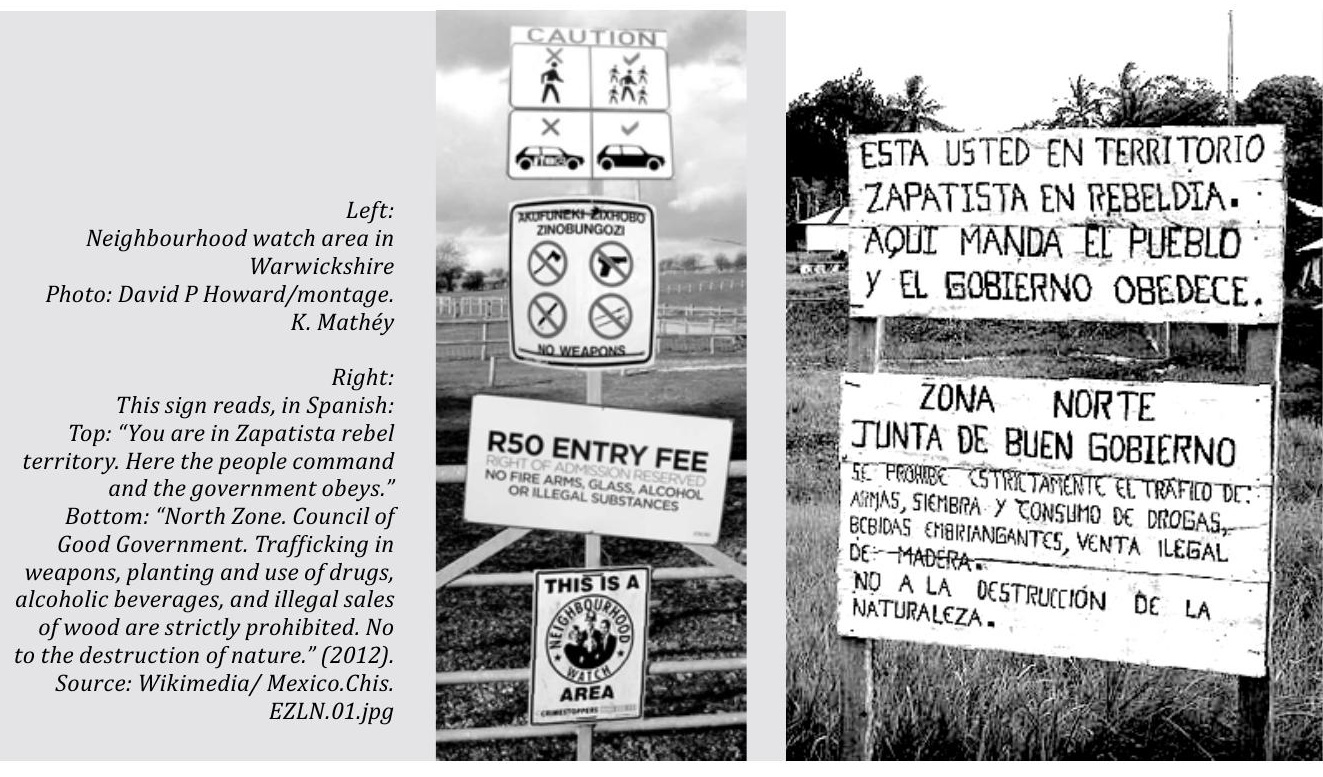

III.

The production of this collection was only possible with the help of numerous institutions and individuals. First of all, we have to express our gratitude to the Volkswagen Foundation, which not only provided the scholarships to the three young African researchers over three years thus allowing them to conclude their doctoral thesis- but also facilitated the final conference in Berlin, where the larger part of the contributions to this volume were presented and discussed. Furthermore, the foundation continues to sponsor one of the scholars through a post-doctoral program, which enables the continuation of research on this very relevant topic.

A second institution to which explicit thanks must be extended is the Berlin State Office for Development Cooperation of the Senate of Berlin, especially Eckhart Bock and Joan Picard. Their consistent support was particularly integral during the preparation and realization of the conference: they not only provided the venue but were also fundamental in the reception of visas for the international contributors.

The United Nations Human Settlement Programme (UN-HABITAT), with special mention to their urban safety expert Juma Assiago, is the third institution to warrant acknowledgement, with special thanks for their support over the entire research period. The integration of the U-CARE Program into the UN-HABITAT Safer Cities Network connected us with experts from all over the world and offered us the floor to present our work at several internationally relevant events.

We also want to express our gratitude to the cooperating African professors and thesis supervisors Kengne Fodoup in Cameroon, Winnie Mitullah in Kenya and Alan Mabin in South Africa for their support and hospitality during the joint field visits to their countries. Equal mention must deservedly go to María Clara Echeverría, Cecilia Inés Moreno Jaramillo and Rafael Rueda Bedoya of the School of Habitat at the National

Photo on opposite page:

Back lane in

Vancouver. A place that is associated with crime in many people's minds.

Photo:

Kosta Mathéy 
University of Colombia in Medellin and to José Alexander Caicedo and to Aaron Zea for his assistance during our comparative field work in Medellín.

Within the coordinating institution in Berlin, the Global Urban Studies Institute (GLOBUS), we owe our thanks to the project staff Elisabeth Peyroux, Peter Gotsch, Nicholas Kasang, and Cibele Kojima de Paula who assured the consistent organization and realization of the project during their consecutive periods of involvement. At all instances there were many more individuals who provided decisive input to the project; to them we are eternally grateful.

Finally, we were impressed by the efficient and quick response of the publisher, Transcript Verlag, and especially our contact person Annika Linnemann who facilitated the publication of the book within only three months. To these individuals and all others not mentioned here: thank you for your fundamental support!

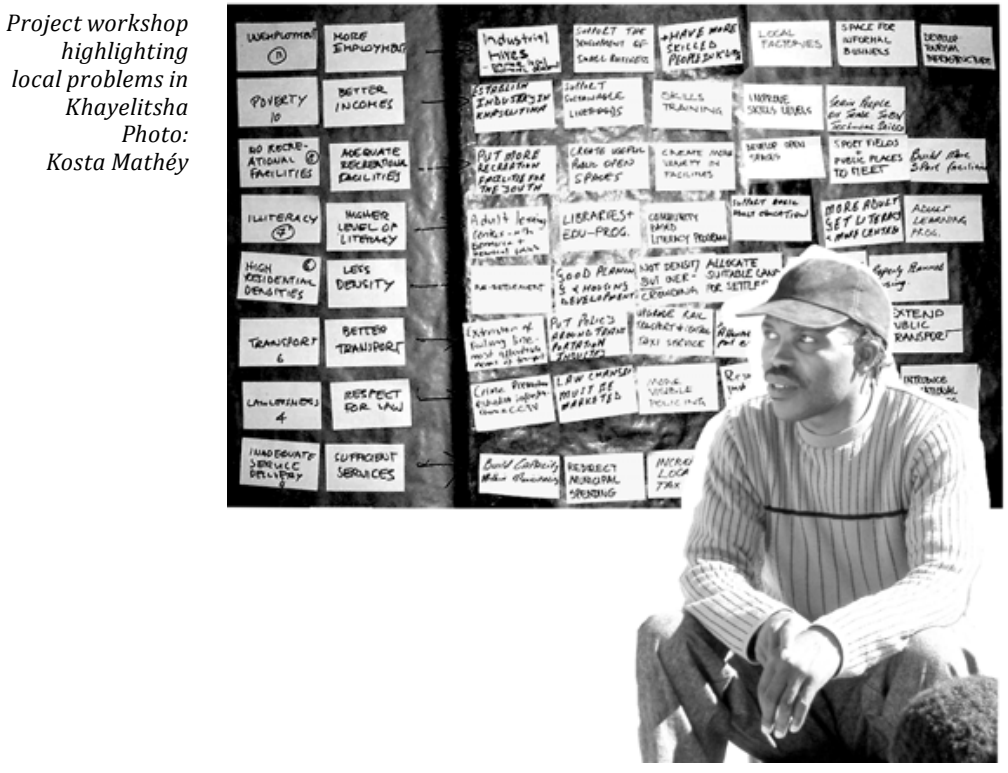

\section{References}

Das Erbe der Diktatur. Exzessive Polizeigewalt prägt den brasilianischen Alltag. Behn, Andreas. 9. 8. 2014.. 9. 8. 2014., Die Tageszeitung, S. 11.

Hays, Alain; Matuk, Silvia. 1995. Construire pour la Paix, des abris pour la guerre, des maisons pour la paix. Paris : Ed. UNESCO, 1995. http://unesdoc.unesco.org/Ulis/cgi-bin/ulis.pl? catno $=108916 \&$ set $=53$ F0E642_0_184\&gp=0\&li $\mathrm{n}=1 \& \mathrm{ll}=2$
Humanity, Vision of. 2013. Global Peace Index. http://www.visionof humanity.org/\#page/ indexes/global-peace-index/2013/GNB/CRIM: s.n., 2013. http://www.visionofhumanity.org/ \#page/indexes/global-peace-index/2013/GNB/ CRIM.

Mathéy, Kosta. 2006. Reduction of Urban Violence through Neighbourhood improvement. A Strategy for Khayelitsha Township in Cape Town, South Africa. 2006, pp. 17-24. 



\section{Violence, Cities, and Prevention: A Conceptual Framework for Reducing Violence in the Urban Realm}

Nicholas Kasang

Contemporary urban growth in various cities worldwide has been increasingly accompanied by the occurrence of urban violence. The coalescence of this violence, and the fear it precipitates, exacerbates the unequal spatial, societal, political, and economic structures intrinsic to many cities. Moreover, such insecurity undermines the very foundations of the economic and social development that are offered by concurrent urbanization. Therefore, continued urban violence in its current extent has a strong inhibitory affect on sustainable urban development.

To address the phenomenon of urban violence, many theories and strategies have emerged to confront the multiple expressions of insecurity in various metropolitan contexts. Among others, the physical manipulation of space has received significant attention due to its capacity to "weave together socio-cultural development aspects, economic aspects, as well as operation and maintenance solutions," and accordingly address the multi-faceted influences that contribute to violence in the urban realm (Krause 2011: 108). However, to sufficiently appraise this capacity, it is first necessary to contextualize violence, its categories, and instigators in urban space. With such a conceptual grounding, it is then feasible to evaluate the various prevention initiatives, which are detailed in the subsequent chapters of this book.

The following work therefore seeks to establish a conceptual grounding in the theory of violence, while likewise providing an introduction to the predominant place-based approaches that have developed to prevent violence in cities. It likewise introduces six fundamental attributes of successful violence prevention that have been developed by the author to complement such place-based approaches. 


\section{Violence: categories and instigators}

In order to sufficiently understand the contemporary situation of violence in the urban realm, it is first necessary to conceptualize the theory of violence, particularly in its relation to cities. Despite its significant presence in nearly every metropolitan area internationally, the term violence receives different definitions, based on the intensity of form, contemporary relevance, and cultural norms/perceptions of its existence. Nevertheless, the World Health Organization (WHO) defines violence as "the intentional use of physical force or power, threatened or actual, against oneself, another person, or a group/community, that either results in or has a high likelihood of resulting in injury or death" (Krug et al 2002: 4). Besides these tangible outcomes, the WHO also includes the myriad and often less obvious consequences of violent behaviour, "such as psychological harm, deprivation, and mal-development that compromise the well-being of individuals, families, and communities ${ }^{1 \text { " }}$ (Krug et al 2002: 4). This complexity within the definition of violence alludes to the multiple attributes and influences of the concept, and has provoked social scientists to further distinguishing between the varying forms of violence. In its most encompassing classification, violence is first differentiated into direct, structural, and cultural forms, with direct violence composing the most common understandings of the term: direct violence is the direct infliction of physical or psychological harm on another individual resulting in intentional fatalities, assault, and/or sexual harassment (Marc \& Willman 2010: 11; Muggah 2012: 19). Direct violence is further divided into three subcategories:

- Self-directed violence - Which includes suicidal behaviour and self-abuse such as self-mutilation;

- Interpersonal violence - Which comprises:

- Family and intimate partner violence - Violence largely between family members and intimate partners, usually, though not exclusively, taking place in the home;

- Community violence - Violence between individuals who are unrelated, and who may or may not know each other beforehand, generally taking place outside the home;

- And Collective violence - The instrumental use of violence by people who identify themselves as members of a group against another group or set of individuals, in order to achieve political, economic, or social objectives (Figure 1.) (Krug et al 2002: 5).

These direct forms of violence generate uncertainty -expressed as fear and insecurity- thus promoting the notion that particular institutions or cultural establishments require protection (Moser 2004: 4). To generate such protection, mechanisms are often constructed to negate this threat. Yet, intrinsic to many of these mechanisms are structural or institutional attributes that exclude or inhibit certain portions of a population from achieving a just and equitable lifestyle. In response to this reality, the concept of structural violence was introduced by Galtung (1969) to
01.

This definition of violence is contrasted with the definition for crime, which is delineated as "an act (usually a grave offence) punishable by law, i.e. the breach of a legal prohibition. Violent crime, in turn, has been defined as any act that causes a physical or psychological wound or damage and which is against the law" (Moser 2004: 4). 


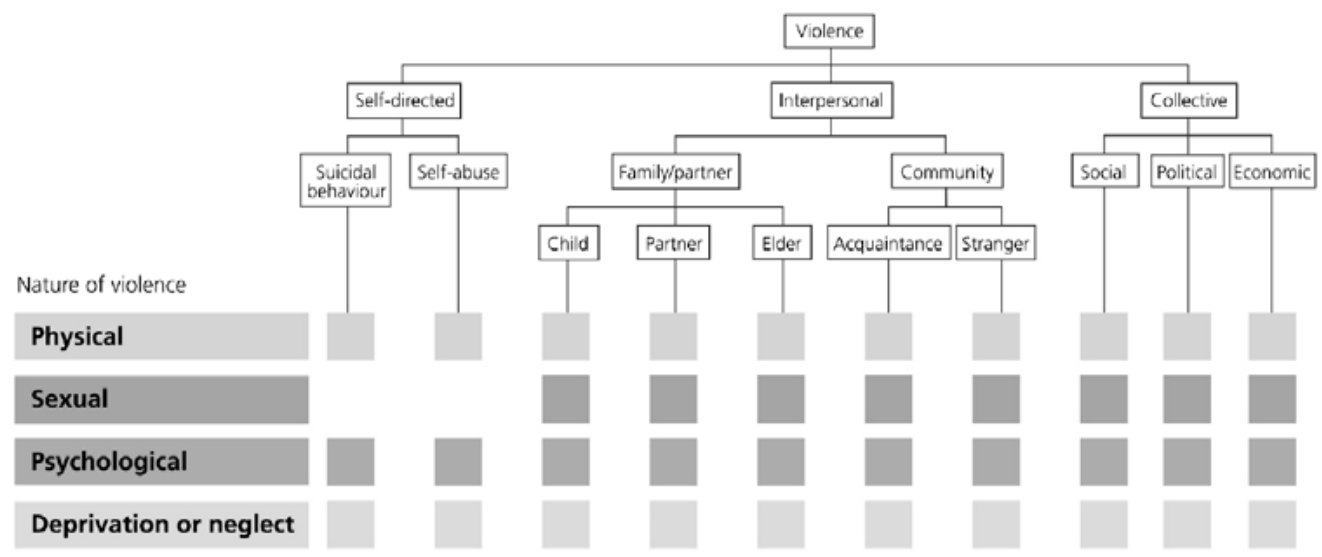

Figure 1: A Typology of Direct Violence. Souce: Krug et al 2002: 5

address the issue of "how various institutions and organizations cause harm to others as a normal consequence of the way they are structured and operate" (Santa-Barbara 2007: 234). Recently, Fischer (2007) has elaborated on this designation by further refining structural violence into two categories:

- Structural I Violence- Which is violence derived from injustices such as "the slow death from hunger, preventable diseases, and other suffering, caused by unjust structures of society," commonly defined as misery;

- And Structural II Violence- Which is violence derived from the "deprivation from freedom of choice and participation in decisions that affect people's own lives," which in this sense, is defined as oppression (Fischer 2007: 188).

The injustices (real or perceived) derived from structural violence, "may provoke direct violence as a response to exclusion from social, political, or economic systems" (Marc \& Willman 2010: 11). These forms of structural and direct violence, in turn, can be exacerbated by cultural violence, which is the "justification of direct and structural forms through nationalism, racism, sexism, and other types of discrimination and prejudice" (Fischer 2007: 188). Therefore, a situation of violence frequently perpetuates itself through the multi-faceted and interrelated components intrinsic to its origin.

A secondary manner of classification for violence evaluates the motivation behind violent actions. Such motivations fall under three broad characterizations -social, economic, and political motives- which degrade into further forms of violence (social, economic, or political violence) when conflict arises from the incompatible or contradictory goals of individuals or groups. Moser and Mcllwaine (2004) provide greater contextualization of the intentionality in these further forms of violence:

- Social violence-Violence, predominantly interpersonal, and motivated by the "will to get or keep social power and control"; 
- Economic violence-Violence "motivated by material gain that [takes] the form of street crime, drug-related violence, or kidnapping";

- And Political violence-Violence "inspired by the will to win or hold political powers” (Moser \& McIlwaine 2004: 60).

The final form, political violence, can take a range of violent outcomes, such as "the normalization of violence, [deriving] a system of norms, values, or attitudes which allow, or even stimulate, the use of violence," and culminate in a form of state violence, perpetrated through a lack of reform within the police and judiciary systems, or the inability to provide legitimate institutional control over violence (Agostini et al 2010: 3). The propensity of violence to grow/diminish in intensity across space and time is a third mechanism through which violence is categorized, ranging along a continuum from "acute", "endemic", and "chronic", to "everyday", "common", and "petty"(Muggah 2012: 19).

On account of this multifaceted and interrelated nature of violence, the necessity to evaluate the phenomenon by examining factors that influence behaviour -or aspects which increase the risk of committing or becoming a victim of violence- in a complex and comprehensive fashion, became obvious to many scholars early on in the development of conceptual theory (Krug et al 2002: 9). At the beginning of the 20th Century, The Chicago School proposed the Social Disorganization Theory, which predicted that many risks for violence were aggravated by socio-spatial characteristics of cities themselves, such as their "heterogeneity, inability to absorb surplus low-skill labour, uneven provision of services, and jarring inequalities" (Muggah 2012: viii). "Economic disadvantage, ethnic [diversity], and residential instability," contributed "to community disorganization and ultimately violence," purported the Social Disorganization Theory (Ibid). These ideas were further advanced through the Ecological Systems Theory, developed by Urie Bronfenbrenner (1977), which sought to demonstrate that no single cause determined or explained violence, but rather that multiple types of nested-factors, with bi-directional influences in and between each other at different levels, combined to contributed to violence (Krug et al 2002; Moser 2004). Such factors include:

- The biological and personal history/identity factors that influence how individuals behave and increase their likelihood of becoming a victim or perpetrator of violence ;

- Close relationships, such as those with family, friends, intimate partners, and peers, which might "increase the risk of being a victim or perpetrator of violence" (Krug et al 2002: 9);

- The community contexts in which social relationships occur -such as at schools, workplaces, and neighbourhoods- which might perpetuate the risks for violence ;

- And the broad societal factors that help create a climate in which violence is encouraged or inhibited (Krug et al 2002). 


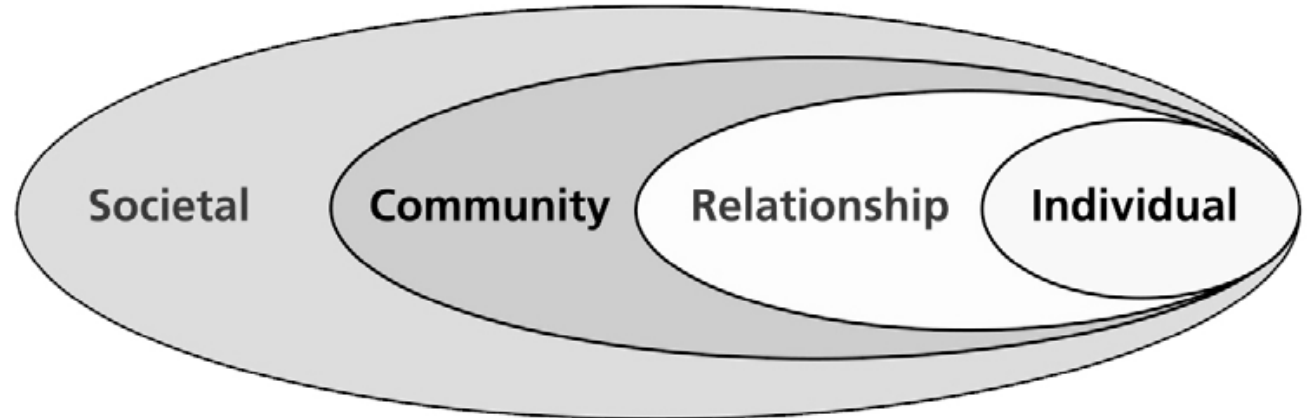

Figure 2: The nested-factors of the Ecological Systems Theory model. Source: Krug et al 2002: 9
Through such an evaluation of violence, the Ecological Systems Theory illustrated how factors were not linear in culminating in violence, but rather strengthened and modified by each other in an overlapping and continuous manner (Krug et al 2002: 9). This concept, illustrated in Figure 2. below, is contemporarily considered as the basic methodology when evaluating situations of violence, independent of the scale or context within which the sample is addressed.

In the vein of the Ecological Systems Theory, urban violence, particularly in the Global South, has recently been prescribed to follow a specific, concomitant pattern across metropolises: "rapid growth of cities feeds the chaotic formation of [marginal areas], in which overcrowding and competition for scarce resources combine with weak state security presence to foster criminality and violence" (Marc \& Willman 2010: 15). Within this pattern, the urban growth rate has been expressly attributed to enhanced violence -compared with city size or population density (Ibid: 17) - as rapid urban growth contributes to infrastructure deficiencies that exacerbate the everyday pressures of earning a living and raising a family, thus increasing tensions within families and communities, and making it easier for everyday conflicts to escalate into violence (Ibid: 66). Poor spatial allotments are proposed to contribute to the propensity of conflict by creating "situational opportunities for perpetrators to commit crimes without being seen or pursued by neighbours or police" (Ibid). Similarly, limited service provisions in one community as opposed to another are suggested to exacerbate a sense of social exclusion, itself a driver of violence, which then has the power to convert areas of a city into "no-go zones" for other non-residents and law enforcement professionals (Ibid: 26). In this way, the real and perceived threat of violence combines to generate what Davis (1990) has called "security-obsessed urbanism": "increasingly higher walls and barriers, more elaborate security systems, the presence of private security, and, often, a stronger [and discriminative] police presence in wealthier areas," thus, fragmenting public space, breaking down social cohesion, perpetuating widespread insecurity, and diminishing the overall quality of life (Agbola 1997: 26).

Nevertheless, there is nothing inevitable about violence in the urban environment, as evidenced by Moser's (2004) declaration that the popular concept of poverty as the predominant determinant of violence is "too simplistic" (Moser 2004: 8). Some megacities characterized by informality, such as Cairo and Mumbai , are professed to be among the 
safest cities in the world, while others with similarly large quotients of informal populations, such as Bogotá and São Paulo, have seen a remarkable drop in violent crime despite dense and growing populations (Marc \& Willman 2010: 15). It has therefore been concluded that, "the relationship between cities and violence is [somewhat more] complex" (Ibid) and accordingly requires greater study.

Indisputable on the urban scale however, are the costs which violence incurs. Direct damage caused by violence includes death, injury, destruction to public infrastructure, loss of personal property, and diminished returns on economic assets, while indirect costs such as psychological trauma, population displacement, the disruption of social services, "brain drain", and increased spending on law enforcement are also attributed to violence and insecurity (Muggah 2012: iii). Globalizing growth and international connectivity have been proposed to exacerbate these problems, as aspects of globalization contribute to conflict, particularly through "the fragmentation and marginalization of some countries and groups [via] the intense competition for resources and the widening [of] inequalities"(Krug et al 2002: 23). "Though these factors may not be sufficient alone to cause conflict, they may create conditions in which violence will erupt," particularly relevant in the face of continued urbanization over the forthcoming decades (Ibid).

\section{Violence prevention}

In response to the proclivity of increased urban violence, a number of mechanisms have been developed to deal with the incidence of insecurity. These mechanisms have predominantly followed three general directions of the public health approach , pursuing the prevention of violence through primary, secondary, or tertiary means (Krug et al 2002: 10). Greater description of these mechanisms is provided in Table 1. below.

Within these mechanisms, four major place-based crime prevention approaches have developed since the early 1970s. All of these approaches focus on the role of the physical environment within prevention, though each emphasizes a different scale of analysis. The approaches consider the integration of crime prevention measures into the fields of architecture, urban design, and urban planning, accordingly assuming that certain qualities of the physical environment may reduce opportunities for crime or violence.

The first and possibly best-known of these spatial violence prevention approaches is the concept of "defensible space", which was formulated by the architect Oscar Newman in 1972. Newman argued that an environment's physical characteristics -building layout and overall site plan- functioned to allow inhabitants themselves to become key agents in ensuring their own security (Newman 1996: 9). In his studies of public housing estates across the United States, he criticized "the large scale of the buildings, which made it impossible for residents to recognize strangers; the multitude of unsupervised access points that made it easy for offenders to enter projects and escape after committing [a] crime; the location of projects in high crime areas; and their stark appearance, which 
Table 1. Mechanisms for Violence Prevention

\begin{abstract}
Mechanism Description
"Primary violence prevention aims to prevent violence before it occurs" (Meade 2009: 13). Such intervention involves strategies that reduce the factors that put people at risk for experiencing violence, while simultaneously acting to increase other factors that protect or buffer individuals from such risk (Centre for Disease Control and

Primary Violence Prevention Prevention). These mechanisms usually act on the community or societal level and can include a range of social, educational, health, or training programs (Shaw 2010:12). Yet, such approaches necessitate engagement with the dense and diverse complexities of individuals, communities, cultures, and societies; thus, "primary violence prevention [is] under-utilized, even though [it] holds promise for reducing and ultimately eliminating the trauma and burden of violence" (Meade 2009: 13).
\end{abstract}

"Secondary violence prevention focuses on treating immediate injury and harm resulting from violent incidents" (Meade 2009: 13). These Secondary efforts may include emergency services or medical care for victims; Violence Prevention thus secondary prevention concentrates much more on individual or relational attributes than larger group dynamics. Along with tertiary violence prevention, secondary violence prevention mechanisms are acknowledged as more widespread (Meade 2009: 13).

"Tertiary violence prevention refers to a range of activities aimed at addressing the medium and long-term effects of violence and includes therapy and other rehabilitation efforts" (Meade 2009: 13). Programs focusing on the latter often seek to prevent recidivism by assisting in the social reintegration of offenders, as "those convicted of offences run the greatest risk of re-offending, given that they have already broken the law, have few opportunities and skills to pursue legitimate non-criminal lifestyles, and may have strong links with other offenders and offending lifestyles" (Shaw 2010: 14). Thus, pro-

Tertiary Violence Prevention viding previous offenders with life and job skills, training, education, alternative lifestyles and role models, and good support and housing in the community are ways that are purported to assist with reintegration (Ibid). Such mechanisms "form an important part of comprehensive [prevention] strategies, since many of those dealt with by the criminal justice system and who are incarcerated will eventually return to the community" they molested (Ibid: 99). Thus, a number of reintegration programs also include restorative justice components which aim to restore community order and relationships while simultaneously promoting peace, in order to reaffirm community values, encourage change, and reintegrate the offender (Ibid).

contributed to the stigma [attached] to them" (Clarke 1997: 7). Consequently, Newman developed four key characteristics for the production of "defensible space" in North American housing projects, including:

- Territoriality, which referred to an individual's perceptions of, and relationship with his or her environment ;

- Boundary definition, which alluded to the demarcation and division of spaces in order to differentiate between public and private use;

- Image, which included the capacity of the physical design to impart a sense of security on the resident or intruder; 
- And milieu, which referenced other features that affected security, such as proximity to a police station or a busy commercial area.

Simultaneous to the development of "defensible space", though largely ignored throughout the 1970s, was the multi- disciplinary approach of Crime Prevention through Environmental Design (CPTED), formulated by the criminologist $C$. Ray Jeffery. More comprehensive than the concept of "defensible space", CPTED acknowledged that an urban fabric of highly segregated land uses, unavailability of mixed and diverse urban functionality, badly managed public spaces, inadequate provision for movement and other pedestrian amenities, deficient attributes with which residents could identify, empty buildings, insufficient lighting, and occasionally clusters of night entertainment were some of the factors that isolated, or in combination, contributed to insecurity in cities. Accordingly, CPTED argued for the amendment of the built environment in order to deter criminal behaviour. With the publication of the Broken Window Theory by Wilson and Kelling in 1982, CPTED achieved larger acceptance across the prevention community and was subsequently implemented across North America and Europe for public spaces, private housing facilities, businesses, banks (including automatic teller machines), industry, and other private structures (Rand 1984). Similar to the concept of "defensible space", the central components of CPTED reflected the work of Jane Jacobs (1961), arguing for an increase in natural surveillance of streets and other public spaces, while simultaneously encouraging an enhanced sense of territoriality or belonging to place. These central components included:

- Surveillance and visibility;

- Territoriality and defensible space;

- Access and escape routes;

- Activity support;

- Image and aesthetics;

- Target hardening;

- And maintenance or management (Coaffee 2003)

Advancing this comprehensive view, the concept of situational crime prevention incorporated management and use issues into the prevention of criminal opportunities that arose from the routines of everyday life. The concept of situational crime prevention strongly relied on the Routine Activity Theory of Cohen and Felson (1979) and the Rationale Choice Theory of Clarke and Cornish (1985). It conceived crime as a specific function of the opportunities and rewards offered by the physical and temporal environment: certain situations and physical forms were argued to provoke individuals to commit particular types of crime (Schneider \& Kitchen 2002: 106). Therefore, the concept recommended opportunity-reducing techniques such as the securing or hardening of potential targets, the improvement of surveillance for areas that might attract crime (through, for example, closed-circuit television surveillance), and the deflection of potential offenders from settings in which crimes might occur (by, for example, limiting the access of particular people to 
shopping malls and other locales (von Hirsch et al 2000)). Compared to CPTED, situational crime prevention encompassed the entire range of environments (and objects) involved in crime and likewise incorporated legal and management, as well as design solutions; therefore, it has been argued to be broader than CPTED, which tended to be solely focused on the design of the built environment (Clarke 1997: 9).

Resultant from these various approaches to violence and crime prevention, environmental criminology developed in the early 1980 s as a scientific study to evaluate crime, criminality, and victimization as they related to 1.) particular places, and 2.) the way that individuals and organizations shaped their activities on account of the spatial form of such places. The environmental criminology approach argued for "objective analysis of the spatial and temporal variation in crime patterns in order to discover aggregate factors influencing [these] patterns" (Brantingham and Brantingham, 1991: 239). Specific focus was given to space, time, law, offender, and target or victim, which were professed to be interdependent factors in producing crime: without one, the other four, even together, would not constitute a criminal incident (Ibid). Environmental criminologists, in line with the CPTED and situational crime prevention approaches, therefore began appraising land usage, traffic patterns, street design, and the daily activities and movements of victims and offenders in evaluating criminal occurrences. Such a focus precipitated the proliferation of statistically-based crime mapping tools, which transformed crime data into spatial crime patterns and trends. Consequently, crime mapping has become an "invaluable" tool in police management across North America, enabling the assessment and replication of prevention ideas which have shown particular success (Schneider \& Kitchen 2002).

The review of these approaches and the progression of violence prevention into its current focus communicates three fundamental attributes of violence prevention, namely that successful methods for prevention must incorporate the capacity to:

- Address the comprehensive factors contributing to violence;

- Transform spaces of chronic violence;

- And provide mechanisms, through which programs can be consistently evaluated, and thus, accordingly amended, when necessary.

These attributes are integral in developing, realizing, and continuing violence prevention programs. However, place-based approaches to crime evaluation and prevention have been argued to neglect important social and management vectors. Specific critique has been directed at the deficient linkages between physical intervention, social violence prevention, and community participation (Marc \& Willman 2010: 79; CSIR 1997). Moreover, as one of the most common weaknesses in country experiences with violence prevention has been inadequate coordination between the reform of security systems and complementary action to improve justice systems, the necessity to strengthen security and justice functionality, alongside physical upgrading programs, is paramount (World Bank 2011: 18). 
Therefore, crime and violence prevention must complement the three attributes above with the capacity to:

- Incorporate social components into prevention;

- Strengthen security and justice institutions;

- And facilitate community interaction and participation in the development of violence prevention programs.

These additional attributes enable prevention to address visible (direct) incidences of violence while simultaneously affording the capacity to attend to the invisible (structural and cultural) occurrences of violence as well. For further contextualization, these additional attributes are expounded upon in the following sections, which likewise communicate practical examples with a spatial (place-based) orientation.

\section{The Incorporation of Social Components into Prevention Initiatives}

Violence prevention programs must sufficiently incorporate social components into programmatic elements, as many situations of urban violence derive from societal discrepancies of poverty and inequality, or exacerbate social functionality such as deficient social control, limited communal cohesion, and perpetual gender disparities. As such, significant attention should be given to the needs of women as well as children and youth affected by insecurity: these groups are disproportionately represented in crime and violence statistics (World Bank 2011: 6) and moreover, show particular capabilities for instilling the mechanisms needed for the long-term reduction of violence. Therefore, prevention mechanisms should focus on improving the ability of individuals, groups, and communities to challenge the problems of crime and violence, while simultaneously advancing the provision of community facilities that endorse the production of social capital (UN-HABITAT 2007: 96). "The outcomes of many social intervention programs indicate that investing in individuals bears greater results than [simply] investing in structures" (Ibid).

Recognition of this is illustrated in the Green Line initiative of the municipality of Aguascalientes, in central Mexico, which introduced spatial mechanisms to directly address social functionality, such as insufficient recreational infrastructure for an increasingly young population, as well as programs to attend to deficient cultural and educational opportunities (Municipio de Aguacalientes 2011: 9). Through the Green Line initiative, the municipality redeveloped $12 \mathrm{~km}$ of land covering a gas pipeline (60 ha), installing a community centre -with game room, library, medical facilities and spaces to develop citizenship skills -, 10 parks and recreational facilities for children, and areas for social and family life (civic plazas, terraces, and rest areas), all with universal accessibility (Figure 3.) (Ibid).

The short term results of the initiative have been substantial: an immediate decrease of $20 \%$ in crimes in the communities neighbouring the Green Line has been experienced, including tangible reductions in the occurrence of fights, homicides, rape, and robberies of homes, cars, and 


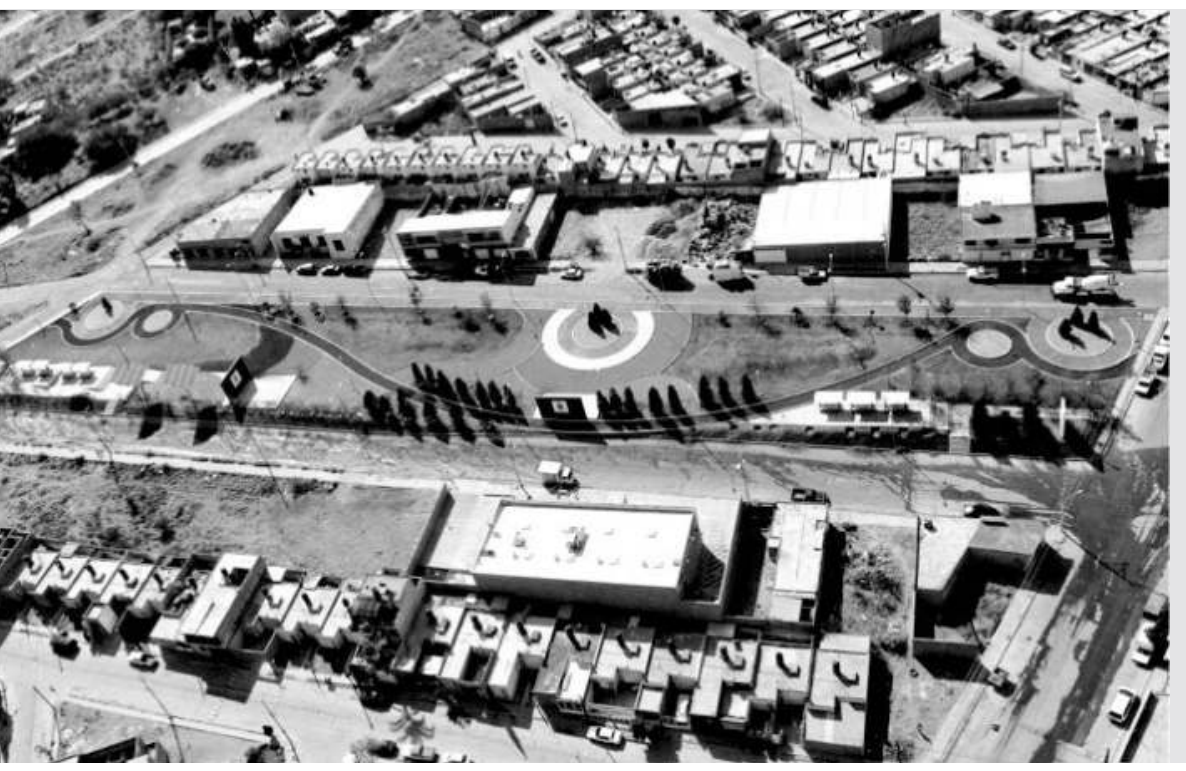

Figure 3: A Section of the Green Line Redevelopment in Aguascalientes, Mexico. Source: Municipio de Aquascalientes 2011

automotive parts (Municipio de Aguascalientes 2011: 13). Further examples of the incorporation of social components into prevention initiatives are communicated later in this anthology.

\section{Provisions for the strengthening of security \& justice institutions}

Supplemental to the incorporation of social components into violence prevention initiatives, significant provision for the strengthening of security and justice institutions is particularly important, as such endeavours can often be enacted fairly quickly, thus garnering communal support for violence prevention activities. The support of existing security and justice structures reduces the probability that citizens "will take the law into their own hands via vigilante justice or the hiring of private security" (Morrison et al 2003: 11). Both these actions tend to "escalate the degree of violence employed in crimes against people and property that are protected by such ['institutions',] and concentrates crime and violence among populations who cannot afford private protection, thus increasing [their] vulnerability" (Ibid).

Security and justice reform programs should initially "focus on simple basic functions ; include civilian oversight, vetting, and budgetary/expenditure transparency to dismantle covert or criminal networks; and link the pace of reform between the police and civilian justice systems" (World Bank 2011: 18). As previously noted, one of the most common weaknesses in country experiences has been increasing actions to reform security systems without complementary action to reform justice systems. Such a situation causes several problems, "as increases in arrests by the security forces -not processed by the court- results in either grievances over prolonged detention without due process " or the direct release of offenders back into the communities they have previously molested (Ibid: 256). Furthermore, "where civilian justice systems are absent in insecure areas, the military and police will end 


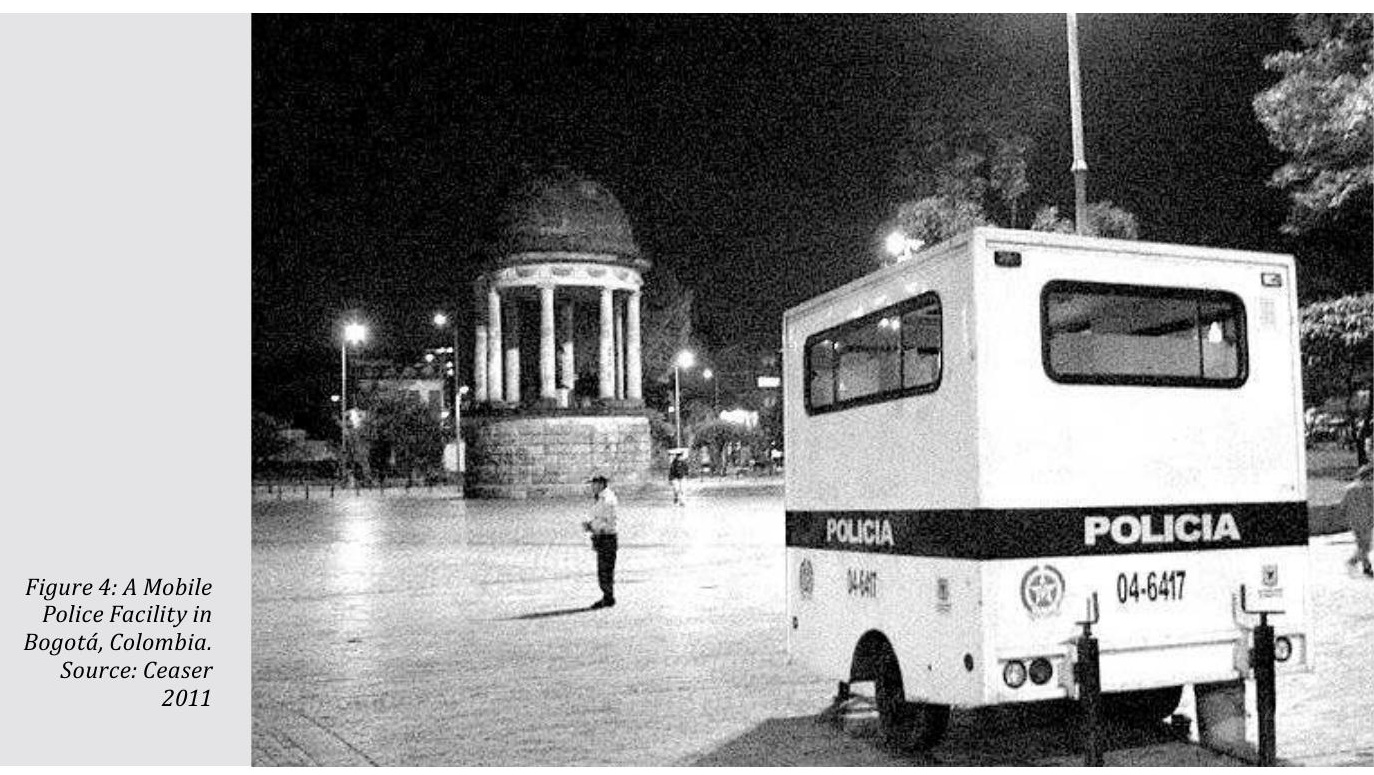

up performing justice and correction functions beyond their mandate and capacity" (Ibid). This has a high propensity for reiterating perverse individual coping mechanisms to insecurity, and further perpetuating violence.

In response to deficient municipal security and justice coverage, Colombia provides exemplary prevention planning precedent through the delivery of local justice institutions in under-served informal communities. In Bogotá and Cali, one to two room 2 policemen police stations were created in strategic locations to detect and prevent violence and crime (Figure 4.) (Shaw \& Carli 2011: 73). In the capital alone, 6,600 of such stations were realized to increase the cooperation between the police and the community, and generate rapid and significant results (Marc \& Willman 2010: 92). Also in Bogotá, family police stations (Comisarías de Familia) were similarly created in predominantly informal communities so that families would be "informed about conflict resolution, domestic violence prevention, and child abuse issues" (Ibid). Such institutions incorporated an interdisciplinary team consisting of a lawyer, psychologist, doctor, and social worker, and provided comprehensive familial mediation services to prevent violence in the home (Ibid). Two congruent programs, Houses of Peace (Casas de Paz), in Cali and Houses of Justice (Casas de Justica) in Bogotá were likewise established "to resolve everyday conflicts, such as disagreements, rights violations, and alimony issues" on the communal level (Ibid: 93). These institutions have achieved substantial success: Houses of Justice alone have assisted over 7.8 million citizens, predominantly from low-income communities, since their inception (World Bank 2011: 155).

\section{The incorporation of community participation}

Perhaps the most important and decisive attribute in the prevention of violence is the capacity to facilitate community interaction and engender participation in violence prevention initiatives. As stressed in the 
Guidelines for the Prevention of Crime, governments cannot preventcrime and victimization or develop safe societies without the participation and involvement of citizens. Private citizens, community organizations, nongovernmental organizations, the private sector, and the business community "offer in-depth knowledge and creative insights [pertaining to violence], based on their experiences and innovative responses" (Shaw 2010: 103). Furthermore, such individuals hold a spatial allegiance to localities, which is key to "creating a sense of community: if residents do not identify with a neighbourhood and view it as a temporary home, it makes it difficult to create meaningful social networks" (Davis 2012: 6). Thus, "participation must be understood as a [key] instrument for effective community organization and management" (Alemán 2009: 17).

"In order to strengthen the bonds of cooperative autonomy, communities should be delegated greater responsibility for management, assessment, and decision making about daily urban conditions in their immediate localities" (Davis 2012: 19). Programs focused on the care and management of public spaces or other shared community infrastructure "can go a long way in keeping sustained connections within and between citizens and governing authorities," especially in growing metropolises of the developing world (Ibid). Such connections between the state and citizens "links them to each other in ways that allow increased community autonomy from the agents of violence," and promotes the realization of focused practices, which will in turn, more directly address the origins of violence (Ibid).

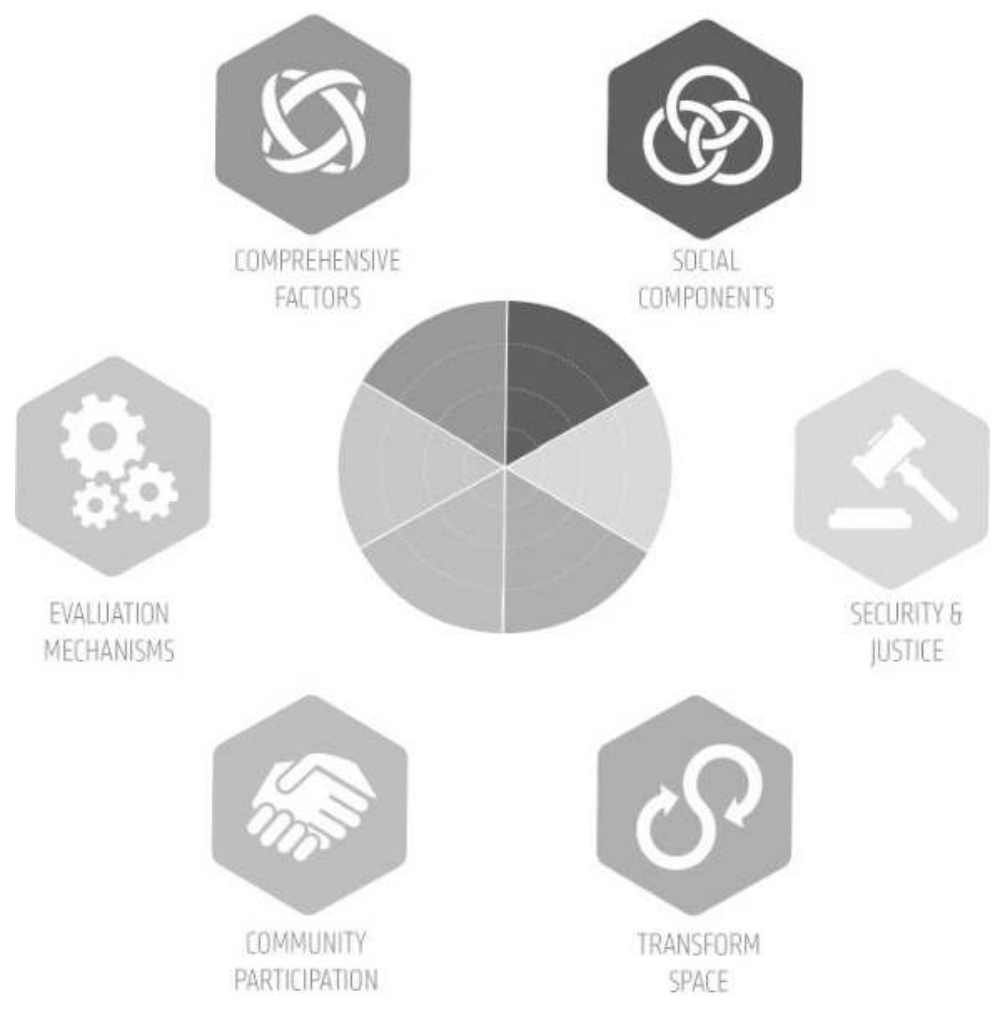


Understanding this reality, the Instituto Sou da Paz in São Paulo, Brazil, included members of the community, particularly young adults, in discussions and debates about public space. Such activities were realized to engage adolescents in the conception, implementation, control, and management of the public realm (Shaw \& Carli 2011: 125). The construction of the space marked the second phase of the project: "young people in the community [were] selected and trained on a range of issues relating to the management and maintenance of the space, [which included] training in accessing resources, building relationships with public authorities and services, and conflict resolution/peace building" (Ibid: 126). Such participation encouraged public spaces of safety -in which community activities could take place- through strengthen community solidarity (Ibid: 125). The experiences of other authors in this volume reiterate this finding; therefore, community participation is one of the most important attributes of violence prevention practice, largely determining the longevity of any violence prevention initiative.

In an attempt to reiterate the affiliation of these individual attributes, along with the previously communicated ones, Figure 5. exhibits the six attributes assembled as a collective unit to represent the corresponding processes through which they work with and across each other in constant development for enhanced security. Though it might be argued that some attributes are more important than others, enhanced violence prevention cannot be achieved without the inclusion of all six: successful provisions for social functionality, the transformation of space, and enhanced security and justice institutions cannot be derived without a comprehensive understanding of a situation of violence; nor can such provisions be sufficiently achieved without community participation or significant evaluation to determine a program's progress, according to original objectives.

The following works in this volume echo this appeal for more comprehensive and socially-cognizant violence prevention. Moreover, they highlight the need for greater discussion of violence prevention within the context of urban design, development and planning: as metropolitan populations across Latin America, Sub-Saharan Africa, and South and Central Asia continue to grow, the increasing number of individuals exposed to limited resources, competition for employment, dense settlement patterns, and the occurrence of crime has the propensity to exacerbate the incidence of violence. Therefore, mechanisms for the prevention of urban insecurity -particularly in currently violent and urbanizing regions - will be increasingly relevant over the proceeding decades.

\section{References}

Agbola, T. (1997): The Architecture of Fear; Urban Design and Construction Response to Urban Violence in Lagos, Nigeria. Ibadan: IFRA/ ABB.

Agostini, Giulia; Chianese, Francesca; French, William; Sandhu, Amita (2010): Understanding the Processes of Urban Violence:: An
Analytical Framework. European Interagency Security Forum (4/11/2013). Available online at http://www.eisf.eu/resources/item/?d=4176.

Ayala Alemán, Alonso (2009): Community Organisations, Misiones, and Integration of Barrios of Caracas, Venezuela: The Case of the CAMEBA Upgrading Project. Rotterdam 
(6/30/2013). Available online at http://www. ihs.nl/fileadmin/ASSETS/ihs/IHS_Publication/IHS_Working_Paper/IHS_WP__021_Ayala_Aleman__Alonzo__Community_organisations_misiones_and_integration_of_Barrios_of_ Caracas_2009.pdf.

Aslam, Abid; Szczuka, Julia (2012): State of the World's Children 2012: Children in the Urban World. New York (5/7/2013). Available online at http://www.unicef.org/sowc2012/.

Brantingham, P. J. \& Brantingham, P. L. (1991): Environmental Criminology. Prospect Heights, IL: Waveland Press.

Ceaser,Mike.(2011):Crimein LaCandelaria.Unas Escenas Y Comentarios Desde Bogota, Colombia. Blogger, 28 Apr. 2011.(6/05/2014). Available at $<$ http\%3A\%2F\%2Fmikesbogotablog.blogspot. de $\% 2$ F 2011\%2F04\%2Fcrime-in-la-candelaria. html>.

Center for Disease Control and Prevention: Veto Violence: Violence Education Tools Online. Atlanta (7/7/2013). Available online at http://vetoviolence.cdc.gov/basics-primaryprevention.html.

Clarke, R. V. G. (1997): Situational Crime Prevention; Successful Case Studies. Second Edition. New York: Harrow and Heston, 1997.

Clarke, Ronald V. and Cornish Derek B. (1985): Modeling offenders' decisions; a framework for research and policy. In M. Tonry and N. Morris (Eds.): Crime and Justice; An Annual Review of Research. Chicago: University of Chicago Press, Volume 6. pp. 147-85.

Coaffee, Jon. (2003): Terrorism, Risk, and the City: The Making of a Contemporary Urban Landscape. Aldershot: Ashgate.

Cohen, Lawrence E., and Felson, Marcus. (1979): Social Change and Crime Rate Trends; A Routine Activity Approach. American Sociological Review 44.4: 588. Available online at: http://www.jstor.org/discover/10.2307/ 2094589 ? uid $=3737864$ \&uid $=2$ \&uid $=4$ \& si $\mathrm{d}=21104529511133$.

Davis, Diane E. (2012): A Toolkit for Urban Resilience in Situations of Chronic Violence. Massachusetts (5/09/2013). Available online at http:// web.mit.edu/cis/urban_resilience.html.

Davis, Mike. (1990): City of Quartz: Excavating the Future in Los Angeles. London: Verso.

Fischer, Dietrich (2007): Peace as a Self-Regulating Process. In Charles Webel, Johan Galtung (Eds.): Handbook of Peace and Conflict Studies. London, New York: Routledge, pp. 187-205.

Galtung, J. (1969): Violence, Peace, and Peace Research. In Journal of Peace Research 6 (3), pp. 167-191, checked on 4/30/2013.

Galtung, Johan (2007): Introduction: Introduction: Peace by Peaceful Conflict Transformation - the TRANSCEND Approach. In Charles Webel, Johan Galtung (Eds.): Handbook of Peace and Conflict Studies. London, New York: Routledge, pp. 14-32.
Horwood, Chris (2007): The Housing Crisis: Cairo: Sheltering the Urban Poor. In Chris Horwood (Ed.): Tomorrow's Crises Today. Malta, pp. 74-83. Available online at http://www.irinnews.org/IndepthMain.aspx? InDepthID=63\&R eportID=74973, checked on 5/7/2013.

Jacobs, Jane (1961): The Death and Life of Great American Cities. New York: Random House.

Krause, Michael (2011): Violence Prevention through Urban Upgrading in the Township of Khayelitsha, Cape Town, South Africa. In TRIALOG Journal for Planning and Building in the Third World 1 (108), p. 26, checked on 6/30/2013.

Krug, Etienne; Dahlberg, Linda; Mercy, James A. (2002): World report on Violence \& Health. Summary. Geneva (4/8/2013). Available online at http://www.who.int/violence_injury_prevention/violence/world_report/en/.

Marc, Alexandre; Willman, Alys M. (2010): Violence in the City: Understanding and Supporting Community Responses to Urban Violence. Washington D.C (3/6/2013). Available online at http://web.worldbank.org/WBSITE/EXTERNAL/TOPICS/EXTSOCIALDEVELOPMENT/EXT CPR/0,,contentMDK:22801148 menuPK:40774 6 pagePK:64020865 piPK:51164185 theSite PK:407740,00.html.

Meade, Fiona (2009): Inside Out: An Organizational Map for Primary Violence Prevention. Adelaide (7/4/2013). Available online at http:// www.who.int/violenceprevention/inside_out. pdf.

Morrison, Andrew (2003): Guidelines for the Design of Violence Reduction Projects. Washington D.C (4/10/2013). Available online at http:// www.iadb.org/en/publications/publication-detail,7101.html?id=26152.

Moser, Caroline 0. N. (2004): Urban Violence and Insecurity. An Introductory Roadmap. In Environment and Urbanization 16 (2), pp. 3-16, checked on 3/18/2013.

Moser, Caroline 0. N.; McIlwaine, Cathy (2004): Encounters with Daily Violence in Latin America: Urban poor perceptions from Columbia and Guatemala. New York: Routledge.

Muggah, Robert (2012): Researching the Urban Dilemma: Urbanization, Poverty and Violence. Ottawa (4/9/2013). Available online at http://www.idrc.ca/EN/Programs/Social_ and_Economic_Policy/Governance_Security_and_Justice/Pages/ArticleDetails. aspx?PublicationID=1096.

Municipio de Aguascalientes (2011): Green Line: A Comprehensive Social Rescue Project. Municipio de Aguascalientes, 1/1/2011, checked on 6/19/2013.

Newman, Oscar (1972): Defensible Space: Crime Prevention through Urban Design. New York: Macmillan.

Peirce, Neal R.; Johnson, Curtis W.; Peters, Farley (2008): Century of the City: No Time to 
Lose. New York: Rockefeller Foundation.

Santa-Barbara, Jack (2007): Peace Business: An Introduction. In Charles Webel, Johan Galtung (Eds.): Handbook of Peace and Conflict Studies. London, New York: Routledge, pp. 232-247.

Schneider, Richard H., and Kitchen, Ted. (2002): Planning for Crime Prevention: A Transatlantic Perspective. London: Routledge.

Shaw, Margaret (2010): Handbook on the Crime Prevention Guidelines: Making them work. New York (3/07/2013). Available online at http:// www.unrol.org/article.aspx?article_id=130.

Shaw, Margaret; Carli, Vivien (Eds.) (2010): Practical Approaches to Urban Crime Prevention: Proceedings of the Workshop held at the 12th UN Congress on Crime Prevention and Criminal Justice. 12th UN Congress on Crime.
Salvador, Brazil. Montreal: International Centre for the Prevention of Crime. Available online at http://www.unodc.org/pdf/criminal_justice/ Practical_Approaches_to_Urban_Crime_Prevention.pdf, checked on 4/8/2013.

The World Bank (2011): World Development Report 2011: Conflict, Security, and Development. Washington D.C (3/07/2013). Available online at http://web.worldbank.org/WBSITE/ EXTERNAL/EXTDEC/EXTRESEARCH/EXTWDR S/0, contentMDK:23252415 pagePK:478093 p iPK:477627 theSitePK:477624,00.html.

University of Maryland Institute for Governmental Service and Research (2013): What Is CompStat? College Park (21/7/2014). Available online at: http://www.compstat.umd.edu/ what_is_cs.php\#references. 



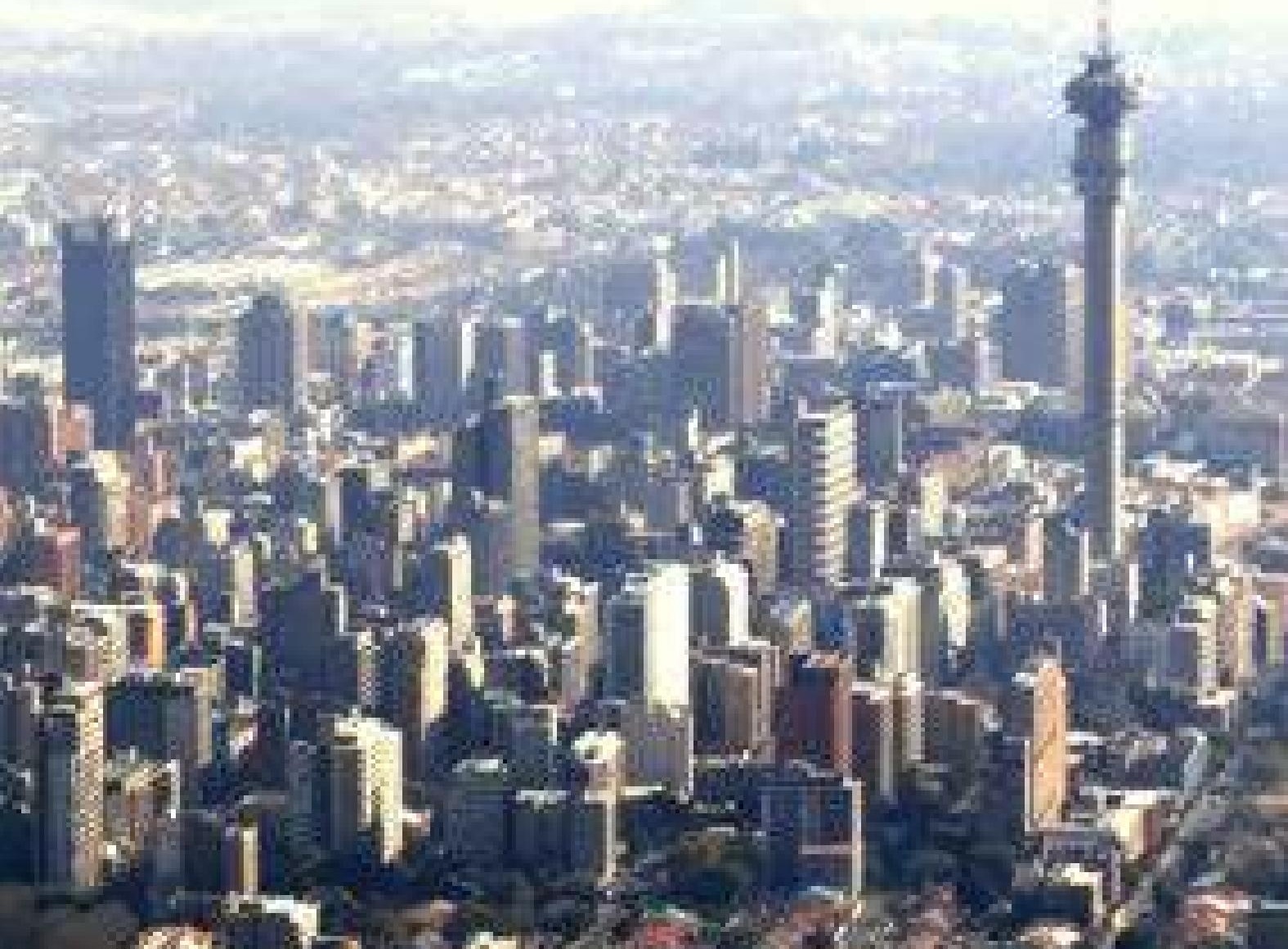
Hat

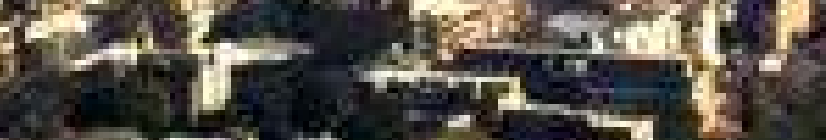

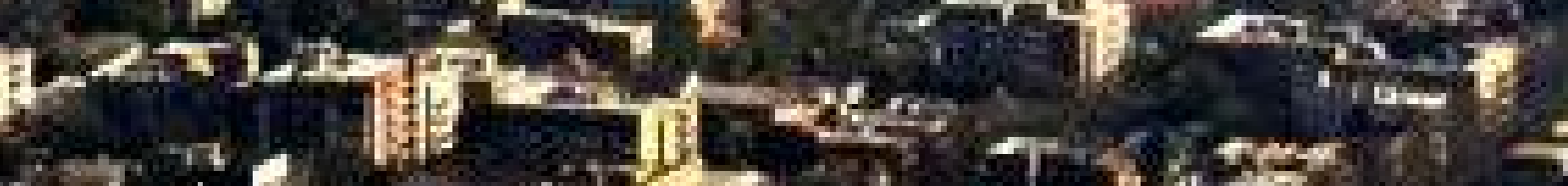

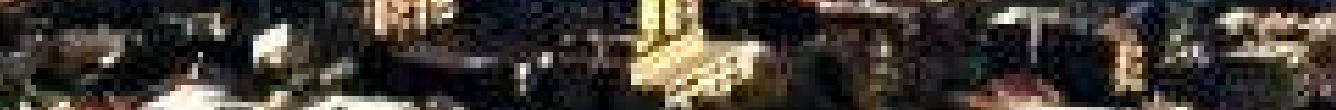

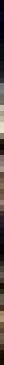




\title{
Ethnopolitics, Fear and Safety in a Johannesburg Neighbourhood
}

\author{
Obvious Katsaura
}

Fearfulness appears to have become a way of life in modern society. Many of us - or so we are told - are afraid to go out on the streets of our towns, at night certainly, but even during daylight hours as well. Yet staying at home carries its own threats: a whole industry manufacturing alarms, locks and surveillance mechanisms has been founded on our conviction that our homes are wide open to dangerous intruders. We view strangers with suspicion and the future with trepidation (Tudor 2003: 238-239).

This chapter, focusing on a cosmopolitan urban context of a Johannesburg neighbourhood, examines otherising and counter otherising dynamics in the field of community safety governance. The study examines the extent to which fear of crime and violence in Johannesburg is also cast as a fear of supposed strangers, especially in contexts of existence in superdiverse contexts. Fear of real or imagined violence and crime (and other urban disorders) has a huge impact on the spatial and social organisation of contemporary cities (Sandercock 2003; Tudor 2003). Spatial impacts include the creation of gated neighbourhoods, road closures and adoption of military technologies by residents seeking to protect their spaces (Davis 1998; Landman 2004a; Landman 2004b; Landman 2008; Murray 2011). Social impacts include the formation of safety governing community organisations, neighbourhood associations, mob justice and other preventive, adaptive or reactive individual or social group practices (strategies and tactics) (Armstrong, Francis and Totikidis 2005; Haefele 2002; Olima 2006; Totikidis, Armstrong and Francis 2005a; Totikidis, Armstrong and Francis 2005b).

Previous page: Johannesburg city centre. Source: istockphoto. Order 23921918

Fear is a ubiquitous perception of many cities' residents, visitors, planners, managers and politicians, among other stakeholders (Body-Gendrot 2012; Dirsuweit 2002; Dirsuweit 2007; Sandercock 2005; Tudor 2003). In Svendsen's (2008:48) words, "fear has become a way of looking at the 
world" - a "culture" (Svendsen 2008). Bauman (2006:2) formulates the concept of "liquid fear" to describe the fearsomeness of "diffuse, scattered, unclear, unattached, unanchored, free floating fear"; which has "no address" and supersedes rationality in influencing human action (Bauman 2006). "Fear has become an emotion that controls the public and a number of social scientists now claim that today's society can best be described as a culture of violence", writes Svendsen (2008:12). The view that we are increasingly experiencing what Febvre describes as "fear everywhere, fear always" captures the reality of life in in many cities (Tudor 2003). Given this background, I argue that fear is a liquid institution (cf. Bauman 2004) - formless and permeative. Fear can therefore be conceptualised as a social fact (Liska, Lawrence and Sanchirico 1982) - a reality that imposes itself on individual conscience ${ }^{1}$ (Charles 2006). Fear is therefore to be conceptualised as a phenomena as old as the city itself.

Johannesburg is, anyway, a city founded on violence and crime; and on continued attempts among strangers to seek fortune in this so-called "city of gold" in contexts of various performances of ethnopolitics ${ }^{2}$ - starting as early as the late 19th century when the city was founded on the discovery of gold at the Witwatersrand; attracting populations from the width and breadth of the world (Kynoch 2011). It is the contention of this chapter, that fear of the unknown, unpredictable and the strange - of crime and violence - and of the unfamiliar social agent or "the foreigner" percolates community organisation for safety governance, shaping imaginations or representations of crime and violence; as well as associated ethnonational prejudices and stereotypes. Ethnopolitics, as explored in this chapter within a context of dynamics of community safety activism and governance, is an expression of "urbanisms of fear"3.

From an empirical grounding in Johannesburg's innercity neighbourhood of Yeoville, I examine the socio-political contradictions associated with community organisation for safety governance. Yeoville is of interest because of its pan-African outlook - being a host to an African immigrant and South African population (Palomares and Quiminal 2012). Given its social diversity, Yeoville presents a potentially interesting case for understanding the ethnopolitics of community safety governance in the city of Johannesburg. In a context of Yeoville's co-habitation by a largely fragmented African immigrant and South African population (Katsaura 2012; Palomares and Quiminal 2012), one can question the efficacy of an invocation of "community" in safety governance policy and practice. Yet the South African government has officially turned to community as a panacea to crime and violence confronting South African societies (Pillay 2008).

However, this chapter shows that "community" in cosmopolitan contexts does not refer to a unitary and coherent entity as assumed in these invocations, but is rather, a constellation of multiple and often competing or coalescing social fragments. It argues further that the field of community security governance generates a socio-political space in which various ethno-national groups mobilise, take positions and jostle for recognition or protection. I examine two elements: i) the representations

01.

Reality sui generis in the Durkheimian sense.

02.

Ethnopolitics refers the allocation of differences, based on ethnic and/or national origin of a person or social group; otherwise referred to as ethnonational politics in this context. See Nederveen, 1996, 2007. Fumagalli 2007. Jamal, Amal. 2007.

03.

I use the concept of 'urbanisms of fear' to depict the culture of fear that pervades urban society. 
04

The concept of "other other" is used by Susan van Zyl to show the persistence of a differentiating and differentiated citizenship in postcolonial or post-apartheid South Africa despite attempts to wish away racism, classism sexism and other discriminatory classifications. I therefore develop this concept to analyse the exclusion or discrimination of non-South African blacks from South African public life, including participation in civic bodies. See van Zyl 1998. Siziba, Gugulethu. 2014.

05.

Ethno-discourses - ideas or debates informed by ethnicity or perceptions thereof/ ethno-talks - speeches informed by ethnicity or perceptions thereof/ ethno-practices actions and rituals informed by ethnicity or perceptions thereof/ ethno-practices - actions and rituals informed by ethnicity or perceptions thereof.

06.

The "established" are those neighbourhood residents that have been there for a long time and in this case, being South African citizens, while "outsiders" are the non-citizens (the African immigrants). and manifestations of the politics of ethno-national otherness and othering in the community security field; and ii) associated counter-otherisation discourses, practices and strategies Before getting into a narration and discussion of the two elements above, I lay out the theoretical context of the study.

\section{Theoretical grounding}

I start this discussion from the premise that social groups, based on their (foreign) ethnic and national origins, could be excluded from participating in community organisations and be accused of causing anomie and disorder (Barry 1998; Brubaker 1992; Elias and Scotson 1994; Kymlicka 2001; Kymlicka and Norman 2000; Nyamnjoh 2010b). I argue that ethno-nationality (and stereotypes thereof) constitutes a rule for inclusion or exclusion of individuals and groups in spaces of participation in community safety governance activities and discourses. If not deliberately excluded, ethno-national minorities can choose to isolate themselves due to their (acceptance of the) perception that they are different and do not belong (Barry 1998; Brubaker 1992; Kymlicka 2001). Ethnonational minorities, if poor, easily occupy the status of margizens (Schuilenburg 2008), urban outcasts (Wacquant 2008) or pariahs (Goffman 1963) - people with no or limited access to public goods or services (including safety). They are likely to suffer isolation, rejection and vilification by mainstream society. This typifies what Comaroff and Comaroff (2009:118) refer to as "the identity economy" - a socio-economy in which ethnic identity becomes a rule for access to economic, social and political resources. In referring to the status of African immigrants in South Africa, I deploy the concept of the other other ${ }^{4}$ to depict their multilayered social exclusion or isolation based on the stitched notions of ethnicity, nationality, race, class and gender, amongst others.

Processes of other othering - imaginary or real - and group making or unmaking as well as ethno-national "boundary maintenance" (Barth 1970) are akin to what Bourdieu conceptualises as regionalisation (Bourdieu 1991). Regionalisation is characterised by struggles over classification and definition of regional and ethnic identities and the properties (stigmata or emblems) linked to ethno-national origin (Bourdieu 1991). In the community security field, this is played out in discourses and practices - otherwise construed as "ethno-talks", "ethno-practices" or "ethno-consciousness" (Comaroff and Comaroff 2009). Such discourses and practices name, divide and rally social groups - creating divisions between "the established" (insiders) and the "outsiders"6 (Bourdieu 1991; Elias and Scotson 1994; Nyamnjoh 2006). The discourse of Kwerekwere ${ }^{7}$ is a typical example in the case of South Africa (Landau 2010; Landau and Freemantle 2010). The linguistic market of the security governance field, where such discourses are fermented, serves to generate and perpetuate stereotypes about crime and violence - its perpetrators, victims, spatialities and everyday-ness. This is reflected in what Caldeira, based on her studies in São Paulo, refers to as "talk of crime"8 (Caldeira 2000).

Faced with ethno-nationalist othering, social groups are likely to engage collective and individual strategies of protecting themselves. I 
refer to these as counter-otherisation tactics and strategies. This chapter therefore examines ethnopolitics in and of community safety governance; against a backdrop in which urban safety studies in South Africa overlook the importance of ethno-nationality in the configuration of local discourses, practices and strategies of community safety production. The South African body of available literature demonstrates connections between ethnicity and xenophobic discourses and practices in the public domain (Harris 2002; Kupe, Verryn and Worby 2008; Landau, Ramjathan-Keogh and Gavatri 2005; Neocosmos 2010; Nyamnjoh 2010a; Nyamnjoh 2010b); leaving a scholarly lacuna as far as understanding how these discourses and practices percolate community-based safety initiatives. I thus, here, explore dynamics of ethno-nationalist posturing, exclusion and isolation in the socio-political space of urban community safety governance. Below are highlights of the characteristics of the case study area, and their relevant socio-economic, crime and violence historical trajectories.

\section{Violence and crime discourses}

\section{Writing Johannesburg and the world from Yeoville}

Johannesburg is conceptualised as a city of contradictions; one epitomising the bifurcated nature of South African society and its ills (Mbembe 2004; Metileni 2011; Murray 2011; Nuttall and Mbembe 2007). There is a common perception that Johannesburg is a violence, crime and fear ridden city (Dirsuweit 2002; Dirsuweit 2007; Hook and Vrdoljak 2001; Louw et al. 1998) - one where the imminence of "terror" or "catastrophe" hovers (Bremner 2004). The city therefore battles with labels such as "crime capital of the world" (Boisteau 2005; Schönteich 2000), "the most

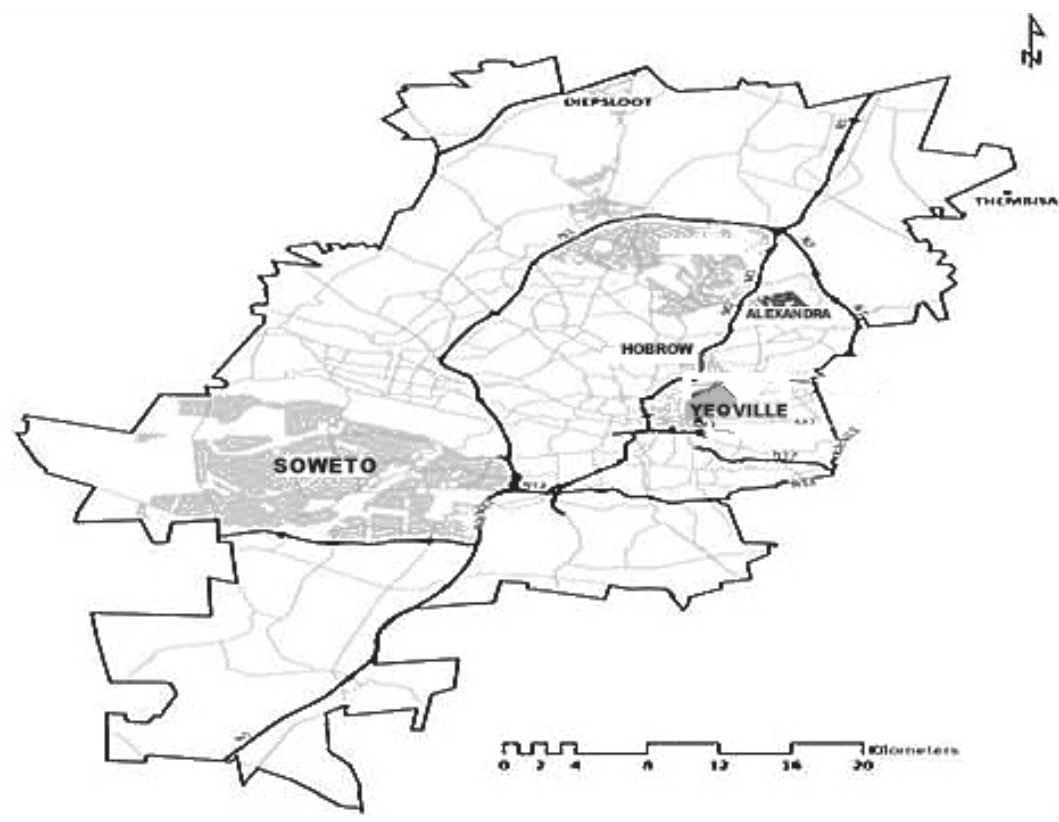

07.

The word

Kwerekwere is a South African derogatory term referring to people considered to look foreign and strange and to speak languages that one cannot decipher.

08.

That is everyday talks and legends about crime.
Figure 1: Map of Johannesburg showing location of study area Yeoville 
09.

Yeoville, Bellevue and Bellevue East geographically and politically constitute a single entity as they have a common economic hub in RockeyRaleigh Street. Unless clearly indicated, this study shall refer to the area comprising Yeoville, Bellevue and Bellevue East as Yeoville as is the tradition.

10

"Problematic" in that the city tries to stop street trade in Yeoville, generating tension with the traders. Street trade is also considered in many circles as criminogenic and contradicting the designated use of public space.

Map of the study area

violent city in the world" (Louw et al. 1998) and "fearful city" (Dirsuweit 2002). It is not surprising, therefore, that Johannesburg is considered as South Africa's "test case for controlling and preventing urban crime"; one in which success would "boost the confidence of both the public and police in the attempt to reduce crime" (Louw et al. 1998:4).

To explore ethnopolitical dynamics of safely community production in Johannesburg, I delve dynamics of community safety activism in Yeoville, one of the most cosmopolitan neighbourhoods of Johannesburg. The area loosely referred to as Yeoville here incorporates the neighbourhoods of Yeoville (proper), Bellevue and Bellevue East ${ }^{9}$.

Yeoville is an innercity neighbourhood located peri-centrally to the eastern side of Johannesburg City Centre. It is a low-income neighbourhood characterised by a long history of community activism, local and international migrancy and a vibrant, and yet "problematic"10, microeconomy of street trade (Benit-Gbaffou 2006; Harrison 2002). Observatory, which is a middle income area adjacent to Yeoville, is part of this study given that it falls in the same policing zone as Yeoville; being served by the Yeoville Police Station and by the Yeoville Community Policing Forum.

As the map shows, the policing precinct of this area that is loosely referred to as Yeoville is divided into three sectors (Sector 1 - Yeoville proper; Sector 2 - Bellevue and Bellevue East; Sector 3 - Observatory). Although not the primary thrust of my study, I find fruitful a reflective relational analysis of the politics of community safety initiatives in an inner-city area (Yeoville) and a middle income suburb (Observatory). Yeoville was selected because it typifies the ethno-national diversity, "socio-spatial deprivation" and socio-economic "fractality" characterising socio-spatial

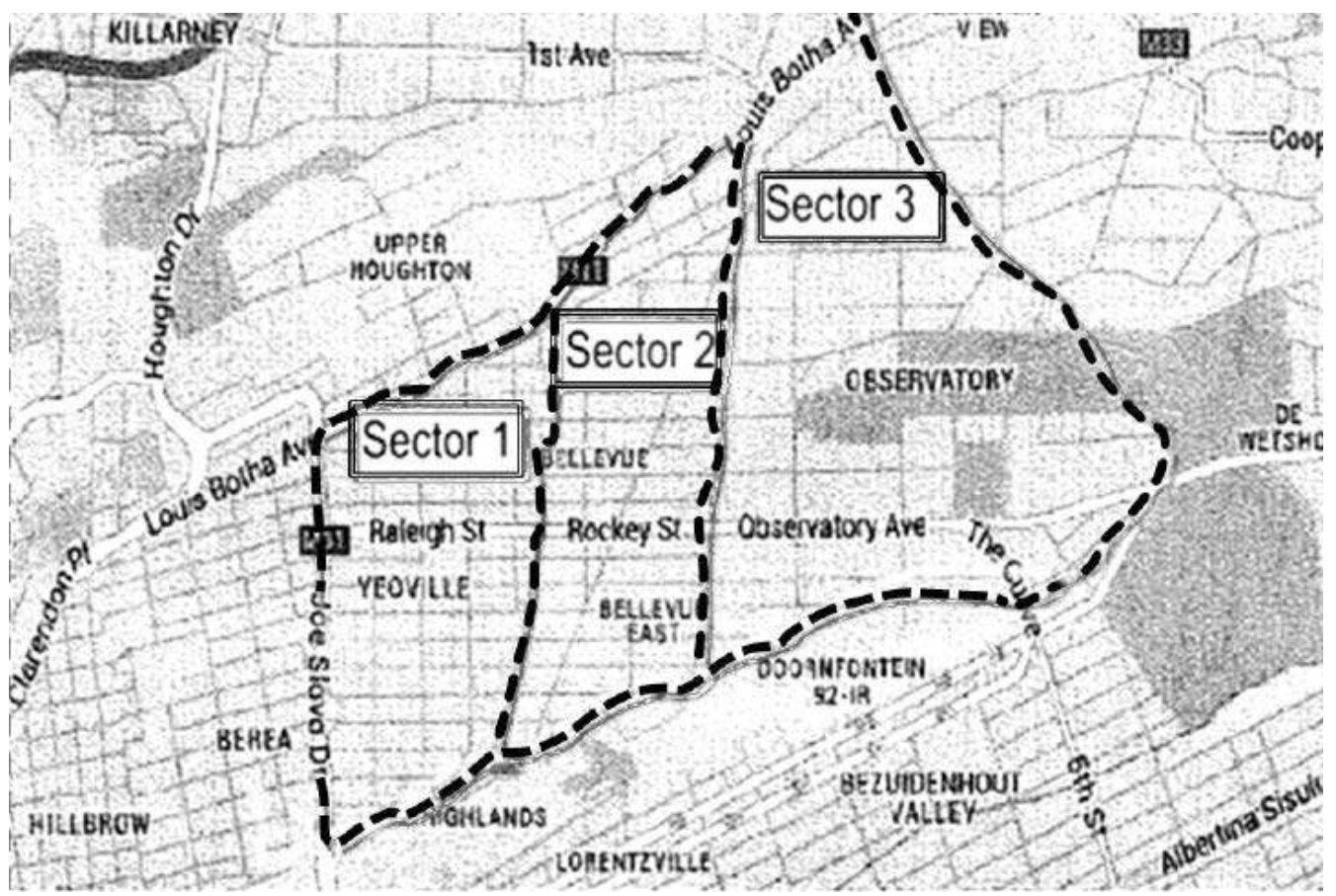


cityscapes of Johannesburg. Below, I briefly discuss the history of Yeoville, focusing on its socio-economic trajectory, crime, violence and fear histories.

\section{Yeoville's socio-economic, crime, violence and fear histories}

Yeoville's founding coincides with the early history of the founding of Johannesburg and is only 4 years younger than Johannesburg (YBCDT undated) ${ }^{11}$. It became designated as a "White only" neighbourhood during the apartheid era (Ibid). In the 1970s, it became a mainly Jewish suburb and an epitome of Jewish culture (Ibid). In the 1980s Yeoville is shown to have shifted into a cosmopolitan suburb where Blacks and whites coresided despite the context of apartheid. It largely retained this cosmopolitan urbanism as it hosted a largely migrant population from different parts of Africa and South Africa. Yeoville's population shifted from being 85\% White in 1990 into being 90\% Black by 1998 (Ibid).

Also, Yeoville is a suburb with a long history of activism against apartheid and the activist culture has been carried over to the post-apartheid era (Benit-Gbaffou 2006). Benit-Gbaffou (2006:303) observes that Yeoville is known to have quite a "vocal and energetic" Community Policing Forum because of the long history of political activism in the area (see a table 1 detailing organisations engaged in safety activism in Yeoville during the time of research).

The history of fear of violence and crime in Yeoville is sometimes corelated to white flight in the 1990s and the concomitant occupation of the neighbourhood by a largely Black population (Beavon 2004). White flight and associated fears of violence were justified on events that took place during the 1990-1994 period of political transition from apartheid to post-apartheid South Africa (YBCDT undated). This period marked the changing perceptions of Yeoville from one of a safe haven to one of a troubled space. The Yeoville Bellevue Community Development Trust notes:

"The death knell for that period was, ironically, the death of a Black Jamaican. Ridley Wright had married a South African exile and returned with her after 1990. He was owner of Crackers Deli, a popular cafe, and head of the Yeoville Trader's Association. In an altercation in which he attempted to protect a street corner drug dealer's wife from being abused by the drug dealer, he was fatally stabbed. It was downhill from there and by 2000, all of the shops and restaurants that gained fame in the 1980s were gone or transformed unrecognisably" (YBCDT undated).

Perceptions of Yeoville as a violent and crime ridden area have resulted in neighbourhood disinvestment and urban decay (Ibid). Increasingly, Yeoville, alongside other Johannesburg inner city areas like Hillbrow, Berea, Joubert Park and Betrams, has come to resemble what Murray (2011) describes as an outcast ghetto. The image of post-apartheid Yeoville is connected to the general image of Johannesburg, Gauteng and more generally, South Africa as places suffused by crime, violence and fear ${ }^{12}$.

Below, I describe and interpret dynamics and discourses of ethno-national regionalist scapegoating in the community safety field, starting off with

11.

YBCDT - Yeoville Bellevue Community Development Trust

12.

Crime statistics of Yeoville reflect the neighbourhood as inundated with violent crime. In 2011, 20 murders, 35 attempted murders, 555 assaults (GBH) and 479 cases of common assault were registered in Yeoville, a neighbourhood which only covers an area of $10 \mathrm{~km} 2$ with an estimated population of less than 40000 people as of 2011. 


\section{Table 1: \\ Community \\ Organisations/ \\ Forums engaged \\ in community \\ safety activism in \\ Community organisation \\ YCPF - Yeoville Community Polic- ing Forum / CPF - Community Policing Forum}

Yeoville
SCFs - Sector Crime Forums

YSF - Yeoville Stakeholders Forum

YCF - Yeoville Community Forum

ADF - African Diaspora Forum

\section{Brief description of activities}

It was a partnership between elected community members and South African Police Service. The main focus of YCPF was to help reduce crime in Yeoville. YCPF held monthly meetings with members of the police to discuss the local crime challenges in Yeoville. They also held occasional public meetings as and when necessary. They were the link between the police and the community, facilitating communication between the two. They also co-supervised and co-organised the street patrollers in conjunction with the police. I use abbreviations YCPF and CPF interchangeably in this thesis, the former being used where there is a need for specificity of the CPF being referred to and the latter is used in general terms.

Sector Crime Forums were sub-forums of the CPF. There were 3 sectors in the Yeoville poling precinct - Sectors 1 (Yeoville), Sector 2 (Bellevue) and Sector 3 (Observatory). SCFs conducted monthly meetings to discuss safety and security challenges.

It was an affiliation of 22 community organisations in Yeoville, operating as an umbrella body of these organisations. It was formed in 2004 at the behest of the Johannesburg Development Agency (JDA) as a contact community organisation during the period when JDA was implementing an infrastructural development programme in Yeoville's Rockey - Raleigh Streets. YSF conducted monthly meetings bringing together representatives of community organisations and other stakeholders in Yeoville. It was a platform for information sharing and solution seeking about and on local challenges in Yeoville.

It was an organisation created by a group of South Africans living in Yeoville to respond to the housing situation by lobbying the municipality and government to address the challenge of lack of housing, high rentals and the issue of hijacked building $\mathrm{s}^{13}$. During the early days of its inception in 2010, the YCF threatened militancy and violence in responding to the issue of hijacked houses.

ADF was formed in 2008 to respond to respond to the xenophobic violence that rocked South African in May 2012. The ADF claimed to have about 23 migrant organisations affiliated to it. It initiated education programmes and awareness campaigns to improve tolerance and co-living between South Africans and non-South Africans. 
mapping out the ethnopolitics of fear - of who fears, who is feared and what is feared.

\section{Constructing the criminogenic other}

Perceptions of and about African immigrants in Yeoville, like in the broader South African context, reflect the stereotypical problematisation and criminalisation of their very identities and beings (Landau 2010; Nyamnjoh 2006). A community activist in Yeoville underscored: "The easiest people to blame are foreigners. People who are illegal migrants get into criminal activities because they can't work ..." (Interview, Maurice: 22/09/2010). Commenting on relations between South Africans and African immigrants in Yeoville, an African immigrant stated:

"The relationships between foreigners and South Africans are not good. However, foreigners are still tolerant towards the behaviours of South Africans ... The problem is with South Africans seeing us as invaders. We as foreigners accept them, but for them to accept you it's a problem. They accuse us of taking their jobs. This behaviour is probably like that because most South Africans have never travelled... The ones who went outside [who have travelled] are friendlier to foreigners" (Participant, group interview with migrants: 11/08/2011).

In many cases African immigrants were scapegoated as the causers of rising socio-economic problems in South Africa, including crime and violence (Landau 2006a). They were viewed as a category deserving containment if further decay in South Africa's urban spaces, societies and economies is to be curbed (Hornberger 2011).

\section{"The easiest people to blame..."}

At the level of perception, the genesis of crime, violence and other urban disorders in innercity Johannesburg was, in many instances, associated with some regimes of city space occupancy by African immigrants (Legget 2002; Simone 2004; Vetten and Sadiyya 2005). Some public discourses classified criminal activities or potentials on the basis of stereotypes about ethno-national groups. A CPF leader expressed:

"The people who commit violent crimes are mostly Zimbabweans and Zulus. These ones use guns and knives. The Nigerians normally commit technical crime: electronic money transfers. Zimbabweans for crime are number one and Zulus as well. Mozambicans are good in muthit ${ }^{14}$. They make you sleep and come to collect everything in your house. Hey! Hey! We are in a shit... Everybody is coming here ..." (Interview, Mduduzi [YCPF member]: 08/08/2010).

Though controversial, there seemed to be a tendency amongst South Africans to criminalise "foreignness". In everyday common sensical understanding, as confirmed in an opinion and attitude survey and interviews contacted as part of this study, the tendency to criminalise "foreign nationals" was common place. In this regard, imaginations of connections between nationality and criminality generally put Zimbabweans at the top, followed by Nigerians and then South Africans. Zimbabweans

14.

Muthi is an African name for charms or traditional medicines.
13.

Hijacked houses are those houses that have been squatted and are under the unlawful control of an individual or group without the consent or approval of the owner. 
were generally associated with crimes such as muggings, robberies, petty theft, fraud and domestic violence. Nigerians were associated with drug dealing and fraud, while South Africans were associated with use of fire arms and robbery. Other nationalities mentioned included Mozambicans who were associated with car-jacking and use of firearms. Congolese nationals were associated with domestic violence. Generally, nationalities from West Africa were associated with fraud. Those who did not see any correlation between nationality and criminality indicated that they would not want to pinpoint any nationality, that crime was sometimes committed by syndicates composed of various nationalities including South Africans.

While the association of criminality with African immigrants was common in public discourses, there was also public sceptism about it. Asked if there was a connection between nationality and crime or violence types, a senior police officer responded:

“... I cannot just say a particular nationality [commits crime], because Yeoville is a multi-national community. So we cannot single out a particular nationality. Even South Africans are being arrested. For example, in January our team arrested 13 youths for carjacking and robbery. All of them were South African nationals. I cannot just make a correlation between crime and people's nationality." (Interview, Constable Mbuli: 18/08/2010).

In public and academic perceptions, innercity decay in Johannesburg was correlated to the immigration of a pan-African cohort from inside and structures...

The chairperson of Yeoville Stakeholders Forum (YSF). outside South Africa ${ }^{15}$. Urban decay, in Yeoville, was thus considered as concomitant with "white flight" the incoming of a predominantly Black population in the late 1980s, early 1990s and 2000s (YBCDT undated). With the wave of international immigration of Africans into Yeoville, there were allegations that these immigrants had turned many spaces in Yeoville into hubs of crime and social malaise.

\section{Problematic spatio-economic presence}

16. During a key informant interview and transect walk, Thabang ${ }^{16}$ described how the various spaces in Yeoville's main business street have been appropriated by various groups of migrants for various purposes. He indicated that corner Raymond and Rockey Street was a hub for Zimbabwean. At that corner, he indicated that there was a building called the green house where a crowd of Zimbabweans was found. Most of these Zimbabweans, according to him used cell phones to rob people and defraud banks and they also robbed shops and sold stolen goods. Thabang characterised Corner Hunter Street and Fortesque as a little Kinshasa. He stated that there were people who illegally produced passports, South African ID books and death certificates. At corner Grafton and Raleigh Street, according to him, there were Nigerian drug dealers who were always dressed in expensive clothes and drove expensive cars. According to him, Times Square, at corner Raleigh Street and Fortesque, there were many Zimbabweans. Behind Times Square, as he stated, there were lots of Ethiopians and Somalians. This place, according to him was a 


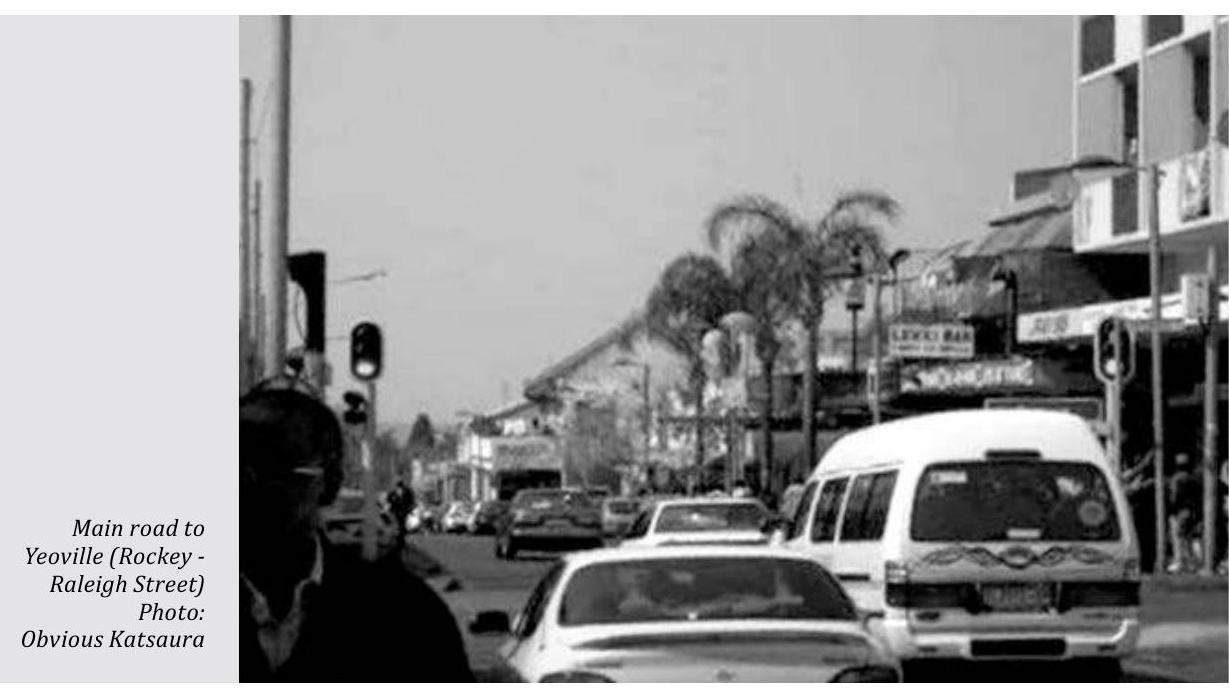

port of call for trafficked humans. He indicated that there was a big truck that came there at night to drop off trafficked Ethiopians and Somalians. He stated that Corner Hunter Street and Kenmerre Street was a place for Ghanaians. He alleged that these Ghanaians committed internet crimes together with Nigerians. He expressed that Nigerians were the masters of internet crime. In Raleigh Street, between Kenmerre Street and Bedford Street in front of Shoprite, according to Thabang, there were lots of young men hanging closer to ATMs ${ }^{17}$. At that spot pin numbers were memorised and money was being withdrawn fraudulently. At corner Raleigh Street and Bedford Street, as Thabang narrated, there was a cohort of Tanza17. Automatic Teller Machines nian dagga dealers doing business there.

In a bid to verify Thabang's description of ethno-national geo-strategies and spatial occupancy of street corners in Yeoville, I noted that his characterisation was grounded in his "common-sensical" observations of everyday socio-economic spatial trajectories of ethno-national groups. His characterisation was by and large simplistic given the maze of population mixing and criss-crossing characterising Yeoville. This maze makes it difficult, if not impossible, to confidently pinpoint the occupancy of a particular street corner by a specific ethno-national group.

What was a bit obvious, however, was a conglomerated network of business groupings based on ethno-national similarity or proximity; operating as cultural-economic enclaves (Caldeira 1996; Kahera 2002; Marcuse 2005a; Marcuse 2005b). These cultural-economic enclaves were, however, not always readily clear-cut as they tended be a hotchpotch people that was not easily readable. Such cultural-economic enclaves, apart from being enclaves of commerce, were also represented or labelled as criminal enclaves. A local activist stated: "There are certainly more serious crimes being committed in Yeoville such as bank fraud. I can talk about the various spaces and clusters of criminal activities associated with particular nationalities" (Interview, Thabang: 25/08/2010).

These ethno-national enclaves were perceived as criminogenic and the occupying African immigrants as potential or real criminals - as crimmigrant bodies (Aas 2011). 
Writing in Yeovue News, a South African contributor described the economic and spatial implications of the presence of African immigrants as problematic:

"Every self-respecting migrant should abide by the laws, by-laws, rules and regulations in their host country, in this case, South Africa. Migrants must not expect to do in a host country what they were doing in their original countries or, indeed, things they were not allowed to do in their countries because of stricter law enforcement...The reality we must boldly face is that most migrants in Yeoville Bellevue come from unplanned, underdeveloped cities with little infrastructural development and no effective by-laws or enforcement. Migrants need to orient themselves to life in South Africa [...]. Education around such things needs to take place without ill feelings." (Majombozi 2010).

The typical "African immigrant" was thus publicly represented as one who hailed from an anarchic African country and as ignorant and disrespectful of South African laws. Many African immigrants, by virtue of fleeing economic or political crises from their countries of origin and seeking better economic opportunities in South Africa, were viewed with contempt and as endangering others (Landau 2010).

It is therefore not surprising that "African immigrant" was already a targeted "object" of everyday policing in innercity neighbourhoods of Johannesburg (Hornberger 2004; Hornberger 2011). In light of this, a migrant human rights activist complained: "The law enforcement agencies are promoting crime. They are taking bribes. If you see someone getting arrested, they won't be having a bribe to give to the police" (Interview, Yonga-Yonga: 08/04/2011). This ethno-nationalised policing was abusive of African immigrants as police officers, who were supposed to protect the public, were even alleged to be harassing African immigrants and extorting bribes from them (Hornberger 2011). The scapegoating and criminalisation of immigrants was also overtly and covertly performed in spaces of public dialogue of spaces - referred to here as spaces of participatory safety governance.

\section{Discrimination in spaces of participatory safety governance}

18.

The Gauteng Province Communi-

ty Policing Board ( $\mathrm{CPCPB}$ ) is the one that oversaw the establishment and running of all $\mathrm{CPF}$ in the Gauteng Province.

Mirroring the culture of xenophobic otherism and scapegoating pervading South African public culture (Nyamnjoh 2010b), conditions in spaces of community deliberation on matters of local safety and security (wittingly and unwittingly) isolated African immigrants. They faced exclusion from official positions in the Community Policing Forums and related bodies. In its specifications of persons who should not hold positions in the Community Policing Forums in the Gauteng Province in which Johannesburg falls, the Gauteng Province Community Policing Board's ${ }^{18}$ constitution of 2010 clearly outlined that people who were not citizens of the republic of South Africa were not legible [section 22, subsection 22.2.5 (GPCPB 2010)].

Apart from this conscious institutionalisation of exclusion of non-South Africans from established spaces of public participation in community safety initiatives, there were other un-institutionalised means through 


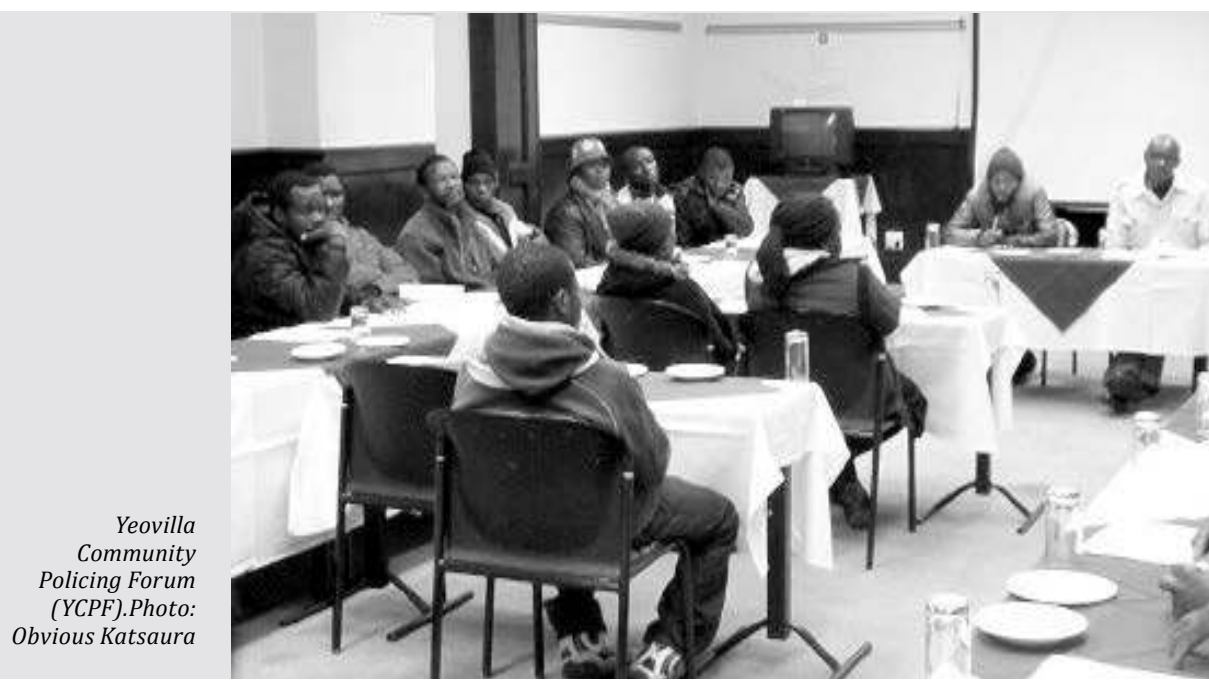

which this exclusion took place on the ground. For instance, the use of local languages in spaces of public participation was a constant cause of the isolation of "foreign nationals" in these meetings. Although some or most of the organisations officially used English as their main language of community engagement, many times South African speakers would switch to Zulu, Sotho or Xhosa; to the exclusion of some African immigrants and also some South Africans who did not understand these languages. In a ward public meeting, the chairperson of ADF had this to say:

"[...] I am busy learning the local languages. We want to participate and contribute as well, but we don't understand everything if you use the local languages. Somebody here said they are from Rwanda, another from Uganda and I am from Ivory Coast. Can you speak in a shared language please?" (Ward Public Meeting, Fagbibo: 14/08/2010).

Language as a means of human association is therefore a political tool, one that is deployable to confirm and entrench of socio-political difference. It can be a tool for the exclusion of particular groups of people who do not share the same language, by those whose language and cultural group is dominant. African immigrants were therefore excluded in that if they attended participatory or deliberative spaces of safety governance they were excluded linguistically or constantly reminded of their outsider status and had to sit through discussions in which they were scapegoated and criminalised during the drama of public participation.

\section{Encountering otherism: discourses and practices}

In a context characterised by the logic of otherisation and otherism, vulnerable groups have a tendency of inventing survivalist strategies of navigating hostile social and physical terrains. Thus amongst other things, immigrants can generate counter-otherisation discourses and practices that range from lobbying and engaging the perceived otheriser to withdrawal from intensive interaction with the perceived otheriser. 


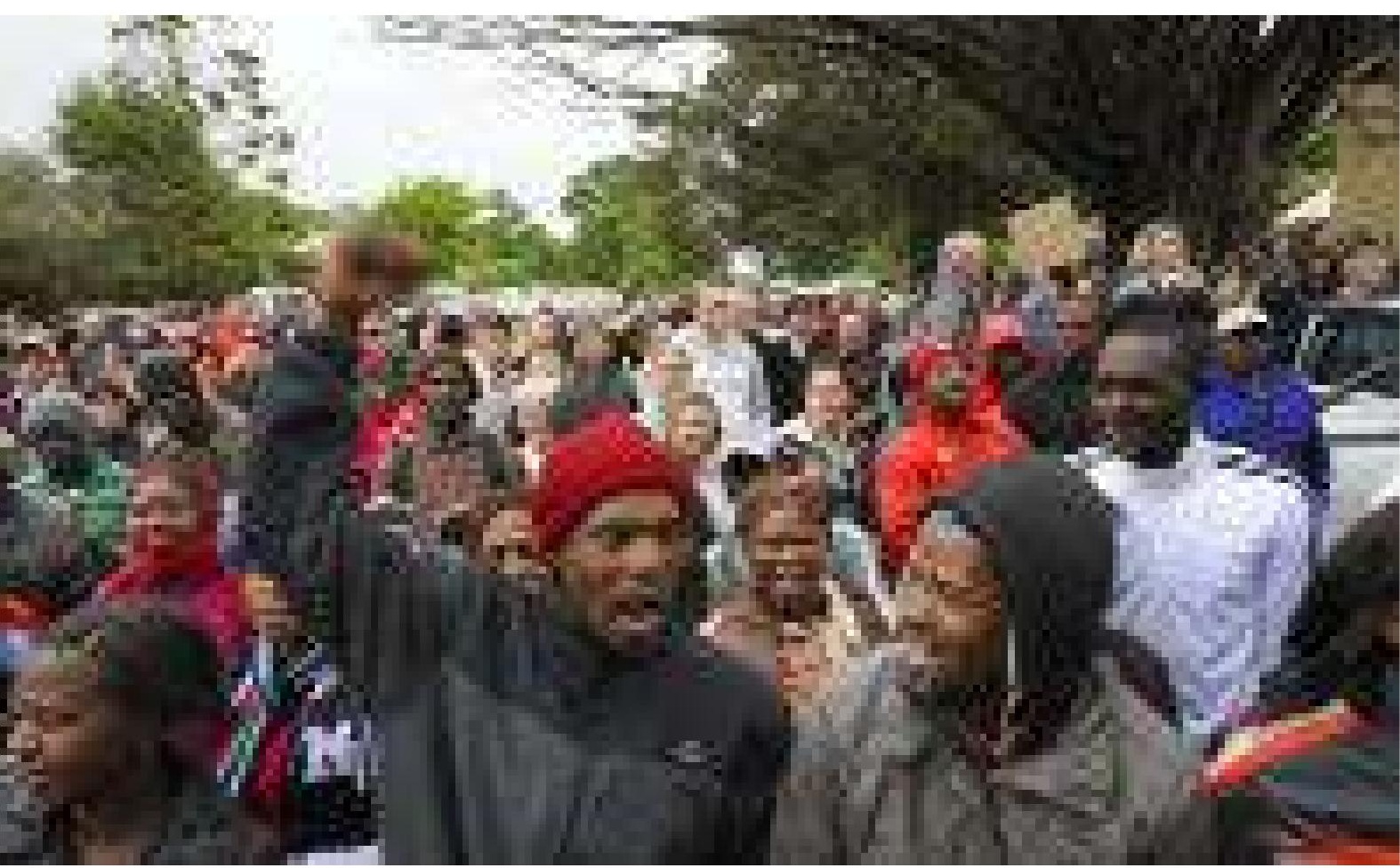

A community unites in a public demonstration at the local court to protest the brutal bludgeoning to death of Dan Knight, 2013. The savagery of this expression of ethnic violence sent shockwaves throughout the community, uniting the population across lines of race and social affiliation. Photo: iStockphotoLic. 834886821 RT0001

\section{Lobbying and engagement}

The association of criminality with African immigrants was dismissed by some Yeoville residents (African immigrants and South Africans included) as not fact, but a matter of just scapegoating. A migrant activist questioned:

"These people behave as if there was no crime before 1994 in South Africa. When someone breaks the law they write foreigner and the magistrate will know that you are a foreigner. It's not easy for migrants to get bail. Having the majority of people in prison as migrants doesn't mean that migrants are committing too much crime. The fact is that South Africans can easily get bail" (Interview, Omokoko: 08/04/2011).

In this hostile environment characterised by discrimination, exclusion, scapegoating and criminalisation of immigrants, it is not surprising that immigrants form associational spaces to advance their interests and where necessary, defend themselves. This is the context in which African Diaspora, an immigrant organisation headquartered in Yeoville, was formed. The chairperson of African Diaspora Forum explained:

"When the xenophobic violence started in May 2008, the government didn't do anything. We thought that the government would send the police of army to stop the violence, but it didn't. That's why we formed ADF to 
respond to this violence and to lobby government and other stakeholders to act. I had to use my own network, being a leader of the Ivorian community, to make sure that this endeavour was a success. As ADF, we work with migrants and we want to work with the South African community to combat xenophobia. We had projects in Alexandra and we worked with the police and CPF to deal with the people, educating them about other African countries... We have a strong network. We have a relationship with high ranking police officers. This helps us. When members of the migrant community are arrested unfairly we can deal with the matter easily. We can make phone calls to these high ranking people so that we get assistance. We also work closely with councillors and other local politicians who are useful to us" (Interview: Fagbibo: 26/08/2011).

Thus, African immigrants were not passive bodies or groups upon which criminalising and othering labels simply stuck. They engaged in countercriminalisation and counter-otherisation practices and tactics.

The African Diaspora Forum played an important role in lobbying and advocating change of perceptions of immigrants among the local population; with the hope if nurturing a spirit of peaceful co-existence. One migrant activist from African Diaspora Forum proposed:

"How do we get migrants to be accepted in South African communities and their contribution to the country and the communities they live in to be appreciated? I think it is important for us to publish profiles of migrants contributing towards the well-being of South Africa and we can do this through the proposed Diaspora News [...]" (ADF Meeting, YongaYonga: 26/02/2011).

This was a proposal for use of the media to reconfigure the public representation and image of immigrants; profiling their progressive contributions to the economy and society. In this respect, ADF used to have a newspaper insert called African Diaspora Forum News in The Star newspaper in 2009. Lobbying activities thus played a role in attempts to improve the perception of African immigrants by the South African public. On 3 March 2012, ADF created a task team to deal with policing issues affecting migrants. The task team was expected:

"To work in cahoots with the SAPS and CPF structures to encourage inclusive policing in relation for foreign nationals living in South Africa... This involves in particular regular participation in CPFs (meetings, activities, executives) in areas where migrants are numerous, and/or where there are specific issues of xenophobic policing... This task team should formulate, jointly with policing bodies or on its own, projects that address the challenges of xenophobic policing..."

Such lobbying was meant to encourage and promote migrant inclusive and friendly policing by SAPS. Activism against police harassment of immigrants involved other civic organisations. In the face of identitybased adversity, African immigrants have at best also adopted blameshedding strategies in public forums; campaigning against being scapegoated for local problems, including crime and at worst withdrawing from participating in public safety governing initiatives. 


\section{Withdrawal from spaces of perceived discrimination and danger}

Given the embeddedness of othering behaviour at governmental and grassroots levels, it was not surprising that there was a low level of attendance of YCPF and other (South African dominated) public forums by immigrants in Yeoville. The lack of participation of immigrants in YCPF meetings became an issue for South Africans running these institutions. There were allegations, by participating South Africans, that African immigrants were disinterested in participating in community initiatives. A South African YCPF member complained: "These people don't come to the meetings. People from Congo and Nigeria don't come to meetings..." (Sector Crime Forum 1 meeting, Mduduzi: 02/06/2011)

The lack of participation of African immigrants in community safety initiatives was not just a result of forced exclusion but also a question of "self-isolation" (Barry 1998). Asked why he did not participate in YCPF meetings, a Zimbabwean immigrant staying in Yeoville responded:

"Because I don't care about that. It doesn't give me food on the table. I have better things to do. I am not permanent here, so I have got nothing to contribute to the community and my days are numbered. I am just a tenant here and I will be leaving the area" (Interview, Reggy: 12/02/2011).

The above statement shows that some "foreign nationals" were economically calculative and found no motivation to attend meetings leaving their economic activities. The other issue was the temporarily of their stay in neighbourhoods, and also in the country; which made them feel as though they did not belong and had no obligation to contribute to initiative aimed at improving the well-being of "community". In light of this, I conceptualise most African immigrants as having a habitus of survivalism, as opposed to a habitus of volunteerism; a habitus abstracted from community and its dynamics and focused on acquiring economic gain.

Individual immigrants also withdrew from certain spaces or places as self-preservation. Withdrawal from spaces of public dialogue on safety and security was one way of avoiding being noticed and exposed to xenophobic discourses - a strategy of self-preservation. On the other hand, the navigation of the city itself demanded care from immigrants, to avoid being victimised for being "strangers". People generally avoided places with a history of xenophobic violence. One participant explained:

"I will not go to places such as Alexandra or Diepsloot unless it is inevitable. In those places you can become exposed, especially if you cannot speak the local languages. If I happen to go to those areas, I avoid wearing tradition African dresses [African attire], lest they notice that I am from West Africa and attack me. I spent most of my time in the inner city of Johannesburg. Although there are huge challenges of crime in the inner city, the risk of suffering xenophobic violence is quite low. It is our place - our own little Lagos" (Interview, Chukwu: 12/02/2012).

Thus, counter-otherising strategies also took place at individual levels as people live, traversed or "walked in the city" (de Certeau 1984); prioritising self-protection against potential violent and non-violent xenophobic 
practices in the process. Through such collective and individual practices, African immigrants gained a special kind of street knowledge or "street science" (Corburn 2005) which they used to navigate the fearopolis ${ }^{19}$ that Johannesburg is. I refer to this kind of knowledge as part of the capital of security; accumulated through everyday practices and discursive exchanges, and usable in everyday navigation of the city.

Below, I conclude by crystallising the lessons that can be drawn from the analysis of the field of community safety governance as one characterised by ethno-politics; especially in ethno-nationally diverse contexts as of Yeoville, Johannesburg.

\section{Conclusion}

This chapter, through the notion of ethnopolitics, suggests community safety governance is a field of "ethno-discourses", "ethno-talks" and "ethno-practices" 20 through which ethno-national groups pursue and defend their interests. Overall, the chapter confirms the argument that xenophobia has become part of public culture in South Africa (Nyamnjoh 2010b); with the state being complicit in the generation and sustenance of this public culture (Neocosmos 2008).

The imageries of African immigrants as major culprits in the genesis of local crime and disorder made Yeoville a neighbourhood that lived at the border of cosmopolitanism and anti-cosmopolitanism (or countercosmopolitanism) - of peace and ethno-national conflicts. The criminalisation of (poor) African immigrants in Yeoville correspond to Caldeira's (2000:53) observation, in her São Paulo studies, that criminals are publicly represented as people "from the fringes of society, humanity and polity". While poor African immigrants were represented as the scum of the city ${ }^{21}$, within the ranks of the criminalised scum of the city also were the South African poor living in marginal spaces which, paradoxically, were abhorred and avoided by many African immigrants. It is in these marginal spaces of the city where xenophobic violence was common and acute (Misago 2011).

The linguistic market of the local security governance field in Yeoville was generally ethno-nationally exclusionary. The language used in spaces of participatory safety activism was unfriendly to African immigrants who could not fluently speak or adequately understand local South African native languages. When African immigrants attend community meetings on matters of security governance, they have to sit through discussions that stereotypically criminalised them and in which their contributions were not taken seriously. Therefore, in these meetings, when African immigrants participated, they tended to occupy a position of what I call the absent present - as their presence was rarely appreciated or respected. When they did not attend, they still remain the subject of criminalising talk - occupying a position of what I refer to as the present absent. Spaces of deliberative community security governance can therefore be conceptualised as sites of performative symbolic violence against African immigrants. It is important also to note that some African immigrants isolated themselves from participation in community safety activism because they saw more value in pursuing their economic interests
19.

A concept I coin to capture the city as a space of fear see Katsaura Obvious. 2013. Socio-spatial politics of community safety in Johannesburg. Doctoral Dissertation, University of the Witwatersrand.

20.

See Comaroff, John $\mathrm{L}$, and Jean Comaroff. 2009. Ethnicity, Inc. Chicago: University of Chicago Press.

21.

I develop and modify this notion as adapted from Koestler, Arthur. 1968. Scum of the Earth. New York: Macmillan. 
From the foregoing it emerges that community safety governance requires an appreciation and understanding of the role of social diversity in shaping or influencing public participation and social group and individual placing in the field of community safety governance. One has to be cognisant of the dynamics or potentialities of conflict and contradictions in such a context. An understanding of the anatomy of the social infrastructure of the neighbourhood - sometimes casted in the dichotomy between the "established" (insiders) and "outsiders" (Elias and Scotson 1994; Nyamnjoh 2006) - is an important first step for any intervention in or review of the security governance at a local level in situations characterised by migrancy and poor levels of collective efficacy and responsibility (Sampson, Raudenbush and Earls 1997). Above all I stress, as an epilogue to this chapter, that a theorisation or understanding of social diversity is central to profitable scholarship on urban dynamics; especially in cases of urban community mobilisation and organisation in response to urban challenges.

\section{References}

Aas, Katja Franko. 2011. “'Crimmigrant' bodies and bona fide travelers: Surveillance, citizenship and global governance." Theoretical Criminology 15(3):331-46.

Armstrong, Anona, Ronald Francis, and Vicky Totikidis. 2005. "Towards a sustainable partnership in crime prevention and community safety." in Paper presented to the referreed stream in the conference: Australian Universities Community Engagement Alliance (AUCEA) National conference 2005 "Universities and Community learning and engaging through sustainable partnership.

Barry, Brian. 1998. "Social exclusion, social isolation and the distribution of income." Pp. Available at SSRN:http://ssrn.com/abstract=1158903. London: Centre for the analysis of social exclusion, London School of Economics

Barth, Fredrick. 1970. Ethnic groups and boundaries: The social organisation of culture differences. Bergen-Oslo: Universitet Forlaget.

Bauman, Zygmunt. 2006. Liquid fear. Cambridge: Polity Press.

Beavon, Keith. 2004. Johannesburg: The Making and Shaping of the City. Pretoria: University of South Africa Press.

Benit-Gbaffou, Claire. 2006. "Police-Community Partnerships and Responses to Crime: Lessons from Yeoville and Observatory, Johannesburg." Urban Forum 17(4):301 -26.

Body-Gendrot, Sophie. 2012. "Nights in the Global City." Pp. 606-16 in The New Blackwell Companion to the City, edited by Gary Bridge and Sophie Watson. Cambridge: Blackwell.

Boisteau, Charlotte. 2005. "Dynamics of exclusion: Violence and security policies in Johannesburg." Pp. 255 - 68 in Public problems - Private solutions?: Globalising cities in the South, edited by Klaus Segbers, Simon Raiser, and Krister Volkmann. Aldershot: Ashgate Publishing Limited.

Bourdieu, Pierre. 1991. Language and symbolic power. Cambridge: Polity Press.

Bremner, Lindsay. 2004. "Bounded spaces: Demographic anxieties in post-apartheid Johannesburg." Social Identities 10(4):455-68.

Brubaker, William Rogers. 1992. "Membership without citizenship: The Economic and Social Right of noncitizens." in Immigration and the Poltics of Citizenship in Europe and North America, edited by William Rogers Brubacker. Havard: Havard University.

Caldeira, Teresa P. R. 1996. "Fortified Enclaves: The New Urban Segregation." Public culture 8(2):303-28.

Caldeira, Teresa P.R. 2000. City of walls: Crime, segregation and citizenship in São Paulo. Berkely University of Califonia Press.

Charles, Lemert. 2006. Durkheim's ghosts: cultural logics and social things. Cambridge: Cambridge University Press.

Comaroff, John L, and Jean Comaroff. 2009. Ethnicity, Inc. Chicago: University of Chicago Press.

Corburn, Jason. 2005. Street science: community knowledge and environmental health justice. Massachussets: MIT Press

Davis, Mike. 1998. Ecology of fear: Los Angeles and the imagination of disaster: Wiley Online Library.

de Certeau, Michael. 1984. The practice of everyday life. Berkeley CA: California; University of California Press.

Dirsuweit, Teresa. 2002. "Johannesburg: A 
fearful City?" Urban Forum 13(3):4 - 19.

Dirsuweit, Teresa. 2007. "Between ontological security and the right difference: Road closures, communitarianism and urban ethics in Johannesburg, South Africa." Autrepart (2):53-71.

Elias, Norbert, and John L Scotson. 1994. The established and the outsiders. London: SAGE Publications Limited.

Fumagalli, Matteo. 2007. "Informal ethnopolitics and local authority figures in Osh, Kyrgyzstan." Ethnopolitics 6(2):211-33.

Goffman, Erving. 1963. Stigma: Notes on the management of spolied identity. Englewood Cliffs NJ: Prentice-Hall.

GPCPB. 2010. "Constitution of the Gauteng Provincial Community Police Board (GPCPB) adopted on Saturday, October 16, 2010 in Germiston." edited by Gauteng Province Department of Community Safety. Johannesburg: Department of Community Safety, Gauteng Province.

Haefele, Benjamin. 2002. "Vigilantism in the Western Cape." Cape Town: Department of Community Safety, Provincial Government of the Western Cape.

Harris, Bronwyn. 2002. "Xenophobia: A new pathology for a new South Africa." Psychopathology and social prejudice:169-84.

Harrison, Philip. 2002. "Less say more, but still counts: the state of social capital in Yeoville, Johannesburg." Urban Forum 13(1).

Hook, Derek, and Michele Vrdoljak. 2001. "Fear and loathing in Northern Johannesburg: The security park as heteropia." Psychology in Society 2001(27):61-83.

Hornberger, Julie. 2004. "My police - your police: the informal privatisation of the police in the inner city of Johannesburg" African Studies 63(2):213-30.

Hornberger, Julie. 2011. Policing and Human Rights: The Meaning of Violence and Justice in the Everyday Policing of Johannesburg. London: Routledge.

Jamal, Amal. 2007. "Nationalizing states and the constitution of 'hollow citizenship': Israel and its Palestinian citizens." Ethnopolitics 6(4):471-93.

Kahera, Akel Ismail. 2002. "Urban enclaves, Muslim identity and the urban mosque in America." Journal of Muslim Minority Affairs 22(2):369-80.

Katsaura, Obvious. 2012. "Community Governance in Urban South Africa: Spaces of Political Contestation and Coalition." Urban Forum 23(3):319-42.

Koestler, Arthur. 1968. Scum of the Earth. New York: Macmillan.

Kupe, Tawana, Paul Verryn, and Eric Worby. 2008. Go home or die here: violence, xenophobia and the reinvention of difference in South Africa. Johannesburg: Witwatersrand University Press.

Kymlicka, Will. 2001. "Politics in the vernacular:
Nationalism, Multiculturalism and Citizenship." Oxford: Oxford University Press.

Kymlicka, Will, and Wayne Norman. 2000. "Citizenship in culturally diverse societies: issues, contexts, concepts." Citizenship in diverse societies:1-41.

Kynoch, Gary. 2011. "Of compounds and cell blocks: The foundations of violence in Johannesburg, 1890s - 1950s." Journal of African Studies 37(3):463 - 77.

Landau, Loren. 2006a. "Discrimination and Development? Migration, Urbanisation, and Sustainable Livelihoods." in Forced Migration Working Paper Series Johannesburg: University of the Witwatersrand.

Landau, Loren B. 2010. "Loving the alien? Citizenship, law, and the future in South Africa's demonic society." African Affairs 109(435):21330 .

Landau, Loren B. and Irianne Freemantle. 2010. "Tactical Cosmopolitanism and idioms of belonging: Insertion and Self - Exclusion in Johannesburg." Journal of Ethnic and Migration Studies 36(3):375-90.

Landau, Loren, K. Ramjathan-Keogh, and S. Gavatri. 2005. "Xenophobia in South Africa and Problems Related to it." in Forced Migration Working Paper Series Johannesburg: Forced Migration Studies Programme, University of the Witwatersrand.

Landman, Karina. 2004a. “Gated communities in South Africa: The challenge for spatial planning and land use management." Town Planning Review 75(2):151-72.

Landman, Karina. 2004b. The Storm that Rocks the Boat: The Systemic Impact of Gated Communities on Urban Sustainability. Paris: Universite de Paris, Institute de Geographie.

Landman, Karina. 2008. "Gated neighbourhoods in South Africa: An appropriate urban design approach?" Urban Design International 13(4):227-40.

Legget, Ted. 2002. "A den of iniquity: Inside Hillbrow's residential hotels." SA Crime Quarterly 2(November 2002).

Liska, Allen E., Joseph J. Lawrence, and Andrew Sanchirico. 1982. "Fear as a social fact." Social Forces 60(March 1982):760-70.

Louw, Antoinnete, Mark Shaw, Lala Camerer, and Rory Robertshaw. 1998. "Crime in Johannesburg: Results of a city victim survey.” Pp. 65. Pretoria: Institute for Security Studies.

Majombozi, Tembi. 2010. "Migrants must be more responsible." in Yeovue News. Johannesburg, Yeoville: YBCDT.

Marcuse, Peter. 2005a. "Are social forums the future of social movements?" International journal of urban and regional research 29(2):417-24.

Marcuse, Peter. 2005b. "Enclaves yes, ghettos no: Segregation and the State." Pp. 15-30 in 
Desegregating the city: Ghettos, enclaves, and inequality, edited by David P. Varady. Albany: State University of New York.

Mbembe, Achille. 2004. "Aesthetics of superfluity." Public culture 16(3):373-405.

Metileni, Moses Nzama Khaizen. 2011. "In the name of growth?: Exploring state/spatial restructuring in Johannesburg (1990-2009)." in School of Architecture and Planning. Johannesburg: University of the Witwatersrand.

Misago, Jean-Pierre. 2011. "Disorder in a changing society: Authority and the micro-politics of violence." in Exorcising the demons from within, edited by Loren Landau. Johannesburg: Wits University Press.

Murray, Martin J. 2011. City of extremes: The spatial politics of Johannesburg London: Duke University Press.

Nederveen, Pieterse Jan. 1996. “My paradigm or yours?: Alternative development, post-development, reflexive development." ISS Working Paper Series/General Series 229:1-36.

Nederveen, Pieterse Jan. 2007. Ethnicities and global multiculture: pants for an octopus. New York: Rowman \& Littlefield Pub Inc.

Neocosmos, Michael. 2008. "The politics of fear and the fear of politics: reflections on xenophobic violence in South Africa." Journal of Asian and African Studies 43(6):586-94.

Neocosmos, Michael. 2010. From 'foreign natives' to'native foreigners': Explaining xenophobia in post-apartheid South Africa: citizenship and nationalism, identity and politics. Dakar: Codesria.

Nuttall, Susan, and Achille Mbembe. 2007. "Afropolis: From Johannesburg." PMLA 122(1):281-88.

Nyamnjoh, Francis B. 2006. Insiders and outsiders: citizenship and xenophobia in contemporary Southern Africa. Dakar: Codesria books.

Nyamnjoh, Francis B. 2010a. "Analyses and Reports Racism, Ethnicity and the Media in Africa: Reflections Inspired by Studies of Xenophobia in Cameroon and South Africa." Africa Spectrum 45(1):57-93.

Nyamnjoh, Francis B. 2010b. "Racism, Ethnicity and the Media in Africa: Reflections inspired by studies of Xenophobia in Cameroun and South Africa." Africa Spectrum 45(1):57 - 93.

Olima, Washington H.A. 2006. "Residents' participation in Neighbourhood management and maintenance: Experiences and lessons from Nairobi, Kenya." Housing Symposium 3.

Palomares, Elise, and Catherine Quiminal. 2012. "Migration in South Africa: Tensions and post-apartheid inter-ethnic compromises." Pp. 121-40 in The Challenge of the Threshold: Border Closures and Migration Movements in Africa, edited by Jocelyne Streiff-Fénart and Aurelia Segatti. Maryland: Lexington Books.

Pillay, Suren. 2008. "Crime, community and the governance of violence in post-apartheid South Africa." Politikon 35(2):141-58.

Sampson, Robert J, Stephen W Raudenbush, and Felton Earls. 1997. "Neighborhoods and violent crime: A multilevel study of collective efficacy." Science 277(5328):918-24.

Sandercock, Leonie. 2003. Cosmopolis II: Mongrel cities in the twenty-first century. London: Continuum.

Sandercock, Leonie. 2005. "Difference, fear and habitus: A political economy of urban fears." Pp. 220 - 34 in Habitus: A sense of place (2nd edition), edited by Jean Hillier and Emma Rooksby. Aldershot: Ashgate.

Schönteich, Martin. 2000. "South Africa's position in Africa's crime rankings." African Security Studies 9(4):51-65.

Schuilenburg, Marc. 2008. “Citizenship Revisited-Denizens and Margizens." Peace Review: A Journal of Social Justice 20(3):358-65.

Simone, AbdouMaliq. 2004. "People as Infrastructure: Intersecting Fragments in Johannesburg." Public culture 16(3):407-29.

Siziba, Gugulethu. 2014. "Language and identity negotiations: an analysis of the experiences of Zimbabwean migrants in Johannesburg, South Africa." Journal of African Cultural Studies 26(2): 173-188.

Svendsen, Lars. 2008. A philosophy of fear. London: Reaktion Books.

Totikidis, Vicky, Anona F Armstrong, and Ronald D Francis. 2005a. "The concept of community governance: A preliminary review." in Refereed paper presented at the Govnet Conference, Monash University, Melbourne 28th - 30th November, 2005: Centre for International Corporate Governance Research, Faculty of Business and Law, Victoria University.

Totikidis, Vicky, Anona Armstrong, and Ronald Francis. 2005b. "Local safety committees and the community governance of crime prevention and community safety." in Paper presented to the Beyond Fragmented Government: Governance in the public sector conference, Victoria University, Melbourne, 15 - 17 August 2005.

Tudor, Andrew. 2003. "A (macro) sociology of fear?" The Sociological Review 51(2):238-56.

van Zyl, Susan. 1998. "The other and other others: Post-colonialism, Psychoanalysis and the South African Question." American Imago 55(1):77-100.

Vetten, Lissa, and Sadiyya. 2005. "Gang rape: A study in inner-city Johannesburg." SA Crime Quarterly No 12 , June 2005.

Wacquant, Loic. 2008. Urban outcasts: a comparative sociology of advanced marginality. Cambridge: Polity Press.

YBCDT. undated. "Back in the day. Yeoville Bellevue Community Development Trust" http:// www.yeoville.org.za/yeoville-history.php. Accessed on January 10, 2011. 


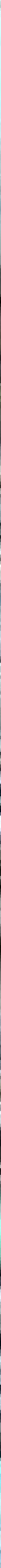




\section{Land Transformation and Criminal Violence in Dandora Neighbourhood, Nairobi, Kenya}

Romanus O. Opiyo

Violence and the fear of violence is gaining currency as one of the major threats of sustainable urban life in Kenya that not only affects the economic and social milieu but also limits people in their choice of space and time for all activities. This paper originates from a study carried out in Kenya's capital city, Nairobi, and is concerned with understanding how land use and its changes ultimately influence crime prevention. The

U-Care: Urban Violence in Sub Sahara Africa. It's impacts, Coping Strategies and Peace Building. Technische Universität Darmstadt and Global Urban Institute Berlin (GLOBUS)

Previous page: Kids playing with timber guns in Kibera informal settlement in Nairobi. Photo: Kosta Mathéy research for this work was part of a wider study ${ }^{1}$ on urban violence in Sub-Saharan Africa funded by the Volkswagen Foundation and is dedicated to examine the link between land use and opportunities for crime prevention.

The study on changing land use(s) and their impact on the criminal violence was carried out in Dandora neighbourhood and can be useful in further crime prevention. The study was guided by a combination of complementary theories, such as opportunity and situational crime theories, which help to understand the structure of criminal opportunities in context of the physical environment.

\section{Research on crime and violence in Kenya's residential areas}

Changes in land use have, through new development and redevelopment, had an impact on the routine activities of people, which in turn create or alter opportunities to commit crime. This has been acknowledged by social disorganization theorists, routine activity theorists, and situational crime prevention theorists, as well as environmental criminologists. However, profiling of land use changes in relation to crime prevention is still exceptional, as most studies focus on the causation aspects, without addressing the contextual part.

In addressing the contextual part, this study sought to answer the following question: Does the type and nature of land use change(s) in a 
neighbourhood explain crime occurrence and its prevention? This will enable contextualization of land use changes in relation to neighbourhood crime prevention.

In answering the main question, a number of sub-questions have been formulated:

1. What is the crime pattern in the area?

2. What drives land use transformation experienced in Dandora?

3. Are there crime(s) attributable to land use transformation?

4. What is the implication of land use transformation on crime prevention?

5. What are the existing crime coping mechanisms and preventive strategies adopted individually and collectively?

\section{Theoretical framework}

A number of theoretical approaches have sought to explain urban crime by criminologists, sociologists, urban planners, and geographers. Criminologists and sociologists tend to believe that crime results from social stress and conflicts and that the rates of crime in urban neighbourhood are highly affected by the demographic and socio-economic contexts (Reith, 1996). The theoretical frameworks explaining the interaction between land use and crime incidences can be divided into two categories, namely:

- Compositional frameworks, also known as non-ecological theories such as classical, formative, and social control theories, and

- Ecological frameworks, such as positivists, place-based (situational crime prevention), structural-functional, social-disorganization, broken windows, routine activity, rational choice, and situational crime prevention theories.

Both concepts use different units of analysis to explain crime.

This study largely relies on two interrelated ecological theories namely the routine activity and social control disorganization theories. The latter theory focuses on the ability (or lack thereof) of residents of a spatial territory (e.g. a neighbourhood) to collectively achieve a common goal, like reducing predatory crime. The routine activities theory, on the other hand, focuses on the presence of opportunities for crime in an area, as shaped by residents' daily activities, which, in turn, are molded by land uses. The interaction of the two theories harmonizes analysis of both individuals and community in relation to land use. The two theories suggest different levels of analysis: social control theory considers community explanations for crime, while routine activities theory is often interpreted as focusing on the individual, with three distinctive actors: the offender, victim, or the guardian.

Munda (2004:663) noted that each theory can continuously add new relevant qualities/attributes that must be considered when explaining, describing, or forecasting individuals' behaviour (i.e. human systems are learning systems). The strength of the multi-contextual theoretical framework is evident as no single theory and theoretical analysis can 
simultaneously explain crime incidences in relation to land use changes and was infused in the data collection and analysis for this study.

\section{Conceptual framework}

As mentioned before, the study conceptualizes the land use and the alteration of the physical environment as an important factor in explaining a concentration of violent criminal activity in a given neighbourhood. Planned land use transformation has potential for being the most peaceful way of managing and preventing violent crime as land use decisions inform the condition and use of spaces, which later influence the nature of activity generation, pace, and intensity of space use.

Land use regulations tend to be rather static whereas in practice the functions performed in any given location, whether residential, productive, or administrative shift over time and depend on many factors, which can be local, national or even global (UN-Habitat, 2005). In the case of the intensification of land use development in Nairobi, Kiamba (1986) drives a continuous process of re-zoning, either informally (means: illegally or criminal) but also formally by raising maximum allowable zoning and development densities. This process also provided opportunity for land owners and developers to fully exploit the economic yielding capacity of
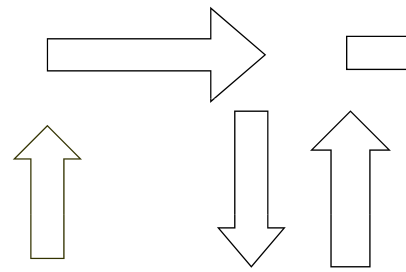

\begin{tabular}{l}
\hline LAND USE \\
-Land Use Types \\
-Zoning Regulations \\
-Transportation \\
Infrastructures and \\
Facilities \\
-Site Layout \\
-Building Design \\
-Development \\
Regulations
\end{tabular}

\begin{tabular}{|l|}
\hline URBAN FORM \\
-Physical Structures \\
-Streets Patterns \\
-Buildings pattern \\
-Plot Pattern \\
-Types and Location of \\
Activities \\
-Overlapping of Private \\
Activities in Public \\
Spaces and vice-versa \\
\hline
\end{tabular}

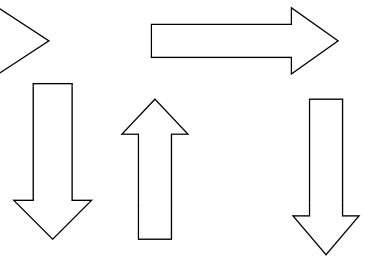

CRIME INCIDENCES
-Minimum Risk
-Minimum Effort
-Changing Radius of
Responsibility
-Maximum Reward
-Specific Crime in Specific
Places

Figure 1 illustrates how Land use and the built environment play a pivotal role in shaping the occurrence and patterning of criminal activities. Land use and land use changing patterns in individual neighbourhoods can have impact on residents; various activity choices, such as when and where to be engaged in which activity, including the possibility of being engaged in crime. It further shows that physical forms such as buildings enhance natural surveillance; accessibility networks also produces and reproduces various social forms which lead to certain patterns of interaction. This influences residents' routine activities and the presence or absence of guardians watching over the users, which may inhibit or promote incidences of crime in a neighbourhood. 
the given spatial unit, and individually benefit from the social and economic process of urbanization (Kiamba, 1994).

Land use transformation, whether achieved by legal or illegal means, can either improve or worsen the security aspects of space. For example, according to the Muchai, (2001) on Kenya Crime Survey, conducted in (2001), notes that land use conversion from residential to commercial was followed by sharp rise in rental fees in Central Business Districts. Lower income housing was converted into shops and executive flats while crime rates went up simultaneously as same report highlights.

Central Business Districts are unique in every city, whereas different types of residential districts repeat each in the same municipality or countrywide. Therefore this study concentrates on the neighbourhood scale (Dandora in this case), which was chosen as an example for the most immediate planning context, or unit and in which people live and conduct their livelihoods. Neighbourhood is understood within a "place" concept in which urban violence and crime as well as land use transformation will be analyzed.

\section{Case study on Dandora}

Dandora is located in the South Eastern suburb Embakasi in the Nairobi East district. It was developed from 1977onwards under the site and service scheme for low income households, partially financed by the World Bank, with the aim of providing shelter for the urban poor who could not otherwise afford decent housing. However, as shown in various pieces of literature, the original allottees did not take full advantage of this opportunity because of their financial constraints. Many of them ended up selling their plots to richer families or entrepreneurial developers, who later on developed multi-storey blocks and commercial buildings.

Dandora has the third highest population in the Division with 142,046 inhabitants (GoK, 2010) and covers an area of $3.9 \mathrm{~km}^{2}$ resulting in population density of 3625,4 inhabitants per hectare. In the 1990s, the United Nations rated Nairobi as one of the world's most crime ridden capital cities and within that city, Dandora was perceived to be one of the most unsafe residential neighbourhoods (KIPPRA, 2004).

According to Skogan (1986) stability in a neighbourhood requires that neighbourhoods, as social systems, reproduce themselves.

Left:

Dandora sites-

and-services

housing scheme in

1979.Photo:

Kosta Mathéy

Right:

Dandora informal development

for commercial

income generation

1979. Photo:

Kosta Mathéy
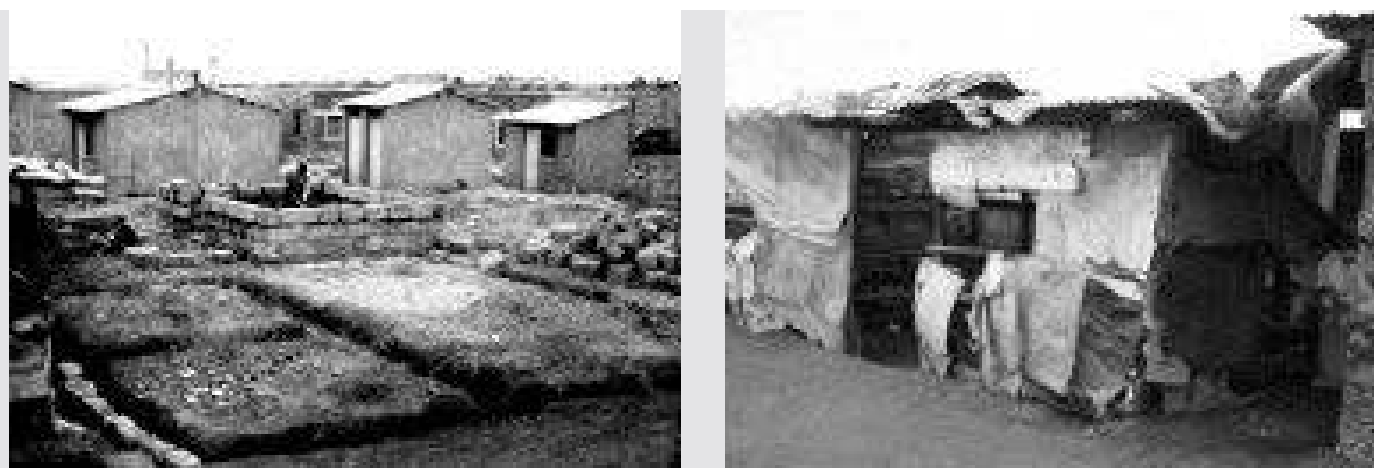
Map 1: Location of Dandora in Nairobi (Source: Adapted from Survey of Kenya)

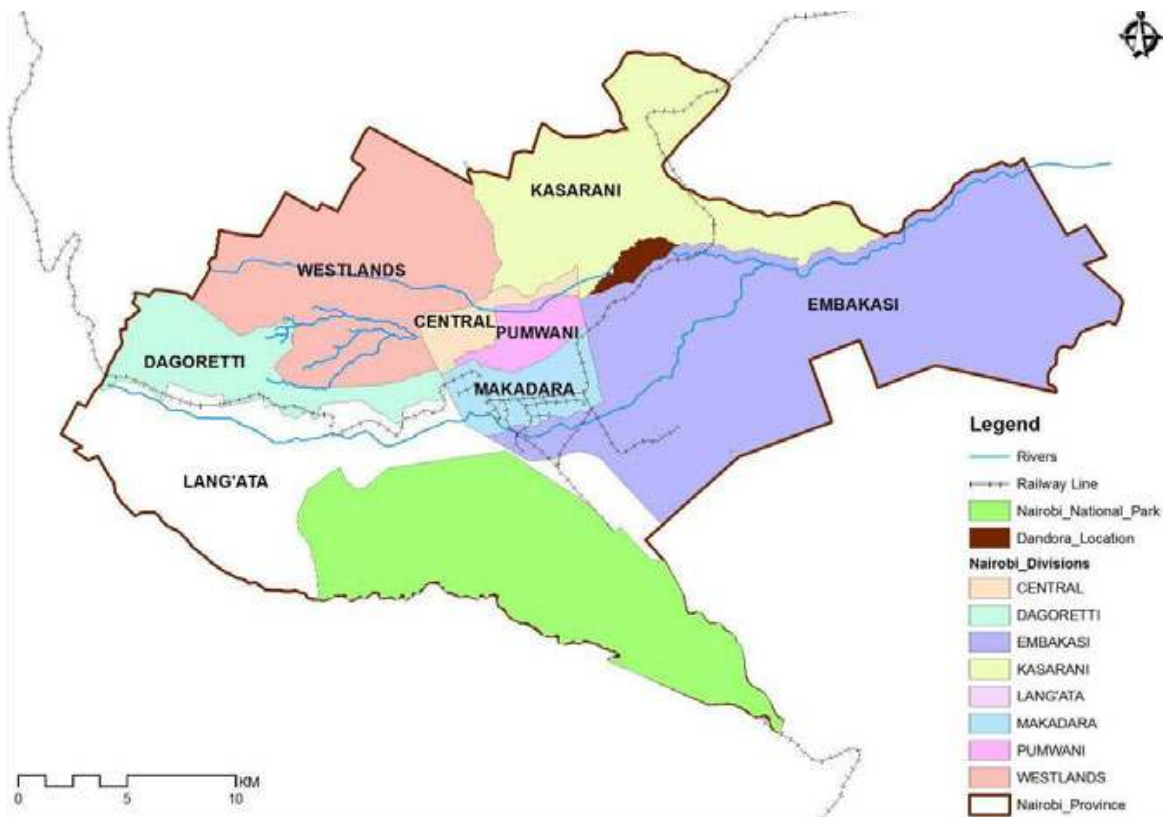

Dandora (shaded brown) was the first community development housing project in the East of the city. Dandora is located in Embakasi Constituency,which is the largest con-stituency in Nairobi. It borders Kassarani to the North and Makadara to the West.

Neighbourhoods are stable if the housing stock is continually repaired and renewed and if people can sell and buy or rent homes at prices appropriate for the structures and the social class of the resident (1986). However other studies of low income urban housing projects in Africa show that, like Dandora, very few of such projects reproduce themselves since they are infiltrated by medium and high income earners from a very early stage in their development.

\section{Dandora's land use transformation}

The factors explaining Dandora's land use transformation are in themselves, multi-contextual and can be characterized as follows:

- Penetration by higher income groups, both as landlords and tenants.

- Lack of development control, such as on-plot economic activities including the constraint of uses such as beer halls and other drinking places.

- Informal interference in allocation by the Nairobi City Councilors and council officials.

- Eviction of owners from the plots in cases mortgage arrears

- Renting of entire houses by absentee allottees who found the rental income preferable to being accommodated there themselves 
(UNCHS, 1987:65). , a number of allottees moved from Dandora to other informal settlements like Mathare Valley or Korogocho.

- In-migration of lower-income individuals due to rent increases in other parts of town (UNCHS, 1987:63).

- Delays in completion of the commercial centres and markets in Dandora led to flourishing small businesses within Dandora, which is related to the reputation of insecurity (UNCHS: 1987:68).

Hence, Dandora represents a case of an unstable neighbourhood incapable of renewing itself. Financially the initial low-income housing project it was a failure as many of the poor were unable to service the loans and more affluent families moved in. Later on, investors started developing cheap high rise apartment buildings and commercial spaces. That process not only altered the land use but also changed the image, aesthetics, and dreams of the community. The estate has earned a bad reputation because of the high crime rates and for it's population density. The initially provided infrastructure and community facilities are highly insufficient for occupancy rates prevailing in Dandora today.

Map 2: Spatial Layout of the Phases of Dandora Source: Adapted from HDD Original Map of Dandora.

\section{DANDORA: ORIGINAL LAND USE PLAN}

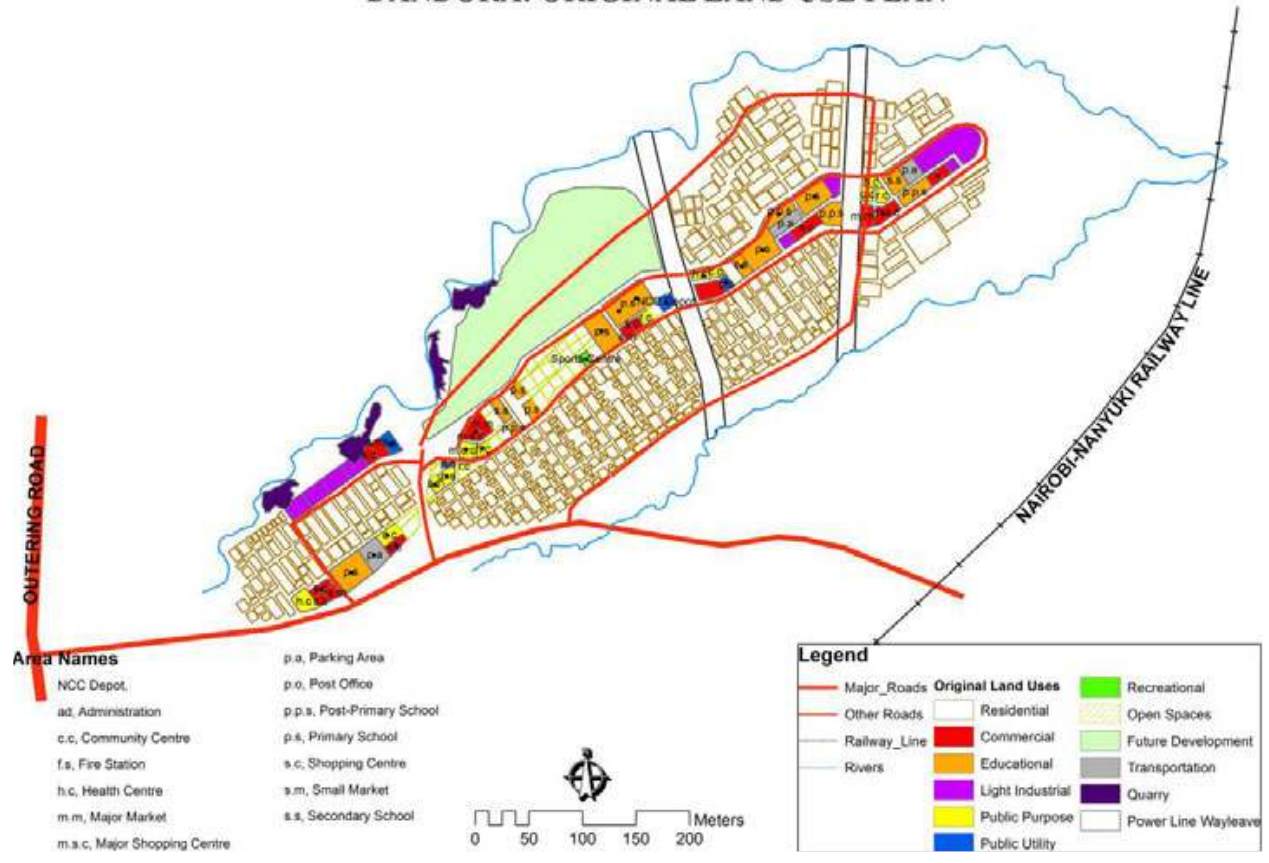

The Dandora Community Development Plan was organized around a central core of public facilities and amenities. It was divided into six residential areas.

There are corner shops located in various strategic locations. However, the central core is the major centre for various community facilities and services, which include primary schools, health centres, and a multi-purpose community centre incorporating day care facilities, sports facilities, and markets (Soni, 1981; DPU, 1983; UNCHS, 1987). 


\section{Primary problems associated with land use changes in Dandora}

In relation to housing demand, it was noted that Dandora is one of the estates which is most attractive to those who have just moved into Nairobi and need to rent housing as they do not have stable incomes and only chose the neighbourhood for lack of better alternatives.

Several problems associated with land use changes in Dandora were

02.

Mungiki is a terrorist organization in Kenya

Table 1:

Major Problems

Encountered

Associated with Land Use Changes.

Source: Field

Survey, 2009 identified in the course of the research (see Table 1). High population density coupled with disinvestment in public infrastructure were responsible for poor sanitation (especially blocked drains, which have been blamed for cholera epidemics and other diseases), strain on other available services (mainly associated with the population pressure), and traffic congestion. The commercial development attracted operations by the Mungiki gangs, ${ }^{2}$ who harassed residents $(28.1 \%$ affirmations) and business people $(33.1 \%$ ) from whom they demand regular 'protection' fees.

These high levels of perceived insecurity and fear of crime and violence led to further disinvestment in the older residential areas and implied restrictions in personal mobility.

\begin{tabular}{lrr} 
Problems & Residents & Enterprises \\
High levels of insecurity/harassment by Mungiki & 28.1 & 33.1 \\
\hline Pollution/Poor sanitation/health risks & 22.2 & 7.2 \\
\hline Strain on available services and utilities e.g. sewer lines & 19.8 & 26.6 \\
\hline Congestion resulting from overpopulation & 7.1 & 18.7 \\
\hline High house rents/Business premise rents & 6.8 & 4.2 \\
\hline Poverty and unemployment & 5.1 & 0.0 \\
\hline Inaccessibility due to congestion/bad roads & 2.1 & 0.0 \\
\hline Harassment by Police & 1.5 & 0.0 \\
\hline Noise pollution by bars and public transport vehicles & 1.5 & 1.5 \\
\hline High fares & 1.5 & 0.0 \\
\hline Poor planning/housing provision & 1.2 & 2.4 \\
\hline Lack/ inadequate street-lighting & 1.2 & 0.0 \\
\hline Inadequate recreational spaces & 0.9 & 1.8 \\
\hline Tribal clashes & 0.9 & 0.0 \\
\hline Increased prostitution & 0.3 & 1.5 \\
\hline Total & $\mathbf{1 0 0 . 0}$ & $\mathbf{1 0 0 . 0}$ \\
\hline
\end{tabular}
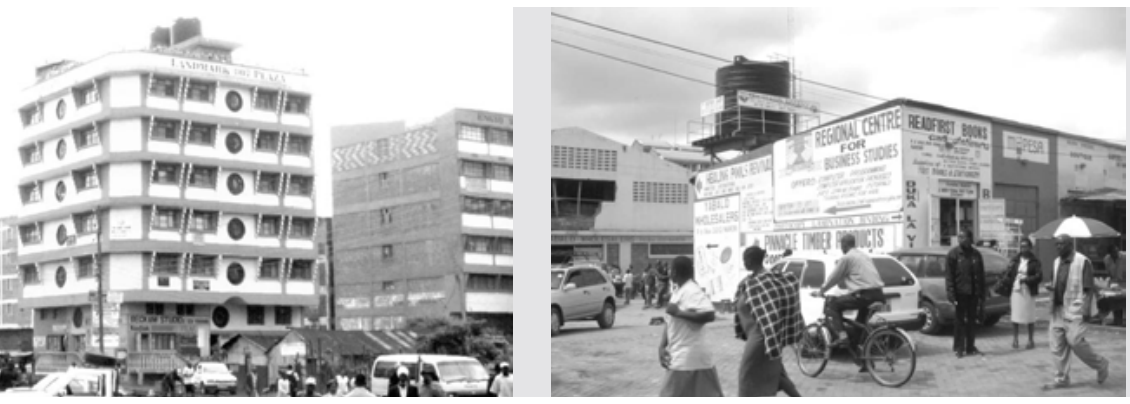
High levels of insecurity in Dandora which are associated with the likelihood of driving law-abiding residents away, especially those whose income enables them to do so Power (2004). This is further explained by Taylor, (2001); Sampson and Raudenbesh, (2004), who argue that such situations make neighbourhood less stable because of its bad status and perceived identity.

\section{Crime patterns in Dandora}

Robbery was found to be the leading type of crime in the area as reported by business people and residents. This was followed by burglary, assault, and carjacking, rape and kidnapping. Except for burglary and pick-pocketing these are all violent forms of crime. The survey findings seem to confirm the official police crime record indicating that robbery is the leading crime in the area and also that the area experiences violent crime. The study findings in relation to victimization and crime reporting show that there was an increase of violent crime incidences in Dandora over the period from 2007-2008, mostly attributed to the political campaigns and post election violence in 2007. Business enterprises were the major casualties. The findings also show that the neighbourhood also suffers from under-reporting of crime, with $42 \%$ of business people and $41 \%$ of residents not reporting crime. Fifty eight per cent blame the police for not taking action on reported crime. The reasons are in line with Shaw and Carli's (2011) notion that crime reporting is based on the effectiveness of police response; this consequently leads to the lack of community trust in the police and legal system to effectively apply justice.

According to police records and the community policing group, crime occurrences were said to be influenced by the following factors: land use activities, time of the year, day, political campaigns, knowledge of the neighbourhood, unemployed youth, nature or status of the building, availability of crime deterrent such as gates, perimeter walls, security personnel, and location of various uses. These findings partially support Brantingham and Brantingham (1993) who noted that crime events occur at a specific site in a specific situation. The complex interaction of these causal factors can possibly be approached by the multi-contextual framework which was noted by Stucky and Ottensmann (2009). These authors related land use patterns with the alteration of routine activities

\begin{tabular}{|c|c|c|}
\hline $\begin{array}{l}\text { Incidents of crime in Dandora } \\
\text { (survey results) }\end{array}$ & Residents & Enterprises \\
\hline Robbery & 57.5 & 18.9 \\
\hline Burglary & 15.0 & 18.1 \\
\hline Assault & 17.9 & 17.9 \\
\hline Car Jacking & 1.3 & 16.2 \\
\hline Rape & & 15.8 \\
\hline Kidnapping & & 11.7 \\
\hline
\end{tabular}


over time and noted how such alterations potentially influence opportunities for crime.

Map 3 shows the crime hotspots and violent crime prone areas identified by both the households and community policing members. Crime hotspots were associated with different land uses and ranged from residential, commercial, transport oriented, and public utility in Dandora. Areas associated with crime were:

\section{1: DUMPSITE \& BOREHOLE AREA}

Criminal Hideout zone, Crime Planning area, Mugging zone, Arms store

\section{2: WAMWARE STAGE}

Muggings, Robbery, Petty thefts

\section{3: BETWEEN WAMWARE STAGE AND TOTAL PETROL STATION}

Robbery, Stealing goods from moving vehicles

The many bumps in the area make it attractive for such activities

\section{4 \& 5: JUA KALI BLOCK G \& Phase 5 EXTENSION MWOROTO}

Muggings, House break-ins, Robbery with violence

The area is a slum and this is contributes to crime activities

\section{6: ALONG THE RAILWAY LINE}

Hideout zone, Rapes, Muggings, Drugs/Changáa brewing, Arms store, Robbery with violence

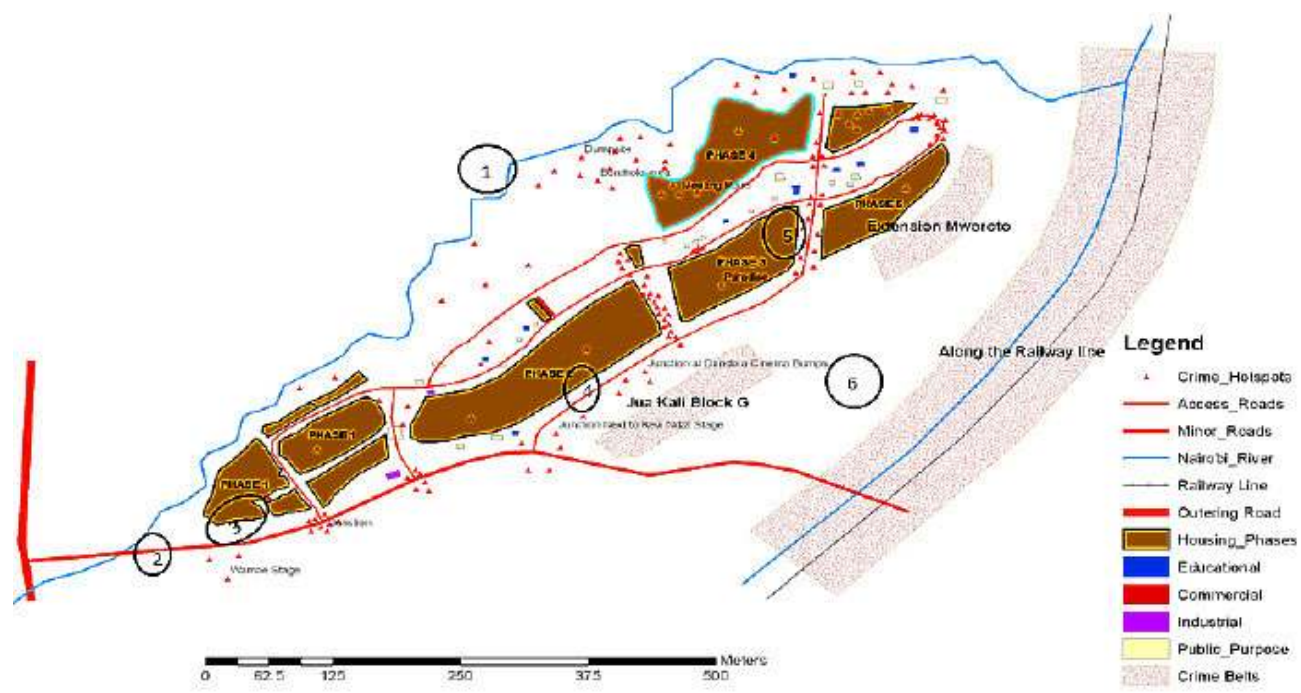

Map 3: Crime Hotspots in Dandora. Source: author 2009
There are many incomplete buildings in the area and this has made them easy criminal hideout zones

The leading causes of crime as interpreted by the Dandora community are unemployment (30.1\%), poverty (17.2\%), and idleness among the youth. Other causes such as the proximity of the dumpsite (5\%) and 
lack of development control are also acknowledged. As noted in the theoretical framework section above, the interactions between the compositional and ecological factors are important in understanding the context of crime and responses to it.

Police records suggest a slight reduction of crime in Dandora over the last years, but community policing members think that these figures are not representative because crime is rarely reported to the police. Community policing members ${ }^{3}$ and the area chief ${ }^{4}$ noted that a "Criminals' Exchange Program" was emerging in Dandora: criminals living in Dandora provided details on targets in their area to criminals living in Korogocho, Kayole, or other settlements details and vice versa. When crime occurred, the perpetrators seemed to have intimate knowledge of the area and potential target(s).

\section{Crime response and coping mechanisms}

Table 4 lists the prevention measures taken against the threat of crime and violence by the interviewed respondents. A closer look at the responses shows that $79.5 \%$ of the measures are individually oriented, which coincides with the World Bank report (2010) that found crime coping mechanisms in many urban areas mostly individual rather than collective.

\begin{tabular}{lr} 
Incidents of crime in Dandora (survey results) & $\%$ \\
reporting to the police/community support centre & 30.2 \\
\hline going home early & 19.8 \\
\hline avoiding danger spots & 12.4 \\
\hline community policing & 9.9 \\
\hline walking in trusted company at late hours & 15.8 \\
\hline hiring watchmen & 11.7 \\
\hline having gates and closing of gates early & 5.0 \\
\hline mob justice & 3.7 \\
\hline
\end{tabular}

03.

Community policing focus group discussion conducted on 29th November 2009, at Holy Cross Catholic Church in Dandora phase four.

04.

Key informant interview with the Dandora chief conducted in the chief's camp on 15th of March 2009, in Dandora phase four.

Table 4: Crime response patterns in Dandora. Source: Field Survey, 2009

Various arguments about effectiveness or coping strategies were raised. $41.2 \%$ of respondents said that increased visibility and ruthlessness of security personnel, commonly known as the "Kwekwe Squad", had led to the switch in crimes becoming less violent. Community policing members revealed that the high crime rates left community members with little choice for protection other than deliberately forming a group that could defend the neighbourhood. It was also noted that the current practice of community policing had a long historical background, and was similar to most low income neighbourhoods of Nairobi. They argue that when communities don't act on their own and wait for police, crime levels tend to rise.

This statement relates to the rational choice theory: in their analysis of criminal location choice Bernasco and Nieuwbeerta (2005) explained that the target choice of an individual offender reflects a comparison of the attraction of all potential target areas against the risks and resistance that can be expected. 

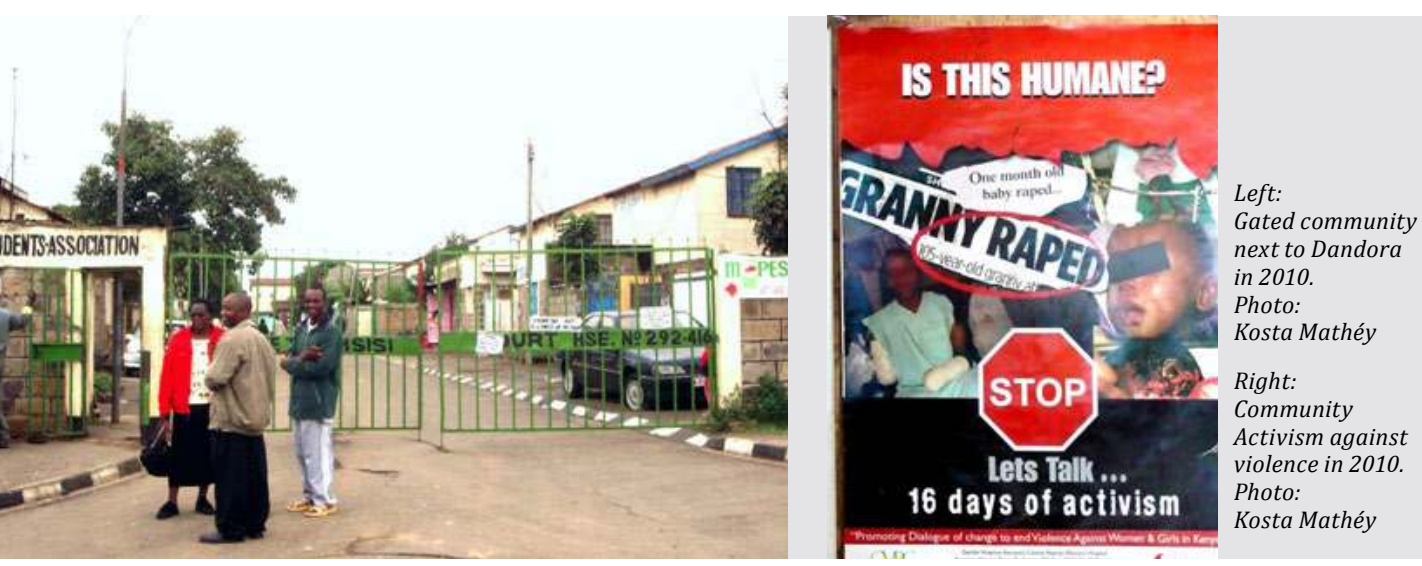

Another frequently expressed opinion says that high level of violence has caused considerable residential mobility and migration away from Dandora - some of the leaving families enter into zones that operate road

05.

A road closure means that the through roads are blocked and the remaining access road gated and equipped with guards. The idea is similar to a 'gated community' except that it happens inside the existing urban texture rather than green field development.

06.

Such as YARD, DYMES, Dandora Women Forum,

Dandora Uprising, Vision, Wafraha, faith based organizations, Hope

Worldwide, and Goal International

Kenya, among others. closures. ${ }^{5}$ Many premises have changes from residential to commercial use and vice-versa in response to market demand. This has contributed to what Skogan (1986) referred to as an unstable neighbourhood, were there is no consistent community feeling and no collective defense arrangement - implying relatively easy play for criminal ventures.

The collective protection strategies adopted in Dandora, such as community policing, aim at taking charge of security communally. The policing groups team up with other community-based organizations ${ }^{6}$ and occasionally organize activities and functions that bring the community together. This provides residents with a platform to meet and know each other and engage in community activities.

The different crime prevention strategies are acknowledged to carry bothpositive and negative results: residents and enterprises believe that they result in a reduction in crime $(70.3 \%$ for residents and $43.1 \%$ for enterprises) and bring neighbours closer to one another regardless of tribe and other status (12.6\% for residents and 25\% enterprises), which counts on the positive side. Negative impact would include limitations to economic activities, since most residents cannot afford to conduct their businesses until late in the evening (9.9\% for residents and $16.7 \%$ for enterprises), and keeping the family indoors at night (7.2\% for residents and $15.3 \%$ for enterprises), which is mostly practiced by parents worried about the security of their adolescent sons and daughters.

\section{Land use impacts on crime dynamics}

Key informant interviews with Kenyan police officers confirmed the evident correlation between land use and types of crime, whereby the time of day (or night) represents a third variable. As shown in Table 5, in low-density (middle-income)residential areas theft by servants was high in the daytime while robberies typically occurred at night but are not very frequent since most of the houses are guarded or had alarm systems. However, in high density residential areas waylaying and pick-pocketing was common during daytime while robbery, break-ins, and muggings 
mostly happen at night. In most transportation nodes, petty theft such as snatching of mobile phones are a common nuisance during daytime while at night carjacking, assault and robbery with the added aspect of violence were frequent.

\begin{tabular}{|c|c|c|}
\hline \multirow{2}{*}{ Land Use } & \multicolumn{2}{|c|}{ Type of crime } \\
\hline & Daytime & At Night \\
\hline $\begin{array}{l}\text { Residential- Low density e.g. } \\
\text { Runda, Karen etc }\end{array}$ & Theft by servants & Robbery (rare) \\
\hline $\begin{array}{l}\text { Residential- High density e.g. } \\
\text { Kayole, Dandora etc }\end{array}$ & $\begin{array}{l}\text { Waylaying, offences against } \\
\text { persons }\end{array}$ & Robbery, breakings, mugging \\
\hline Industrial & $\begin{array}{l}\text { Muggings-Hovering/roaming } \\
\text { robbers from adjacent } \\
\text { residences }\end{array}$ & Muggings \\
\hline $\begin{array}{l}\text { Educational e.g. Schools, } \\
\text { colleges }\end{array}$ & $\begin{array}{l}\text { Corruption, Economic crimes, } \\
\text { Violent Crime Not Common }\end{array}$ & $\begin{array}{l}\text { Break-ins, Theft by servants } \\
\text { or watchmen }\end{array}$ \\
\hline $\begin{array}{l}\text { Recreational e.g. Uhuru Park, } \\
\text { National Park }\end{array}$ & $\begin{array}{l}\text { Muggings, Offences targeting } \\
\text { tourists }\end{array}$ & Rape, Assault \\
\hline $\begin{array}{l}\text { Public Purpose e.g. Churches, } \\
\text { Social halls }\end{array}$ & $\begin{array}{l}\text { Theft of vehicle parts in the } \\
\text { parking lot }\end{array}$ & Break-ins \\
\hline Commercial & Stealing, Theft by servants & Theft by servants \\
\hline $\begin{array}{l}\text { Public Utilities e.g. dump sites, } \\
\text { road reserves }\end{array}$ & Muggings & Rape \\
\hline $\begin{array}{l}\text { Transportation e.g. bus stops, } \\
\text { roads }\end{array}$ & Petty theft, pick pocketing & $\begin{array}{l}\text { Assault, robbery with vio- } \\
\text { lence, carjacking }\end{array}$ \\
\hline Undeveloped and open spaces & Waylaying, assault and rape & $\begin{array}{l}\text { Rape (offences against } \\
\text { morality) }\end{array}$ \\
\hline $\begin{array}{l}\text { Mixed Use e.g. Shop and } \\
\text { Residential }\end{array}$ & & Public nuisance \\
\hline
\end{tabular}

The linkage between crime incidences and unpopulated land appears surprising at first sight. But the absence of other people in deserted locations, like the dumpsite, deferred building sites or agricultural land will delay the discovery violent crime - an advantage for any perpetrator. On the other hand, congestion in high density areas and busy commercial streets facilitates to approach a victim without being noticed by the same, and in the same way to disappear again in the crowd.

Most of the reasons associating distinct land uses with various sorts of crime of violence have also been described in the literature: Chamlin and Sanders (2008) noted that undeveloped land can be crime-ridden because it usually is overgrown with vegetation, unlit and offers hiding places for stolen good, drugs, corpses and the perpetrators themselves.

Concerning development control, the situation in Dandora confirms the experience of most low income informal settlements in Kenya, as noted by Koti (2000). Lock of coordination between the Central Government and local authorities has hindered well orchestrated land development in

Table 5:

Perceptions on Land Use and

Crime $^{07}$

07.

Based on the interviews with the Nairobi PPO, Buruburu OCPD, and Dandora OCPP on 27 th of May 2009, 25th of March 2009 , and 26th of March 2009 respectively 
most Kenyan cities. In Dandora this is manifested by an overriding influence by the provincial administration and its development control which often clashes with the policy of the City County of Nairobi. Legitimate urban development is halted and informal development mushrooms. In an optimistic perspective, Hentic (1997:369) notes that until local government possess the legitimacy, credibility, and ability to perform their functions effectively, the generalized non-transparent land use control continues to impact negatively on the living conditions of citizens.

\section{Conclusions}

Faced with high rates of crime and deficient protection from the police, the local community in Dandora relies on various forms of community based and individual violence prevention strategies. But also these do not seem to be working fully due to mistrust among members of different ethnic groups. For example, these initiatives regularly break up during political campaign periods, as different ethnic groups become protective of their own clans, and at times even protect suspected criminals belonging to their own ethnical group.

Nonfunctional land use management prevents to consider violence and crime prevention concerns in urban development practice in Dandora although a two-way correlation between violent crime and different land use forms is an acknowledged fact and supported by different theories.

The different theories are part of the multi-contextual theoretical framework introduced at the beginning.

- The routine activity theory proposes that land use changes led to changes in human behavior, legal, illegal or even violent. It explains the interaction between offenders and victims.

- The social disorganization theory argues that rapid (land use) changes in a neighbourhood can weaken social cohesion in a community, leading to rising cases of crime and fear of crime as a secondary consequence.

- According to the rational choice theory maintains that those perpetrators decide on the location of their activity also on the physical suitability defined by land use patterns.

However, the findings do not empirically support the defensible space theory or the broken windows theory, although the study's theoretical framework confirms that land use transformation leads to a change in neighbourhood form. The built environment plays a pivotal role in shaping the spatial pattern of criminal activity. While certain combinations of land use and design elements can foster criminal activity by blocking lines of sight and providing easy access to potential targets, other combinations can virtually eliminate the opportunity for criminal events (Wuscke et al, 2010). 


\section{Annex: Methodological Remarks}

Given the limitations of systematic randomization, the study employed the use of non-equivalent groups before (pre-test) and after (post-test) design. In this design, the crime incidences (dependent variable) were measured both before and after land use transformation, as depicted in Table 6. The main difficulty of such a design, as noted by Beins (2004), is that with the passage of time, considerable extraneous variations may develop in its treatment effect. In minimizing the extraneous variations effect, the study made use of interrupted time-series design, which makes use of numerous pre-tests and post-tests. In this case, as noted by Kazdin (2003), periodic measurements were made on a group prior to the interruption of the intervention (transformation) to establish a stable baseline.

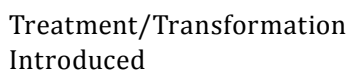

Level of Crime Incidences

After Land Use Transformation in Dandora (Y)

Treatment Effect=(Y)-(X) (Posttest-Pretest)

In order to get the situational analysis of community crime prevention strategies, focus group discussion were conducted with the community policing members, representing all the phases of Dandora.

Surveys were undertaken with three groups of respondents:

1- Residential Land Use (Tenants and Land Owners). 5 phases, total of

Table 6: Non-equivalent Group Pre-test \&Post-test QuasiExperimental Design. Source: Opiyo, 2011 144 samples

2- Commercial Land Use (Businesses), 5 phases, total of 121 samples

3- Land use regulators and Security Providing institutions namely Nairobi City County Government, community crime prevention groups, police, and former residents; 10 samples

\section{References}

Anderson, E. (1999). Code of the Street: Decency, Violence, and the Moral Life of the Inner City. New York: W.W. Norton.

Beins, B. C. (2004). Research methods: A tool for life. New York: Pearson Education

Bernasco, W. \& Nieuwbeerta, P. (2005). Do Residential Burglars Select Target Areas?

Brantingham P.L. \& P.J. Brantingham (1993).
"Nodes, Paths, and Edges: Considerations on the Complexity of Crime and Physical Environment," Journal of Environmental Psychology, Vol. 13, pp. 3-28.

Cahill, M. (2005). Geographies of Urban Crime: An Intraurban Study of Crime In Nashville, TN; Portland, OR; and Tucson, AZ. Unpublished PhD Thesis, The University of Arizona 
Chamlin and Sanders (2008) "Reintroducing 'Time' into the Time Series analysis of the Police Size-Crime Relationship: An Error Correction Approach." Policing. An International Journal of Police Strategies \& Management 31, 499-513.

DPU (1986). Women In Sites and Service Scheme Dandora: A Gender Analysis of Housing Development, DPU Gender and Planning Working Paper, No. 13, DPU University of College, London

GoK, (2010). Kenya's Population and Housing Census, Volume 1A. Nairobi, Kenya National Bureau of Statistics (KNBS).

Government of Chile (2003). National Urban Survey on Citizen Security. Santiago, Chile: Ministry of the Interior and the National Institute of Statistics.

Hentic, I., (1997).Globalization and Decentralization. In Kirdar, U., 1997. Cities Fit For People. New York, Nations University Press. pp. 368-374.

Kazdin, A.E. (2003). Research Design in Clinical Psychology (4th Edition). Needham, Heights MA:Allyn and Bacon.

Kiamba, C.M. (1986). "The Role of the State In the Control of Urban Development: Urban Land Policy for Nairobi Kenya". Unpublished PhD Thesis, University of Cambridge.

Muchai, A. (2001) Kenya Crime Survey 2001: Security Research and Information Centre, Nairobi, Kenya.

KIPPRA, (2004) Security Risk and Private Sector Growth in Kenya: A Survey Report. Special Report No. 6. Nairobi.

Koti, F.T., (2000). Production of Urban Space in Kenya: Central-Local Government Power Relation in Mediating Space in Athi River Town. MA Geography Thesis, West Virginia University; Morgantown, West Virginia.

Merry (1981). Urban Danger: Life in a neighbourhood of strangers, Temple Univ. Press, Philadelphia.

Mundia G. (2004). "Social multi-criteria evaluation (SMCE)": methodological foundations and operational consequences, European Journal of Operational Research, Vol. 158/3, pp. 662-677.

Power (2004). Neighbourhood Management and the Future of Urban Areas. CASE paper 77, Centre for Analysis of Social Exclusion, London School of Economics, London.

Reith, (1996). The Relationship between
Unemployment in Society and the Popularity of Crime Drama on TV , Journal of Broadcasting \& Electronic Media, 40: 258-264.

Ross, C., John, M., and Shana, P. (2001). 'Powerlessness and the Amplification of Threat: Neighborhood Disadvantage, Disorder and Mistrust', American Sociological Review 66 (August): 568-91.

Sampson, R. \& Raudenbesh, S. (2004). “Seeing Disorder: Neighbourhood and Stigma and the Soial Construction of Broken Windows". Social Psychology Quarterly 67 (4):319-42

Shaw, M and Carli, V.(Eds) (2011). Practical Approaches to Urban Crime Prevention: ICPC. 12th UN Workshop Proceeding held in Salvador, Brazil, April 12-19th 2010.

Skogan, W. (1986) 'Fear of crime and neighborhood change'. Crime and Justice, 8, 203-229.

Soni, N. (1981). On Self-Help in a Site and Service Project in Kenya. Unpublished Masters Thesis, Massachusetts Institute of Technology.

Stucky, T\& Ottensmann, J,. (2009). Land Use and Violent Crime. American Society of Criminology, 47(4) (1223-1264).

Taylor, R. (2001). Breaking Away From Broken Windows: Evidence From Baltimore Neighbourhoods and the Nationwide Fight Against Crime, Grime, Fear and Decline. New York: Westview.

UNCHS. (1987). National Human Settlements Institutional Arrangements: Selected Case Studies. Nairobi: United Nations Centre for Human Settlements (Habitat).

UN-Habitat, (2005). Responding to the Challenges of an urbanizing world. 2005 Annual Report. United Nations Centre for Human Settlements (Habitat).

World Bank report (2010): Violence in the City: Understanding and Supporting Community Responses to Urban Violence. Washington, DC: World Bank.

Wuschke, K., and Brantingham, P., (2010). Landscapes of Crime: Exploring Urban Crime and Land Use. Retrieved on November 13th 2011 from http://www.geoplace.com/Media/MediaManager/Kathrynper cent20Wuschke.pdf.

Wilson (1995)- Sampson, R., and Wilson, W.J., (1995) 'Toward a Theory of Race, Crime and Urban Inequality', in John Hagan and Ruth D. Peterson (eds) Crime and Inequality, pp. 37-54. Stanford, CA: Stanford University Press. 


\section{Communities and the Prevention of Crime and Violence in Douala, Cameroon}

Christophe Sados Touonsi

Since 1990, Douala has gained the reputation of being a dangerous city.

01.

U-Care: Urban Violence in Sub Sahara Africa. It's impacts, Coping Strategies and Peace Building.

Technische Universität Darmstadt and Global Urban Institute Berlin (GLOBUS), funded by the Volkswagen Foundation.

02.

Cameroon is divided in then regions. Douala is the capital of Littoral region and the biggest town of the country.

03.

According to the

Third General Population and Housing Census in Cameroon
For example, in only two years from 2009 to 2011, an increase of robberies and the reselling of stolen goods rise to about $156 \%$. In the period from 2008 to 2011, the city of Douala accounted for $60 \%$ of the homicides in the coastal region and $86 \%$ of assaults implicating bodily harm.

This paper, summarizes the Country related results of a joint research program on violence prevention in Sub Sahara Africa ${ }^{1}$ and examines the manifestations of urban violence and prevention strategies by the community in six neighbourhoods with different income levels in Douala. The inadequate capacity of government and the municipality to provide meaningful protection against crime and violence has led the communities to attempt defending their homes and neighbourhoods on their own. In the residential zones visited as part of this study, 35\% of households have been victims of robbery, $23 \%$ of physical aggression and $16 \%$ of burglaries within the previous 2 years.

In this light, the study evaluates the ability of communities to implement local prevention strategies to reduce crime and violence in their immediate urban environment. Specific interest was directed towards Neighbourhood Watch Committees (NWC) as opposed to the conventional efforts made by individual households and families.

\section{Criminality in the city of Douala}

Douala is the largest city in Cameroon and the capital of Cameroon's Littoral region. ${ }^{2}$ With its large port it handles most of the country's exports, and is the commercial capital of the country. As of 2010 Douala and its surrounding area had an estimated population of 2,5 million inhabitants ${ }^{3}$.

According to police statistics violent crime is increasing in Douala. ${ }^{4}$ The inventories of burglaries and robberies shows a jump from 81 and 
102 points on then crime index from 1998 to a 1999 (Meutchehé Ngomsi, 2009). In the same way as did damage to property (2008-2011) infractions to bodily integrity (rapes, physical aggression). Certainly some zones of the city are more affected than others, what the paper will also illustrate.

One deficit in the public discussion about crime, but also in the literature, is an imprecise differentiation between various expression of crime and violence - which become particularly problematic when it comes towards the design of prevention strategies. For example, domestic violence and rape cannot be compared with gang and drug violence and requires completely different prevention strategies. Therefore this text starts with an attempt to clarify at least the terminology commonly associated with crime and violence.

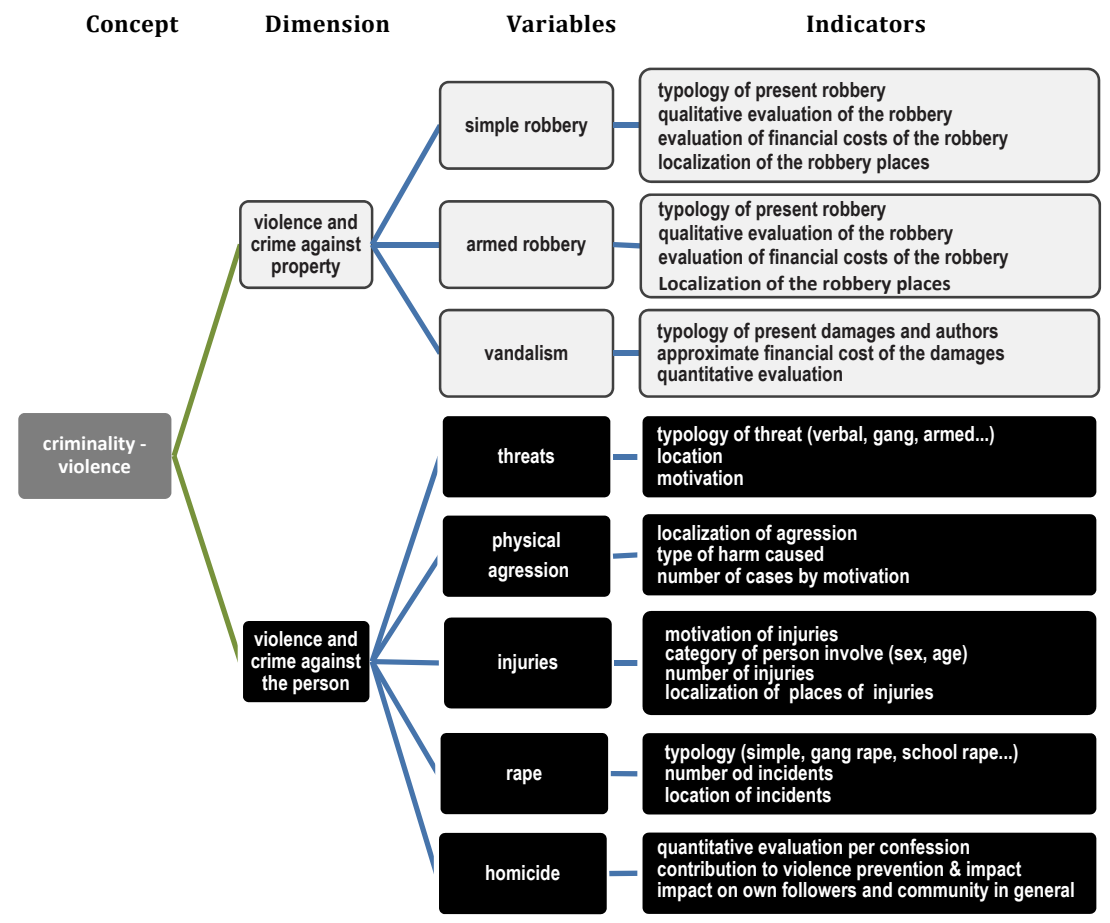

04.

It is difficult to have global data on the criminality in Cameroon and particularly in Douala. Nevertheless the scientific publications (M'packo, 2000; Meutchehé, Sados \& Tchoko, 2003; Issa, 2004; Loé, Meutchehé Ngomsi, 2010; Nga Ndongo, 2008),

the daily press, the results of the enquiry of victimization realized in Yaounde (2001) and Douala (2003) in the framework of the project "Safer Cities" of the UNHabitat, indicate that the Cameroon is facing an augmentation of criminality in the urban area from the decade of 1990.

Figure 1: catégorisation of criminality and violent crime. Source: author 2011

A first and very simple distinction is achieved according to the object of criminal aggression: if it is directed against goods the adjective 'violent' is rarely used whereas in the case that the object is a person violence is almost always part of it, even if in some cases legislation fails to declare it to be a criminal act (as in the case of state violence).

Crimes against goods are subdivided in three variables (burglary, pickpocket and destruction of goods). The perpetrators can be local residents or aliens to the neighbourhood. Crimes against persons can be distinguished by five variables (rape, homicide, physical aggressions, threats and injuries)

Another important characteristic is territoriality with a first and simple distinction between indoors (private) and open space (public). In public 
The open fields space surrounding Mbappé Leppe stadium in the Akwa neighbourhood, the stadium of Camp TSF in New Bell, the stadium of Cité CICAM in Bassa and around the Reunification Stadium, along the fence of the International airport of Douala, the crossroads of the Cité des Palmiers and the Congo Market are place frequented by dealer and users of marijuana.

Figure 2: Neighbourhoods of Douala having a vigilante committee and selected neighbourhoods for the field studies space markets and crossroads are the main public spaces considered dangerous by the populations. According to the victimization survey of 2003, the Central Market of Douala is the public space felt to be most dangerous in town (more than $28 \%$ of the respondents). It is followed by the Ndokoti-Tunnel and crossroads (these two sites were indicated by $13,8 \%$ and $13,1 \%$ of responses). Some areas have a bad reputation because they are frequented by dealers and users of marijuana. ${ }^{5}$

\section{Case studies on urban violence in different neighbourhoods}

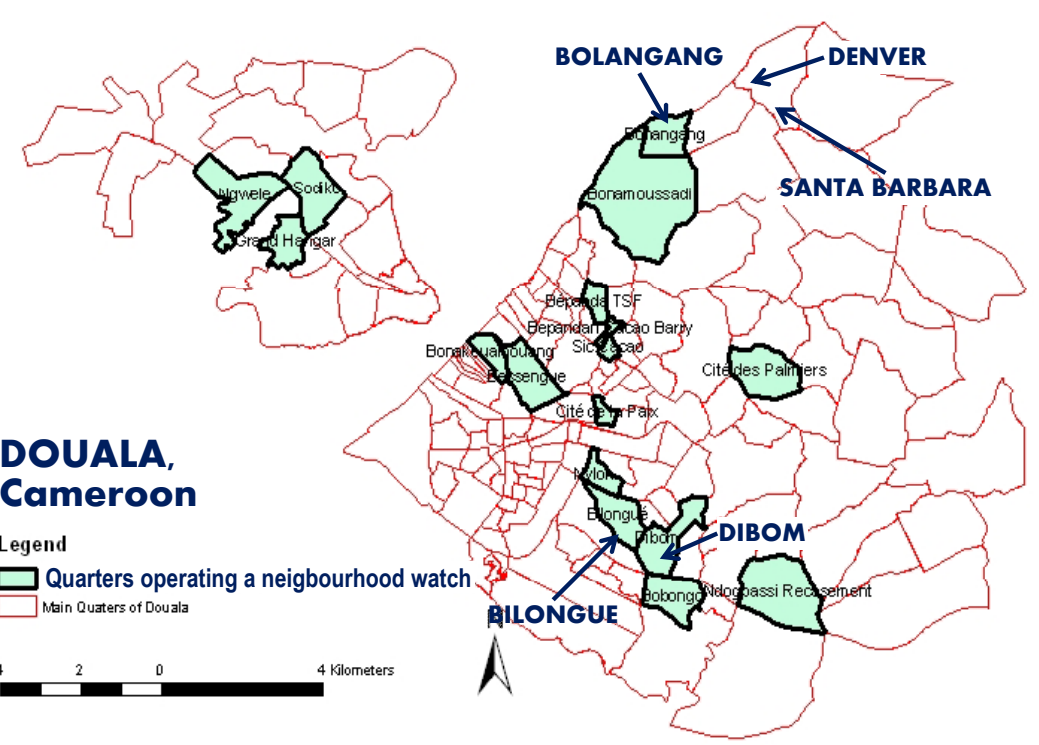

In order to collect information on violence prevention strategies in a large variety of different neighbourhood situation, six neighbourhoods with different economic and social status were selected for the field work: three with poor status (Dibom II, Dibom III and Bilongué II), two middle income areas (Bonangang, Mobil Guinness) and one rich neighbourhood (Denver-Bonamoussadi).

\section{Denver (high income)}

Denver is a neighbourhood of high standard developed to accommodate the wealthy individuals. In this neighbourhood, we see are comfortable villas with raised concrete fences. The owners are looking for privacy and more security. The average size of plots varies between 400 and $500 \mathrm{~m} 2$. The height of the surrounding walls, the size and decoration of houses symbolize 'architecture of fear'. Population densities are less than in the other study areas. Most houses have decorative gardens, some have swimming pools, video surveillance and watch dogs. Each home is secured by at least one guard. At various entrances and exits of the neighbourhood are checkpoints and controlled by guards every night from 9o'clock. The streets of these neighbourhoods are well designed, sufficiently broad, and paved and distinguished by the cleanliness of their 

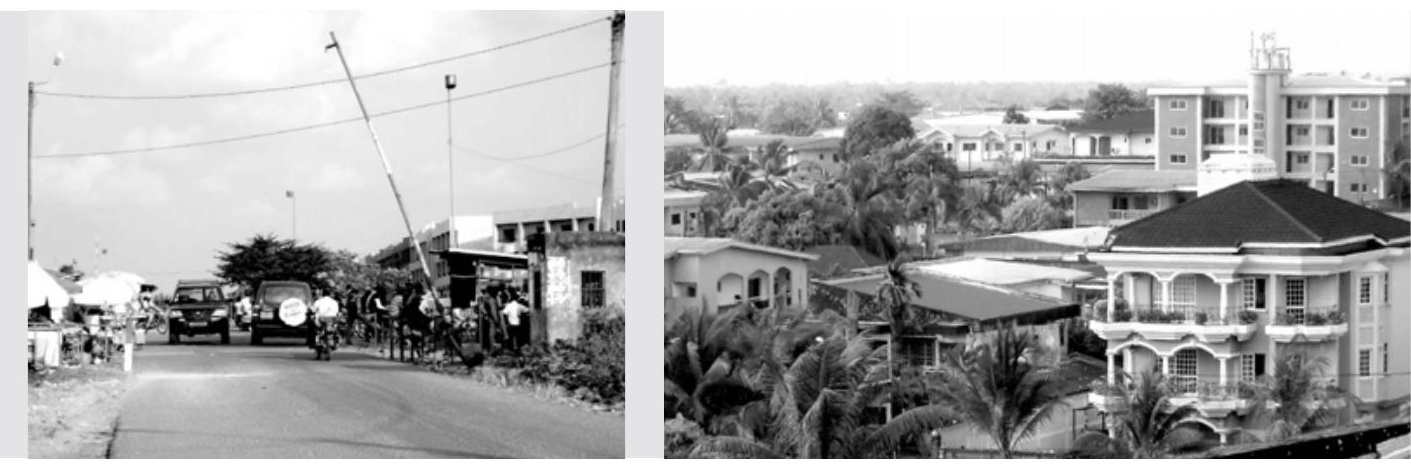

streets. The garbage collection company HYSACAM regularly collects the wastes. The nature of houses, cleanliness of streets, the presence of guards and abundant lighting indicate high incomes of the residents

\section{Middle income areas Bonangang, Mobil Guinness}

Bonangang is located north of Douala and is close to Denver-Bonamoussadi. Bonangang is divided into two areas: the first is on a plateau and well structured with some comfortable villas and the second is on the valley part and unstructured with slum. The two parts are separated by an escarpment of 100 meters. On the plateau the streets are large but are generally in poor condition due to the passage of trucks which go to carried sand from Wouri River. In the slum area, the houses are built of temporary materials; population density is very high like in Bilongué II and Dibom II. The high density housing and spontaneous vegetation imply low visibility, which restricts surveillance on the slum part of Bonangang and is believed to increase the risk of crime.

As the name suggests, the neighourhood Mobil Guinness is located between the Mobil petroleum company and the Guinness beer factory. It is located about 500 meters from the crossroad Ndokoti. The houses are modern and luxurious but more modest than in Denver-Bonamoussadi. Many houses have fence, gardens, guards and guard dogs. Houses and population are less dense than the one of Bilongué II, Dibom II and III. A portion of the streets is unpaved and poorly maintained. Public lighting covers almost the whole neighbourhood, but remains insufficient as in Dibom and Bilongué.

\section{Low-income Dibom and Bilongué neighbourhoods}

Located south of the town, ten miles from Denver, the Bilongué II and Dibom II and III neighbourhoods are unstructured areas and slums. The houses are built of temporary materials, including boards, low quality wood and roofing sheets. Population density is very high. Along the main (paved) roads across these neighbourhoods, most houses are built in concrete and house commercial activities. The average plot size varies between 200 and $300 \mathrm{~m} 2$. The fences exist at all they are made from scrap material. The streets are not wide enough and include many dead-endstreets. Informal activities narrow the usable roadway of certain streets, which provides a pretext to HYSACAM for not regularly collecting the

Left:

Entrygates

around the Denver estate

Right:

Inside Denver estate 

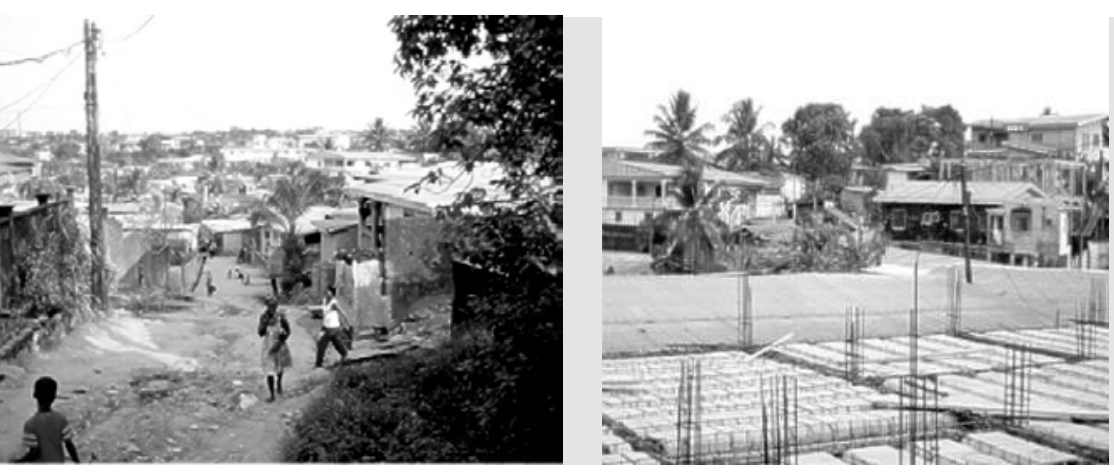

View of

Bonangang estate

Photos:

Christophe Sados

waste - and what does not help to keep the streets clean... These neighbourhoods attract relatively poor individuals who seek to rent houses that are less expensive than downtown. Despite the donations of some charitable persons in these neighbourhoods, street lighting remains inadequate and a number of streets are unlit. These are said to be popular as hiding places for criminals.

The Dibom III neighbourhood on the other hand is relatively well structured. This is a resettlement zone with plots of 150 to $200 \mathrm{~m} 2$ which had

06.

L'ARAN means: l'Agence de Restructuration et d'Aménagement de Nylon. This company was created by MAETUR (Society for Planning and Equipment of Urban and Rural Land) to widen a number of streets in Nylon and to complete missing infrastructure. been urbanized by MAETUR-ARAN ${ }^{6}$ to accommodate households evicted from a rezoning project in the Nylon area. The construction of identical houses had been imposed by the MAETUR ARAN Company, and the building materials are conventional. The streets were well equipped initially but became degraded, dirty and blocked in certain places for lack of maintenance. The lighting is very poor. Some sites are still unoccupied land and rumours claim that they serve as hideouts for bandits.

The Dibom III neighbourhood has a market located in the so called "Carrefour des Billes." The space occupied by the market and adjoining areas are continuously infested with all kinds of waste left behind by the merchants. The trading activities cause the disruption of vehicular and pedestrian movement and the streets around the market are muddy and impassable during the rainy season. The presence of garbage on the streets, in the gutters, bushes along some streets indicate that the maintenance of these areas is poor. Poor housing standards, lack of safe public places, bad road conditions, and inadequate street lighting have indicated that they are poor neighbourhoods.

\section{Crime before the installations of neighbourhood watches}

Acts of violence and crime were recorded through a victimization survey (2011) evaluating the situation two years before a neighbourhood watch was set up in their neighbourhoods. The results are shown in Table 1.

According to the results of victimization survey, robberies constitute $35 \%$ of offenses and ranks first of the criminal acts of the six neighbourhoods survey. The poor neighbourhoods record the biggest number of robberies (28\% to Dibom III and 26\% in Dibom II), while the middle income neighbourhood of Mobil Guinness and the rich neighbourhood of DenverBonamoussadi have fewer robbery cases (6\%). The most stolen objects are the electronic appliances $(32,2 \%)$, money and jewelry $(25,8 \%)$, cell 

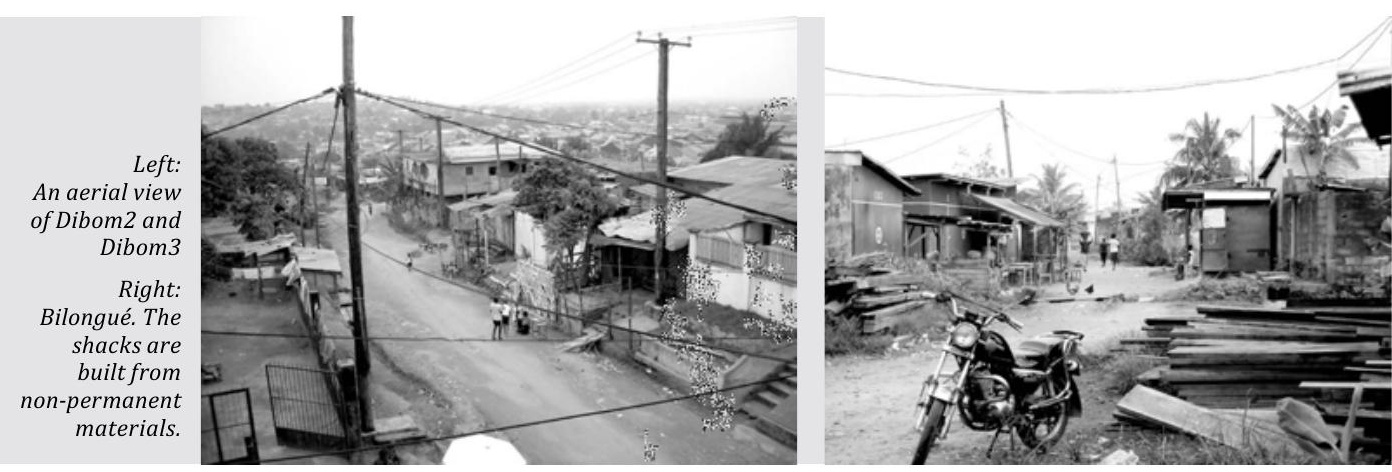

\begin{tabular}{|c|c|c|c|c|c|c|c|}
\hline $\begin{array}{l}\text { District of } \\
\text { Investigation }\end{array}$ & $\begin{array}{l}\text { Physical } \\
\text { Agression }\end{array}$ & $\begin{array}{r}\text { Home } \\
\text { Burglaries }\end{array}$ & Robberies & $\begin{array}{r}\text { Sexual } \\
\text { Agression } \\
\text { or Rape }\end{array}$ & $\begin{array}{r}\text { Insults } \\
\text { and } \\
\text { injuries }\end{array}$ & Threats & Total \\
\hline Dibom III & 23 & 26 & 32 & 1 & 14 & 14 & 110 \\
\hline Bilongué II & 19 & 4 & 22 & 1 & 8 & 11 & 65 \\
\hline Dibom II & 13 & 8 & 30 & 0 & 2 & 2 & 55 \\
\hline Mobil Guinness & 8 & 3 & 10 & 0 & 6 & 1 & 28 \\
\hline Bonangang & 9 & 8 & 18 & 0 & 13 & 12 & 60 \\
\hline Denver-Bonamoussadi & 5 & 3 & 4 & 0 & 0 & 0 & 12 \\
\hline Total & 77 & 52 & 116 & 2 & 43 & 40 & 330 \\
\hline
\end{tabular}

phones $(16,1 \%)$, gas bottles and motorcycles $(6,5 \%$ each). Jewelry and mobile phones were stolen at homes and in the streets, whereas the electronic items (televisions, DVD, musical chain), gas bottles, motorcycles and dresses are stolen from the residence.

The physical aggressions are the second demonstration of delinquency in the survey neighbourhoods. $23 \%$ of respondents had been victims of physical aggression once and $2 \%$ at least twice. Among the attacked people, $38,5 \%$ have been wounded, $7,7 \%$ had some bruises, $7,7 \%$ fainted, Table 1: Crime face by the population of the neighbourhood before the creation of the neighbourhood watch.

Source : Field Investigation, July but $42,2 \%$ didn't suffer any bodily harm. 18,2\% think that they were victim of a single perpetrator whereas $72,7 \%$ say that they were attacked by a group of criminals. When the aggressors act in a group, their tasks are well distributed: some control the places and others attack the victim. In the six neighbourhoods of our survey, the majority of aggressions take place at night $(71,4 \%)$. The presence of many empty plots, notably in Dibom III and the availability of hiding places in the different neighbourhoods of survey were blamed for the biggest number of the aggressions in the night. Otherwise, some kiosks, left unclosed during the night by their owners are used by the delinquents to the consumption of marijuana and for ambushes.

The poorest neighbourhood, Dibom III experienced the biggest number of physical aggressions (30\%), it is followed by Bilongué II with $25 \%$. Dibom II occupied the third position with $17 \%$, and fourth position is Bonangang with $12 \%$. Mobil Guinness and Denver-Bonamoussadi are the neighbourhoods that record little aggressions with respectively 10 and $6 \%$. This linkage between status of the neighbourhood and exposure to crime and violence is also expressed in the victimization rate. 


\begin{tabular}{lcrr}
$\begin{array}{l}\text { District of } \\
\text { Investigation }\end{array}$ & $\begin{array}{c}\text { S=Number of house- } \\
\text { holds surveyed }\end{array}$ & $\begin{array}{c}\text { V=Number of } \\
\text { victimization }\end{array}$ & $\begin{array}{r}\text { Average number of } \\
\text { persons victimized per } \\
\text { household (V/S) }\end{array}$ \\
Dibom III & 60 & 110 & 1,8 \\
\hline Dibom II & 36 & 55 & 1,5 \\
\hline Bilongué II & 31 & 65 & 2 \\
\hline Mobil Guinness & 31 & 28 & 1,2 \\
\hline Bonangang & 50 & 60 & 1,2 \\
\hline Denver-Bonamoussadi & 23 & 12 & 0,52 \\
\hline
\end{tabular}

Table 3: Level of victimization of household in the survey neighbourhoods. Source : Field survey, july 2011

\section{Level of victimization of household in the survey neighbourhoods}

The level of victimization of the households above shows that the status of the district generally influences its level of safety. It clearly enough appears that the households of the poor neighbourhoods are three to four times more victims than the households of rich neighbourhoods, and the middle income neighbourhoods are two times more victimized than the households of the rich neighbourhoods. The victimization comparison of the households between the middle income neighbourhoods and poor neighbourhoods shows that the latter are 1,5 times more victimized than the middle income neighbourhoods.

Localization of aggression: Among the acts of physical aggression 41,2\% of victims were attacked at home, 33,3\% to the surroundings area, 11,8\% further away in the neighbourhood and 13,8\% out of their residential neighbourhood.

Hour of aggression: Only $2 \%$ of the perpetrators were less than 15 years of age, 68\% were aged between 15 and 30 years and 30\% were older. It has been reported that particularly the young perpetrators are becoming more and more violent and that organized crimes seem to be specializing in stealing of vehicles or selling drugs, especially in Bilongué I and Makia.

Burglaries: Also the incidence of burglaries decreases with rising income (who can afford to pay for better protection): Dibom III accounted for 27,5\% of burglaries, followed by Dibom II with 25,9\%, Bilongué II with $19 \%$ and Bonangang with 15,5\%. Mobil Guinness and Denver-Bonamoussadi have less burglary with $8 \%$ and $3 \%$ respectively. The level of burglaries could also be explained by the type of housing prevailing in the survey neighbourhoods. In the poor neighbourhoods of Bilongué II and Dibom II, about one house out of three is constructed with temporary materials. The doors of houses have generally been manufactured with less resistant materials and don't have sophisticated locks. They are easy to break in. On the other hand, in rich Denver-Bonamoussadi or middle-income Mobil Guinness, high walls and strong gates or even guards present a much better protection.

$19 \%$ of burglaries take place during daytime between 6.a.m and 6 p.m, $20 \%$ between 6.p.m and mid night and $61 \%$ occur between midnight and 6 a.m. According to Cohen and Felson (1979), "as the women integrate the job market, the number of houses left without surveillance in full day increases. Thus, one observes a rise in the number of burglaries." 


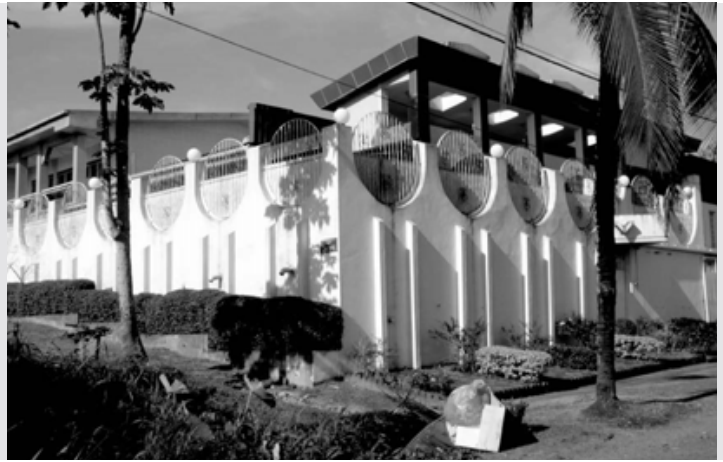

\section{Violence prevention strategies}

The sex theories have been considered to be most relevant for our research and its collection and analysis of data. There are :

- the theory of social disorganization;

- the theory of defendable space;

- the theory of Crime Prevention Through Environment Design (CPTED);

- the theory of rational choice;

- the theory of routine activity ;

- the theory of criminal motivation .

These theories are complement and focus the link between social and physical environment and the criminality or on the manipulation of the physic and environmental characteristics of the underworld. From this theoretical base, the following prevention strategies have been identified (see Figure 4 in the next page).

This diagram categorizes different strategies of prevention'. It details the different dimensions, variables and indicators permitting to determine the meaning given to each concept. Conceptionally there appear two principal dimensions: traditional and situational.

The traditional type of prevention is essentially based on the customs or communities member's culture to avoid or at least to restrain the violence by the dissuasive practices and mode of conflicts' prevention can be subdivided in five variables. Every variable presented in the conceptual table is appreciated and evaluated by the verifiable indicators. These five variables can also be split further in three approaches: namely (1) the conventional approach to dissuade against thief and unmask offenders $\left(\mathrm{Cadi}^{7}\right)$; and (2) the strategy to assure the personal protection (fetishism and magical potion) and (3) the strategy to preserve peace between members of the community (tribunal of reconciliation).

The situational type of strategies are subdivided in ten variable (supervising, physical protection/ gates, access control, alert, road maintenance and various network, collaboration with the FMO, weeding, sanitation, mob justice and sensitization) that represent different popular practices of communitarian or private care of security. These strategies are named "situational" because they link the criminal activities to the
High walls and strong gates

in Denver-

Bonamoussadi make burglaries less likely

Photos:

Kosta Mathéy
07.

Cadi is a beverage and other occult objects to detect authors of sinful acts. It's a practice from the Bamileke tradition. Bamileke is one of the 250 tribes of Cameroon 
Concept

Dimension

Variables

Indicators

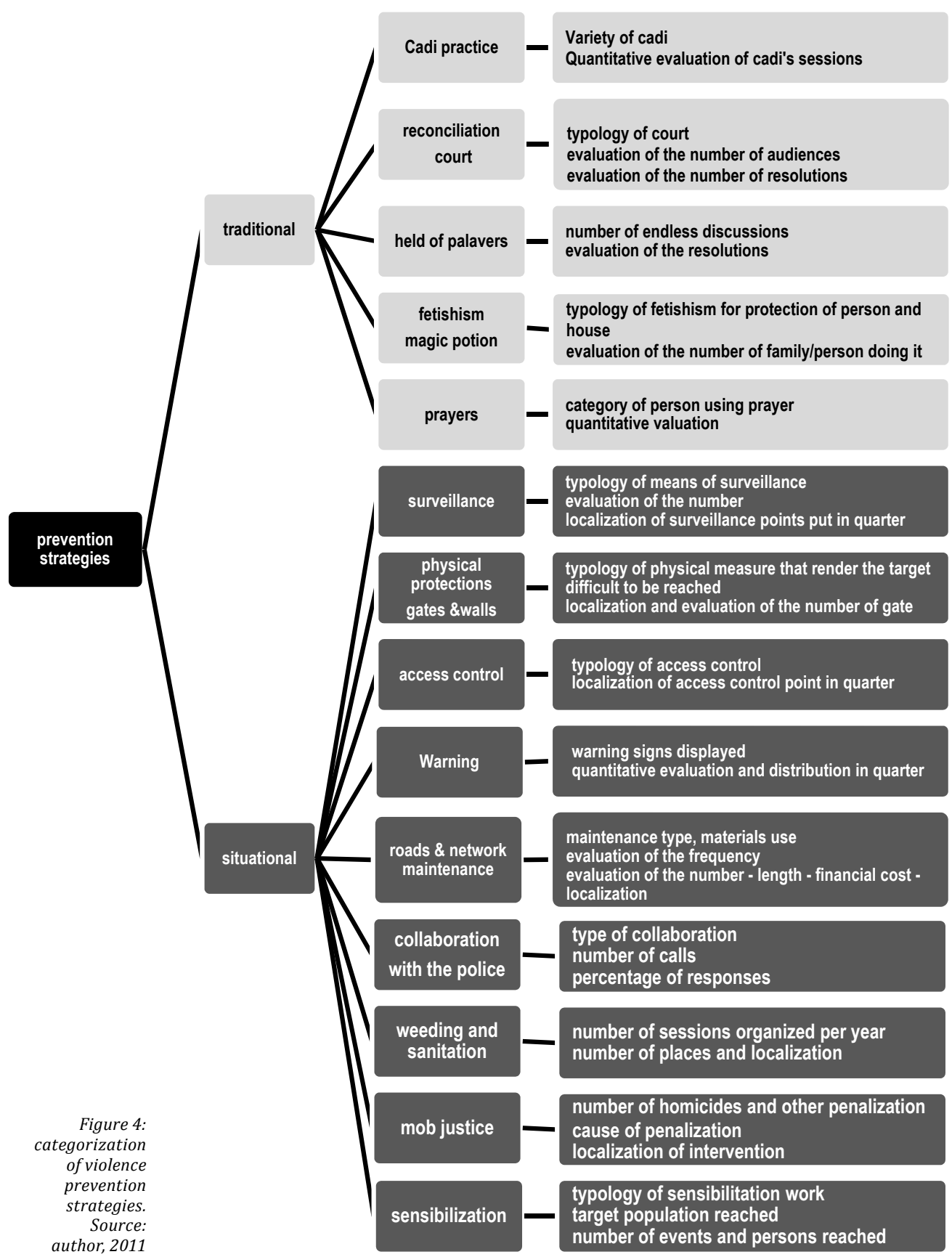




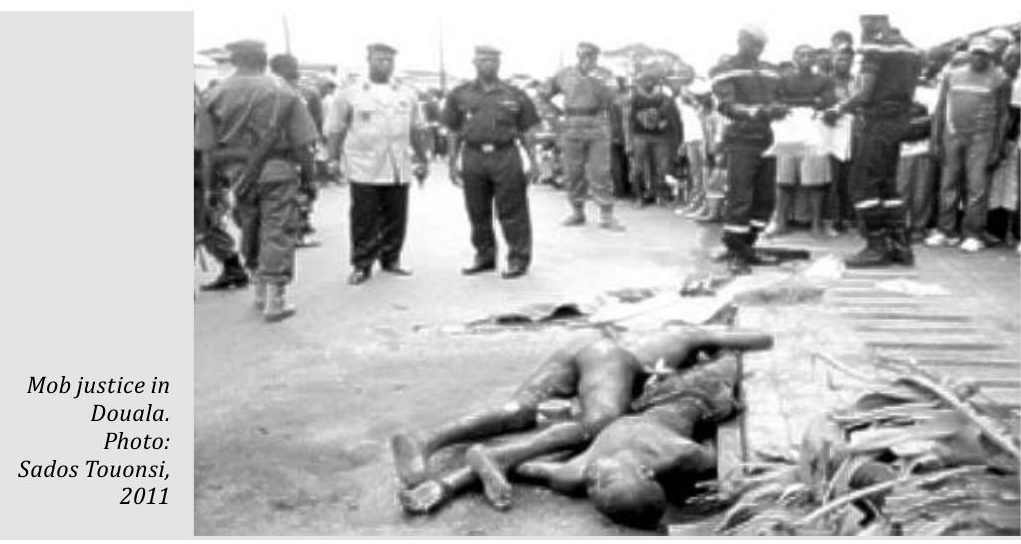

specific features of the physical environment (redevelopment areas) and to targeted precaution (improvement of the visibility, supervision, cleanliness campaign) or a particular reaction (call to policemen, mob justice). The indicators spell out practical examples of such practice.

As mentioned already, prevention measures can be individualistic or collective. In the context of this book we define the collective forms of prevention strategies 'community based' which is still a rather broad concept and merits some clarification in the case of Cameroon. The diagram on the following page visualizes the case:

The diagram details the different dimensions and variations of community-based prevention, and indicators' helping to identify the meanings within the broader concept. Thus, the community does not only have a social dimension (like a group of persons or a specific social agent, or a cultural habit) but also can refer to physical territory with specific environmental characteristics. Hence the diagram differentiates between two principal dimensions: "social organization" and "physical organization".

The dimension "social organization" is subdivided in five variables (family, town's association, town's kingdom, vigilante committees, religious communities) that represent different groups that use to intervene in efforts to reduce levels of crime and violence in Douala's townships. Examples of collective efforts are variable: presence to the meeting, financial contribution to the town activities, implication in the awareness of inhabitants, participation to the work of public interest and the monitoring support of the town.

The dimension "physical environment" is also subdivided in five variables (the habitat, road maintenance and cleaning, public lighting, public space, sanitation improvement). These variables principally relate to "ecological" theories of violence prevention which suggest increasing urban safety through modifications in physical component of urban space... Again, the indicators list measurable examples to be identified in the field. 
$\begin{array}{lll}\text { Concept Dimension } & \text { Variables }\end{array}$

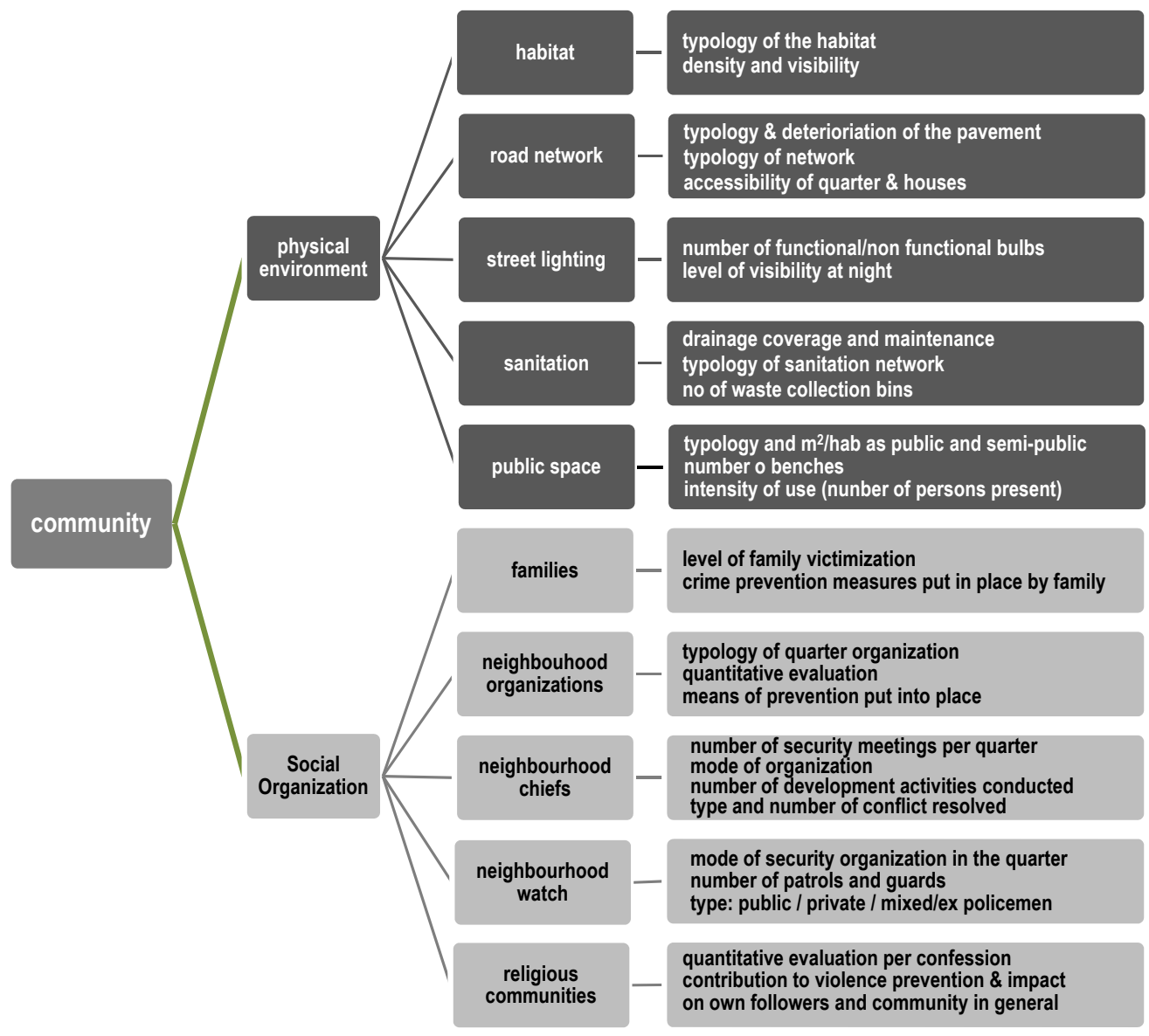

Figure 5: The practice of collective strategies in Douala

Conceptualization of communitybased strategies. Source: author

2011
Collective strategies take, in most cases, the form block watches and / or the development committees, but may also be delegated to the commercial sector. Each neigbourhood tends to develop its own operational mode.

\section{The setting up of the block watch}

$76 \%$ of the respondents of our survey affirm that the elevated levels of insecurity that justifies the setting up of the block watch in their neighbourhood. However, the strategies to put these committees in place are not uniform in Dibom III and Dibom II. The chiefs of the Dibom neighbourhoods confided the recruitment of the watchmen to the private security company "Africa Security". This agent, with the help of some chiefs of blocks, chooses 21 watchmen and trains them in the techniques of selfprotection. In Bonangang, the neighbourhood security chief chooses the watchmen among the adolescents of the neighbourhood which must have a good moral standing and "physical aptitude". In Denver-Bonamoussadi, 

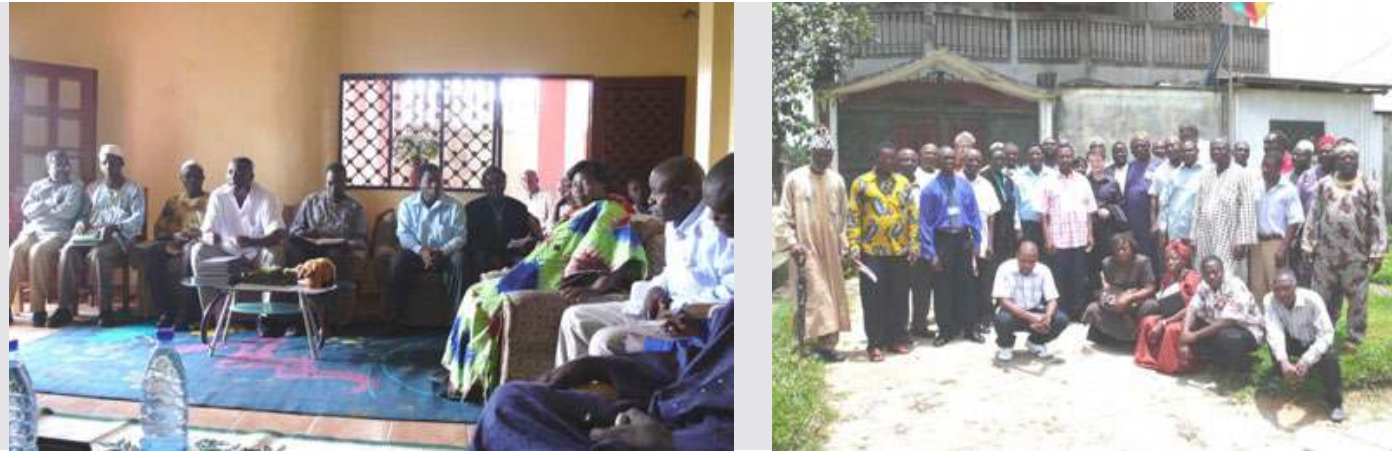

the parents do not accept that their children become watchmen and confide this task to members of the Toupouri tribe originating from the Far Northern Region of Cameroon. ${ }^{8}$ The recruitment of these watchmen must be endorsed by a certificate of hood conduct issued by the state police. Then a list of retained candidates is deposited with the sub-divisional office of the locality, and from there it is passed on to the chief of the neighbourhood concerned. In the middle income neighbourhoods of Bilongué II and Mobil Guinness the local youth organizes the community watch on their own, with the approval of the security chief of the neighbourhood.

\section{The functioning of the community watches}

Several strategies have been developed on the field by the watchmen: the control, the sensitization, the collaboration with the police and gendarmerie.

\section{The controlling strategies of the neighbourhoods by the vigils.}

Most frequently, community watches start operating every night at 8 p.m or 9.p.m. They check all people that enter or leave the neighbourhood, especially the cars that do not belong to residents of the neighbourhood. Other watchmen move on foot, on motorcycle (case of Dibom III) or by car (case of Denver) all over the place while others just concentrate on the known hot spots. In addition, the mobile telephone numbers of the chief of vigil or the security chief of neighbourhood are distributed to be distributed to all heads of household. Bonangang, has organized a "rapid intervention team" composed of four watchmen which can be reached around the clock. Hence the neighbours feel safer once they know that they call for help even in the middle of the night. They can issue a general alarm because most houses keep a whistle for that purpose.

In the rich neighbourhood of Denver-Bonamoussadi or the middle income neighbourhoods of Mobil Guinness and Bonangang, a "road closure" or "security gate" with an iron bar is installed in every street which enters the neighbourhood whereas in the poor neighbourhoods of Bilongué II and Dibom II and III, the watchmen tie ropes across the roads very night between 8 and 9 o'clock., but the rope cannot block or stop a driver or a motorcyclist who intends to break it. In Bonangang, the watchmen register the names of all those that enter or leave the neighbourhood

A community meeting in the house of Dibom III neighbourhood chief in Douala. Photo:

Kosta Mathéy

Community meeting organized by the community chief.

Photo:

Kosta Mathéy

08.

In Denver, the chief of neighbourhood signed a contract with the company ERG in 2008 to guide and help the vigils of the neighbourhood. Every night, this company comes to make a patrol by car in the neighbourhood 


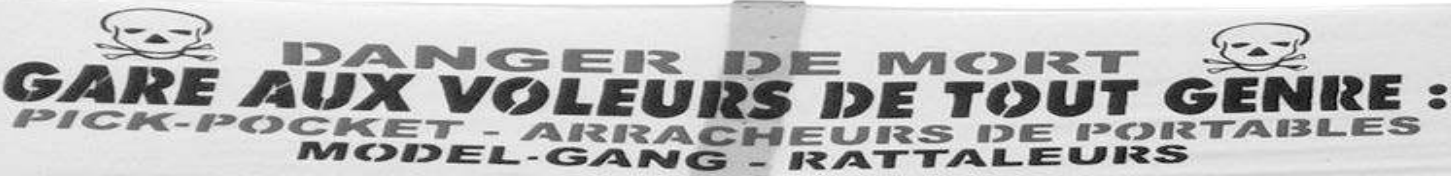

Warning after midnight in a book. In addition to the control, the vigils collaborate displayed by the neighbourhood chief to distract possible invaders.

Photo:

Sados Touonsi 2010. with the police and gendarmerie to different extent.

Another element of the strategy that one meets in the neighbourhoods of Douala is the collaboration with the police and gendarmerie. One can distinguish several types of collaboration:

The first aid: in cases when the watchmen are attacked by "heavy banditry", they can call the police and ask for help. They can also solicit the police who happen to live in the neighbourhood. They are also supposed to alarm the police when the population wants to commit mob justice. This was the case in January 2010 when a bandit, trapped after having stolen a bag of bread, was beaten up by community members but finally saved through the intervention of the gendarmerie of Nylon (after a call by the chief of Dibom II). In general, when a thief is arrested by the watchmen, he is handed over to the police or gendarmerie. Also stolen goods are being delivered and recollected to and from the police stations.

\section{Action by traditional institutions of the community}

Two strategies of prevention notably the communication and the realization of amenities of safety are present in the neighbourhood.

In the poor neighbourhoods, the neighbourhood chief of the community security chief display warning to potential criminal by means of a signboard or banderole displayed at the entry of the neighbourhood. They may also call all parents at the beginning of the neigbourhood watch to inform on the consequences if their children are arrested for crime, since very often the perpetrators are children of the neighbourhood.

\section{The physical amenities aiming to warn criminality}

Place based prevention strategies by groups of neighbours may consist in improving street lighting, for example by fixing lamps on the facade of each house - especially close to known hot spots or improving visibility by collectively removing weeds on public ground.

In 2009, a number of 58 streets lamps were being installed in Bonangang by the "Development Committee and Security of the Neighbourhood". In the five other neighbourhoods, an average of 60 street lamps are installed or replaced each year by the leaders of the neighbourhood with money collected from all households. Very regularly, the vacant plots are reclaimed and gutters cleaned. The kiosks that clutter the streets and serve as hiding places to the delinquents are removed if they are not regularly closed by their owner.

In Bilongué II, Dibom II and III, Bonangang, community work sessions are organized regularly upon the call or the person responsible for hygiene and public healthiness of the neighbourhood and the support of the chief of the neighbourhood and the development committee. The entire 

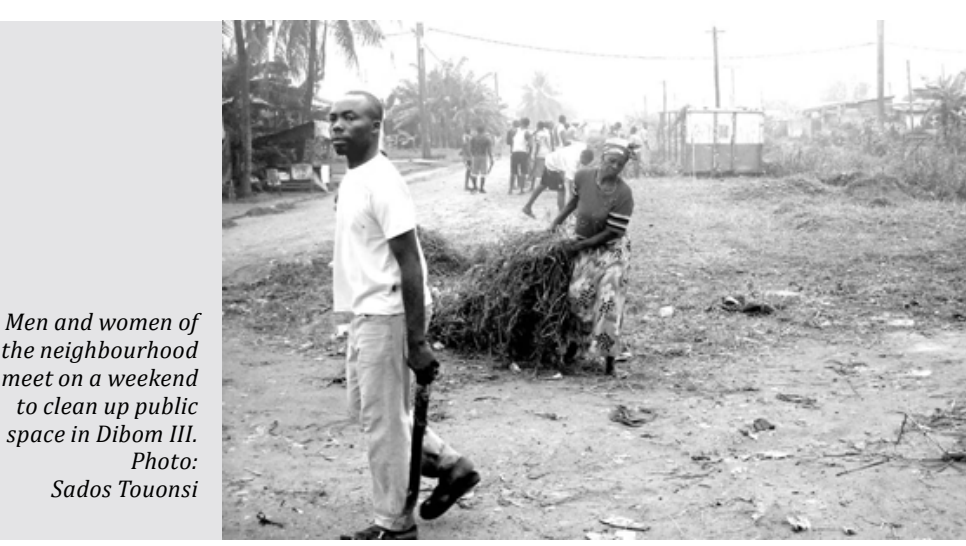

population, men, young and women are expected to participate in these works which are generally held on a Sunday morning. Absentee neighbours donate some money to pay for food and drinks of the rest. Typical tasks include weeding the drains as well as some abandoned lands, or the gutters are scoured. On other occasions the main streets are repaired through the neighbourhood development committee with funds contributed by the inhabitants. For example, a much circulated road $1.5 \mathrm{~km}$ of roads was repaired connecting Dibom III with Bilongué II from 'Entrée Billes' to 'Dibom III Market' in 2009. ${ }^{9}$

\section{The prevention of the robberies by market shop owners}

Shop owners of the Market of Dibom III organized themselves to improve the security of their shops while recruiting three night guards. From 6.pm, these guards take service. They are equipped with spears, bows, whistles and knives. They patrol the shops together. Each shop owner pays between $1000 \mathrm{~F}$ and $2000 \mathrm{~F}$ (1,5 to 2 Euros) for the security per month depending on the size of the shop and the value of the goods. The guards collect money together and share among themselves. In case of attack of a guard, he alerts his colleagues by a whistle and the aggressor generally runs away or is arrested. The surveillance seems to be efficient in the sense that traders rarely report a burglary.

\section{Individual preventive measures of criminality}

In addition to the collective measures, every household head develops additional strategies to secure his or her home. The figure below shows that the main practice of prevention is securing the doors and windows with locks (50\%). This technique is a most used by all households in the different neighbourhood of the study. However, in the rich neighbourhood of Denver-Bonamoussadi, this measure is doubled up with an interphone device, the electronic alarms, bolting systems and similar devices. Some families go back home early (19\%) to secure their houses and to reduce the risks of burglary. The use of watch dogs (8\%) to dissuade the delinquents comes in third position. This measure is especially observed in the Denver-Bonamoussadi neighbourhood where many households have trained dogs and gardens to keep them. Increasing the height of

09.

According to the chief of this neighbourhood, funds collected amounting to $700000 \mathrm{FC}$ FA (1032 Euros) which permitted to rent a tractor, to pay fuel and the technician who did the work. 


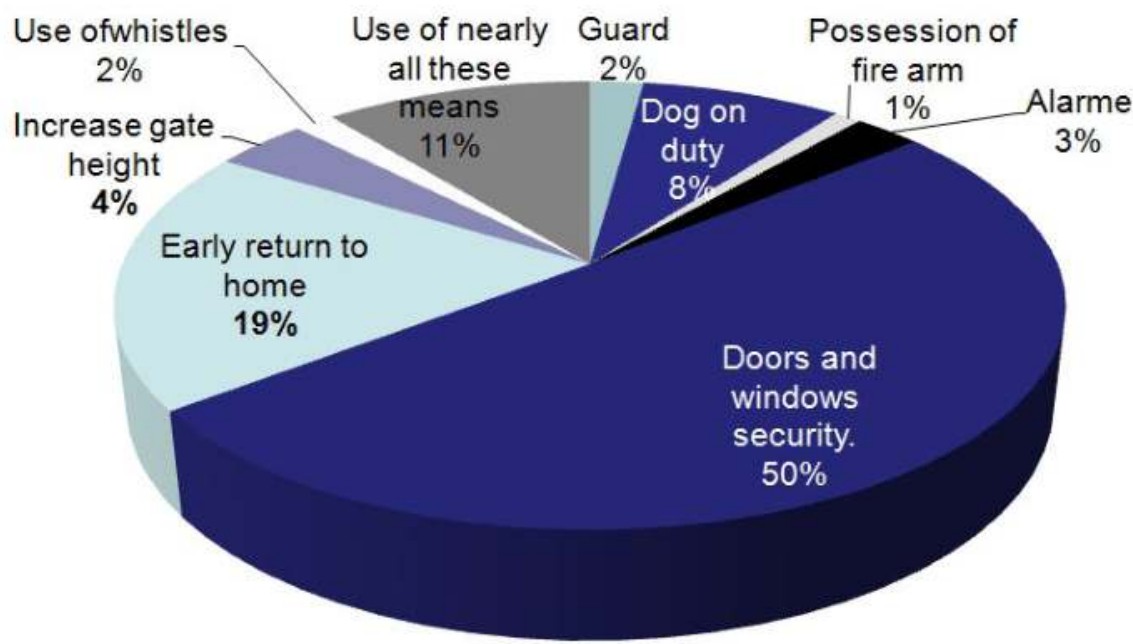

Figure 6: Preventive measures against the burglary of home by the households in Douala in July 2011. Source: field investigation July 2011

existing gates and walls to stop invaders from climbing them comes in fourth position (4\%) followed by alarm padlocks, guards and whistles $(3 \%, 2 \%$ and $2 \%)$. Some households possess some fire arms (especially members of police or the army, the political elite or a business man).

\section{Preventions against the physical aggressions.}

Fear is always present in the life in Cameroon, and precautions are generally taken to reduce the risk of being attacked. The respondents of the survey use four main principal measures to avoid the physical aggressions. Thus, $34,9 \%$ choose to go back early at home; $21,7 \%$ avoid dangerous corners; $16,5 \%$ avoid to go out at night and $8,5 \%$ use vigilance to protect against the aggressions. However 18,4\% don't undertake anything to avoid the aggressions but hand themselves to God's protection.

In the six surveyed neighbourhoods, the most common strategy against being attacked is to avoid a possible encounter. According to Skogan and Maxfield (1981), avoidance implies that a person moves away physically from a hazardous situation in order to reduce his risk of victimization. Thus, the inhabitants when they can, avoid all places having bad reputation. It is notably about the dangerous places (hot spots), and the places having physical features capable to facilitate the commission of crime as the non illuminated streets and the vacant or less frequented locations. 10 A number of respondents of our investigation say that they keep a good distance from unknown persons in the street, notably during the night. Other people, notably in Denver-Bonamoussadi and in Mobil Guinness don't use the public transportation, avoid frequent shopping, or don't walk alone in the street.

\section{Commmunity watches}

All block watches of Douala are financed by the voluntary contributions of the habitants of the neighbourhood. In the six neighbourhoods surveyed, 
$36 \%$ of households paid a contribution for the development committees and/or security of the neighbourhood in January 2010. Dibom III recorded the highest contribution rate with $49 \%$ of households, followed by Bilongué II with $44 \%$. In Dibom II, one household out of three paid its contribution whereas in Bonangang it is only one household on four. On the whole, two households out of three don't pay their contribution for collective security prevention of the neighbourhood. The amount of the contribution varies between 500F CFA for the tenants and 1000F CFA ${ }^{10}$ for the owners in Dibom II, Dibom III, Bilongué II and Bonangang. In the medium and rich neighbourhoods of Mobil Guinness and Denver-Bonamoussadi, the contribution varies between 2000F CFA and 5000F CFA (3 to 7 Euro) by household depending on whether one is tenant or owner. These contributions are collected by the chiefs of block in Dibom II and III at the end of the month. In Bilongué II, Mobil Guinness and Bonangang, the watchmen pass from one house to collect the contribution. In Denver the security chief is managing the accounts.

In Dibom II and III, notebooks have been printed per block and signed by the chief of the neighbourhood and head of the block. The chief of block receives the contribution of the household against a receipt. Subsequently, the chiefs of blocks inform the residents on the use of previously collected funds and remind them on the necessity to sustain the block watch. In Mobil Guinness and Bilongué II, the guards address to the chief of the quarter every month a correspondence on the financial balance and security activity of the neighbourhood.

In general, the recovery of contributions is difficult because of its voluntary character. Some inhabitants don't react even after reminders of payment, what may motivate the collector to give up on them in the end. Others attack the collectors verbally. At times, unconventional means must be applied to motivate the residents to pay their dues for the watchmen - like not letting pass the cars at the checkpoint of those who refuse paying their dues (in Denver). Because of little valuation of the service the salary of the watchmen are low and irregular, adding up to some 25 000 FCFA to 35000 FCFA (38 to 53 Euros) per month.

With that level of salary, the guards do not have any uniform or other clothing (shoes, dresses) suitable to perform their work properly. In the raining seasons, they feel more difficulties to go round the neighbourhood because they lack coats and waterproof shoes. ${ }^{11}$ The equipment of watchmen tend to be limited to whistles and sticks to defend themselves in case of necessity, the ropes to bar the access roads at night and a cell phones to inform the authorities or the police in case. Since the equipment is rudimentary the watchmen are not a real hindrance to stop professional bandits. Their only realistic use is to alert a big number of residents and this still serves to dissuade many bandits to operate in the neighbourhood guarded by the watchmen.

\section{The impact of community watches on security.}

In all neighbourhoods where the block watch operates, robberies, burglaries and physical aggressions decreased considerably: according to $99 \%$ of the respondents in the six neighbourhoods of study, criminality rates

11.

Only the watchmen of Bonangang are equipped with safety shoes.
10.

1000 CFA equals about $1.5 €$ 
decreased with the setting up of the block watch whereas $1 \%$ maintains that there was no change. Disaggregated figures are less overwhelming but still impressive:

- $\quad 45,6 \%$ of the interviewed said that the robberies and the aggressions decreased;

- $23,8 \%$ confirmed a drop in the amount of aggressions and robberies

- $\quad 20,7 \%$ reported that it is now safe in the neighbourhood to go out at night

- $\quad 9 \%$ feel that there are no more emergency screams at night

The following declarations, gathered at the time of interviews by the populations support this reduction of criminality:

"Before, every time that a feast was organized in the neighbourhood, the vandals always came to spoil. It's not anymore the case" declared an inhabitant of Bilongué II.

"Before, we were attacked both day and night. We find some dead bodies as we wake up, people were mutilated with machetes. This is not currently the case since the month of June 2009; we do not hear any emergency screams anymore here and there" declares the chief of block of Dibom III

"Our neighbourhood is more secured now. There are some thefts, stealing of fowls here and there. These are the isolated facts that sometimes come from inside family members. Before then it was armed robberies, local weapons "(The secretary of Dibom II )

The return of the security also resulted in the overnight movements in these neighbourhoods by the inhabitants and the late closing of the trade places, the presence of children playing in the streets, but also a drop of the mob justice that consisted in putting to death all bandits or presumed bandits arrested in these neighbourhoods.

"With the sensitization of population and the decrease of insecurity, the population accepts that the bandits are delivered to the police and gendarmerie", explained to us by the chief of the vigils of Dibom II.

However, all these improvements on the security of the neighbourhoods can be attributed to the block watches, but, it is also the fruit of other initiatives by associations based in the neighbourhood (youth associations, women associations, ethnics associations ); the impact of the activities of the hygiene committee and healthiness; of development promotion of the neighbourhood led by the development committee and the authorities of the neighbourhood (notably the improvement of the streetlights and the street maintenance); the collaboration of the neighbourhood with the police and gendarmerie; and the construction of a communal mind by the regular organization of the meetings between the residents of the neighbourhood. 


\section{Conclusion}

The level of victimization of the households carries a direct correlation with the status and income levels of the respective neighbourhood. The figures clearly show that the poor households become victims of crime and violence three to four times more than the households of the rich quarters, and the middle income quarters are two times more victimized than the households of the rich quarters. The victimization comparison of the household's middle income and the poor one show that the latter are 1,5 times more victimized than the middle income quarters

In both rich and poor neighbourhoods of Douala, security is more and more provided by non-state actors, notably private guards and neighbourhood watches. Although the exposure to crime and violence is not comparable in rich and poor quarters, the results of community watches and associated measures at improved the felt security in all investigated settings to a similar extend. Nevertheless, rich neighbourhoods distinguish themselves from poorer neighbourhoods through efficient road closures whereby awareness building strategies seem to be more efficient in loser income communities. The guards of poor quarters are generally dwellers of their respective neighbourhood; meanwhile those of the rich quarters come from elsewhere. These guards work especially at night and pretend to keep watch over public spaces, control different entrances to the quarters, come to the help to the population when alarmed and collaborate with the police and the gendarmerie. But their efficiently is hampered by miserable pay and equipment. They are not in the position to stop well prepared bandits. Their main strength is the ability to drop an alarm when needed which seems to be efficient. Everywhere these committees have been founded, a considerable drop in violence and fear of crime has been reported by the residents.

The intervention of the civil actors in securing the lives in their vicinity became a dominant feature in the neighbourhoods of Douala. On the whole, the strategies of the communities in the neighbourhoods are worth of interest because they present original approaches that have been adapted to the local realities.

\section{References}

BAKER, B. (2010) Forces non étatiques de maintien de l'ordre : élargir les paramètres pour faire face à la violence urbaine en Afrique. In Bulletin de la sécurité africaine $\mathrm{N}^{\circ} 7, \mathrm{pp} 1-8$

BENIT, C. (2004) Nous avons dû prendre la loi entre nos mains : pouvoirs publics, politiques sécuritaires et mythes de la communauté à Johannesburg. Raisons politiques, 15, pp. 53-68.

BÉNIT-GBAFFOU, C. (2006) Police-Community partnerships in responses to crime: Lessons from Yeoville and Observatory, Johannesburg. Urban Forum, October-December, 17(4), pp. 7-32

COHEN, E; FELSON, M. (1979) Social Change and Crime Rate Trends: A Routine Activity Approach. American Sociological Review, Vol. 44, No. 4, pp. 588-608.
ECHEVERRIA, P.L. (2009) L'impact de l'insécurité urbaine sur les entreprises manufacturières d'Amérique latine: une étude de cas, Puebla au Mexique. Thèse de Ph D. Université du Québec à Montréal.

FABIYI, O. (2006) Analysis of inter-community levels of urban street networks and social interaction in enclusure neighourhoud in Johannesburg. Humanity \& Social Science Journal 1(1), pp 79-95.

GAROFALO, J. (1981). "The Fear of Crime: Causes and Consequences" dans The Journal of Criminal Law \& Criminology, Vol. 72, No. 2, pp. 839-857.

HARNISCHFEGER, J. (2003) Bakassi boy: fighting for crime in Nigeria. Journal of Modern African Studies, Vol. 41, $N^{\circ} 1$, pp 23-49. 
HALE, C. (1996) "Fear of Crime: A Review of The Literature" dans International Review Of Victimology, No.4, pp. 79-150.

HEALD, S. (2007). Controlling crime and corruption from below: Sungusungu in Kenya. International Relations 21, No 2, 183-199

ISSA SAIBOU (2004) La répression du grand banditisme au Cameroun, entre pragmatisme et éthique. In Annales de la Facultés des lettres, langues, arts et sciences humaines de Bamako $\mathrm{N}^{\circ} 3$, http://www.recherches-africaines.net/ document.php?id=242

LOE M., MEUTCHEHE, N.C. ET NKEN, M. (2006) Stratégie de prévention de la délinquance à Douala, Rapport d'étude, PNUD-PNUEH-MINDUH-CUD, Douala

M'PACKO M. (2000) Violence, délinquance et insécurité à Douala, http://www.ucl.ac.uk/dpuprojects/drivers_urb_change/urb_society/pdf_ violence_rights/HABITAT_NDongo_violence_insecurite_yaounde.pdf

MEUTCHEHE N.C.A., SADOS T.C. ET TCHOKO I. (2003) Pour des aménagements urbains sécuritaires à Douala, PNUD-PNUEH-MINVIL, rapport d'étude, Douala : CUD.

MEUTCHEHE N.C.A. (2009) Sécurité et bonne gouvernance, binôme d'un management inclusif et productif de la ville de demain, cas de Douala. In Ville-Management 7.
MEUTCHEHE N.C.A. (2010) Contexte urbain et criminalité à Douala. Thèse de $\mathrm{Ph}$ D. Université de Yaoundé 1. Département de géographie.

MUTATIONS (journal) du mercredi 2 septembre 2009.

NGA NDONGO V. (2008) Violence, délinquance et insécurité à Yaoundé. Informations générales. http://www.ucl.ac.uk/dpu-projects/drivers urb_change/urb_society/pdf_violence_rights/ Mpacko_violence_douala.pdf

NKOU, M. (2002) Justice parallèle au Cameroun : la réponse des populations camerounaises à la crise de la justice de l'Etat. Droit et société 51/52, pp 369-381.

OMS, (2002), Rapport mondiale sur la violence et la santé. OMS, Genève

PEYROUX, E., BENIT-GBAFFOU, C. (2010) Quartiers résidentiels fermés, privatisation de la sécurité et gouvernance urbaine : lecture croisée des phénomènes observé dans les villes d'Afrique sub-saharienne. In PEYROUX, E., BENIT-GBAFFOU, C. Sécurisation des quartiers et gouvernance locale : Enjeux et défis pour les villes africaines (Afrique du Sud, Kenya, Mozambique, Namibie, Nigeria), Karthala, pp 5-37.

SKOGAN, W. ET MAXFIELD, M. (1981) Coping with Crime, Londres: SAGE publications 


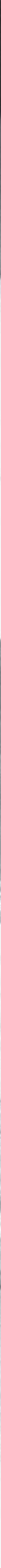




\title{
"There is no Justice in Guinea-Bissau" Strategies of Preventing, Handling, and Aggravating Conflicts in Local Dispute Settlement
}

\author{
Anne-Kristin Borszik
}

\section{1.}

Fieldwork in eastern Guinea-Bissau was carried out during 9 months between 2007 and 2009. Empirical data includes predominantly transcribed interviews (mainly aggrieved parties' narratives on cases and dispute settlers' accounts on their strategies of dispute settlement) and varied observations related to local dispute settlement, written down in a comprehensive field diary. This contribution is based on arguments developed in my PhD thesis (Borszik 2013a).

02

Cf. field diary, 22 December 2008.
"We are sitting here on a powder keg", an interviewee tells me during fieldwork in a little town in eastern Guinea-Bissau, West Africa ${ }^{1}$, referring to unresolved local disputes and controversial national politics that threaten to provoke social turmoil. In this contribution I discuss which concrete forms of interaction between disputing parties and dispute settlers the metaphor of the powder keg conveys and how the sensation of sitting on a powder keg can possibly be mitigated.

At first sight, no powder keg is visible in Gabú. It is a rural little town in eastern Guinea-Bissau, and it is the area's economic and political hub, a historically important site where ethnic groups fought for political and economic domination, where the Portuguese nominated traditional rulers and where there is now hope on decentralized political structures. In this town, most roads are made of sand, and buildings are mainly single-floored. Donkeys pass by, sometimes dragging a trailer loaded with charcoal or firewood behind them, heading for the town's central market. A group of young men is hanging around in a backyard, chatting and preparing green tea as jobs are rare. During early afternoon Gabú's streets are deserted, and many people enjoy lunch or a nap in the shadow, and the local radio broadcasts a discussion on "why people say that GuineaBissau is nice" (ke ku manda djintis fala kuma Guiné-Bissau sabi) ${ }^{2}$ while some listeners shake their heads saying blankly that there is nothing nice about Guinea-Bissau.

Less visible is, evidently, Gabú's other face: people threaten to kill others in disputes over land; guns rest under beds for use in defense or attack; drug dealers traffick cocaine in Gabú's neighborhoods; stories abound about the police beating suspects at night; people carry out ritual washings in order to protect themselves against evil and misfortune.

Political and societal turbulences in Guinea-Bissau are now more frequent than ever in the country's history. Accordingly, "the pressures on 
the judiciary of the country [have multiplied]".3 Impunity and vigilante justice are possibly the traits related to the legal sector that most worry Bissau-Guineans, not only with regard to conflicts of national scope, but also concerning petty crimes. Despite many efforts of international organizations and institutions to reform Guinea-Bissau's legal sector, impunity is still "the most important public enemy of Guinea-Bissau", as the country's Solicitor General Abdu Mané noted in 20124.

03.

Cf. http://www. gbissau.com/ ?p=2000; accessed 17 January 2013. Expressions in italic are cited in Kriol, Guinea-Bissau's lingua franca.

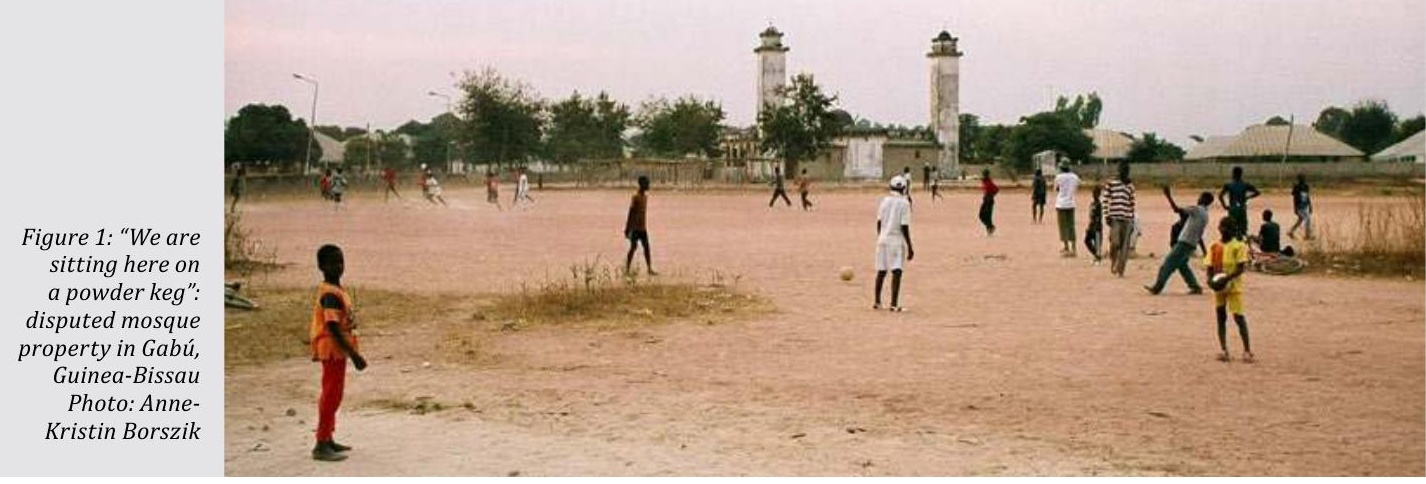

To development aid agencies, conflict prevention is a main goal, particularly in post-conflict societies as Guinea-Bissau. "Investing in conflict pre04. vention pays off", as the UNDP (2013) claims, arguing that in general this can be achieved by "strengthening national capacity for the prevention, management, and resolution of conflicts, more concretely by building the conflict management capacities of key national institutions and by training national and local mediators" (ibid). Nonetheless, to some observers, conflict prevention remains an enigma for development aid as conflicts continue to emerge, often becoming violent, despite the "impressive body of literature" (Tanner 2000) on the topic. Moreover, international organizations tend not to be able to "credibly and accurately predict and rapidly respond to conflicts that threaten to turn violent, [which] is due both to the complex dynamics of internal, ethnic, and communal conflicts and to the reluctance of many states to take steps that involve risks and costs" (ibid).

For my reflection on conflict prevention, mitigation, and settlement in this local setting, I conceptualize conflicts as a fundamental property of human existence, and not as exceptional, undesirable phenomena. In this sense, conflicts have the potential to launch learning and selection processes (Elwert 2001), thus making social change possible. Conflicts may be constructive if those involved in them find ways to settle them (Thomas 1976). It is, therefore, not the very existence of conflicts which 
may threaten social order but the society's lacking capacity to handle conflicts and domesticate violence (Trotha 1997: 22, cf. also Klute et al. 2006).

Why, if conflicts by themselves are part and parcel of any social interaction and should be accepted as such, is conflict prevention a desirable goal in development aid and likely part of any dispute settler's tools of the trade? According to Lund (2002), conflict prevention is "any structural or intercessory means to keep intrastate or interstate tension and disputes from escalating into significant violence and the use of armed forces" (Lund 2002). In this sense, conflict prevention is not a means to prevent conflicts from emerging but a way of preventing them from becoming violent.

05. Let us look now at the legal setting in eastern Guinea-Bissau. ${ }^{5}$ A major-

Refers to eastern region of Guinea-Bissau. The western area of this country has among other features, a lower percentage of Muslim population (accordingly less influence of imams). ity of Muslims, pertaining to various ethnic groups, live in this semi-rural area which is, as such, possibly comparable to many other (African) settings. Disputes in the town of Gabú are on a wide range of issues: from cattle and poultry theft to extra-legal sale of properties and cellular phone misuse; from bodily injury and adultery to death threats and defamation. Disputing parties (aggrieved parties and suspects) - mainly of Mandinga and Fulani ethnic affiliation - engage various state and nonstate dispute settlers, the most important among them being quarter heads, imams, chiefs, police officers, and court personnel (Borszik 2013a: 91ff). Besides dispute settlers, supporters (ibid: 353ff) like journalists, politicians, members of the military, as well as disputing parties' neighbors and relatives intervene in the handling of cases.

When analyzing interaction in dispute settlement, I use the term 'conflict' for referring to an "objectively existing contrast of interests" (Röhl 1987: 452) between two parties. It is "the process which begins when one party perceives that the other has frustrated, or is about to frustrate, some concern of his" (Thomas 1976: 891). Against this, the 'dispute' is a phenomenon that both parties are aware of (Röhl 1987: 452) and that generally results from their opposed interests. Disputes occur when a conflict is made public or when at least one of the parties addresses a legal institution. The analyzed cases concern "disputes of daily life" (Strijbosch 1985: 338) between two persons. Most of them are distributional conflicts (Raiser 2009: 297).

\section{Forms of conflict prevention}

When asked about the legal system and dispute settlement, many informants reply that "there is no justice in Guinea-Bissau" (djustisa ka ten na Guiné), meaning that some cases are not handled justly by the various institutions, that dispute settlement is not administered at all or that those who suffer wrongly cannot take revenge. Even though many Bissau-Guineans have little trust in the legal sector (Gacitua-Mario et al. 2007: 35) and blame its corruptibility (cf. Mazza et al. 2009), saying that

06.

Cf. field diary, 31 January 2009. "there is no justice for the poor" (djustisa pa pobre ka ten) ${ }^{6}$, some dispute settlers - and also supporters of disputing parties - dispose of strategies to prevent conflicts or at least to prevent their escalation and perpetuation. Let us first look at some of these strategies and then consider the 
implications for disputing parties when dispute settlers and supporters fail to prevent violent, aggravated, or perpetuated conflicts.

\section{Disputing parties' contribution: avoiding conflicts and controlling feelings towards opponents}

Schiefer (2002) argues that the high degree of Bissau-Guineans' sensitivity can enhance their disposition to conflict. Therefore, much effort is made to avoid conflicts altogether:

Many encounters are latently marked by a great huffiness that can anytime change into a disposition to conflict. Only proximity and acquaintance, which arise particularly from kinship or joint ritual experiences, counteract this. Therefore, great value is placed on the avoidance of conflict during encounters in formal and informal contexts. (Schiefer 2002: 98; author's translation)

According to Lund (2000), conflict prevention occurs when potential parties to violent conflict are able to handle their conflicts peacefully. In Gabú, disputing parties may contribute to the peaceful settlement of conflicts by controlling their anger and their wish for revenge and by "cooling down their hearts" (firia korson).

\section{The police's efforts in preventing conflict}

For the analysis of dispute settlement, I conceptualize dispute settlers' accounts as self-presentations. Self-presentations are their "impression management" (Goffman 1959: 238) as well as their formulated interpretations of their post which also involves explanations with regard to applied and concrete strategies of handling disputes.

In their self-presentations, police officers argue that the primal task of the police is to prevent conflicts as such, also because this causes fewer costs than does the prosecution of cases ${ }^{7}$. But in fact, work overload (cf. also Bierschenk 2008: 110) is an issue at Gabú's police station which is, besides the daily market, the best-attended place in Gabú ${ }^{8}$. Besides this, police officers' financial means for prosecuting cases are limited.

\section{Imams' role in dispute settlement}

Imams in Gabú are strongly entangled with their neighborhood and religious community. Social relatedness and the responsibility for protecting disputing parties allow some imams to handle cases that had initially been communicated to the police. Imams apply two main strategies in order to prevent conflicts from rekindling or remaining pending: they appeal to the parties to avoid false oaths and they appeal to them to refrain from compensation and revenge.

\section{Preventing the perpetuation of disputes in the consequence of false oaths}

In various cases, imams demand disputing parties to confirm their testimonies by making an oath on the Qur'an, which is "almost universally accepted to be a gesture of truth" (Lund \& Hesseling 1999: 144f). Disputing parties may intend to make false statements or use such statements as a strategy to defend their interests. Imams refer to the mortal danger

07.

Interview with police officer Mamadu Alfa Seidi, 15 January 2008.

08.

Cf. field diary, 20 December 2008. 
of swearing a false oath on the Qur'an, saying that Allah will immediately punish those who pronounce a false oath. It seems to depend on the parties' faith in or fear of Allah as well as on each imam's perceived religious credibility whether his warning may in fact prevent false oath. By informing the parties that a false oath may provoke their death, imams attribute supernatural powers to the Qur'an and thus turn it into a fetish. Werthmann (2007: 43) argues that Islam has been widely adopted by Africans because its features - existence of a God, importance of spirits (jinn) and the veneration of saints (a feature of Sufi Islam) - are compatible with African religions practiced prior to Islamization or in syncretic co-existence with Islam. The widespread practice of 'fetishizing' the Qur'an (cf. Anderson 2008: 230) is in line with co-existing African religions and Islam.

Imams announce to disputing parties both this-worldly punishments and undesirable prospects in the afterlife; a false oath on the Qur'an may provoke the Muslim's immediate death, and those who act against Allah's will be "burned by God in the other world" (na utru mundu Deus na

Interview with Imam Aladje Fá Fodé Sané, 21 February 2009.

10.

Interview with Imam Aladje Fá Fodé Sané, 1 February 2009.

11.

Concerning forgiveness between Muslims, one of the hadiths reported by 'Oqbah Ibn 'Amer reads: "you shall keep relationship with one who cut it off from you, you shall give

one who disappointed you, and you shall pardon on who oppressed you" (Karim 1938:

548).

12.

Cf. Surah AlMā'idah 5:39: "But whoever repents after his wrongdoing and reforms, indeed, Allah will turn to him in forgiveness. Indeed, Allah is Forgiving and Merciful" (http://quran. com/5; accessed 12 September 2013). kemau) ${ }^{9}$. Since the 11th century, Islamic legal scholars have argued that reducing crime could only be accomplished by this-worldly penalization as transcendent penalization would hardly prevent people from committing crimes (Rohe 2009: 4, cf. also Scholz 1999: 92).

\section{Preventing the aggravation of disputes by appealing to sufri}

As a second strategy when handling cases, imams appeal to the aggrieved party to refrain from compensation and revenge (appeal to sufri). They argue that the disputing parties' decision to seek revenge or compensation may aggravate the problem. There is an explicitly religious connotation to the appeal to sufri as "God likes those who sufri" (Deus misti kin ke sufri $)^{10}$. However, Imam Aladje Fá Fodé Sané's statement that it is Allah's desire for Muslims to sufri is only part of the Qur'an's message. Vengeance and the law of retaliation, lex talionis, seem to be generally accepted, though the attitude of forgiveness is considered desirable ${ }^{11}$; moreover, in some Surahs, the act of revenge is reserved to Allah Himself. Other Surahs, however, hint at the acceptability of Muslims' revenge. Allah is considered the "Owner of Vengeance" (Surah 'Āli `Imrān 3:4), particularly in case of repeated sin and concerning those who do not belief in Him.

While aggrieved parties are asked to sufri, the suspect is expected to acknowledge his fault and compensate the costs involved in his offense (cf. Anderson 2008). Repentance may follow the acknowledgement of fault. This is the condition for Allah's forgiveness ${ }^{12}$. Both a suspect's attitude of repentance and his / her readiness to compensate costs tend to increase the aggrieved party's willingness to sufri, thus reducing or preventing sentiments of enmity as well as the wish for (violent) revenge. Strikingly, and taking into consideration that according to Islamic Law repentance is crucial for the suspect being forgiven by Allah, the notion of repentance does not form an essential part of imams' dispute settlement strategies in Gabú. It remains an open question why imams tend not to explicitly demand suspects' repentance, as it might heighten the propensity for future offences. 
Whether the parties are ready to sufri or willing to compensate costs depends - besides the parties' individual dispositions, their personal motives, and their relation to each other, among others - also on each imam's power to impose his will, even against reluctance (Weber 1978 [1922]), in relation to disputing parties. The power of imams can feed on their spirituality and credibility ${ }^{13}$, their degree of acquaintance with the disputing parties and with other dispute settlers (i.e. their socio-structural embeddedness), their ethnic affiliation, as well as their seniority and the respect associated with this. Put another way, we would assume the imam's efforts to have failed either if the aggrieved party aims at revenge by insisting on the opponent's fine payment, detention or physical punishment, or if the suspect insists on his innocence, deciding possibly to subsequently address another institution that might prove him right. Since imams' dispute settlement does not involve fine payment, detention, or physical punishment and since they can only appeal to the suspect to acknowledge his fault - often by reference to Allah - but not enforce a confession, only those aggrieved parties and suspects who consider imams' proceedings satisfactory and convincing will accept them to settle their cases. Since imams dispose of little sanctioning power, some disputing parties decide not to present their cases to imams, on the one hand, and preventing conflicts from aggravating is usually beyond imams' means, on the other hand.

\section{Conflict prevention over the radio}

Not only dispute settlers - like police officers and imams - make efforts at preventing the escalation or aggravation of conflicts, but also radio journalists (who act as some disputing parties' supporters in specific cases) engage in conflict prevention. One way of journalists contributing to reduced conflict occurrence is to put repeat offenders under pressure when threatening to name names. A journalist says over the radio:
13.

An imam's exemplary status in religious and moral terms, for instance in the form of perceived vast knowledge of the Qur'an or a perceived moral conduct, may enable him to diminish the aggrieved party's wish for revenge and motivate the suspect to acknowledge his fault.

Figure 2: Gabú's radio station. Photo: AnneKristin Borszik

When you take part in an offence twice or three times, we will name names. If it is Mariama [who committed the offence; A.B.], then we call Mariama. When it is Binta, we call Binta (...). We will reveal your name here. When you go to the market tomorrow, people will point a finger at you. They will know that this woman is a criminal because she injures people. ${ }^{14}$

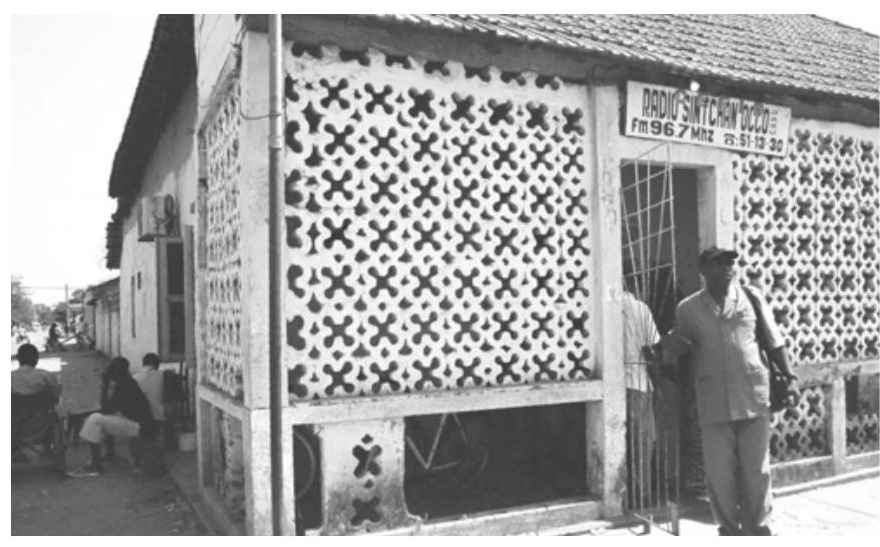

With such remarks, the journalist pronounces many people's longing for making those people individually accountable who have 'done wrong'. The journalist's announcement that names will be revealed may contribute to preventing future offenses. Another device is to invite criticized

14.

Radio program "Mon ku Fundinho", 25 February 2009. 
15.

Cf. field diary, 31

January 2009.

Interview with Sa-

ico 'Dakar' Embaló, 19 December 2008.

Tertius gaudens is, according to Simmel (1908: 83), "the third who enjoys": applied to dispute settlement, tertius gaudens is the dispute settler who benefits from the conflict between two disputing parties. public figures for an interview and allow listeners to comment on the interview. Another journalist confronted a former representative of the local Delegation of the Ministry for Public Buildings, Construction, and Urbanism during a radio interview with money misuse. People who participated over the phone in the subsequent discussion insulted the representative and accused him of "destroying Gabú" (dana Gabú) ${ }^{15}$. The seemingly wide influence of the radio with regard to denouncing the perceived misuse of power shines through the journalist's comment on the referred debate:

The representative was stuck between a rock and a hard place. He fared badly during that debate. He had serious difficulties. This debate even provoked his transfer. He left his post, and [his successor] came. ${ }^{16}$

Also the cousin of the current chief in Gabú, Saico 'Dakar' Embaló, engages in conflict prevention over the radio when appealing to cattle owners that they should not release their cattle before the rice harvest. The cattle enjoy the new shoots of rice plants and the wet soil, and some cattle owners allow their cattle to graze on other people's rice fields ${ }^{17}$, thus inciting conflict.

\section{The person-boundedness of dispute settlement: operative thirds, perturbing thirds, and supporters}

For understanding interaction in dispute settlement, it has proven useful to categorize dispute settlers as thirds in an 'interaction triangle' with aggrieved parties and suspects (cf. Borszik 2013a: 70). Dispute settlers are operative thirds when they perform according to the respective institutions' official directives or Organic Law. Operative thirds' decisions are expected to respect established law, i.e. a normative order that claims prevalence and that is nonpartisan (Trotha 2000: 330); furthermore, they "embody the society's interest in quiet and order, in peace and justice" (ibid.: 331; author's translation). One of the tasks of operative thirds is to prevent aggravated, violent conflicts.

When dispute settlers in Gabú do not manage to handle cases, thus maintaining them pending or aggravating them, I denominate dispute settlers as perturbing thirds (Borszik 2013a: 159ff) because it is frequently their involvement and specific performance which provokes an undesirable course of the settlement. Dispute settlers as perturbing thirds refuse to engage in dispute settlement, or their refusal of case attendance and their tacit approval of suspects' offences entail the aggravation of the dispute and worsen relations between the disputing parties. Besides refusing engagement or tacitly approving of offences, perturbing thirds may also actively contribute to the aggravation of the dispute and to further tensions between disputing parties, for instance by deciding a case in the favor of the suspect. Perturbing thirds ally frequently with suspects, thus acting against their function as neutral figures in disputes (cf. Trotha 2000: 330). When acting in this way, aggrieved parties perceive dispute settlers as 'the actual perpetrators', the "causal agents of conflicts" (autoris di problemas) ${ }^{18}$. In other cases, dispute settlers appear as tertius gaudens ${ }^{19}$ (cf. Simmel 1908: 83) when interacting with disputing parties. 
Case analysis has revealed that dispute settlement in this specific setting is particularly person-bound. This notion emphasizes that the personality of dispute settlers, as well as the way in which this personality is perceived by people, shapes their way of embodying state- and nonstate institutions of dispute settlement. Aspects of dispute settlers' personality are their charisma, their degree of "mediator neutrality" (Pruitt 2001: 2533), their political ambitions, but also their professional ethos and ambition or capacity to make a living as a dispute settler. The personbounded character of dispute settlement has multifaceted implications for the course and outcome of many cases. Both the performance of perturbing thirds and disputing parties' decisions to avoid or threaten their opponent are associated with this feature of local dispute settlement.

In Gabú, both state and non-state dispute settlers - quarter heads, chiefs, police officers, and imams - can act as perturbing thirds. In the following, I will exemplarily discuss how police officers handle cases and how their involvement as perturbing thirds can trigger future conflicts.

\section{Bribe payment and pending procedures}

According to one of Gabú's journalists, police officers are happy about every disputing party that addresses them because it means that "money will enter [their pockets]" (dinheiro na ientra) ${ }^{20}$. 'Pocket jurisdiction' (djustisa de bolso) is one of the main features of police work, referred to by some interviewees during fieldwork; it implies, among others, that one disputing parties' payment to a dispute settler influences the latter's decision on a case.

A simple form of appropriating funds is police officers' reported practice of keeping compensation payments that are paid by suspects to aggrieved parties via police officers. Police officers may also handle cases that they know to have been 'enacted' or 'invented' by the alleged victims. Bringing about a quarrel with her boyfriend and being thrashed and taken away jewelry as a consequence, is broke young girls' pretense for approaching the police and demanding compensation ${ }^{21}$. Another strategy, seemingly frequent among young girls in Gabú, is to address the police and claim to have had a gold chain stolen from them, even though "their mother does not even have the money to buy them a plastic chain" (si mame tene nin dinheiro pa kumpral fiu di plástico) ${ }^{22}$. Police officers may admit the (alleged) aggrieved party to be correct, demand the accused offender to pay the sum equivalent to the (allegedly) stolen object, and keep half to two-third of the money for themselves, while paying out to the victim only half or one-third of the total sum. Stories reveal that concerning such enacted or invented cases, police officers seem to be more interested in the financial gain than in professionally checking such accusations for their verisimilitude. These and other forms of police officers' claiming money payment qualify them as perturbing thirds. Disputing parties tend to project their anger at their opponent who provoked the police officers' claim: "when he [the aggrieved party; A.B.] gets angry and meets his opponent on the streets, he may harm him" (si i panha raiba, si i kontra ku bo na rua, i na fasiu mal) ${ }^{23}$, reasons an imam. In such cases, police intervention provokes anger, hatred and physical aggression

20.

Cf. field diary, 29 January 2009.

21.

Cf. field diary, 20 December 2008.

22.

Cf. field diary, 25 February 2009.

23.

Interview with Imam Aladje Fá Fodé Sané, 24 February 2009. 
between the aggrieved party and the suspect in addition to the negative feelings that arise out of the offence itself.

Another important trait of the police and their everyday work, depicted in the stories of some interviewees, is often related to money payment. Police officers put people off from day to day, telling them to 'leave and come back [later]' (bai bu bin). Aggrieved parties perceive this strategy as a form of 'delaying the dispute's settlement' (nomora problema). One of the causes underlying the delay of dispute settlement, referred to as bai bu bin, is suspects' money payment to the police, which may result in an absent decision on cases. One interviewee explains this variant:

If I get to know that he is guilty and the other one is in the right, [and] you give me a little bit [of money; A.B.], I put it in my pocket and I will not say anymore: "you are guilty". I will just remain silent. And [I will] keep telling the other one: "no, leave and come back later". And he leaves and comes back later. If he gets tired, he will stop. Hence, the thing will be

24.

Interview with Imam Aladje Fá Fodé Sané, 21 February 2009. pending. ${ }^{24}$

In such a case, the police officer may be interested in gaining time (cf. also Hanser \& Trotha 2002: 241ff), and by repeatedly putting off the aggrieved party he may in fact manage to have him / her desist. Against this, police officers themselves tend to explain the non-pursuing of cases by lacking means.

Being told to 'leave and come back' creates uncertainty. An elder man who had a foam mattress stolen from him was "vexed with [the police officer on duty]. I came here many times, but [the police officer] has still not resolved my problem". It is inexplicable to this man why the police officer delays the case's settlement.

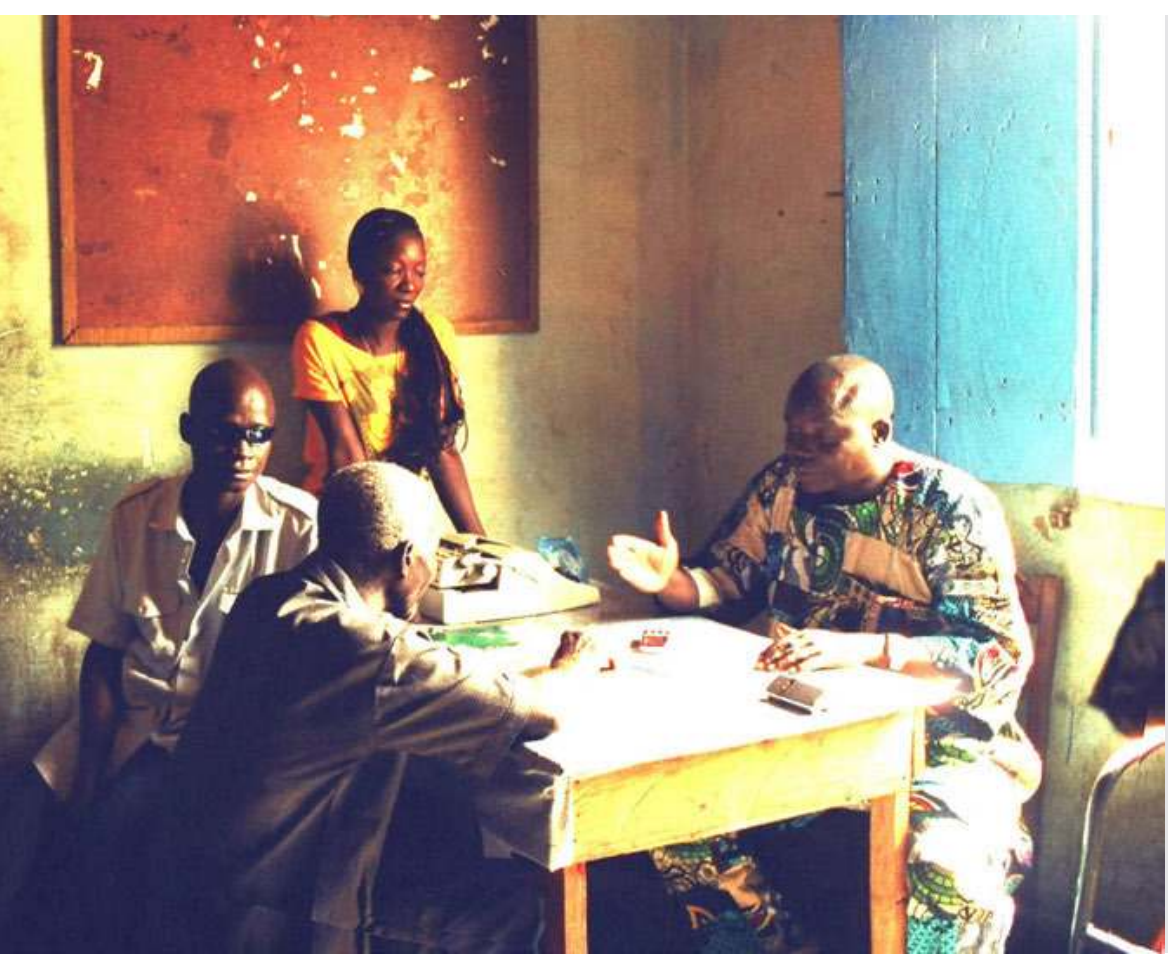

Figure 3: Police officers as dispute settlers in Gabú. Photo: AnneKristin Borszik 
When faced with police officers delaying their case's settlement, many aggrieved parties opt for avoidance, i.e. for desisting from further clarifications and 'letting the matter rest' (dicha) (see below). To them, it only remains to "hope for God's help" (pega Deus) ${ }^{25}$ and to ascribe retribution to an external entity. Besides this, in future cases they may no longer consider the police as an appropriate dispute settler.

Telling disputing parties to 'leave and come back later' is a form of keeping the procedure pending (pindra). Elwert argues that "a pending procedure is a way of perpetuating the conflict, not of resolving it; a pending procedure can be considered a form of warring with reduced violence" (2001: 2544). In fact, the anger about an unsettled case - about a lost parcel of land, a broken cell phone or stolen cattle - persists as long as the case remains pending. "Reduced violence", as Elwert (ibid) puts it, is manifest in the hatred that rumbles on in the aggrieved party's heart.

\section{Accepting soldiers' and thieves' offences: the state as plunderer}

Police officers in Gabú are reported to "collaborate with bandits" ( $t a$ kolabora ku bandidos) ${ }^{26}$ who are either currently imprisoned at the police station or known to police officers from past cases (cf. also Schiefer 2002: 193). Police officers equip these 'bandits' with guns and pistols, release them from the police station's detention center and have them steal cattle and other items at night ${ }^{27}$; victims may consider themselves lucky if they are not killed during such operations. In cases of cattle theft, cattle are slaughtered in nearby forests and the meat sold at Gabú's market. Police officers also seem to equip their private fridges with the meat or share the profits with thieves in other ways ${ }^{28}$. If such cases come to light, police officers argue that aggrieved parties' accounts "are not true" (i ka bardadi) ${ }^{29}$. In this way they express their acceptance of the criminals' actions, thus being themselves "no better than common thieves" (Hills 2000: 7). They may also maintain that the criminals had escaped from the detention center unobserved, because its windows are not properly secured, arguing that "Guinea-Bissau is badly equipped" (Guiné-Bissau ka ten condiçoes) ${ }^{30}$ and that there is no way to improve the detention center's security (cf. also Hanser \& Trotha 2002: 249).

Different from police officers' cooperation with suspected thieves, their interaction with soldiers is characterized by the existing, general power differential between the military and the police. One interviewee tells the exemplary story of soldiers having entered a village by car and assaulting and robbing various stalls at the local market. The villagers were able to seize one of the soldiers while the others fled to Gabú, taking away the robbed items. When the victims came to Gabú, telling the police that looting had occurred in their village, the police refused to investigate the case ${ }^{31}$. Also Kohl (2011) refers to Bissau-Guinean soldiers' power over police officers:

Five traffic policemen, four of them women, were mistreated by soldiers on 6 July [2010]. (...) [The then President] Sanhá made a vehement attack on the army (...), declaring that Guinea-Bissau was not the 'property' of the military, whose task it was to defend the country, not to kill people. (Kohl 2011: 119)

26.

Cf. field diary, 3 February 2009. For similar phenomena in Ghana, cf. Beek (2008: 70).

27.

Cf. field diary, 3 February 2009.

28.

Cf. field diary, 5 February 2009.

29.

Cf. field diary, 4 February 2009.

30.

Cf. field diary, 3 February 2009.

31.

Cf. field diary, 4 February 2009. 
The power differential between the police and military in Africa is also highlighted by Hills (2003) who argues that:

(...) the military can dramatically affect state legitimation processes by the exercise of force. They frequently intervene in politics, usually have considerable resources, are largely isolated from the population, and tend to see themselves as a superior, highly specialized, and self-sufficient caste. Public police forces (...) are less elitist; they are neither wellresourced, apolitical, nor respected (...), their status and educational level tend to be low, and they are more susceptible to political influence (though less likely to intervene in politics) than are the military. (Hills 2000: 3)

Police officers' perceived covering of looting operations by soldiers may be explained by this power differential: they may have no option but to back and defend soldiers' looting. State-supported looting and state agents' cooperation with "pirates or bandits" (Tilly 1987: 173) has a long history. Having first occurred in the context of European state-building, looting was one variant of states' organized violence with the purpose of state-building; organized violence implied efforts to extraction, which could range "from outright plunder to regular tribute to bureaucratized taxation" (ibid: 181). The societal consequences of such police-supported looting in contemporary Guinea-Bissau range from disrespect for and distrust in the police to the population's increased disposition to vigilante justice as a reaction to potential police-supported offences (see below).

\section{Supporter activation}

The institutional hierarchy and the tense relation between the police and the military appears in some of interviewees' stories as an 'institutional acquaintance' where police officers make common cause with soldiers to the disadvantage of aggrieved parties. Disputing parties may take advantage of the military's power by involving family members who are in the military when aiming to have a case with the police settled in their favor; due to the military's perceived capability of intimidation, the involvement of soldiers and generals may prevent these disputing parties from experiencing money payment claims, pending procedures, or police violence. I refer to this phenomenon as supporter activation (Borszik 2013a: 353ff), a powerful tool which aggrieved parties avail themselves of when dispute settlers - like police officers - are absent or perturbing. Supporter activation reduces feelings of uncertainty and makes a satisfactory outcome of dispute settlement more promising. When addressing supporters, aggrieved parties and suspects contribute actively to the settlement of their cases, and the occurrence of pending cases is reduced.

When dispute settlers do not manage to satisfactorily respond to aggrieved parties' expectations on dispute settlement, aggrieved parties tend to either renounce further regulation or wish for vigilante justice. 


\section{Thrown back on the dyad: Avoidance and the wish for vigilante justice}

Disputing parties have a number of possibilities to handle conflicts directly with their opponents when dispute settlers are perturbing or absent. These include:

(...) avoiding or discontinuing the conflictive relation; yielding of one party and prevailing of the other; compensation through adjustment payment; negotiation and compromise; and employing force, for instance as a threat, a form of extortion, or as a hindrance (Raiser 2009: 299; author's translation).

I will highlight two of the mentioned variants: avoidance and the threat of /wish for vigilante justice.

\section{Avoidance}

I conceptualize avoidance in Gabú's dispute settlement as a "conflict-handling mode" (Thomas 1992: 266) ${ }^{32}$. Avoidance can be a way of "limiting the relationship with the other disputant (...) so that the dispute no longer remains salient" (Felstiner 1974: 70). This may also imply that dispute settlement is avoided altogether; with regard to this, Bierschenk speaks of "the renunciation of regulation" (2008: 123). According to Raiser, avoidance in this double sense is the "simplest and probably most frequent way of handling conflict" (2009: 299).

\section{Avoiding dispute settlement and dethematizing law}

"The bottle does not join the game of the stones" (garafa ka ta djuntu na djugu di pedra), as a Kriol proverb goes ${ }^{33}$. "What else than going to pieces is it looking for?" (si ka kebra ki ba buska), formulate the Bissau-Guinean singers Iva \& Ichy, highlighting the evident destiny of this weakest member of the interaction triangle in their song "I no Balur" ('It is Our Value') ${ }^{34}$. In a case on an illegally sold property, the aggrieved party appears as the fragile 'bottle' that does not join the game of the more powerful 'stones' - his opponent (who purchased the property on illegal grounds) and the aggrieved party's supporter and uncle who is an influential politician in Bissau.

The aggrieved party opts for a behavior characterized by Thomas (1976: 900) as avoidant orientation (i.e. a little degree to which the aggrieved party wishes to satisfy his concerns). Accordingly, he decides to remain passive and to "let the problem go" (dicha problema) ${ }^{35}$. Instead of provoking his uncle by not following his advice to withdraw from the case, he accepts his defeat without even having attempted at a victory. Besides 'letting the problem go', the aggrieved party also copes with his apparent defeat by dethematizing law. Luhmann argues that:

(...) one can, in some cases at the suggestion and with the help of thirds, shoo legal issues out of the joint field of attention by substituting them with other issues (...). An obvious possibility is to consider the consequences for the involved persons that may, in the future, loom on the horizon and exceed legal issues. (...). (Luhmann: 1980: 109; author's translation)
32.

Thomas (1976:

900) distinguishes avoidance from competition, cooperation, and accommodation.

33.

Cf. http://www. didinho.org/proverbioscriouloguineenses.htm; accessed 30 April 2013.

34.

Iva \& Ichy, Kanua ka na Nkadja, CD, track: "I no Balur" (C) 2002 NBV.

35.

Interview with aggrieved party in case on illegally sold property, 10 February 2009. 
For the aggrieved party, dethematizing law becomes a relevant option. Avoidance in this sense is feasible because no obligatory relations of cooperation (at the economic or family level) exist between the disputing parties (cf. Alber 2004: 183). If such relations exist, severing all contact with the opponent is associated with high social costs, considering that "(...) the cost of avoidance is always a reduction in the content of the relationship which has been truncated or terminated" (Felstiner 1974: 76). Since the aggrieved party's relationship with his opponent is geared to a single interest, i.e. regaining his house, the social costs of avoidance are relatively low. It is also for this reason that the aggrieved party can even interprethis decision for avoiding dispute settlement, as well as his resulting defeat vis-à-vis his opponent, as a victory: in the future, the aggrieved party may "have a house that is larger than this one. There are chances

36. Ibid. served to "traditional authorities" (autoridades tradicionais) like chiefs or quarter heads who ask disputing parties to "renounce revenge and compensation, to forgive each other" (sufri, purda utru) (Ibid.). for me to live a better life [than the suspect]." ${ }^{36}$ The aggrieved party's decision for avoidance is mainly motivated by his uncle's advice, which is based on the assumption of the suspect's superior spiritual power. Spiritual power is a legitimate argument in this local context where "cosmology is a key element in the understanding of most political and social events [and where] there is also a generalized understanding that every rich or famous person, every scientist, and every powerful country, has one or several spirits working for them" (Temudo 2008: 256). While allowing for the aggrieved party's withdrawal, his uncle's advice also incurs the aggrieved party's feelings of anger towards the suspect.

\section{Avoiding police and court involvement as a socially restorative measure}

Avoiding the involvement of dispute settlers like police officers or court personnel can be a way of preventing the conflict's future escalation. According to interviewees' accounts, it is practically unavoidable that taking a suspect to the 'authority' (autoridade), i.e. to state legal institutions, provokes the suspect's feeling of hatred against the aggrieved party and worsens social relations, because, by involving the police or courts, the aggrieved party reveals his 'antipathy' towards the suspect. The suspect may reason that "he takes me to the authority because he does not like me" (i leban autoridade pabia i ka gosta di mi), as an interviewee suggests ${ }^{37}$. Perceived antipathy or defamation, when the case has become publicly known (which easily happens in the semi-rural context of Gabú), is most reprehensible and can be highly consequential socially (cf. also Schiefer 2002: 82). The popular notion that to take one's opponent to court breaks up social relations (kebra relacionamentos) ${ }^{38}$ also exists in Northern Ghana (Beek 2008). Beek's interviewee explains why:

They hate the court. According to them, the relationship, you see, they are interrelated. If you take my family to court, you are only accusing the one who has offended you, but the whole family will hate you for that. They will come to you: If this is what our brother has done, then we settle it [extra-judicially; A.B.]. But if you ignore and go to the police, they won't have anything to do with you. (...) This is why they just mobilize themselves (...). They settle it so that the relationships stay intact. (Beek 2008: 90f) 
Glinga (1989) suggests that there is a nexus between the degree of prevailing orality in a society and this society's forms of achieving social cohesion. With this, the author provides an interesting explanation for why social relations in Gabú are perceived to break up subsequent to court involvement. Glinga argues that orality (and the oral mode of communication) as the prevailing mode of social organization in predominantly orally organized societies (like Gabú) contributes most significantly to social cohesion $(1989$ : 92,96$)$. This allows us to assume that the scripturality, which prevails in court dispute settlements, provokes people's general unease with regard to this institution and their fear of breaking social relations, which the written mode seems to entail.

The phenomenon of social distanciation between disputing parties with regard to court involvement in dispute settlement is well-known among legal sociologists (cf. Luhmann 1980; Röhl 1987: 459). Luhmann (1980) argues that the perceived breaking-off of social relations with regard to court dispute settlement is context-sensitive; it depends on the type of social relations concerned whether serious problems between the disputing parties are to be expected when disputing parties address courts. Luhmann assumes that by relying on and referring to a third instance (i.e., the state legal system), the concerned party demonstrates its independence and distance from the other party. Thus, resorting to the legal system implies the distancing of both disputing parties, and "not every interaction system can tolerate such a distancing effect" (Luhmann 1980: 104; author's translation). Repeated stories on emerging hatred as a form of 'total distancing' seem to confirm this observation. Accordingly, in Senegal, addressing the court is considered the second of three "warnings" (avertissement in French, cf. Le Roy 2004: 184). These warnings are expressed during disputes with a view to appealing to mutual obligations. Avoiding the police or court in order to prevent hatred or social distanciation from emerging is, in this sense, a form of conflict prevention.

Avoidance seems to be an easy way out of existing conflicts. But "[even] though avoidance strategies allow for the individual coping with a conflict, the causes of the conflict situation remain in place and unchanged" (Hegenbarth 1980: 53f; author's translation). The absence of thirds does not only impede individual disputing parties' compensation; it also perpetuates the various social problems that provoke conflicts and make dispute settlement a complicated enterprise. Furthermore, 'letting the matter rest' (dicha) as the main form of avoidance in Gabú is closely related to continuing feelings of anger and perceived pending procedures.

\section{The wish for vigilante justice}

In the most diverse socio-political contexts, vigilantism emerges as "a moral complaint against state inadequacy" (Goldstein 2003: 22). In line with studies of legal anthropology carried out in Africa, Latin America , and Asia, the tendency to violently confront opponents in Gabú also results from ineffective (state) legal institutions (cf. Wilson 2000, Embaló 2008, and Tankebe 2009 for Africa; Eilenberg 2011 for Asia; Sierra 2005 and Handy 2004 for Latin America). Vigilante justice means that: 
(...) the aggrieved party reacts with his own means against the one who caused him harm; this act is associated with a sense of right and wrong. The aggrieved party interprets the damage inflicted on him as wrong and his own reaction to it as right. (Spittler 1980: 145; author's translation)

In Gabú, aggrieved parties' reactions to ineffective state or non-state jurisdiction in the face of suspects' offences are predominantly restricted to the wish for vigilante justice or threats of violent self-help. In various social contexts, violence is considered an appropriate measure for reacting to undesired behavior. Physical violence occurs frequently at Gabú's police station; many Bissau-Guinean parents consider beating an impor-

39.

Interview with village head Mambela Embaló, 6 January 2008.

Cf. field diary, 19 December 2008.

41.

Cf. field diary, 25 January 2009. tant disciplinary measure in the education of children; and among spouses, beating is an accepted way for husbands to express their dissatisfaction with their wives' conduct. Also in public life, beating can be a measure for correcting undesired actions ${ }^{39}$.

A "culture of war" (cultura di guera) ${ }^{40}$ has characterized pre-colonial power struggles, the war of independence, and post-colonial political assassinations in Guinea-Bissau. Besides this, drug business disputes have been decided violently and sometimes resulted in homicide ${ }^{41}$. Certainly, only a small group of Bissau-Guineans have acquired this "culture of war" in the full sense. While executions at the highest state level within political and military circles occur with some regularity and represent the "spiral of violence" (Bock 2012: 20; author's translation), homicide committed by average Bissau-Guineans - whether as an original offence or as the reaction to an offence as vigilante justice - is a rare phenomenon. At this societal level, the apparent "culture of violence" (ibid: 18; author's translation) as the inclination to violent responses is manifest in a 'rhetoric of killing'. But some Bissau-Guineans also opt for violence on a small-scale level when beating others, slashing their backs with a razor blade, or throwing hot oil in someone's face. One interviewee explained a certain propensity of some Bissau-Guineans to violence by their "lacking civilized mode of behavior" ( falta de cultura) ${ }^{42}$ and other people's readiness to resort to violence by the fact that "their nerves are raw" ( $e$ tene si nervos na flor di pele $)^{43}$, according to which minor tensions can provoke anger and subsequent violent interaction. Besides this, taking revenge or wishing to do so - is a way for handling feelings of impotence, shock or anger caused by an unpunished offence.

Most aggrieved parties in the analyzed cases are conscious of possible vigilante justice. When an aggrieved party appeals over the radio to the police and the court to attend to his case because "somebody may be killed" (kabesa bin fika la) ${ }^{44}$, he reveals his consciousness of possible violent responses to the dispute, which these institutions would have to account for. In another case, the aggrieved party's pronounced wish for vigilante justice and his intention to fight directly with his opponent results from perturbing thirds' performance:

It is now time for us to protest, and it will be violent (...). Our intention is to catch [the suspect] and to fight with him until one of us dies, because the authority is not able to put an end to the problem. ${ }^{45}$ 
However, taking the law into his own hands is difficult for the aggrieved party in this case since the suspect has the support of the quarter head, chief, and police.

Another case on stolen cattle suggests that aggrieved parties walk a fine line between avoidance and the wish for vigilante justice when being confronted with an unpunished opponent. "I will do justice in my head" (n'na fasi djustisa na kabesa) ${ }^{46}$, announces the aggrieved party in this case when referring to a potential third theft by the suspect. While legal proceedings with regard to this suspect's first theft had not reached court, his second offence had been handled by police officers and court staff in Bissau and Gabú. But "they [dispute settlers; A.B.] ate my money while I didn't eat" (e kumen dinheiro kontra n'ka na kume) ${ }^{47}$, i.e. dispute settlers had taken financial advantage of the case while the aggrieved party had derived little benefit from the dispute settlement. While he avoided prosecution in the past case and decided to take the present case to court, he does not intend to address dispute settlers anymore in case the suspect should steal his cattle once again. Instead, he would attempt to immediately kill his opponent.

Different from self-help as discussed by Spittler (1980: 145), however, this and other aggrieved parties' wish for vigilante justice, formulated in their 'rhetoric of killing', has no immediate impact on their opponent. In this sense, it rather expresses their wish for revenge and their actual fear, anger, or impotence vis-à-vis their opponents.

\section{Conclusion: the need for forgiveness}

The aggrieved party in a pending case on defamation and bodily injury recounts a conversation with his opponents when the latter had realized that they would not gain redress at the police and court. He remembers that "they asked me to forgive them, to sufri (...), and I said: 'forgive you? No'"' ${ }^{48}$ His refusal to forgive his opponent reflects his frustration about the unsettled dispute, and it accompanies his decision to renounce from further case prosecution in the face of this seemingly insoluble dispute. Here, the decision for avoidance does not entail a disposition for forgiveness; rather, the refusal to forgiveness is the aggrieved party's last coping strategy (cf. Temudo 2008: 262).

Forgiveness and hope are major issues that resonate in Gabú's dispute settlement, and they reflect, at the micro-level, the overarching societal concern with national reconciliation and justice. Musicians have frequently formulated the need for hope despite adverse conditions (cf. Borszik 2013b). Tino Trimó's "No Tene Fé" ("We have Faith", 2009) ${ }^{49}$ or Super Mama Djombo's recent version of "Fé na Bo" ("I set my Hopes on You", 2008) ${ }^{50}$, among many others, put Bissau-Guineans' hope for a better future into poetic words.

Forgiveness as “(...) a willingness to abandon one's right to resentment, negative judgment, and indifferent behavior toward one who unjustly hurt us" (Enright \& Coyle 1998: 46f) is distinct from reconciliation as the latter "implies the restoration of a relationship" (McCollough et al. 2000: 8). Forgiveness is, in fact, a prerequisite for reconciliation. When impunity prevails and many cases remain pending, aggrieved parties find it,
46.

Interview with aggrieved party in cattle theft case, 22 February 2009.

48.

Interview with aggrieved party in case on defamation and bodily injury, 16 December 2008.

49.

Cf. http://www. youtube.com $/ \mathrm{h}$ ?v=eiVoKyA3ZxY; accessed 31 July 2013.

50.

Super Mama Djombo, Ar Puro, CD, track 1, "Fé na Bo," (C) 2008 Mama Djombo Islandia. 
51. however, difficult to forgive their opponents and rather refuse to do so. If

Cf. for instance

http://www. gaznot.om/?link= details_u\&id=536 \&titre=Nacional; accessed 21 May 2013.

52.

Interview realized by collaborators of the research programme

Pesquisa - Acção

para a Consoli-

dação da Paz na

Guiné-Bissau/

Voz di Paz (Action Research for the Consolidation of Peace in Guinea-Bissau/Voice of Peace) (http:// www.interpeace. org/pdfs/EVALUATION_BISSAU

_2008_Final.

pdf, accessed 12 August 2010; author's translation). forgiveness at the local level is difficult in a context of 'absent justice', how are the chances of forgiveness at the national level? Gacitua-Mario et al. are rather pessimistic when stating that: "while at the local level communities work together to resolve some immediate problems, the capacity to work together beyond the local dimension and to resolve differences in Guinea-Bissau is poor" (2007: 25f). Seemingly, low chances for forgiveness at the local level reflect equally low chances at a larger societal level.

When forgiving one's opponent and resolving differences on the national level is difficult, reconciliation - as an enterprise of the BissauGuinean society as a whole - becomes an even greater challenge. Debates on national reconciliation are recurring in Guinea-Bissau (cf. GacituaMario et al. 2007: 28, Schiefer 2002: 117). They refer to past acts of violence that were committed during the independence war, the 1998/99 war, and over the course of the various political assassinations and putsches; most of them have neither been penalized nor compensated. Emphasizing the need for national reconciliation seems to be more a part of politicians' speeches, however, than the object of concrete efforts ${ }^{51}$. "There is no reconciliation and no forgiveness without the recognition of culpability"52, argues Imam Aladje Fá Fodé Sané. Instead, offences need to be compensated so that forgiveness - and at a later stage reconciliation - can be granted.

\section{References}

\begin{abstract}
Alber, Erdmute 2004, "Meidung als Modus des Umgangs mit Konflikten", in: Julia Eckert (ed.), Anthropologie der Konflikte. Georg Elwerts konflikttheoretische Thesen in der Diskussion, Bielefeld: transcript: 169-185.
\end{abstract}

Anderson, James Norman Dalrymple 2008, Islamic Law in Africa, London \& New York: Routledge.

Beek, Jan 2008, "Friend of the Police. Polizei in Nord-Ghana (Upper West Region)", Working Papers 93, Mainz: Johannes-Gutenberg-Universität (Department of Anthropology and African Studies).

Bierschenk, Thomas 2008, "The Everyday Functioning of an African Public Service: Informalization, Privatization and Corruption in Benin's Legal System", Journal of Legal Pluralism and Unofficial Law 57: 101-139.

Bock, Augusto 2012, "Dilema dos combatentes da liberdade da pátria da Guiné-Bissau: Razão de orgulho e mágoa", Bissau: INEP (unpublished working paper).

Borszik, Anne-Kristin 2013a, "Dispute Settlement in Eastern Guinea-Bissau: Self-presentations, Stories and Agency", Bayreuth: University of Bayreuth (PhD thesis).

Borszik, Anne-Kristin 2013b, “Telling the Truth and Commenting Reality: 'Harsh Criticism' in Guinea-Bissau's Intervention Music", in: Jonathan C. Friedman (ed.), The Routledge History of Social Protest in Popular Music, New York \& London: Routledge: 331-345.

Crook, Richard C. 2004, "Access to Justice and Land Disputes in Ghana's State Courts: The Litigants' Perspective", Journal of Legal Pluralism and Unofficial Law 50: 1-28.

Eilenberg, Michael 2011, "Flouting the Law. Vigilante Justice and Regional Autonomy on the Indonesian Border", ASEAS - Austrian Journal of South-East Asian Studies 4, 2: 237-253.

Elwert, Georg 2001, “Conflict: Anthropological Aspects”, in: Neil J. Smelser, Paul B. Baltes (eds.), International Encyclopedia of the Social and Behavioral Sciences, Amsterdam: Elsevier: 25422547.

Embaló, Birgit 2008, “Local Conflict Management and the State in Bissau: A Case Study in Three City Quarters", Soronda Especial: Experiências Locais de Gestão de Conflitos - Local Experiences of Conflict Management, December 2008: 175-211.

Enright, Robert D.; Catherine T. Coyle 1998, "Researching the Process Model of Forgiveness within Psychological Interventions", in: Everett L. Worthington (ed.), Dimensions of Forgiveness. Psychological Research and Theological Forgiveness, Philadelphia: Templeton Foundation Press: 139-161. 
Felstiner, William L.F. 1974, "Influences of Social Organization on Dispute Processing", Law \& Society Review 9, 1: 63-94.

Gacitua-Mario, Estanislao; Sigrun Aasland, Hakon Nordang, Quentin Wodon 2007, "Institutions, Social Networks, and Conflicts in Guinea-Bissau. Results from a 2005 Survey", in: Barry Boubacar-Sid, Edward G. E. Creppy, Estanislao Gacitua-Mario, Quentin Wodon (eds.), Conflict, Livelihoods, and Poverty in Guinea-Bissau, Washington, D.C.: The World Bank: 23-41.

Glinga, Werner 1989, "Mündlichkeit in Afrika und Schriftlichkeit in Europa. Zur Theorie eines gesellschaftlichen Organisationsmodus", Zeitschrift für Soziologie 18, 2: 89-99.

Goffman, Erving 1959, The Presentation of Self in Everyday Life, New York: Doubleday Anchor Books.

Goldstein, Daniel M. 2003, "'In Our Own Hands'. Lynching, Justice, and the Law in Bolivia", American Ethnologist 30, 1: 22-43.

Handy, Jim 2004, "Chicken Thieves, Witches, and Judges. Vigilante Justice and Customary Law in Guatemala", Journal of Latin American Studies 36, 3: 533-561.

Hanser, Peter; Trutz von Trotha 2002, Ordnungsformen der Gewalt. Reflexionen über die Grenzen von Recht und Staat an einem einsamen Ort in Papua-Neuguinea, Siegener Beiträge zur Soziologie, Köln: Köppe.

Hegenbarth, Rainer 1980, "Sichtbegrenzungen, Forschungsdefizite und Zielkonflikte in der Diskussion über Alternativen zur Justiz", in: Erhard Blankenburg, Ekkehard Klausa, Hubert Rottleuthner (eds.), Alternative Rechtsformen und Alternativen zum Recht (Jahrbuch für Rechtssoziologie und Rechtstheorie, 6), Opladen: Leske + Budrich: 48-82.

Hills, Alice 2000, Policing Africa. Internal Security and the Limits of Liberalization, Boulder: Lynne Rienner Publishers.

Karim, Fazle 1938, AL-HADIS, Vol. 1, Lahore: The Book House.

Klute, Georg; Birgit Embaló; Idrissa Embaló 2006, "Local Strategies of Conflict Resolution in Guinea-Bissau. A Project Proposal in Legal Anthropology", Recht in Afrika - Law in Africa, 2: 253-272.

Kohl, Christoph 2011, "Guinea-Bissau", in: Andreas Mehler; Henning Melber; Klaas van Walraven (eds.), Africa Yearbook. Politics, Economy and Society South of the Sahara in 2010, Leiden \& Boston: Brill: 117-123.

Le Roy, Étienne 2004, Les Africains et l'Institution de la Justice. Entre mimétismes et métissages, Paris: Dalloz.

Luhmann, Niklas 1980, "Kommunikation über Recht in Interaktionssystemen", in: Erhard Blankenburg, Ekkehard Klausa, Hubert Rottleuthner (eds.), Alternative Rechtsformen und Alternativen zum Recht (Jahrbuch für Rechtssoziologie und Rechtstheorie, 6), Opladen:
Leske + Budrich: 99-112.

Lund, Christian; Gerti Hesseling 1999, "Traditional Chiefs and Modern Land Tenure Law in Niger", in: E. Adriaan B. van Rouveroy van Nieuwaal, Rijk van Dijk (eds.), African Chieftaincy in a New Socio-Political Landscape, Hamburg: LIT: 135-154.

Lund, Michael 2002, "Preventing Violent Interstate Conflicts: Learning Lessons from Experience", in: Paul van Tongeren, Hans von de Veen, Juliette Verhoeven (eds.) 2002, Searching for Peace in Europe and Eurasia: An Overview of Conflict Prevention and Peacebuilding Activities, Boulder, CO: Lynne Rienner.

Mazza, Giuseppina; Lalao Ramanarivo Raharisoa, Guy de Araujo, Maria Adiatu Djalo Nafidigna 2009, "Strengthening Justice and Security Sector Reform in Guinea-Bissau (MDG Achievement Fund)", Bissau \& Dakar: UNDP, UNFPA, UNODC, UNIFEM.

McCullough, Michael E.; Kenneth I. Pargament, Carl E. Thoresen 2000, "The Psychology of Forgiveness. History, Conceptual Issues, and Overview", in: Michael E. McCullough, Kenneth I. Pargament, Carl E. Thoresen (eds.), Forgiveness. Theory, Research and Practice, New York \& London: The Guilford Press: 1-14.

Pruitt, Dean G. 2001, "Social Psychology of Conflict and Conflict Resolution", in: Neil J. Smelser; Paul B. Baltes (eds.), International Encyclopedia of the Social and Behavioral Sciences, Amsterdam: Elsevier: 2531-2534.

Raiser, Thomas 2009, Grundlagen der Rechtssoziologie, Tübingen: Mohr Siebeck.

Röhl, Klaus F. 1987, Rechtssoziologie. Ein Lehrbuch, Köln: Carl Heymanns Verlag KG.

Rohe, Mathias 2009, Das islamische Recht. Geschichte und Gegenwart, München: C.H. Beck.

Schiefer, Ulrich 2002, Von allen guten Geistern verlassen? Guinea-Bissau: Entwicklungspolitik und der Zusammenbruch afrikanischer Gesellschaften, Hamburger Beiträge zur Afrika-Kunde, Hamburg: Institut für Afrika-Kunde.

Scholz, Peter 1999, "Fortbildung der Scharia am Beispiel des malikitischen Verfahrensrechts", Der Islam 76, 1: 88-138.

Sierra, María Teresa 2005, "The Revival of Indigenous Justice in Mexico. Challenges for Human Rights and the State", PoLAR: Political and Legal Anthropology Review 28, 1: 52-72.

Simmel, Georg 1908, Soziologie. Untersuchungen über die Formen der Vergesellschaftung, Berlin: Duncker \& Humblot.

Spittler, Gerd 1980, "Konfliktaustragung in akephalen Gesellschaften: Selbsthilfe und Verhandlung", in: Erhard Blankenburg, Ekkehard Klausa, Hubert Rottleuthner (eds.), Alternative Rechtsformen und Alternativen zum Recht (Jahrbuch für Rechtssoziologie und Rechtstheorie, 6), Opladen: Leske + Budrich: 142-164.

Strijbosch, Fons 1985, "Recognition of Folk Institutions for Dispute-Settlement in Lombok, 
Indonesia", in: Anthony Allot, Gordon R. Woodman (eds.), People's Law and State Law. The Bellagio Papers, Dordrecht: Foris Publications: 331-348.

Tankebe, Justice 2009, "Self-Help, Policing, and Procedural Justice. Ghanaian Vigilantism and the Rule of Law", Law \& Society Review 43, 2: 245-268.

Tanner, Fred 2000, "Conflict Prevention and Conflict Resolution: Limits of Multilateralism", International Review of the Red Cross 839.

Temudo, Marina Padrão 2008, “From 'People's Struggle' to 'This War of Today'. Entanglements of Peace and Conflict in Guinea-Bissau", Africa Journal of the International African Institute 78, 2: $245-263$.

Thomas, Kenneth W. 1976, "Conflict and Conflict Management”, in: Marvin D. Dunnette (ed.), Handbook of Industrial and Organizational Psychology, Chicago: Rand McNally: 889-935.

- 1992, "Conflict and Conflict Management. Reflections and Update", Journal of Organzational Behavior 13, 3: 265-274.

Tilly, Charles 1987, "War Making and State
Making as Organized Crime", in: Peter B. Evans, Dietrich Rueschemeyer, Theda Skocpol (eds.), Bringing the State Back In, Cambridge: Cambridge University Press: 169-191.

Trotha, Trutz von 1997, "Zur Soziologie der Gewalt”, Kölner Zeitschrift für Soziologie und Sozialpsychologie, Sonderheft 37: 9-56.

- 2000, "Was ist Recht? Von der gewalttätigen Selbsthilfe zur staatlichen Rechtsordnung", Zeitschrift für Rechtssoziologie 21, 2: 327-354.

UNDP 2013, “Conflict Prevention", Fast Facts, February 2013.

Weber, Max 1978 [1922], Economy and Society. An Outline of Interpretative Sociology, Berkeley \& Los Angeles \& London: University of California Press.

Werthmann, Katja 2007, "Islam in Afrika Ein Überblick", in: Thomas Bierschenk, Marion Fischer (eds.), Islam und Entwicklung in Afrika, Köln: Köppe: 37-50.

Wilson, Richard A. 2000, "Reconciliation and Revenge in Post-Apartheid South Africa. Rethinking Legal Pluralism and Human Rights", Current Anthropology 41, 1: 75-98. 


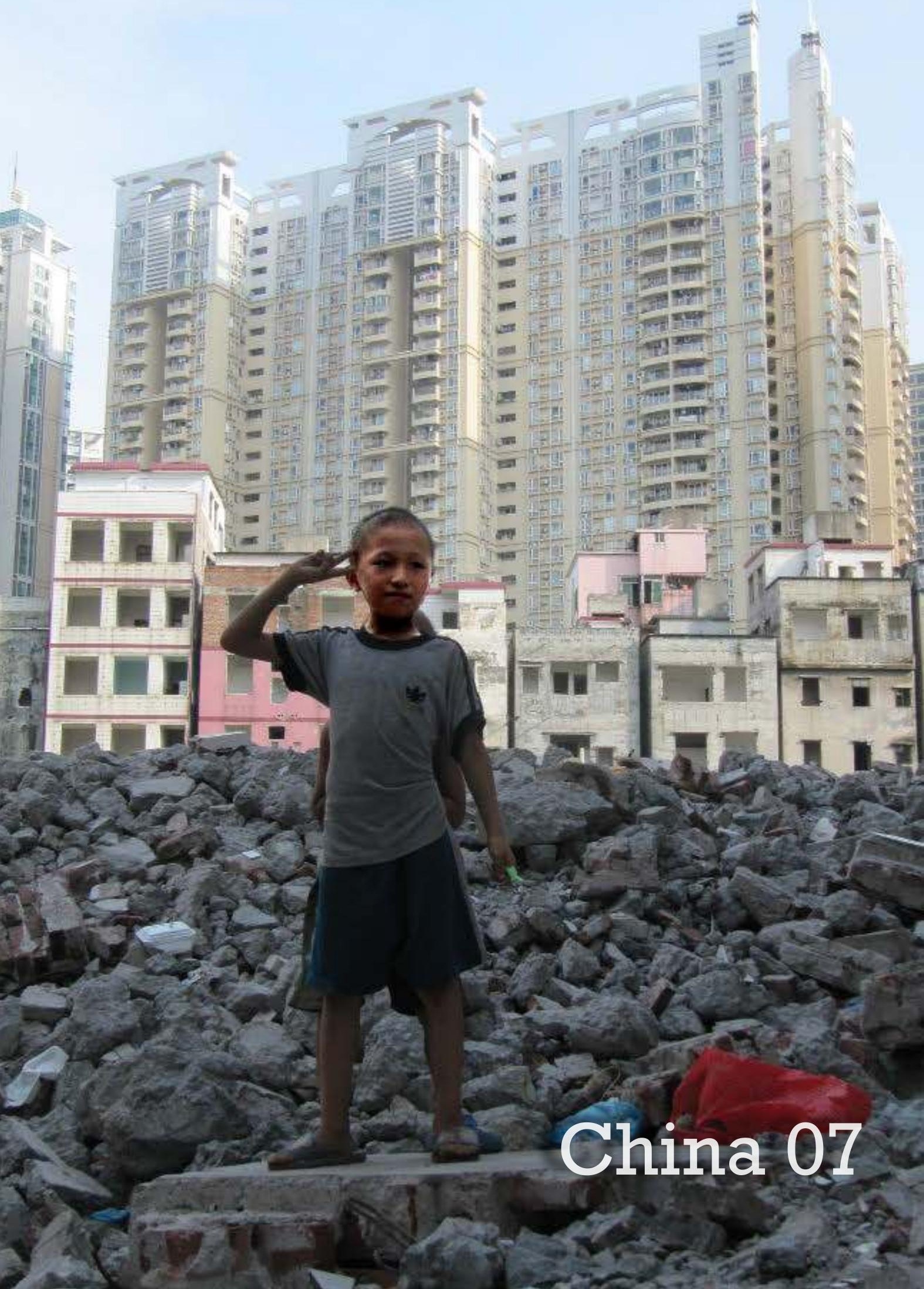




\section{Urban Violence and the Chinese State in the Post-Mao Reform ${ }^{1}$}

Qin Shao

02

http://www.economist.com/news/ china/21575767 official-figuresshowing-sharpdrop-chinasmurder-rate-aremisleading-murder-mysteries, accessed June 30 2014.

Previous page: Demolition site of an informally built 'urban village' in Guangzhu, China.
For casual as well as learned observers of contemporary Chinese society, it is clear that despite the rapid urbanization, Chinese cities are still relative safe places to live compared to some crime-ridden communities in other parts of the world. According to a recent report, murder rate has been dropping in China since $2002 .^{2}$ On the other hand, reports on seemingly random violent incidents are on the rise, from students committing murder on college campus to attacks in train stations, suicides at airports and other public spaces, and mass protesters turning to angry mobs. What has not gained enough attention is the often localized but pervasive violence in urban communities and neighborhoods generated from the economic reform and state policy. This paper focuses on urban demolition and relocation, a process that has been at the heart of China's neck breaking development and that has produced the localized urban conflict and violence. The paper points to the Chinese state as a source of this increased urban violence and explores the various strategies local communities have employed to deal with and prevent such violence.

Since its brutal crackdown of the 1989 Tiananmen Square student demonstration, the Chinese state has not been identified as a force that activates violence against its people. In 1990, on the eve of the large and rapid urban development in China, Jonathan N. Lipman and Stevan Harrell edited a volume on Violence in China: Essays in Culture and Counterculture. ${ }^{3}$ This book looks at religious, ethnic, communal, historical, rural, and urban conflict and violence and explores the motivation and cultural dimension of such violence. It mentions little of state sponsored or economic development induced violence. But the Chinese state has a history of taking violent actions against its own people and creating a violent culture from which the Chinese people suffer. In 1991, the Princeton political scientist Lynn White III published Policies of Chaos: The Organizational Causes of Violence in China's Cultural Revolution. White 
suggests that the widespread violence unleashed in the Cultural Revolution was structurally embedded in the Chinese Communist system and policy that legitimated violence.

White's approach is instrumental in understanding the violence against urban communities in the post-Mao reform. As has been reported, violent incidents have been taking places in urban demolition and relocation, a key step in China's housing reform and urbanization process. Such violence is mostly carried out through domicide, the "murder of the home," against the owners' will. It is also perpetrated against residents in the form of physical abuse, beating, black jail, arson, imprisonment, murder, and suicide as they resist demolition and relocation on the government's terms. What was least recognized is that those violent incidents of forced demolition were not just random occurrences, but a systematic pattern sanctioned by the Chinese state in its policy governing urban development.

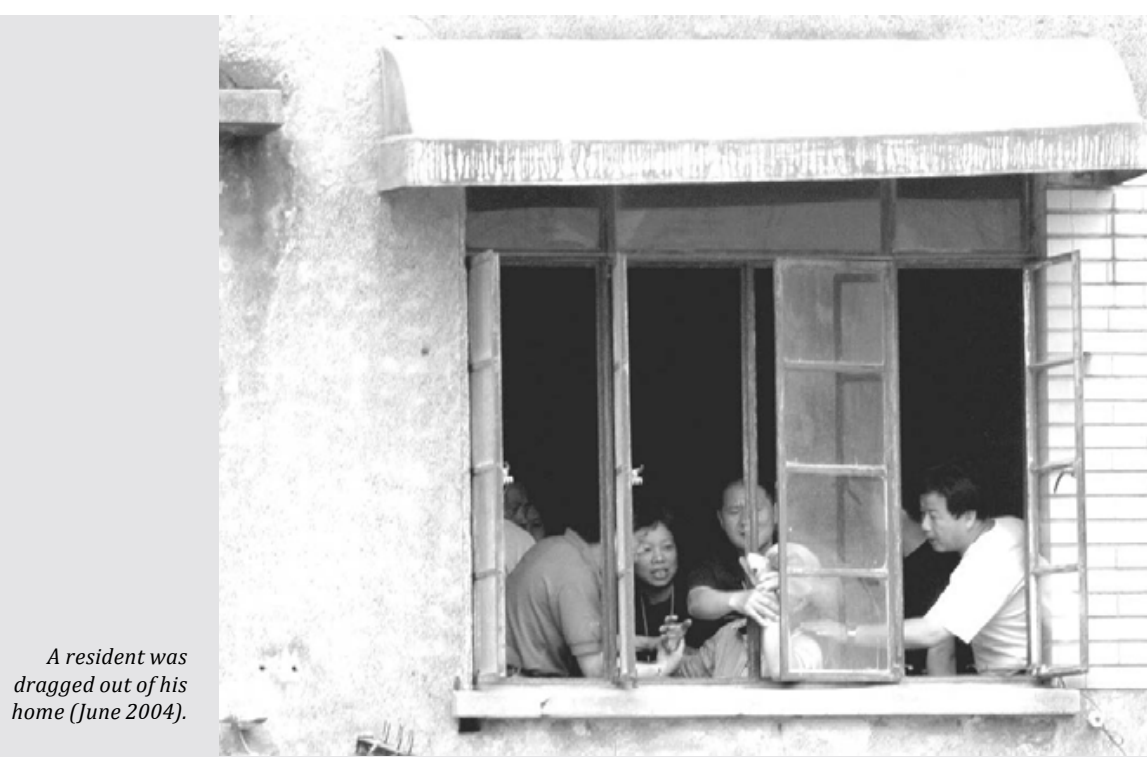

An examination of the evolving state policy on urban development proves the point. In 1991, on the eve of large scale urban renewal in China, the State Council issued "Regulations on Urban Housing Demolition and Relocation," the first systematic guideline for demolition and relocation in urban China. The priority at that time was to improve residential housing through urban renewal and, accordingly, the purpose of the 1991 Regulations was to "ensure the smooth undertaking of urban development." ${ }^{4} \mathrm{~A}$ decade later, in 2001, in the height of commercial real estate development, the State Council revised the 1991 Regulations and issued Document 305 as the new overall guideline. Its stated purpose, not surprisingly, was to meet "the demands of the market economy" and to "ensure the smooth

04 .

http://house.focus.cn/ews/199106-01/4326.html, accessed $26 \mathrm{Au}$ gust 2012. undertaking of construction projects." This reflects a narrower, progrowth and business approach compared with the 1991 Regulations and is responsible for the increased violence in urban development. 
The 1991 Regulations explicitly required a "written contract" between the demolisher and the resident about a compensation and settlement plan before demolition could start. Document 305 omitted the crucial word "written," which created loopholes for some developers and officials to use vague, oral, and casual exchanges as the bases for settlements, im $\neg$ posing them on residents that often led to violence against residents who in turn resisted violently.

Additionally, Document 305 expanded on some of the punitive measures against residents included in the 1991 Regulations and thus further strength $\urcorner$ ened the government's power. For instance, item 15 of the 1991 document stated that local government could force residents out if they refused to relocate "without justifiable reasons." Yet item 17 of Document 305 simply allowed the authorities to evict such residents, regardless of whether or not they had valid reasons to stay. More specifically, Document 305 stipulated that in cases where residents disagreed with the demolisher on a settlement, relevant authorities could make an administrative ruling on demolition. If the residents objected to that ruling, they could, within three months, appeal their cases in court. But during the three-month period, the government could implement the demolition, by force if necessary. Document 305 failed to address the obvious absurdity of this ruling, which completely ignored the question of if-granted a big if, since it hardly ever happens - the court did, in fact, rule in favor of the resident by granting his or her appeal, what would be the point if the house had already been destroyed? Clearly, Document 305 legiti-matized the use of force, which opened the floodgates to domicide. It is in this sense that the Chinese party state is responsible for the violent nature of urban development in China.

As Beijing called the tune, provincial and municipal governments followed suit. Some of the documents on demolition and relocation issued by the Shanghai government in the 1990s emphasize the importance of a signed agreement between the parties involved before any action is taken. Yet immediately after Document 305 was issued, the Shanghai government announced Document 111, titled "Detailed Regulations on Shanghai City Housing Demolition and Relocation Management," which fully reflects the same hardline approach toward residents. Furthermore, while previous documents set a limit on the number of applications for administrative compulsory ruling on demolition at 5 percent of all households involved in any given two-year period, Document 111 had no such limit. As a principal guideline for future demolition and relocation in Shanghai, it took a step backward from protecting residents' interests.

With the liberty to use force, the local government hired demolition squads to beat up resident protesters, vandalize their property, cut off their utilities, drag them out of their homes, and set their houses on fire to force them out-all of this led to more violence and more cases of domicide. In August 2005, a demo 7 lition squad in Shanghai committed arson that claimed the lives of a couple in their seventies. A subsequent investigation revealed that the demolition squad had already committed arson five times in this neighborhood since 2004 , when it was slated for 
demolition. But the district government did nothing to stop it until the loss of the two lives caused public outrage. ${ }^{5}$

For seven years from 2004-2011 I conducted field research in Shanghai and studied various cases elsewhere about the impact of the Chinese state's housing policy on urban demolition and relocation. I came across many cases concerning both neighborhoods and individual families who faced or suffered forced demolition. I detailed six such cases in my book, Shanghai Gone: Domicide and Defiance in a Chinese Megacity. In almost every cases, violence or the threat of it, was involved, all because the government and developers used Document 305 to relentlessly push residents out, with violent means if necessary.

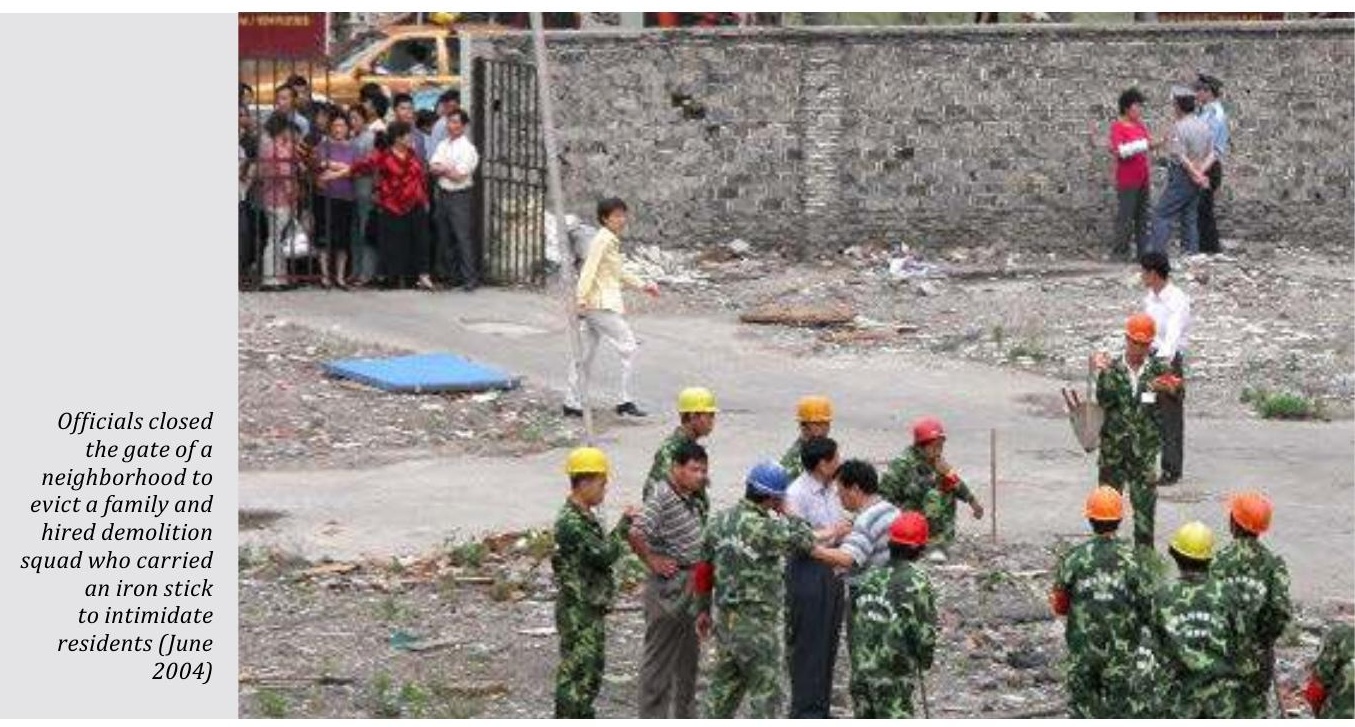

In June 2004, I was on a site in a downtown Shanghai neighborhood where the district government demolition squad spent five hours evicting a family from an apartment. The members of a hired squad carried iron sticks walking around among the neighbors who gathered to support the family under siege. They broke into the apartment and carried the belongings of the family to two trucks, and then pulled the family out of their apartment. This was after almost a two-year struggle between the residents and the district government over the demolition of this neighborhood. The process resulted several incidents of violent clash, in which a number of residents were beaten and hurt. In another case in Shanghai, the district demolition squad broke into a privately-owned home, went straight upstairs to the bedroom, wrapped an 80-years old woman and her daughter in blanket and tied their hands, and dragged them from the third floor to a van, and then knocked down their home. The district locked the old woman and her daughter in a basement where the old woman swallowed her gold ring in an attempt to commit suicide. While her life was saved, she was so traumatized by the violence that she lost sight in her left eye overnight and was hospitalized for a week. ${ }^{6}$

At the height of urban development in China, such violence was routine rather than exception. Violence and the threat of it not only instilled fear

05.

Fazhi ribao (Legal Daily), August 25, 2005.
06.

These and the other cases mentioned below are detailed in Shao (2013). 
in the individuals affected by the process, but also terrorized the entire neighborhood. Since negotiation for an acceptable settlement and resistance to government forced demolition could take years even a decade to reach a conclusion, some neighborhoods and families had to live in the shadow of violence for a prolonged period. Some of them were arrested and beaten periodically. Violence became part of their lives. Furthermore, the government's use of Document 305 in carrying out domicide legitimated violence and created a violent culture against urban residents. In this sense, the violence in post-Mao economic development, just like that in the Cultural Revolution, was a product of the Chinese state policy.

Many residents in China condemned Documents 305 as "evil law" and petitioned for years to have it rescinded. Finally, in January 2011, after a decade-long trail of violence, the Chinese State Council issued Document 590 to replace Document 305. The new Document eliminated

07.

http://www. gov.cn/zw$\mathrm{gk} / 2011-01 / 21 /$ content_1790111.

htm, accessed 21 August 2012. some of the most oppressive and punitive measures against residents. ${ }^{7}$ But the damage was done. The violent culture and the legitimacy of violence created by Document 305 continue to affect the practice of urban development. Incidents of violent demolition and relocation still takes place in urban China today.

In dealing with and preventing this kind of violence that was directly resulted from the policy of the Chinese state, urban communities in China faced unique challenge. For violence generated in society, be it murder, homicide, gangsters, gun violence, riots, and community feuds, the state and its security and legal apparatus, including the police, the court, and public security force, are powerful allies that can assist local communities in their response and prevention measures.

But in China, since the violence in demolition and relocation was sanctioned by the state which has absolute control over its legal and security apparatus, those suffer from such violence lost the protection of the government and the law. The dominance of the Chinese Communist Party state weakens the rule of law and judiciary independence. The police were often on site of domicide to protect the authorities and deter, and attack if necessary, the residents if they resisted. Very few residents who were forcibly evicted got a fair hearing in court and recovered their property. Some of them have been struggling for justice for decades. Even those who documented their injuries in the hands of demolition squad and sometimes the police, with photographs, video recordings, eye witness reports, and doctor and hospital diagnosis, were turned away by the court and government petition offices that were supposed to hold justice for them. In short, the police and the court are on the government side. They are part of the state force that allowed the violence to develop in urban demolition and relocation in the first place.

Despite the difficulty, urban communities in China did not just roll over and play dead. In-stead, they have tried to prevent such violence and protect themselves. Unlike street violence, one characteristic of violent demolition and relocation is its predicability. Often a neighborhood would learn about its fate and government-decided compensation package shortly after the local government targeted it for demolition. The compensation package was usually below the market price of their homes, 
a primary source of tension and conflict between the residents and the gov-ernment and developers. Residents understood if they rejected the compensation package or if they failed to negotiate a better package and refused to relocate, they were likely to suffer from domicide and other violent attack. Many residents would prepare themselves for an active and sometimes prolonged negotiation with the local government for the best deal they could achieve.

Residents organized a legal study forum and met regularly to study the law and regulations as part of their resistance to forced demolition (June 2004).

In the meantime, they also tried to deter the government from using force. One of the keys is for the residents to study the relevant law, regulations, and policies to gain sufficient knowledge and information that would protect themselves. In fact, it was most common for residents to use legal defense to prevent them from becoming the victims of violent demolition and relocation. Despite or perhaps because of the weakness in the law, residents often try to identify loopholes in official and legal documents and used them to their advantage. For instance, while Document 305 openly permitted the use of force in demolition and relocation, regardless the nature of the property, the 2007 Chinese Property Law gave protection to private property rights. Property owners often highlighted this inconsistence to argue that since their property was privately owned, Document 305 didn't apply to their cases, and forced eviction would be illegal. With this strategy, some residents were able to delay the demolition of their homes, gain a better compen-sation package, and avoid domicide. This process, though, could be long and stressful. In one case, it took the family more than a decade that was marked by setbacks and the threat of vio-lence to negotiate a deal for their relocation. The family finally moved out on their own terms; they escaped domicide.

Residents also manipulate Maoist cultural remains and the Communist Party's own political symbols to both resist unjust demolition and protect themselves from state sanctioned violence. One common sight in neighborhoods under siege in many urban areas is a red banner, the CCP's national flag. Residents put it on their property to forestall forced demolition. One resident told me that it would make the officials antirevolutionaries if they dare to demolish his home with the red flag flying on it. Residents also sing The Internationale and other revolutionary songs from the Mao era to vent their anger toward the authorities and avoid attacks. Such a strategy is more effective in attracting media and public attention and delaying domicide, but not necessarily avoiding it altogether.

The purposeful use of open, public space was another way for urban residents to deter and prevent government violence. An open and public space, unlike a small, isolated alleyway, is under the watchful eye of the public. The public will judge. Both the residents and authorities explicitly understand the implication of such a space. It is therefore not surprising that in urban demolition and relocation, spatial politics plays a major role, with residents want to keep their neighborhood open and government attempts to isolate it. One such case I studied involves a neighborhood of a few thousands of families in downtown Shanghai, just one block 
off the commercial center of Nanjing Road West. In the summer of 2004, a few hundreds of families still remained. They lived in debris since the government had demolished the homes of those who had moved out. This partially demolished large piece of neighborhood in downtown Shanghai was an eye sore and an embarrassment to the district government. The government's use of force was inevitable to move out the remaining "nail

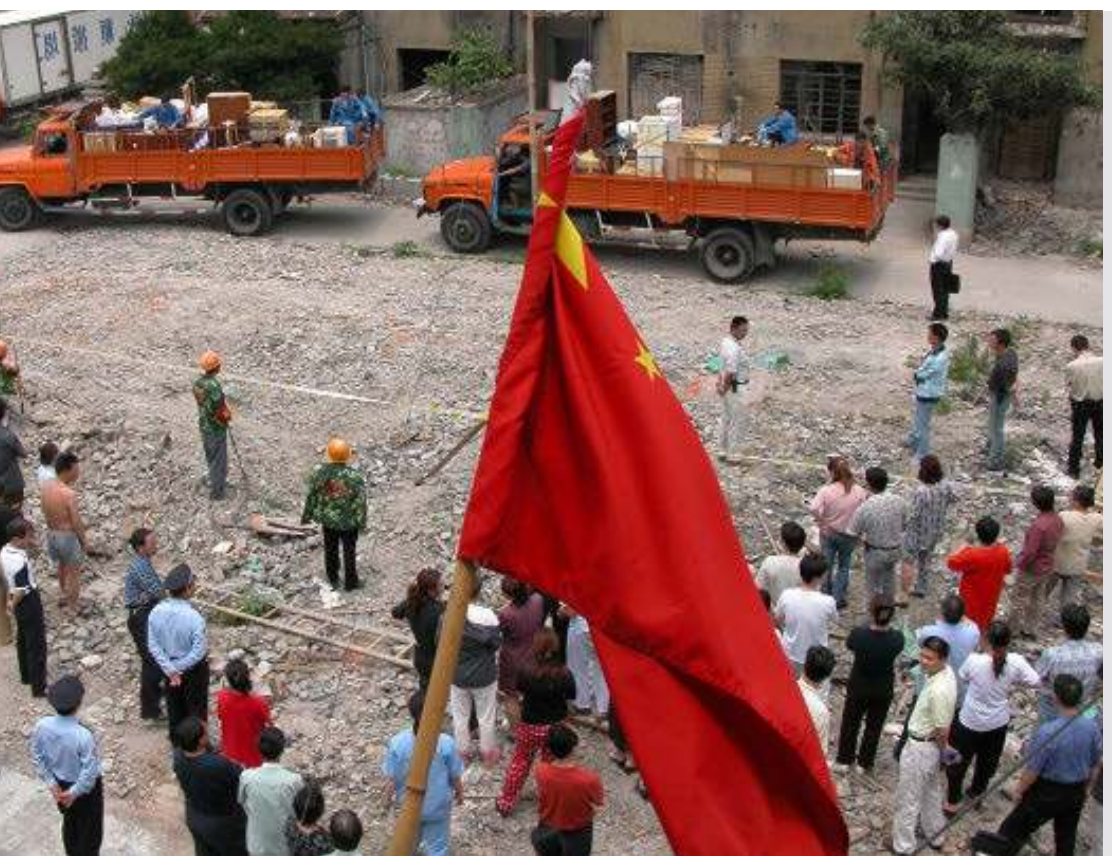

Residents flew the red flag and came out to support one of their neighbors who was being evicted (June 2004).

households"-those tough-minded residents who refused to relocate. But the neighborhood was completely exposed to the busy streets in downtown Shanghai and any violent actions against the residents would invite media and public scrutiny. The government thus decided to erect a tall wall to isolate this neighborhood from the public view. But the residents fought against it. Initially, they organized day and night watches to prevent government- hired workers from building the wall, and they then tried to destroy the wall at night as it was being built. This struggle led to violent clash between the residents and the workers. A number of residents suffered injury. Though in the end the government did build the wall and clear out the remaining families, the residents, in part because of their open location, were able to delay the inevitable for more than a year. During that time the Shanghai real estate market went up which enabled some of the families to negotiate a better compensation than what they were initially offered.

Related to the spatial issue is the use of various medium and media to document demolition and relocation, another strategy that residents had employed to check the government's violent impulse. The ready access to camera, camcorders, various recording devices, now the I-Phone and I-Pad, and the Internet has allowed the residents to document officials' abuse and post such information online to rally public support or present 
such information to the court for their law-suits. Residents often openly videotape an eviction to make sure that officials know their actions are being recorded and watched so as to compel the officials to refrain from using violent means. Here spatial politics also matters. Residents in large neighborhoods with a street view and public audience are more likely to succeed in video recording and photographing demolition and reloca-tion and deterring violence. In secluded small alleyways, authorities would confiscate and smash residents' recording devices to prevent the residents from documenting official actions. In such cases, the government is more likely to use violent means to relocate the residents. By the same token, in a large neighborhood where many residents come out and gather around their neighbor who suffers eviction, officials are less likely to use force, for fearing open confrontation with a large, angry crowd. Residents, understand their collective power in deterring government vio-lence, often do come out to support each other in demolition and relocation.

Government sanctioned violence creates unique characteristics and challenges for urban com-munities to respond. In the case of China, this new round of violence took place in the name of economic development and is accepted as "creative destruction." As such, it often escapes critical attention and scrutiny. But what has happened in urban China under Document 305 and in the name of promoting economic growth is a violent disregard of dignity, property rights, and human rights. The government has also created a culture that, just like the Cultural Revolution, legitimates violence in society. As resourceful and tenacious as the Chinese urban residents have been in dealing with this violence, they are ultimately vulnerable to such authoritarian state power.

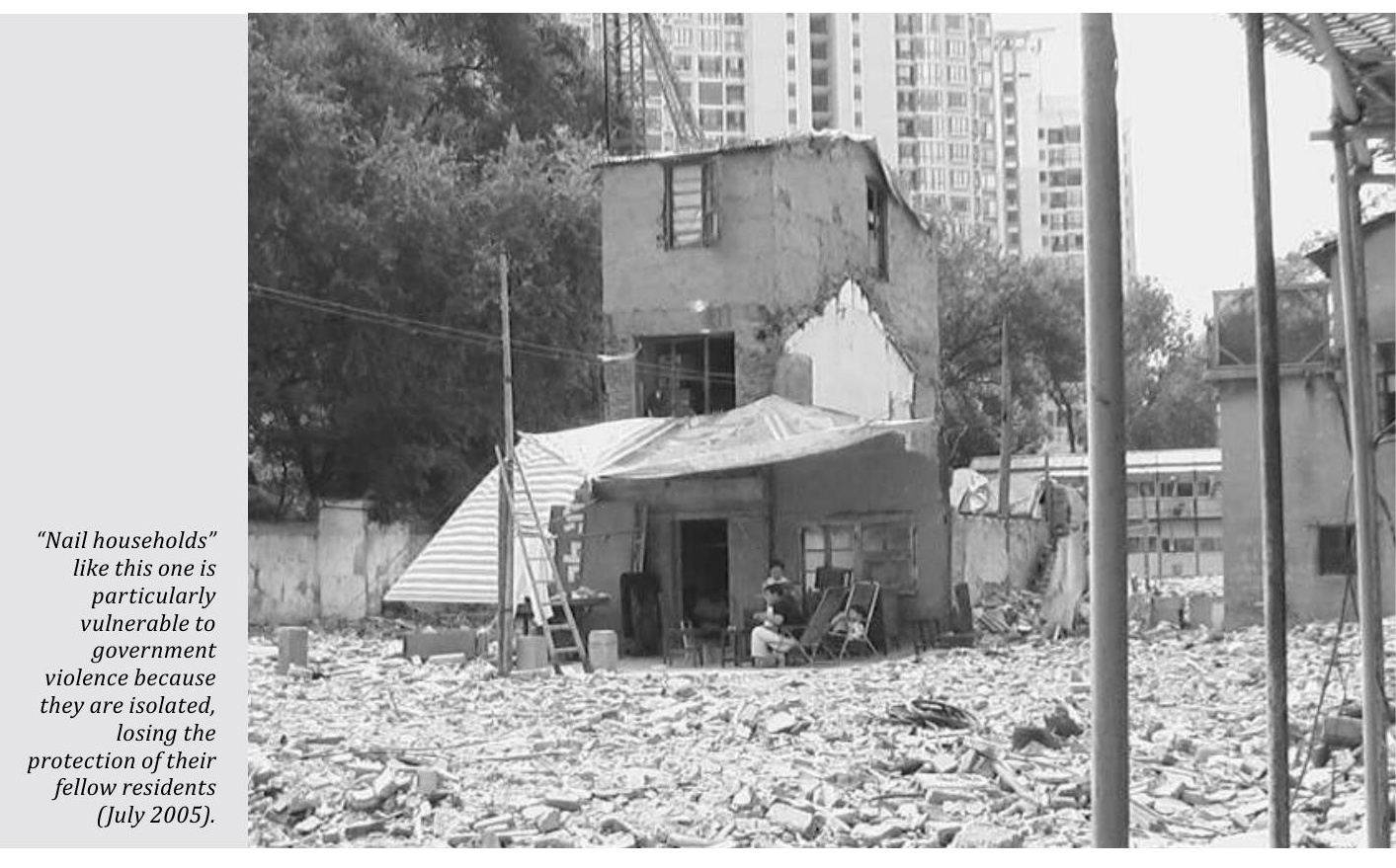


It is important to point out that China is not the only country where urbanization and economic development have generated violence against urban communities. To build sta-ble, safe, and healthy urban communities, we must study all kinds of violence, and especially the kind sanctioned by the state, and we must recognize such violence as it is--a disruptive and threatening force to urban life. Furthermore, we should go beyond specific violent actions to study some of the root causes of urban violence. Specifically, we should study how to neutralize the destructiveness of a capitalist market economy, how to promote a more humanistic approach to economic growth, and how to limit state power in dismantling urban communities. These are some of the challenges faced by not just China, but the global community at large.

\section{References}

Cailiang, Wang 2004. Fangwu chaiqian jiufen jiaodian shiyi (Guide to Solving Disputes over Urban Housing Demolition and Relocation) (Beijing: Falü chubanshe, 2004),

Falü chubanshe fagui zhongxin (The Center of Law and Regulations at the Law Press), ed. 2004. Fangwu chaiqian fagui zizhu (Self-help in Laws and Regulations on Housing Demolition and Relocation) Beijing: Falü chubanshe, 27.

Lipman, Jonathan N.and Stevan Harrell (eds), 1990. Violence in China: Essays in Culture and Counterculture. New York, NY: State University of New York Press,

Porteous and Sandra E. Smith 2001. Domicide: The Global Destruction of Home . Montreal \& Kingston McGill-Queen's University Press.
Shao, Qin 2013. Shanghai Gone: Domicide and Defiance in a Chinese Megacity. Lanham: Rowman \& Littlefield

White III, Lynn 1991. Policies of Chaos: The Organizational Causes of Violence in China's Cultural Revolution. Princeton, NJ: Princeton University Press, 1991

Zhongguo fazhi chubanshe, ed. 2007, Chaiqian buchang shiyong falü shouce (Compensation in Demolition and Relocation: A Practical Legal Handbook) (Beijing: Zhongguo fazhi chubanshe), 281-91. 



\title{
Local Civil Society and the New Puzzle of Violence in Central America
}

\author{
Heidrun Zinecker
}

\section{The new puzzle of violence in Central America}

01.

Central America is not a geographical or cultural concept, but a historical-political one. It includes - with Honduras, El Salvador, Guatemala, Nicaragua and Costa Rica - the countries that, during the colonial period.

02.

A differentiation is needed between between the gangs in Nicaragua and Costa Rica and those in Honduras, El Salva-

dor, and Guatemala: the former are called "pandillas", while the latter are

"maras". All maras are pandillas, but all pandillas are not maras (Argüello 28.09.06; Demoscopía 2007: 12).

Previous page: Salvadorian military. Source: istockimages Lic. $834^{\prime} 8446821$ RT0001
Central America ${ }^{1}$ is currently considered the most violent region in the world. It leads the world in homicide rate, ahead of the Middle East and Sub-Saharan Africa. The ratio of murders is ten times higher than the world average (ONU 2012-05-16). Unlike periods of recent history, when Central America was characterised by revolutions, civil war, and military dictatorship, nowadays violence in this region is predominantly criminal and generated within civil society, where it imposes a far higher risk for life and security than political violence, (Fox/Hoelscher 2010: 1).

The extent of violence differs considerably within the region: $87 \%$ of all homicides in Central America are committed in the "Northern Triangle", Honduras, El Salvador and Guatemala; only 13\% occur in Costa Rica and Nicaragua. In 2012, Honduras topped Central American and international rankings with 85.5 homicides per 100,000 inhabitants (El Heraldo 2014/07/19) - in 2013, it reached 90 -, followed by El Salvador with 68.5 (SICA 2013) and Guatemala with 42 (El País 2013/07/11). On the other end of the scale, Nicaragua had a ratio of 11 (Insight Crime 2013/05/31) and Costa Rica 8.9 (Nuevo Diario 2013/02/28) [see: Figure 1]. About $20 \%-30 \%$ of today's violent crime in Honduras, El Salvador and Guatemala can be attributed to youth gangs, especially the $\operatorname{maras}^{2}$ (see: Cruz 2007: 16; Aguilar 24/02/12). The mara is a relatively durable, robust, hierarchically-organised, cross-border, highly militant, and violent form of youth gang with - occasional - links to the drug trade, while the pandilla (insofar as it is not a mara) is a less durable and robust, essentially non-hierarchical, and less violent youth gang with younger members that agitates only locally and not on a cross-border level.

To put this in context with the rest of the world, today, violent crime in Honduras exceeds that of Germany by 90 times $(1.0$ per 100,000 
inhabitants). South Africa, another internationally recognised epicentre of violence, "only" shows an index of 39.5 and, hence, is surpassed by every violence-prone country in Central America (Honduras is even double the ratio of South Africa).

This comparison gives rise to an interesting issue, which I infer as "the new puzzle of violence": even though the Central American region shares historical-structural similarities, how can we explain the extremely high levels of homicidal violence in the three countries of Honduras, El Salvador, and Guatemala, and the low levels in the two neighbouring countries of Costa Rica and Nicaragua?

If one only looks at Costa Rica, this difference isn't surprising. A democratic welfare state known as Central America's "Switzerland", Costa Rica resembles Western European countries. But Nicaragua, on the other hand, also has low levels of violence despite displaying almost the exact same structural indicators as its northern neighbours of El Salvador, Guatemala, and Honduras (notably inequality, social exclusion, poverty, and past civil war).

The explanation for this puzzle is highly complex (see Zinecker 2014), but in reference to the focus of this publication, I will concentrate on the role of local civil society at the community level and try to answer the question in which way does local civil society engagement at the community level contribute to the enormous differences in the level of violence constituting the new puzzle of violence in Central America?

Prior to discussion of the empirical evidence in the countries concerned, I will briefly outline the theoretical framework of the research fundamentals, especially the roles of enabling and inhibiting the conditioning of criminal violence.

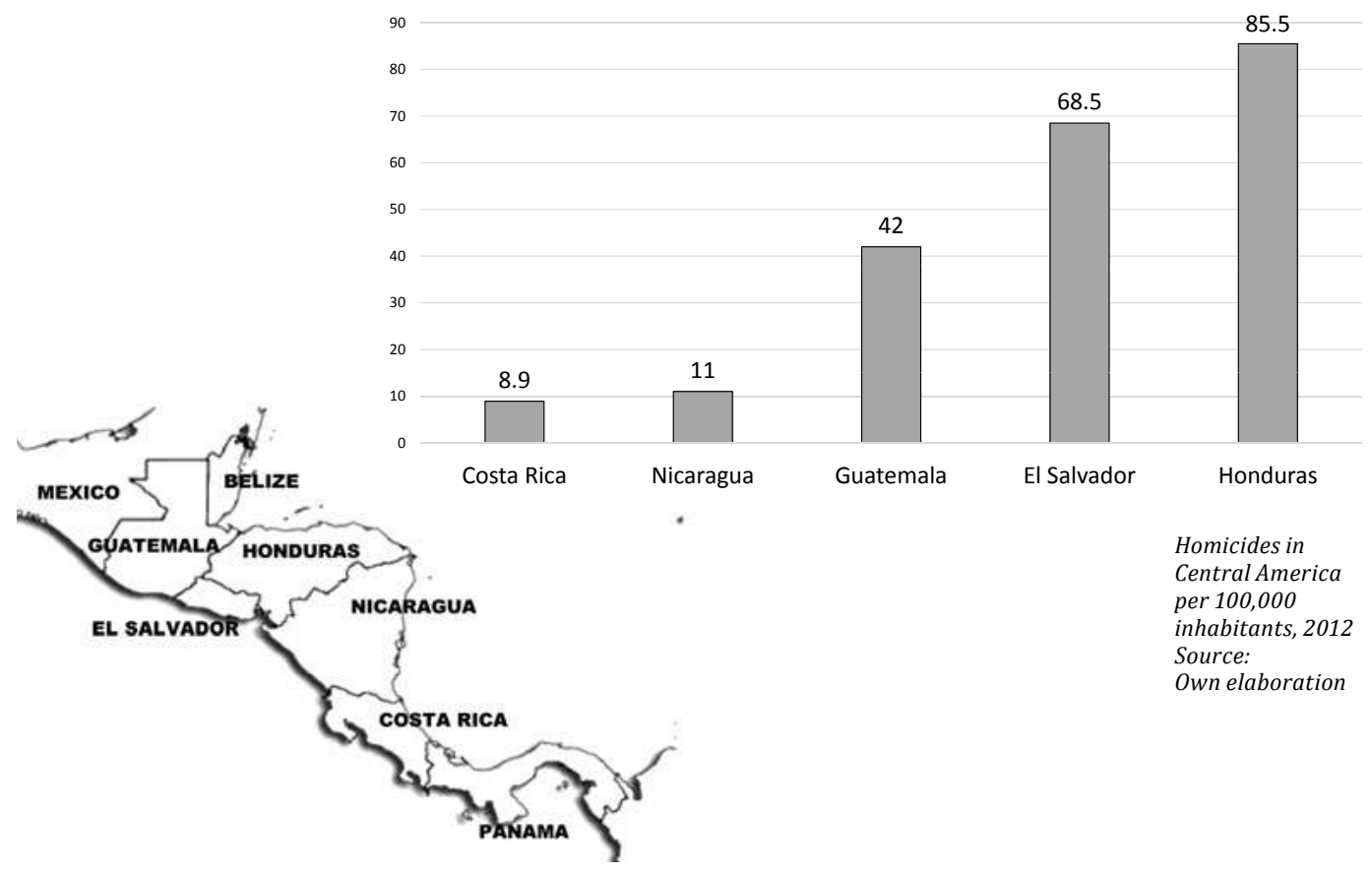




\section{Theoretical framework: enabling and inhibiting structures of criminal violence}

High levels of criminal violence are a result of both (present) enabling and (absent) inhibiting structures and arise from specific structural configurations of the state and civil society:

1. Existing enabling structures of criminal violence arise from the precarity and the lack of empowerment of labour, as well as from the lacking democratic substance of the political regime. Above all, political exclusion and/or missing political inclusion strongly influence enabling structures of criminal violence.

2. The absence of inhibiting structures of criminal violence are the result from a poor performance of the political regime alone, and here particularly of the state's part of the security sector and discouragement of civil society engagement.

Enabling structures form the structural breeding grounds for violence. Inhibiting (or preventive) structures can - alone or in combination with individual precautions - help to ensure that violence, despite the general existence of enabling structures, never erupts. Well-functioning preventive structures, can decisively curb violence, even if enabling structures exist.

Preventive structures function well when the external ${ }^{3}$ controls mechanisms are neither defunct (inability of the security sector in a weak state) nor excessive (mano dura ["iron fist"] policies of a repressive state). Hence, a functional security sector is characterised by a balance of controls and can preventively intervene in the tide of violence with a policy somewhere in between the undesirables extremes of laissez faire and repression Such a balance in the application of state control mechanism (police, judiciary, prisons) should be mirrored by an equivalent balance in violence prevention strategies in civil society ( also excluding both, control deficit and control surplus). This assertion is based on the general comparison of two characterisations of civil society: civil society in its democratic and therefore necessarily civilised form, and civil society in its non-civilised, and therefore a non-democratic form (see Zinecker 2011). The particular character of civil society, then, is to be found in a co-operative and peaceful relationship with the state.

A democratic civil society implies the acceptance of a separation of executive, legislative and juridical powers and therefore participates in the prevention of violence peacefully, which means unarmed. This differs from a vigilante civil society which claims autonomous juridical powers at the community level and, in the case of a weak state, can even do so in consent of government authorities. To resume:

a) In the first case, a democratic civil society agrees on symbiotic control together with the state. Both sides are strong in terms of not lacking the necessary control, but also without accumulating a surplus of control. In this case civil society will not react to violent intervention by a third party by a violent act on its own. 
b) In the case of civil society resorting to vigilantism, the control surplus is an expression of imbalance in both the civil society and the state (who tolerates vigilante engagement among civil society).

The underlying concept of control (im)balance has been developed by different authors and especially by Charles Tittle (1997, 99 pp.), whose theory on self-control likewise fits for analyzing external control. Tittle assumes that both a deficiency as well as a surplus of social control would lead to deviance. Since crime is commonly understood as deviant behaviour, this theory explains crime and violence. Tittle's model resembles both Peter Wallensteen's (1999) distinction between "under consolidated" and "overextended states" in relation to state failure, as well as the Theorem of Democratic Civil Peace, which has been verified in the case of civil wars and political violence (Ellingsen/Gleditsch 1997; Henderson 2002; Hegre/Ellingsen/Gates/Gleditsch 2005). The corresponding alternative would be a balance of external social control which eliminates control deficiencies as well as surpluses. Hence, rampant crime can be explained as a result of imbalanced control.

Tittle's theory is also very close to the model suggested by Jaime Suchlicki:

"When force (punishment) is very permissive as well as very restrictive, anomic violence is negligible. Punishment in the mid-levels of intensity (apparently acting as frustrator) elicits high levels of anomic violence." (Suchlicki 1972: 32)

While self-control avoids the automatic link from frustration to aggression, external control eliminates the turning point from aggression into violence. This, however, is only true if external control is balanced as outlined above.

The theoretical framework, only partially outlined here, served as a guide for the empirical field studies in the five countries covered in this paper.

\section{Empirical Findings}

In countries characterised by high levels of violence, notably Honduras, El Salvador and Guatemala, a surplus of control exists both on the part of the state, as well as on the part of civil society. Civil society thus interferes in matters of security by resorting to vigilantism, eventually overcoming both its own control deficiencies as well as the deficiencies of the state's security sector. Therefore, civil society engagement corresponds to those control surpluses provoked by the state.

In contrast, in countries characterised by low levels of violence, notably Nicaragua and Costa Rica, the following assumptions apply (and will be tested in the remainder of the paper):

Nicaragua's violence inhibiting structures of the state and particularly of civil society can be characterised as a well-functioning external control equilibrium. Neither the police (in contrast to the judiciary) nor civil society has control deficiencies or surpluses. 
This also holds true for Costa Rica. However, an increase in homicide rates was observed since 1990 , and particularly since 2008 , and may be attributed to a conservative movement of "citizens' security" (seguridad ciudadana). This campaign makes reference to the broken-windows-theory and call for vigilante justice justified by an irrational need for civil society engagement to take the fight against criminal violence into their own hands.

\section{Honduras}

Honduras, as the country with the highest incidence of homicide in the region, is poorly equipped with police. Moreover, the reputation of police work cannot be worse, in terms of repression and the violation of human rights. The Honduran judiciary is the least independent and the most politicised in Central America and receives the lowest level of trust in its rulings - except for decisions by the Supreme Court. Equally, the conditions of prisoner detention ranks among the most inhuman in Central America (along with El Salvador, see Zinecker 2014, Chapter 10.4.2.).

However, Honduras has surprisingly for a short time earned a relatively good reputation in terms of co-operation between civil society and the communitarian police (Policía Comunitaria), second only to Nicaragua (see below). Being part of the Programa de Comunidad Más Segura it was governed by the idea that the police can assume full responsibly for security in cooperation with civil society.

President Ricardo Maduro (2002 - 2006), being known for his "iron fist" policies (mano dura), promoted neighbourhood networks to prevent violence under the command of the Policía Comunitaria. Different from the former Comités de Seguridad, which had transformed into paramilitary groups, the new Comités de Seguridad Ciudadana were unarmed and engaged in the restoration of public spaces, particularly public parks, and in improving security by providing electric lighting in the neighbourhoods. Furthermore, these committees were supposed to collaborate with the police by revealing locations where drugs and alcohol were traded, by reporting about the possession of guns, as well as building a sense of community and vigilance without falling back into panic. In the case of "extraordinary incidences", these committees finally should call the Policía Comunitaria (Romero, R. 21.02.07) for assistance. Although less democratic and unstable in comparison with Nicaragua, this kind of civil society engagement was considerable stronger in Honduras than in other countries suffering from high levels of violence.

The subsequent president Manuel Zelaya (2006 - 2009) inherited Maduro's plan and pursued it under the new title "one thousand round tables and citizens for security" (un mil mesas de ciudadanos y ciudadanas por la seguridad). Initial suspicion that the round tables would be a catalyst for vigilantism has not realized (Peetz 2012: 190/191). However, with the coup against Zelaya (2009) and the repressive tendencies against "his" civil society by the governments of Roberto Micheletti (2009 2010) and Porfirio Lobo (2010 - 2014), the democratising engagement with civil society has been reversed. Even the initial positive appearance of the Policía Comunitaria and local civil society in Honduras should not 


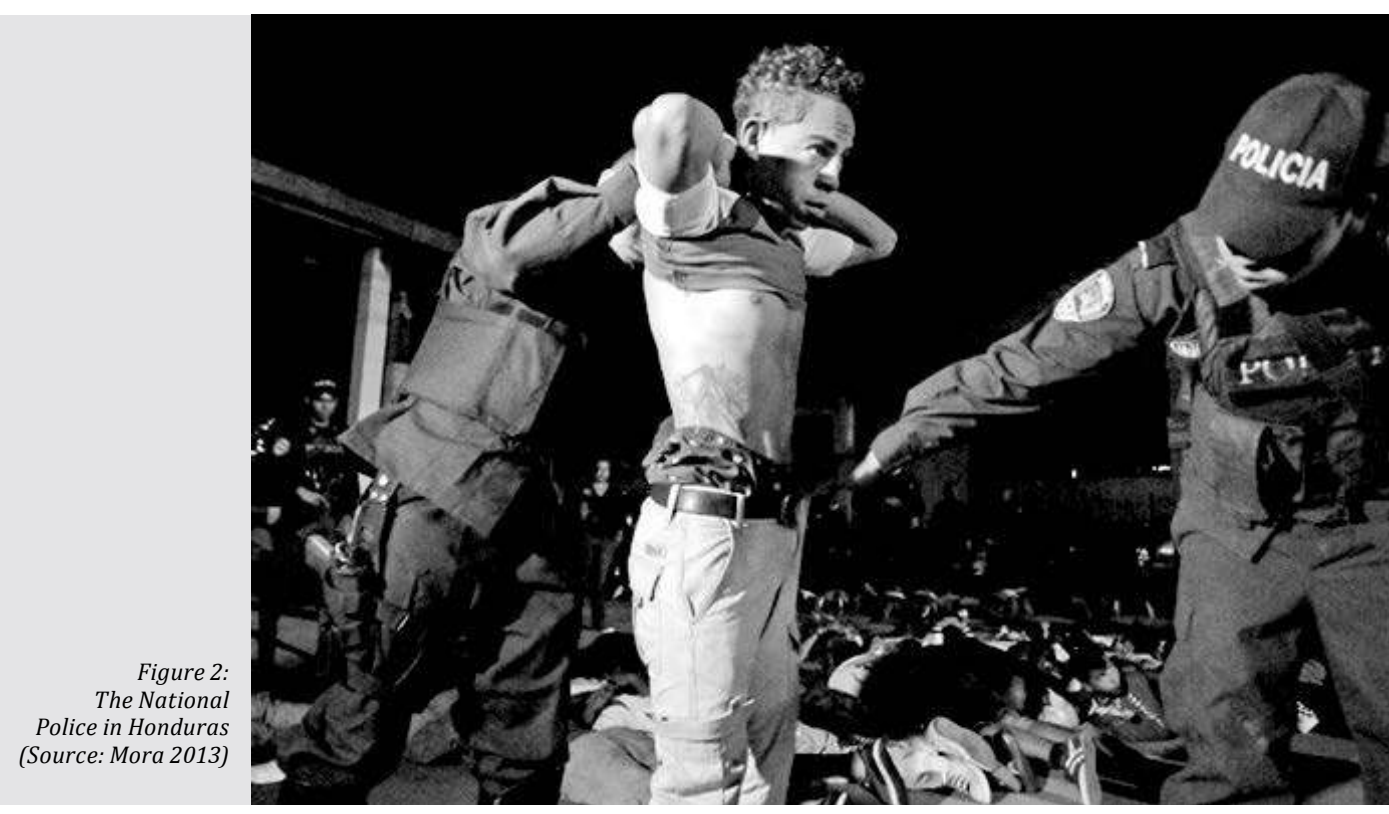

be praised without also mentioning the dark sides of the state's security sector. Other elements of the state security sector (i.e. police, judicature and penal system) are rather dim, even in comparison with its neighbouring countries. Finally, the (temporary) community-oriented security policy did not produce any sustainable positive outcomes. In summary, civil society in Honduras has been unable to compensate the poor performance of the state in matters of security.

\section{El Salvador}

El Salvador, ranking second highest in homicide rates in Central America, has detention conditions for prisoners as poor as Honduras. Regarding the two other components of the state's security sector, the police (Policía National Civil, PNC) and the judiciary system, El Salvador however can still be considered the best within the "Northern Triangle" (see Zinecker 2014, Chapter 10.4.2) but still worse than Nicaragua and Costa Rica further South.

However, even compared to Honduras before the coup of 2009, Salvadoran civil society's participation in state security policies remains weak. For most parts, civil society has been less vigilantism compared to Guatemala (see below), by assuming passive role. The inactivity of civil society in El Salvador combines with a particular weakness of the communitarian police, which have played only a minor role in crime and violence prevention (a positive exception is Santa Tecla ${ }^{4}$ ). La Policía Comunitaria existed for some time but it never had a clear assignment until 1999, when it's cooperation with civil society was attempted in the form of the Patrullas de Intervención Policial Comunitaria. They engaged in neighbourhood patrols, but according to the view of a higher police officer, they never believed in the idea of violence prevention. ${ }^{5}$ In 2004 , this program

04.

In 2013, Santa Tecla was declared a peaceful Municipio (municipality). Under the leadership of Mayor Oscar Ortiz, who followed a consequent (primary) preventive security policy, Santa Tecla became one of the safest cities in the country (see: La Prensa Gráfica 2013-01-24).

05.

Official interview with PNC, cited in: Savenije 2010, 74. 
developed as repressive as those in the other two countries. Public trust in the Supreme Court is the lowest in the region and resources of its judiciary system are the scarcest. Nevertheless, compared to the neighbouring countries of the "Northern Triangle", Guatemala offers the best conditions of detention for its prisoners (see Zinecker 2014, Chapter 10.4.2).

Explanations given for the presence of vigilante practice in civil society engagement in Guatemala refer to the (after-) effects of the Civil War, in which the civil society was - on both sides - even more involved than in El Salvador or Nicaragua. In that period social networks at the community level were accordingly ruptured and destroyed. Specifically destructive was the appearance of Patrullas de Autodefensas Civiles (PAC) ${ }^{7}$ and, from 1993 onwards, the Grupo Guardianes del Vecindario are crucial.

Public trust into the police is low while the police keep complaining about civil society's lack of cooperation. According to the argumentation by the police, civil society would often have no idea of what was happening on the ground at the community level and would avoid reporting crime... (Member of PNC, cited in International Crisis Group 2011: 12). Consequently, more money is spent on private security protection in Guatemala than on the police (Oficina de Derechos Humanos 2012: 59). The vigilante tendencies in civil society thereby are much stronger than its 'democratic' representation, the Guardianes del Vecindario, Grupos de Ronda (civilian patrols equipped with sticks, machetes, pasamontañas (ski masks), but frequently also carrying guns) or the Juntas Locales de Seguridad (neighbourhood watches).

The vigilante neighbourhood groups were founded under the government of Álvaro Arzú $(1996-2000)^{8}$ and often led by a chief of police, and in $75 \%$ of cases, even by the military (Carballido Gómez o. J.: 19). Their activities lack any democratic endorsement or consultation with civil society and include lynching (Handy 2004: 534), social cleansing, kidnapping, and extortions. Furthermore, these groups and committees tend to

07.

The Patrullas de Autodefensa Civil (PAC) were founded by the Guatemalan military at the end of 1981 under the government of General Romeo Lucas García. By 1985, the PAC incorporated approximately one-third of Guatemala's rural male population.

08.

Their operations were mostly coordinated by the government, especially by the Oficina de Relaciones e Información de la PNC (ORIS) and the Consejo $\mathrm{Mu}$ nicipal de Seguridad Ciudadana (CMSS).

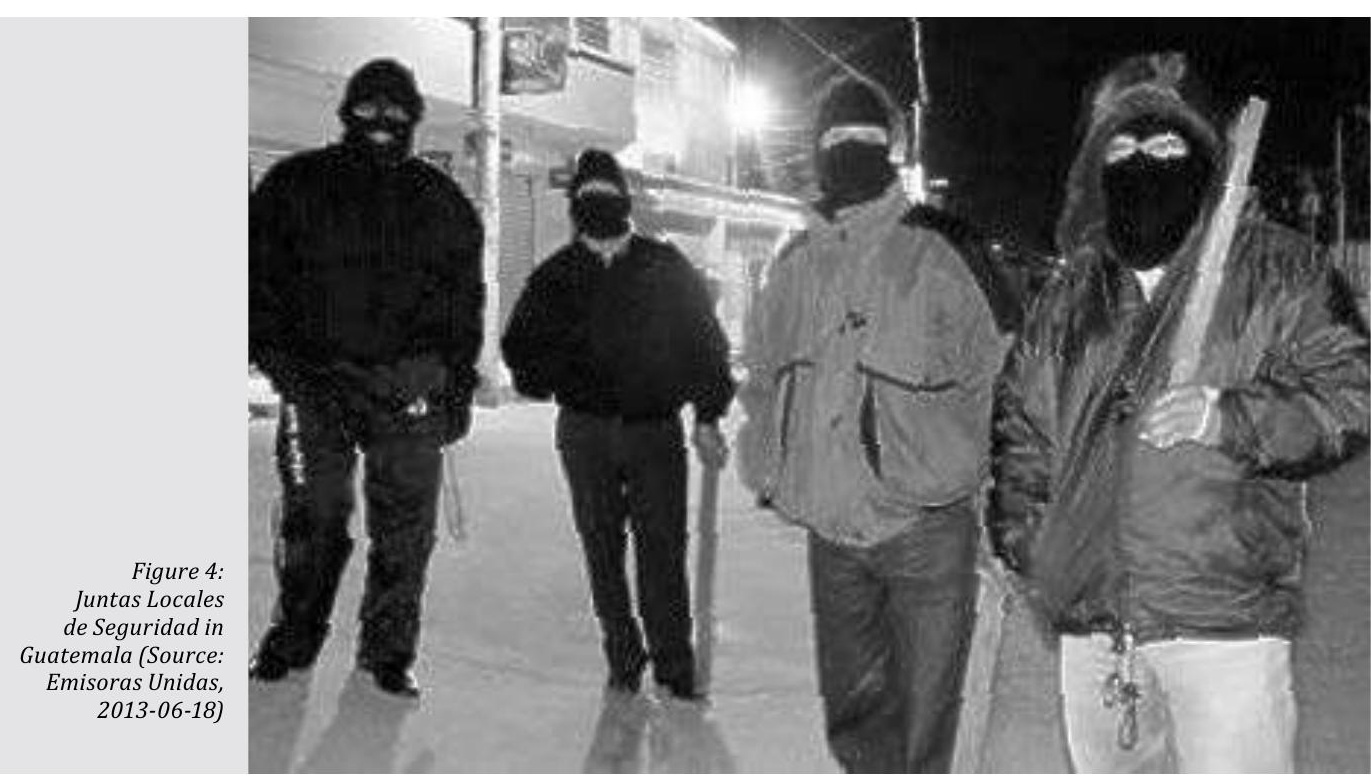


09.

combined with marginality and non-democratic political regimes, is typical of developing countries.

10.

The securitisation approach works in particular in conjunction with labeling and moral panic (see: "politics of panic").

11.

For this distinction, see the paper by the Friedrich-

Ebert-Stiftung (2008: 24 pp). The FES paper, however, is only theoryoriented and does not integrate the case of Costa Rica.

12.

Laura Chinchilla was first minister of security and then president of the country between 2010 and 2014.

In New York, commissioner William J. Bratton initiated the 'iron fist' strategy in 1994. He assumed that the severe punishment of petty crime (or at least having information about these crimes) would prevent the

same perpetrators from committing serious acts of crime later on. At the same time, the impression of hard external control could and should

be made (see

Frühling 2000: 231). be better equipped than the police and frequently have helicopters, night vision aids, wiretap devices, and GPS at their disposal (Argueta 2010: 13).

In some municipalities these groups were mixed up with former members of PACs. Parts of PACs - calling themselves leader de comunidad - maintain close links with private security services. Vigilantism thereby "substitutes" state authorities by "convicting" (suspected) offenders. As a result, the population now seeks to protect itself against vigilantism, consequently founding additional local security groups.

\section{Costa Rica}

In contrast to all other countries in Central America, Costa Rica is not as prone to violence because of its flourishing market economy (instead of rent economy) ${ }^{9}$ and democracy. Costa Rica, in this sense resembles Western industrialised countries (see Zinecker 2014) which are characterised by similar low levels of violence.

In respect to violence prevention, the framework of a strong democratic government provides good inhibiting structures against crime. The state security sector in Costa Rica is considered to be the best and most robust in Central America and even in Latin America, along with Chile. (Programa Estado 2008: 485). This is the main contrast to the countries of the "Northern Triangle": Honduras, El Salvador and Guatemala. Inhibiting structures in Costa Rica are even more encompassing compared to Nicaragua, as they are strengthened by the good performance of the judiciary. The police, however, according to Elías Carranza (18.05.06), are not only worse than in Nicaragua, but also inferior to Costa Rica's judiciary system.

While Costa Rica never has a serious security problem in the past, the homicide rate suddenly increased in Costa Rica from 4.5 to 11.5 homicides per 100,000 inhabitants between 1990 and 2010 (Huhn 2011: 345). This triggered off an exaggerated political discourse and process of "securitisation"10, sometimes even preceding public perception of the announced problem: an image of the offender was discursively constructed as an "enemy" of the community. The theory of "securitisation" is based on the assumption that safety is built upon "securitising". That means, as in accordance to Wæver (1995: 51): "(I)n naming a certain development a security problem, the 'state' can claim a special right (...). Power holders can always try to use the instrument of securitisation of an issue to gain control over it. By definition, something is a security problem when the elites declare it to be so."

Such discourse referred to a conservative version of the broken windows theory ${ }^{11}$. In particular, Rico/Chinchilla ${ }^{12}$ referred to New York's police strategy with reference to that broken windows theory ${ }^{13}$. Such propaganda prepared the field for real "securitisation" involving 'iron fist' security programs and a growth of the private security sector.

According to Lara Blanco (17.05.06) from UNDP, the Costa Rican population perceives the threat of being victimised 20 times more than what actually occurs. Thus, the perception of insecurity in Costa Rica is the highest among Central American countries. ${ }^{14}$ On the whole Latin American continent, this perception is only exceeded in Venezuela (Lagos/ 

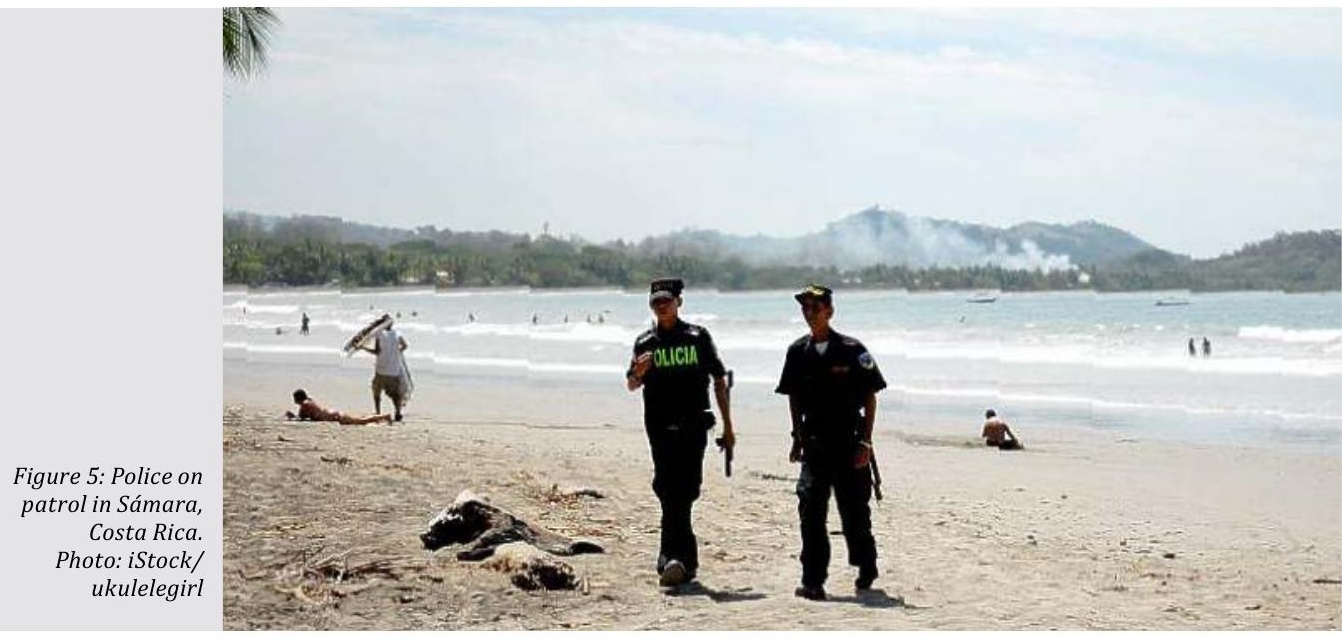

Dammert 2012: 5). This perception includes that maras would be present in the country, although these youth gangs never developed in Costa Rica. Moreover, if four of five youngsters meet somewhere, this is perceived as a gang (Espinoza 12.05.06). Huhn (2011: 121) claimed that fear of crime led to "punitive populism" in Costa Rica.

The inflated debate about insecurity obviously had an effect on the local and central state levels and a top-down stipulation of community policing. The first Comités de Barrios were founded on the provisions ruled in the Ley de Policía in 1994 (Policía Comunitaria) as well as later in the police reforms of 1998. The slogan appeared that civil society had to take the law into its own hands since the state was not able to provide security. Implicitly, vigilante civil society engagement has been legitimised in the fight against crime and violence. Consequently, schools of security were opened and neighbourhood watches founded, and for some time all adults became voluntarily members of the Comités de Seguridad Comunitaria. ${ }^{15}$ Yet, these activities and the civil society engagement exclusively were organised on the neighbourhood level and never became part of central planning or coordination. The police, long since having lost its relations towards civil society, now hurried to re-establish these bonds in a vigilante manner. In the long run, however, only elders and women stayed involved while the youth never could be enlisted (Matul 18.05.06).

Initially, the population inside the barrios even were trained in selfdefence (Guzmán, J. 16.05.06), and learned how to "swing the stick" (Loría 16.05.06). Later on, civil society's focus shifted increasingly towards providing information. Most of the time, civil society stayed passive. But on a few occasions it happened that the population of the barrios engaged in self-defence and sometimes even lynching (Chaves 1996: 32 pp.). A number of people bought guns and rifles to defend themselves against delinquents (Matul 18.05.06).

Although signs of vigilante civil society engagement developed and were backed by the state it would be wrong to refer to vigilantism as a characteristic of civil society in Costa Rica. On the whole, Costa Rica generally remained a country with relatively low homicide rates. But precisely

14.

The existing difference between perception and reality is a characteristic of both low-violence countries (in other words, of Nicaragua - although on a lower level - as well) It is not, however, characteristic for highly violent countries, where the perception is also (somewhat) higher than the reality, but equal to the trend (Lagos/ Dammert 2012: 5).

15.

This was accompanied on the community level by COVIRENAS (Comités de Vigilancia de Recursos Naturales), by Comités Tutelarias de los Derechos de la Niñéz, and by Juntas de Salud. 
as in Costa Rica). In contrast to those reactive and repressive policies it can be interpreted as proactive. "What I recognised", mentioned Bishop Monseñor Hombach (27.09.06), "was that the police in Nicaragua had an extraordinary interest in getting into contact with the population." The police, furthermore, values and supports civil society's capabilities in tackling violence via proactive, community-oriented, as well as democratic, and certainly not vigilante methods.

The origins of cooperation between the police and civil society date back at least to 1990 when there existed a program called "Friends of Police". Since 2007, this relationship has been enhanced by the Policía Comunitaria Proactiva (Savenije 2010: 30), representing a citizenfriendly and progressive community policing approach. The level of civil society engagement serves as an indicator for the success of this policy. ${ }^{16}$

Innovative forms of security governance have been developed in cases where youth gangs send out signals of violence. In such an occasion, grandmothers, mothers, or respected individuals in the district approach gang members in the first instance and talk to them. These gang members perceive that they are being taken seriously, listen to the arguments of the community members, and will cooperate most of the time. This, of course, will not dismantle the pandilla. If trouble continues, members of the community will notify the police. The latter will visit the adolescents' families; eventually address their schools and churches. They approach the adolescents, listen to them, and try to offer professional and cultural alternatives. At the same time, they make note of complaints about administrative and economic deficits in the district and pass them on to the government. Eventually, conflict settling meetings in the presence of a local authority or the police are arranged between conflicting gangs, aiming at a cease fire or peace pact and voluntary disarmament. The handing over of guns proceeds with similar solemnity as during the demobilisation of guerrillas. ${ }^{17}$

All together, Nicaraguan inhibiting structures, both on the side of the state as well as from the side of civil society, can be seen as a testimony of well functioning external control balance. Neither the police nor civil society holds significant deficiencies or surpluses of social control.

The country's judiciary system is less impressive. Its flaws cannot be denied; it is by no means independent from the other two political powers and is also more prone to corruption and clientelism than the police (López, Cairo 25.09.06, and Serrano Caldera 29.09.06). But since the police plays the role of "frontman" within the public security sector; the judiciary only performs the last step in crime and violence prevention. As long as the preceding steps function well, the consequences of a malfunctioning judiciary system are much less severe.

The Nicaraguan case may be valued a 'best practice' in security oriented governance, and a rare example of Public-Private as well as PrivatePrivate Security Partnerships. Since 2000, security governance functions as a well-organised interplay of:

- a community-based, preventive, proactive (instead of repressive and reactive) police force;
16.

Statement by Comisionada Mercedes Ampié

$(11 / 09 / 06)$. Cordero, Gurdián, and López (2006: 97) state that civil society is responsible for informal control mechanisms, whereas the state is in charge of formal social control. At the same time, these authors even make a special effort on "transfers of power to civil society organizations" (Ibid.).

17.

This assessment is based on the author's own observations during her fieldwork in Managua and Estelí in September 2006. 

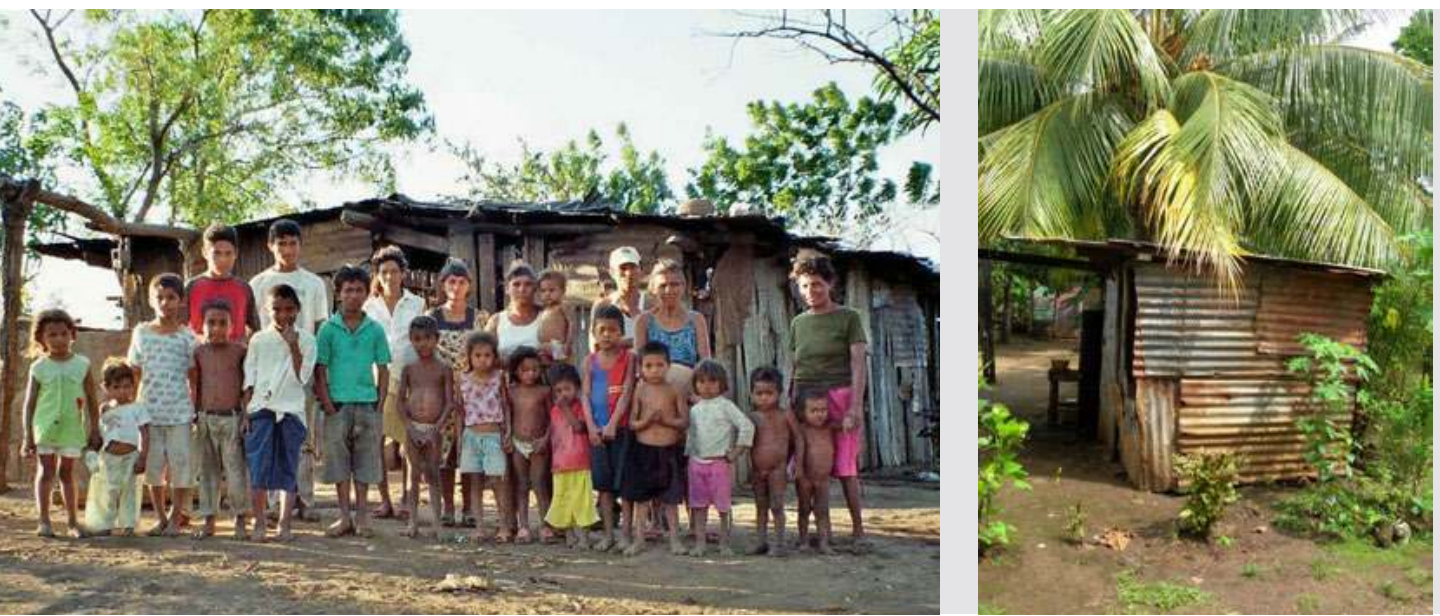

Left:

Figure 7: A family and it's house in Los Cedros, Managua Source: iStock/Robert Picard 2007

Right:

Figure 8: In spite of wide spread poverty, there is no excessive violence in Nicaragua. Source:

istockimages Lic. $834^{\prime} 8446821$

RT0001.

18.

These consejos are led by President Ortega's wife, Rosario Murillo, and should ensure direct democracy at the community level. The opposition critizises these consejos because, essentially, they function vertically, are dominated by the FSLN, and they are a non-pluralistic, parallel political structure.
- a democratically self-organising civil society at the community level (and on the national level);

- and a business sector collaborating with institutions of the security sector.

In summary, the Nicaraguan experience provides conclusive evidence for the validity of the theoretical proposal outlined at the beginning of the paper. The key explanation for the new puzzle of violence in Central America can be found in Nicaragua: although being the poorest country in Central America and without having established either a strong market economy or democracy before, Nicaragua managed to install effective inhibiting structures against criminal violence.

With a relatively well organised civil society in Nicaragua, there is furthermore no "need" for pandillas to provide an alternative or substitute a sense of belonging for the youth without a realistic future, and who would otherwise fall prey to the maras. In the current democratic society configuration of Nicaragua, cooperation and social engagement provides a better alternative to violence-prone adolescents than the short and painful life in a youth gang. While maras in the countries of the "Northern Triangle" the maras present a common nightmare, even the less violent pandillas can offer an attractive alternative to the rewards of a productive and contributing position in civil society.

However, there is no paradise without snakes. in Nicaragua too, the borders between vigilante and democratic social practice is narrow. The controversy surrounding the Consejos del Poder Ciudadano under the Ortega government ${ }^{18}$ illustrates this issue in detail. Yet, it is certainly a democratically-committed civil society that has been predominant.

\section{Conclusions}

The empirical findings largely support the theoretical proposals presented at the beginning. On the whole, the state security sector has not been able to stop the cycle of violence in Honduras, El Salvador, or Guatemala. Different as in Nicaragua and Costa Rica, violence remains a 
constant threat. The empirically most obvious correlation between negative indicators of security such as a bad state performance (i.e. security strategies, police, judiciary, penal system) and a vigilante civil society on the one hand, and on the other hand notoriously high levels of violence (measured in numbers of homicides) can be found in Honduras. Even if El Salvador ranks best among the three northern countries in terms of a functioning police and judiciary, its security performance is worse than in both Southern countries. This finds its explanation in the Salvadoran security strategy, in its reliance on the mano dura-policies, the militarisation of the security sector, the particularly weak cooperation between the police and the less vigilante but inactive civil society. The result is the elevated homicide rates.

Furthermore, democratic engagement of civil society at the community level is low in all of the countries of the "Northern Triangle". Democratic civil society engagement was comparatively strong in Honduras until the coup against Zelaya, but the state security sector was weak and civil society engagement in security issues had to be limited by the lack of support from the state security sector. Salvadoran democratic civil society indicators are weak and also atomised - the local civil society remains democratically inactive there - which coincides with a failed strategy of community policing and exhibits a lesser degree of vigilantism (contrary to Guatemala). Guatemala represents a weaker and less repressive state strategy in terms of mano dura - in comparison to Honduras and El Salvador - but is accompanied by a civil society profoundly entangled with vigilantism. In none of these three countries does a balance of external control exist - neither within the state security sector nor civil society - which would present, according to the theory communicated at the beginning of this work, an inhibiting environment to violence.

In Honduras, El Salvador, and Guatemala, civil society's part in security strategies has to be characterised as vigilante and at least (in El Salvador), democratically inactive. Together with weak state performance, it contributes to deficiencies of external social control. This confirms the above mentioned hypothesis of Peter Wallersteen saying that not alone an under consolidated state but equally an overextended state is marked by control deficits (over the development of crime and violence in this case). This cannot be compensated through excessive repressive control but such an attempt would rather make things worse. Finally, compensating these deficiencies, both parts of the security sector, the state and civil society, produce surpluses of control. Thus, civil society's predominant surplus of external control corresponds to the state's surplus of control. Consequently, well-functioning inhibiting structures are nonexistent and therefore the stream of violence produced by enabling structures cannot be stopped by it, neither in general or at the community level.

In comparison to the three countries of the "Northern Triangle", in Nicaragua and Costa Rica violence is much less predominant as Error: Reference source not found clearly illustrates. In contrast to Nicaragua, however, homicides slightly increased in Costa Rica between 1990 and 2010. It may be true that police performance waned to a certain extent, but this did hardly justify the political reaction expressed by the 
introduction of harsh 'securitization' politics that partly replaced the previous welfare state model. These new politics cannot be justified rationally through the recorded homicide rate in the country, but may be better understood as part of a manoeuvre to by stabilize political power (and in itself generated more violence).

Nicaragua has achieved a good balance of control - despite high susceptibility to violence - through a proactive-preventive security strategy, in which the police and civil society have built a strong relationship with each other.

These comparisons furthermore show that civil society cannot be more efficient in preventing violence than the state and, in particular, the police. This is especially true if civil society disregards the rule of law and intervenes on its own in sanctioning violence. External control balances are not able to do without both components. Moreover, it should be clear that very low as well as exaggerated external social control (excreted by the state and civil society), cause imbalances of control - which is necessary to regulate the reaction of the security apparatus and at the same time to deter potential offenders.

It is evident that the civil society sector tends to resort to self-help justice (vigilantism) if the state fails to provide the needed protection against crime and violence. In the countries of the "Northern Triangle", lacking performances of the state's security sector are evident: the state itself remedies its deficiencies with surpluses of control. The same can be said about civil society as by turning towards vigilantism intents not only to resolve its own control deficiencies but those denied by the state as well.

All points elaborated above, taken together, produce in the countries of the "Northern Triangle" a "double" and therefore extreme external control imbalance. Regarding the state, this imbalance is caused by a number of factors:

a) the lacking conceptualisation of a logical, compact, as well as democratically intended security strategy;

b) the systematic priority of sanctions over (primary) prevention and rehabilitation (sanction thereby is understood merely as physically repressive than oriented towards the rule of law);

c) the militarisation of the police and the penal system (sometimes even the whole security sector);

d) and finally a dysfunctional judiciary system, fully dependent on the other two political powers, all contribute to this imbalance.

Concerning civil society, vigilantism as an expression of self-defence is a consequence of lacking cooperation between the police and civil society at the community level. In no way have surpluses of control were compensating deficiencies of control, neither on the part of the state nor in civil society. In contrast, these deficiencies of control have even been reinforced. These findings are summarized Table 1. 


\begin{tabular}{|c|c|c|c|}
\hline \multirow[b]{2}{*}{$\begin{array}{l}\text { Performance of } \\
\text { the state secu- } \\
\text { rity sector }\end{array}$} & Honduras & El Salvador & Guatemala \\
\hline & $\begin{array}{r}\text { low: control deficit } \\
\text { and surplus }\end{array}$ & $\begin{array}{r}\text { low: control deficit } \\
\text { and surplus }\end{array}$ & $\begin{array}{r}\text { low: control deficit } \\
\text { and surplus }\end{array}$ \\
\hline \multirow{5}{*}{$\begin{array}{l}\text { Performance } \\
\text { of civil society } \\
\text { in the security } \\
\text { sector }\end{array}$} & $\begin{array}{r}\text { control deficit within } \\
\text { the police, judici- } \\
\text { ary, and penitentiary } \\
\text { systems }\end{array}$ & $\begin{array}{r}\text { control deficit spe- } \\
\text { cifically within the } \\
\text { Policía Comunitaria } \\
\text { and penitentiary } \\
\text { system }\end{array}$ & $\begin{array}{l}\text { control deficit spe- } \\
\text { cifically within the } \\
\text { police and judiciary }\end{array}$ \\
\hline & $\begin{array}{r}\text { control surplus } \\
\text { through mano dura } \\
\text { policies }\end{array}$ & $\begin{array}{r}\text { control surplus } \\
\text { through mano dura } \\
\text { policies }\end{array}$ & $\begin{array}{r}\text { control surplus } \\
\text { through (attenuated) } \\
\text { mano dura policies } \\
\end{array}$ \\
\hline & $\begin{array}{r}\text { low: control deficit } \\
\text { and surplus }\end{array}$ & $\begin{array}{r}\text { low: control deficit } \\
\text { and surplus }\end{array}$ & $\begin{array}{r}\text { low: control deficit } \\
\text { and surplus }\end{array}$ \\
\hline & $\begin{array}{l}\text { control deficit due } \\
\text { to the suppression } \\
\text { of a democratically } \\
\text { active civil society }\end{array}$ & $\begin{array}{r}\text { control deficit due } \\
\text { to an inactive civil } \\
\text { society }\end{array}$ & $\begin{array}{l}\text { control deficit due } \\
\text { to the substantial } \\
\text { absence of a demo- } \\
\text { cratic civil society }\end{array}$ \\
\hline & $\begin{array}{r}\text { control surplus } \\
\text { through a vigilante } \\
\text { civil society }\end{array}$ & $\begin{array}{r}\text { control surplus of } \\
\text { the state cannot be } \\
\text { prevented by civil } \\
\text { society }\end{array}$ & $\begin{array}{r}\text { particularly } \\
\text { strong control } \\
\text { surplus through an } \\
\text { extremely vigilante } \\
\text { civil society }\end{array}$ \\
\hline
\end{tabular}

\begin{tabular}{|c|c|c|}
\hline & $\begin{array}{l}\text { Low reality of violence } \\
\text { despite high suscepti- } \\
\text { bility to violence }\end{array}$ & $\begin{array}{l}\text { Low reality of violence } \\
\text { due to low susceptibil- } \\
\text { ity to violence }\end{array}$ \\
\hline \multirow[b]{2}{*}{$\begin{array}{l}\text { Performance of } \\
\text { the state secu- } \\
\text { rity sector }\end{array}$} & Nicaragua & Costa Rica \\
\hline & $\begin{array}{r}\text { high: control balance in police } \\
\text { and penitentiary system (slight } \\
\text { imbalance in the control of the } \\
\text { judiciary) }\end{array}$ & $\begin{array}{r}\text { high: but a little damage to the } \\
\text { control balance by the control } \\
\text { surplus and shortcomings of the } \\
\text { police }\end{array}$ \\
\hline \multirow{3}{*}{$\begin{array}{l}\text { Performance } \\
\text { of civil society } \\
\text { in the security } \\
\text { sector }\end{array}$} & $\begin{array}{r}\text { control balance through proac- } \\
\text { tive and preventive security } \\
\text { policy }\end{array}$ & $\begin{array}{l}\text { slight damage to the control } \\
\text { balance due to conservative } \\
\text { and "securitizing" variant of the } \\
\text { broken-windows theory }\end{array}$ \\
\hline & high; control balance & $\begin{array}{l}\text { medium; control equilibrium, } \\
\text { but with a slight control surplus }\end{array}$ \\
\hline & $\begin{array}{r}\text { control equilibrium through a } \\
\text { democratically engaged (and not } \\
\text { vigilante) civil society }\end{array}$ & $\begin{array}{r}\text { slight damage to the control } \\
\text { balance by a temporarily vigi- } \\
\text { lante civil society }\end{array}$ \\
\hline
\end{tabular}

Table 1: External social control and performance in the security sector. Source: Author's own elaboration. 
- the ongoing democratic experiences of indigenous communities in Guatemala (in the areas populated by indigenous people, the homicide rate is especially low ${ }^{19}$ ) and certain advantages of their customary law, as well as

- (Non-indigenous) municipalities with successful state-led, as well as civil society-led security governance. The examples of Santa Lucía de Cotzumalguapa ${ }^{20}$ in Guatemala and Santa Tecla in El Salvador are cases in point in this regard.

Together with the Nicaraguan model, all these cases share the following features: first, the community level is strong enough and the meaning of "community" has a high status, leading to the second point that particularly local civil society in the security sector is acting on a democratic and non-vigilante basis. Third, therefore, a rather (primary) preventive approach in containing violence prevails.

However, there still exists at least one reservation against relying on this model: in the Nicaraguan case, (primary) prevention is a standalone feature which is not supported by the secondary elements, namely criminal prosecution, deterrence, and protection of victims. This transmits the impression of a police that confines itself to (primary) preventive strategies, hence mutating into a "club of social workers".

The Nicaraguan success story, however, directly or indirectly conceals two important issues:

- the incorrect perspective (as it implies to the dichotomy) on sanctions and (primary) prevention, in the sense that sanctions (founded on the rule of law) are assumed to be less important; but also

- the problematic view that in spaces where violence is already present primary prevention does not make sense.

Both perspectives are obviously wrong, as I showed in detail above. Thereby, and related to development cooperation, essential conclusion can be drawn: Regarding the three countries of the "Northern Triangle", there is a much-needed development cooperation which requires the implementation - besides primary prevention - of sanctions into the security sector within the framework of the rule of law. This becomes even more important as an attempt to strengthen the framework eventually de-legitimises counteracting discourses, which denigrate the rule of law as a "sistema ultra-garantista"21.

The approach by no means simply intents to replace the weak state's part of the security sector by civil society - not only in the case of civil society being prone to vigilantism but also if civil society is democratic in nature. In contrast, this is because security policy always needs both pillars: civil society and the state. Civil society cannot be any better and more democratic in matters of security than the state, and vice versa. As malfunctioning security sectors are currently integral parts of the political reality in Central America's "Northern Triangle", the concept serving to overcome these restrictions has also to be integral and include equally all four components I discussed in this chapter: the police, the judiciary, the penal system, and civil society, particularly at the community level.

20.

In Santa Lucía Cotzumalguapa which once, like Villa Nueva, belonged the Guatemalan municipalities with the highest homicide rates - the mayor managed not only to reduce the previously high rate of violence, but to keep it low. This required close and democratic cooperation with the civil society, in other words, without the favoritism of political affinities, and with respect for local leaders (Live recording 22.03.06).

21.

At the time of the interview, Ulíces del Dios Guzmán, at the time

(14.02.07), magistrate in the Supreme Court in El Salvador, stated that the rule of law would be for delinquents, not for the victims. He and like-minded persons call the present system a "sistema (ultra)garantista" that benefits delinquents and that is based too much on the rule of law.

22.

This originally much more detailed paper has been shortened by the volume editors, which implies a certain degree of simplification. They apologize for any misinterpretations that $>>$ >> may have incurred in the process. For more accurate explanations and precise data please refer to Zinecker (2014). 


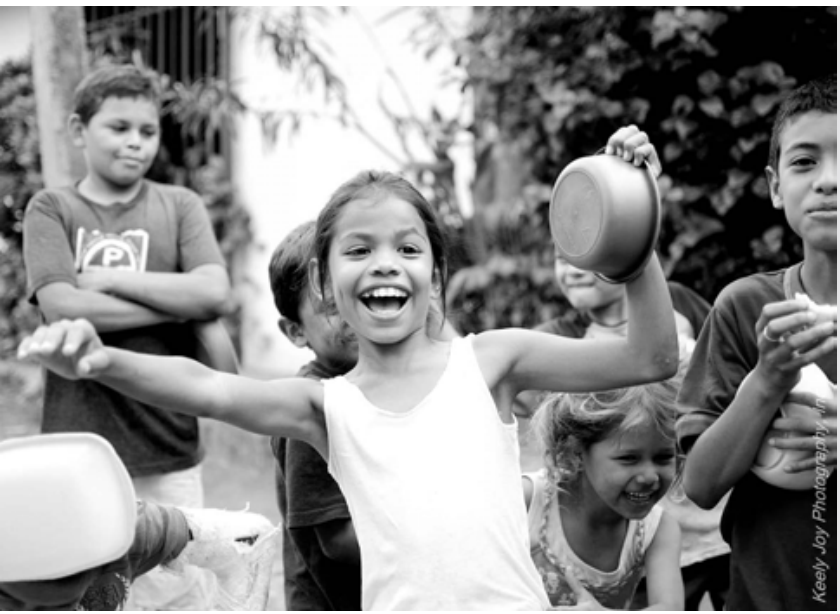

Figure 9:

Girl in Managua.

Source

Wikimedia/Feed

My Starving

Children 2011

This, however, only becomes feasible if not mutual compensation in the security sector is anticipated or expected from the beginning but rather autonomous strengthening of both the state and (local) civil society is likewise realized. ${ }^{22}$

\section{References}

Agnew, Robert (2001): Building on the Foundation of General Strain Theory. Specifying the Types of Strain Most Likely to Lead to Crime and Delinquency. In: Journal of Research in Crime and Delinquency, Vol. 38, No. 4, 319 - 352.

Aguilar, Jeanette (24.02.12): Directora IUDOP, UCA, Interview by the author in El Salvador.

Ampié, Mercedes (11.09.06): Comisionada, Jefa de Comisarías de Mujeres y Niñez, Policía Nacional, Interview by the author in Nicaragua.

Argüello, Deyanira (28.09.06): Viceministra, Ministerio de Gobernación, Interview by the author in Nicaragua.

Argueta, Otto (2010): Private Security in Guatemala. The Pathway to its Proliferation. GIGA Working Papers 144. Hamburg.

Blanco, Lara (17.05.06): Coordinadora de Programas PNUD, Interview by the author in Costa Rica.

Campos Santelices, Armando (2010): Capítulo Costa Rica. In: Campos Santelices, Armando/ Calderón Umaña, Rodolfo (eds.): Gestión municipal de la seguridad ciudadana en Centroamérica y República Dominicana, San José, 1 - 106.

Carballido Gómez, Armando (o. J.): Seguridad pública y privada. Guatemala. OEA/Departamento de Seguridad Pública. 0. 0.

Carranza, Elías (18.05.06): Director Instituto Latinoamericano de la UN para la Prevención del Delito y el Tratamiento de Delincuentes (ILANUD), Interview by the author in Costa Rica.

\section{Cordero Ardila, Edwin/Gurdián Alfaro,} Hamyn/López Hurtado, Emilio (2006):
Alcanzando un sueño. Managua.

Cruz, José Miguel (2007): Factors associated with Juvenile Gangs in Central America. In: Cruz, José Miguel (ed.): Street Gangs in Central America. San Salvador, 13 - 66.

Demoscopía (2007): Maras y Pandillas, comunidad y policía en Centroamérica. Hallazgo de un estudio integral. Guatemala. Washington D. C.

El Heraldo (2014-04-19): http://www.elheraldo.hn/content/view/full/170796 (Last access 10.07.14).

El País (2013-07-11): http://internacional.el pais .com/internacional/2013/0 7/11/ actualidad/1373497088_247693.html (Last access 16.06.13)

Ellingsen, Tanja/Gleditsch, Nils Petter (1997): Democracy and Armed Conflict in the Third World. In: Volden, Ketil/Smith, Dan (eds.): Causes of Conflict in the Third World. Oslo, 69-81.

Emisoras Unidas (2013-06-18): http://www. google.de/imgres?imgurl=http $\% 3 \mathrm{~A} \% 2 \mathrm{~F} \% 2 \mathrm{Fn}$ oticias.emisorasunidas.com $\% 2$ Fsites $\% 2$ Fdef ault $\% 2$ Ffiles $\% 2$ F2013\%2F06\%2F18\%2Fjunt as_locales_de_segridad_foto_tomada_de_publinews.jpg\&imgrefurl=http $\% 3 \mathrm{~A} \% 2 \mathrm{~F} \% 2 \mathrm{Fnotici}$ as.emisorasunidas.com $\% 2 \mathrm{Fnoticias} \% 2 \mathrm{Fnacion}$ ales\%2Fgobernacion-busca-cambiar-caracteristicas-juntas-seguridad $\& \mathrm{~h}=414 \& \mathrm{w}=570 \& \mathrm{tbni}$

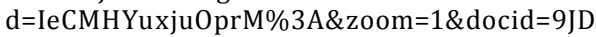
sbqnTwDBwHM\&ei=1222U4zKGfHX7AbM84Gw DQ\&tbm $=$ isch\&iact $=r c \& u a c t=3 \&$ dur $=891 \&$ pa ge $=1 \&$ start $=0 \&$ nd $\mathrm{sp}=18 \&$ ved $=0$ CCUQrQMwAQ (Last access 2014-07-04). 
Espinoza, Ana Yancy (12.05.06): Fundación Arias para la Paz y el Progreso, Humano Oficial de Programas Área de Paz y Seguridad Humana, Interview by the author in Costa Rica.

Flores, Luis Enrique (25.02.12): Director de Planificación y Gestión, Ministerio de Justicia y Seguridad Pública, Interview by the author in El Salvador.

Fox, Sean/Hoelscher, Kristian (2010): The Political Economy of Social Violence: Theory and Evidence from a Cross-Country Study. Working Paper No. 72. LSE. London.

Friedrich-Ebert-Stiftung (2008): Sistematización de experiencias sobre violencia juvenil en Costa Rica: Elaboración de criterios para su evaluación y selección. San José.

Frühling, Hugo (2000): La modernización de la Policía en América Latina. In: Sapoznikow, Jorge/Salazar, Juana/Carrillo, Fernando (eds.): Convivencia y seguridad: un reto a la gobernabilidad. Alcalá, 207 - 238.

Guzmán Canjura, Ulíces del Dios (14.02.07): Magistrado, Corte Suprema, Interview by the author in El Salvador.

Guzmán León, Juany (16.05.06): Coordinadora Académica Regional, FLACSO, Interview by the author in Costa Rica.

Handy, Jim (2004): Chicken Thieves, Witches, and Judges: Vigilante Justice and Customary Law in Guatemala. In: Journal of Latin American Studies, Vol. 36, No. 3, 533 - 561.

Hegre, Håvard /Ellingsen, Tanja/Gates, Scott/Gleditsch, Nils Petter (2005): Toward a Democratic Civil Peace? Democracy, Political Change, and Civil War, 1816 - 1992. In: Diehl, Paul (ed.): War. Library of International Relations. London, 165 - 193.
Henderson, Errol A. (2002): Democracy and War. The End of an Illusion? Boulder.

Hombach, Bernardo (27.09.06): Monseñor, Bischof der Katholischen Kirche, Granada, Interview by the author in Nicaragua.

http://cb24.tv/autoridades-hondurenas-buscan-mas-cuerpos-en-cementerio-clandestino/ (Last access 04.07.14)

http://www.google.de/imgres?imgurl=http $\% 3$ $\mathrm{A} \% 2 \mathrm{~F} \% 2 \mathrm{Fnoticias.emisorasunidas.com} \% 2 \mathrm{Fsite}$ s\%2Fdefault $\% 2$ Ffiles $\% 2$ F $2013 \% 2$ F06 $\% 2$ F $18 \%$ 2Fjuntas_locales_de_segridad_foto_tomada_de_ publinews.jpg\&imgrefurl=http $\% 3 \mathrm{~A} \% 2 \mathrm{~F} \% 2 \mathrm{Fno}$ ticias.emisorasunidas.com\%2Fnoticias\%2Fnac ionales\%2Fgobernacion-busca-cambiar-caracteristicas-juntas-seguridad $\& \mathrm{~h}=414 \& \mathrm{w}=570 \&$ tb nid=IeCMHYuxjuOprM\%3A\&zoom $=1 \&$ docid $=9 \mathrm{~J}$ DsbqnTwDBwHM\&ei=1222U4zKGfHX7AbM84G $w D Q \&$ tbm $=$ isch\&iact $=r c \& u a c t=3 \&$ dur $=891 \&$ pa ge $=1 \&$ start $=0 \&$ ndsp $=18 \&$ ved $=0$ CCUQrQMwAQ (Last access 04.07.14).

Huhn, Sebastian (2011): Kriminalität in Costa Rica. Baden Baden.

Infosur hoy (2012-12-21). Foto: Abigail Hernández López, http://www.google.de/imgres?im gurl=http $\% 3 \mathrm{~A} \% 2 \mathrm{~F} \% 2 \mathrm{Finfosurhoy.com} \% 2 \mathrm{Fs}$ aii\%2Fimages\%2F $2012 \% 2$ F $12 \% 2$ F $21 \% 2 \mathrm{Fph}$ oto1B-800_600.jpg\&imgrefurl=http $\% 3 \mathrm{~A} \% 2$ F\%2Finfosurhoy.com\%2Fes\%2Farticles\%2F saii $\% 2$ Ffeatures $\% 2$ Fmain $\% 2$ F $2012 \% 2$ F $12 \%$ $2 \mathrm{~F} 21 \% 2 \mathrm{Ffeature}-01 \& \mathrm{~h}=600 \& \mathrm{w}=800 \&$ tbnid $=\mathrm{tfWLj} 8 \mathrm{kqg}$ Px $2 \mathrm{rM} \% 3 \mathrm{~A} \& \mathrm{zoom}=1 \&$ docid $=5 \mathrm{P}$ obF9b3RbP3M\&ei=y3a2U9-pOILG7AbW94HQ $\mathrm{AQ} \& \mathrm{tbm}=\mathrm{isch} \& \mathrm{iact}=\mathrm{rc} \& u a c t=3 \& d u r=511 \& \mathrm{pa}$ ge $=1 \&$ start $=0 \&$ ndsp $=17 \&$ ved $=0$ CFAQrQMwEA (Last access 04.07.14).

Insight Crime (2013-05-31): http://es.insight crime.org/noticias-del-dia/tasa-de-homicidios

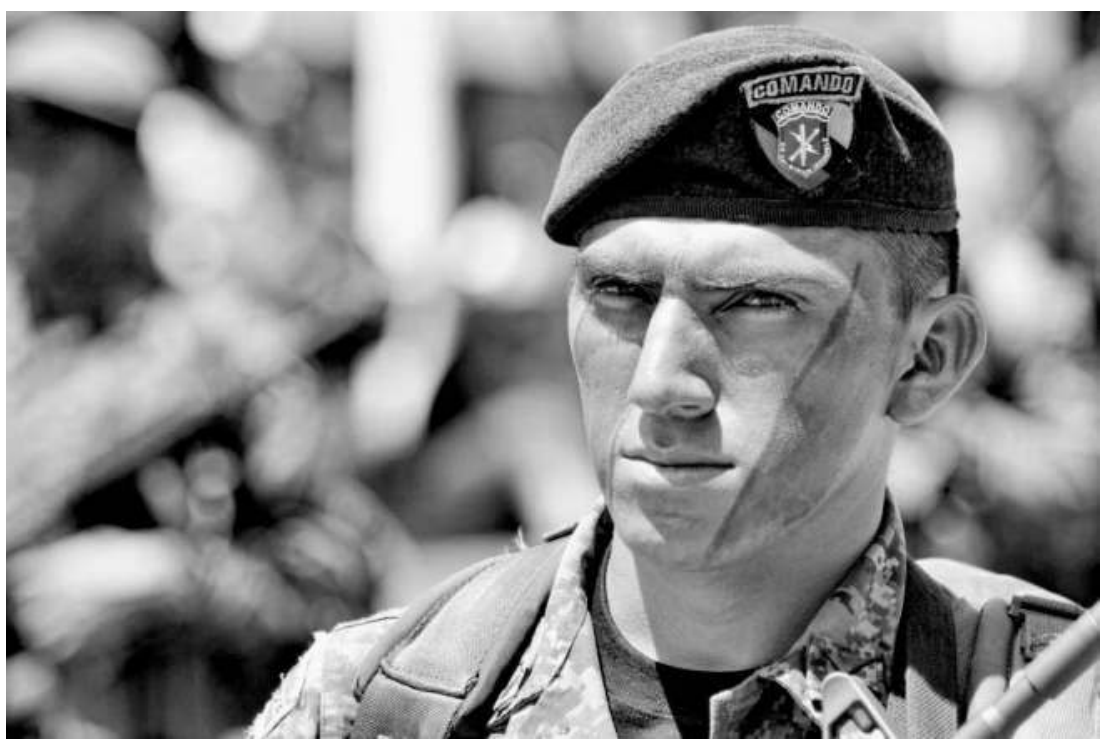

A soldier, with war paint on face, parades along the city streets during the salvadorian independence day celebration, 15-11-2011 in San Salvador. Photo: iStock/ edfuentesg 
-de-nicaragua-cae-a-11-por-cada-100000-habitantes (Last access 20.02.14).

International Crisis Group (2011): Guatemala: Narcotráfico y Violencia. Informe sobre América Latina, No.39, 11 de Octubre. Brüssel.

La Prensa Gráfica (2013-01-24): http://www. laprensagrafica.com/Santa-Tecla-se-incorpora-a-municipios-libres-de-violencia (Last access 19.07.14).

Lagos, Marta/Dammert, Lucía (2012): La seguridad ciudadana. El problema principal de América Latina (Corporación Latinobarómetro). Lima.

Lamnek, Siegfried (2008). Theorien abweichenden Verhaltens II. „Moderne” Ansätze. Paderborn.

Live recording (22.03.06); done by the author, of the meeting of the Comisión de Seguridad Ciudadana in Santa Lucía Cotzumalguapa.

López, Cairo Manuel (25.09.06): Asesor Corte Suprema de Justicia, Interview by the author in Nicaragua.

Loría Ramírez, Max (16.05.2006): Director General de la Escuela Nacional de Policía; later: Viceministro de Paz, Interview by the author in Costa Rica.

Matul, Daniel (18.05.2006): Director de Sub Antena de México y Centroamérica, Fundación para la Paz y Democracia, Interview by the author in Costa Rica.

Mora, Pablo (08.06. 2013). Autoridades hondureñas buscan más cuerpos en cementerio clandestino. CB 24, Noticias CentroAmerica. http:// cb24.tv/autoridades-hondurenas-buscan-mascuerpos-en-cementerio-clandestino/ (Last access 04.07.14).

Nuevo Diario (2013-02-28): http://www.elnuevodiario.com.ni/sucesos/279144-tasa-de-homicidios-costa-rica-disminuyo-14-puntos-2012 (Last access 08.09.13).

Oficina de Derechos Humanos del Arzobispado de Guatemala (2012): Violencia en Guatemala. Una interpretación sobre el aumento de la violencia delincuencial y el trauma psicosocial. Guatemala.

ONU(2012-05-16): http://www.un.org/spanish /News/story.asp? NewsID =23463\#.Ug2vtno7YXk (Last access 16.08.13).

Peetz, Peter (2012): Maras, Medien, Militär: gesellschaftlicher Diskurs und staatliche Politik gegenüber Jugendbanden. Münster.

Prensa Libre (18.12.2012).

Programa Estado de la Nación (2008): Estado de la Nación en Desarrollo Humano Sostenible. San José.

Recording of the Comisión de Seguridad Ciudadana Meeting in Santa Lucía Cotzumalguapa by the author (22.03.06).
Rico, José María/Chinchilla, Laura (2002): Seguridad ciudadana en América Latina. México D.F.

Romero, Ramón (21.02.07): Director de Vinculación Universidad-Sociedad, UNAH, Interview by the author in Honduras.

Savenije, Wim (2010): Persiguiendo Seguridad. Acercamiento de la policía a las comunidades con problemas de inseguridad en Centroamérica. San Salvador.

Serrano Caldera, Alejandro (29.09.06): Director Instituto de Ética, Valores y Desarrollo, Universidad Americana, Interview by the author in Nicaragua.

SICA (2013), cited in: http://elcronistadigital. com/?p=20724 (Last access 16.08.13).

Simon, Jean Marie (1986): Civil Patrols in Guatemala. Americas Watch Report, August. Downloadable under http://papers.ssrn.com/sol3/ papers.cfm?abstract_id=2332787, (Last access 10.07.14).

Suchlicki, Jaime (1972): Sources of Student Violence in Latin America. An Analysis of the Literature. In: Latin American Research Review, Vol. 7, No. 3, $31-46$.

Tittle, Charles (1997): Thoughts Stimulated by Braithwaite's Analysis of Control Balance Theory. In: Theoretical Criminology, Vol. 1, No. 1, $99-110$.

USA (2011): Asocio para el Crecimiento. El Salvador - Estado Unidos. Plan de Accióon Conjunto, 2011 - 2015. http://photos.state.gov/libraries/elsavador/92891/octubre2011/Plan_de_ Accion_Conjunto.pdf. (Last access 30.07.2014)

Wæver, Ole (1995): Securitization and Desecuritization. In: Lipschutz, Ronnie D. (ed.): On security. New York, 46-86.

Wallensteen, Peter (1999): State Failure, Ethnocracy and Armed Conflict: Towards New Conceptions of Governance, Paper presented at the conference "Failed Sates and International Security II: Sources of Prevention, Modes of Response, and Conditions of State Success and Renewal", Purdue University, West Lafayette, April 8-11, 1999: http://www.comm.ucsb.edu/ faculty/mstohl/failed_states/1999/papers/ Wallensteen.html (Last access 30.06.14).

Zinecker, Heidrun (2011): Civil Society in Developing Countries - Conceptual Considerations. In: Journal of Conflictology, Vol. 2, No. 1, 25 - 42.

Zinecker, Heidrun (2012): Gewaltarmut in Nicaragua - Mythos oder Realität? Empirische Befunde, Kausalitäten und Lehren. HSFK-Report, No. 5. Frankfurt a. M.

Zinecker, Heidrun (forthcoming): Gewalt im Frieden. Formen und Ursachen der Gewaltkriminalität in Zentralamerika. Baden Baden (Nomos). 


\title{
Meanings and Practices of Non-violence Lessons learned in the midst of the urban war in Comuna 13, Medellín
}

\author{
Luz Amparo Sánchez Medina
}

The name Comuna, or 'district' in English, is defined as an administrative unit of a middle or large sized city, in which determined sectors or neighborhoods are grouped.

02 .

In 2011 and 2012 District 13 appeared in the top 3 districts most affected by these crimes, according to the source Medellin How Are We

Doing www.del-

lincomovamos. org/seguridad-yconvivencia (Consulted 27th of June 2014)

Previous page: Artist Marlon, "DJ Maya", belonging to the group Kolacho in District 13, Medellin. Photo: Silvia Matuk
In Medellin, Colombia, some districts ${ }^{1}$ and neighbourhoods have become known throughout the city because of the massive occurrence of violence and its actors who exercise control over the territories. This is the case in Comuna 13, known as San Javier. While almost unknown before 2000, it gained international attention around the year 2002, because of the daily confrontations between illegal armed groups and governmental security forces. Its inhabitants remember this period under the label "the true war". In the years following the war, the homicides, threats, and forced displacement of the territory's population ${ }^{2}$ did not stop.

Today, despite the continued presence of illegal armed groups in the territory violence has not stopped completely. However, at the same time Comuna 13 has also turned into a local and national reference point for active non-violence; multiple memorial initiatives have been realized and the community has likewise achieved a form of resistance against social exclusion and the war. Now, the district's most visible personalities are no longer the ones which cause trouble and not every young person is automatically suspected to belong to one of the gangs who are responsible for the majority of homicides. The population, particularly the direct and indirect victims, has developed alternative concepts of life in the Comuna; they run their own media which publicly exposes alternative values and practices in response to the war and authoritarian ruling.

Even in the most intense moments of confrontation between armed actors (in the period 2000-2002), Comuna 13's population responded peacefully to the conflict's authoritarianism and control over life and death. These actions are little known by the public; they were not in the focus of the reporters' cameras, nor were they covered in the interviews diffused through the media day by day.

This paper exposes a collection of non-violent initiatives and practices, memories of the conflict's suffering and social exclusion, and lessons 
learned. These all are related to space and are the basis for the re-appropriation of the meaning of neighbourhood that the war had stolen. Places that had previously carried the image of terror and death are gaining a new meaning through the reflection of the past and the construction of a culture of peace.

\section{Past models}

Different interdisciplinary studies ${ }^{3}$ have been dedicated to the peace initiatives in Medellin's Comuna13. These initiatives show how the population, in creative and at times dangerous ways, managed to recuperate and intervene in said spaces. The report on forced displacement in Comuna 13, recalls:

"in the face of violence and the control of social life by the militias, guerrillas, paramilitaries, and the public forces, Comuna 13's residents responded both directly and indirectly with actions of creative adaptation, with negotiation, and resistance". ${ }^{4}$

Through artistic and recreational practice, through sports, and marches, the population declared "no to violence"; they formed social networks, organizations, and initiatives that allowed new forms of relationships, and avoided the involvement of children and young people in the dynamics of gang warfare. Togetherness was an antidote against fear. These initiatives, at times spectacular and dangerous, generated a feeling of "being together." "Togetherness" continues to work in order to facilitate the construction of a future free from fear. ${ }^{5}$ It is based on a shared trajectory of the population, which invaded the high slopes at the beginning of the 1980 's, and, in a process that took years, made them habitable. This experience, which enjoyed the support of local and international organizations, played an important role in the containment of the war and taught lessons of non-violence and defence of human rights and freedoms.

"The violence lived by the community for a prolonged time, caused a reconfiguration of identity, favoured by processes of reflection on suffering. Non-violent discourses, practices, and cultural transformation were supported, which indicates [that] 'the population's responses to situations of violence and subjugation [did] not stop at mere survival or in passive acceptance'”' (Sánchez, 2011:205).

\section{Comuna 13: emblematic case of urban war}

In Colombia, the name "Comuna 13 of Medellin" was and still is almost synonymous with urban warfare. It stands for a territory where bandits held hegemonic power for over a decade, the most representative being the People's Armed Commandos (CAP). Later it became the battlefield in a dispute between CAP and the guerrilla, and their joint confrontation with the paramilitary incursion (1998-2002).

Subsequently, Comuna 13 was the epicentre of large-scale armed interventions by the paramilitaries, who worked hand in hand with the police and the army to gain control over this Comuna. In 2002, eleven military

03

See: Angarita Canas (2008), Nieto $(2009) 38-$ 59. Sánchez et al 2011, Luz Amparo, Villa, Marta, Inés, Riaño, Pilar (reporters). 2011.

04.

The report on forced displacement in District 13 , was published by the National Centre of Historic Memory (Sánchez, 2011:205)

05.

Throughout the work "The Fear in the West", Jean Delumeau, presents the fears and the social responses that range from spontaneous defensive riots to organized workers' movements. 
operations were carried out. The biggest offensive action against the insurgency was the "Operation Orion", which became famous for having been the biggest military action ever in an urban territory in Colombia. It involved 1,500 soldiers; more than 150 raids were carried out; 355 people were captured, of which 82 were charged. The use of large range weapons, tanks, and fight helicopters created a climate of terror and distress amongst the population, which lost all their personal belongings once they fled and their homes were destroyed.

"The militias and guerrillas maintained positions in trenches constructed around 20 residences, abandoned by the civilian population... In the midst of the confrontations one civilian was killed; 38 more were injured and 8 'disappeared' after being caught by the National Army, paramilitaries, and members of the Technical Investigative Body (CTI)" (Sánchez, 2011 80-81).

The period following Operation Orion (2004-2008), was one of silent action. The paramilitaries repositioned themselves without the need to use firearms, resorting to new and more discrete techniques of victimization such as forced displacement.

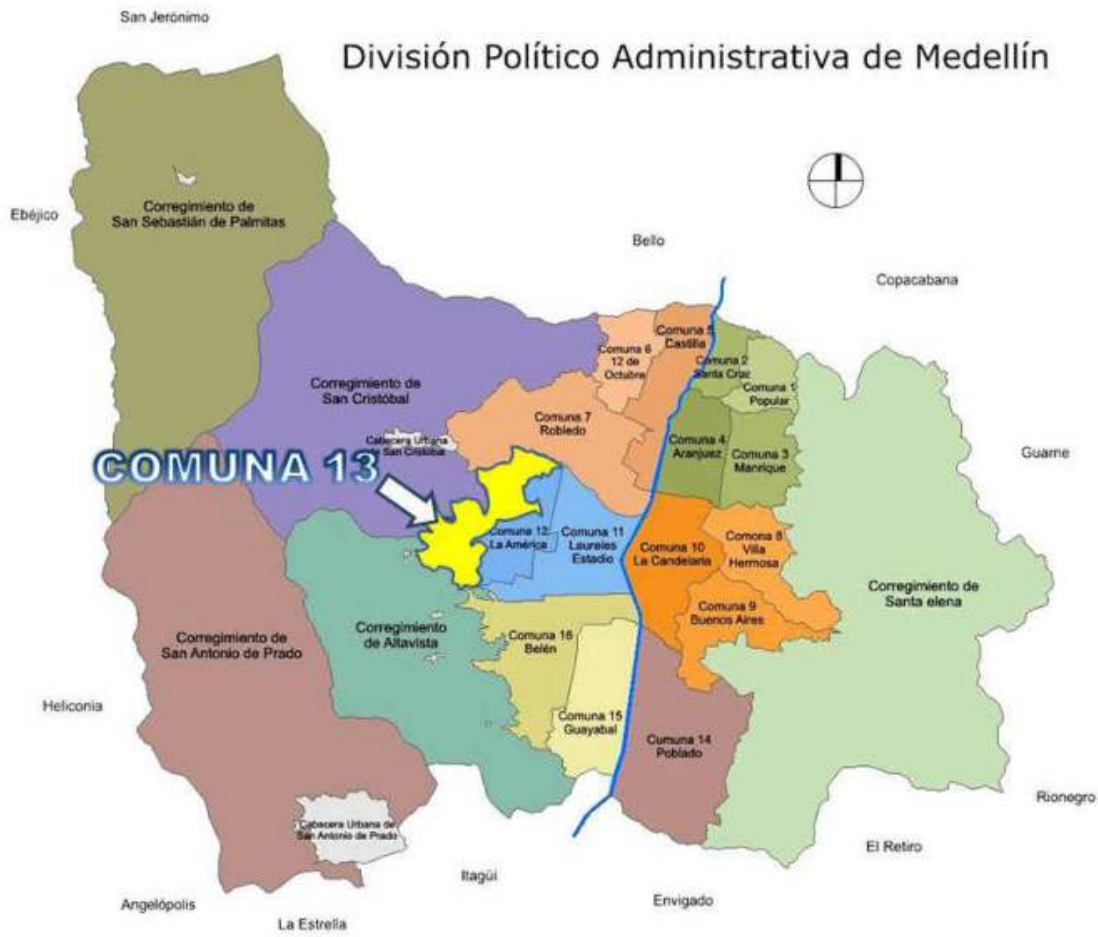

Administratively, Comuna 13 is conformed of 19 neighbourhoods. It shelters older poor neighbourhoods on squatted land next to private residences. Since the 1990s, the Comuna was flooded by displaced people fleeing the armed conflict in rural areas. At the same time, Comuna 13 was the destination with the highest rate of intra-urban displacement of residents forced to flee other parts of the city. 

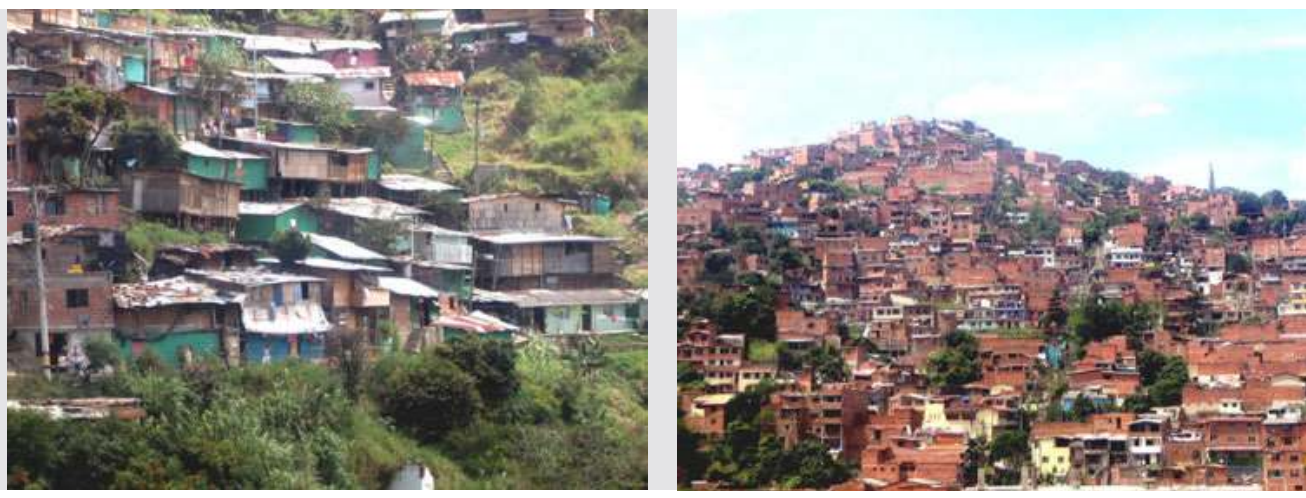

"This consolidation and legitimization of the paramilitary project [subscribed] to the logic of redefining territory in the service of processes for the accumulation of capital on a local and global scale. This went hand in hand with the local political aim to gain control of the urban population and the establishing of a criminal monopoly ... based on the hegemony of paramilitaries in poor districts" (Nieto, 2009:44).

Unlike most other urban communities, Comuna 13 in Medellin exposed a convergence of various authoritarian micro powers of local and national character. They included, among others, the urban militias, criminal gangs known as the BACRIM (illegal groups with paramilitary roots, which control the micro-traffic of weapons and drugs in the poor neighbourhoods), and surviving factions of urban guerrilla cells of the FARC-EP and the ELN. Every one of these players claimed control over part of the territory, which in the day-to-day life of inhabitants, meant the parallel existence of different codes of conduct and rules for mobility within the same neighbourhood. Any breach of the norms imposed by the dominant armed group in their respective zone, like a young man wearing long hair, tattoos or moving from one sector to another at certain hours of the day, could result in death, forced "disappearance", or, in the best case, threats and forced displacement of the offender and his or her family.

As well as the arbitrary use of power, illegal groups extorted invented taxes from shopkeepers, businessmen, drivers, or just passersby. The fights linked to drugs trafficking were another layer of violence superimposing itself on the territorial disputes. The subsequent cycles of violence in Comuna 13 also displayed parallel characteristics:

"In Comuna 13's armed conflict, there are three specific elements that return each time in the form of a repetitive cycle: excess; the installation of a player that resolves the excess and establishes hegemony; then, the rise of new excess and the establishment of a new actor. One of the elements that explain the cycle's repetition of violence is the security/ insecurity axis. The search for security is, paradoxically, interwoven with positions that stimulate violence. For example, the legitimization of an armed actor capable of installing an order of a hegemonic character- that is not how democratic freedoms are respected" (Angarita, P. Jimenez, B. et al., 2007: 260). 

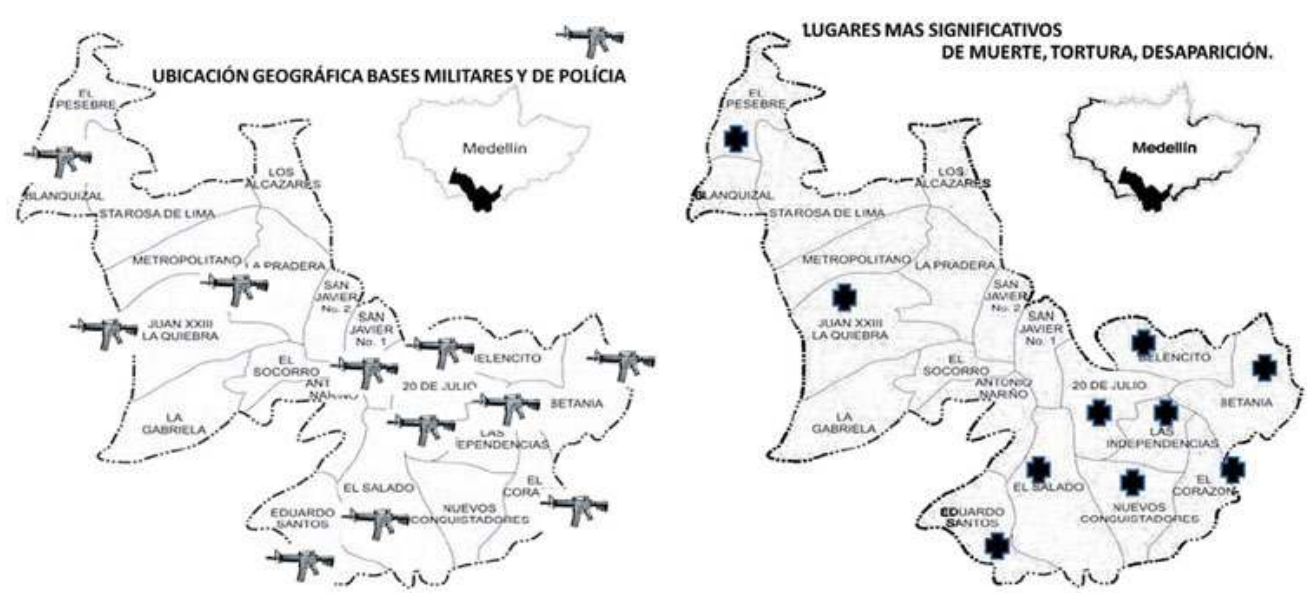

Left:

Bases occupied by police guards and improvised military barracks in the early $2000 \mathrm{~s}$

Right: Places known for frequent killings, torture and the disappearance of people

Maps by Andrés Medina
"The successive disputes for territories and sovereignties are also extending over the civil population, which, along with territory, has become the main and central object of the war. This develops accordingly, as a situation from which the alternating actors impose conflicting orders on the city (either against the state or as a 'para-state')... In this way, the imposition of said orders permits the demarcation of micro-territories and the imposition of an authoritarian (and in many cases totalitarian) control over all facets of the population's everyday life. [This is achieved] through a confuse system of codes and penalizations in which personal and collective freedoms are suspended and replaces by the unpredictable mood ... and the requirements of the group controlling the respective zone." (Nieto, 2009: 44-45).

It is not difficult to imagine the risks that the population underwent while living in the territory under the control of various armed actors at the same time. Even just giving in would not deliver safety in return. In a situation where one does not have anything left to loose, the population created multiple forms of resistance in defence of their rights, the recovery of public spaces, and the conservation of social fabric. In addition, especially since 2003 , the uselessness of war, and permanent threat to life and belongings, had become evident to everyone. Angarita's study, previously referenced, reflects:

"Those who decide to sign on to the immediate benefits of the conflict are faced with an ethical ambiguity that consists in tolerating or supporting acts such as the 'social cleansing', or ridicule through the beating of abusive men, unfaithful women, or youth gone astray, carried out by the delinquents that made up the Comuna's first gangs" (Angarita, P., 2007: 266).

\section{Community responses to the war in the barrios}

The testimonies of collective response to violence in Comuna 13, presented below, stretch across different periods; some have been realized only once and others are repeated regularly, as is the case with the 
memorial weeks or festivals that are convened annually. Some of the initiatives are ongoing while others are a new cooperation between institution and recently created networks. However, the unifying element is the focus and principle of non-violence in Comuna 13, like the one expressed in the following quotation:

"Create a local political culture tied to the protection of life, that confronts those who are violent and the armed conflict and that will democratize public spaces (the streets, parks, alleys, stairways), recovering them for public use and the free movement of all of the population. One adopts the principle of non-violence through a supporting attitude, conscientious objection, and avoidance of collaboration with those who are armed. It implies the autonomy of community action, the promotion of the ethic values of co-existence and respect for differences" (Alzate, 2012:438).

Over several decades, a shift in focus can be observed: in the beginning, physical accommodation and the ability to make the zone more habitable was the dominating common interest. Most of the Comuna was officially classified as inhabitable high risk and zone and not for residential use (in the 1980s and 1990s). After that, especially in the new millennium, the emphasis shifted to social values, like inclusion and democratization of the territory.

\section{Immediate responses: collective action against violence in the midst of the war}

In the most intense moments of the war, community responses were directed to negotiating a ceasefire between the armed groups in order to save lives. The best -known case was the "White Handkerchief March" which arose spontaneously during the military's Operation Mariscal, on the 21st of May, 2002.

"On this occasion a multitude of people waved white handkerchiefs from their windows or went out to the street waving them to demand a ceasefire. The response was triggered by the impossibility to help relatives or neighbours, wounded in the fights, because of ongoing crossfire. When two civilians were hurt and no one was able to help them, a girl stopped in the street waving a white sheet and asking that the gunfire stopped.... Many of the inhabitants' stories coincide in reporting that right after that incident a mass movement of people started waving white sheets from their windows or out in the street" (Sánchez, 2011:209-210).

The collective street presence was the only way to impress and confuse the armed groups that were fighting. "Togetherness", a human response to fear-guided the community's heroic action in favour of life and solidarity. In Comuna 13, diverse manifestations of that kind occurred, to protest against confinement, death, the denial of collective life (resulting from the armed actors' control), and, as in the case described above, actions to save the lives of wounded neighbours.

The occupation and collective use of public spaces at night was another strategy to keep the gangs away, at least temporarily. Some of these 
actions were associated with sports like football matches, which proved to be effective in keeping the control over public space in the hands of residents. Furthermore, such activities served as a pretext for nocturnal movement, meetings, and medical assistance to wounded community members.

\section{"In the 13, violence will not destroy us"}

In the face of large scale military operations, a coordinated collective action developed under the slogan "In the 13 , violence will not destroy us." This action was started by a hip hop group, and can be described as non-violence activism and was a spontaneous and communicative counter action to confront the Comuna 13's military operations. 'Opera-

06.

www.cuentala13.org

07.

In order to recover memory and denounce the conflict, different forms of media have been used including the website www.cuenta-

la13.org, the live radio program on www.morada.co, and social networks such as Twitter (@cuentala13) Flickr, YouTube and Face book (which use the same name) tion Elite Hip Hop' was carried out 4 months after the Operation Mariscal and 24 days before Operation Orion. Subsequently, after 2004, the festival took the name Revolution without Deaths, and continues to be celebrated regularly today.

This action and other similar actions call for active nonviolence, denouncing crime and the reclamation of justice through marches, sitins, performances, festivals, and a range of other symbolic acts.

\section{Long term responses: Nonviolent meanings and practices for cultural transformation.}

Since 2003, barrio leaders and organizations have joined forces in promotion of community initiatives for local development. Since 2010, nine organizations have been known for their more or less continuous activities over those years.

"They prepare peace initiatives with the objective of reconstructing social relationships in the neighbourhood and the quality of everyday life. Most of them display a cultural and artistic orientation ('the clean façade') and the promoters tend to be young people from the neighbourhood" (Sánchez, 2011:217).

These initiatives are started by women or by men, whereby the womenled movements more specifically tend to address topics of resistance and the memory around injustice and suffering. In 2010, the following collective initiatives emerged in Comuna 13: "Cooperative Games for NonViolence;" Jughandi, Corpades, "Caravan for Life", "Making dreams come true", "Salt and Light Corporation", "Express Art Cultural Network", "Association of Women of Independence-AMI", "Elite Hip Hop" and "We are Batá". Further groups have evolved since then. Examples include the following:

The 13 Talks (Cuenta la 13) ${ }^{6}$ : Initiated in 2009 and led by Comuna 13's young people, this was a self-administered website, social network, and radio program where children, young people, and women could take ownership of digital narratives to tell ${ }^{7}$ stories using photos, audio, text, and videos, about the "day to day life" of the conflict. The reporting community - accompanied by journalists- documented their frequently difficult reality, culture, acts of resistance, and bravery, as 

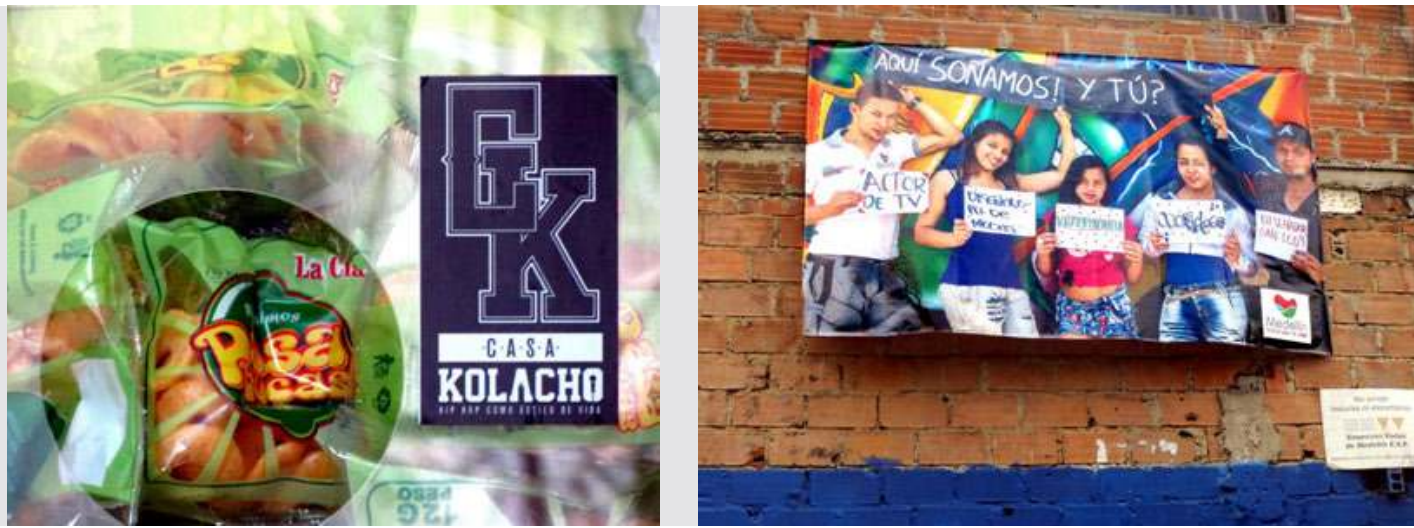

well as the daily violence which they were subjected to by the drug tracking gangs, paramilitaries, and the security forces. In the interviews done over the years, Comuna 13's direct and indirect victims repeatedly identified stigmatization as a collective harm caused in part by the media's portrayal. After some years, they founded and consolidated collectives such as "The 13 Talks", dedicated to telling their own versions of what has happened: essentially, an insider's Left:

Casa Kolacho Group. Photo: Kosta Mathéy

Right:

We are Bata

Corporation /

Corporación Son narrative.

For a long time this group is committed to prevent the forced recruitment of children or young people by gangs and do so through providing alternative perspectives through schools for artistic training. Similar groups include, among others, the collectives: Kolacho House, We are Bata Corporation, and the Culture is Art Corporation.

Kolacho House (Casa Kolacho) is a Comuna 13 youth collective. It was initiated in 2013 as a way of keeping the memory of Héctor Enrique Pacheco Marmolejo -KOLACHO- alive. Kolacho was a member of the hip hop group C15 and was assassinated in 2009 near his residence. It is for this reason that these young people come together around art as a strategy for memory, using music and graffiti as tools to claim their rights, denounce violence, and the generate spaces for the training of young women and men. In Comuna 13, the school, Hip Hop Kolacho, and the graffiti-tour, (a series of graffiti on the Comuna's walls that

Posters of the group Cuenta la 13
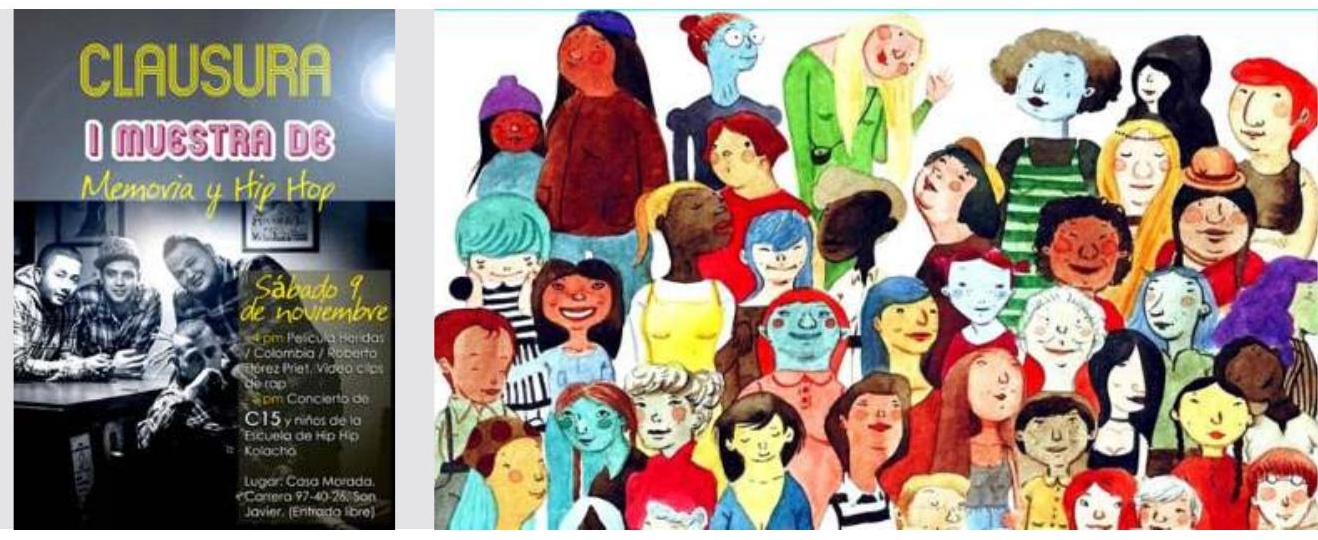
demonstrate the feelings of young people) serve to express their commitment to non-violence and their fight for social and cultural rights, as well as for the memory of the conflict's victims.

We are Bata Corporation, (Corporación Son Bata): Operating for more than ten years now, the corporation became particularly known in 2010, because of the assassination of one of its members. The group engages in community art and culture programs; works against the recruitment of children and young people by armed groups; and against social or racial exclusion - which is especially experienced by the Afro-Colombian community, which has mostly been displaced from the coastal region in result of the armed conflict there.

Culture is Art Corporation (Corporación Culturizzarte) was initiated in 2009 by a group of art professionals. The offer artistic education aimed at the creation of a new mentality and respect for human beings. The group also aims towards the construction of a historic memory and artistic training from a non-violence focus.

\section{The political dimension of suffering- memory and resistance}

State led security efforts tend to mostly be concerned with detecting and catching the perpetrator of a criminal or violent act, and maybe deliver him or her to the system of justice. They do not perceive it their mandate to take care of the victim, who is often left on his/her own, with bodily or psychological injuries, many times for years. In Comuna 13, several victims' support organizations, sometimes self-help initiatives, fill that gap as much as possible. They directly offer counselling to victims, share their pain and loss and help individuals to reconfigure their identities.

The following initiatives are mostly led by women and young people who collectively have reflected on their suffering, passing from memory to reflection and eventually claiming their rights. They have generated physical and mental spaces for reflection, for mourning, and for the construction of victims' own testimonies about what happened and for the denouncement of social exclusion.

"The Dump" is an open deposit for waste and rubbish, located in one of the high parts of District 13's hills. According to witnesses, the bodies of approximately 150 "disappeared" individuals can be found there, people that it is assumed were killed or that have been moved from other places in the city to be buried there. Currently, local authorities are exhuming the premises.
"Memory Room" - Women walking for the truth, (Salón de Ia Memoria - Mujeres Caminando por la Verdad). The organization was founded in 2010 by women from Comuna 13 who witnessed the forced "disappearance" of relatives. Their work centred on the search for their missing family member as well as a battle for turning the "The Dump" ${ }^{\prime}$ into a memorial monument for being a place where bodies of family members could possibly be found.

I am Comuna 13, (Soy Comuna 13). This group was founded in 2012, with the slogan "Where Memory and Life Unite." They fight the concealment of human rights violations in Comuna 13, especially since Operation Orion (2002). They further stand for the demilitarization of their residential territories, call for justice for the disappeared, and petition for providing of adequate conditions allowing the displaced population to return home. They denounce human rights violations 
at the local, national, and international levels. At the same time, they extend their solidarity to the various community organizations in Comuna 13.

Convergence: Comuna 13's Committee Actions of Memory (Convergencia: Comité de Acciones de Memoria de la Comuna 13). This is a joint initiative uniting several organizations in Comuna 13 and other parts of the city with the objective to promote the construction of memory. Examples of their work include memory murals in several of the Comuna's open spaces or the organization of the yearly conference on "Peace, Memory, and Non-violence in Comuna 13" to commemorate victims from the military operations Mariscal and Orion.

Women for Independence Association (AMI), (Asociación Mujeres de las Independencias). This organization, founded at the end of the 1990s, witnessed the persecution, detention, and the forced displacement of some of its leaders. Since 2003, AMI broadened its objectives by including the defence and promotion of human rights, education with a gender based focus, and the narration and production of historical memories (community memories) of victims of the armed conflict and civil resistance.

Revolution without Deaths Festival, (Festival Revolución sin Muertos). This yearly festival is an initiative of the Hip Hop Elite Network that was initiated in 2004 as an expression of resistance to the armed conflict. Furthermore, in recent years the festival has also led an initiative for the construction of memory and non-violence, which made the festival one of the most important music events at the local and national levels. The festival takes place in Comuna 13 as part of the "Peace, Memory and Non-violence Conferences".

\section{Repossession of public space by the community}

Movements for the recovery of public space aim to establish the safe, public, and free use of territory, which have been, or continue to be, controlled by armed actors.

"Because limits are not borders", ("Porque los límites no son fronteras"). As part of the conference "Peace, Memory and Non-Violence" in October 2008, a march was organized bearing the slogan "Because limits are not borders."

"[The march] began in the sector Cuatro Esquinas and went towards the football field in the El Salado neighbourhood. The route was chosen in order to "unmark" the stamp of violence on the territory, which at that time was clearly controlled by opposite armed groups. This [was] a direct action of reclaiming the right to life and territory that [could] only be carried out collectively because crossing a border from one neighbourhood to another [represented] a risk to someone's life (suspicion of passing on information ABOUT the rival gangs operations)" (Sánchez, 2011: 217-218) 
09

Ortiz, 2013

http://www.el-

colombiano.

com/Banco/nocimiento/C/13/ comuna_13_territorio_de_artistas

Photo:

Kosta Mathéy
Left: Beautification of Comuna 13 initiated by the municipality of Medellin to impress visitors of the World Urban

Foum in 2014.

Right: Memory walk organized by an initiative of Comuna 13
"Corners We are Bata", ("Esquinas Son Batá"). A member of the initiative We Are Bata recounts how the initiative was born:

"We got a map of Comuna 13, we identified the points that were most violence took place due to the lack of institutional presence, and we strategically occupied these place with group manifestations - like the result was a flash gathering with a percussion performance in front of the San Javier metro station and various similar ones in representative points for the neighbourhood which we named We Are Bata Corners" 9

Giving new meaning to the territory necessarily implies localizing our action. Street corners are intersections of pedestrian movement where gatherings for solidarity or for the control of armed actors are most effective.

Sustainable life gardens. The collective "Agro-Art - Seeds of the Future" is a youth organization. Since 2010, they promote the defence of human rights under the name "gardens of resistance and memory". During their activities violent acts are denounced and victims of the conflict were defended. From its beginning, this organization attracted young people from the Comuna's different neighbourhoods through music, graffiti, agro-ecology, and art and communicating the meaning of a culture of peace and non-violence.

The Memory Room. This initiative, previously outlined as a political movement against forced disappearance, also is a physical space for mourning, collective memory, and actions oriented to the search for truth and justice. It constitutes one more point in the geography of memory and resistance to the war and violence.

The Graffiti-tour is defined as a walk that allows young people to express their vision of how they want things to be and to promote changes in society through the graffiti on the Comuna's walls. This youth initiative has aesthetic, historic, and political interests and contributes to the creation of a new geography in the Comuna through

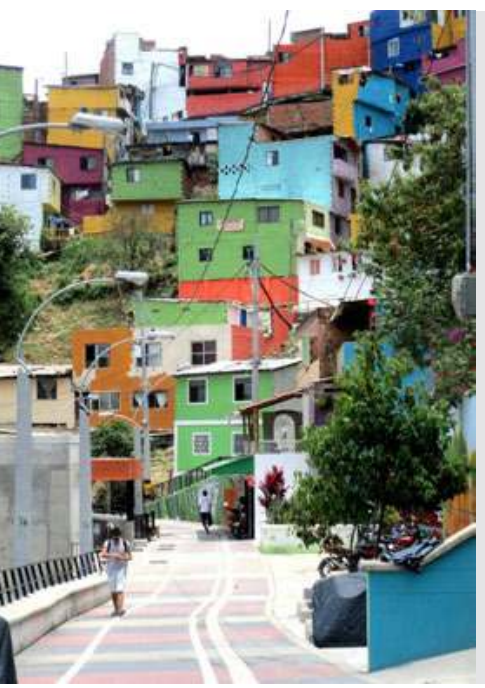

\section{VIGILIA EN MEMORIA DE LAS VICTIMAS DE DESAPARICIÓN FORZADA EN LA COMUNA TRECE.}

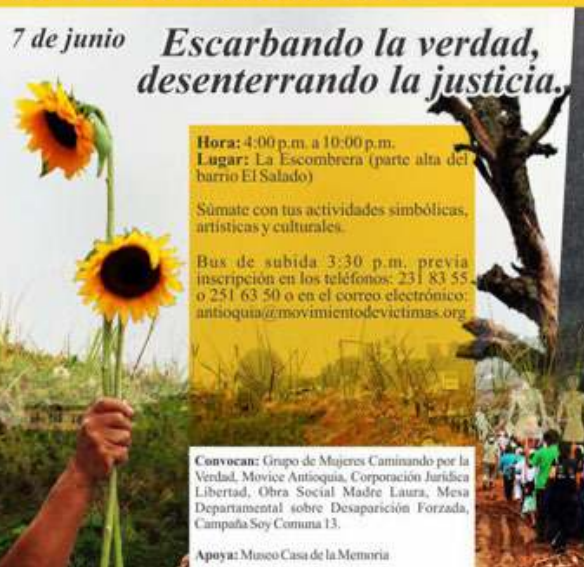

IN MEMORIAM

A las victimas de desaparición forzada de la comuna 13 de Medellín a manos del

Bloque Cacique Nutibara.

Para no olvidar. para no blvidarlas.

Tribunal Supeffior de Medelitin

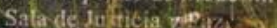

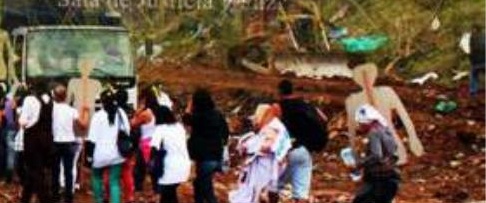


day-to-day interventions in its spaces. One of the graffiti reads "Orion Never Again".

"The walls, the microphone, represent different ways of telling stories that transmit a political message, which at times is of anger, but also one of hope. They tell all the sad stories, which are the most publicized, but also others which are less known; stories of joy and love, of which they have created quite a few." (Viajer0el. 2013)

\section{Precedents to non-violent discourses and actions}

Young people and women, through their organizations and community expressions, generate of their own new culture. The effectiveness of collective action is based on the tradition of neighbourhood self-management as well as creativity and cultural imagination; it can be interpreted as the key to civil resistance. A relationship of trust and solidarity was generated through the networking of locally based social organizations, as well as through the emergence of new social actors defending freedom of expression, neighbourhood autonomy, and the withdrawal of armed actors from the territory.

\section{Lessons learned}

While the results of each of Comuna 13's collective actions are singular, locally focused, and at times ambiguous, they share a significant potential of weakening, and even overcoming, what were once considered impenetrable patterns of domination. Although the social mobilization has not succeeded in transforming the violent situation in Comuna 13 altogether, it has opened spaces for communication and concrete strategies to peacefully confront the warlike activities that are still going on. These initiatives have resulted in the formalization of unplanned settlements initially born by the needs of displaced persons. They managed to mobilize political support for the recognition and defence of the residents' civil and political rights up to a point where the municipality began to built public housing schemes, improved access and even public transport (through escalators and cable cars) to the remote neighbourhoods in the hills and engaged young artists from the Comuna 13 community in the beautification of their formerly illegal settlement on the occasion of the World Urban Forum in 2014.

Artistic interventions and cultural protests have proven to be a peaceful approach to manage daily life in a warlike environment, maintain citywide public attention and overcoming social stigmatization. Furthermore, joining forces in community work and co-operation in social networks are effective means to create collective memory, expose truth, and demand justice. A local leader expressed it like this:

"After the conflict, an important change took place in the Comuna in terms of participation. It was born through the need to come together, form spaces where strengths can unite, and to begin to plan concrete action, like the Comuna 13 development plan. The cultural youth organizations 'Corapaz', 'Realizadores' and 'Salt and Light' led the process. In 
2003, the three organizations sat down and thought about the process of uniting the community. In 2004, the development plan was initiated, but the conflict continued. Nevertheless, the process allowed people to react and generate changes. The work that Comuna 13's organizations carried out formed part of the resistance. Being a peaceful movement cannot mean direct confrontation in the conflict, but we are showing to the city that Comuna 13 is not how they are used to perceive it" (Líder 5, 2007. Cited by Alzate, 2012:445).

The disillusionment created by the government made the people question the way they have acted in the past, evaluate their role in the conflict, and adopt a position of confronting the difficulties without violence" (Angarita, P. Jiménez, B. and others, 2007: 266).

\section{References}

Alzate, Mary Luz. (2012) Collective actions in the face of the violence. Disquisition based on a case study. Comuna 13, (Colombia). http://www. scielo.br/pdf/op/v18n2/a08v18n2 (Consulted 25th of June, 2014)

Angarita, Pablo Emilio; Gallo, Héctor; Jiménez, Blanca Inés (editors). (2008) The Dynamics of War and Construction of Peace. Interdisciplinary study of Medellin's armed conflict in Comuna 13. Antioquia University, Medellin University, Corporacion Region.

Nieto, Jaime (2009) Unarmed civil resistance in Medellin. The voice and the escape of urban communities. In Political Analysis Number 67. Bogota, September December, 2009. Pgs 38-59.
Ortiz, F. Juan David (2013) Comuna 13. Territory of artists. http://www.elcolombiano.com/ Banco/Conocimiento/C/13/comuna_13_territorio_de_artistas. (Consulted 26th of June, 2014

Sánchez, Luz Amparo; Villa, Marta Inés; Riaño, Pilar (reporters). (2011) The invisible trace of the war. Forced displacement in Comuna 13. Report, National Center of Historic Memory. CNRR. Edition week, Bogota.

Viajer0el (2013) Revolution without deaths: School of Hip Hop Kolacho. http://www. viajer0el.com/2013/12/08/revolucion-sin-muertesescuela-de-hip-hop-kolacho/ (Consulted 3rd of July, 2014) 


\section{Integrated Urban Upgrading and Violence Prevention in San Salvador Results of an Impact Evaluation}

Joanna Kotowski, SUM Consult

\section{Background and context}

01.

There are more than 1 million expatriates, mainly identified by their remittances

02.

CIA: The World Factbook 2014. Data for 2009
El Salvador is the smallest country in Central America, with an area of $21,041 \mathrm{~km}^{2}$ and a population of 6.3 million. Population density is very high, with 291 inhabitants per $\mathrm{km}^{2}$; in the metropolitan area of the capital city, San Salvador, it can reach more than 2,000 people per $\mathrm{km}^{2}$.

El Salvador is one of the most violent countries in the world. There are various reasons for this particular situation, which collectively produce conflicts and insecurity. The Civil War (1980-1992) left many scars in the social fabric of Salvadoran society. Social networks were destroyed, with many young ex-combatants remaining in search of a new livelihood. Families were fragmented with many absent members living in the USA. ${ }^{1}$ Post-conflict delinquent returnees from the USA introduced the gang culture to the country; since then, the number of youth gang members (the so-called maras) increased gradually, as did murder rates. Youth gangs interrelate with organised and drug-related crime, which is turning the country into one of the principal corridors for the illicit drug and weapon trade. Although indicators suggest that human development is improving, social inequality remains very high. Income distribution is extremely uneven: $10 \%$ of households earn $37 \%$ of national income whereas the poorest $10 \%$ only have access to $1 \% .^{2}$ El Salvador is classified as a lower middle-income country: the GDP per capita is US\$3,720 (2013), almost twice as much as the poor neighbouring countries of Nicaragua, Honduras, and Guatemala, but only one third of the South American average. Nearly thirty five percent of the population is considered poor. $^{3}$

Though murder rates dropped since 2009, the country was among those with the highest homicide rates worldwide in 2012:4 
- Honduras - 90.4 (number of annual homicides per 100,000 population)

- Venezuela - 53.7

- Belize - 44.7

- El Salvador - 41.2

- Guatemala - 39.9

- Colombia - 30.8

- South Africa - 31.0

- [for comparison: USA - 4.7; Germany - 0.6 $]^{5}$

The development of homicide rates in El Salvador partly coincides with political changes in the country. After winning the election in 1994, the right wing party ARENA pushed a market oriented approach and a restrictive crime control and law enforcement policy ("política de mano dura"). Homicide rates subsequently increased. In the 2009 and 2014 presidential elections, FMLN (Farabundo Martí National Liberation Front) candidates won the presidency. The new government switched to a prevention oriented approach ("política de mano extendida") and introduced some social reforms. Homicide rates first slightly decreased and then dropped significantly after a truce (cease-fire) between the two major gangs Mara Salvatrucha and Barrio 18 - in March 2012 was signed. Current data suggest, however, that murder rate will double in 2014, as compared to 2013. This trend is attributed to increasingly tough police action against violent gangs, low public support of the truce, and inner-gang conflicts.

Around $90 \%$ of murder victims are male ${ }^{6}$, most of them between 15 and 30 years of age. Although exact data are not available, there is evidence that most perpetrators are also young men, though the number of female perpetrators is increasing. Many of the perpetrators are members of youth gangs. The majority of violent deaths happen in urban areas $\left(63 \%\right.$ in $2010^{7}$ ), with a high concentration in the metropolitan area of San Salvador.

It is not solely homicide that contributes to the sensation of insecurity, however. Particularly in poor communities, insecurity is predominantly attributed to theft, robbery, threats, extortion, and other types of crimes.

05.

Source: PNC, Prensa Gráfica, own calculations

06. According to "Instituto de Medicina Legal (IML) de El Salvador", in 20132,261 of murder victims were men and 218 women.

07.

PNC data
Homicide rates El Salvador 2000 - 2013

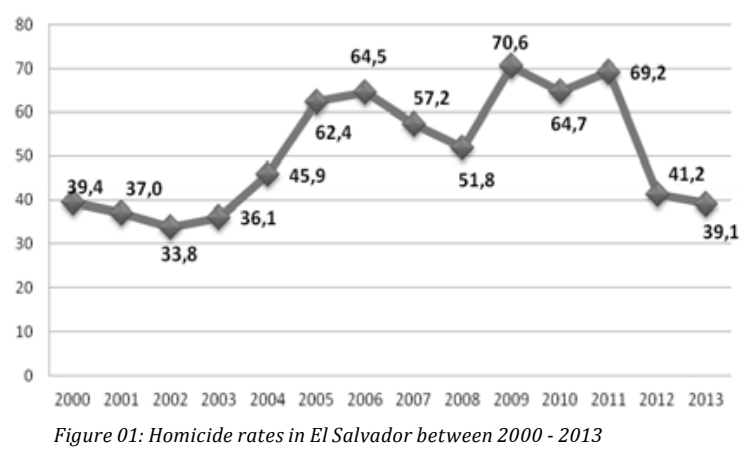

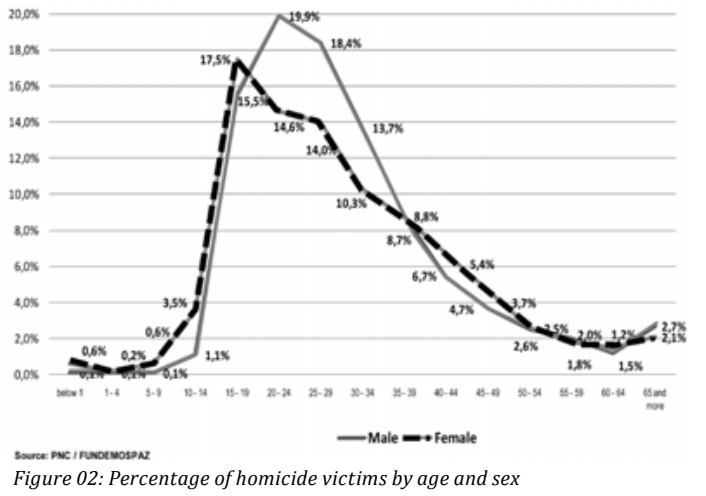



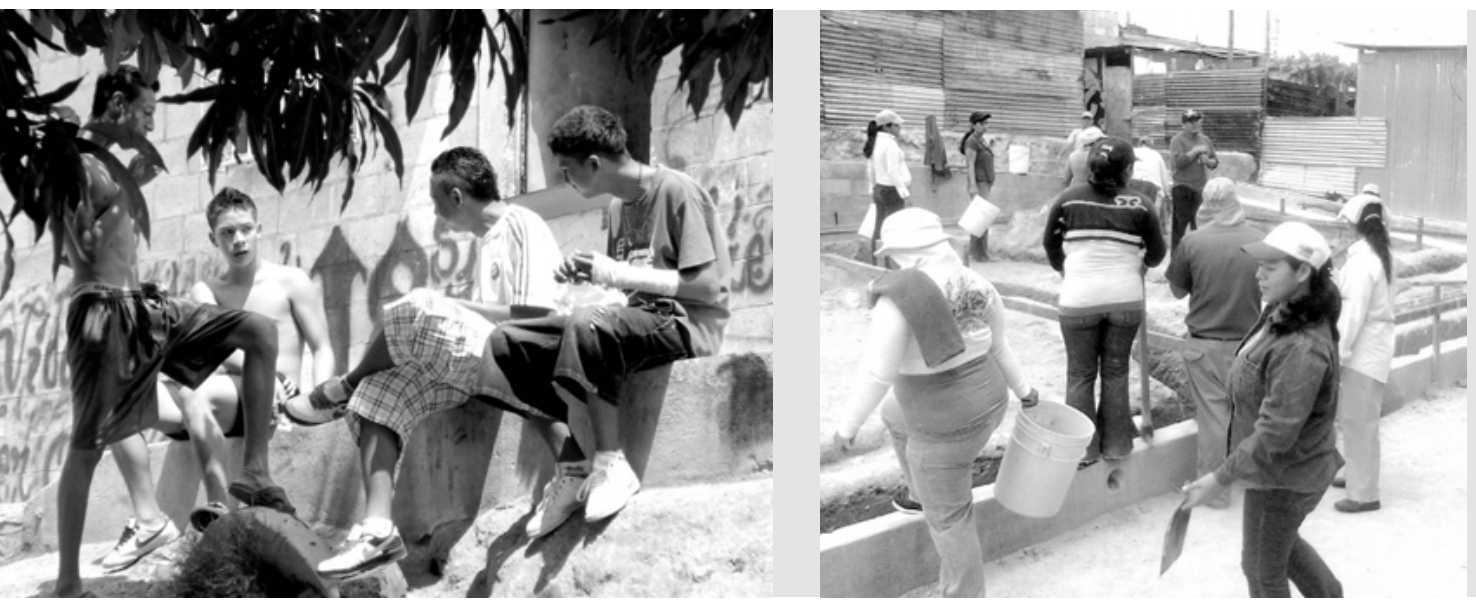

Left:

The male homicide rate is highest between 15 and 25 years of age. Photo: Michael Kleinekathöfer

Right:

FUNDASAL mutual aid project Photo: Michael Kleinekathöfer

\section{8.}

Originally, 42 communities were foreseen to participate in the PMB. Due to time constraints, one of them has been removed from the Programme.

\section{The FUNDASAL Integrated Urban Upgrading Project}

FUNDASAL (Fundación Salvadoreña de Desarrollo y Vivienda Mínima) is a Salvadoran NGO focusing on the improvement of housing and living conditions in rural and urban areas. Since its foundation in 1968, FUNDASAL has concentrated on construction of low-cost housing for the poor and organising community groups in cooperatives and self-help brigades ("equipos de ayuda mutua"). The first FUNDASAL-supported settlement upgrading project, carried out on-site in the community of Las Palmas in San Salvador (1997-2006), implemented physical improvements, better provisions of urban services, and an organisation for self-help housing and facility construction. During the second upgrading project, Los Manantiales (2003-2007), including interventions in 12 interconnected communities in the east of San Salvador, FUNDASAL increasingly introduced socio-educational and youth promotion components; still social development was heavily related to the cautious implementation of physical infrastructure.

Between 2006 and 2014, FUNDASAL implemented the Urban Upgrading Programme (Programa de Mejoramiento de Barrios - PMB) in several poor settlements. Youth promotion and violence prevention components gained importance, due to the presence of maras and high levels of petty crime in these settlements, but also because problems of extortion and intimidation were prevalent.

The PMB has been an open programme that has intervened in 41 communities ${ }^{8}$ scattered across the four municipalities of the Metropolitan Area of San Salvador (AMSS): Mejicanos, Soyapango, Ilopango, and San Martin. It has three principal components:

- Improvement of the physical environment and infrastructure;

- Organization of community groups in self-construction brigades;

- Social development, including:

- The organisation and empowerment of community groups;

- Horizontal information exchange between the different groups and communities; 
- Social work specifically with children, youth, and women;

- And capacity building for disaster risk prevention.

The German financial cooperation agency, the KfW ${ }^{9}$ Development Bank, has supported FUNDASAL for more than 20 years. KfW also co-financed the FUNDASAL upgrading projects with more than 30 million EUR. Instead of supporting mere infrastructure improvements, KfW switched to integrated upgrading approaches in poor urban settlements and, specifically, to violence prevention through urban upgrading. KfW now stands for a multi-sector and multi-level approach, considered to be most

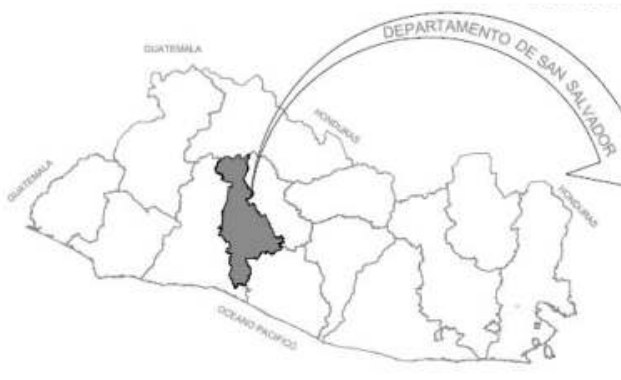

EL SALVADOR, CENTROAMERICA Y COMUNIDADES ATENDIDAS

\begin{tabular}{|c|c|c|c|}
\hline PROYECTO & MUNICIPIO & COMUNIDAD & $\mathrm{N}_{\text {FAMILIAS }}^{*}$ \\
\hline \multirow{2}{*}{$\begin{array}{l}\text { LOS } \\
\text { MANANTIALLS }\end{array}$} & SAN SALVADOR & 12 & 1,417 \\
\hline & \multicolumn{2}{|c|}{ TOTAL } & 1,417 \\
\hline
\end{tabular}

\begin{tabular}{|c|r|r|l|c|}
\hline \multicolumn{2}{|c|}{ PROYECTO } & MUNICIPIO & NOMUNIDAD $^{*}$ & $\begin{array}{c}\text { N. } \\
\text { FAMILIAS }\end{array}$ \\
\hline \multirow{2}{*}{1} & \multirow{2}{*}{0} & SOYAPANGO & 3 & 287 \\
\cline { 2 - 4 } & & TO T A L & 287 \\
\hline
\end{tabular}

\begin{tabular}{|c|c|c|c|c|}
\hline \multicolumn{2}{|c|}{ PROYECTO } & MUNICIPIO & $\begin{array}{l}\text { N. } \\
\text { COMUNIDAD }\end{array}$ & $\begin{array}{l}\text { N } \\
\text { FAMILIAS }\end{array}$ \\
\hline \multirow{2}{*}{2} & & SOYAPANGO & 8 & 574 \\
\cline { 3 - 5 } & MEJICANOS & 3 & 340 \\
\cline { 2 - 5 } & \multicolumn{2}{|c|}{ T O T A L } & 914 \\
\hline
\end{tabular}

\begin{tabular}{|c|c|c|c|}
\hline PROYECTO & MUNICIPIO & $\mathrm{N}^{*}$ COMUNIDAD & FAMILIAS \\
\hline \multirow{3}{*}{3} & SOYAPANGO & 2 & 160 \\
\hline & MEJICANOS & 8 & 440 \\
\hline & TO & $A L$ & 600 \\
\hline
\end{tabular}

\begin{tabular}{|c|c|c|c|c|}
\hline \multicolumn{2}{|c|}{ PROYECTO } & MUNICIPIO & $\mathbb{N}^{*}$ COMUNIDAD & $\begin{array}{l}\mathrm{N}^{*} \\
\text { FAMILIAS }\end{array}$ \\
\hline \multirow{2}{*}{4} & & LLOPANGO & 14 & 1,100 \\
\cline { 2 - 5 } & \multicolumn{2}{|c|}{ T O T A A } & 1,100 \\
\hline
\end{tabular}

\begin{tabular}{|c|c|c|c|c|}
\hline \multicolumn{2}{|c|}{ PROYECTO } & MUNICIPIO & $\begin{array}{l}N^{*} \\
\text { COMUNIDAD }\end{array}$ & $\begin{array}{l}\text { N. } \\
\text { FAMILIAS }\end{array}$ \\
\hline \multirow{3}{*}{5} & & SOYAPANGO & 1 & 86 \\
\cline { 3 - 5 } & MEJICANOS & 1 & 150 \\
\cline { 3 - 5 } & & SAN MARTIN & 2 & 135 \\
\cline { 2 - 5 } & \multicolumn{2}{|c|}{ T O T A L } & 371 \\
\hline
\end{tabular}

CUADRO RESUMEN POR MUNICIPIO

\begin{tabular}{|c|c|c|c|}
\hline SIMBOLOGIA & MUNICIPIO & $\begin{array}{l}N^{\circ} \\
\text { COMUNIDAD }\end{array}$ & $\begin{array}{l}N^{*} \\
\text { FAMILIAS }\end{array}$ \\
\hline \multirow{5}{*}{} & SAN SALVADOR & 12 & 1,417 \\
\cline { 2 - 4 } & SOYAPANGO & 14 & 1,107 \\
\cline { 2 - 4 } & ILOPANGO & 14 & 1,100 \\
\cline { 2 - 4 } & MEJICANOS & 12 & 930 \\
\cline { 2 - 4 } & SAN MARTIN & 2 & 135 \\
\cline { 2 - 4 } & T O T A L & 54 & 4.689 \\
\hline
\end{tabular}

09.

Kreditanstalt für Wiederaufbau (KfW), German Bank for Reconstruction and Development

Figure 3:

Project areas and number of communities.

Map compiled by FUNDASAL. 


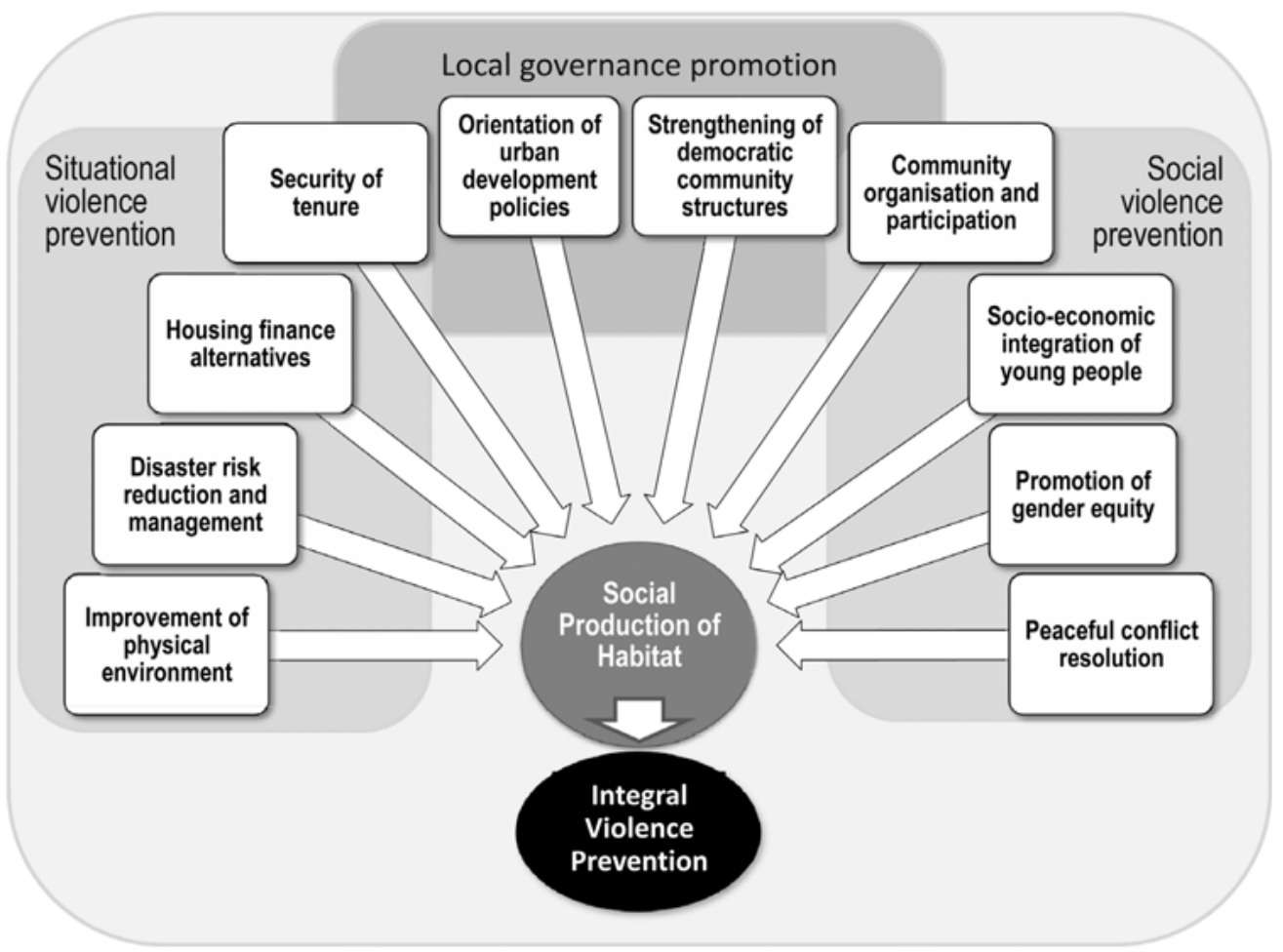

Figure 4:

Integral approach to social production of the habitat and to violence prevention

KfW Bankengruppe: Violence Prevention Through Urban Upgrading, effective when facing urban violence, which consists of three interlinked components: ${ }^{10}$

- Situational violence prevention, by improving the physical / spatial environment;

- Social violence prevention, by promoting community involvement;

- And local governance promotion, by focussing on improvements of the institutional and political landscape through capacity building, aiming at the reduction of structural violence and social injustice.

The FUNDASAL-PMB (Programa de Mejoramiento Barrial - Urban Upgrading Programme) concept is focused on the social production of habitat; it provides several elements that are very similar to this integral approach to violence prevention:

$\mathrm{KfW}$ is co-financing urban upgrading programmes in many other countries and is keen to observe and assess the impacts of this approach, especially with regard to the interrelation of the three levels of violence prevention. SUM Consult from Germany was in charge of conducting an evaluation of the PMB experience in El Salvador in 2012 on behalf of the KfW.

\section{Evaluation process and results}

The main evaluation objectives were:

- To identify principal approaches, lessons learnt and impacts of the 
FUNDASAL-PMB project and it's contribution to violence prevention; and

- To contribute to the reorientation of urban upgrading in poor settlements, focused on more effective prevention of violence through the promotion of community development and social cohesion ("convivencia").

Neither the urban upgrading projects implemented until 2006 nor the PMB concept designed in 2005 explicitly included violence prevention as an integral component. However, the integrative FUNDASAL approach to social and physical development was considered appropriate for the promotion of peaceful neighbourhood development and violence prevention, and implicitly contributed to social cohesion and conflict reduction.

The major project achievements of the programme are summarised below under the areas of situational, social, and structural violence prevention. Their contribution to crime reduction and control is likewise appraised.

\section{Physical works and sustainability}

Improvement of social infrastructure and public services accounted for the bulk of the programme investments including:

- Social and community infrastructure (community centres, playgrounds, and sports fields);

- Disaster prevention (retaining walls, river bank stabilisation for flood control, and similar works);

- Water supply and sewerage;

- Improvement of deteriorated urban spaces (roads, stairs, footpaths);

- And the introduction or completion of public lighting.

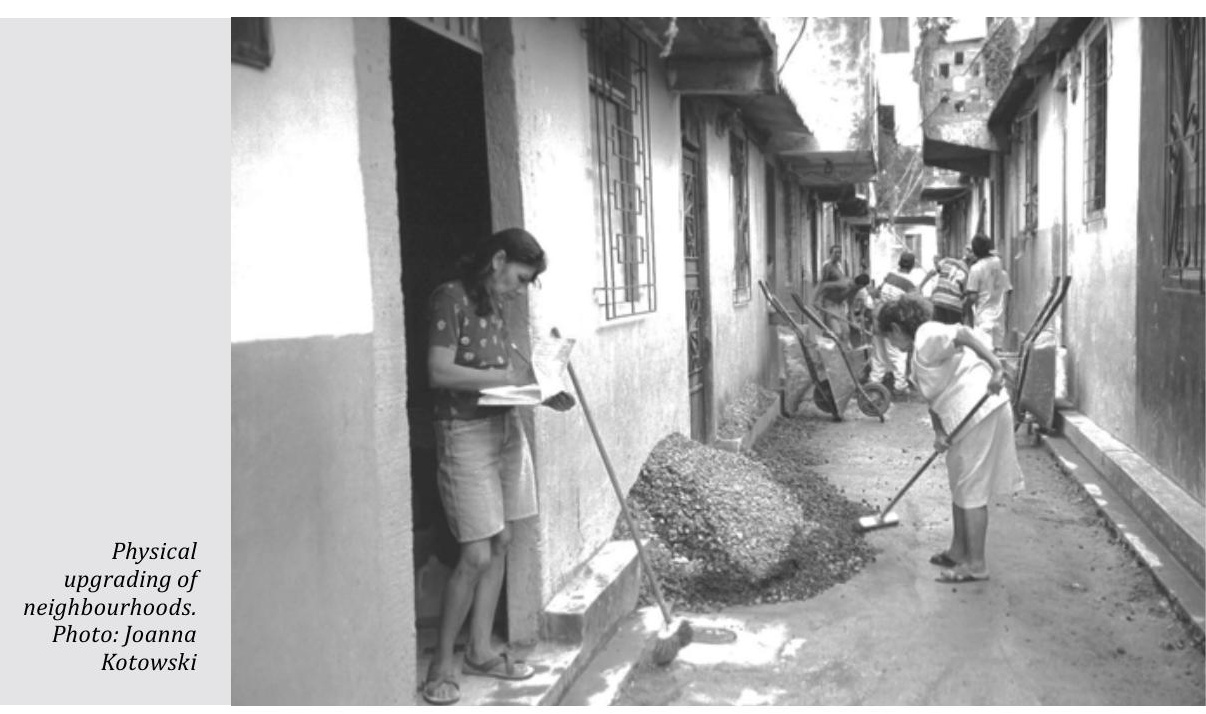


- Revitalized public space appropriate for neighbourhood meetings and as communication areas;

- Public lighting contributing to improved visibility.

The interviews suggest that the upgraded social and community infrastructure was really designed for and utilised by children and youth. However, the low security level, mentioned generally as a negative aspect in the communities, affected the use of facilities by this cohort. Due to the lack of security guards or municipal policy patrols, insecurity in public space is still an issue today.

Public lighting, frequently portrayed as an important element of situational violence prevention (also by community representatives), was not considered to account for improved crime control or violence reduction in the analysed communities. There was only a slightly better public light provision in the intervened communities, compared to those in the process of or expecting intervention.

Other elements that contributed to peace enhancement and violence prevention were:

- Disaster risk mitigation by reducing physical and environmental insecurity;

- Rearrangement and rehabilitation of footpaths and roads, improving communication and connectivity between peripheral neighbours and the city;

- Sanitation by recovering health and hygiene;

- Increased water connection and coverage by reducing conflicts between neighbours;

- Renovation of social facilities and public spaces by reducing crime opportunities and facilitating cultural, recreational, inter- community exchange, and preventive programmes.

The intervened communities noted better maintenance of public spaces and facilities, as compared to the communities where intervention had not yet occurred. This might indicate improved sustainability of investments, as well as a contribution to crime and violence prevention. According to the broken windows theory ${ }^{13}$, urban disorder and vandalism attract additional destruction, delinquency, and anti-social behaviour. In contrast, maintaining urban space in a well-ordered condition may inhibit delinquency from developing into more serious crime. Where deficiencies of maintenance were detected, like in Los Manantiales, the oldest of the six evaluated projects, more attention was required to avoid the physical and social deterioration of these communities.

\section{Social, educational, and community development work}

FUNDASAL supported the development of community organisations at local, community, and municipal level. Almost all participating communities developed their own community council or local representing body (93\% of coverage); around one third now have youth (32\%) or women's

13.

Wilson, James Q. \& Kelling, George E, 1982
11.

Refer to methodological remarks at the end of this article.

12:

Selected young people were allowed to determine what a priority was for them and what was not, when investments in children- and youth-related infrastructure were discussed. 
Figure 09:

Identified

community organizations

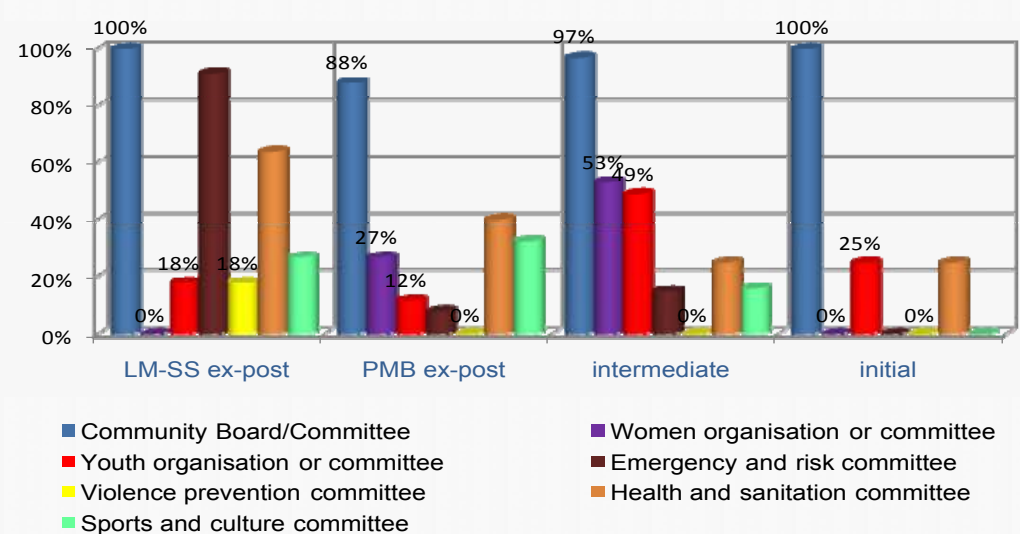

Source: SUM - PRODEC, focus group interviews, May 2012

organisations (34\%); in 32\% of the communities, there is now a functioning health and sanitation committee; $27 \%$ of communities likewise have emergency and risk mitigation committees now. Ten of the 53 participating communities have established a sports and culture committee (18\%). But only $4 \%$ explicitly established a security, violence prevention, or conflict mitigation committee.

The comparison of communities at different stages of project intervention reveals additional insights. All communities show a strong presence of local representative boards. As a matter of fact, the existence of a strong and committed community organisation was a precondition for FUNDASAL's project entry; but their functioning might decline over time. Youth organisations - not considering youth gangs - were not very active
Figure 10: Participation in mutual aid construction groups: all respondents and youth.

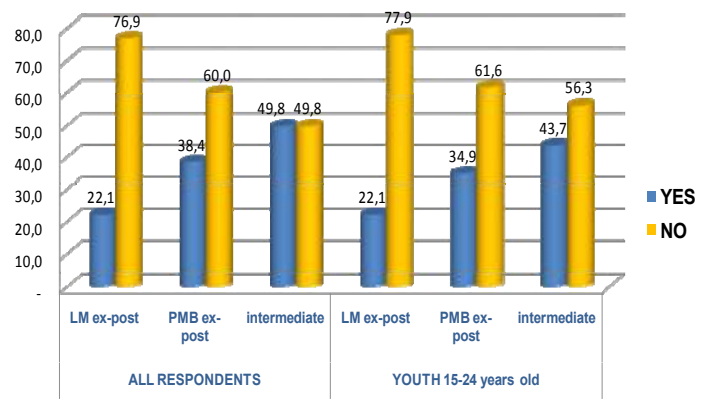

Source: SUM-PRODEC-CIOPS, community survey, May 2012
Figure 11: Learning through mutual aid construction groups (respondents from finalised and ongoing projects)

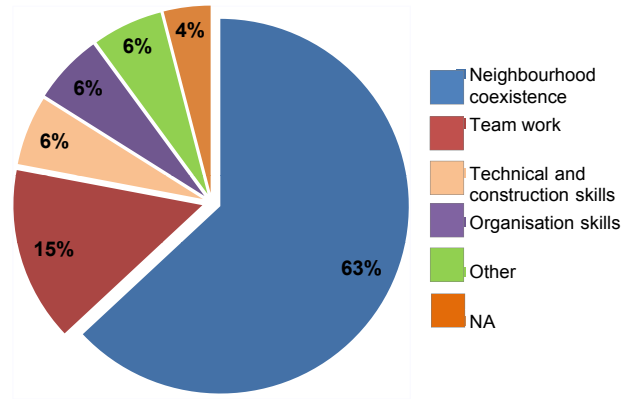

Source: SUM-PRODEC, focus group interviews, May 2012

Figure 12: Perception of neighbourhood inter-relations

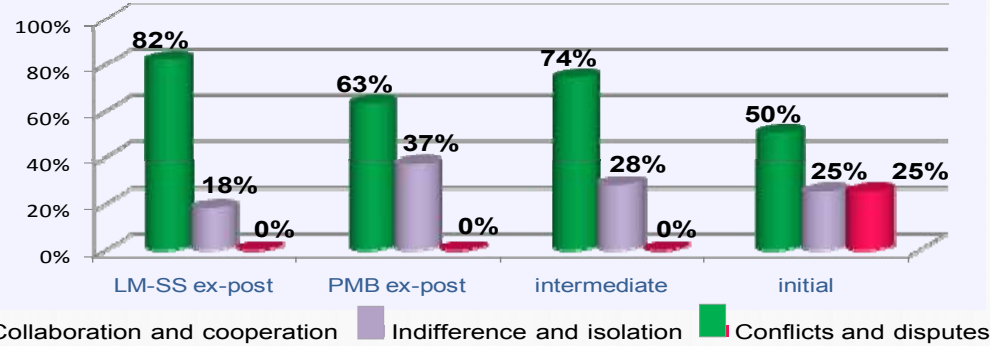


in settlements where FUNDASAL did not intervene; the highest presence of youth organisations was reported in communities with current project involvement. Ultimately, the existence and functioning of youth committees depended very much on adult support, which was provided by FUNDASAL. Violence prevention committees have been established in only two of the twelve Los Manantiales communities, and in none of the other PMB settlements. FUNDASAL did not support the establishment of such committees nor did it provide orientation to community leaders to do so.

A particularly successful component of FUNDASAL's work was the organisation of mutual aid construction groups. In the 49 communities (not counting the four initiating ones), FUNDASAL mobilised 264 groups, 5.4 per settlement on average. Usually, 10-20 family representatives participated in the groups and rotated according to a jointly agreed schedule. Some families also sent a representative who was not a family member or subcontracted unskilled workers. FUNDASAL data suggest that half of the families would personally involve themselves in group work; others would rather delegate or subcontract. This was confirmed by the survey: in communities where FUNDASAL still was involved ("intermediate evaluation"), participation in mutual aid groups was reported by half of the respondents. In the remaining groups ("ex-post evaluation"), only $22 \%-38 \%$ of the respondents affirmed to have participated in the selfhelp groups; it seems that over time the participants' memories fade or, less likely, the population has changed.

In total, one third of survey respondents confirmed to have participated in construction groups. The closer the experience, the more palpable it was. The results also corroborated a high participation of young people in self-help groups.

Asked for the benefits of working in mutual aid construction, the majority of respondents highlighted the positive effects on peaceful neighbourhood coexistence. Some mentioned the possibility of working in a team that acquired construction and organisational skills.

Participation in the project experience, and in particular mutual aid construction, tended to result in a more collaborative neighbourhood environment. In the intervened settlements, community leaders described neighbourhood interrelations as rather cooperative after collaborative projects. As opposed to the communities in incipient stages, none of the focus groups from the ex-post or intermediate phases reported prevailing conflicts or disputes. Almost unanimously, focus group participants confirmed that the mutual aid approach would lead to more social cohesion and less conflict.

Examples from other contexts confirm the positive effects of organised community work. In Rwanda, for instance, the traditional Umuganda approach was introduced as part of efforts to reconstruct the country after the civil war. Each month, communities came together to conduct a variety of public works; close to $80 \%$ of Rwandans took part in these events. ${ }^{14}$ Since 2007 in Mexico-City, the local Government has implemented a community-based settlement upgrading programme, which involve community organisations in the planning, management, and execution of rehabilitation works in deteriorated public urban spaces. ${ }^{15} \mathrm{In}$

14

http://www.rwandapedia.rw/explore/umuganda, accessed 14.07.2014 15. http://www.uclgcisdp.org/es/observatorio/programa-comunitariode-mejoramientobarrial-pcmb, accessed 14.07.2014 
Honduras, after positive, community empowering experience in rural areas, the German financial cooperation started to support urban upgrading projects implemented by the community (PEC - Proyectos Ejecutados por la Comunidad).

A direct influence of project interventions on knowledge, attitudes, perceptions, and practices related to conflicts and violence could not be observed among the surveyed communities, however. When comparing selected statements in projects of different intervention status, no clear differences were identified. Only some respondents confirmed to report offences to police or prosecutors $(2.5 \%)$. Two thirds would not interfere in neighbourhood disputes and only one third would offer dialogue in the case of conflicts.

All communities were highly exposed to youth gangs: $56 \%$ of respondents confirmed this fact and $36 \%$ perceived an increase in the gang presence. Despite these high figures, knowledge of prevention programmes continued to be low (on average only $30 \%$ of respondents were aware of such an offer), but the majority of respondents (74\%) expressed the need for more educational and economic opportunities for young people, in order to address youth violence levels.

\section{Social organisation and governance}

The level of internal and inter-community organisation improved considerably in the project settlements. Leadership powers became better distributed, as more women and youth began participating in local decision making processes. Moreover, as a result of horizontal exchange, the social movement MAPUS (Movimiento de Asentamientos Populares Urbanos) was initiated. MAPUS engaged with local and national government representatives, requesting land and housing rights. The strengthening of democratic structures at community level was not part of FUNDASAL's core interventions. In fact, this is a key responsibility of municipal administrations. However, in some communities, the municipal contribution to local organisational development was substantial; in others it was almost nothing. But the responsibility of municipalities for the provision of urban and social services likely increased alongside other project interventions.

\section{Did these programmes impact crime and reduce violence?}

Opinions of police officers collected during the evaluation suggest that crime levels in Los Manantiales and the other project communities had been considerably reduced. There is no baseline data at community level to validate these statements. However, residents confirmed this trend: $24 \%$ of interviewees from the "ex-post" communities perceived that security conditions in their settlement had improved. Only $13 \%$ and $17 \%$ of the "intermediate" and "initial" intervention project respondents respectively thought security conditions had improved. At the same time, a lower percentage of respondents from "ex-post" communities (32\%) stated that insecurity had increased, as opposed to $50 \%$ of informants from the other cohorts who observed increasing insecurity levels. 


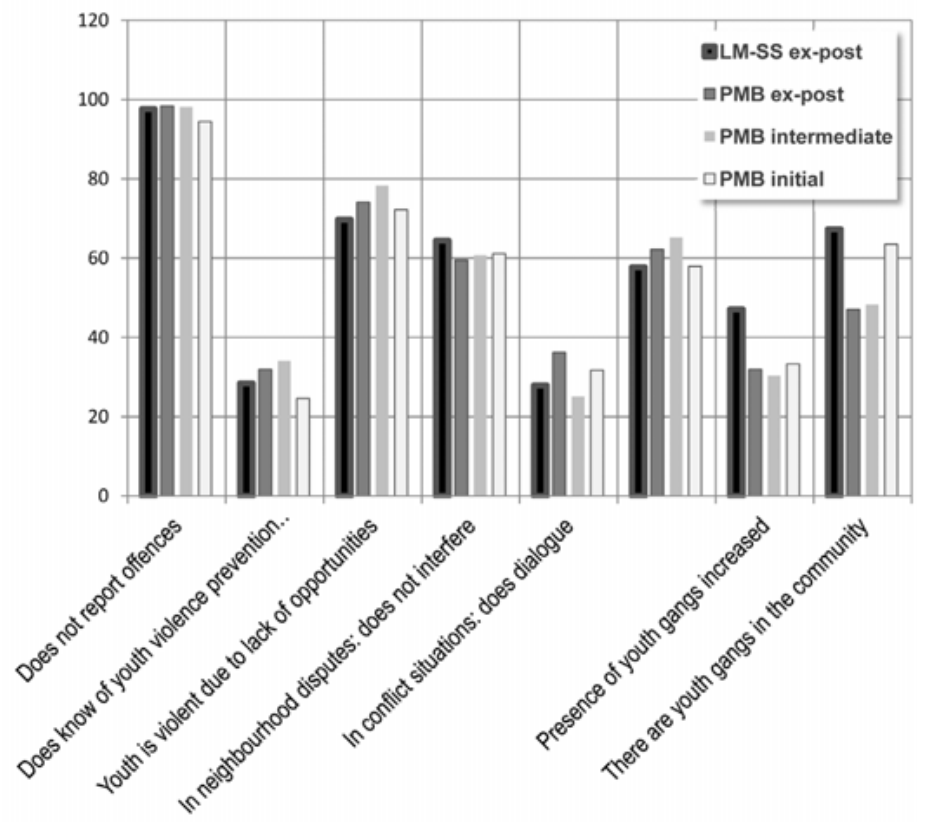

Figure 13:

Selected

knowledge

attitude,

perception

and practice

statements

regarding conflict

and violence in

different projects.

Source: SUM-PRODEC-CIOPS, community survey, May 2012

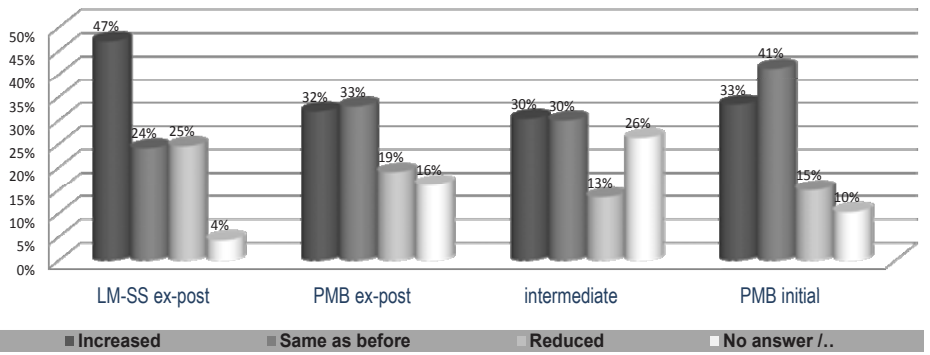

Figure 14:

How do you

perceive the

security level in

the community

as compared to 5 years ago?

Source: SUM-PRODEC-CIOPS, community survey, May 2012

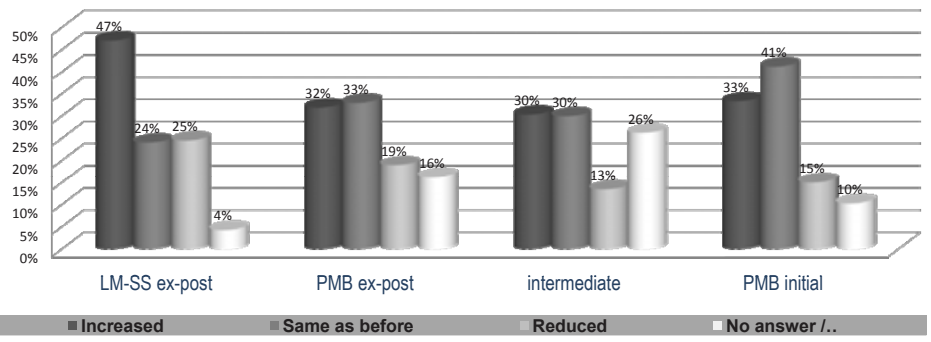

Figure 15:

How do you

perceive the

presence of

youth gangs in

the community,

compared to 5

years ago?

Source: SUM-PRODEC-CIOPS, community survey, May 2012 
These perceptions are not necessarily related to the presence of youth gangs: the highest incidence was reported in the "oldest" programme communities (Los Manantiales), and in the incipient ones. Also in Los Manantiales, the highest percentage of respondents (47\%) affirmed that the presence of maras had increased. Many interviewees did not respond to this question, a sign of fear and intimidation.

Crime and violence continues to be a reality in the programme communities. When comparing victimisation reported by informants from the four cohorts, a slightly lower occurrence of robberies, assaults, and aggression in the "ex-post" and the "intermediate" status communities was observed and was different from the initial communities. There is no clear difference between the projects regarding cases of murder, and there was no extortion reported in the initial communities as opposed to the other ones. Project staff reported that they had to pay "gate-money" in intervention communities.

It can be summarised that evident effects of the Urban Upgrading Programme on crime and violence prevention and reduction could not be corroborated. In fact, representatives of community organisations are very clear on this. They affirm important programme contributions such as infrastructure, health, and housing improvements, a better integration into the urban network, and also generally peaceful neighbourhood development. But, from their point of view, the programme's contribution to public security and safety has been rather low.

Figure 16: Crime and violence incidence reported by community members $1 \%$ responses; logarith-mic scale)

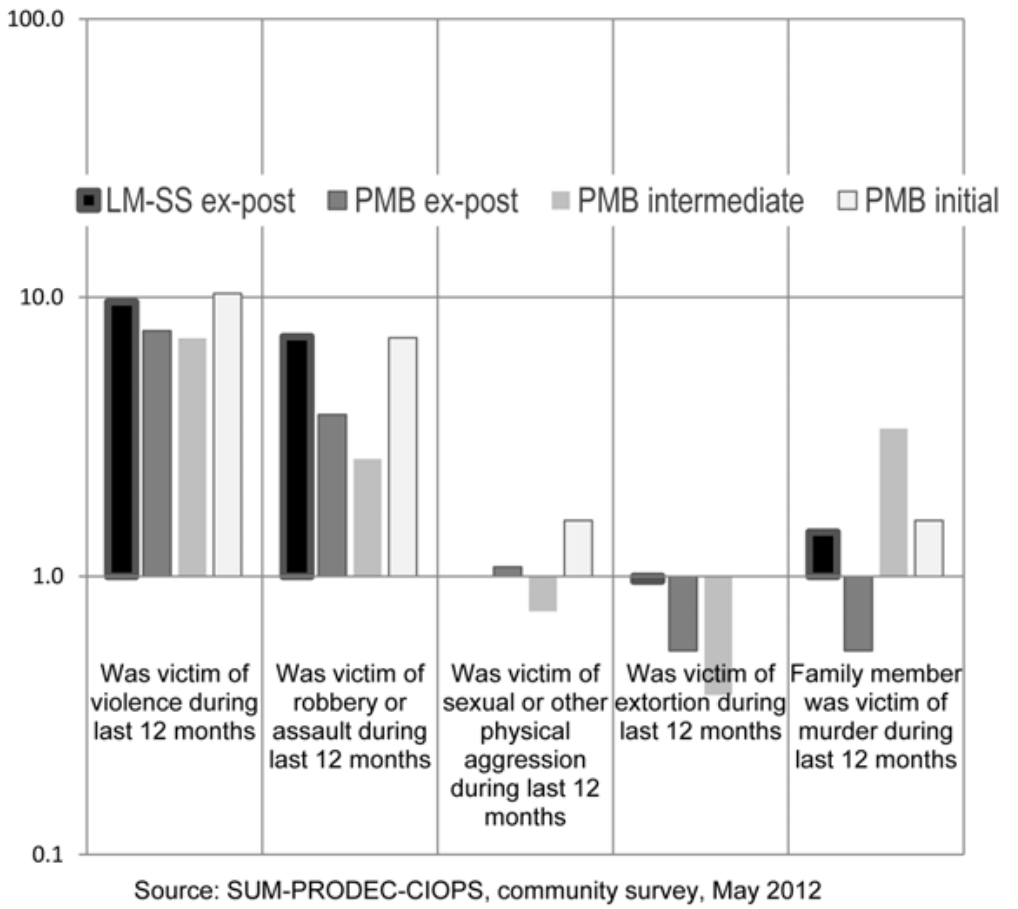




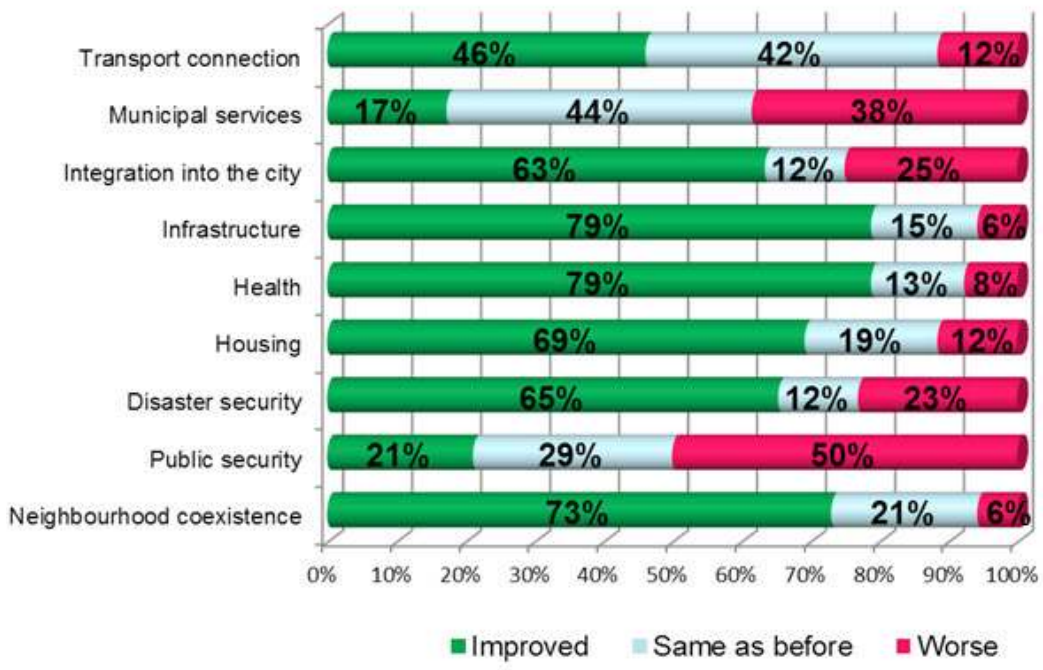

Figure 17:

Perception of

changes generated

by the Urban

Upgrading

Programme

(ex post and

intermediate

project

communities)

Source: SUM-PRODEC, focus group interviews, May 2012

\section{Conclusions and recommendations}

The FUNDASAL Urban Upgrading Programme has had (and continues to have) very positive effects on infrastructure improvements, health conditions, community organisation, and peaceful neighbourhood development, particularly through the mutual aid type of construction works. Construction brigades proved to be an effective tool for promoting community organisation and integration (including young people), providing skills and income opportunities, and generating peaceful coexistence and social cohesion between neighbours. The programme however has not really addressed the incidence of crime and violence. In light of the extremely difficult and conflictive framework conditions, this aim might have been too ambitious. But the programme could have done more in this respect, if an explicit strategy for prevention of urban violence would have been designed from the very beginning. For future programmes of similar scope, the evaluators therefore recommend:

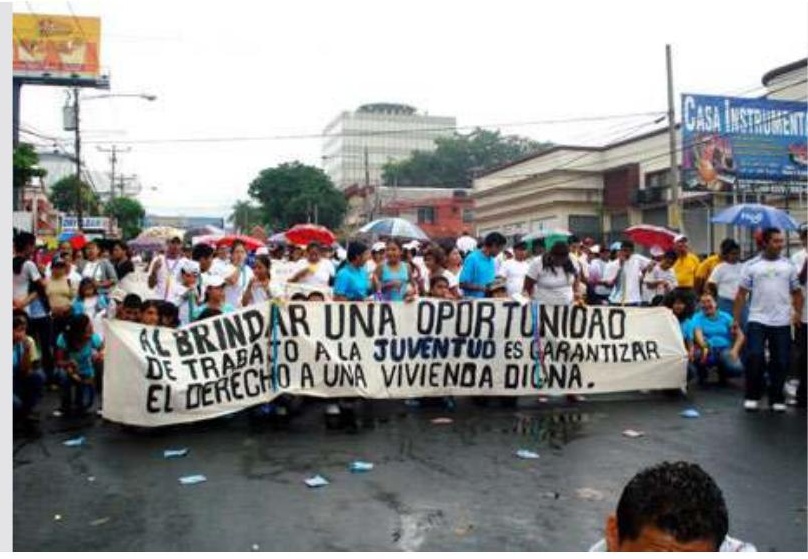


- Explicit integration of components aiming at improvement of the social, cultural, and physical conditions that generate insecurity, with a particular focus on young people who most likely are attracted to gangs and crime. Such an explicit focus could involve, for instance, the improvement and social control of public space; cultural activities in crime hot spots; conflict management training; inter-gender and inter-generational sports, cultural, and educational activities; democratic community organisation; life skills, vocational, and employment training; and the establishment of community-based violence prevention committees.

- Replicate the mutual aid (ayuda mutua) construction methodology as a viable strategy for improving community development, adapting it lo local conditions.

- Involve all relevant community organisations and local stakeholders in project concept development and the elaboration of community-based violence prevention action plans, strengthening democratic and transparent procedures.

- Create confidence between communities and public security agents and involve, if possible, police officers in project activities ("community policing").

- Promote the inclusion of integrated upgrading approaches in local, national, and regional urban development and violence prevention policies.

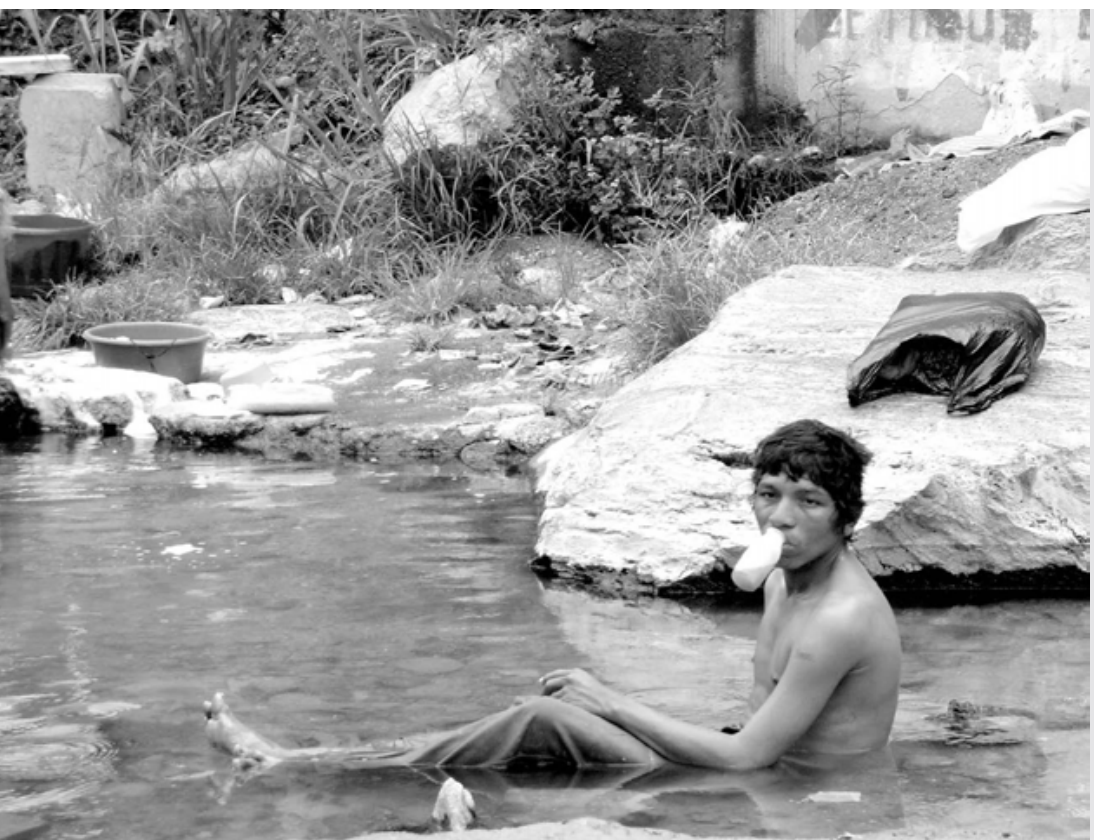




\section{Annex: methodological remarks}

The impact evaluation was carried out between March and October 2012 and encompassed six urban upgrading projects in different stages of implementation, covering 53 communities of the metropolitan area of San Salvador (AMSS), with almost 4,550 families or 22,000 people, including approximately 6,000 young people between 15 and 24 years of age. The evaluation team integrated nine national and international experts (including the author). FUNDASAL professionals participated in the whole process with information and logistical support, but were also involved in the discussion of evaluation steps and results. Methods and instruments applied by the evaluators involved:

- Anonymised survey with 786 respondents (of which $62 \%$ were women and $51 \%$ were young people) in the intervention communities of Los Manantiales and PMB;

- Fifty six focus group interviews with 461 participants who discussed key topics and jointly filled out a questionnaire (14 groups with community leaders, 16 women's groups, 15 youth groups, and 11 mutual aid construction groups);

- Interviews with representatives of inter-communal organisations;

- Interviews with municipal representatives, with other local and national stakeholders, as well as representatives of donor organisations;

- Interviews with staff of FUNDASAL;

- Situational, organizational and documental analysis;

Grandma and niece in San Salvador proudly showing a paper about her son who won a championship as a sportsman. Photo: Joanna Kotowski.

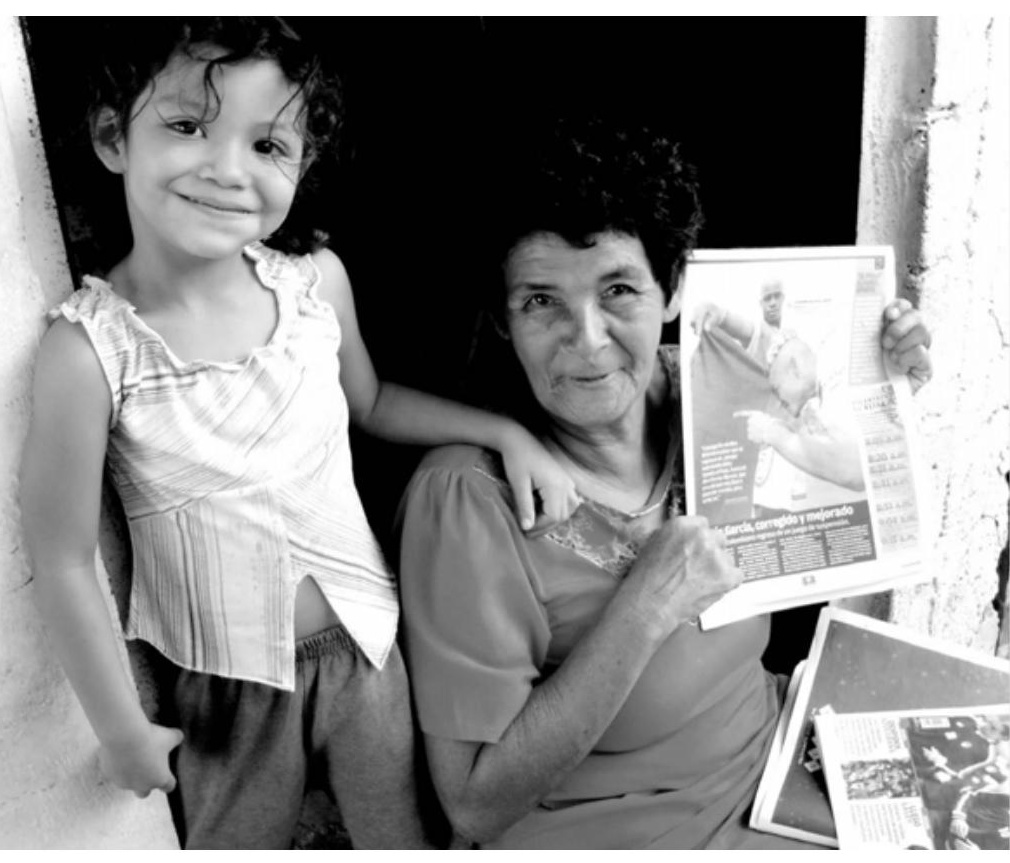


- Quantitative and qualitative analysis of the different projects, which allowed for a comparison between the projects, despite various implementation phases:

- Ex post 1 - Los Manantiales in San Salvador (LM-SS), finalised in 2007, and benefiting 12 communities in total;

- Ex post 2 - 2 PMB-projects in Soyapango and Mejicanos finalised between 2008 and 2010, which benefited 14 communities in total;

- Intermediate - 2 PMB-projects still in implementation in Soyapango, Mejicanos, and Ilopango, which were scheduled to benefit 23 communities;

- And Initial: 1 PMB-project, initiating in 2012 in San Martín, Mejicanos, and Soyapango, that was set to benefit 4 communities.

\section{References}

CIA: The World Factbook 2014. Available online at https://www.cia.gov/library/publications/the-world-factbook/geos/es.htm l. Accessed 14.07.2014

KfW Bankengruppe: Violence Prevention Through Urban Upgrading (2010). https:// www.kfw-entwicklung sbank.de/Download-Center/PDF-Dokumente-Sektoren-Berichte/2010_03_Violence-Prevention_E.pdf Accessed 14.07.2014

Programa Comunitario de Mejoramiento Barrial (PCMB). Available online at http:// www.uclg-cisdp.org/es/observatorio/programa-comunitario-de-mejoramiento-barrialpcmb. Accessed 14.07.2014
Umuganda. Available online at http://www. rwandapedia.rw/explore/umuganda Accessed 14.07.2014

UNODC: Global Study on Homicide 2013. Available online at http://www.unodc.org/documents/gsh/pdfs/2014_GLOBAL_HOMICIDE_ BO0K_web.pdf Accessed 14.07.2014

Wilson, James Q; Kelling, George E (1982): Broken Windows. The Police and Neighborhood Safety. Available online at http://www.theatlantic.com/magazine/archive/1982/03/brokenwindows/304465/ Accessed 14.07.2014

World Bank:World Development Indicators. Available online at http://data.worldbank.org/ country/el-salvador Accessed 14.07.2014 


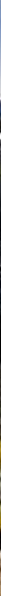

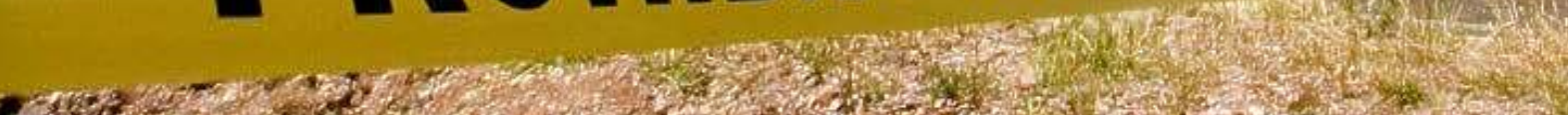

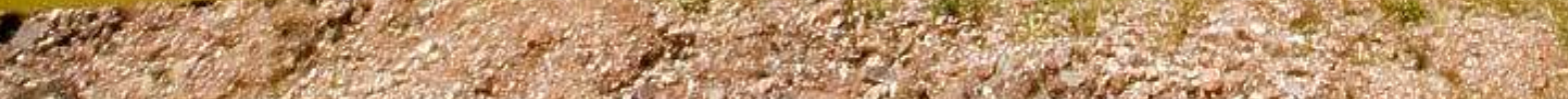

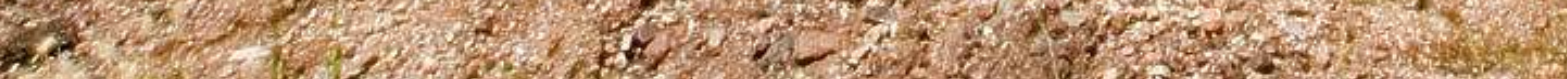

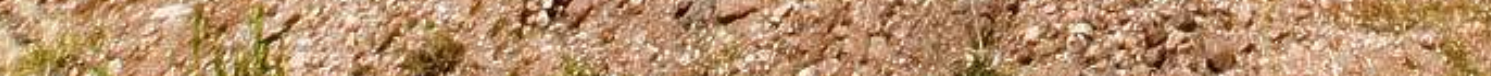

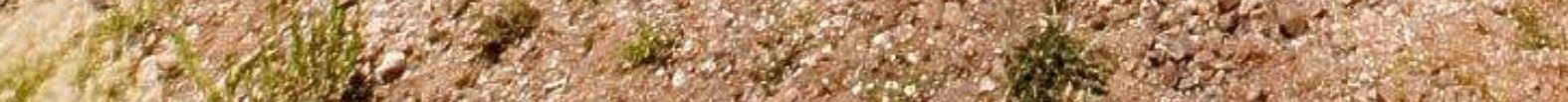
2. 3 (2) 37.

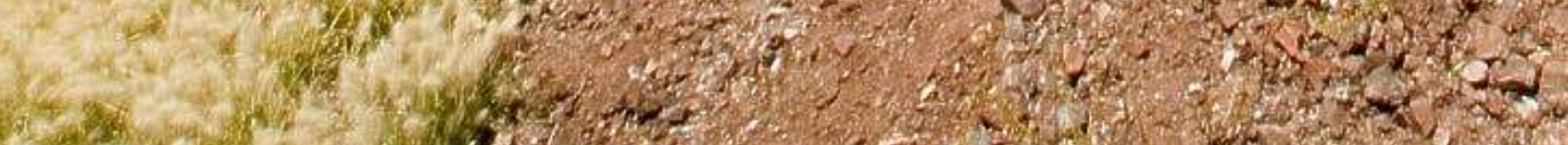

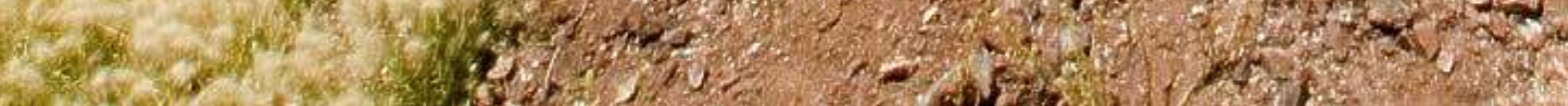




\title{
Drug-Related Violence in Mexico: State and Community Responses. A qualitative Approach
}

\author{
Veronica Martinez-Solares ${ }^{1}$
}

In the last decade, Mexico has moved from being a country of moderate violence and limited drug issues to a country that has experienced a huge loss of life and injuries associated with street violence and violence against women. Associated problems such as kidnapping, enforced and involuntary disappearances, extortion, and other serious and complex crimes have likewise substantially increased. However, until the end of 2013 , victimization and its prevention were not on the national policy agenda, nor were they effectively featured in the public debate. In order for Mexico to effectively tackle drug-related violence, it is crucial to understand the experiences of victimization as well as to recognize victims as strategic actors in the recovery of their communities and the country's social fabric as a whole.

This study used a qualitative research methodology by documenting victims' realities and describing federal, local, and community responses to drug-related violence. The research project aimed to develop more effective policies for victims and prevent further victimization by identifying: (a) how the violent conflict, related to drug trafficking and the state response to it, has impacted individuals and communities in six municipalities with high presence of organized crime; (b) the logic behind the state's response to deal with people affected by this violence; (c) the mechanisms through which the state has sought to mitigate the impact of violence on victims and their communities; (d) community responses to both state violence and the violence of cartels; and (e) the impact of these strategies on the legitimacy and effectiveness of the state.

Despite some effective responses, critical elements for reducing violence are citizens' and business leaders' community participation in local security strategies. Key challenges remain however, including how to institutionalize such state-society collaboration and trust building 
efforts; how to eliminate corruption of public authorities; and how to improve police, judicial investigation, and due process.

\section{The new landscape of violence}

After nearly two decades of steady decline in the homicide rate of Mexico, a new pattern of criminal violence emerged in 2007- linked to growing drug trafficking, the recent government strategy by the new administration of President Felipe Calderon, among other international factors. This new situation was characterized by an increase in the homicide rate, an expansion of the areas affected by violence related to organized crime and an increase in the incidence of high-impact crimes such as disappearance, kidnapping, and extortion, among others.

In the context of a post-electoral conflict that raised questions concerning the transparency of the presidential election of 2006 (Curcó 2010), the new government announced a "war against crime [and] against the enemies of Mexico"2. Such a war against drug trafficking was intended to provide legitimacy for the battered electoral process. One of the first actions was to engage the Armed Forces in the realm of public safety.

In 2006, at the beginning of the Calderon administration and the "drug war", the homicide rate in Mexico was 10 homicides per 100,000 inhabitants. This rate rose to 13 in 2008, 18 in 2009, 23 in 2010 and reached a peak of 24 murders per 100,000 inhabitants in 2011. Among the murder statistics, the specific increase of those allegedly related to drug trafficking was particularly dramatic: December 2006 counted 63 executions; in 2007, almost 2,600 were registered; in 2008, there were 6,183; in $2009,8,906$; in 2010,15,185; and in 2011, these figures slightly dipped to $12,903 .^{3}$ Drug-related violence concentrated in places historically associated with the cartels: Sinaloa, Baja California, and Chihuahua. However, by 2009,27 of the 32 states had increased their intentional homicide

02.

Words pronounced by Felipe Calderon on September 12, 2008. Presidencia (2008). For some reason the original document has disappeared, but the statement was recorded by various electronic media agencies.

03.

Deceases occurred due to alleged criminal rivalry. Attorney General's Office database (2012) rates between 30 and 439 percent.

\begin{tabular}{l|rrrrrrrr} 
Type of crime & 2006 & 2007 & 2008 & 2009 & 2010 & 2011 & 2012 \% Growth \\
\hline Thefts & 545,251 & 610,730 & 656,877 & 680,566 & 738,138 & 749,414 & 711,168 & $30.42 \%$ \\
$\begin{array}{l}\text { Intentional Injury } \\
\text { Intentional }\end{array}$ & 175,738 & 189,383 & 186,585 & 183,421 & 176,451 & 160,995 & 155,567 & $-11.47 \%$ \\
Homicide & 11,806 & 10,253 & 13,193 & 16,117 & 20,585 & 22,480 & 20,555 & $74.11 \%$ \\
Kidnapping & 733 & 438 & 907 & 1,162 & 1,284 & 1,344 & 1,267 & $72.85 \%$ \\
$\begin{array}{l}\text { Extortion } \\
\text { Total of High } \\
\text { Impact Crimes }\end{array}$ & $\mathbf{7 3 6 , 6 8 5}$ & $\mathbf{8 1 3 , 9 2 7}$ & $\mathbf{8 6 2 , 4 3 7}$ & $\mathbf{8 8 7 , 5 9 8}$ & $\mathbf{9 4 2 , 8 3 3}$ & $\mathbf{9 3 8 , 6 3 7}$ & $\mathbf{8 9 4 , 5 9 5}$ & $\mathbf{2 1 . 4 3 \%}$
\end{tabular}

Since 2007, in addition to intentional homicide rates, violent robberies, kidnappings, and kidnapping extortion-related deaths also increased. Between 2006 and 2012, high impact crimes grew by 21 percent, while crime in general likewise increased by 13 percent (see Table 1). Among the fastest growing high-impact crimes were extortion (91\%) and kid-

Table 1: High Impact Crimes 2006-2012. Source: México Unido Contra La Delincuencia, 2014 napping (73\%). 
The process of militarization of public order saw about 60,000 members of the Armed Forces deployed to carry out tasks belonging to civil authorities: searches, arrests, and checkpoints. Between January 2007 and November 2012, the National Human Rights Commission of Mexico received 7,350 complaints of military abuses and issued reports on 109 cases in which it was determined that members of the Army had committed serious human rights violations.

As an emerging phenomenon, the country began to experience something that in people's minds belonged to the distant past and was linked to singular political moments: the dictatorship or "dirty war" with its disappearances. Between 1969 and 2001, only 557 involuntary or forced disappearances were registered; but at least 20,851 persons disappeared as a consequence of the „war on drugs” between 2006 and 2012.

Moreover, the high levels of violence, and actions to combat it, also brought consequences in the form of forced displacement of individuals and entire families seeking a safe place to live. At the end of 2010, internal displacements had an estimated range of $115 \mathrm{mil}$ to $160 \mathrm{mil}$ people. Depending on the source, such displacement incorporated two identifiable dimensions: mass movements of populations directly affected by fighting, threats, or well-founded fear and the quiet abandonment by primary or secondary victims of their communities, which were generally barely perceived.

All of this coincided with a period in which Mexico moved from the socalled "inquisitorial justice" to another of "accusatory court"; a period where the acceptance of guarantor-type governance models, developed elsewhere in the region, were legalized through a constitutional amendment published in the Diario Oficial de la Federación (Official Gazette) on June 18, 2008. Additionally, the reconfiguration of the national system of public order, juvenile justice, and a reform of larger scope in 2011saw human rights become central to all national legislation. Accordingly, the Mexican state presented itself as an effective guarantor country and law enforcer.

With widespread violence and victimization, the reality that many people faced on a daily basis was completely different from the one envisaged by the Constitution. An immense gap between the daily violation of rights, effective access to justice, and full respect of the rule of law developed while the interconnection between these became either very weak or nonexistent. In particular, the Mexican state became unable to address the needs of victims of high-impact or complex crimes (these terms are used here to identify those associated with violence due to organized crime and the state's own acts of violence in response to it).

In order to provide empirical evidence for a better understanding of the effects of violence and likewise to supply a grounded information base for better public policies, an empirical research project called "state and community responses to drug-related violence in Mexico" was initiated. Funding was assured by the International Development Research Centre, which helped collect data on the following questions: 
- What has been the impact of the violent conflict related to drug trafficking?

- How has the state's response affected communities living with different levels of violence, originating from organized crime?

- Which changes caused increased violence and victimization in terms of personal life, family life, and community life?

- What kinds of measures have been taken by individuals, families, and communities to prevent and protect themselves against victimization?

- What have been the experiences of violence and the impact of victimization?

- What proposals for the prevention and control have emerged from the victimized communities?

\section{Methodology}

This essay cannot comprehensively address all aspects of the research project. The information was mostly collected through interviews with primary and secondary victims of drug-related violence in six municipalities of four Mexican states. Further information was also collected in other locations with higher crime rates. As a matter of principle, ethical and security guidelines were given absolute priority before adding quantity to the project findings, in order to guarantee safety for the participants and research group itself.

The locations were selected according to the level of violence experienced in recent years. The first states considered were those whose homicide rates were above the national level and who had experienced an accelerated growth rate in the number of homicides two years prior to the commencement of the investigation (2012). Other selection criteria were ease in access to institutions, security aspects, possibilities of direct contact with academic institutions, civil society organizations, and local authorities. In two municipalities the investigating institution received support from the state's human rights commission. In two other municipalities, the state's attorney general's office assisted the investigation. In another state, support came from the government secretariat while in another there was no official support (the situation did not require it).

So far, 60 semi-structured interviews have been conducted with direct and indirect victims of serious crime: mainly kidnapping, murder, disappearance, rape, and injuries caused by the use of firearms. Another 240 people participated in focus group discussions. The participants were selected through the "snowball" strategy. The interviews covered the following topics: victimization experience, needs of recognition and emotional support, economic consequences of victimization, protection needs, contact with the police and other authorities, contact with the prosecutor, and participation and social activism.

A very important point of discussion, within the research group and accompanying specialists was how far anonymity should be upheld in 
Murders in Mexico since 2006 related to drug trafficking activities Source: Author $=$ Grupo Reforma 2011/ wikimedia.org oftware Atlas.ti was used to build a database

\section{Drug-War Related Murders in Mexico}

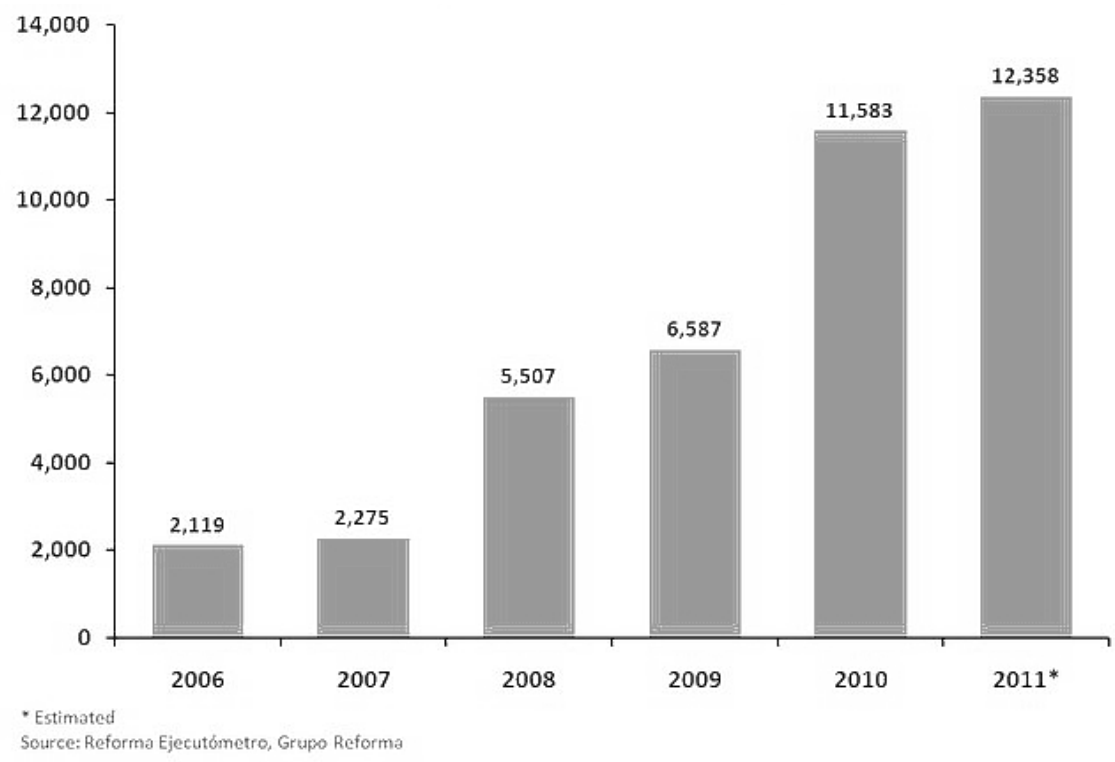

the interviews. Absolute confidentiality was a principle. All conversation transcripts from the focus groups and from the interviews were coded using the open coding technique of Grounded Theory. ${ }^{4}$ The investigation needed to exclude the possibility of relating the testimony to the victim; therefore, the victimization fact, the origin of victimization, the circumstances of manner, time and place, the state response, and the identity of the informant were kept anonymous. The territory where the information had been gathered was the only distinguishing characteristic of each data entry.

\section{Insecurity and changes compared to the past: impacts}

\section{The new situation of unsafety}

On August 11, 2011, a request for information was made to the Secretary of National Defense and the Office of the Presidency of the Republic for the documentation used "to design the project and plan combat strategies against organized crime, especially drug traffickers during the administration of President Felipe Calderon " (Lizarraga, 2011). It was found that such documentation was non-existent. In other words, the use of federal forces (navy, army, and federal police) to combat drug trafficking had been decided without a diagnosis or plan and was only a unilateral mandate by the then head of the Federal Executive. Hence, the far reaching consequences of these top-down decisions took little account of possible suffering people and communities would experience.

The extent of violence that is gripping the country is now known and recognized. It is a phenomenon that developed through a number of identifiable stages but started from a dispute around a possible election fraud; it has been deeper entrenched through the ignorance of the 

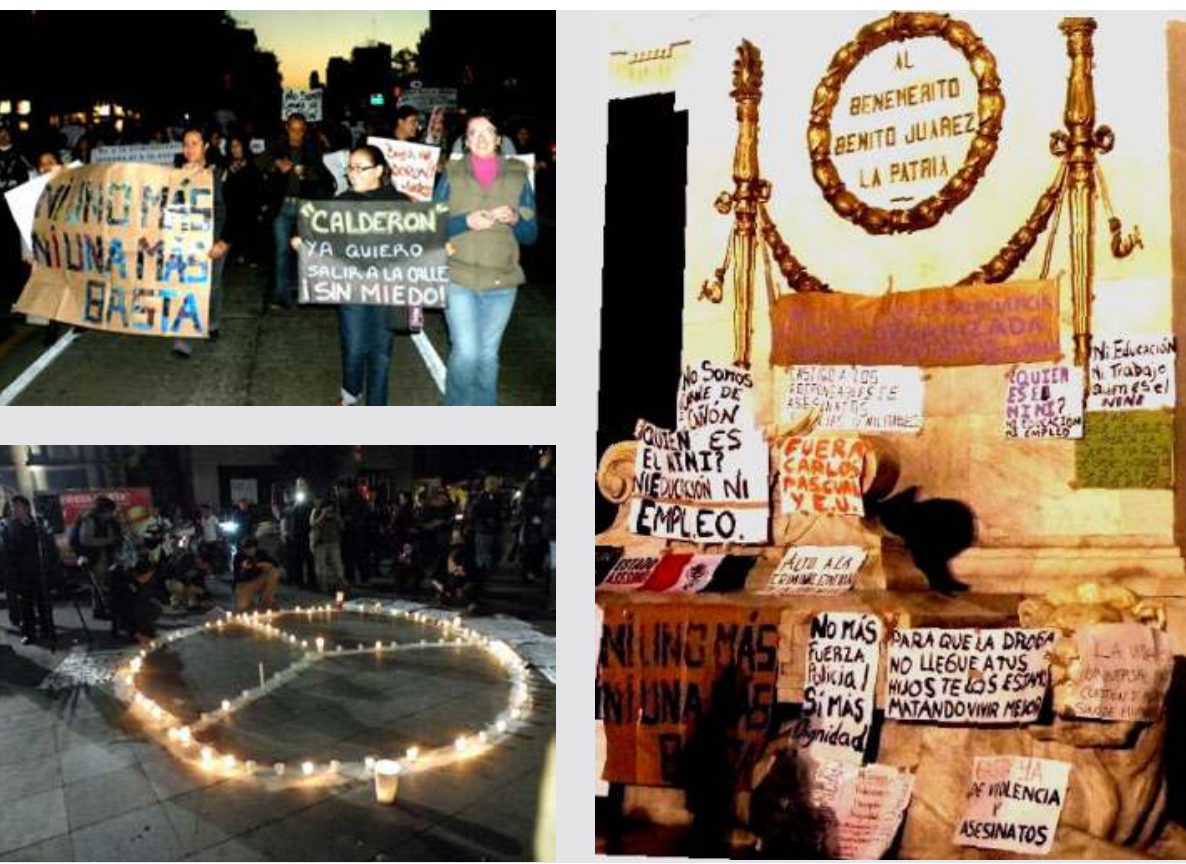

Veronica Martinez

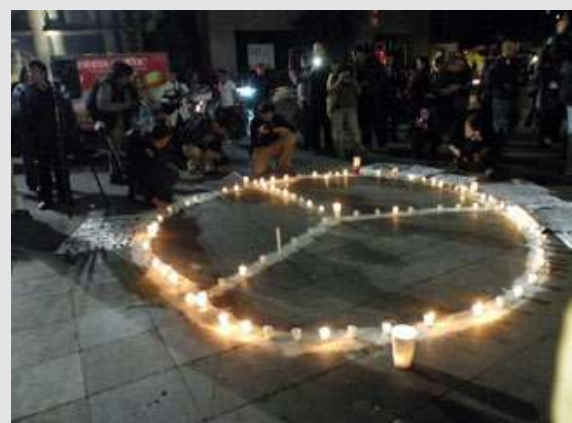

country's culture; and has been promoted under the name of the "war against the enemies of Mexico", "war on narco trafficking", and "the war against drugs". ${ }^{5}$ The term 'war' was used initially as a metaphor whereas the effects were very real: death, pain, and destruction. The development was well monitored by the National Survey on Victimization and Perception of Public Insecurity (ENVIPE) by the National Institute of Statistics and Census (INEGI 2013) as well as the National Crime Survey (ENSI) conducted by the INEGI (2011) and Citizen's Institute on Insecurity Studies (ICESI). In the series of surveys conducted by ENVIPE until 2013, there was an increasing perception of violence in public: a greater presence of frequent assaults and drug use (38 percent), gangs or gang violence (30 percent), drug sales (21 percent); high-impact crimes extortion and kidnappings ( 9 percent), and homicides (12 percent). Furthermore, one in 10 Mexicans in 2012, reported having knowledge of kidnappings in the vicinity of their homes, a third of the population lived with violent gangs operating in their community, and nearly four in ten Mexicans were exposed to theft or robbery with violence in their neighbourhood.

Complementary to the ENVIPE's survey, the perception of violence appeared rapidly in the discussions and focus groups conducted in the visited municipalities. Once the theme "major problems in their neighborhoods and municipalities" would be brought up, "insecurity" always ranked as the biggest concern. Later, often with caution (particularly by men), concrete details regarding personal or second hand experiences were communicated. It was not uncommon that the issue of insecurity would be brought up directly by naming those forms of crime or problems of violence that most concerned them. Representative accounts of the "new reality" of insecurity in their communities and municipalities were:

05.

Presidential statement from September 12, 2008. 
- The main problems are of insecurity, because just the day before yesterday I happened to see a couple being mugged. (Women's Group,Municipio 1)

- Right now the main problem in my neighborhood, for example, is that many people are appearing dead on the street; there are about five of them every month. (Women's Group, Municipio 2.)

- The level of offences has risen from thefts to assaults, to kidnappings; all those crimes are becoming more violent each time. (Male, Municipio 3).The neighborhood where I live is not as problematic in itself, that is why we have shops here or you have groups ... But they come to throw away people that they already killed, or hanged ... they have done a thousand things to them. They come and throw away the bodies. (Men's Group, Municipio 4).

Right now in the light of day we see things that we did not notice before. Those things only happened in the movies, right? [...] And right now this is the normal day and we get scared and say what's going to happen? Since children cannot walk on the street at certain times of ... well right outside the house playing, because certain people may pass by with guns ... and a bullet may hit them. These are very rough things. (Women's Group, Municipio 5)

Communities generally have a number of problems with violence and crime that concern most individuals, but, according to participants, the highest concerns are the killings (often referred to as the "dead" found in neighbourhoods or "executed"; clearly indicating the type of homicide), kidnappings, violent robberies, extortions, cartel's protection charges, and shootings and clashes between groups of drug traffickers or authorities. To a lesser extent, violence against women was also mentioned (particularly in two municipalities in the Midwest of the country) before other criminal or violent acts.

However, this range of crime and violence that takes place, that doesn't seem to have a logical pattern, according to participants, is consistently present. Furthermore, two of the northern municipalities mentioned the "dead", but the focus of concern, and the experiences reported, emphasized "shootings", "confrontations", and "operations". In the remaining municipalities, these problems, in addition to abductions, kidnappings, extortion, and other forms of social violence had greater resonance in the comments and stories from participants

\section{Changes in reference to the past}

On a more general level, common to all informants is the perception of increased violence and the concomitant fear of violence. The discourse on the situation of insecurity often includes a reference to the not-so-distant past, with five main features embodying this difference:

1) The new graveness of violence and crimes such as disappearances, executions, collections of cartel's protection fees, shootings, and confrontations. Assaults and robberies, where violence is a clear new manifestation, are also incorporated into this new form of violence. 
2) The increased presence of firearms (especially larger gauge firearms).

3) The "appearance" of centrally organized entrepreneurship stipulating violence (i.e. drug trafficking or the "narco" and now gangs incorporated into drug dealing). It is also important to consider the detentions by the authorities that acted as the trigger for this transformation -clearly the case in two municipalities;

4) A much higher level of fear and social distrust among the population.

5) And finally, all these changes have a more or less a shared typology, with different time lines for each municipality -according to the views expressed by the groups- but that clearly falls between 2007 and 2010.

It's not only a dead person, someone beaten to death, a death from a bullet, now they do more sadistic things. So that is another fear. They disappear, and the lucky one pops up again, but appears in terrible condition; those who don't appear ... well you don't hear from them again. (Women's Group. Municipio 2.)

Before they would sell their [narco] things and even the governor knew that they sold, but there wasn't that "I don't like you, I will kill you" or "if you do not give me some of your share, I will take it out on you", we had never seen people hanged, butchered; we had never seen that.(Women. Municipio 4).

It is not just for organized crime ... there is many more people involved in these crimes, many, many women, but is not just for that that they have killed so many women ... it has been known in many cases, just because "look, at this pretty girl; pick her up" they rape her, extort money from her, and throw her out. (Male. Municipio 5).

In group opinions and evaluations the expanding violence was noted in three aspects: the level of violence in relation to offenses; the emergence of new forms of crime that are more violent, and an exaggeration of masculinity in interpersonal domination of women.

Also new was the increased presence of weapons which are not only used as instruments for killing, but also as cultural symbols of their hierarchical position as "men" (Page 2009; Dolan 2003). If the model of traditional masculinity requires demonstrations of dominance and intimidation over other men (while female subordination is a given), the weapon accomplishes this and explicitly represents it. In particular men that can be considered as socially or economically excluded can easily resort to violence, armed in particular, to gain access to consumer goods, but also for the articulation of status and power.

Also having access to "women" can seem attractive, which is considered another "consumer good" in this new status and lifestyle. That is why strategies for reducing gun violence should not be limited to economic markets and incentives, but also take into account the current cultural value of the weapons, which necessarily means the consideration of psychological and gender perspectives. 
On the other hand, in the five municipalities, the incorporation of youth (the reference term is 'padillas' but the terminology is somewhat more fluid) into drug dealing gangs is one of the clearest changes in urban violence issues. The incorporation of the "youth", "cholos", "pandilleros" or "narco" (narco-trafficking) youngsters in (or nearby) their field of violent operations seems to be not only a new violence problem, but also a element that is deeply affecting the social dynamic of communities and hampering conventional forms of social control. Szabó de Carvalho, Garzón and Muggah (2013) underline:

"Cartels, commandos, and larger scale structures of organized crime service local criminal factions like gangs and bands, to expand their influence and gain territorial control. This explosive mixture has provided weapons, resources, knowledge, and contacts to these groups, which until now were considered minor structures. Through this symbiotic framework, which has become a problem of national importance, drug trafficking has infiltrated the local level and [become] a serious safety threat at the community level."

The capacities of informal social controls of violent and criminal behaviour have eroded due to the presence of weapons and the involvement of youth and adults in criminal groups. The feeling that is transmitted in the interviews is that violence increasingly covers more spaces and forms and can be driven by more and different motivations, or worse, without identifiable motives.

In respect to conflict conciliation opportunities within the community, the merger between local "youth" or "pandillero" gangs and the big drug trafficking syndicates introduced new challenges. On the one hand, although the drug trafficking networks in communities seems to include young people as well as adults, the use of the label "youth" gangs (or more disparagingly of the "cholos" in the north of the country) is a way to build the figure of the "others" as those who engage in and are responsible for criminal activities. Second, the presence of weapons and external resources or contacts (which in turn are capable of exercising violence) limits the intra- community containment potentials do real with "criminals" and "gangs" without necessarily involving state instances (who, for example, will necessarily appear on the scene once a person is shot).

\section{Changes in personal, family, community, and social life}

Direct or indirect experiences of crime and violence have invariably modified many aspects of personal, family, and social life in communities. The participants' accounts and opinions on new forms of violence and crime that have taken place in their towns and neighborhoods testify to the appearance of new levels of worry and fear. This is not to say that the new fear and anxiety are a simple consequence of the increased presence of violent crimes in their municipalities- especially in light of more complex mediation opportunities than in the past. However, the anxiousness and emotional stress resulting from the new social order in the communities are important elements in the narratives captured by the interviews. 
Generic questions in population surveys like how safe residents felt in their neighborhoods at certain times of night or what crime generates more fear do not allow a full understanding of the type of fear and other emotions that most violent criminal activities, like kidnapping, executions, tend to produce... Such feelings may be communicated best from the stories where the talk of fear, anxiety, or despair is linked to crimes such as abductions or homicides. The level of self-concern, and even more so for children or other close relatives, drives most of the personal and family related measures that participants say they have taken to try and prevent victimization (or the repetition of victimizations, in several cases). It is a state of being permanently alert that has quickly become naturalized in Mexicans' daily activities and is something that has become as common as going to the market in the morning, transmitted in the following quotes:

- It was Saturday and around there by the food market I found some heads.

- Yes, at eight in the morning and there it was: all the police "oh, now what happened!? Now what happened? Should I enter? Will I get there or not? What should I do?" So one is with fear, anxiety and stress and all that. (Woman. Municipio 5.)

Emotions surrounding violence and its impact on the lives of people and their families, and the ever-present risk of becoming a victim of violent crime, will have invariably led to the re-definition of spaces and activities that once were perceived without any potential danger. This social phenomenon of increased risk perception and anxiety could be associated with many contingencies of contemporary life (the risk of job loss, for example), which already existed in the communities under study along with other cities in Mexico where there was a general concern about becoming a victim of property crime (like forced sales or donations of land). However, in the case of the selected municipalities, the risks linked to serious forms of violence (abductions, kidnappings, rapes, murders), caused emotions that were much more extreme. The groups who expressed these emotions most frequently were women and, in particular, those with young children.

Another reason for fear and anxiety related to the phenomena of widespread violence alludes to the 'new solitude' that individuals or their families experienced while taking precautions against everyday risks of becoming victims. Community and institutional distrust has isolated the population, which does not know where to turn for help. In the following quote, the doubts of the boundaries between gang crime and the authorities are evident alongside the helplessness felt by people who are left with only their closest family circle as a resource.

One day there was a reunion at my house with my mom's friends and there was a call ... "Am I talking to the home of the John Doe family?" And I say, "Yes, how can I help you?" and the caller says "I'm from the police" I can't remember what kind of police he said, just that he was Commander of who knows what, and he said: "I have just been informed that close to 
your house a van of drug traffickers just passed by, and you better tell me the truth because we're going to go there you son of a ...." I just hung up because if you go with the flow they will continue ... but I kept thinking ... "what if it is true that they are coming?" I was afraid, I was anxious and I said to myself "now what?" I told my mom "we better go inside"; we were in the courtyard. Yes I was left with that fear: "what if it's true and they arrive?" (Woman. Municipio 2).

The sources of fear and anxiety about crime are multiple and cannot be thought of as simply direct or indirect results of the actual occurrence of crime. To that, the impact of permanent accounts on crime and violence through the media, conversations with friends and neighbors, stories of crime victims, observation, and daily conversation about police activities and other security forces, as well as direct observation of violence in the street must be added. Therefore, it becomes a real challenge to develop anti-fear strategies by reducing the permanent "subjective" feeling of being at risk for violence. As for institutional security and justice actors, this implies that consideration of the emotional aspects of the people must cover all types of contacts between the public authorities and citizens who turn up for help. Of course, the way in which the police and justice institutions act also affects the public perception of crime and the possibilities to control it. If government institutions do not seem to care about the possible containment of crime and if their performance gives raise to certain levels of distrust, the chances for correcting negative effects of stress, anguish, and despair of people decreases. While changing beliefs and emotions about crime cannot be altered at will, the authorities must learn to adapt their style of communication to the affected population, particularly in areas where the crisis of insecurity and violence is lived firsthand.

\section{Individual and community responses}

The group conversations led to the conclusion that the authorities were not considered as an appropriate mechanism to solve security problems: sometimes they only provided a partial solution, while in other situations they even caused a new problem. Therefore, as the levels of violence rose (including retaliation) the already socially established pattern of "not

06.

According to ENVIPE 2013, in 2012 the overall percentage of non-reporting was $92.1 \%$. This percentage reached $98 \%$ on the kidnapping by an estimate of 105,600 cases in the same year.

Common non-violence stickers currently circulating in Mexico reporting" became further strengthened ${ }^{6}$.

Thus, the possibility of retaliation for reporting certain crimes (more if the perpetrators are part of or have links in the community) was always
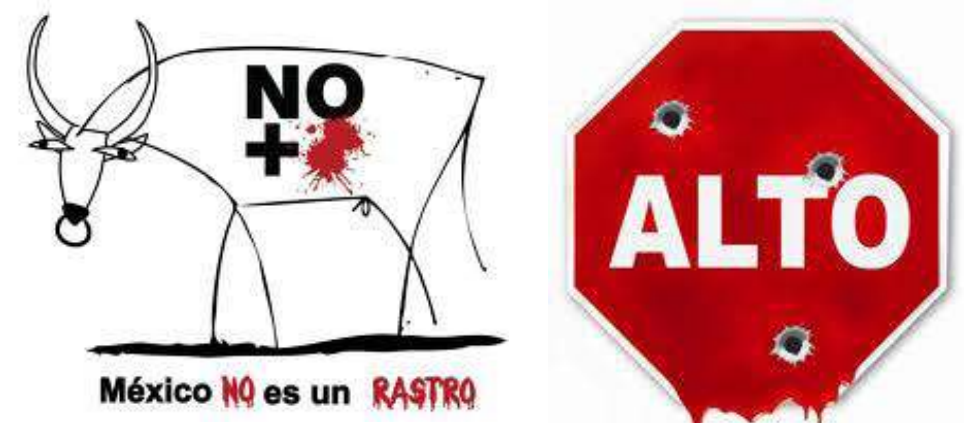
one of the reasons for not reporting. ${ }^{7}$ In the conversations, the practice of "no complaint" was usually associated more with fear of reprisals than a waste of time. Retaliation is often facilitated through corrupt prosecutors and local police who frequently conspired with criminals or organized groups and identify the person who has denounced a criminal.

On the other hand, in a context where violence not only increased, but also where the uncertainty of its occurrence grew, omission strategies were not limited to the possible reporting of crimes. The group discussions also highlighted fears associated with getting involved in violent conflicts between others (such as helping wounded people or questioning police or strangers' behaviors, etc.).

Not knowing which people may be involved in transactions of drug trafficking, were members of a gang, or might "simply" react violently (e.g. by owning a gun or pistol) represented the risk of publicly questioning any type of unusual behavior. This way, informal social control mechanisms were weakened while the terrain for social violence expanded. The risk of "getting involved" in others' problems or behaviors is also communicated in various "instructive" tales, which, if followed, contribute to the dismantling of social capital and increased distrust and weakening of social ties.

07.

This logic was reinforced if reprisals increased in violence and authorities could not guarantee its containment.

Anti-violence protest march. Source: cipamericas.org.es archive

The process of enforced social isolation. minimizing interactions, words, and wanderings in common space, have also become palpable. Some people who belonged to the middle classes, who lived in urbanised housing developments (known as the 'colonias' in Mexico), are less affected by the processes of social fragmentation, since for them the residential neighborhoods is not much more than the places they sleep and enjoy family life, while their social networks and the places they identified with extends to other locations and to social contacts beyond their own residential neighbourhoods. But the more popular section of society derives greater meaning, identity, and satisfaction from their involvement 
in the local community and its space characteristics (St. Jean 2007). For them, the impact of isolation is greater and their community ceased to exist with the exception of a few family members and friends that they trusted without second thoughts.

On the other hand, a kind of "social agreement" in the popular language to not talk about the violence committed by specific gangs (which are often indirectly and loosely referred to as "they", "the bad ones", not to talk about "that", etc), was reiterated by the group participants. These stories confirm, on the one hand, that conversations about violence and its consequences were daily practice among circles of friends and within the family, but on the other, that speaking about violence was forbidden by the rules of social interaction: local acts of violence should never be discussed with strangers and, with respect to new violence in communities, it should never be reported.

Practices, in respect to personal and family precautions against insecurity, varied considerably. Some measures related to securing the houses, most of them being protective and defensive. However, in the case of three municipalities where violence had a longer presence (and moreover, in households which had been engaged in some kind of commercial activity), more aggressive measures were indicated (presence of weapons and a belligerent attitude), which could have a deterrent effect, but also turn counterproductive in the case of exaggerated self-defense, as happened in another federal state (Michoacán).

Changes in the use of public spaces were even more varied. The victimization surveys showed that there are certain social routines that are not practiced any more, such as meeting relatives and friends. This is a commonly observed phenomenon in recent years and represents the weakening of social bonds. Both the focus groups' discussions and the interviews with victims showed that rather than stopping routines, most of them are modified with clear intention to minimize risk.

This behaviour is in line with the common theory of situational crime prevention (Clarke 1997) or routine activities (Cohen, 1997). Participants understand that they have to reduce their probability of being available targets for potential offenders, especially in the absence of capable guardians (which in this case would be different types of police). However, such behaviour only favors a reduced perception of violence by mechanisms of depersonalization or avoidance of habit.

Also, individual, family, or community vigilante justice has become a common and legitimized strategy. Vigilante justice also applied to more 'ordinary' crimes, such as theft. The experiences of vigilante justice described by respondents constitute acts of retributive justice, made with some degree of planning and premeditation, and perpetrated by autonomous citizens (Johnston, 1996). In some cases they resorted to this strategy after the failure of the formal mechanisms, but vigilante justice has also been treated as a legitimate primary form of justice. Such vigilante justice only applied to certain types of violations of order and when there was certainty that the offenders lacked relations to organized crime (generally known youth neighbors). The typical proverb legitimizing a violent response goes like this: "One has to choose if there will 
be crying in your home or crying in mine" (essentially, "better you than me").

It can be assumed that [vigilante justice will occur] when we catch someone who got out of line, and since our government ignores us, we will give [that person a] lesson, and see if they return back to the neighborhood. But until now it was not necessary. We have seen thieves, but they know who we are and they will not return to our neighborhood again because they know that people will defend themselves. (Men's Group. Municipio 1).

\section{The State's response.}

One point of interest in this research project has been the contact of victims with the criminal justice system. After experiencing a violent crime, victims had to overcome several challenges. The first was how to overcome the personal experience of victimization: the physical, psychological, spiritual, economic, and social impacts of crime or violence on their lives. Second, there was the harm to which victims were subjected to by the justice system. That is, the damage that the victim experienced as a result of their interaction with the justice system, better known as secondary victimization.

Police occupy a key position in the delivery of criminal justice; the same applies to crimes or human rights violations. This means that when victims decided to report a crime, the police were the gateway to justice. The result of the contact established between the two actors -police/ victim- often depended on the nature of the crime in which the person was victimized: the kind of police that the victim approached for support, the paths taken thereafter to access law enforcement, and the actions taken by the officers themselves was often determined by the institution the victim contacted.

Most of the victims interviewed never got in contact with the police after witnessing or suffering a crime. The reasons were diverse: some victims decided to go directly to the prosecutor to report the crime. In other cases, the police never attended to the call for support, and in most cases victims distrusted the police or considered that the police could be linked to organized crime.

From the total number of interviews conducted with primary or secondary victims who contacted the police -which was mostly the municipal police-, the officer's support was nil, both at the physical or emotional level. Only in the case of a rape that happened in the first municipality, the victim acknowledged that the police officers provided her with material and physical support in the immediate aftermath of the crime. In other situations, people described a general lack of concern and interest by the authorities to provide trust and security to victims; others reported a significant refusal by the authorities to provide physical aid to injured persons. A critical limitation in evaluating police performance was that just a few of the interviewed participants could differentiate between different police agencies (municipal, state, federal, or detectives). 


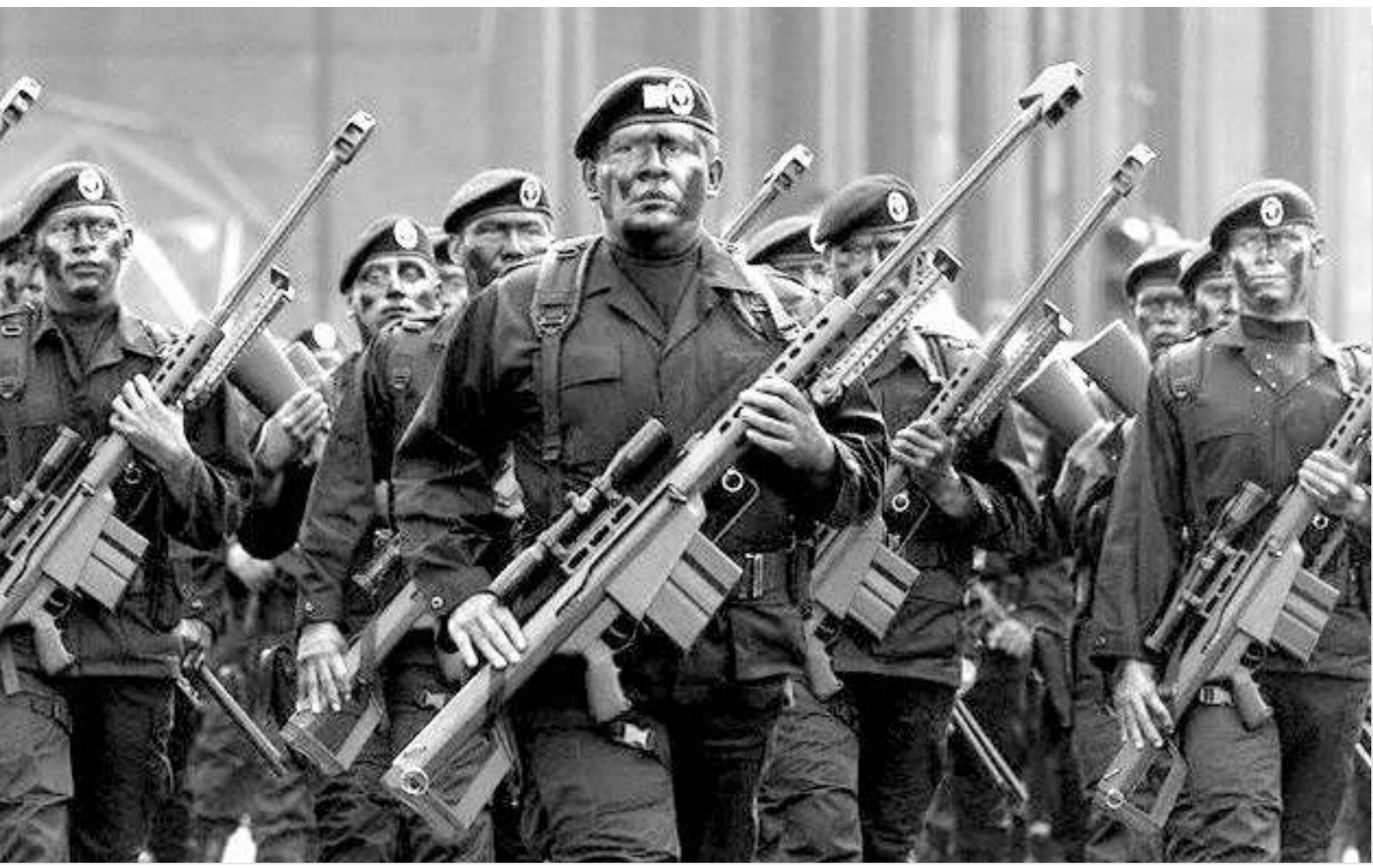

The War on Drugs: Insertation of the Fuerzas Especiales Avanzadas of the mexican army in the raids realized in Michoacán. Photo: Wikimedia/ Diego Fernández
Another point of interest for the research project was the assessment made by victims on the work done by the prosecutor, when they had contact with that authority. Testimonies can be divided into three main categories, derived from victims' opinions and perceptions. These are: (a) treatment and care; (b) legal procedure and performance of duties; and (c) suspicion of collusion and corruption. From the interviews one can conclude that the work of the prosecution, unlike the police, was more heterogeneous and, in some cases, more than one response was given within a singular account.

The general perception on the performance of the public prosecution service was inefficiency, dishonesty, and impunity. One of the arguments for reforming the criminal justice system was to overcome this perception and target better management of cases, greater transparency, and increased trust through better treatment. However, both in municipalities with the "new" system and those with the "old" model, victims faced the coldness of the criminal justice system, which was categorized as an excessively complex administrative setup with lengthy paperwork and bureaucratic forms. Moreover, indifference service with a lack of sensitivity and empathy on the part of public servants was noted.

The first duty of the prosecutor is to provide information to victims. But for a victim searching for help, the first encounter can rather turn into a demonstration on the deficiencies of the institutions or their staff. For them, the experience with the public prosecutor often transmit a feeling of lacking commitment in the first place and a refusal to provide essential information on the rights of victims or advise them on the procedures 
and formalities of the investigation or trial. Such attitude causes feelings of abandonment, uncertainty, and sometimes helplessness and leaves many not knowing how to proceed or who to contact. Apart from the fear for reprisals from perpetrators, another reason was a lack of knowledge on an individual's personal rights and the proper functioning of the institutions themselves.

Overall, both the focus groups and the testimonies of the victims interviewed showed that the criminal justice system represented a hard and tortuous road. The participants identified contact with the public prosecutor service as a second victimization. Such victimization, as described by the respondents, was noted as being indifferent, apathetic, delaying, negligent, or dissuasive. Compounding these feelings was the victims' level of distrust due to infiltration, corruption, and suspected collusion with criminals. This perception was mostly accentuated among testimonies related to disappearances.

It is in this area where, in addition to the dimensions described, the stigmatization of the primary victim appeared as an excuse to leave the responsibility of the investigation to the victim, either through inaction or delaying, indifference, negligence, or even by encouraging the family to take over the inquiries themselves. In this last case, indeed, some victims conducted investigations with all the problems of someone that does not have the statutory mandate of authority: no access to legal resources to find evidence and no physical support to ensure their safety. Even relatives of disappeared persons went to places where bodies of executed people were found. Some participants told about relatives of victims who interviewed organized crime members and requested help from them to find their missing family members.

Another important point is related to the treatment given by the authorities of the "old" criminal justice system and the changes attributed to the new procedure implemented nationwide since 2008. Of the five visited municipalities, three of them had the accusatory system. ${ }^{8}$ However, from the testimonies of victims, as well as from the focus groups, a widespread ignorance was identified regarding how the new system was supposed to work. For the victims, there was no change in treatment and care: procedure and performance of duties, as well as the suspicion of collusion and corruption persisted. The perception of victims was that the new system created more gaps for impunity because it became easier to get rid of the criminal sanction and carry out the process, which increased the threat to the victims. But neither the „old" nor the "new” criminal justice system has been capable to deal with high-impact crimes so far.

One common thread in the answers of victims was the legitimacy and capacity of State institutions at all levels (federal, state, and municipal) to instigate the appearance of violence, including the "legitimate" use of force in the communities and neighbourhoods of the affected municipalities. The local security institutions were only partially able to deal with current levels of crime, even if complemented by informal responses from the community.

In other sectors of provision with basic needs, like housing or infrastructure, a failure by the state to provide the needed assistance, the

08.

It was not possible to collect testimonials about the judiciary process because none of the cases that we knew came to court, even though some of them had a date of 2006. 


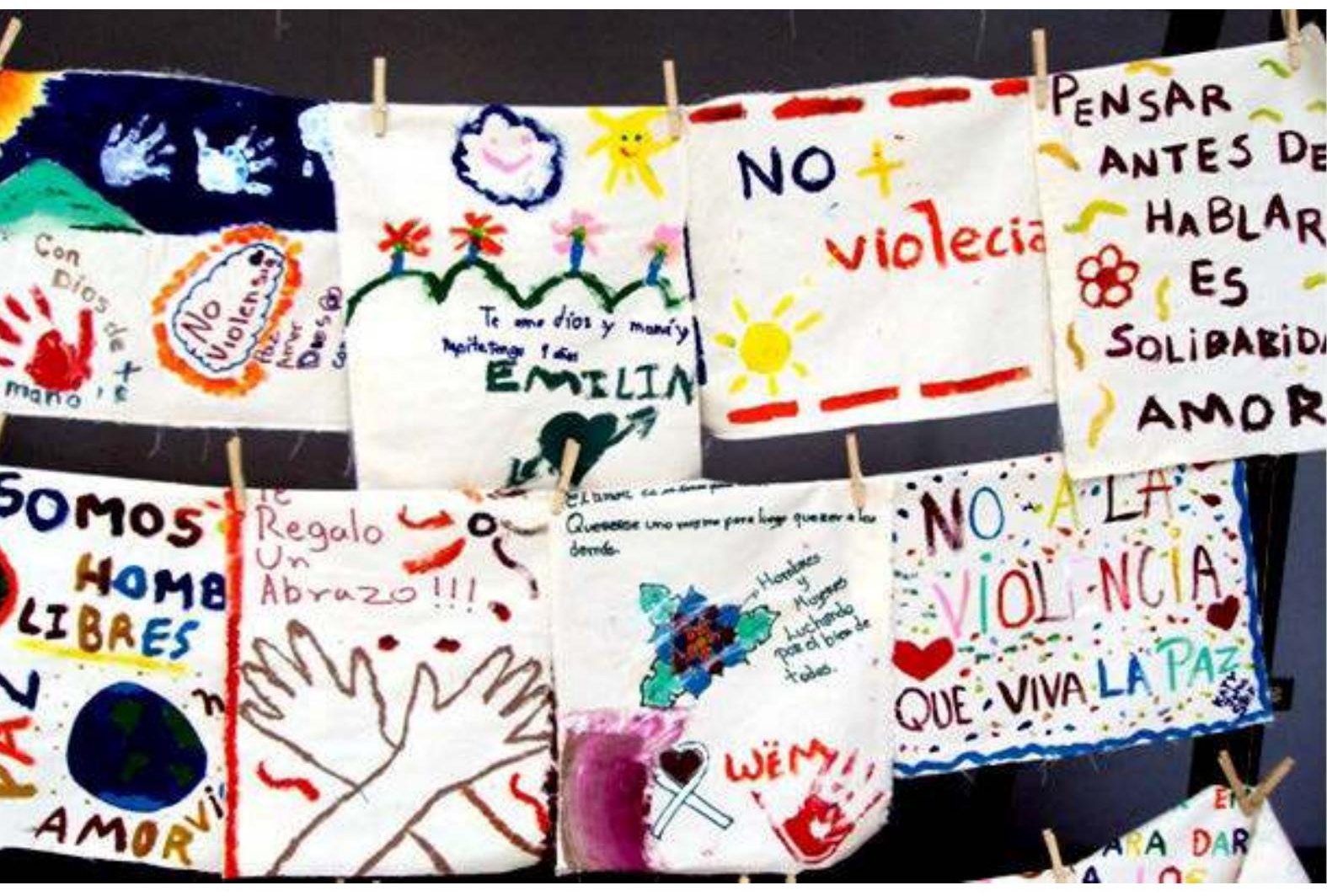

community tends to search for a (often collective) self-help solution. When it comes to protection from armed violence, such approach rarely presents a solution. The Mexican research data confirmed that the community action on its own has clear limits in facing of the real power of armed drug-trafficking groups.

In the context of 'petty violence' the situation can be different, but necessarily desirable either: in such situations of local authorities, professional, and reliable institutions of justice failed to function, various forms of vigilante violence and "mob justice" became spontaneous methods to deal with problems of violence at the community level in other countries in certain periods.

\section{Community action}

While there were very few respondents who participated in some form of social activity following victimization, in some cases, efforts were made to demand clarification on their case while others came together to meet, engage with, and create support networks for other victims and/or their families. Activities, protests, and complaints were intended to highlight the flaws of the institutions of justice, the lack of attention their cases received, corruption, impunity, and the abuse of their rights. In short, such actions were made to address the lack of access to justice, to demand their right to know the truth about what happened, and preserve the memory of victims, especially in cases of abduction and murder. It should 
also be noted that such activities by the victims were a response to an emotional need: through such actions, empathic processes and cathartic, emotional recognition between people who have gone through similar circumstances could be achieved.

In this sense, three types of social participation of victims can be identified in the testimonies. The first is that such social interaction tried to communicate victim's experiences so that they served as an exemplary case from which others could obtain empirical knowledge on how to prevent victimization or how to act in light of it (where to go for recognition and emotional support from people who have gone through similar circumstances).

Another way that social participation was manifested was through more public and collective situations, where victims began to promote or participate actively at the neighborhood level. The third type of social participation had to do with an open participation in larger organizational processes through which victims sought to exert pressure on the authorities to provide answers -individually and collectively- to the needs of victims and their families.

Moreover, an important point to consider in the design of public policy is related to the use of social networks. Though not considered in the interview guide, primary and secondary victims, community members, and civil society reported the importance of making visible the reality of their communities, counties, and states. While some censorship issues on drug-related violence and the state response were described, participants stated that social networks were a key to alert one another, learn about violence, and encourage sufficient responses by the authorities to actions of organized crime.

\section{References}

Attorney General's Office database (2012): deceases occurred due to alleged criminal rivalry. http://www.pgr.gob.mx/prensa/2007/bol12/ Ene/b01112.shtm

Clarke, Ronald V. (1997)“The Theory of Crime Prevention Through Environmental Design" Available under www.e-doca.net.

Cohen, Lawrence and Felson, Marcus (1979). "Social Change and Crime Rate Trends: A Routine Activity Approach", American Sociological Review, 44 (4), pp. 588-608.

Curcó, Felipe (2010). La guerra perdida: dos ensayos críticos sobre la política de combate al crimen organizado 2006-2010. México, Ediciones Coyoacán

Dolan, Chirs (2003). Collapsing Masculinities and Weak States - a case study of northern Uganda. In: Cleaver F (ed), Masculinity Matters: Men, Masculinities and Gender Relations in Development. Zed Books, London.

INEGI (2011). Instituto Nacional de Estadítica y Geografia. Encuesta Nacional sobre Inseguridad (ENSI) http://www.inegi.org.mx/est/contenidos/proyectos/encuestas/hogares/especiales/ ensi/default.aspx. Consulted 02/08/2014.

INEGI (2013). Instituto Nacional de Estadítica y Geografia. Encuesta Nacional de Victimización y Percepción sobre Seguridad Pública (ENVIPE). http://www.inegi.org.mx/est/contenidos/proyectos/encuestas/hogares/regulares/envipe/default.aspx. consulted 8/2/2014.

Johnston, L. (1996). "What is Vigilantism?" British Journal of Criminology Vol. 36 No. 2 (1996).

Lizarraga, Daniel (2011) Public information request folio number 0000700117911 by Daniel. http://www.sedena.gob.mx/leytrans/ ifai/pdf/2011/RI.0000700117911.pdf, Consulted 02/08/2014

México Unido Contra La Delincuencia, (2014). Seguridad Pública en México 2006-2012. http:// mucd.org.mx/recursos/Contenidos/Estudiosycifras/documentos2/Seguridad\%20Publica $\% 20$ en\%20Mexico\%202006-2012.pdf. Consulted 02/08/2014

Page, Ella (2009). Hombres, masculinidades y armas de fuego, ¿podemos romper el vincula? Ella Page, Red de mujeres de IANSA (http:// 
www.iansa-women.org/cs/)

Presidencia (2008). Words pronounced by Felipe Calderon. www.presidencia.gob.mx/ 2008/09/en-la-guerra-contra-la-delincuenciano-habra-tregua-ni-cuartel-presidente-felipecalderon/ Consulted on November 11, 2011. (For some reason the original document has disappeared, but the statement was recorded by various electronic media agencies).

St. Jean, Peter K.B (2007). Pockets of Crime. Broken windows, collective efficacy and the criminal point of view. The University of Chicago Press. Chicago 


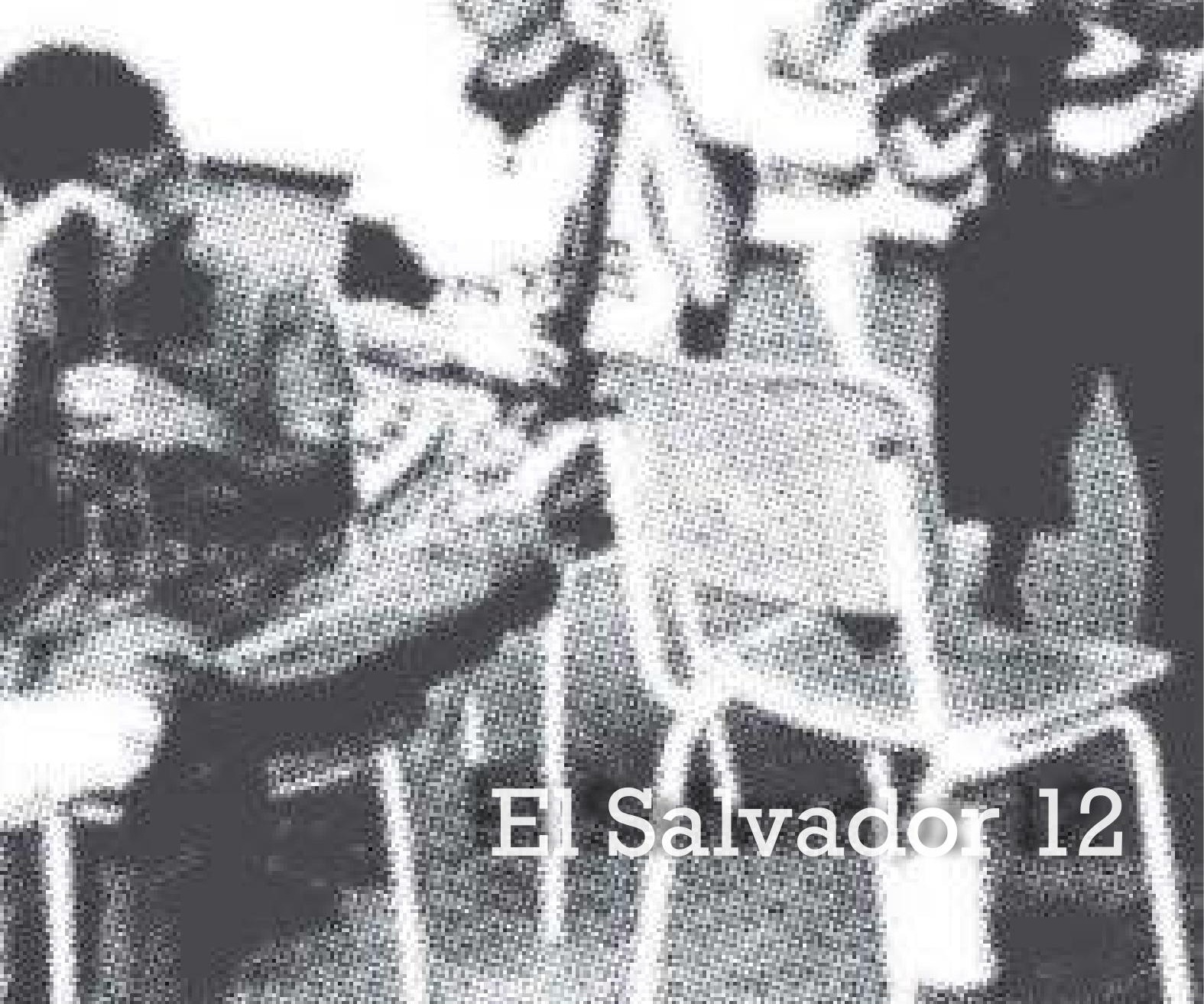




\title{
Youth as Key Actors in the Social Prevention of Violence The Experience of PROJÓvenES II in El Salvador.
}

\author{
María Antonieta Beltrán \& Wim Savenije
}

\section{Introduction}

Two rather extreme images of youth tend to appear when speaking of violence and crime in Latin American cities. The first refers to young people from groups who perform illegal practices or violence, such as that carried out by street gangs or maras, gangs linked to drug distribution, paramilitary groups, or hit men. The second presents young people as the main victims of the activities of these same groups (UNDP, 2013).

'Popular neighbourhood' is a literal translation of the term as used in Latin America: 'barrio popular'. In English the terms 'slum' of 'urban ghetto' are also used.

Previous page: A group of young Maras in El Salvador. Photo: TRIALOG / SUM Consult / Roland
Urban ghettos or popular neighborhoods ${ }^{1}$ are often witness street and youth violence (Savenije \& Beltrán, 2012). The control that gangs and other criminal groups exert, the occasional exchanges of gunfire and the recurrent threats to physical integrity can make these places very dangerous. Many locals prefer not to move around the neighborhood or not to stay long on the street, and confine their children to their homes to protect them.

Beyond these images of violence where young people are presented first, as the bad guys, perpetrators, or offenders, and second, as poor or helpless victims; this article seeks to propose the notion that young people can play an important role in efforts to improve the social relationships in their own communities. Particularly, this article highlights the appropriateness of youth participation in efforts to prevent violence and crime, even in areas of high insecurity.

Many young people in the neighborhoods affected by violence and crime have left school early and experience difficulties finding a job. Others do go to school, but can only access poor quality education or find unstable jobs with low payment (ILO, 2012). Nonetheless, when given the opportunity, they show great willingness to spend their free time in activities that are beneficial for the community. The local youth grasp not only the 
dangers, but they also know the existing resources in their neighborhoods. They interact with their neighbors; some have learned the ways to cope with the dangers on the streets and even manage to establish cordial relationships with gang members, drug dealers, or others who commit unlawful acts in the community. Therefore, assets such as being accepted in the community, being familiar with the rules that govern the street, and knowing the members of the violent groups, may facilitate the work of social prevention of violence and crime in highly insecure areas. This does not rule out the fact that the youth are also exposed to adverse reactions or menaces from violent groups. Handling such risks, however, can and must be an integral part of violence prevention initiatives. They should be considered in the budget of every project, as resources, training and monitoring are required for this purpose(Savenije \& Beltrán, 2012).

This paper will start with a brief description of urban popular neighborhoods in Latin America. The difficulties faced by the youth, which set them at a risk for violence, are highlighted. After this, the idea of the social prevention of violence and crime is explained in further detail, emphasizing some considerations for the work in neighborhoods with high levels of insecurity and economic and social precariousness. The third section presents some experiences in which young people worked to improve relationships and reduce insecurity in their communities. These experiences were acquired during the project 'Social Prevention of Violence with Youth Participation - PROJÓVENES II', implemented by the National Institute for Youth (INJUVE) of El Salvador. These efforts have not only been beneficial for community relations, but they have also provided a new sense of life and social integration. Last but not least, they have fostered local youth's social and personal development.

\section{Urban youth in Latin America: poverty and social exclusion in popular neighborhoods}

Latin America has experienced a rapid urban growth in the recent decades. However, much of this growth has been marked by poverty and violence (Muggah, 2007). Latin American cities have become unequal and segregated, i.e. their populations are unevenly distributed in socioeconomic terms (Rodriguez \& Arriagada, 2004). ${ }^{2}$ Urban areas where the poor tend to concentrate, and where also violence is more present, are commonly known as "barrios populares". Although statistically the proportion of the urban population living in conditions of social exclusion has decreased from $33 \%$ to $24 \%$ in the last 20 years, the absolute number of people currently living in slums increased from 106 to 111 million in Latin America and the Caribbean (UN-Habitat, 2012, 2014). Urban popular neighborhoods are often located in areas prone to natural hazards or human-caused risks, as houses tend to be built on river banks, dump sites, streams, steep slopes, along roads, or next to rail lines.

The dwellings often have poor provision of basic services and are typically built with low quality materials (Sabatini \& Brain, 2008; UN-Habitat, 2014). Residents are usually left out of welfare programs and social protection networks (UNDP, 2013, UN-Habitat, 2014). Schools in these neighborhoods tend to be deteriorated, lack sufficient resources, and offer low

02 .

Segregation is also attributed to ethnic background, religion, or age (Sabatini, Cáceres y Cerda, 2001, in Rodríguez \& Arriagada, 2004). 
hinder the effectiveness of initiatives that could counteract the attraction of these alternative paths.

\section{Violence and crime}

Violence and crime in Latin American cities are indeed very high. Latin America is certainly one of the most violent regions in the world. In 2005, the homicide rate in the region was 25 per 100,000 inhabitants (UNDP, 2009). It is worth mentioning that there are substantial differences between the countries in the region. The Northern Triangle of Central America has significantly higher rates than those of the Southern Cone (UNDP, 2013). By 2012, for example, Honduras reported a homicide rate of 90.4 per 100,000 inhabitants, Guatemala 39.9 and El Salvador 41.2; whilst Uruguay reported 7.9 and Chile 3.1 (UNODC, 2013). Similar heterogeneity can also be found within countries. In the same country there are areas with a murder rate that exceeds 10 times that of other cities or regions. Cities, neighborhoods and even streets can also show great differences (UNDP, 2013). The victims of homicide are in most cases young men (ibid.).

Other forms of crime, such as theft, organized crime, kidnapping and extortion, gang fights, and domestic violence, have also a strong presence in Latin American cities, especially in poor neighborhoods (UNDP, 2013). In addition to these precarious conditions of their neighborhoods, Latin American youth have great difficulty in continuing their education and finding jobs.

\section{Working and studying}

Entering the labor market is difficult for youth in many Latin American countries. Often this situation is linked to their level of education (Weller, 2006 in UNDP, 2013; ILO, 2012). Without completing secondary school, their employability in the formal market is reduced (Kliksberg, 2010). Youth unemployment rates are indeed very high, between 2.3 and 5.5 times higher than that of adults; moreover, young people usually only manage to get precarious jobs and low payment (ILO, 2011).

In Latin America, just less than half of the young people finish secondary education: only $48.5 \%$ of 20 year olds have completed secondary school. In some Central American countries (such as Guatemala, Honduras, or Nicaragua) only about one-fifth of youth reach that level. In those countries that have achieved higher levels of education coverage (such as Chile, Peru, or Argentina), still between a quarter and a third of all adolescents fail to complete secondary education. This picture is more critical in the most disadvantaged areas, where the vast majority of young people is far from completing secondary education (SITEAL, IIEP and OEI, 2009). "It suffices to note that at the age of seventeen, nine out of ten adolescents from the better socio-economically positioned homes attend school, while half of the poorest young people at that age have already interrupted their studies" (D'Alessandre, 2010, pp.10-11).

The educational level of the parents or heads of the household is strongly related to the socioeconomic status of their families (Croso, 2010). Only $20 \%$ of the young people from the households in the lowest 
income quintile completes secondary education (ECLAC, 2007 Croso, 2010). As indicated in the previous section, urban slums are home to parents with little education and low income. However, they also tend to consider education of little importance (Feldman, García Méndez \& Araldsen, 1997). These factors hinder the achievement of children's education. In fact, the most common reasons given by young people for why they leave school early are economic problems at home $(31.6 \%)$ and the need to start working (27\%). In Central America, a link between the high number of dropouts in the age group ranging from 12 to 14 years old and the level of insecurity that young people experience has also been identified (Eljach, 2011).

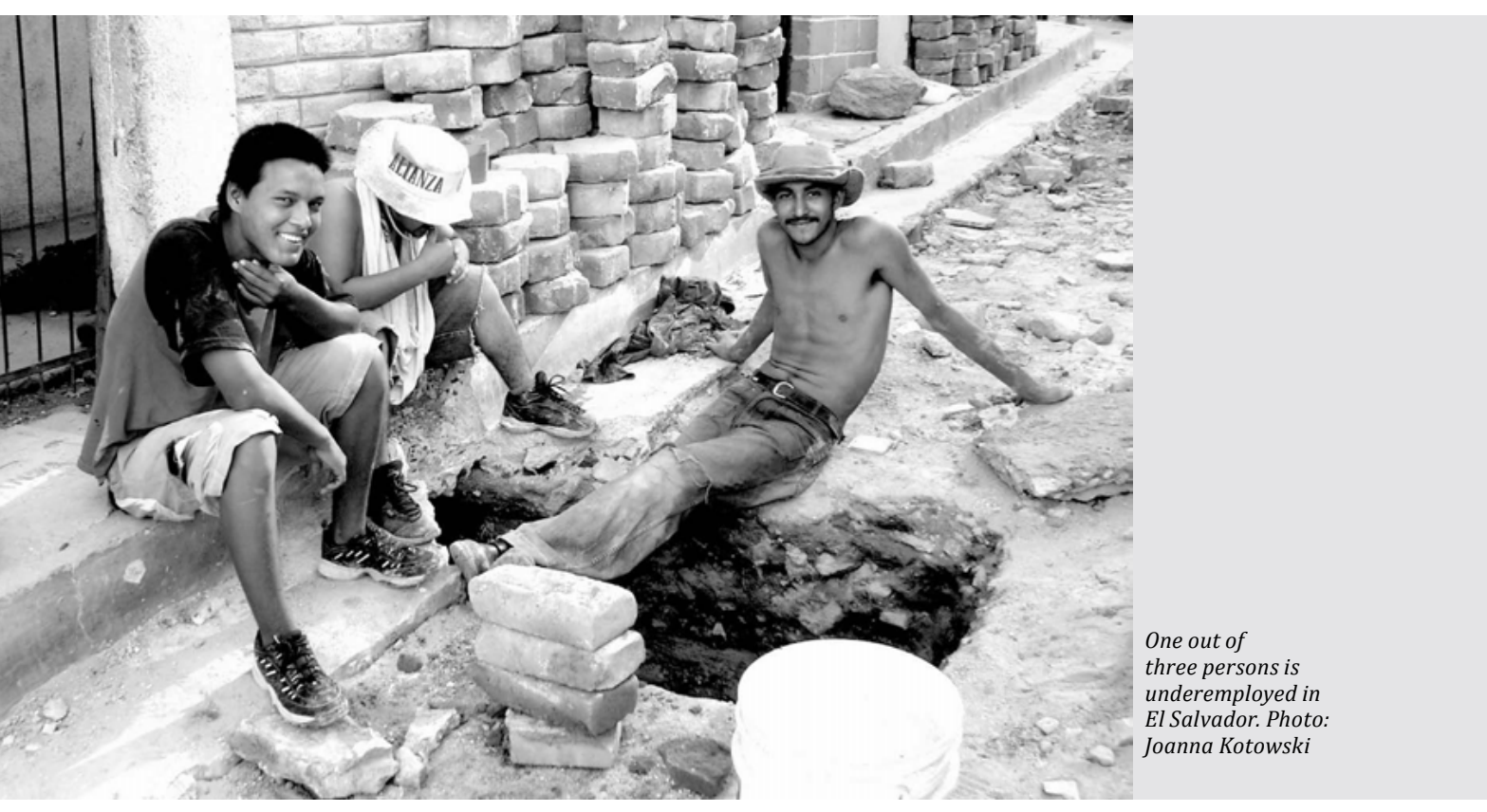

Many young people drop out from school, but not all of them enter the labor force. In 2012 it was estimated that in urban areas of Latin America $13.5 \%$ of the youth and adolescents neither studied nor worked (SITEAL, IIEP - IEO, 2014). This prevalence increases in the poorest countries. The proportion of young people aged 12-17 who neither work nor study in Guatemala, Honduras, and Nicaragua is three times higher than that same group in Chile or Argentina. Also the probability to find a teenager who does not study or work is more pronounced among households with a lower education than in those where adults accumulated more years of study (D'Alessandre, 2010). Without better options to spend their time, youth tend to spend more time on the streets and consolidate friendships with other young people in the same situation. When this happens, the likelihood of joining street oriented groups increases.

\section{Insecurity}

As said before, young people are not only the group most affected by violence, they are also the most common perpetrators. The violence 
and crimes committed by juveniles are usually group related. In Latin America the groups that routinely use violence differ from country to country and are linked to local dynamics (UNDP, 2013). For example, in Colombia the phenomenon of "child soldiers" (adolescents recruited by non-governmental armies) and "sicarios"3 is widespread, like in the Province of Buenos Aires (Argentina) the so-called "pibes chorros", who are linked to all sorts of crime and drug use. In the Northern Triangle of Central America, the phenomenon of street gangs, also known as maras, are responsible for much of the insecurity in poor neighborhoods, while in Brazil similar groups (gangues) operate. In general, these groups or gangs can be considered spaces of encounter and mutual protection among excluded or marginalized young people (Rodríguez, 2007, pp.543-544).

Street gangs flourish in situations of marginalization (Savenije, 2009). Undoubtedly, the everyday social exclusion that exists in the places where young people circulate (e.g., deteriorated schools, parks and urban centers), forms part of the daily environment of many urban youth. The deteriorated physical environment and existing social fragmentation increase the risk that young people join street oriented groups (Savenije \& Beltrán, 2012). For example, some authors estimate that in Central America between $3 \%$ and $5 \%$ of young people living in poor neighborhoods with gang presence, affiliate with gangs. Although in particular neighborhoods, the percentage can be higher (Jütersonke, Muggah \& Rodgers, 2009).

Many young people, including children, that grow up in slums consider it attractive to belong to a street oriented or criminal group. Not only because of the intense friendships, women, access to money, alcohol and drugs, or other material goods that would normally be inaccessible, but also because they can present themselves as powerful, untouchable, and worthy of respect. These groups can be understood as "street elites" who regard the neighborhood as their territory (Katz, 1988). The common people, especially the young ones, fear the damage that gangs can cause to them or their families; especially if they do not obey the rules imposed by these groups, do not treat their members with all due respect, or if they are perceived to be interfering in their affairs.

However, the vast majority of youth do not join the gangs or criminal groups. They have a desire to study and work, and aspire to advance and to improve their life situation and that of their family, and even to improve the conditions of their community. These young people -some closer/further from joining criminal groups than others- should be incorporated as important actors in social prevention programs.

\section{Prevention in highly insecure areas}

The previous section has shown that crime and violence in Latin America occur disproportionally in neighborhoods with economic difficulties, employment instability, deficits in the provision of basic services, and social fragmentation. However under conditions of limited economic and social resources, and frequent incidents of violence and crime, it is difficult to implement projects focused on prevention (Savenije \& Beltrán, 
2012). The police are generally mistrusted by local people; moreover, they often do not have sufficient knowledge of the local situation in order to do an effective job. For the police, doing prevention work often means parking a police patrol car in a street corner, and expecting that nobody will infringe the law because of their presence (Savenije, 2010). Furthermore, frequent patrolling and frisking of pedestrians gives the residents the feeling that the police are targeting them and stigmatizing everyone, especially the young people, who live in the area. For that reason it is essential to develop a different perspective of crime prevention and to implement policies or programs of social prevention that, among other things, offer opportunities to at risk youth with few chances for development.

Beyond the labels of perpetrators or victims, the youth of popular neighborhoods need to be recognized as young people living in difficult circumstances who deserve better opportunities. Instead of abandoning them and stigmatizing them as potential criminals or treating them as helpless victims, it is important to provide them with possibilities for leisure and exercise, to create opportunities for the development of their social and academic skills, to generate access to academic careers and jobs that stimulate personal and professional growth and offer a real prospect for a better future for themselves and their families (Savenije \& Beltrán, 2012). Situate such opportunities in the context of the local neighborhoods may serve as part of a more comprehensive effort of social prevention of violence and crime.

\section{Crime prevention versus social prevention}

Prevention can be understood in many different ways and therefore various approaches have been developed to address it (Crawford, 1998). Understood as "crime prevention", it is often conceived as a task that is the primary responsibility of the police, who are accountable for ensuring public order and security. A broader approach considers that security problems are related to larger social phenomena and accepts that other actors should participate in prevention efforts, and not only security forces (Savenije \& Beltrán, 2012).

The latter approach is based on findings that show that violence and crime are rarely the only problems present in a community. When these issues do arise, there is also the presence of other social problems such as poverty, deteriorated physical environment, overcrowding, or the virtual absence of upward social mobility opportunities (Crawford, 1998; Tolan, Gorman-Smith \& Henry, 2003). The recognition that structural factors have an important influence, has led to the acknowledgement that these factors need to be addressed first of all (Tolan, Gorman-Smith \& Henry, 2003). However, such factors are not the only cause of the presence of violence and crime. In fact, not all popular or crowded neighborhoods suffer from elevated levels violence and delinquency. Social relations between groups and individuals present in the neighborhoods, as well as the quality of such relationships, intervene in their emergence and development. For example, a neighborhood where adults spend time on the streets and in the parks, supervising and participating in the games of 


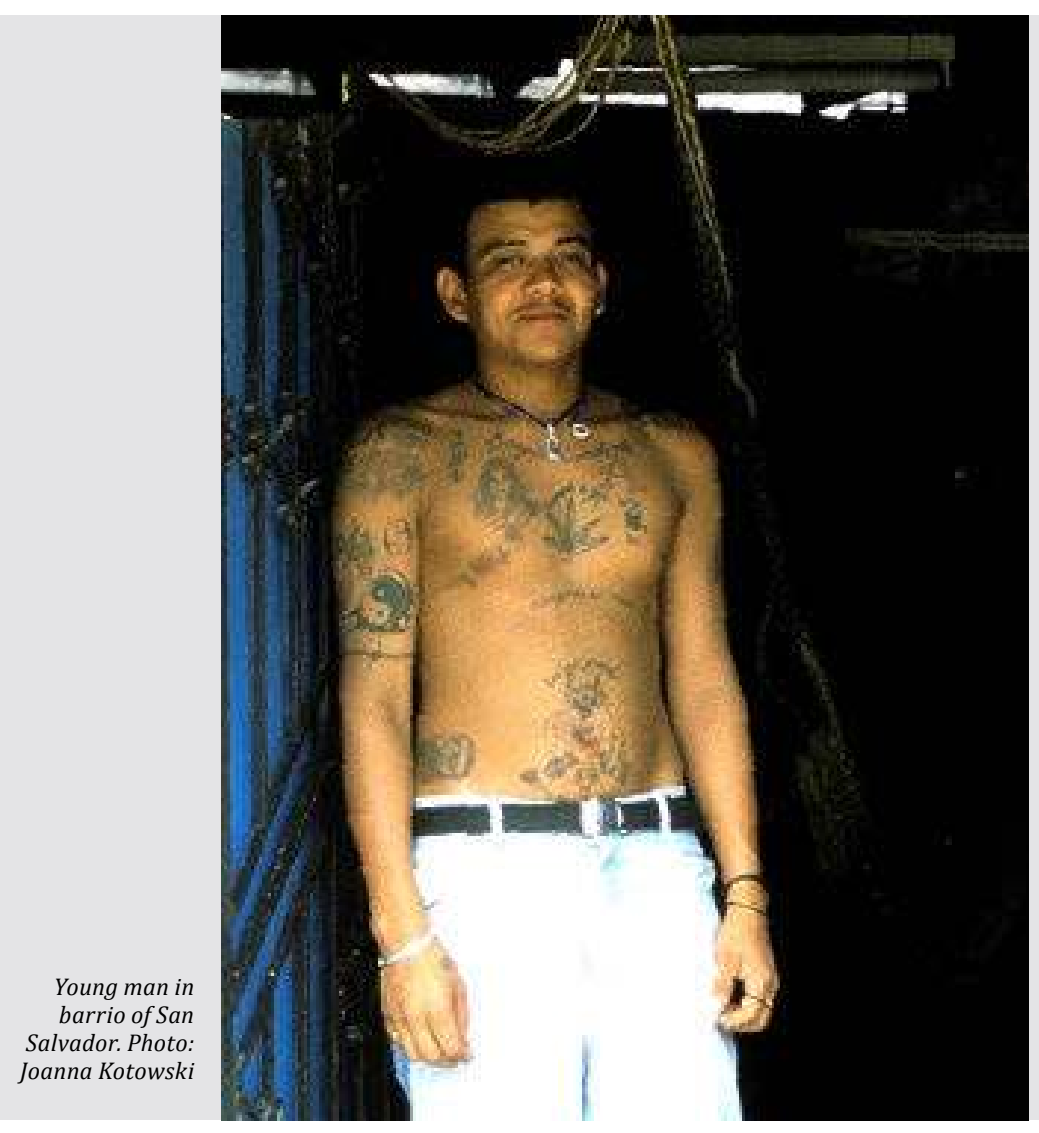

the children and youth, collaborating in the maintenance of public spaces, and organizing activities in them, stimulates social interaction among neighbors and neighborhood cohesion. On the contrary, a locality where residents confine themselves to their homes, with lonely streets and empty desolate parks, raises the possibility that others seize the public spaces in a less desirable manner: they can congregate to drink alcohol, abuse drugs, assault passersby, and even consider the neighborhood as solely their territory.

This paper addresses prevention from the perspective of local communal living or active coexistence. ${ }^{4}$ Such approach recognizes that although violence manifests itself disproportionally in precarious social contexts, certain social dynamics and processes are maintained that facilitate or impede its manifestation. Working towards a better quality of community life and relations between the neighbors is itself valuable. Recent studies have also shown that in communities where good social relations, mutual trust, and a willingness to work for the common good exist, violence and crime rates are usually lower (Sampson, 2006, 2012).

04 .

Translation of the word 'convivencia' in Spanish. Convivencia is a difficult to translate concept referring to the quality of actively sharing the same physical and social space. This finding is the starting point of the social prevention approach. Interventions based on this approach focus on social processes, in order to strengthen relationships between neighbors and to prevent individuals or groups from committing crimes or violence (Sutton, Cherney \& White, 2014; Savenije \& Beltrán, 2012). 
The more recent debate argues that social prevention must start with identification of 'root causes' that eventually motivates an individual to break the law and accordingly, should seek to change them. These 'causes' may include low self-esteem, lack of discipline, weak ties between the individual and the family or school, and low social or vocational skills (Sutton, Cherney \& White, 2014). However, it is difficult or impossible to identify and get some consensus on an individual cause or main causes. It is even more difficult to isolate and modify the 'root causes' (Crawford, 1998). Intervening in the social processes in which violent or delinquent actions are embedded and appear in, constitutes a different approach. People, neighbors, and local groups are in constant interaction and therefore it is important to keep in mind the relationships and dynamics between families, neighbors, and other community groups when designing and implementing a prevention initiative. Therefore, in this paper, social prevention of violence is defined as the modification or weakening of social dynamics or processes that lead groups or individuals to use violence or commit crime, through the promotion of social relations and interactions that encourage personal and communitarian development and strengthen peaceful coexistence, creating alternative opportunities and legitimizing informal social control.

Such integrated approach does not only require the need to reduce the presence and impact of street groups as principal actors of crime and violence, but moreover to foster the creation of new and alternative activities, as well as to assist the formation of local groups that enhance community and personal development of young people. Fostering new social endeavors, routines and leisure activities, and creating groups that promote, among others, (youth) culture, sports, environmental care and alternative conflict resolution, make possible the development of new social dynamics among neighbors -young and old- that improve social relations, reduce the attraction of gangs, and diminish the opportunity to commit violent or criminal acts.

\section{Prevention in highly insecure situations}

As previously noted, young people from popular neighborhoods are less likely to finish high school, pursue an academic career or to find a well remunerated job, in comparison to their peers with higher educational levels. Their surroundings host the kind of conditions that invite them to spend their time on the streets or to get close to street gangs. The same conditions also produce the risk that young people get victimized by these groups. Therefore young people that live in those insecure neighborhoods usually develop 'special' skills and strategies to keep them at a distance, at the same time as they maintain friendly relationships with those who consider themselves the 'owners of the streets'. In other words, young people have to avoid getting too close, whilst trying to avoid the impression of being disrespectful or to hold them in contempt. Initiatives of social prevention of violence and delinquency should be aware of these kinds of tensions and integrate them into account. Taking into account the risks present in popular neighborhoods, the initaitives must target both immediate actions and long-term achievements so that young 
people can visualize a more advantageous future. This can be achieved as long as these paths maintain the youth engaged in the education system and stimulate work in the formal sector, at the same time as the participants further the development of their communities or partake actively in social and civic activities that associate them to wider social networks.

Prevention initiatives should never be understood as short-term projects limited to vocational training, reintegration into the educational system, promotion of sports or recreation activities, that dry-up when the funding ends. Projects should be beneficial to the community, encourage the participation in new activities and motivate the residents to keep practicing them. Youth and other inhabitants of popular neighborhoods frequently feel abandoned when a project finishes or an organization retires from the neighborhood, while they continue to face the same difficulties as before: low possibilities of integration into the wider society, limited capacities created, persistent low motivation for communitarian work and small improvements in their communities. Activities such as sports, art, or training courses are not the objective itself, but a means to modify or reduce social interactions and processes that often lead to violence or delinquency. When young people maintain their interests in an academic career and have the opportunity to go to school, play sports or participate in exciting cultural or artistic activities, etc., they tend to distance themselves from the street culture and the related dangers. Therefore, it is important that young people are integrated into local activities and groups that have continuity, but also that they form skills and abilities that enable them to sustain these groups and interests. In this way, they also can open doors to other young people and help them in their personal development. In doing so, they become an integral part of their community and wider society.

An example of such an approach is the project 'Social Prevention of Violence with Youth Participation PROJOVENES II - INJUVE' -described in the following section - which has approached these issues in two ways. First, it has considered youth as a population willing to learn and engage in activities that benefit their community. Young people are therefore the driving force of the project. Secondly, it has aimed for sustainability, trying to involve community organizations, municipalities, and other institutions. The idea behind the project was that these organizations should remain in contact with young people and their communities after the project was completed, providing support and resources. In other words, the aim was to promote sustainability by establishing a sense of joint ownership and shared responsibility. The model PROJOVENES Prevention II-INJUVE will be explained in more detail in the next section.

\section{The prevention model of ProjóvenEs II - INJUVE: An example}

The first part of this section briefly describes some components of the model of "Social Prevention of Violence with Youth Participation" (for a more comprehensive description, see Savenije \& Beltrán, 2012). This model is relevant to this article because it considers youth as a target group in two ways: first, youth form an important part of the beneficiaries of the prevention efforts, and second, young people are active 
that the municipalities got involved in the project, came to know about social prevention and accompanied the young people in their activities. ${ }^{5}$

\section{Incorporation of the youth}

Considered as a cornerstone for crime prevention, youth were encouraged to work actively in the organization of activities with the explicit aim to foster community relations and social cohesion in their communities. Three different positions were designed to enhance the participation of youth: community operators, youth facilitators, and volunteers.

Community operators were the young people who had been immersed in the project for a relatively long time. They received a two-year scholarship to allow them to pursue prevention activities in their neighborhoods. Part of their preparation consisted of practical training in different issues related to prevention. They also participated in a social prevention of violence program, offered by the National University of El Salvador (UES) and received an official diploma to certify them as specialists trained in prevention. Youth facilitators were young people who joined the project as volunteers. After participating in the project for at least one year, they were offered a scholarship to support them while they dedicated themselves more intensively to prevention activities. The facilitators also received various types of training in the field of prevention, as well as in other topics, depending on the area they participated in (e.g. sports, environment, etc.). Volunteers were those who participated without receiving payment and who supported the different activities in their neighborhood whenever they had the time for it. ${ }^{6}$ Several volunteers also received trainings on specific topics.

The training and participation in activities in their neighborhoods were not isolated from other prevention activities developed in the municipality. During their training, volunteers, community operators, and youth facilitators supported neighborhood associations, the mayors' office, the Municipal Committees of Violence Prevention (CMPV), NGOs, and INJUVE in the organization and implementation of various activities.

\section{Objectives and work areas}

In order to focus on different target groups (individuals, families, communities and municipalities), and to involve different actors and institutions in prevention initiatives, the model established 4 general goals and structured the work by subject areas: (a). family; (b). sport and recreation; (c). art and culture; and (d). health and environment. In each subject area different activities were developed in order to achieve the following goals:

\section{The management of public spaces}

This objective consisted in the restoration or rescue of public places, which enabled the development of communal activities. This was done through cleaning of the areas, lighting, rehabilitation, improvement, or construction of public places, such as sports complexes, parks, squares, streets, cultural or community centers. ${ }^{7}$ Furthermore, it included the

06.

Volunteers were not exclusively young people; adults were also involved.

07.

Interventions limited to the manipulation of the physical context with the aim of reducing the opportunities to commit crime are known as situational prevention (Sutton, Cherney y White, 2014). 
administration of these places, aimed at the sustainability of the restoration efforts through maintenance, proper use and environmental care.

\section{Vocational training}

As mentioned previously, scholarships were given to the community technicians and youth facilitators, to prepare them for work in the area of social prevention of violence and to facilitate their active involvement. In order to expand opportunities for the inclusion, scholarships were also granted to other young people from the communities so that they could participate in different training programs and receive help from a special employment agency. Finally, some scholarships were awarded to young single mothers, so that they could participate in vocational trainings.

\section{Community development}

This objective was aimed at strengthening local community organizations, such as neighbors' associations, sports committees, environmental groups, etc. Community operators were primarily responsible for laying the groundwork that should stimulate improvements in the relations between neighbors. For this matter, they were trained in management, planning, and the implementation of projects and activities. They promoted the work of local organizations; some even joined the community development associations of their neighborhoods. They also formed, together with volunteers, groups that organized activities focused on topics of interest (football matches, martial arts, environment, etc.) in order to attract more neighbors. Their major challenge was to improve the functioning of the local organizations, promote links between these organizations and the community, but also among the neighbors, and even among members of the same family. The underlying idea was to promote close social relationships and community participation through diverse activities.

\section{Institutional development}

Institutional development consisted of two main objectives: promoting violence prevention efforts by mayors' offices of the AMSS, and strengthening their capacities for community work. In order to achieve these objectives, the project worked to promote organizational skills and regulations of municipalities, supported by an adequate legal and financial framework. This was done through a strategy of technical training in key areas such as public participation, outreach, culture, youth and childhood development, environmental management, infrastructure, and social prevention. Community operators also participated in the CMPV to promote and support their efforts.

At the time the project concluded, the municipalities were expected to assume the responsibility for continuing social prevention initiatives in their territory. They are considered the main entities that should accompany youth and the entire community in prevention processes and promote the active participation of volunteers and local organizations in the communities. In this way the project sought to secure the 
sustainability of activities that stimulate community life and the prolonged social integration of young people.

The main expectation was that through the development of these activities the youth and other participants increased their sense of belonging to their community, while they also improved their ability to participate in educational, employment, cultural, and artistic atmospheres. The project aimed to socially include the participants by making them parts of local actions and local decision making, recognizing them for their efforts, and stimulating their relationships with and the support of local, municipal, and even national organizations.

\section{The experiences of young people: testimonials}

The work of youth has largely consisted of strengthening their community, that is, activities have focused on improving relationships, common use of public places, individual resources, and local organizational capacity. In the process many youth have also become community leaders; not only because of the learned skills and gained experiences, but also because of the new interests that evolved and the relationships they established.

Community work requires social skills that allow the individuals to get along in their neighborhood, interact with neighbors, and find access to social organizations and institutions of the "wider society" that can facilitate or sponsor local activities. Community leaders must have a level of personal development, or maturity, in order to establish good relations with different types of people in a variety of contexts. They should not only feel comfortable with communicating ideas or purposes clearly; they must also have the patience and vocabulary to speak to different audiences.

During the various trainings, the participants did not only learn these social skills, many of them also gained confidence to use their newly developed skills. In this way, they learned to work better in their neighborhoods and specifically, how to address their neighbors. "As a volunteer, I have learned to be more communicative, more dynamic. Before, I was very quiet, now I feel more confident when talking to people and inviting them to events. I am not shy anymore when I approach other people". Young participants also learned to stand in front of groups and talk to big audiences; relate with different people, many very different from them; work in teams; and to remain open-minded to different visions and opinions. "I improved my character. In the past I did not discuss, propose ideas, or talk. Now I don't feel uncomfortable anymore!" Another volunteer reported a similar idea: "I learned to talk in public. Now I have a better vocabulary and I know how to use the right words to express myself."

In the process, the participants developed skills and attitudes that help them in interaction with other people. Many have become more patient with others and tolerant when they face different opinions. "I became more patient and understanding with my family and with other people. Now I help to find a solution when there are problems." Some reported even that they got to know themselves better, and that this has helped 
them to become more understanding with others. "I changed my attitude. I used to be very closed-minded but now I talk more with people. I relate better with others."

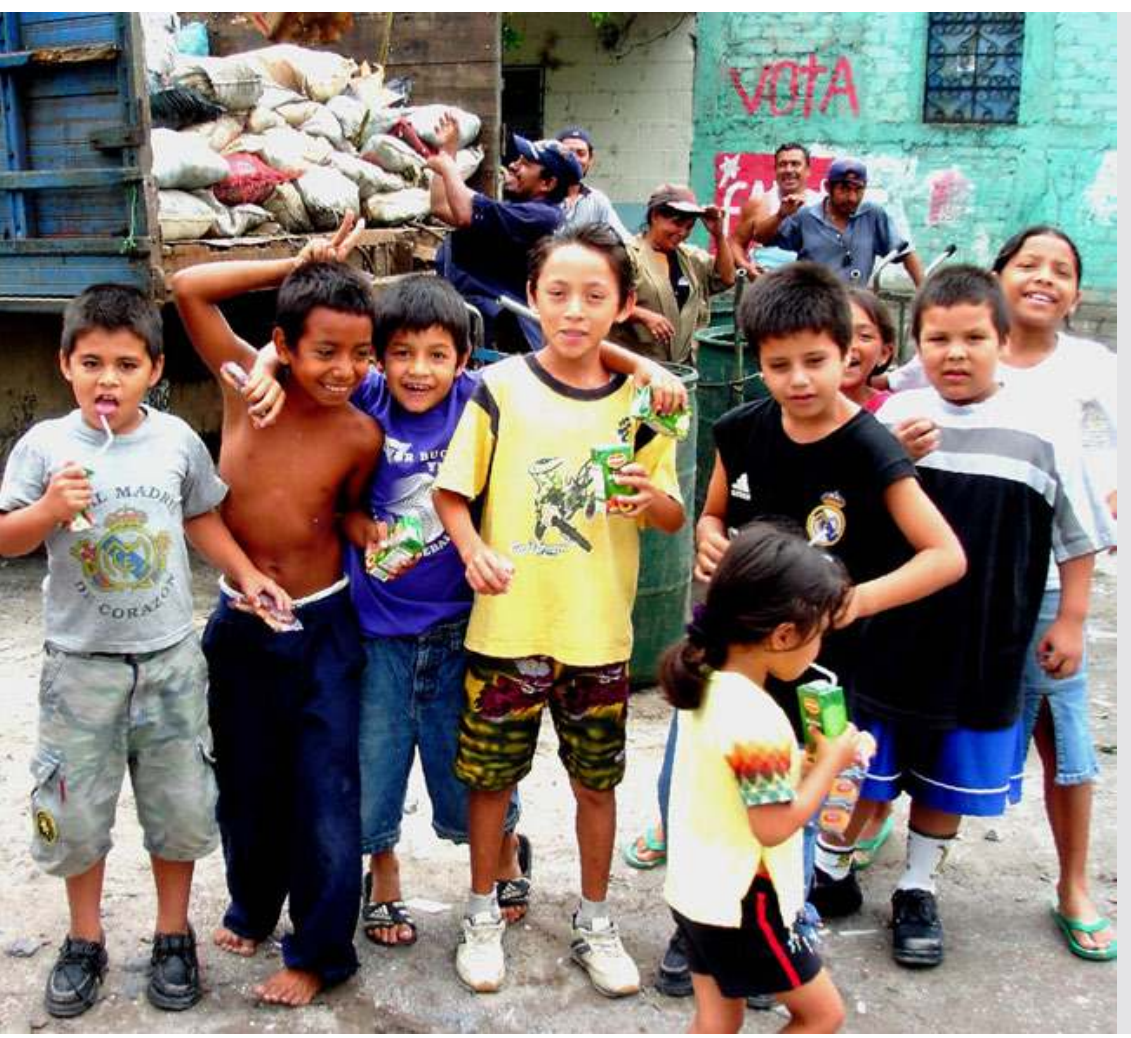

In the context of the project young people can make friends and gain respect in different group contexts than the gangs. Photo:

Joanna Kotowski

Learning social skills and achieving greater personal development did not only have an impact on an individual level, but -more importantlyit created useful resources for the community. Despite being relatively young, many consider that they thrived in the project and are now recognized as leaders in their community. "Relationships with the neighbors changed a bit. Previously I only taught martial arts classes. But when I started to work for the community, people began to notice me. I started to interact more with the people and now they look for me. They respect my work and I have gained prominence. They see me as a leader." The participants generally have managed to establish good relations with the neighbors and formed groups that voluntarily help them in their community.

For some, these experiences have reoriented their ambitions for the future, as they have decided to continue their formal education. "I thought I was too old [to study]. But I saw people older than me at university, so I decided to finish high school. When I started to attend classes to get the diploma, I got even more enthusiastic and I got the two qualifications. I thought that the diploma and a high school degree would improve my CV."

However, there was always the risk that the groups that controlled the neighborhoods, such as street and drug distribution gangs, would think that these people were interfering with their interests. Therefore the 
participants had to sort-out these possible hazards and avoid provoking difficulties to themselves and their activities. The recognition of these groups as neighbors allowed the establishment of cordial relationships, as well as some confidence. The interaction with these groups, therefore, required a lot of social and communication skills. Generally, the participants, especially the community operators, have learned to establish relationships that have allowed them to move with relative ease through the neighborhood and even, when necessary, to negotiate with gangs. "With them I do not relate directly. I invited some to a family happening and many attended. That time about 55-60 people came and half of them were gang members. They recognize the work we do in the community." Sometimes gang members have even joined the community work. "Before, I had no contact with them. Now we communicate, because they help with the work in the community."

\section{Reflections for sustainable social prevention}

The previous statements show that the active participation of young people in implementing prevention projects is feasible, even in situations with high levels of insecurity. In fact, they may have a key role in efforts to improve relationships, promote active use of public places, and stimulate the willingness to work for the common good in their communities. However, in order that the active participation of young people and other neighbors produce the best results, a systematic process of training and methodology transfer should be established. With continued support, young people are able to make social prevention work and, at the same time, further their personal development.

In addition, the experience of PROJÓVENES II - INJUVE indicates that many young people are willing to do community work. They have the

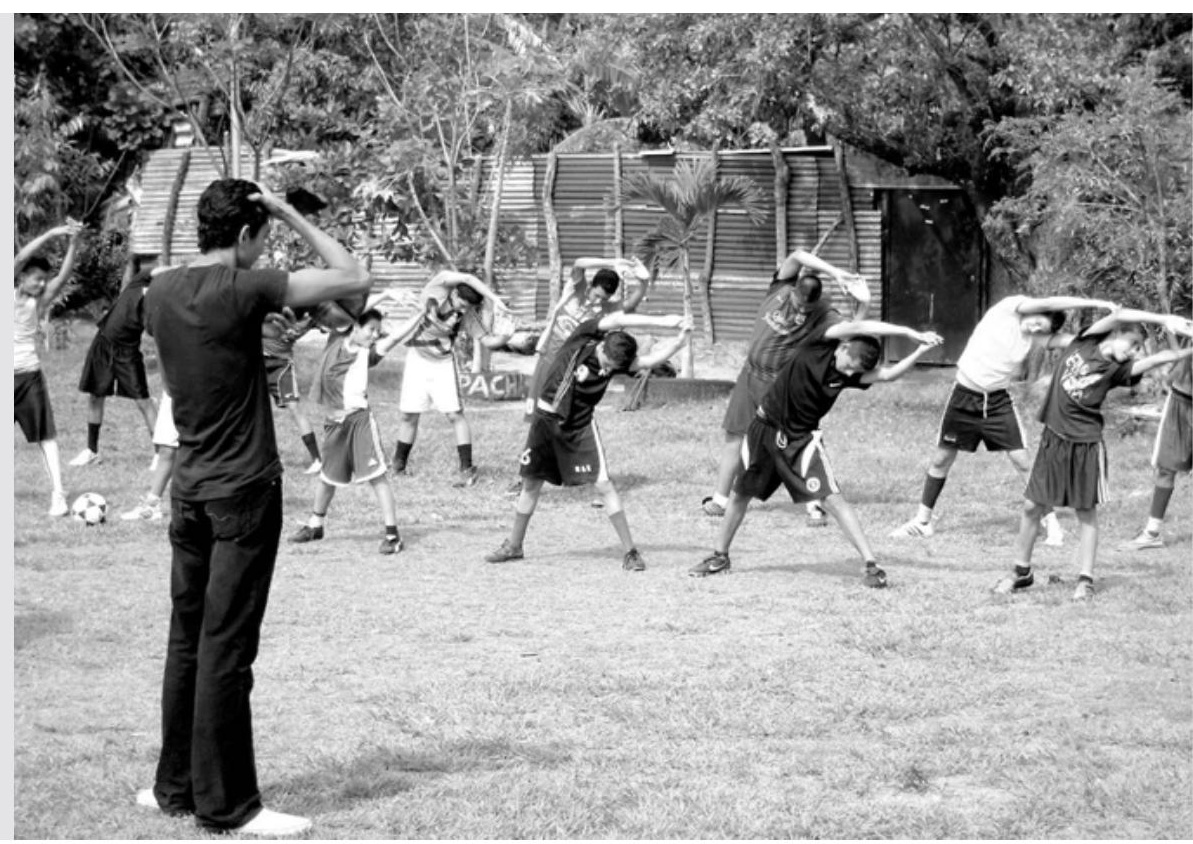


time, the energy, and show commitment to the assignments and responsibilities they assume. Their efforts are mostly voluntary. However this does not mean that they can be left alone. In community work, youth have faced and will face new challenges constantly; they need the support and experience of adults in order to solve many of the problems they encounter. Community leaders, people working in neighborhood associations, or experts at the municipality in the areas of social, communitarian, or cultural work, can be excellent advisors to youth.

Another important element is formal training. Ideally, young people who are already working in prevention should continue to be trained in the areas of management, development of participatory methodologies, practical modes of social prevention, or in any other areas that arise from the demands of the community. In this manner, it is not only the community who will benefit from youth efforts for prevention, the young people themselves become specialists in working with communities. Training youth methodically and to bestow them with a formal diploma does not just give them recognition, it prepares them for the future. At the same time, this kind of recognition also generates appreciation in the community and becomes an incentive to continue working with other young people in the neighborhood. It is also important to consider the incorporation of new volunteers to community work. Since volunteers need to have specific skills or knowledge to pass on to others, they must be trained in the areas (for instance in drawing, sports, dancing, sexual and reproductive health and environment) where they desire participate.

Without resources, social violence prevention work cannot succeed. Thus resources might include scholarships for young people, but also allowances required to cover the expenses that volunteers use during the planning, organization, and coordination of activities. It is important to note that the volunteers must move from the places the live to spaces where they carry out their activities. They often lack the resources to pay for their transportation and food while they are away from home. A stipend to deal with these costs is an important consideration. The availability of material resources to realize their activities is likewise essential. Community initiatives also benefit from adequate space (for example community centers, sports courses), and various materials (such as sports equipment, paint, brushes, musical instruments, seeds for planting, fertilizer, etc.). Without such resources even volunteers cannot carry out activities, despite the good will to do so.

Like providing trainings, resources and support for young people, their safety is a constant concern. Working in areas of high insecurity involves contact with gangs or other violent or criminal groups. To the extent that they consider the neighborhood their territory, participants must acquire special "abilities" to deal with these actors. They must develop ways to operate in a non-threatening and respectful manner that also earns them the respect of these groups. However, experiences of intimidation or assaults, for example, can cause fear, discouragement, and even withdrawal from community work. Psychological support is essential, in addition to the training and support during their work. If participants are 
shown that they are not alone, they can more easily overcome difficult experiences.

Projects of social prevention can reinforce the social ties that transform geographical neighborhoods into social communities, especially when they emphasize the active participation of young people and adults. These projects strengthen local organization, enhance existing leadership, and promote new leaders. They also reconnect communities with local government and articulate their actions with other external organizations. Above all, in order to promote the work of young people in communities, it is vital to recognize the presence of these young people, their potential, and their desire to help. Incorporating the young population in community work is not only a way to work for the common good, it is also a way to reduce difficulties and insecurity in their lives, and a way to bring their dreams closer to a feasible level.

\section{References:}

Crawford, A. (1998). Crime Prevention \& Community Safety. Politics, Policies and Practices. Essex, England: Pearson Education.

Croso, C. (2010). Universalizar el acceso y completar la educación secundaria. Entre la meta social y la realidad latinoamericana (pp. 20-28). En N. López y F. Sourrouille (Comps.), Universalizar el acceso y completar la educación secundaria. Entre la meta social y la realidad latinoamericana, Debate 07, Buenos Aires: IIEPUNESCO y OEI.

D'Alessandre, V. (2010). Adolescentes que no estudian ni trabajan en América Latina. Cuaderno ${ }^{\circ} 4$ del Sistema de información de tendencias educativas en América Latina. Buenos Aires: IIEP-UNESCO y OEI.

Eljach, S. (2011). Violencia escolar en América Latina y el Caribe: Superficie y fondo. Panamá: Plan y UNICEF.

Feldman, S., García Mendez, E., \& Araldsen, H. (1997). Los niños que trabajan. Buenos Aires: UNICEF.

Jütersonke, O., Muggah, R., \& Rodgers, D. (2009). Gangs, urban violence, and Security Interventions in Central America. Security Dialogue, 40(4-5), 373-397.

Katz, J. (1988). Seductions of Crime. New York: Basic Books.

Katzman, R. (2001). Seducidos y abandonados: el aislamiento social de los pobres urbanos. Revista de la CEPAL, 75, 171-185.

Kessler, G. (2002). La experiencia escolar fragmentada. Estudiantes y docentes en la escuela media en Buenos Aires. Buenos Aires: IIEP UNESCO.

Kliksberg, B. (Comp.) (2010). Es difícil ser joven en América Latina. Buenos Aires: Sudamericana.

Muggah, R. (2012). Researching the Urban Dilemma. Ottawa, ON: IDRC.
Organización Internacional de la Juventud [OIT]. (2012). Tendencias actuales del empleo juvenil. Ginebra: Autor.

Organización Internacional del Trabajo [OIT]. (2011). Panorama laboral 2011. América Latina y el Caribe. Lima: Autor.

Programa de la Naciones Unidas para el Desarrollo [PNUD]. (2013). Informe Regional de Desarrollo Humano 2013-2014. Seguridad Ciudadana con rostro humano: diagnóstico y propuestas para América Latina. Nueva York: Autor.

Programa de las Naciones Unidas para el Desarrollo [PNUD]. (2009). Desarmar la violencia. Una década de prevención de la violencia armada en El Salvador. San Salvador: Autor

Rodríguez, E. (2007). Jóvenes y violencias en América Latina: Priorizar la prevención con enfoques integrados. Revista latinoamericana de ciencias sociales, niñez y juventud, 5(2), 539571.

Rodríguez, J., \& Arriagada, C. (2004). Segregación residencial en la ciudad latinoamericana. Revista Eure, 89, 5-24.

Sabatini, F., \& Brain, I. (2008). La segregación, los guetos y la integración social urbana: mitos y claves. Revista Eure, 103, 5-26.

Sampson, R. J. (2006). How does community context matter? Social mechanisms and the explanation of crime rates. In P.-O. Wikström, \& R. Sampson (Eds.), The explanation of crime: Context, mechanisms and development (pp. 31-60). Cambridge: Cambridge University Press.

Sampson, R. J. (2012). Great American City: Chicago and the Enduring Neighborhood Effect. Chicago: University Of Chicago Press.

Savenije, W. (2009). Maras y barras. Pandillas y violencia juvenil en los barrios marginales de Centroamérica. San Salvador: FLACSO El Salvador. 
Savenije, W. (2010). Persiguiendo seguridad. Acercamiento de la policía a las comunidades con problemas de inseguridad en Centroamérica. San Salvador: FLACSO El Salvador.

Savenije, W., \& Beltrán, M. A. (2012). Conceptualización del Modelo de Prevención Social de la Violencia con Participación Juvenil. San Salvador: Instituto Nacional de la Juventud (INJUVE).

Sistema de Información de Tendencias Educativas en América Latina [SITEAL]. (2014).

Base de datos. Porcentaje de adolescentes y jóvenes que no estudian y son económicamente inactivos en Latinoamérica. Año 2012. Disponible en http://www.siteal.iipe-oei.org/base_de_ datos/consulta

Sistema de Información de Tendencias Educativas en América Latina [SITEAL]. (2009). Datos para el debate $n^{\circ} 7$. Universalizar el acceso y completar la educación secundaria. Entre la meta social y la realidad latinoamericana. Buenos Aires: IIPE-UNESCO y OEI.
Sutton, A., Cherney, A., \& White, R. (2014). Crime Prevention. Principles, perspectives and practices. Port Melbourne: Cambridge University Press.

Tolan, P.H., Gorman-Smith, D., \& Henry, D.B. (2003). The Developmental Ecology of Urban Males' Youth Violence. Developmental Psychology, 39 (2), $274-291$.

UN-Habitat [United Nations Human Settlements Programme]. (2012). Estado de las Ciudades de América Latina y el Caribe 2012. Rumbo a una nueva transición urbana. Nairobi: Autor

UN-Habitat [United Nations Human Settlements Programme]. (2014). Construcción de ciudades más equitativas. Políticas públicas para la inclusión en América Latina. Nairobi: Autor.

United Nations Office on Drugs and Crime [UNODC]. (2014). Global Study on Homicide 2013. Trends, context, Data. Vienna: Author. 

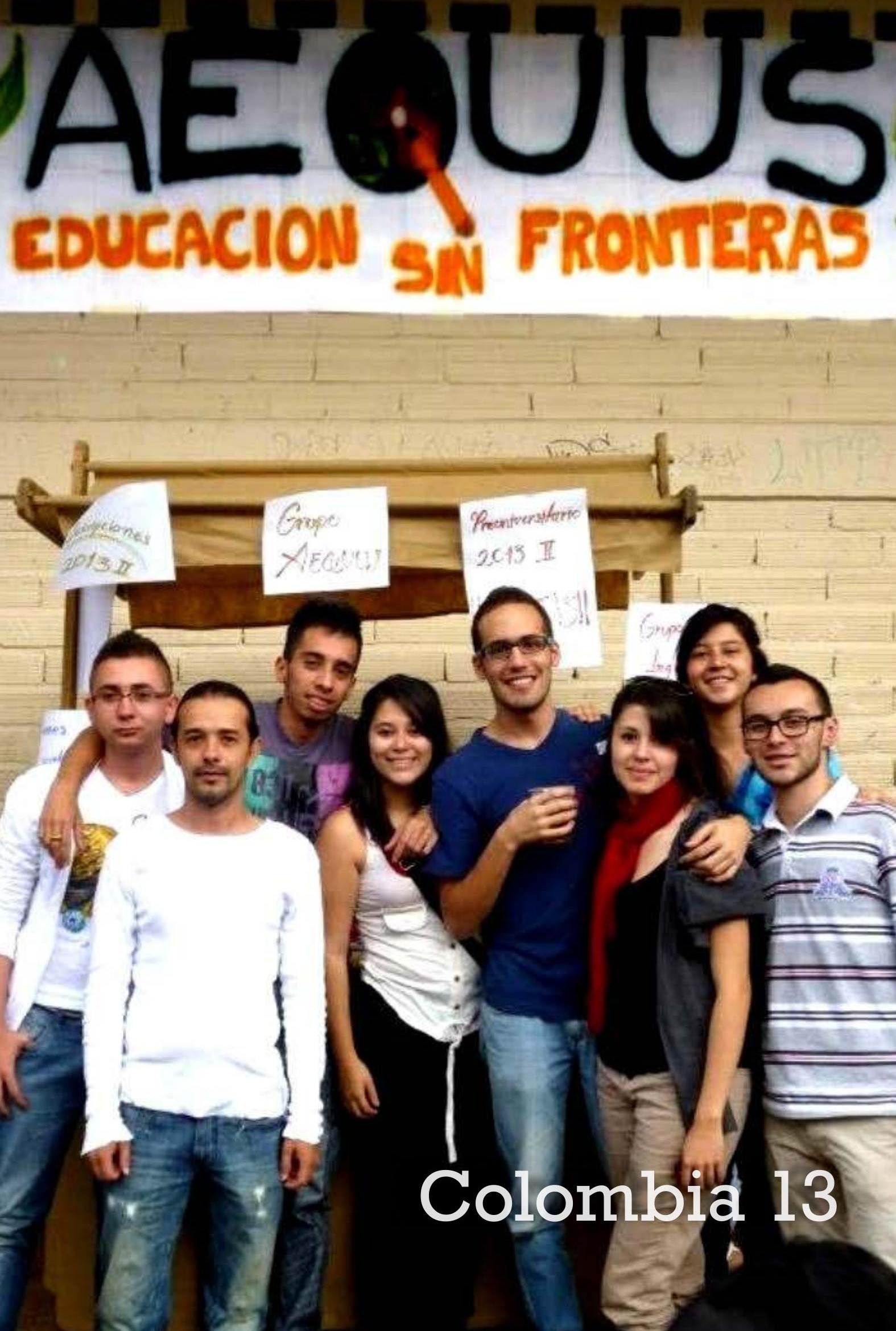


\title{
Overcoming the Invisible Boundaries of an Informal Neighborhood: A Youth Initiative in Itagüi, Colombia
}

\author{
Leiman Julieth Sánchez Betancur \& Carlos Andrés Restrepo Arango
}

\section{Introduction: Violence in Itaqui in the 1990s}

This case study reports from an extraordinary initiative, started and maintained by group of young local men and women, responding to drastically increased level of violence after Colombia's maximum Security prison was had been located in their neighbourhood.

The Municipality of Itagüi forms is located in the Southern section of the greater Medellin Metropolitan Region in Colombia's state of Antio-

Except for Pablo Escobar who had declared war on the Government

02.

"Los Extraditables" was an organization created by Colombian drug lords in the early 1980s. Their motto was: "We prefer a grave in Colombia to a prison the United States." (Wikipedia)

Previous Page: Community Organization GRUPO AEQUUS: Education without Borders: Nonprofit community organization for educational projects. quia, and counts a population of 258,520 inhabitants. The municipality is divided into a six comunas apart from the rural territory, and each comuna hosts between 4 and 17 districts. We are located in the community San Francisco which belongs to the Comuna 3 with the highest population number $(8,850$ people), of which approximately two thousand are adolescents between 14 and 26 years of age.

In 1990, the Maximum Security Prison was built in Itagui right next to community San Francisco and was referred to as "a new prison for the repentant drug dealers of Medellin" (El País, December 9, 1990). It' special status is grounded on a "treaty of transitional justice" (conflict management in a period of transition), which had been signed between the Colombian drug traffickers ${ }^{1}$ and the Colombian Justice Department. This treaty allowed the drug traffickers, known as "Los Extraditables" to be imprisoned in Colombia instead of being extradited to the USA in exchange for disclosing certain types of information.

When drug lords arrived, life changed for the neighbourhood close by - and not only because of stigmatization that the presence of the prison created. The inmates still disposed of financial fortunes had close connections to the paramilitaries. From inside the prison they could organize targeted killings, persecution, disappearances, intra-urban 


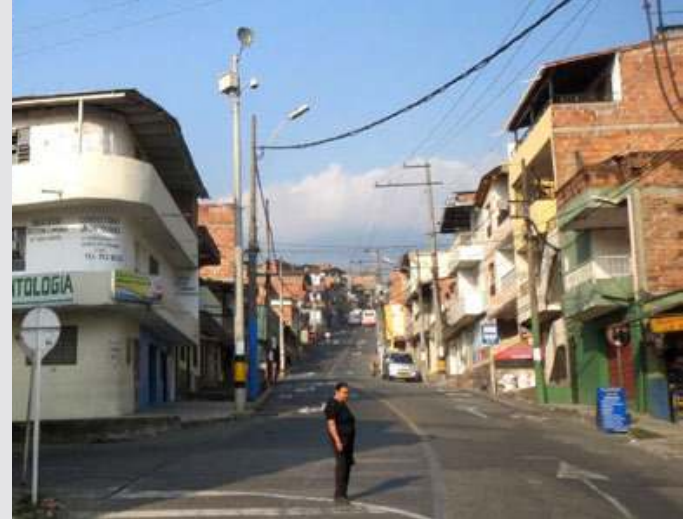

displacement, and the death of social, labor, and political leaders (which actually still happens today). They started the recruitment of young people outside the prison who would exercise the killings, extortion, and trafficking of narcotic substances in their service. Meanwhile, women have been hired to visit the inmates, prostituted and abandoned later, not only by the inmates of the prison, but also by institutional members such as the police, military, and prison guards).

\section{0 and the arrival of paramilitary leaders}

A key figure for violence the municipality of Itagui was Diego Fernando Murillo, the boss of the criminal gang Bloque Cacique Nutibara, who appeared around 2001 (Noren, 2007: 62). This group fought a war against different other gangs to achieve the absolute rule and military hegemony of Medellin and its surroundings and turned Itagüi into one of the most violent places in the country, where street murder lured at virtually any street corner. Especially in San Francisco, even those who did submit to the Bloque Cacique Nutibara lived through violence, as members of different informal structures came to dispute the territory. Taxing for the "vaccine" (whether or not it is called by its real name, extortion) has become commonplace, with those who provide security seen almost heroically. Such security provision is exercised with impunity, which fosters an "invisible border", arbitrarily created to mark territory or simply delete the other.

Territories are small independent republics, whose hierarchy is properly planned. The chief is called "el duro" (the tough one), "el boss", "el patron", and commands everyday life in the neighborhood. The man that is installed on the corner to monitor all movements of people sustains the power of "the boss" through money obtained from the sale of narcotics and "taxes" collected from retail traders or transporters. The "boss" is also shielded by a group of armed youths who have had other opportunities, but nonetheless ended up as actors in the conflict: it is a very tempting offer for a young man without study, without preparation, and with all the vital needs of a home to get involved in such groups.

Thus, not only men, but also women were recruited, the latter as a trophies of war, which worked to control the population. Ironically, those who sought to control the population often wished to do so through local
Left:

Main road of San Francisco, Itaqui

Right:

Comunas of Itagüi 

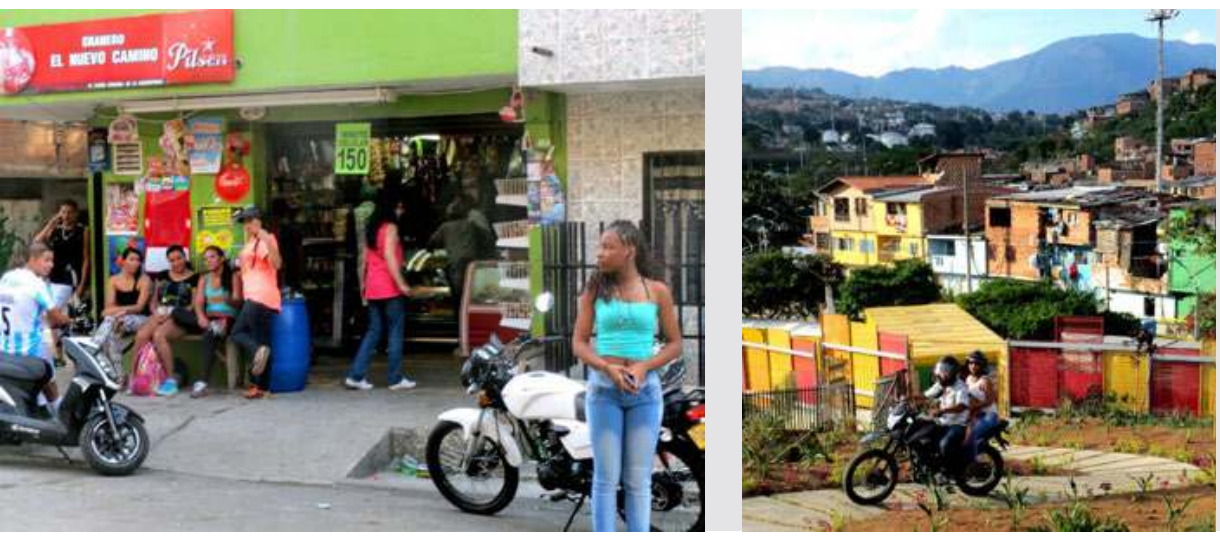

Motos and women are status symbols for men in the youth gangs. Photos: Kosta Mathéy

Álvaro Uribe Vélez, born in Medellín where he was mayor in 1982 and Governor of Antioquia between 1995 and 1997, served as president of Colombia from 2002 to 2010. He was following a strong arm politics against the guerilla and some members of his government were accused for having close links with Paramilitary groups. action and accordingly sponsored social events with the hope that the population would legitimize their actions as community benefactors.

The "boss" has different strategies of social control at his disposal. On special dates, he donates gifts; congratulates moms on Mother's Day; buys uniforms for the football team of the neighborhood; and provides community lunches. At Christmas, all children mysteriously receive a gift from Father Christmas and in the process, the "boss" becomes a respectable gentleman to be defended from the onslaught of the state, at least in the minds of people.

In 2003, under the government of Alvaro Uribe, ${ }^{3}$ a demobilization process of the terrorist and ultra right group, the United Self Defense Forces of Colombia (AUC), was began within the frame of the "Justice and Peace Act". This law allowed the demobilization of 31,000 combatants, who could confess their crimes and receive a reduced imprisonment of 5 to 8 years maximum (Act 975 of 2005 Justice and Peace). Diego Fernando Murillo, alias "Don Berna" surrendered in December 2003 and eventually become the most significant paramilitary inmate at Itagüi prison.

Today, although insecurity has diminished, there is still violence between criminal gangs over various territories and the rearrangement of leadership, which continues to affect directly the population. Not only are the people living in Itagüi affected by the protracted violence but subsequent generations, who grew up without knowing their parents, also carried the burden of social stigma for the simple fact of inhabiting a territory socially marked as violent and insecure.

\section{Results of the violence in the neighborhood of San Francisco de Itagüi}

\section{Invisible borders}

An invisible border is a means used by the gangs to control a territory and its population, often defining a neighborhood against another and preventing people from moving freely. Territory is sought for various reasons (including economic reasons or territorial strategy for the mobilization of weapons or drugs) with those desiring the territory gradually and arbitrarily marking it as if it were merely a border between two countries. The big difference, however, is that the boundaries between 


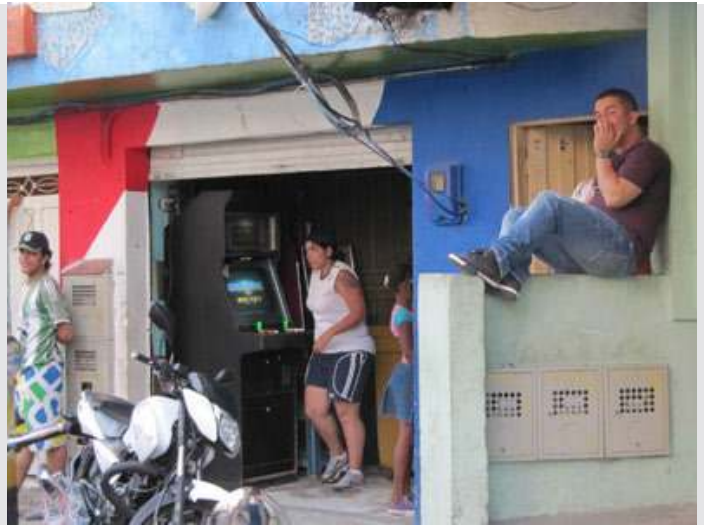

criminal organizations are invisible and, via the exercise of violence and threats, are imposed on the population through fear. In Itaqüi, for a certain period, crossing the river to the neighbouring territory implied risk of life and therefore stopped completely.

\section{Collection of tax by criminal gangs: Extortion}

The idea of a "war tax" came from the nascent guerrilla movements of the 1950s as a way to sponsor confrontations with rival criminal gangs. Rapidly, groups made taxes a central purpose of their operations, for financing weapons, acquiring real estate, to bribe the police and to create a network of support for maintaining their established order of control. As the capital accumulation lead to greater power by these groups, confrontations began to diminish,

Extortion also became an effective means to control the population because those who did not pay the tax received a form of retaliation that could increase from beatings and other physical attacks, or persecution to death. Anyone who owned a car or neighborhood store was required to pay a tax in order to carry out their day-to-day activities. Thus, extortion strongly influenced the economy of the district.

\section{Persecution of organizations and community leaders}

For criminal gangs, social organizations that were outside their control or supervision represented a virtual enemy. Usually, organization that arose from within the community - which often implicitly dealt with the defense of human rights- were turned into military targets by the gangs, particularly the leaders of such organizations. Many of these individuals were thus forced to leave their communities, while others were even exiled abroad. These instances occurred quite regularly, as the state was unable to effectively combat the criminal groups, or in many cases, directly supported them. A climate of anxiety was thus experienced across communities and their organizations, and the result was a lack of faith in the institutions that the state established to defend citizens. The abandonment of communities from state protection and the fear produced as a consequence allowed illegal groups to form a monopoly of influence, which left vacuum of justice that enabled everyday conflicts to escalate into violent reactions.
Left:

The

geographically determined neighbourhood is the home of a youth gang Photo: Silvia Matuk

Right:

The river valley looks like place to relax. But in reality it represents one of the invisible boundaries around San Francisco. In certain periods crossing that river was a deadly venture.

Photo:

Silvia Matuk 


\section{How the Grupo Aequus proposal arose}

The attacks generated physical and symbolic violence, and the constant fear of violence in the population conditioned the formation of unarmed defense movements and groups. These organizations sought alternatives to violence, and particularly focused on preventing the recruitment young people for the armed conflict. Throughout Colombian history, this kind of resistance that originated in the "popular sphere" tried to provide an alternative to the conflict. Therefore, the connotation 'popular' was stigmatized and used as a synonym for members of the insurgency or the political left. This very soon called the attention of the paramilitaries who started to pursue the groups and their social leaders whose projects conflicting with the right wing ideology of paramilitaries.

Being affected directly by the various mechanisms of illegal control exposed above, and having seen killed some of their closest friends by the gangs, a pacifist group, called Grupo Aequus: Education without Borders was born in San Francisco de Itagüi in 2011 with the aim to promote socially productive (instead of destructive) career opportunities to the youth in the neighborhood of San Francisco. Grupo Aequus is a non-profit community organization (not a foundation or a corporation) that "seeks to prepare and sensitize the general population, especially youth, to the need of entering public higher education, and accordingly, as part of their overall activities, provides educational tools that allow students to achieve academic study."

The word aequus comes from Latin and means "equity", and is intended to expresses an integral characteristic of the neighborhood San Francisco which they follow an aim. Through the choice of this term, the group seeks to recognize the value of solidarity in order to promote an organization that can transform the pessimistic mindset, inhibit urban violence, and promote inclusion. One of the specific goals of the organization is

Yeyson Andrés Castañeda and Jhoan Stivens

Arango, members of the AEQUUS group in their library office.

Photo: Kosta Mathéy to implement a much more inclusive and liberating education system. In more concrete terms the group encourages young people to take charge of their own lives through educational processes and promote the free movement across the territory, both in terms of unhindered physical mobility across the territory as well as the movement of ideas for the prevention of violence in its various expressions.
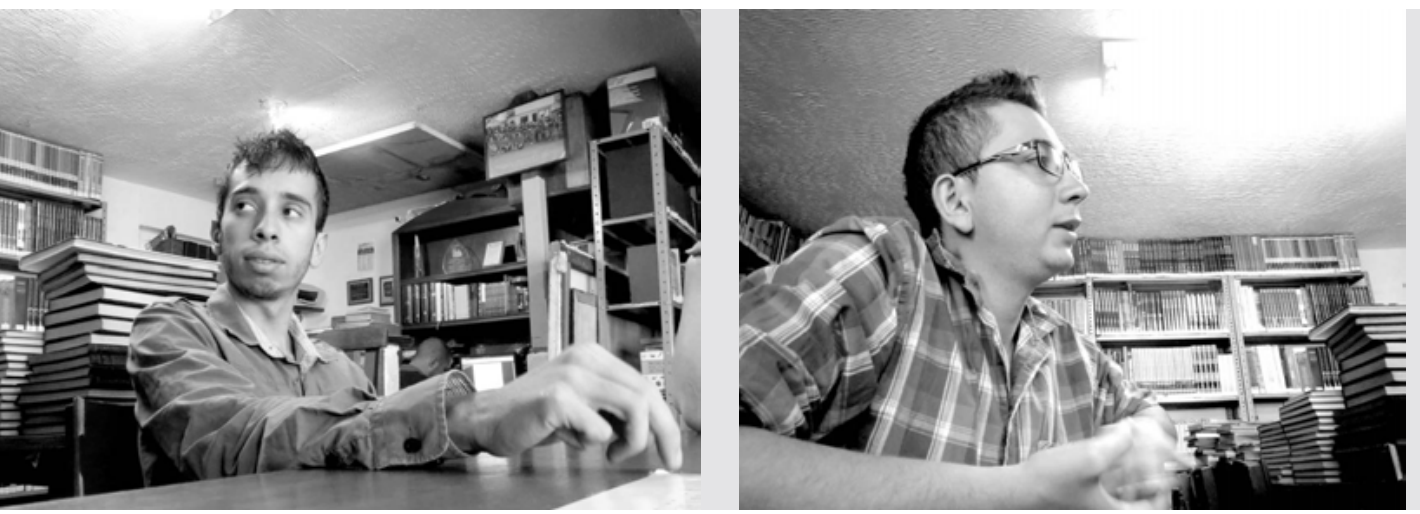
The founders of the initiative have had the opportunity to enter public higher education, and wanted to help other adolescents to equally achieve access to college through assisting them with their preparation for admission tests. Thousands of adolescents are unable to access higher education, as the costs for formal preparation for the tests are very restrictive. Moreover, public universities have limited places for applicants from lower economic situations; private universities are wholly inaccessible to these young people, on account of their higher tuition fees.

The organized program of AEQUUS began with two members giving classes to 11 young people living in the neighbourhood. Over a period of two years, this initiative has gathered 8 lecturers reaching 90 students from different neighborhoods. New educational programs were started to diversify the opportunities also students who for their educational background would have usually been excluded from such programs. Apart from the formal classes, the youth would gather voluntarily to share the knowledge that they had learned in the structured programs. English language classes for children and young people called "My Neighborhood Bilingual" have exposed adolescents to the world of language and travel. A group education approach has also fostered different environmental partnerships with corporations in order to generate leaders on environmental issues, which then can be contextualized to the needs of the community. A group for music has also introduced children and youth to guitar, while another group called "Young Writers" has allowed many young people to utilize their talent for reading and writing as a method of exposing their ideas. Finally, a dance and leisure group was created through which adolescents can learn regional music and Latin rhythms such as salsa, merengue, cumbia with other age groups, such as the elderly. The groups was granted use of a premise, which they transformed into a library and where neighbours could also find a space to gather, discuss or learn outside the often crammed and overpopulated homes.

These results have not only occurred at the high school level, but have also assisted younger students in achieving academic success. Of particular importance to the program has been the Pre Universitario offered by members that had recently started studying at the university and wanted to share their experiences with the next generation, who were also interested in studying.

Aequus actions do not only have an impact on the community, but also on the facilitators, i.e. on young people from the community who are committed to this project. A physics student at the University of Antioquia and co-founder of the group commented:

"Since the beginning of Grupo Aequus we have initiated activities focused on solidarity and social responsibility in our community. This encouraged me to share my limited knowledge and experiences with those who wanted to grow academically and personally, and has enabled my community to address many social problems such as inequality, intolerance, violence, poverty, among others. But when it comes to poverty, we are not just talking about material poverty, but also about mental poverty. The group has generated a sense of belonging for me in my community, 
countless experiences, meetings with a lot of great people, and significant academic growth, mainly in the area of knowledge development. (Yeyson Andres Castaneda Guzman)

One of the participants of the educational project affirmed:

"For me Aequus represents friendship, and that is what motivates me to do things for the group, no matter how small they are, I want to help them, they are my friends now, they work hard to alleviate the problems of society, they provide me with support and joy" (Deivy Alexander Marimón Gómez).

To summarize, Grupo Aequus is based on the concept of communitarian education which is contextualized and can be adapted to the needs of the neighbourhood and is flexible enough so that individuals with different knowledge and human capital can participate enriching spaces of personal and academic growth. The results achieved so far include the following:

- In the popular neighborhoods of Colombia, especially in Medellin and its metropolitan area, street corners in popular neighborhoods are commonly the meeting sites for criminal gangs, where they plan illicit activities but also engage in threats, murder, or extortion. With the support of various social leaders, the AEQUUS community

Left: The premises of today's AEQUUS public library once used to be well known hang out for the members of the youth gangs. Photo: Silvia Matuk library was founded on one such corner. The role of the library is to provide free educational services to the community, such as the free use of internet for learning purposes, poetry classes, and different courses from Grupo Aequus (including English, literature, and math courses). The creation of this educational space is progressively changing the perception of spaces that have historically been identified as violent and dangerous spaces.
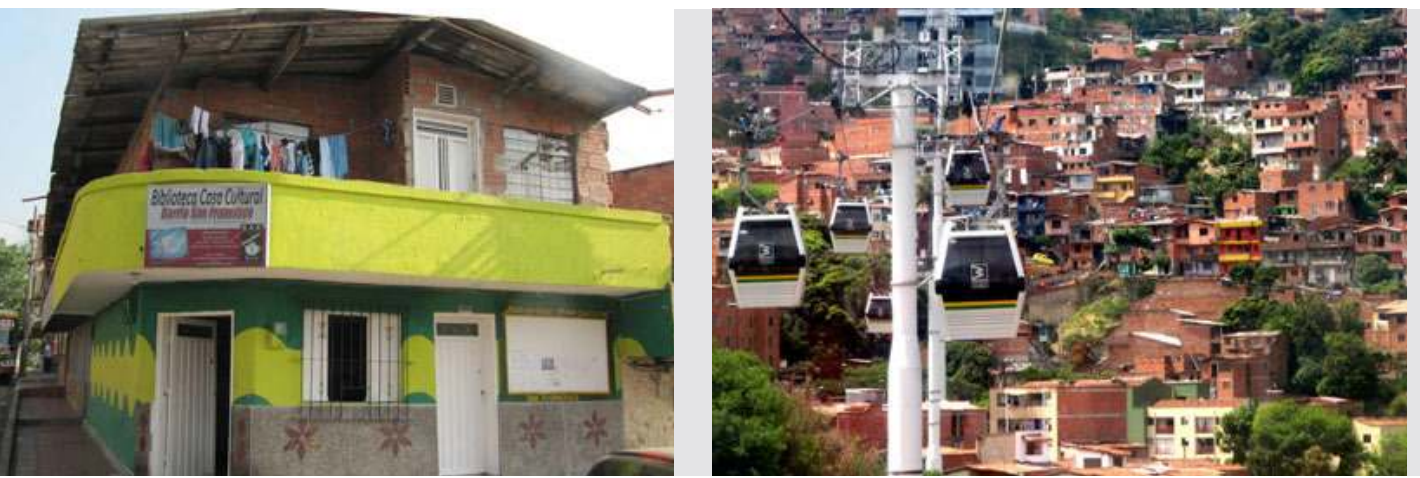

Right: The Medellin 'Metro Cable' is the public transport facility reaching out to (only a small number of) informal settlements on the hills. Photo: Silvia Matuk
- With the entrance of many young people into the different educational groups, the community has stopped assuming that young people are the sole perpetrators of violence. Instead, community members started to perceive the youth as agents of change and social transformation.

- Gangs have acknowledged the group's non-offensive discourse, and accordingly allowed the movement of students without instigating 
fear when they cross the so-called invisible boarders.

- One of the most important results is that many children and adolescents see educational programs as part of their life project, and something through which they can grow as active citizens. In this way, their qualities and potentials are recognized and they get to use them to involve other kids and young people in their visions about the community and the country.

- Perhaps the most visible and evident achievement is the inclusion of over fifty young people in the public higher education system; these youth are studying for careers such as economics, sociology, food engineering, environmental engineering, communication, etc. This has been beneficial in the sense that a cooperation network is built between the students and people in their communities. Moreover, the groundwork for future local development has been laid.

- Grupo Aequus has taught English to over 40 children, who did not have the means to pay for an English course in a formal institution. The leader of this English learning group studied "languages and literature" at the university, and serves the newer generation by sharing knowledge with them and their families by including the parents in the learning process. In this way, not only the children benefit from learning a second language, but their parents become active in the process as well.

- After seeing the motivation of many young people and children who are taking part in the educational programs, even various members of the criminal gangs have decided to participate in some of the courses, studying music, English, or preparatory courses for the university. In cases where a gang member has not been able to attend the courses themselves, they have supported some of their relatives (brothers, cousins, children) so that they can take part in the educational programs - aiming at preserving the next generation in their families from following their own path and joining a criminal gang (once being absorbed by a gang it is almost impossible to opt out again).

- Music, literature, and culture are being promoted through music and writing courses. Approximately 15 kids and young people have learned to play the guitar through the teachings of a music student from the public university. On the other side, at least 5 people have developed their writing skills, appreciating literature and writing as empowerment activities.

- The public recognition of the group is another important result to list. In 2013, the group was awarded the prize "Ciudadano del Cambio" (Citizen of Change), for its commitment to transforming the municipality of Itagüí. The reduction in the homicide rate of the neighborhood San Francisco has been partially attributed to the group's work.

- Finally, the group has participated in various academic events, as 
well as with governmental and non-governmental organizations to spread the word about their communitarian education project. The group's members have also participated in trainings with violence prevention leaders, in public budget learning programs, and in law and justice training to learn about the right to a more inclusive and equitable city.

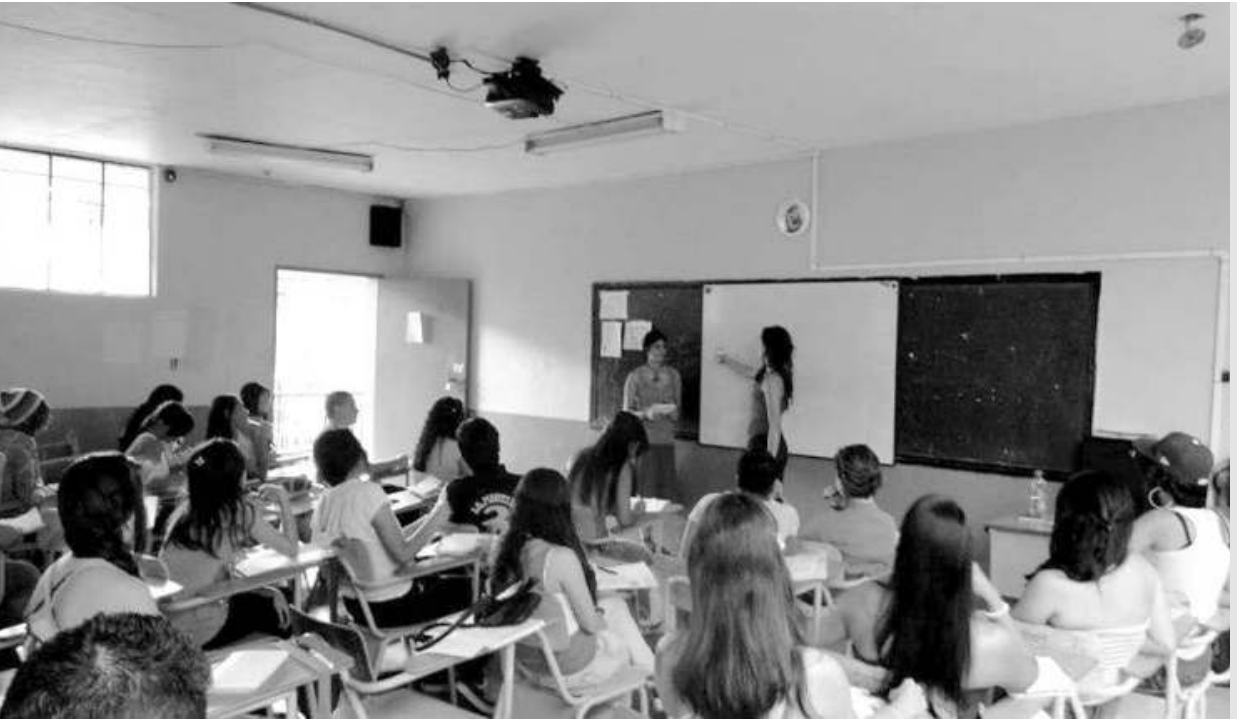

Members of Aequus group giving free preuniversity classes to the local youth

\section{Conclusion: a city according to our vision}

The members of the Grupo AEQUUS dream of a city where everyone has the right to enjoy all the dimensions of the city, not only on paper, but to live in all its potential. Making use of this right, the citizenry could take advantage of its musical, economic, cultural, social, environmental, and political realities. This is a city where human beings and sustainability are the main axes of the future, including everybody's perspectives, and not only those of the technocrats or "politiqueros" (demagogues, corrupt polititians). In this city public resources do not disappear or end up in somebody's private pocket, denying opportunities to people, especially the most excluded.

A city where the night can be enjoyed, without fear of being an object of violence perpetrated by those who hide in the night is also a desire of Grupo Aequus. In this city everyone can enjoy the stars without hesitation, recovering the cosmic dimension of life, which has been lost, as surviving is the priority in the unequal society of Colombia.

Grupo Aequus aims for a city where the corners of neighborhoods are not territories and niches for planning the next crime but rather vital spaces for meetings, playing, and developing community solidarity. This is a place where building the community and its social fabric is not seen as a threat, nor as a subversive act. Respect for the life of others is a supreme value. For example, the library in one of the corners of Itagüi has become a space for daily life, a collective property without restrictions. This experience has resonated with political leadership, as the mayor of 
the municipality of Itagüí has even assumed the building of a community center.

Grupo Aequus wants a city where the urban development sustains a permanent dialogue with environmental sustainability, in which all are committed actors, and where everyone can breathe easily without fear of contracting pneumonia. The group strives for a city where the green spaces are not only for environmentalists, biologists or poets. They want the possibility of riding a bike around the city, without having to go through a war with motorcycles and cars. In this city all will be able to go for a swim in a nearby creek, without having to swim in a toxic soup, produced by the factories that release their wastes in the rivers at night. It should also be possible to go for a walk a night, without this walk having to be an act of courage or a leap of faith when trespassing invisible border lines.

This city should be one where parks, squares, outdoor theaters, and all public places are meeting places and not points of wasteful consumption or street vendors, who do not have another safe and profitable option. The city should not turn its inhabitants into almost compulsive consumers. Going to the park with the family on the weekend should not mean spending two months worth of salary, or where taking the metro cable ${ }^{4}$ is nothing but a dream for a kid from the peripheries of the city.

The city should give all the opportunity to enjoy art, the street, sports, the night, simple things, without restriction or discrimination. A city that is open to the heartbeat of the best of the world and that encourages its inhabitants to open their souls to encounters with new developments and with the concept of difference itself. In this city the rights to a decent home and to public services are recognized. Quality education and a good health system are not restricted to a rich fraction of the population. Young people can work and develop their potentials. Particularly the young people's potentials that entail a creative transformation

04.

The Metro Cable is a recent achievement by the City of Medellin whereby mass public transport has been brought to the otherwise rather inaccessible informal settlements located on the mountain slopes around the city. Cable cars, otherwise used as ski lifts in alpine holiday resorts, have been adapted for the extension of the existing Metro train service in the city.

\section{AEQUUS}

presenting at the World Urban Forum in Medellín 2014

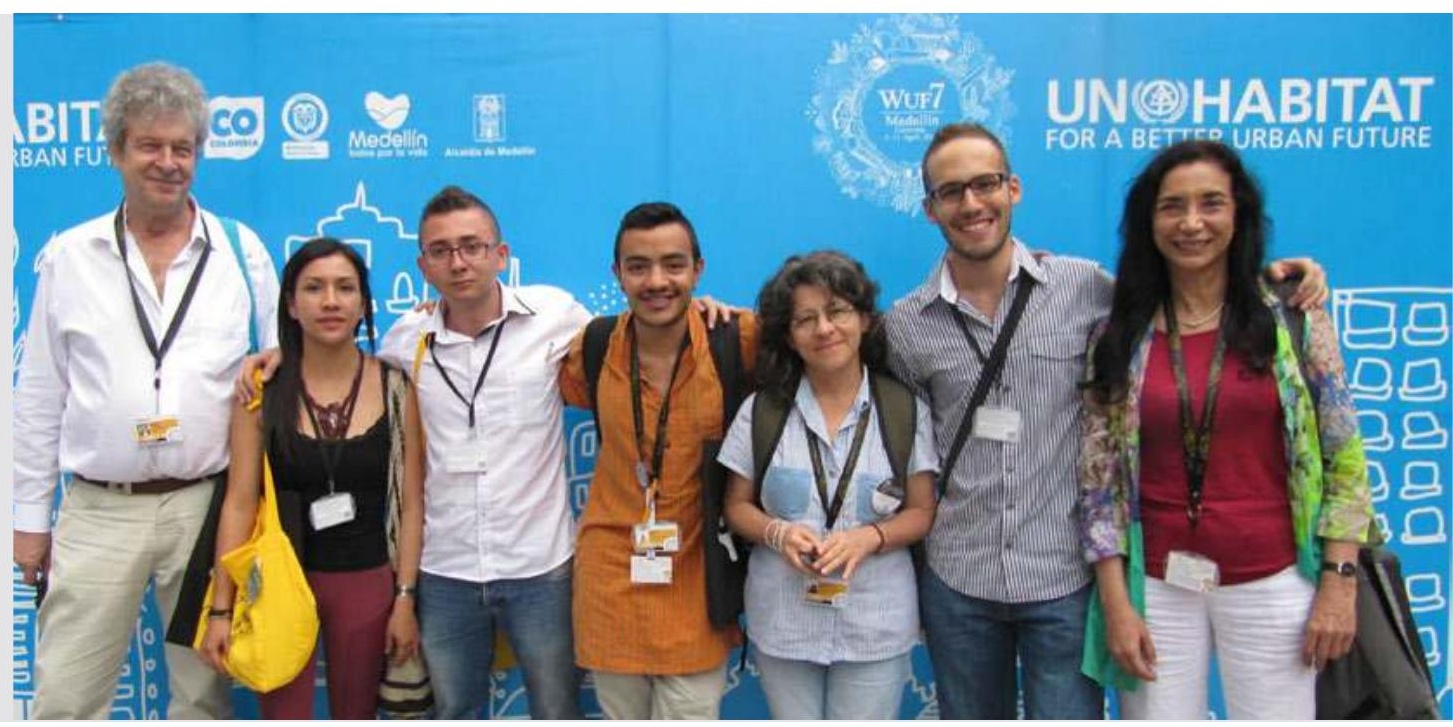


of society are not anchored in the past, paralyzing them, or preventing them from building and enjoying the future.

In such a city the governmental bodies and the state should encourage equality, not inequality - inclusion instead of exclusion. Inequality and lack of opportunities constitute two of the main ingredients of the violence that plagues the reality of Colombia today, especially Itagüi and Medellìn. Grupo Aequus wants a society that encourages, stimulates, and supports organizations and community groups. If equity and opportunities are provided to the citizenry then the people will transform their cities with joy and peace. These cities will be much better and certainly the inhabitants will be too.

In short, AEQUUS stands for a city that everybody can enjoy, not just a minority. We firmly believe that our work and total commitment to our community is already part of the construction of our imagined city, however we are not waiting for someone to come and build it for us. We understand that our vision is the basic input of what it could be or what we hope it could be.

\section{References}

Alonso Espinal, M. Y Valencia Agudelo, G. (2008). Balance sobre el proceso de Desmovilización, Desarme y Reinserción en Medellín. En: Estudios Políticos de la Universidad de Antioquia, núm. 23

Noreña Betancur, E. (2007). Los Paramilitares en Medellín: La desmovilización del Bloque Cacique Nutibara. Medellín: Editorial Universidad de Antioquia.

Plan de Gobierno Municipal de Itagüí (2012 2015) "Unidos Hacemos el Cambio"
El Colombiano, Medellín, 10 de Marzo de 2002, Medellín sí está en disputa.

El Colombiano, Medellín, 1 de noviembre de 2002, Crece tensión entre 'paras' de Medellín.

El País, Medellín 9 de Diciembre de 1990, Una nueva cárcel en Medellín espera a los narcotraficantes arrepentidos. 


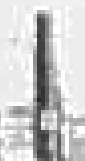

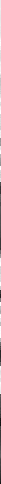

(2)

ten wh

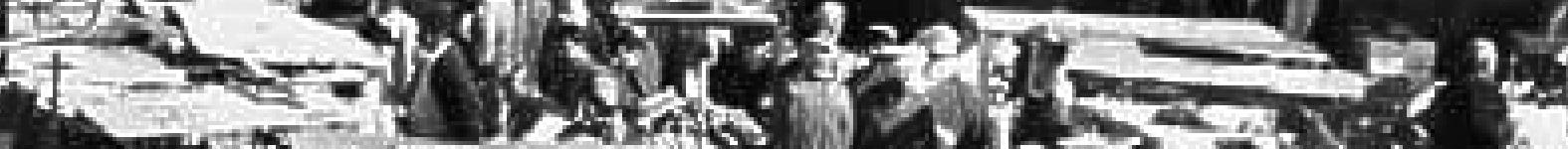

$7.7=0,940$

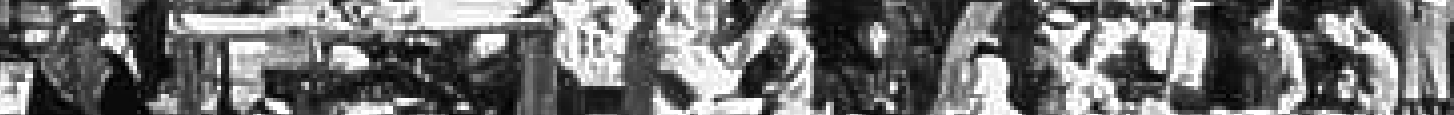

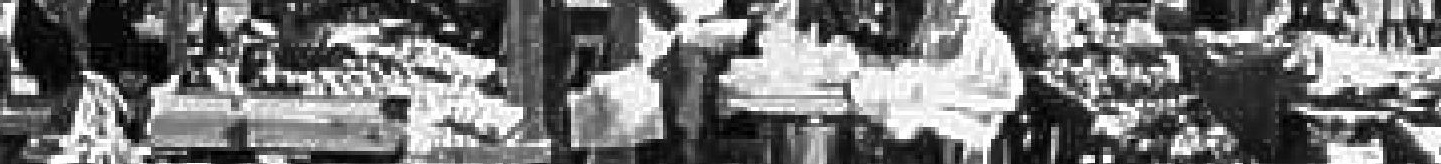

6. - $40 \%$ \%

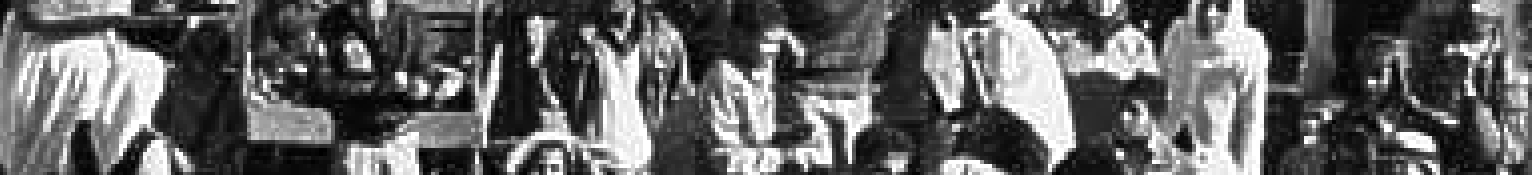

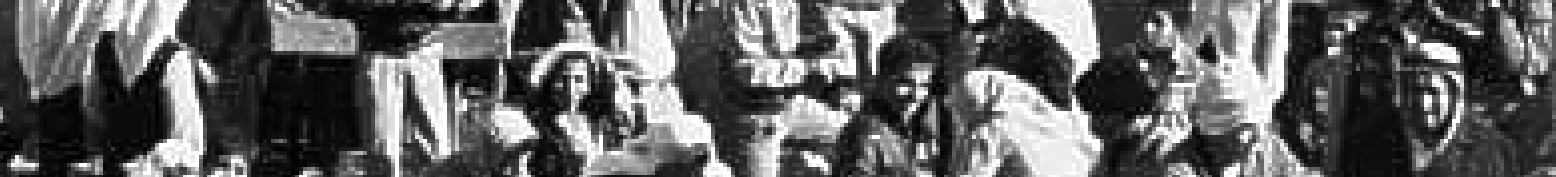

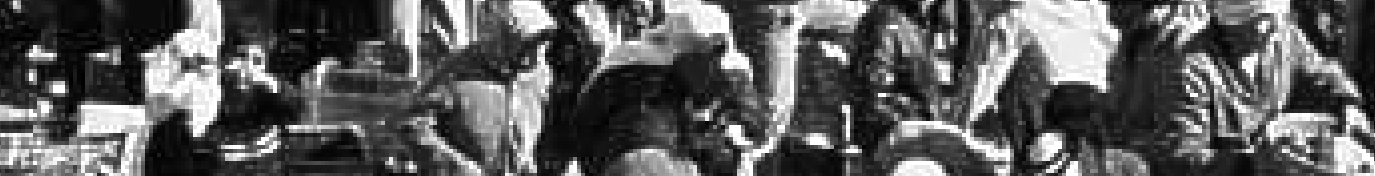

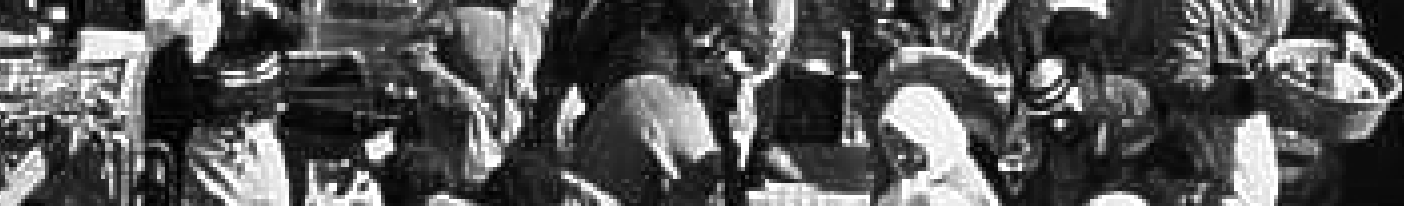
$\left(1 y^{4}, 2\right)$ $\left(\frac{1}{y} y^{-1}\right)^{-1}+y^{2}$,

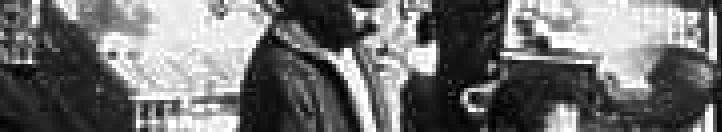

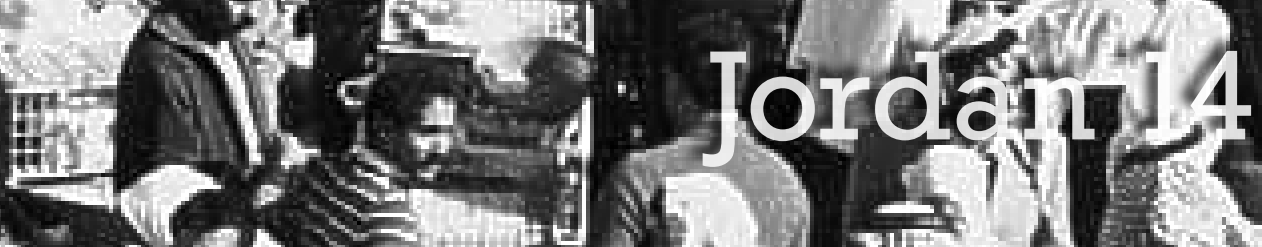

2)

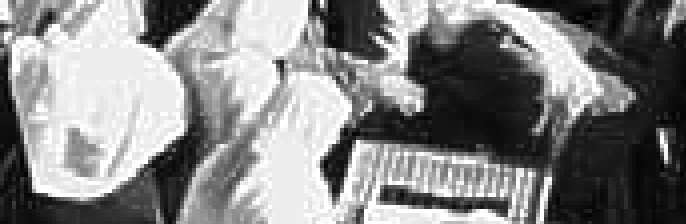




\section{Targeting Adolescence Vandalism in a Refugee Camp

\author{
A Community-Based Initiative from Talbiyeh Camp, \\ Jordan
}

Fatima M. Al-Nammari

The objective of this paper is to present and analyse a case study on how urban space can support a local community in addressing violence by adolescents. The paper presents an initiative in Talbiyeh Palestinian Refugee Camp that attempted to address vandalism among adolescence through a multi-step program that was implemented in the period 2009-2010. The initiative was part of the Talbiyeh Camp Improvement Project, a community-based slum upgrading approach that was initiated in the camp in 2008. As locals identified vandalism as an important risk facing urban spaces in the camp, the project worked with a local NGO, the Women's Programs Center, to develop, implement, and manage the initiative by volunteers. This enquiry uses ethnographic methods based on the author's personal involvement in refugee camps over the last six years, incorporating observation, interviews, and focus groups to understand a.) the varied types of violence that refugees were subjected to and b.) how that violence was reproduced in the camp. The enquiry then explores a community-based endeavour to address adolescent aggression against property, conducted as part of an urban improvement project, in order to generate lessons learned for similar situations.

\section{Urban Violence}

Violence has varied definitions that reflect its complex socio-psychological nature. There is a focus on the explicit expressions of violence impacting personal wellbeing both physically and psychologically, for instance

Previous page:

Palestinians arriving in the refugee camp in Jordan. Historical photo/UNRWA in the American Psychological Association's definition of violence as "an extreme form of aggression, such as assault, rape or murder" (American Psychological Association, 2014). Others address it from a criminological perspective and focus on the safety of persons and their property, in which violence is intentional physical harm against one's self, property, 
or others (Briceño-León \& Zubillaga, 2002). This concept includes vandalism as a type of violence. Still others categorize violence in three parts: economic, social, and political (Moser \& McIlwaine, 2004). Central to all of these definitions is the focus on the use of physical force.

Another typology is from the World Health Organization (2002), which identifies violence as "the intentional use of physical force or power, threatened or actual, against oneself, another person, or against a group or community, that either results in or has a high likelihood of resulting in injury, death, psychological harm, maldevelopment or deprivation" (World Health Organization, 2002, p 5). This definition includes threats and intimidation, and other types of power-related dynamics of control and harm. This typology initially identifies three main types: self-directed, interpersonal, and collective violence.

The World Health Organization report identified the nature of a violent act as physical, sexual, psychological, or involving depravation or neglect. Consequently they developed a composite classification based on a combination sketch of the perpetrator, victim, and the nature of crime. This typology includes: abuse of the elderly, youth violence, child abuse and neglect, violence by intimate partners, sexual violence, self-directed violence, and collective violence (World Health Organization, 2002). The typology also acknowledges a higher level of complexity, especially as it includes neglect as a type of violence, addressing psychological trauma in addition to physical pain.

Another definition of violence focuses on how it climaxes, identifying violence "as the manifestation of distorted power relationships, produced by the complex interaction between risk factors" (Agostini, Chianese, French, \& Sandhu, 2010, p iii). This is of significance as it acknowledges the role of power relationships, a position that supports the need for a wider view on what violence is and how it is perpetuated through social relationships. Hence acute unfair, painful, or distressing social relationships are violence that impacts the body and the psyche, and may lead to physical violence, as discussed below.

Similarly, a wider perspective of violence addresses its totality and its impact on the comprehensive wellbeing of humans. For example, Bourdieu (2004) identified symbolic violence (i.e. domination expressed in daily rituals) as a significant source of violence on the body, the impacts of which are sometimes missed even by the victim. Such effects may include emotions (i.e. shame, humiliation, guilt, anxiety, etc.) or passion and sentiment (hate, respect, etc.), and may become very evident through flustering, stuttering, trembling, and anger. The symbolic relationship between genders, for example, often manifests itself in violence against women.

Pearce (2007) highlighted the significance of this change in perspective, as she discussed how violence and power interplay. Providing a wide perspective into violence, including, but not limited to symbolic and structural violence- in addition to other types of violence- she argued how the presence of violence improved individuals' understanding of the production of violence in a community, as they learn how their actions aggregate and perpetuate physical violence. 
A wider concept of violence would include types of "social -structural" violence that are harmful to the body, psyche, or mind. Structural violence causes pain and suffering; socially unjust structures create injury both physical and psychological. Structural violence perpetuates a culture of violence as it is practiced and legitimized.

This wider view of violence has developed to incorporate psycho-social aspects of pain, harm, and aggression. According to Scheper-Hughes and Bourgois (2004) "violence can never be understood solely in terms of its physicality - force, assault or the infliction of pain - alone. Violence also includes "assaults on the personhood, dignity, sense of worth, or value of the victim" (Scheper-Hughes and Bourgois, 2004, p1). This understanding is an important aspect for explaining the "safe zone" in the study case in Talbiyeh, which provided the participants with a space in which their dignity, sense of worth, value, and individuality was respected.

Similarly, in his study of refugee camps in Lebanon, Hanfai (2008) discusses a different kind of violence that is witnessed by refugees: Spatial violence is exerted over the refugees by controlling movement of persons and materials in and out of camps. Such practices are intended towards segregation and rejection, thus limiting human access to services and resources. This kind of violence is subtle but has long-term impacts on the wellbeing of individuals, both mental and physical.

Consequently, violence may be misrecognized, or even culturally lauded and encouraged. For example, parental violence may be encouraged in some cultures, while violence against certain behaviour that is not acceptable in a community may be sanctioned. Similarly, violence may be practiced as witchcraft and sorcery, an example of invisible violence that some societies perform (Pearce, 2007). This wide understanding of violence is significant as it highlights the fact that violence is produced and reproduced in varied forms, thus when a community expresses signs of criminal violence (violence that is considered illegal, which is often dubbed "urban violence"); it is part of a cycle of violence that includes varied typologies of structural, symbolic, social, and mental harm.

This wider understanding of violence provides perspective, which "enables us to see the continuum of violence, between the direct political, structural, symbolic and everyday violence. It makes us think about how, for instance, the violence of poverty, inequality, hunger, and disease translate into intimate and domestic violence" (Scheper Hughes and Bourgois 2004: 1). As such, this perspective is significant in understating how violence is instigated in a community, as in the case study below, which was otherwise not known for being violent.

Consequently, the understanding of urban violence has changed from considering it as merely acts of crime to an appreciation of its complexity as a multifaceted phenomenon signifying humanitarian affliction and societal injustice, rooted in socioeconomic relationships and environmental conditions. This perspective is of significance as it provides explanation for violence in refugee camps, and was the foundation for developing the initiative below. 


\section{Methodology}

This enquiry utilised ethnographic work done by the author since 2008 in several refugee camps (Talbiyeh, Baq'a, Husn, and Wihdat). Such work included site visits and interviews conducted as part of research work in the period 2011-2014. The enquiry also utilised data from the Talbiyeh Camp Improvement Project documents, in addition to recent interviews and focus groups with the Talbiyeh Women Program Centre and some of the youth who participated in the case study. Furthermore, the author's own experience as project manager of the Talbiyeh Camp Improvement Project was essential for the understanding and presentation of this case. The investigation aimed at offering a grounded perspective of violence in the camps, in addition to exploring a community-based endeavour to address adolescent aggression against property - conducted as part of an urban improvement project.

The enquiry below is preceded by a study of the history of refugee camps in order to communicate the different types of violence that refugees have been subjected to since their arrival in Jordan (the inquiry will not cover the violence that they witnessed before reaching the camp, despite its traumatising effects). It then uses ethnographic methods to understand the local's perceptions of the meaning and reasoning behind local violence and develops a model of understanding that is based on their input. The paper then proceeds with a case study about an implemented initiative targeted at reducing vandalism among teenagers in one of the camps. It is the objective of this paper to move beyond the traditional views of crime and violence towards a more complex understanding of the contextual impact on the generation violence.

\section{Palestine Refugee Camps in Jordan}

Palestinian refugee camps were created after the 1948 and 1967 wars with Israel to house refugees who fled their villages in north, middle, and south Palestine. The total number of camps is ten according to the United Nations Relief and Works Agency (UNRWA) and thirteen according to the Jordanian Government (Department of Palestinian Affairs -b, n.d.; UNRWA, n.d.). The camps started as tent cities, but over time people had to adjust to the needs of their expanding families and the harshness of winter weather. The adjustments for refugees were difficult, as the majority were of a peasant background, had no urban life skills, and were suddenly uprooted from their lands.

Within the camps, UNRWA provided basic health and education services in addition to relief and social aid. The camps did not have any infrastructure until 2006 when a series of projects were initiated; thus most camps were not serviced with sewage, water, and electrical networks at the time they were set up. The camps have grown into urban centers without planning, which resulted in varied environmental and social problems (Al-Nammari, 2013, 2014; Qutub, 1989). The camps are typically of lower environmental quality, and represent poverty pockets, but still express varied living conditions depending on their location, 
the 1960s, every decision adopted by UNWRA was scrutinized politically in terms of its impact on the Right of Return, and its ramifications to the Palestinian national movement.

Palestinian refugees are a very heterogeneous group. Only about 18\% of the refugees reside inside camps, the majority of Palestinian refugees live outside camps, reflecting the diversity in socio-economic conditions. Many Palestinian refugees brought with them higher skills and education levels that were lacking in the host country, facilitating their achievement and economic stability early after their migration (Khawaja \& Tiltnes, 2002). Furthermore, most Palestinian refugees in Jordan were awareded Jordanian citizenship in 1954, in an arranegemnt that targetd facilitating their access to services while at the same time maintinig their right to return to their homaland (some refugees were excluded though, such as refugees from Gaza). This had a significant impact on refugees in Jordan, hence their higher living standards and achivements compared to refugees in the other host countries (i.e. Lebanon, Syria, the West Bank, and Gaza) (Department of Palestinian Affairs, n.d. ; Khawaja, 2003). Still, the living conditions of refugees inside the camps were vastly different, as these camps grew into pockets of severe poverty and social exclusion (Khawaja \& Tiltnes, 2002).

Black September ${ }^{1}$ was a catastrophically violent event that shaped, and continues to shape, the lives of Palestinian refugees in Jordan and their subjugation to varied forms of structural and symbolic violence. The tension between Palestinian factions, located mainly within the camps, and King Hussein resulted in bloody clashes that took the lives of thousands from each side. The results of the clashes were significant for the construction of identities by Jordanians and the exclusion of Palestinians with Jordanian nationality (refugees of the 1948 wars). It was not only about a sense of "Jordanianness" that rejected a Palestinian presence on Jordanian land, but also about excluding all Jordanians of Palestinian origin from public and security employment. Immediately afterwards, a process of Jordanization of government positions was initiated, and still continues (Fruchter-Ronen, 2008).

In the 1970s, Jordan benefited from the oil boom and the salary transfers from Jordanians employed in the Gulf countries, thus, the government launched several development programs targeting socio-economic development, housing, and infrastructure. The tensions of "Black September", on the one hand, and the political implications of development within camps, on the other, gave refugee camps special status, resulting in minimal development inside the camps (Al Husseini \& Bocco, 2009). This period is significant in the construction of meaning of the camp as a space of destitution, want, and relief.

Despite that, from the 1970s-1980s, some refugee families witnessed improvement, as they obtained employment in Saudi Arabia and other Gulf countries (Bocco, 2009). Many camp residents saw a gradual change in their quality of life while others managed to move outside the camp, though usually in the immediate surroundings of the camp. These new local "elite" developed networks within regional and national institutions and became instrumental in the shaping of development activities

01.

The term Black September refers to the Jordanians Civil War that began in September 1970 and ended in July of 1971. 
inside the camp, functioning, through their control of local organizations and government committees, as "gatekeepers". This is important as the case study below shows how such individuals found it difficult to accept the inclusiveness of the Camp Improvement Project and utilized different tactics to maintain their hegemony, often employing structural and social violence to reiterate their power.

Issues of "resettlement" and "alternative homeland" emerged in the1980s, which witnessed an attempt to introduce housing development into camps by the Jordanian government, an act which was completely rejected inside the camps. However, the return of approximately 300,000 Jordanians from the Gulf War in 1990-91, most of whom were Palestinian refugees, resulted in a new economic decline inside the refugee camps. As salary transfers dwindled, the camps suffered new socio-economic challenges. Again, the refugee camp was a space of distress, suffering, poor housing conditions, overcrowding, poverty, inferior environmental conditions, and no infrastructure (Abu Helwa \& Birch, 1993).

These camps are dispersed across Jordan, but within Amman and its immediate vicinity there are four camps of varied conditions. The Hussein and Wihdat camps have capitalized on their location within the city through entrepreneurship, becoming commercial retail centers. These camps attract visitors through their diverse shopping opportunities, low cost, and lively markets (Table 1).

\begin{tabular}{|c|c|c|c|c|}
\hline Camp Names & $\begin{array}{l}\text { Year } \\
\text { established }\end{array}$ & $\begin{array}{l}\text { Number of refugees } \\
\text { registered }\end{array}$ & $\begin{array}{l}\text { Area ( x } 1000 \\
\text { meters square) }\end{array}$ & Economic base \\
\hline Zarqa & 1949 & 18,549 & 182.589 & $\begin{array}{l}\text { Varied (industrial \& business } \\
\text { entrepreneurs }\end{array}$ \\
\hline Wihdat (Amman New Camp) & 1955 & 51,751 & 479.164 & $\begin{array}{l}\text { Commercial and vocational } \\
\text { entrepreneurship }\end{array}$ \\
\hline Hussein & 1952 & 29,560 & 445.241 & Commercial entrepreneurship \\
\hline Irbid & 1951 & 25,000 & 240.00 & $\begin{array}{l}\text { Commercial and vocational } \\
\text { entrepreneurship }\end{array}$ \\
\hline Baq'a & 1968 & 104,000 & 1400.00 & $\begin{array}{l}\text { Agricultural labor, com- } \\
\text { mercial and vocational } \\
\text { entrepreneurship }\end{array}$ \\
\hline Talbiyeh & 1968 & 7286 & 133.433 & $\begin{array}{l}\text { Agricultural and industrial } \\
\text { labor }\end{array}$ \\
\hline Husn (Shaheed Azmi Mufti) & 1968 & 22,000 & 770.00 & $\begin{array}{l}\text { Agricultural and industrial } \\
\text { labor }\end{array}$ \\
\hline Marka (Hitteen) & 1968 & 53,000 & 920.00 & $\begin{array}{l}\text { Light industrial and vocational } \\
\text { entrepreneurship }\end{array}$ \\
\hline Jerash (Gaza) & 1968 & 24,000 & 750.00 & $\begin{array}{l}\text { Agricultural labor vocational } \\
\text { entrepreneurship/crafts }\end{array}$ \\
\hline Souf & 1968 & 20,000 & 500.00 & Agricultural labor \\
\hline
\end{tabular}

Table 1 Refugee camps in Jordan. Sources (Department of Palestinian Affairs -b, n.d.; UNRWA, n.d.; and author)
On the other hand, Talbiyeh, Marka, and Baq'a camps are on the outer edges of the city and have developed a character based on their location. Baq'a is in the midst of an agricultural area, whereas Marka is a vocational and light industrial area. Talbiyeh is a labor center with locals working in public and private institutions in mostly semi-skilled and non-skilled 
labor; it is mainly influenced by the industrial zone in close proximity, nearby agricultural land, and the airport, in addition to small labor and clerical positions in the municipality and UNRWA.

Other camps include Husn (Table 1) located near an industrial zone in the Houran agricultural plains (northern Jordan). Irbid Camp lies inside Irbid city and has become a part of the city center. Souf lies close to a village and has become an urban center for the residents of the village, while Zarqa developed into a city located close to the Jordan oil refinery and became a city center and hub of development for that region.

\section{Understanding Violence in Refugee Camps}

Generally, violence in refugee camps has been linked to socio-political and economic insecurity (Crisp, 2000). The psychological bearings of wars and migration impact stress levels and social interaction within camps. The impact on children has been singled out as camps are not designed for the wellbeing of children (Paardekooper, De Jong, \& Hermanns, 1999).

Multiple researches have been dedicated to the social, economic and political dynamics of Palestinian refugee camps, but primarily on those in Lebanon and the West Bank. Studies have shown that the consequences of poverty, high density, and political tension result in psychological and mental stress as well as trauma (Farah, 2000; Suleiman, 1999; Marx, 1992). The construction of the refugee, as an aid receiving dependant

Life in Jerash Refugee Camp. Photos:

Dina Dahood Dabash
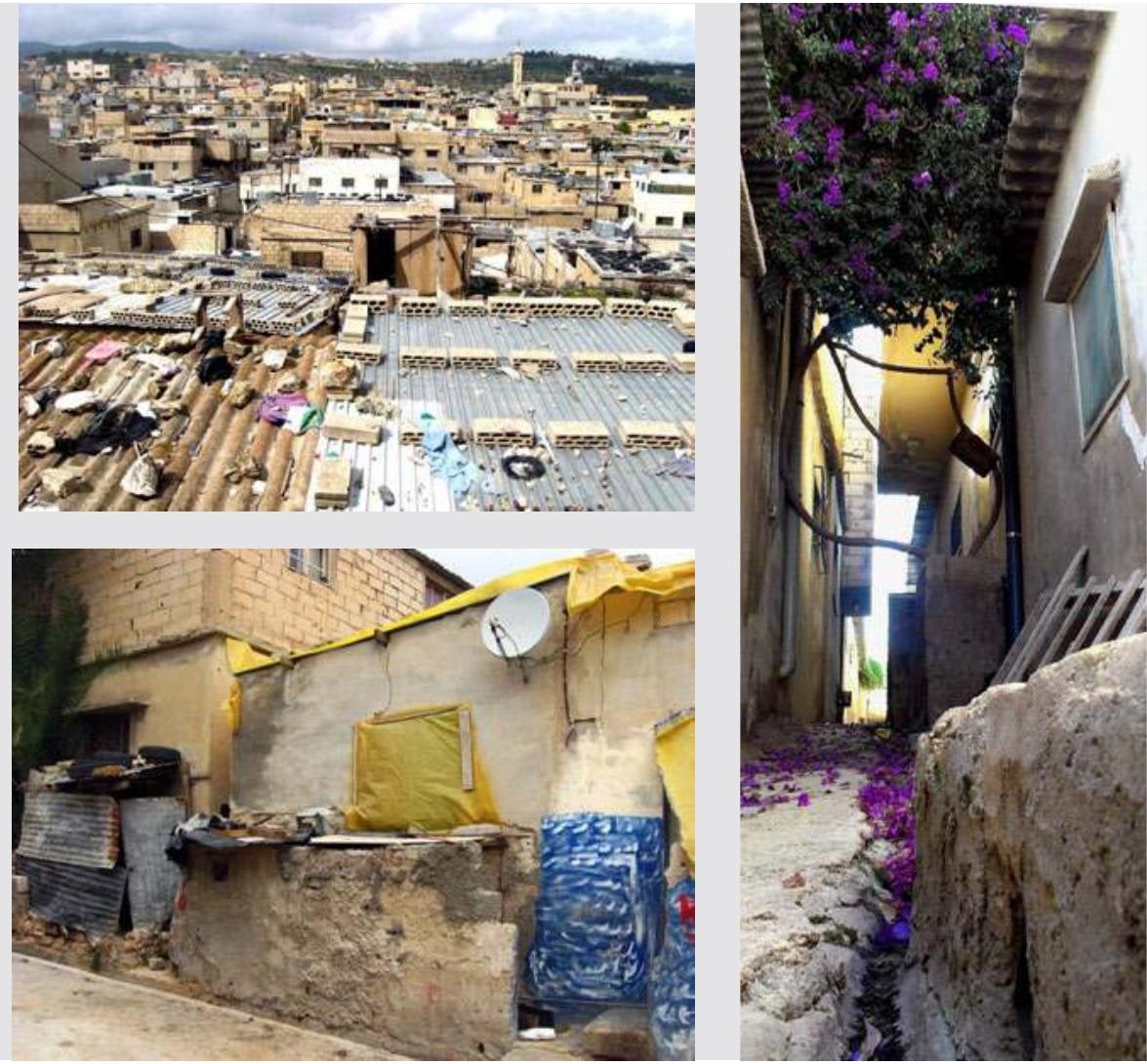
person, and the construction of the place, the camp, are both structurally intertwined with suffering, need, and pain (Peteet, 2005).

Studies into refugee camps in Jordan showed that the refugees believe that overcrowding and poverty are important factors in domestic and street violence. Teenagers and youth spend most of their leisure time on the street, as their homes are overcrowded; this results in them engaging in different activities starting with smoking and drinking and getting in contact with gangs and drugs (Khawaja \& Tiltnes, 2002). The researchers found that refugee camps in Jordan are enclaves of poverty, as the homogeneity of income created a shared identity of "refugeeness" that has shaped the character of camps and confined their residents (Khawaja \& Tiltnes, 2002).

This is further emphasized by the fact that refugees believe that they are discriminated against. For example, in Hejoj's (2007) study on causes of poverty, one half of survey respondents felt that government policies were to blame for their economic situation while approximately $18 \%$ believed that their political status of a refugee was the cause of poverty; less than one third of respondents felt it was something within an individual's control.

Hejoj noticed the causes of their poverty were a "politically-charged" issue that refugees were not comfortable with discussing it (which could be seen as an indicator of their feelings of insecurity). It is not a secret that the government practiced several policies that implicitly and explicitly excluded Palestinians from employment (Hejoj, 2007). Palestinian refugees have been subjected to an exclusionary discourse and actual policies that emphasized their "otherness" compared to Jordanians (FruchterRonen, 2008; Perez, 2011). This structural violence against Palestinians has left marks on the camp refugees in particular, as they are the most vulnerable. The camp, in this sense, is a "political space", where "us" and "them", alongside "in" and "out" borders are clearly demarcated.

No wonder then that mental distress is widespread among all age groups in refugee camps in Jordan, with 15\% reporting taking regular medication, $48 \%$ constantly feeling sad and depressed $60 \%$ feeling nervousness, and $50 \%$ worrying too much about things. Also, $13 \%$ of refugees suffer from four or more psychological distress symptoms. Mental stability closely correlates with occupation, income and housing conditions (Khawaja \& Tiltnes, 2002).

Consequently, domestic violence has been identified as a problem in refugee camps in Jordan. Social, mental, and physical impacts of unhealthy living conditions lead to high levels of stress, depression, conflict between neighbors, and domestic violence (Farah, 2000; Khawaja, Linos, \& El-Roueiheb, 2008).

Some camps have developed a reputation for crime and violence, specifically Irbid, Zarqa, and Ba'qa. The three camps are viewed as "unsafe" by their neighbors and in public discourse. Reports and talks of murder, gangs, drugs, rape, and assault take place and are considered part of the image of the place. In Husn/Al-Shaheed Camp, respondents discussed their image outside the camp and reflected on the title their camp has been awarded: "The Valley of the Wolves". It was possible to see that this 
image was painful for them, but they also felt that it was mainly a result of social tensions. They agreed that residents of nearby villages and towns did not accept their presence and would rather see them leave, and that it why they taint their image. Some narrated stories of trying to find jobs and being denied on account of being from the camp, thus they do not reveal their true place of residence and instead lie about it. They related that to the Black September events and the camps' role in them. They also felt that although crimes did occur in the camp, it was far less than what happened elsewhere. The author's talks with some people of Husn City, the closest neighbor of the camp, revealed that they harbored very negative images of the camp and the refugees.

During a similar visit to Baq'a camp, the author tried to discuss that image and the respondents (both male and female) undermined the violence. They said it was just a stereotype

that was propagated for political reasons. Their political activism and their nationalistic role created negative relationships with their Jordanian neighbors and such an image was intended to exclude and isolate them. Many women were quick to inform me that they were very safe in Baq'a as long as it was not too late, which they identified as after 1am: "where else can a women walk safely in the middle of the night?" Men noted that the crimes committed inside Baq'a or by Baq'a residents were not higher in rate than those of the neighboring areas (a fact that was verbally confirmed by the government officials and security officers on site). The majority of respondents felt that the image of violence was mainly related to aggressive behavior by the youth on the streets, which they acknowledged. The young men claimed that street life made people tough and that was why the youth and teenagers of Baq'a behaved in an aggressive manner - even if the motivation was just wishful thinking of possessing a powerful position.

Although Baq'a is an agrarian area, the camp itself is large (over 100,000 people) and has become an urban center of its own. Thus, the diversity of inhabitants, the high level of poverty, the dire social and economic needs, and the lack of extended familial support (as the limited number of extended family who are present in the same camp) creates a culture of determined uncompromising behavior, which may not necessary be violent, but may have impacted this image of aggression. The respondents highlighted the high number of families receiving UNRWA's relief aid, and the fact that many young men find themselves responsible for their families at an early age. Furthermore, overcrowding pushes the male adolescents and youth into the street, which puts them in direct contact with varied aspects of street life at a very young age. Some felt that delinquency would be greatly reduced should the problem of street youth be addressed. Similarly, both Zarqa and Irbid are camps that have come to be major urban city centers. The socio-economic conditions inside these camps are typical of refugee camps in the region, including high poverty rates, crowding, exclusion and discrimination, in addition to unemployment.

Of particular interest is violence expressed in relation to football matches of the Wihdat camp football team, which can be considered a 
representation and reflection of the structural and social violence committed against refugee camps. The varied hostile attitudes against refugees by the main government discourse, which started after the Black September clashes, resulted in strong form of nationalism among refugees. This is manifested in the zealot support for the Wihad camp football team, who has come to symbolize Palestinians in Jordan. Violence between the two main rivals, Wihdat (representing Palestinian) and Faisali team (representing Jordanian) is ridiculous when remembering that the players are of mixed origins from both Palestine and Jordan. However, the symbolism of the two teams playing, each representing an enclave of nationalism, cannot be missed. This violence related to football games is heavily related to suppressed nationalism in camps, and the hate which was fostered after Black September among Jordanians.

An explanation was offered by a respondent: after the 1970 Black September events, in which refugee camps were strongholds for Palestinian faction fighting, the Jordanian army prohibited any act of activism in the camps. As part of that, suppression of Palestinian nationalism has led to furthering feelings of oppression. Football has become a coping strategy.

Thus, political activism is known to bring clashes with the security forces. Typically, Baq'a and Wihdat Camp in Amman are known for their activism and residents take pride in the fact that they initiate demonstrations in support for the Palestinian cause. Studies show that refugee youth and adolescents suffer high levels of distress and depression due to the prolonged conflict and the structural violence they face as refugees (Chatty, 2007). They have developed several coping strategies such as education, the formation of formal and informal groups, avoidance of tense social relations, the amplification of Palestinian identity, religion, the development of a sense of belonging to the camp, the support of peers, early marriage, and the support of family and kin (Chatty \& Hundt, 2001).

\section{Case study: The Urban Improvement Initiative}

\section{The Talbiyeh Camp Improvement Project}

The Talbiyeh camp is one of the emergency camps created in the aftermath of the 1967 wars. It is located on the southern boundary of Amman in a poverty pocket that is slowly changing from an agricultural to an industrial economic base. The camp of 133.33 square meters houses refugees from Beer Sheba, Hebron, Ramallah, Jericho, and Gaza and faces several challenges of unemployment, poverty, extreme density, poor housing, and poor environmental conditions (UNRWA, 2008). The official camp boundaries include 1,313 shelters housing 810 families; however, the camp and its surrounding spill off include 7,286 individuals.

Today, Talbiyeh camp has semi-urban characteristics. In the past 15 years, the area witnessed many changes. The growth of Amman southwards on the main north-south highway brought the capital closer to this area on the one hand; the establishment of an industrial park has been changing the job market and economic opportunities on the other.

Upon its establishment, each family had a tent, later replaced with a room built with concrete masonry units and asbestos roof. Through time, 
families added rooms according to availability of space and resources. Currently, the average family has about $71 \mathrm{~m}^{2}$ for shelter, but this does not reflect the high density of some of the shelters. The number of families in shelters ranges between one and five, with $10 \%$ of shelters housing 2 or more families. Furthermore, $12 \%$ of families live in abject poverty and $32 \%$ are in relative poverty. The urban context is not very promising either, as there is limited open space, no recreational areas, and limited vehicular access to many camp corners (UNRWA, 2008).

The Talbiyeh Camp Improvement Project was initiated in June 2008 to mark a new phase in how UNRWA handled refugee camps. The newly established Camp Improvement Department, unlike others in the organization, did not adopt an authoritarian relief-oriented approach, but was founded on partnership with the community and sustainable development approaches. It was anticipated that the new department would revolutionize how UNRWA operated, if UNRWA managed to honor their commitment to community-based development (Misselwitz and Hanafi, 2010; Budeiri, 2014).

Consequently, the Talbiyeh Camp Improvement Project used several modes of participation including, but not limited to, door to door surveys, thematic groups, focus groups, public meetings, and neighborhood groups. The main forum for participation was the Work Group (WG), an open council where the planning, discussions, and decisions were made. The Work Group included heads of public and local organizations, activists, family heads, and any interested individual.

The project produced a list of priorities and included several sub-projects, which complemented each other and were all based on community

Talbiyeh Refugee Camp in JordanSource: Al Nammari (2010)

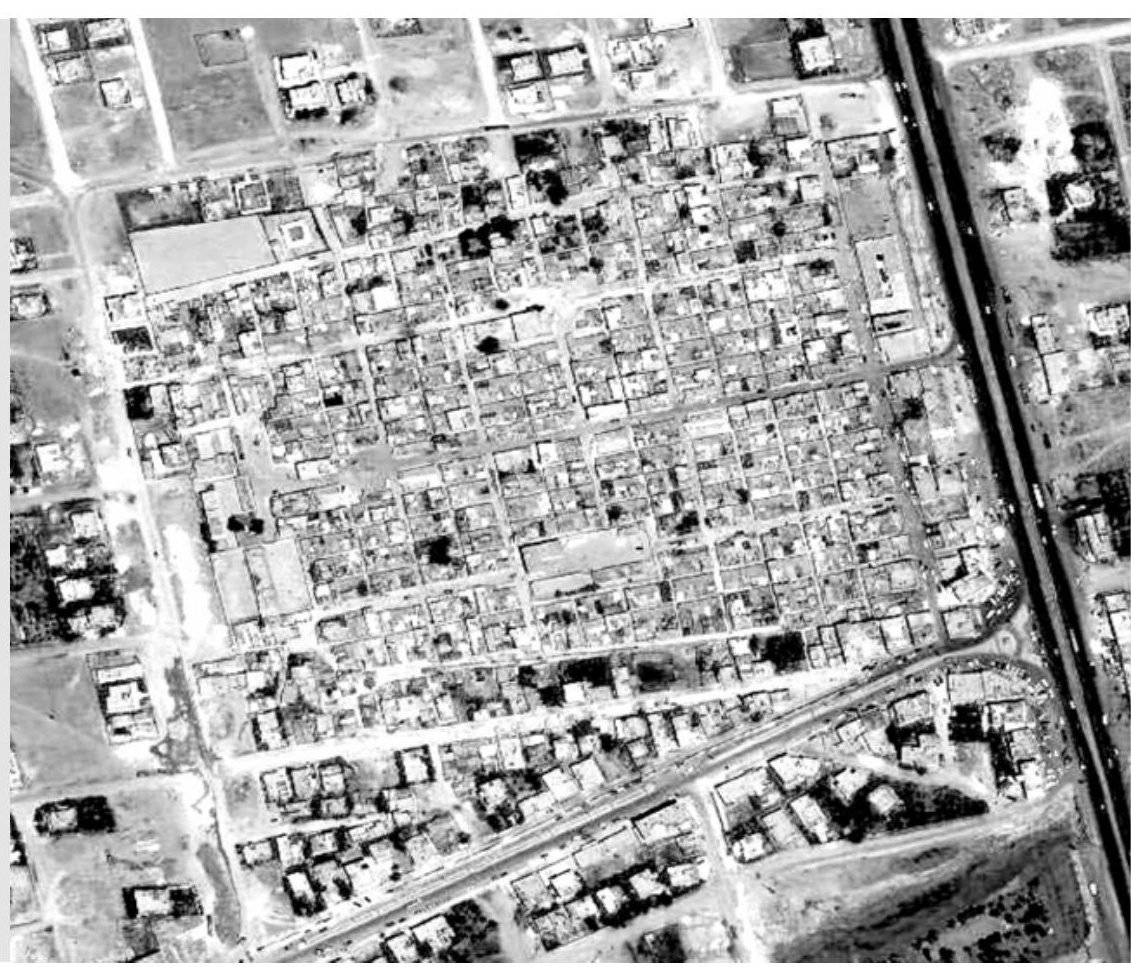



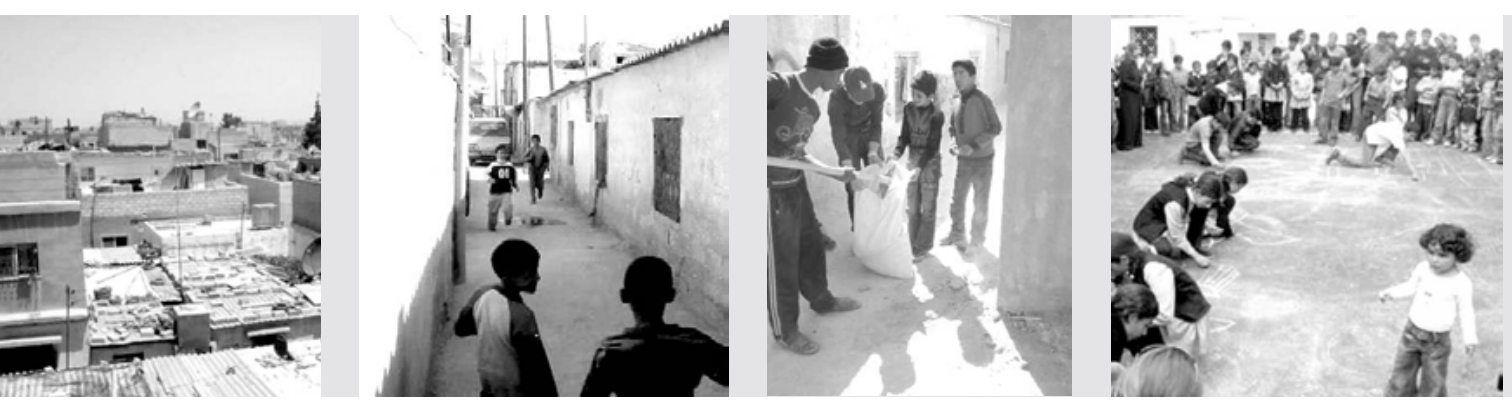

Talbiyeh Refugee Camp

agency (Al-Nammari, 2014). This included components concerning education, health service, infrastructure, shelter, urban space, local NGOs, and economic opportunities. Of relevance was a series of training done with local youth to address employability and life skills; an employment office was likewise established to support job searching; so too were training of local trainers and projects for income generation realized. Adolescents had several trainings and activity projects to facilitate their input and collaboration with the project towards the redevelopment of the play areas and other open spaces.

Violence in the Talbiyeh camp

As part of the planning of the urban upgrade, discussions of the community's priority needs often led to requests for one key concern: "police presence in the camp, especially at night", which was ranked sixth in the community needs. The ranking was done by a random sample composing $10 \%$ of the local community, stratified by age and gender. This feeling of insecurity was mainly expressed by women, youth, and adolescents. However, most males rejected this need and refuted any state of insecurity.

During the focus groups, women and adolescents were the ones who identified violent behavior as problematic. The main concerns were three fold: vandalism, violence between individuals which escalated to become violence between families due to the culture of kin support, and drugs. The discussion showed that types of violence are as follows:

- Against the self : drugs (no suicide took place in the camp);

- Against persons at home (domestic violence);

- Against property, through stealing, damaging, arson, and vandalism.

- Against persons in the public realm, including youth groups (not gangs), and familial quarrels. This was mostly about control of resources and power conflicts. The youth did not engage in serious gang activity but did act violently over conflicts of interest;

The discussion showed how space was a central issue (Table 2). Domestic violence was very much explained in terms of overcrowding and dire economic need. Most social physical violence was attributed to quarrels over space. Neighbors fighting over an available square meter (and sometimes over $20 \mathrm{~cm}$ of expansion) were a recurrent incident and often ended in courts. Once an individual was in a fight the culture of kin created tension between the two families and the conflict often escalated if the families 


\begin{tabular}{|c|c|c|c|c|c|}
\hline Domestic & Wife/ child abuse & - & Theft Arson & - & $\begin{array}{l}\text { discrimination between sib- } \\
\text { lings, children work, early } \\
\text { marriages, and severe finan- } \\
\text { cial hardship }\end{array}$ \\
\hline Schools & $\begin{array}{l}\text { Student quarrels, } \\
\text { teacher-student } \\
\text { violence }\end{array}$ & $\begin{array}{l}\text { Student groups } \\
\text { fighting }\end{array}$ & $\begin{array}{l}\text { Stealing from } \\
\text { classmates }\end{array}$ & $\begin{array}{l}\text { Vandalism at } \\
\text { school }\end{array}$ & $\begin{array}{l}\text { Verbal and mental abuse by } \\
\text { teachers. Drugs reported by } \\
\text { students but denied by school }\end{array}$ \\
\hline $\begin{array}{l}\text { NGOS, UN, and } \\
\text { government } \\
\text { organizations }\end{array}$ & - & $\begin{array}{l}\text { Quarrels } \\
\text { between } \\
\text { rival power } \\
\text { structures }\end{array}$ & - & Vandalism & $\begin{array}{l}\text { Structural and symbolic vio- } \\
\text { lence. Lack of transparency, } \\
\text { corruption accusations, bias, } \\
\text { and no inclusiveness }\end{array}$ \\
\hline $\begin{array}{l}\text { Street and } \\
\text { alleys }\end{array}$ & $\begin{array}{l}\text { Fights between } \\
\text { individuals, espe- } \\
\text { cially youth and } \\
\text { teenagers }\end{array}$ & $\begin{array}{l}\text { Youth group } \\
\text { quarrels - } \\
\text { support of } \\
\text { kin individual } \\
\text { fights }\end{array}$ & Theft & $\begin{array}{l}\text { Vandalism } \\
\text { of street } \\
\text { furniture } \\
\text { and public } \\
\text { property }\end{array}$ & $\begin{array}{l}\text { Nothing was observed } \\
\text { over the visits, which was } \\
\text { explained in term of time, } \\
\text { most violence takes place at } \\
\text { night. Girls reported sexual } \\
\text { harassment. }\end{array}$ \\
\hline $\begin{array}{l}\text { Parks, } \\
\text { playgrounds }\end{array}$ & $\begin{array}{l}\text { Individual quarrels } \\
\text { between children } \\
\text { or teenagers }\end{array}$ & $\begin{array}{l}\text { Fights between } \\
\text { users (children } \\
\text { and teenagers) } \\
\text { on right of use }\end{array}$ & Theft & Vandalism & $\begin{array}{l}\text { Rape of male boys reported at } \\
\text { night in secluded spaces. Drug } \\
\text { abuse also reported. }\end{array}$ \\
\hline
\end{tabular}

had a tendency for violent behavior. Some families in the camp even constructed a reputation for being physically violent against their adversaries, which made people avoid them. However, they seemed to acquire what they wanted most of the time. Few people reported incidents to the police.

Crimes of sexual nature were difficult to assess, as the community would not talk about them. However, during the five years of visiting the camp for research and projects, three cases of sexual violence were discovered by the police. Talks to individuals from the security service revealed that they did not consider the camp violent; on the contrary, it was among the calmer places. Unlike large camps inside Amman the camp did not witness crimes such as murder, gangs, or organized crime (Table 3). This camp's small size probably created strong collective ties and provided strong social capital to youth, relative to other camps. The residents assumed that violence may be associated to the homogeneity of the inhabitants, in terms of their incomes and social value systems. Furthermore, being on the boundaries of Amman and not in its center created less economic and social pressures. Still, a rise in drug abuse and family quarrels were noted in the last ten years. Vandalism, on the other hand, was cited as an incident that was repetitive and created serious damage to public property.

Discussions of the reasons behind the varied forms of violence (Figure 2) showed that the community understood the problem to be rooted in:

- Environmental pressures. The cramped conditions in the camp and lack of space, created tensions and made most inhabitants highly stressed. This was compounded by the poor quality of shelters, as the zinc roofing made rooms very hot in the summer and very cold
Table 2:

Types of violence by location 
in the winter; in addition, these roofs leaked and were not able to control noise. Having an average of 5-6 individuals in a space of 70 square meters "made everybody on edge". One of the respondents complained, "I can hear what my neighbor says to his wife!" Furthermore, many complained about the infrastructure, as they felt that the poor quality was a result of the lack of attention paid to them as refugees: streets executed in the camp, for example, were of poor quality, compared to streets in other places in Amman. The inferior infrastructure and complete disregard of the serious environmental issues (such as the garbage collection point inside the camp, the inadequate rainwater drainage, the poor drinking water service, etc.) were all "intended" and they, as refugees, were excluded for the normal services that were awarded to the average areas of Amman.

- Economic pressures, lack of job opportunities, low wages, high dependency rates, the inability to meet daily life needs, and scarce resources. "I work morning to afternoon as a garbage collector with the municipality, then I work as a male hair dresser until midnight, and I still cannot move to my own place", said one respondent who occupied a room at his parents' shelter, which housed himself, his wife, and their two children. The shelter was composed of four rooms each occupied by one family and they shared the kitchen, washroom, and living area. Most youth had a feeling of complete despair as they felt that they had no possibility of a better quality of life, as long as they remained in the camp. Some felt that the only solution was to immigrate due to the discrimination against Palestinians in Jordan.

- Social pressures of being away from family, expectations from family and the community, feelings of insecurity due to the political situation, worry, pressure by family or relatives, and pressure by the community were also mentioned, especially by women. Many women are forced into marriage at an early age, many are denied education, and varied types of injustices take place as girls feel that they are treated differently than their brothers. A teenager exclaimed, "I have to make tea for my brother when he asks, and he will beat me if I don't....my mother does not help. They ignores my complaints!" Males talked about pressures to meet expectations and the financial requirements of marriage.

- Political: the main source of stress was the lasting temporariness of being in the camp, the inability to return, and the fact that there was no solution on the horizon. The stale peace process, compounded by the continued violence that is continually practiced against family

Table 3: violence as revealed in focus groups, interviews, and through observation members who are still under Israeli occupation, remains a tragic fact.

All of the above mentioned factors are in fact forms of structural, mental, and symbolic violence that refugees faced on a daily basis. One of the most poignant responses during an early interview for the Camp Improvement 


\begin{tabular}{|c|c|c|c|c|c|c|}
\hline Category & Perpetrator & Kind & Spread & Locus & $\begin{array}{l}\text { Reported } \\
\text { by }\end{array}$ & $\begin{array}{l}\text { Corrobora- } \\
\text { tion by formal } \\
\text { gov. and UN } \\
\text { employees }\end{array}$ \\
\hline $\begin{array}{l}\text { Economic } \\
\text { (theft of prop- } \\
\text { erty, damage } \\
\text { to property) }\end{array}$ & $\begin{array}{l}\text { Adolescents and } \\
\text { youth inside the } \\
\text { camp }\end{array}$ & Petty theft & Common & $\begin{array}{l}\text { Any possible } \\
\text { place }\end{array}$ & $\begin{array}{l}\text { Children, } \\
\text { women, men }\end{array}$ & Yes \\
\hline \multirow{13}{*}{ Social } & $\begin{array}{l}\text { Youth inside and } \\
\text { around the camp- } \\
\text { mainly based } \\
\text { outside the camp }\end{array}$ & $\begin{array}{l}\text { Drug } \\
\text { trafficking }\end{array}$ & $\begin{array}{l}\text { Limited } \\
\text { accord- } \\
\text { ing to male } \\
\text { interview- } \\
\text { ees, common } \\
\text { according } \\
\text { to female } \\
\text { interviewees }\end{array}$ & Schools, homes & $\begin{array}{l}\text { Adolescence } \\
\text { and women }\end{array}$ & Qualified \\
\hline & Male Adults & $\begin{array}{l}\text { Scrap (theft } \\
\text { of metal } \\
\text { objects) }\end{array}$ & Limited & $\begin{array}{l}\text { Outside the } \\
\text { camp }\end{array}$ & $\begin{array}{l}\text { Male adults } \\
\text { women }\end{array}$ & Yes \\
\hline & $\begin{array}{l}\text { Unauthorised } \\
\text { vendor booths }\end{array}$ & $\begin{array}{l}\text { Selling items } \\
\text { on streets }\end{array}$ & $\begin{array}{l}\text { Common } \\
\text { amongst the } \\
\text { unemployed } \\
\text { youth }\end{array}$ & $\begin{array}{l}\text { Outside the } \\
\text { camp }\end{array}$ & $\begin{array}{l}\text { Adult males } \\
\text { and females }\end{array}$ & Yes \\
\hline & $\begin{array}{l}\text { Adolescents } \\
\text { mostly }\end{array}$ & Vandalism & Common & Public space & All & Yes \\
\hline & $\begin{array}{l}\text { Families or youth } \\
\text { conflicts, dis- } \\
\text { gruntled students }\end{array}$ & Arson & $\begin{array}{l}\text { Rare in } \\
\text { private prop- } \\
\text { erty (one in } \\
\text { five years) } \\
\text { but limited in } \\
\text { schools (two } \\
\text { in five years) }\end{array}$ & $\begin{array}{l}\text { Private prop- } \\
\text { erty and } \\
\text { schools }\end{array}$ & All & Yes \\
\hline & $\begin{array}{l}\text { Brothers, male } \\
\text { family members }\end{array}$ & $\begin{array}{l}\text { Inheritance } \\
\text { overtaking }\end{array}$ & Very common & $\begin{array}{l}\text { Women forced } \\
\text { to give their } \\
\text { inheritance to } \\
\text { male relative } \\
\text { (brother or } \\
\text { uncle) }\end{array}$ & Women & Yes \\
\hline & $\begin{array}{l}\text { Adolescents and } \\
\text { youth }\end{array}$ & groups & Common & $\begin{array}{l}\text { School, streets, } \\
\text { alleys }\end{array}$ & $\begin{array}{l}\text { Women and } \\
\text { adolescence }\end{array}$ & Some \\
\hline & $\begin{array}{l}\text { Males (adults and } \\
\text { youth) }\end{array}$ & $\begin{array}{l}\text { family fights } \\
\text { over space, } \\
\text { power }\end{array}$ & Common & alleys & $\begin{array}{l}\text { Women, youth, } \\
\text { adolescents }\end{array}$ & Yes \\
\hline & $\begin{array}{l}\text { Parents, teachers, } \\
\text { colleagues }\end{array}$ & $\begin{array}{l}\text { child abuse, } \\
\text { bullying }\end{array}$ & Common & $\begin{array}{l}\text { Home, school, } \\
\text { street }\end{array}$ & $\begin{array}{l}\text { Women, } \\
\text { children } \\
\text { adolescents }\end{array}$ & Yes \\
\hline & $\begin{array}{l}\text { Parents towards } \\
\text { each other and } \\
\text { towards children }\end{array}$ & $\begin{array}{l}\text { Domestic } \\
\text { violence, }\end{array}$ & Common & Home & $\begin{array}{l}\text { children } \\
\text { adolescents }\end{array}$ & Yes \\
\hline & Males & rape & $\begin{array}{l}\text { Comparatively } \\
\text { rare (three } \\
\text { reported } \\
\text { cases in five } \\
\text { years) }\end{array}$ & Varied & $\begin{array}{l}\text { women } \\
\text { adolescents }\end{array}$ & Limited \\
\hline & $\begin{array}{l}\text { Anybody - argu- } \\
\text { ments exploding }\end{array}$ & $\begin{array}{l}\text { Interper- } \\
\text { sonal, } \\
\text { physical } \\
\text { and verbal } \\
\text { assault }\end{array}$ & Common & Streets, school & $\begin{array}{l}\text { All focus } \\
\text { groups }\end{array}$ & Yes \\
\hline & males & Alcoholism & Limited & Homes, & Women & Limited \\
\hline Political & Male youth & $\begin{array}{l}\text { Demonstra- } \\
\text { tion, secu- } \\
\text { rity force } \\
\text { interroga- } \\
\text { tions, secu- } \\
\text { rity clashes, } \\
\text { detentions }\end{array}$ & No & $\begin{array}{l}\text { common in } \\
\text { other camps } \\
\text { (ex. Gaza camp- } \\
\text { Baq'a camp) }\end{array}$ & - & $\begin{array}{l}\text { Camp is not politi- } \\
\text { cally active }\end{array}$ \\
\hline
\end{tabular}


project was "our blood is worthless, our suffering is worthless, we have no rights, and you want to discuss what improvements we need? How about going back home?" One elderly lady, when answering the door-todoor survey questionnaire, started crying upon being asked about her camp's needs. "Dignity" she said. "We had dignity back home, we were on our own land, working and eating what we sowed, but now..." Life in the camp presents a state of being uprooted, homeless and out of place, yet still within a defined space with legal borders and a distinct character. The camp offered a pseudo-home, as a home for waiting, a space for loss, for denial, and for those without rights. The violence of being denied was significant; it was a denial of the people and their story.

Shaden, a young lady who recently graduated from the university, was receiving congratulations for being appointed in a government position, but the following day I saw her sad: "They said I cannot have the job because my father was not born in Jordan". Being excluded because one's refugee status was commonplace, and also legalised. Similar frustrations were reported by male youth, who felt that their career options were limited and that their ability to obtain good jobs was hindered on account of their identity. Options for work were limited to small jobs, mostly as non-skilled laborers paid between 180-200 Jordanian dinar monthly (approximately $\$ 200-\$ 250$ ). Many young men received excellent vocational training, but were still unemployed. Upon discussing that with one adolescent he explained: "such training would allow one to get 300 dinar as a start and an experienced master of this trade gets 700-800 dinar [monthly], but I could not find any vacancy in any factory here. They said there are more positions available in the King Hassan area [in the North Jordan industrial zone], but I don't know anybody there... The number of positions seem to be limited, do you know anybody who can help me find a suitable job?" One of the youth explained why a laborer position at the industrial zone does not offer much: "I keep wondering, how I am supposed to start a family when I cannot even cover my own expenses?" Most respondents were confident that one could not find any promising employment without having contacts (commonly known as wasta), and since they did not have powerful contacts, it would be better to immigrate. Many of the young men participating in the focus groups had plans for immigration to Sweden, Australia, or Canada.

Additionally, the continued political turmoil in occupied Palestine -fear for family and kin- on the one hand, was coupled by frustration over the peace process which did not offer anything for refugees. The "Right of Return" is sacred and refugees have learned not to trust the UN. Thus, upon initiating the project, there was rejection and fear that it was a trap and any improvements would hinder their right to return. However, discussions within the community reached a point of consent on the principle that living in miserable conditions impacts their health and that of their children, thus the improvements were their human right to a healthy environment and accordingly should not be related to their right to return home. The discussions revealed not only the high level of distrust and insecurity they felt, but also reflected self-perception, as they were at a point were improving the quality of life requiredlegitimization. 
It is important to note that the dynamics of participation in the Talbiyeh Camp Improvement Project reflected the structural and mental violence within the camp itself. The Camp Improvement Project offered a first time opportunity for any interested individual to participate and encouraged women and youth to have an input. Typically, public affairs were monopolized by heads of local organizations and a consulting committee created by the Jordanian Government from local elites. The adult males who usually predominated in such matters were not appreciative of the transparency and the inclusion of the project. Different tactics were used to exclude opinions, and varied forms of violence and counter violence were used, none of which was criminal in nature, but more symbolic, mental, structural, and social.

The early meetings witnessed varied attempts to overlook new faces and reflect the power and status of the elite, which discouraged new participants. Invited females in the early meeting rarely spoke, and if they did, they were ignored by the males. Youth, on the other hand, faced ridicule for their opinions and had most of their suggestions undermined. The discussions showed the male elite emphasizing their experience and knowledge and communicated to other participants that they did not belong. Many of the new faces, males and females, felt overpowered and were inhibited from participating, which later required intensive work by the project team in order to maintain participation and input (Al-Nammari F., 2014).

In the decision-making phase, verbal and mental abuse, accusations, and violent arguments were used to control decisions and halt or direct resolutions. Several groups in the camp had their own agenda and the

Sources and cycle of violence according to local focus group discussions

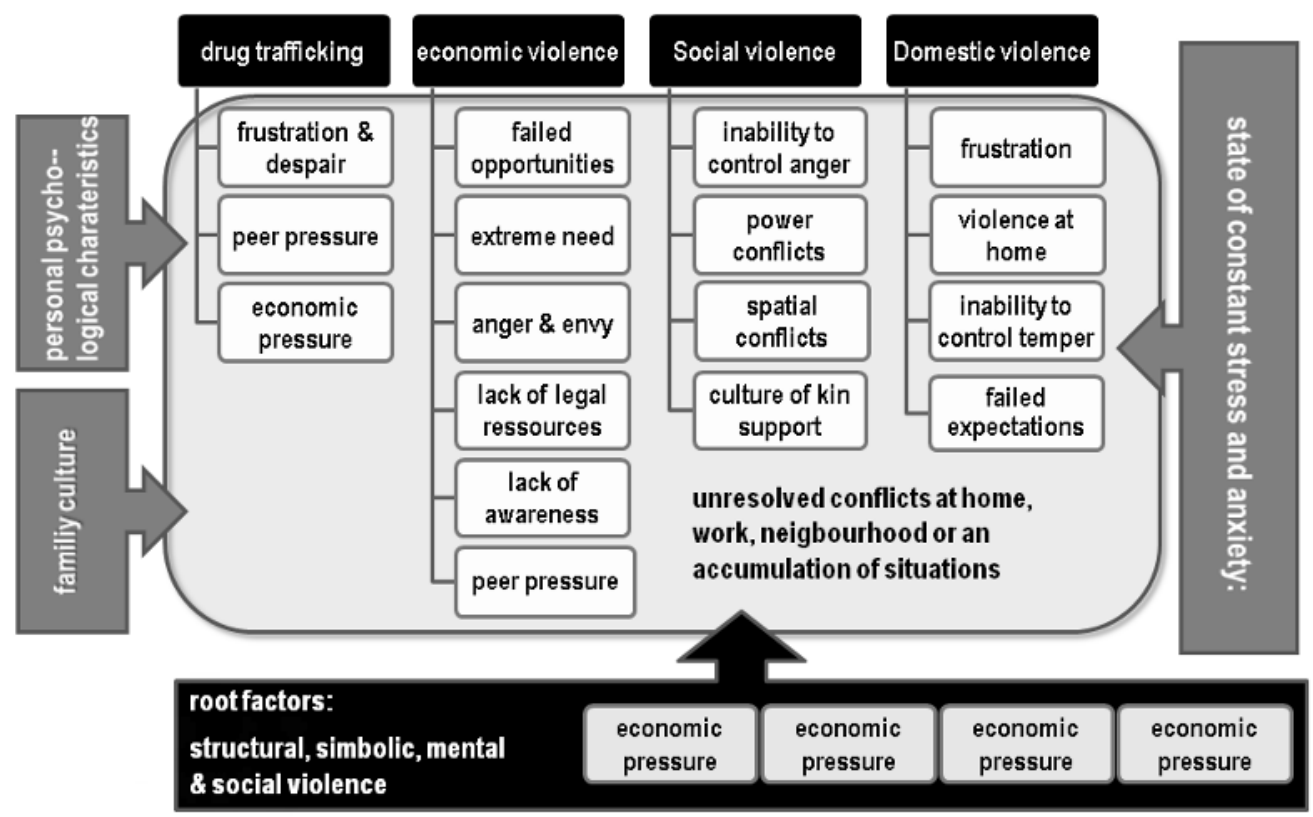


meetings witnessed the consolidation of these groups in one space for the first time. The corresponding struggles for power led to varied tactics inside and outside the meetings. This included rumors intended for social ostracization, mobilization against specific projects, undermining of the capacities of rival groups, and many other tactics that deployed mental and structural violence. The attendance of many youth and women, in particular, quickly dropped as they were subjugated to such verbal and emotional attacks. Within the heat of the arguments there were verbal threats for the use of physical violence against each other and against the project team (Al-Nammari F. , 2014; 2014_b).

Within the camp space varied forms of violence were generated and reproduced in manners that furthered the exclusion of the average refugee. The violent reactions against ideas which questioned the established hegemonic order demonstrate how far the community has internalized varied types of structural violence directed towards them and use similar tactics against each other (Al-Nammari F. , 2013; 2014). The struggle for power depended heavily on such forms of violence. This is significant as the camps space is usually friendly, and those with a different opinion are not criminals. Whenever those opponents in a meeting meet outside the camp most of time they exchange warm welcomes and generous invitations. This reflected a state of heavy mental stress in which people were unable to handle additional pressures. Thus, one of the elder clan leaders explained, when asked about missing meetings "with all the bad news taking place around, there is only so much stress that I can handle". The general context of anxiety, social exclusion, political failure, and absence of just solutions for their predicament created a continued state of stress, which limited residents' ability to manage conflict.

\section{Vandalism}

Upon discussing the suggested urban improvement proposals, focus groups and the Work Group identified a high risk of vandalism, citing stories of previous attempts to improve the urban environment, which were sabotaged. Some even requested the presence of police, while others maintained that any improved space would need a guard.

Vandalism has several definitions, but Moser (1992) provides a definition focusing on the socio-psychology of the phenomenon. Vandalism is mainly an act of "aggression towards the environment, an aggression aimed not at individuals, but at objects, whatever symbolic value they may be granted, and that damaging them allows the vandal to reach the symbolized authority through the object" (Moser, 1992, p21). According to Roos (1992), the vandal has an objective of ritualistic change to the environment, rather than real change. Autonomy is at the heart of this act, which also has a strong symbolism. When an adolescent vandalizes a school, for example, he is actually attacking a symbol of power.

This prompted the project team to conduct a quick evaluation of the problem in 2008. A series of focus groups with male adolescents and youth, in addition to women, and officials from the Department of Palestinian Affairs and the UNRWA resulted in better understating of the problem: 


\section{What?}

Damage to public property in general had limited the presence of any items in the public realm, such as trash bins, trash containers, and traffic signs. A long history of vandalism in the public space was the reason why the only play ground was dysfunctional. Apparently, there had been two previous attempts to improve public spaces that were condemned to failure due to abuse of equipment or the theft of it altogether.

Furthermore, schools in particular were victims of vandalism, including the marking of desks and blackboards to light fixtures and toilets. Graffiti was limited to a few statements on the walls of shelters or in the school; simple words (ex. names, adjectives) that defaced the facades of public organizations as well as private shelters.

Private property was attacked only in discords between families. Such attacks were very few, and were known to the community in general, but seldom reported.

\section{Why?}

Several predominant reasons for vandalism were cited, all revolving around the camp space as a place of hardship and adversity. Although participants were against the behaviour, most would sympathise due to feelings of social oppression:

a) economic :

- immediate cash (by selling items as scrap, or exchanging them for other items of value)

- domestic reuse (items that can be reused such as toilet fixtures, faucets, etc.)

b) social

- adolescents expressing anger or anti-social behaviour, resulting from economic pressures, limited opportunity, domestic violence, peer pressure, and abuse. Teenagers displayed difficulties in their ability to manage life obstacles, anxiety, and frustration about their future, depression, disorientation, or rebellion.

- space conflicts: space was important and families attempt taking over any available space.

- power issues: certain families and networks would act when they saw decisions or actions that undermined their interests.

\section{Who:}

Most respondents agreed that the perpetrators were mostly male adolescents. Discussions with the school, the Women's Programs Center, the Work Group, and other focus groups revealed that many parents felt that the male adolescents had tendencies for behaviour problems in general. They identified several reasons for it: overcrowding in the shelters, 
poverty, domestic violence, economic frustrations, limited job prospects, feelings of discrimination.

Still, there was adult vandalism, though limited, that took place on account of familial conflicts; it would include damage to private property, located in spaces in conflict. Power struggles also create familial conflicts, as families supported their relatives. Such incidents were rarely reported but resulted in damages to private property or physical attacks (limited in general, but known to happen by specific families).

\section{Where:}

Streets, open spaces, playgrounds, and schools were the main targets. In the case of private property, many incidents were not reported, and the community did not cooperate in exposing the perpetrators.

\section{The planned initiative: "Beautify Your Area"}

Through the participatory planning process, the community was able to identify adolescent vandalism as a very high risk to their planned public space improvements. Discussions of the issue with local organizations showed that the Women's Program Center had specialized experience dealing with behavior change programs, adolescent issues, and violence. The administration and the volunteers had many ideas on how teenage behavior could be targeted through a variety of methods, which they had used over the years in sporadic workshops. This was not based on their academic training, but on their accumulated knowledge though the "Training as Trainers", which they received in the projects that they have participated in.

As such, the Camp Improvement Project developed a strategy with the Women's Program Center to approach vandalism (Table 4). This was an interesting happening in which the local organization worked with professionals from UN Camp Improvement to join in addressing a possible risk to the Action Plan, created by the community. The Women's Program Center had no experience in construction or space design; such experience, in addition to funding, was offered through the Camp Improvement Project.

Based on the input by all parties involved, the following initiative was developed: the target group identified was adolescents (teenagers), both male and female (in order to have a gender balance); they were to be composed of two sub groups that were known to the trainees and school administration only; approximately half of the trainees would be adolescents without any behaviour problem, mostly academic achievers or leaders, but the rest were to be adolescence with behaviour problems. The assumption was that a mixture of the two would allow the ones with behaviour problems to work with the others and learn skills and attitudes from them.

The concept was based on providing adolescents with the skills they needed to manage their lives and deal with stress, giving special focus to their personal identity so that they could improve their self-image and develop a future vision of their own. By offering them the opportunity to practice such skills through a project of their own design (under guidance 


\begin{tabular}{|c|c|c|c|}
\hline & Time & Content & Parties involved \\
\hline $\begin{array}{l}\text { Pre-implemen- } \\
\text { tation }\end{array}$ & Two weeks & Identification of targets & $\begin{array}{l}\text { WPC and preparatory } \\
\text { schools in the camp }\end{array}$ \\
\hline \multirow[t]{5}{*}{ Phase 1} & Six days & Self-identity skills & WPC \\
\hline & Six days & Life skills & WPC \\
\hline & Six days & $\begin{array}{l}\text { Planning an urban inter- } \\
\text { vention based on Camp } \\
\text { Improvement Plan }\end{array}$ & $\begin{array}{l}\text { Participants, neighbors, } \\
\text { CIP and WPC team }\end{array}$ \\
\hline & Ten-fifteen days & $\begin{array}{l}\text { Implementation of the } \\
\text { urban intervention }\end{array}$ & $\begin{array}{l}\text { Participants, neighbors, } \\
\text { CIP and WPC team }\end{array}$ \\
\hline & Three days & $\begin{array}{l}\text { Conclusion, reflection, } \\
\text { and planning the next } \\
\text { phase. }\end{array}$ & $\begin{array}{l}\text { Leaders identified for } \\
\text { next phase. selection from } \\
\text { target group of adoles- } \\
\text { cence with }\end{array}$ \\
\hline \multicolumn{4}{|c|}{ Modiffied initiative Phase 2} \\
\hline \multirow[t]{5}{*}{ Phase 2} & Two weeks & $\begin{array}{l}\text { Inviting peers, promot- } \\
\text { ing experience, identi- } \\
\text { fication of new partici- } \\
\text { pants- peer learning }\end{array}$ & \\
\hline & Six days & Workshops: life skills & \\
\hline & Six days & Self-identity skills & \\
\hline & Ten-fifteen days & $\begin{array}{l}\text { Planning an urban inter- } \\
\text { vention based on Camp } \\
\text { Improvement Plan. } \\
\text { Implementation of the } \\
\text { urban interventions }\end{array}$ & $\begin{array}{l}\text { This part was imple- } \\
\text { mented with group } \\
\text { leaders from Phase } \\
\text { 1. Several small pro- } \\
\text { jects were planned and } \\
\text { implemented under } \\
\text { supervision. }\end{array}$ \\
\hline & Three days & $\begin{array}{l}\text { Conclusion, reflection, } \\
\text { and planning the next } \\
\text { phase. }\end{array}$ & $\begin{array}{l}\text { Creation of a core group } \\
\text { for urban improvement } \\
\text { volunteer tasks. }\end{array}$ \\
\hline $\begin{array}{l}\text { Phase } 3 \text { : } \\
\text { expanding } \\
\text { projects }\end{array}$ & \multicolumn{3}{|c|}{$\begin{array}{l}\text { Participating in any initiative or project inside the camp with Camp } \\
\text { Improvement Plan. This included participation in initiatives by the local } \\
\text { youth targeting a variety of issues such as drug awareness, sports, and } \\
\text { arts. }\end{array}$} \\
\hline
\end{tabular}

from the trainers), the participants were granted the independence that they required as adolescence in search of their own identity.

The title of the initiative, as envisioned by the volunteers themselves, was "Beatify Your Area" (Jammel Matiqtak); it was initiated in phases in the spring and summer of 2009, and then again in 2010. It was intended to emphasize positive environmental change, rather than destruction, and encourage a sense of ownership of the environment.

The Women's Programs Center suggested a three tier strategy:

\section{Tier 1: Self-identity}

The training was based on the assumption that achieving an identity was a central task facing adolescents and helped them in their quest 
for autonomy. Therefore, this part targeted self-exploration in a variety of exercises, including understanding the self and building self-esteem (Cobb, 1992). It comprised skills for self-understanding and evaluation, personal identity and development understanding the self, safe zone, personal rights, responsibilities, exploring life options and personally defined goals, gender roles, ego and the self, family, community, autonomy, minority identity, and culture.

\section{Tier 2: Life skills}

Life skills were important for empowering the youth to act responsibly, take initiative, and take control (Cobb, 1992). The training included a variety of relevant skills, essential for surviving, living with others, and succeeding; topics included communication skills, self-regulation, prosaically behavior, problem-solving, decision-making, civic responsibility, conflict resolution, communication with peers, parents, and teachers, and team work. The training was based on the assumption that when young people were able to manage the challenges of their daily lives, they would feel empowered and assertive and thus, would be less likely to resort to anti-social behaviors. The training was conducted through participatory learning, group reflections, and exercises.

\section{Tier 3: Agency through urban space}

This part assumed that adolescents become more autonomous as they choose to be part of the decision-making process. Through agency, the adolescent could achieve the level of autonomy and independence that they described (Cobb, 1992). The objective therefore was to improve self-esteem though engagement with peers in positive and socially-valued activities that the parents also supported. This also offered opportunities for enhancing skills such as self-organization, commitment, responsibility, and peer learning. The latter was a significant part of the initiative. Through this process, teens were expected to improve their communication and interpersonal skills, autonomy, and satisfaction with social support.

The targeted urban space would be selected based on the Camp Improvement Plan, the urban development strategy that the community generated through the participatory learning process. It included lists of needs, plans identifying loci for intervention, and results of the door-to-door surveys, focus groups, neighborhood meetings, thematic groups, and Work Group workshops. The Camp Improvement Plan identified locations for possible urban improvement through simple intervention aimed at improving the urban space. The participants were given the opportunity to choose where to work, but they had to design the intervention and implement it in conjunction with the neighbors, which was an excellent exercise in leadership and communication.

\section{The concept of "safe zone"}

The idea of the safe zone was both locational and conceptual. So during his/her work in the project, the teenagers are offered a space in which they feel safe from violence, including verbal, mental, or physical violence. 
They are treated with respect and their ideas are valued. In return, they have to practice exposing respect to other individuals and not to abuse them verbally, mentally, or physically. The training emphasized the right of each individual to be appreciated, while offering the initiative as a space in which the adolescence could receive that kind of esteem.

It was imperative that the trainers maintained a healthy environment so that none of them was subjected to any kind of violence (relatively speaking, since some of its causes were beyond the trainers' capacity to remove (such as the poverty or the confinement to the refugee camp). The essence of the safe zone is respect for one's self and for others. It requires a change in behaviour so that the adolescents do not abuse each other, which also demands for contemplation of their life and relationships.

\section{Implementation}

In the first phase, each of the four available trainers had approximately 15-20 trainees. However, the second phase included 25 trainees per trainer. Eventually, the number of participants increased to such an extent that four trainers were no longer enough. So a Training of Trainers was conducted for 30 male and female youth in order to teach them how to manage initiatives by other adolescents. This produced a total of 30 trainers, who managed more than 100 trainees (figures 3, 4, and 5). The last phase was an evaluation of the receptiveness of the youth and adolescence to the opportunities provided and to develop their own and independent ideas.

However, as part of the self-evaluation the trainers felt that they needed the help of a trained psychologist. The trainees started to disclose their personal problems or family conflicts and expect guidance and support, which went beyond the trainers' professional preparation and skills.

For each individual environmental improvement location, the trainees had to incorporate the neighbors, which emphasised their feelings of civic responsibility (Table 5). The trainers noted that many mothers came to the Women's Programs Center to ask about the training, as they noticed serious changes in the behaviour and attitude of their children. Of particular interest to all was the concept of "safe zone", about which the teenagers had talked at home with the result that now the mothers started to claim the same from their peers and family.

As phase two started, a local branch of a national NGO donated uniforms to the trainees. This was a significant moment for them as they felt they were being recognised positively. Also, elderly women and men

Project initiatives
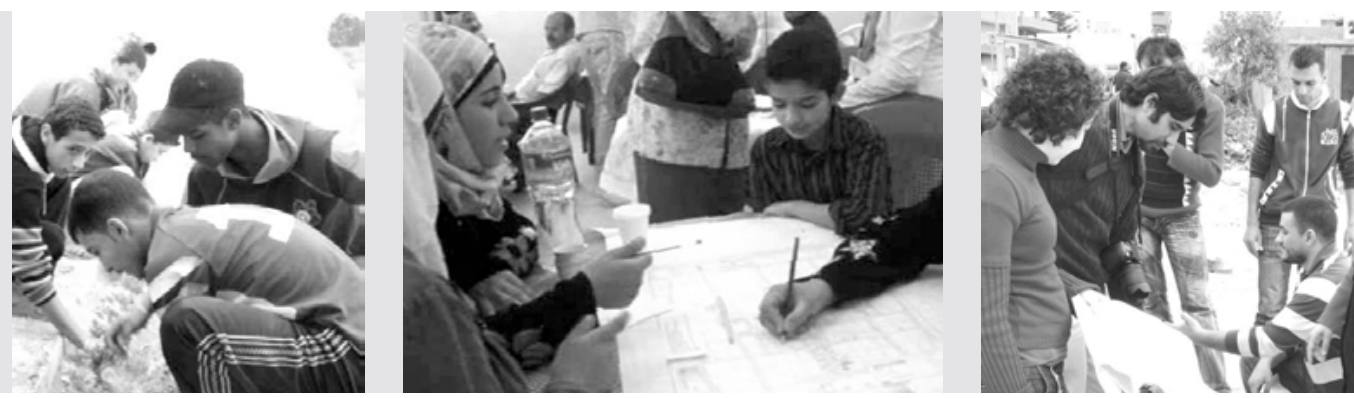
were stopping them around the camp and asking them to work in their alleys. The value of this cannot be over emphasized as they experienced acknowledgement of their agency and independence.

The dynamics of the implementation indicate a snow ball effect, as each stage witnessed more work, more trainees, and more ideas. This reached a point where the training program became a volunteer force that expanded its work beyond urban space. The last stage witnessed initiatives to address drugs and delinquency.

\section{The implemented projects}

Program participants were asked to implement a project that had been recommended by the community. These generally were small projects in urban pockets and became part of the Camp Improvement Plan. The participants discussed the potential spaces and their first project to start

Table 5: with was a space within the alleys. However, due to their negative image, the neighbors did not approve.

\section{Projects done entirely by target group}

Title of Project Type of work done

Side walk improvement (first project)
Tiling, paint, planting

\section{No, but plants died after the} project closed their offices in 2012 as no neighbor was around to water them.

\begin{tabular}{|c|c|c|}
\hline School improvements & cleaning, planting, and paint & \\
\hline CBRC side building & $\begin{array}{l}\text { Cleaning the yards, painting the build- } \\
\text { ing inside and out (work done with } \\
\text { volunteers from outside the camp) }\end{array}$ & Limited graffiti \\
\hline Camp greening & Helping residents plant trees. & No \\
\hline \multicolumn{3}{|c|}{ CIP major projects implemented with help by participants } \\
\hline Title of Project & Type of work done & Vandalism? \\
\hline Play space & Participatory design workshop & Neglect \\
\hline Multi-use space & $\begin{array}{l}\text { Painting of neighbours' walls accord- } \\
\text { ing to the resident's wishes }\end{array}$ & $\begin{array}{l}\text { Vandalism due to power conflicts- } \\
\text { no adolescence involved }\end{array}$ \\
\hline \multicolumn{3}{|c|}{ Urban improvement projects done without target group involvement } \\
\hline Title of Project & Type of work done & Vandalism? \\
\hline School improvements & $\begin{array}{l}\text { Participation in the detailed design } \\
\text { was limited to parents, UNRWA, and } \\
\text { school administration. Student input } \\
\text { sought in the early stages only. }\end{array}$ & Vandalised \\
\hline Clinic improvements & $\begin{array}{l}\text { Participation of adult users and } \\
\text { doctors }\end{array}$ & Limited graffiti \\
\hline $\begin{array}{l}\text { Projects inside local CBOs and } \\
\text { NGOs }\end{array}$ & & $\begin{array}{l}\text { Not vandalised. Design included } \\
\text { window protection bars. Location } \\
\text { highly visible }\end{array}$ \\
\hline
\end{tabular}


Thus, the first realized intervention was in front of the Camp Improvement Office, a walkway that led to the main mosque. The participants opted for that space as they did not need neighbors' approval. They prepared plans and worked on implementation immediately, which proved to be of significance. As all camp residents saw what they were doing, they started talking about it. Upon finishing this project, the adolescent participants had gained the trust of the community.

In phase two several small projects were implemented (Table 5). Some of them included planting trees, others painting facade, while others combined several interventions. It was up to the participants to design, obtain needed materials, and tackle the challenges of the various projects. The Women's Programs Center provided supervision through trainers and the Camp Improvement Project provided the funds.

In designing the Action Plan projects, the flowing adjustments were taken into account:

- for the Camp Improvement Project on open urban spaces

- $\quad$ additional light was provided;

- neighbors were involved and were responsible for the space;

- one neighbor at least committed to watering the plants, other committed to monitoring;

- spaces were designed by the neighbors;

- spaces were located at areas where there was heavy pedestrian circulation (except for the playground which had a corner location);

- ownership of the space was not sufficient to prevent vandalism by adults, due to power and space conflicts (high barrier had to be installed at a later stage).

- for the Camp Improvement Project buildings (clinic, NGO and school):

- the design took into account securing fixtures at the facades, iron bars to prevent access through windows;

- UNRWA regulation applied and did not allow for night lights at schools;

- though NGO buildings were highly visible they were not targeted by vandalism; nonetheless, they were also secured through iron bars on windows and high boundary walls.

Noteworthy in all these adjustments was that they were done based on advice from the local community, who participated in all stages of the projects. It was clear that such coping strategies became standard in the camp. 
the school administration. His teachers noted a change in his behaviour not only towards them but also towards his peers. He was elected to the student senate one year after, and remained in school despite his previous thoughts of quitting.

- $\quad$ S and Y both had no plans to finish their school education and were succumbing to the idea of getting married and leaving school early. Each changed their plans and respectively decided to finish her high school career and pursue a college education.

- Zain had minor behaviour problems at school but distinguished herself during training and continued to volunteer in Camp Improvement activities after the initiative was concluded. Her school performance improved, as did her parents' trust. She had difficulty leaving home earlier as her parents did not approve it, but as her volunteer work continued, she noted that she found it easier to obtain approval to leave the house. She finished her high school, trained as a hair dresser, and continues her volunteerism with the Women's Programs Center.

\section{Long-term impact}

The initiative did not stop vandalism in the camp, for one, not all vandals had participated, and moreover it only functioned for a limited period. However, the long-term impact on the lives of participants was felt by mothers and by the trainers. It has been five years since the end of the programme and participants are now out of school or in college. Although the participants mostly felt that the initiative helped them in contemplating who they were and what they wanted, most importantly they had been given an opportunity to engage in positive activities, of which there are few in the camp. Adolescents did not have many alternatives much to do in the camp before the project started. Many adolescents had expressed that they did not benefit from the existence of two local sports clubs as those focused on soccer, wining matches, and were not at all inclusive but new members were admitted dependent on connections. However, the program initiative offered them a chance to achieve something tangible: they remember the times positively and feel that they have a different approach to life than before their participation.

Teachers noted that the impact of the initiative was limited in time and span. For a short time after the initiative the teenagers where clearly changing. Still, soon after the project was gone there was not much happening and they rejoined their former groups, albeit they maintained a different attitude. Their awareness about what they aspired for in life and their feelings of worth did not change. And, after all, the program did not include all teenagers with behaviour problems but only those who agreed to join.

The participants had hoped that the initiative would continue, as year after year new boys grew up and wanted to get involved. The Women's Programs Center was interested in having to turn the initiative into a permanent program backed by the positive feedback they received from mothers. Yet, the volunteers that implemented the initiative are now 
employed full-time and cannot offer the same free services as before. Also, as the Camp Improvement Project concluded, the funding for the initiative also ceased.

Vandalism in school continued, as did vandalism outside. The spaces created by the participants did not witness much vandalism but remain witness to the ability of local adolescents. The Women's Programs Center and the schools felt that the main benefit from the initiative was its impact on the individuals involved.

\section{Lessons learned}

\section{Successes:}

- Successive training by varied organizations creates opportunities on the local level that are often ignored. Local organizations are also rarely involved in the planning of new interventions and international NGOs often assume that locals do not have the required capacity. In this case, the participation of the Women's Programs Center showed that locals can have a leadership role that capitalizes on previous experiences.

- Adolescents become more autonomous as they choose to be part of the decision-making process. Their input in the urban improvement initiative improved their interest in the civic sphere. Many continued volunteerism with NGOs, especially the Women's Programs Center. The initiative opened a new world for them where they could practice being themselves in positive manners.

- At the heart of the program was the concept of "safe zone", which seemed to help the participants interact with their families and peers. Mothers in particular felt that the notion was very helpful in improving the behavior of their children.

- Local residents helped in improving the self-esteem of the participants, as they were acknowledging of the work that participants were realizing. Their subsequent participation in the implementation of projects selected by the community also helped them create a totally new image for themselves. Over two years of implementation, most of the participants constructed positive new self-images. The fact that people changed how they treated them helped them in their process of change.

- Urban space was an important Factor for the success. It makes the achievements of the initiative visible to the teenager's community, and contributes to the public image of the neighbourhood. Visibility of the achievements also raises the social standing of the participants in the community and many of them reported changes in how their families responded and talked to them.

- The last phase of the initiative created special bonds between the participants and foster new friendships that supported the youngsters to overcome similar problems. 
- The flexibility in the design of the initiative supported its continuous development. At the end of each phase new ideas and evaluation helped in developing the next step. The fact that it was completely run by the local community fostered a sense of ownership and facilitated cooperation with schools, other local organizations, and the local community.

\section{Limitations:}

- A necessary maintenance activity was regular watering the plants which were provided in the improved spaces. This requirement limited the success of the project. Many plants died due lack of watering, although the selected plants were native and drought resistant. - but they did require daily watering in the first two weeks, and then on regular weekly basis for two months until their roots were strong. The required amount of water was too much for the water-impoverished camp. It would be better to have greening campaigns in the winter only as the rain would offer the needed support.

- There was a limitation to the possible number of participants. Not all adolescence with behaviour problems agreed to join, although all those who did, continued to the end of the first phase. Also, the trainers felt that the program should have continued to include new participants. The program expanded to a certain point and was very helpful for the participants at the time, but not sustainable.

- The interruption of youth and adolescence initiatives in 2011 caused a kind of shock in the community. If continuation was not possible, there should at least have been a planned withdrawal that allowed the participants to gradually phase out their input. Most of the participants met by the author recently reflected frustration towards this, as their vision for a role in the camp affairs has been truncated.

- The trainers noted a need for expert psychological support. Once the adolescents started to build trust, they came with personal questions and problems that needed professional training in counselling. Also, they noted a need for the creation of support groups to help participants follow-up on their visions for improving themselves. It should be on a case by case basis; deterministic and generalised approaches have limitations. Each case has its own circumstances.

\section{Conclusion}

Investigating violence should not be focussed activities which are defined 'criminal' according to the law, as violence is produced and reproduced in a community in varied forms. Physical violence is mostly a secondary effect of other existing types of violence, including also systemic and structural violence. Violence passes through cycles of production, exchange and reproduction. 
Sometimes, the heart of violence is a quest for power (Pearce, 2007). Yet, although it is often reduced to acts of acquisition or harm, especially in anti-social behaviour, its essence is embodied in how a community understands their situation and the social capital involved. The study has shown that refugees have developed a very strong sense of community, of shared agony and hardship, and of shared history. This may explain why, for example, vandalism rarely targets private property, and why, despite all the poverty and feelings of injustice, crimes are limited, and no explosion of violence takes place.

The structural, social, and mental violence faced by refugees supports the creation of a violent culture in which violence is lived and recreated. The absorption of social and political violence leads to impacts on behaviour, indicating high levels of stress and frustration. Violence is encountered on a daily basis politically, legally, and economically. It is absorbed and articulated though high levels of stress and anxiety, which can translate to aggressive behaviour and domestic violence. This has a toll on everybody in the camp, especially adolescence and youth.

There are similar experiences internationally for behaviour change through urban improvement (ex. KfW , 2010), yet the focus here has mainly been on how a change of the context of violence for teenagers impacted their behaviour and how agency changed their self-esteem and self-image. The adolescents were given an opportunity to become partners in urban upgrading processes, which enabled them to involve themselves in decisions about public space and be treated as partners in a process of improvement that their communities needed. A state of selfautonomy was felt, not through breaking and vandalising but through creating and designing. For the first time in their lives, many adolescents were not subjects, but rather mobilizers, choosers, authors, and achievers. This was coupled with the fact that their achievement was a space used by, and visible to, their community, aiding them in creating a positive image and foster a process of change.

This initiative did not have a revolutionary impact but a subtle influence on the lives of the participants, which they continue to feel today. As the schools continue to be the principal victim of vandalism, the teachers, mothers, and trainers would love to see the initiative start over and continue for an elongated period, as they believe that it offers a needed change not only in how the local adolescence understand themselves and their surroundings, but also the dynamics of relationships inside the camp.

\section{References}

Abu Helwa, M., \& Birch, B. (1993). The Demography and Housing Conditions of Palestinian Refugees in and around the Camps in Amman, Jordan . Journal of Refugee Studies, 6(4), 403413.

Agostini,G., Chianese,F., French,W., \& Sandhu, A. (2010). Understanding the Processes of Urban Violence: An Analytical Framework. London: Crisis States Research Centre. Retrieved from
www.eisf.eu/resources/library/Understandprocessesurbanviolence.pdf

Al Husseini, J., \& Bocco, R. (2009). The Status of the Palestinian Refugees in the Near East: The Right of Return and UNRWA in Perspective. Refugee Survey Quarterly, 28(2-3), 260-285.

Al Nammari, Fatima (2010). Talbiyeh Camp Improvement Project and the Challenges of Community Participation. https://www.aub.edu. 
lb/ifi/public_policy/pal_camps/pc_events/ Documents/20101008ifi_unrwa60_conference/ conference_presentations/day2/ifi_unrwa conf_day2panel2_ppt2_nammari.pdf. Accessed 1.08.2014

Al-Nammari, F. (2013). Participatory urban upgrading and power: Lessons learnt from a pilot project in Jordan. Habitat International, 39, 224231.

Al-Nammari, F. (2014). Talbiyeh camp improvement project and the challenges of community participation. In S. Hanafi, L. Hilal, \& L. Takkenberg, UNRWA and Palestinian Refugees: From Relief and Works to Human Development (pp. 206-220). NY: Routledge.

Al-Nammari, F. (2014_b). When the global impacts the local: Revisiting Talbiyeh Camp Improvement Project. Habitat International, 44, 158-167.

American Psychological Association. (2014). Violence. Retrieved July 2, 2014, from http:// www.apa.org/topics/violence/).

Bocco, R. (2009). UNRWA and the Palestinian Refugees: A History within History. Refugee Survey Quarterly, 28(2 \& 3), 229-252.

Bourdieu, P. (2004). Gender and Symbolic Violence. In N. Schepher Hughes, \& P. Bourgois, Violence in War and Peace: An Anthology (pp. 339347). Oxford: Blackwell.

Briceño-León, R., \& Zubillaga, V. (2002). Violence and globalization in Latin America. Current Sociology, 50(1), 19-37.

Budeiri, M. (2014). Dynamics of space, temporariness, development and rights in Palestine refugees' camps. In S. Hanafi, L. Hilal, \& L. Takkenberg, UNRWA and Palestinian Refugees:From relief and works to human development (pp. 189-205). NY: Routledge

Chatty, D. (2007). Researching refugee youth in the Middle East: Reflections on the importance of comparative research. . Journal of Refugee Studies, 20(2), 265-280.

Chatty, D., \& Hundt, G. (2001). Children and Adolescents in Palestinian Households: Living with the Effects of Prolonged Conflict and Forced Migration. A Regional Study. Oxford: Refugee Studies Center.

Cobb, N. J. (1992). Adolescence: Continuity, change, and diversity. . Mayfield Publishing Co.

Crisp, J. (2000). A state of insecurity: The political economy of violence in Kenya's refugee camps. African Affairs, 99(397), 601-632.

Department of Palestinian Affairs. (n.d.). 60 Years Serving Refugee Camps. Amman: Department of Palestinian Affairs.

Department of Palestinian Affairs -b. (n.d.). Statistics. Retrieved July 10, 2014, from http:// www.dpa.gov.jo/page.php?55-55

Farah, R. (2000). A Report on the Psychological Effects of Overcrowding in Refugee Camps in the West Bank and Gaza Strip Prepared for the
Expert and Advisory Services Fund. Washington DC: International Development Research Centre (IDRC).

Fruchter-Ronen, I. (2008). Black September: The 1970-71 Events and their Impact on the Formation of Jordanian National Identity. Civil Wars, 10(3), 244-260.

Hanafi, S. (2008). Palestinian Refugee Camps: Disciplinary Space and Territory of Exception. Retrieved July 10, 2014, from http://cadmus. eui.eu/bitstream/handle/1814/8631/CARIM_ AS\%26N_2008_44.pdf?sequence=3

Hanafi, S. (2010). Governing Palestinian Refugee Camps in the Arab East. . Beirut: Issam Fares Institute for Public Policy and International Affairs, AUB.

Hejoj, I. (2007). A Profile of Poverty for Palestinian Refugees in Jordan: the Case of Zarqa and Sukhneh Camps. Journal of Refugee Studies, 20(1), 120-145.

Khawaja, M. (2003). Migration and the reproduction of poverty: the refugee camps in Jordan. International Migration, 41(2), 27-57.

Khawaja, M., \& Tiltnes, Å. (2002). On the Margins: Migration and Living Conditions of Palestinian Camp Refugees in Jordan. Oslo: FAFO.

Khawaja, M., Linos, N., \& El-Roueiheb, Z. (2008). Attitudes of men and women towards wife beating: Findings from Palestinian refugee camps in Jordan. Journal of family Violence, 23(3), 211-218.

Marx, E. (1992). Palestinian refugee camps in the West Bank and the Gaza Strip. Middle Eastern Studies, 28(2), 281-294.

Misselwitz, P., \& Hanafi, S. (2010). Testing a New Paradigm: UNRWA's Camp Improvement Programme. Refugee Survey Quarterly, 28(2\&3), 360-388.

Moser, C., \& McIlwaine, C. (2004). Encounters with Violence in Latin America:Urban Poor Perceptions From Colombia and Guatemala. London: Routledge.

Moser, G. (1992). What is Vandalism? Towards a psycho social definition and its implications. Gen. Tech. Rep.PNW-GTR-293. In H. H. Chrlstensen, D. R. Johnson, \& M. H. Brookes, "Vandalism: research, prevention, and social policy (pp. 50-69). Portland: U.S. Department of Agriculture, Forest Service, Pacific Northwest Research.

Paardekooper, B., De Jong, J. T., \& Hermanns, J. M. (1999). The psychological impact of war and the refugee situation on South Sudanese children in refugee camps in Northern Uganda: an exploratory study. . Journal of child Psychology and Psychiatry, 40(04), 529-536.

Pearce, J. (2007). Violence, Power, and Participation: Building citizenship in Contexts of Chronic Violence. Brighton: Institute of Development Studies. 
Perez, M. V. (2011). Identifying Palestinians: Palestinian Refugees and the Politics of Ethnonational Identity in Jordan. PhD dissertation. Michigan State University.

Peteet, J. M. (2005). Landscape of hope and despair: Palestinian refugee camps. Philadelphia: University of Pennsylvania Press.

Qutub, I. (1989). Refugee Camp Cities in the Middle East: A Challenge for Urban Development Policies. International Sociology March, 4(1), 91-108.

Rempel, T. (2009). UNRWA and the Palestine Refugees: a genealogy of "participatory" development. Refugee Survey Quarterly, 28(2-3), 412437.

Roos, H.-E. (1992). Vandalism as a Symbolic Act in "Free Zones". In H. H. Chrlstensen, D. R., \& M. H. Brookes, Vandalism: Research, Prevention and Social Policy" (pp. 71-87). Portland: U.S. Department of Agriculture, Forest Service, Pacific
Northwest Research.

Scheper-Hughes, N., \& Bourgois, P. (2004). Violence in War and Peace: An Anthology. Oxford: Blackwell.

Suleiman, J. (1999). The current political, organizational, and security situation in the Palestinian refugee camps of Lebanon. Journal of Palestine Studies, 66-80.

UNRWA. (2008). Draft Results of the Socio Economic Survey In Talbiyeh Camp. By Fatima AlNammari. Amman: UNRWA Camp Improvement and BMZ.

UNRWA. (2009). Talbiyeh Camp Improvement Plan. Amman: UNRWA Jordan.

UNRWA. (n.d.). Camp Profiles. Retrieved June 30, 2014, from http://www.unrwa.org/wherewe-work/jordan/camp-profiles?field=13

World Health Organization. (2002). World Report on Violence and Health. Geneva: WHO. 


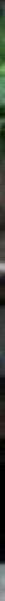
(1)

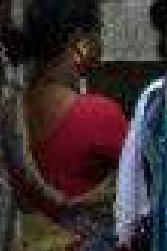

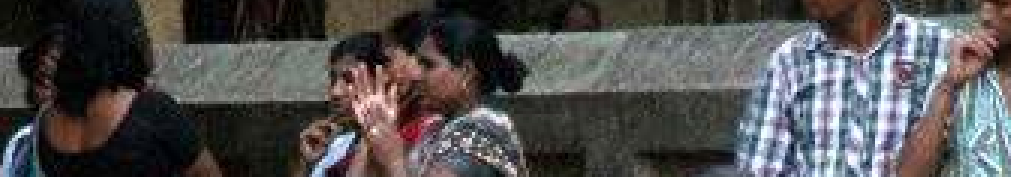
(4) 210 and -103

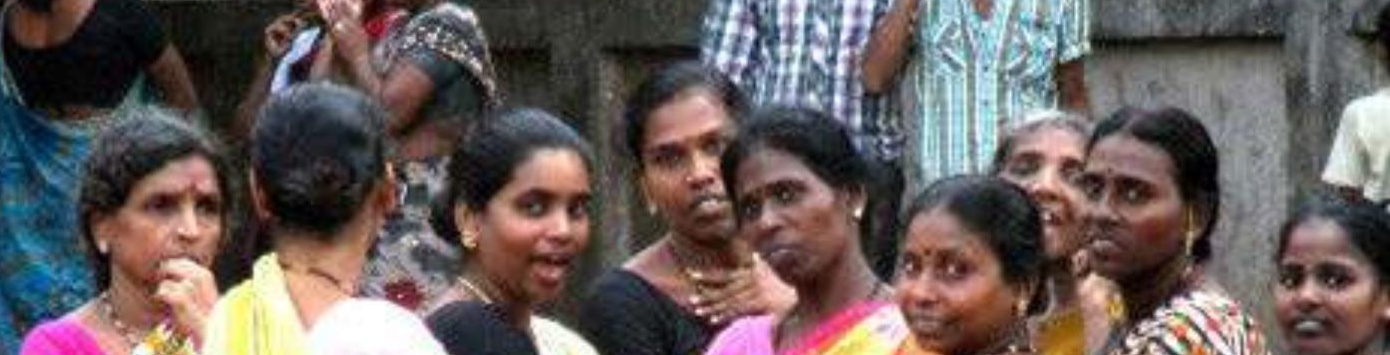

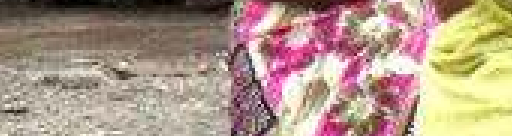

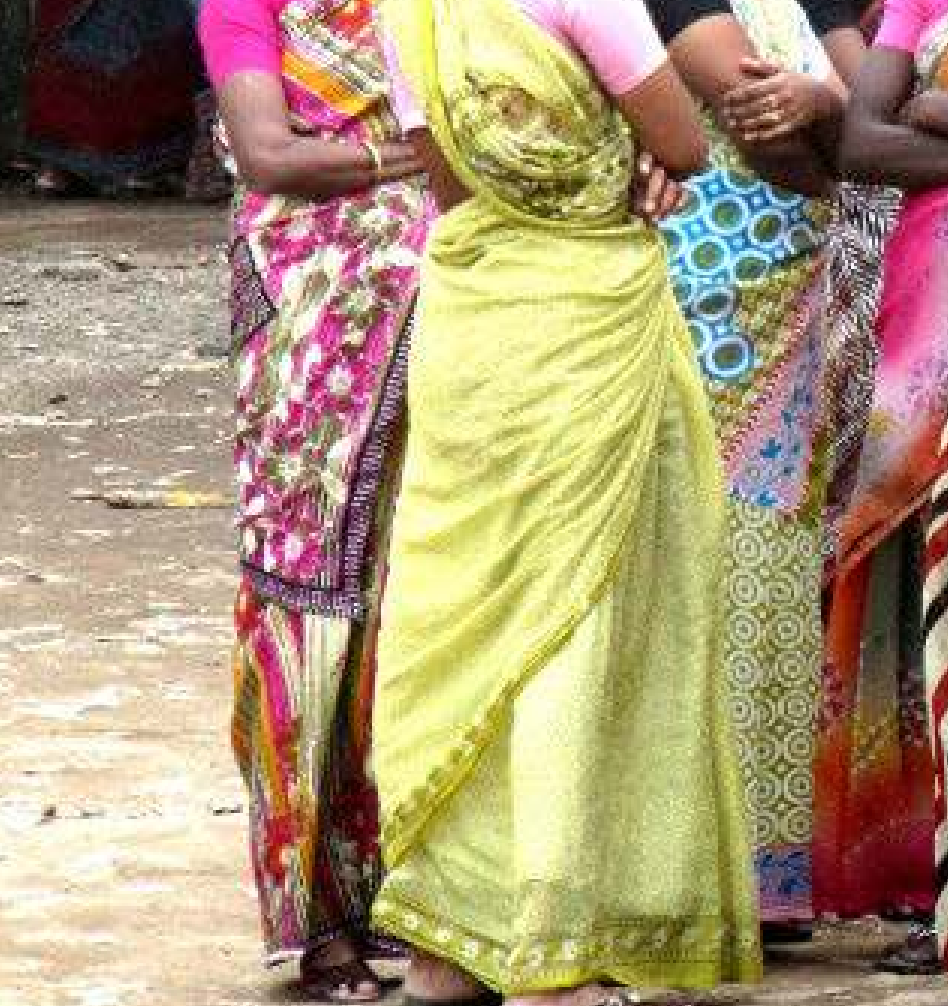

$\therefore-4=40$

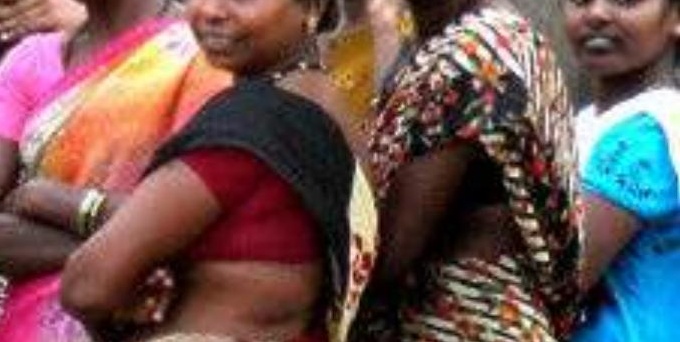




\section{Religious Procession as a Mediator for Social Intimacy: \\ Building Communal Harmony in Dharavi after the 1992 Mumbai Riot ${ }^{1}$}

Reza Masoudi Nejad

01.

This chapter was written during my time, as an Alexander von Humboldt fellow, at Zentrum Moderner Orient (ZMO, Berlin). However, it is the result of my research project at the Max Planck Institute (MPI-MMG,

Gottingen), and

all my fieldworks during 2009-2010

were carried out under the financial support of the MPI-MMG.

02.

'Muharram' appeared in eight different transliterations, often transliterated 'Mohurrum', in archive materials. However 'Muharram' is the most common transliteration used in recent time.

Previous page: Women in the streets of Dharavi,

2012

Photo:

Kosta Mathéy
I interviewed Bhau in his flat at the edge of Dharavi in Mumbai in April 2010. Bhau is his nickname, meaning 'the senior brother', a title that he is honoured with by the people of Dharavi. I was not there to see Dharavi, the biggest slum in Asia, but I interviewed him about the Muharram² procession in Dharavi. The interview revealed to me that Dharavi is socially much richer than I could imagine; it has to be recognised as one of the best cases for understanding how inter-communal harmony can be initiated and practised.

Bhau is a Hindu and was born in 1937 in Ahmad-Negar, which is dominated by Muslims. His parents moved into Dharavi when he was a 3 -month old baby. He is a member of the mohalla committee ${ }^{3}$ of Dharavi that pioneered a participatory initiation to create communal harmony after the 1992 riot between Hindu and Muslim communities. The riot was sparked throughout Indian cities after the destruction of the Babri Masjid (mosque) and turned into the most brutal unrest in the history of Mumbai.

The members of the mohalla committee are from all of the communities in Dharavi, including the Hindu majority and Muslim minority. Bhau explained that they were determined to do something to restore the community after the riot; they initiated a campaign using their own resources to create communal harmony. Bhau proudly commented that the campaign is now well known in India. As a part of the campaign, they began running Muharram and Ganpati ${ }^{4}$ processions on the same route. Muharram procession is a ritual carried by Muslims and Ganpati procession is a Hindu ritual; he stated that this is a way that the two communities exercise respecting each other. Although I had heard of the campaign I had never heard, and was astonished to find out, that the two processions are carried out on the same route in Dharavi. 
Religious rituals construct a 'self' that 'not only integrates the believers but also places a symbolic boundary between them and outsiders' (Van deer Veer 1994,11). As a procession is spatially dispersed, it is engaged with crossing borders and boundaries; thus it usually causes tension and violence among diverse religious and ethnic communities that reside in the same proximity. Although this seems to be extensively evidenced by endless examples of Hindu-Muslim conflict in the modern history of India, the case of Dharavi illuminates that religious procession can be a mediator for socio-religious intimacy as well. The two communities spatially orchestrated Muharram and Ganpati processions to not only establish but also maintain communal harmony. This paper is not aimed at explaining the details of the two rituals, but discussing the entwining of the two processions.

\section{The genealogical link between Muharram and Ganpati}

Ashura is the name of the 10th day of Muharram, the first month of the Islamic lunar calendar. Every year, Shi'a Muslims ${ }^{5}$ observe Ashura as the day of the martyrdom of Hussein ibn Ali and his few companions in the tragic battle of Karbala in the late 7th century. The tragedy was the consequence of dispute over the legitimacy of the Umayyad authority. From the Shi'i point of view, the battle of Karbala is more than a historic battle over a political dispute and it has since transcended into 'meta-history' (Chelkowski 1988, 263).

Myth is classically known as an invented story; however as Calhoun (2002) explains: a myth is a story that 'contribute[s] to the elaboration of a cosmological system and to a cohesive social identity'. The tragedy of Ashura is 'the Shi'i myth', since the battle of Karbala is regarded by Shi'as 'as a cosmic event around which the entire history of the world, prior as well as subsequent to it, revolves' (Ayoub 1978, 141). The tragedy and its observance had a significant role in the process of establishing the division Muslims into Shi'a and Sunni sects ${ }^{6}$. Michael Fischer states that the tragedy 'provides a way of clearly demarcating Shi'ite understanding from the Sunni understanding of Islam and Islamic history' (1980, 21). The memory of the tragedy has profoundly influenced Shi'i creed and rituals to such a degree that Fischer (1980) has called it 'the Karbala paradigm' which Shi'i culture is constituted by.

Shi'a Muslims developed numerous rituals throughout history to observe the tragedy of Ashura. The rituals originated in their Arab environment in Iraq and were particularly developed in Iran during the Safavid era (16th-18th centuries), and diffused on the Indian subcontinent (Calmard 1996). Indians spread the rituals during colonial times as far as the Caribbean island of Trinidad (see Korom 1994, 2004). The remembrance of Ashura is a mourning ceremony accompanied by the bodily expression of grief including weeping, wailing and even flagellation, in the Middle East. However, it has been transformed into a festival in the Indian context.

The commemoration of Ashura signifies the division of Shi'a from Sunni communities in the Middle East. However it has metamorphosed into a non-Shi'i ritual in India. Hasnain (1988) has mentioned that in India not

05 .

Muslims are divided into two major sects of Sunnis, as majority, and Shi' as, as minority.

06.

The division of Muslims into Shi'i and Sunni sects initially emerged based on the dispute over the legitimate successor to the prophet prior to the tragedy of Ashura in the late 7 th century (1963). However it was only in the eight century when a distinctive Imami Shi'i discourse began to emerge (Haider 2011; Newman 2012, 195). 
The historical reports during the most of 18th century show that the Muharram commemoration was generally peaceful. Nonetheless the tolis and taboot processions caused a major disturbance for everyday life of the city. As the processions gradually became more popular and increased in size, a tendency appears in official announcements for regulation of the festival of "half-naked people like tiger, beating drums and tom-tom ${ }^{8}$ frightening other citizen fellow" (TOI, Jan 25, 1845: 64). Since the 1870s, the police regulations for Muharram were announced every year and the policing discourse gradually came to dominate the language of newspaper articles. Nonetheless, there are still enough articles or letters that demonstrate that the negative language of the police exaggerated the level of tension and violence during Muharram. For example, an article published in 1879 argued that the taboot procession passed peacefully in Mumbai with "smaller number of casualty than happen in London at every Lord Mayor's Show" (TOI, Jan 1879, republished on Jan $6,1979: 8)$. As the commemoration during 1870s-80s was relatively free from serious violence, the author of an article who calls the Muharram ritual "the noisiest Indian festival" thankfully mentioned that "happily we are free from the unseemly riot between Hindoos and Mohamedans, which so frequently occur in the Northern districts..."(TOI, Oct 11, 1886: $3)$. In this period, Europeans were commonly occupied every balcony in Crawford Market, from where they enjoyed picturesque scenes of the procession passing along the Esplanade Cross Road.

The explosive growth of Mumbai during the late 19th century generated a constant change in the socio-religious and political landscape of the city, and tension between different socio-religious groups rose by late 1880s, and 1890s. The relatively peaceful commemoration of Ashura ended with the riot of 1893, a riot between Hindus and Muslims, which sparked during Muharram. The riot was the most serious riot of Mumbai during the 19th century and it has been extensively documented by numerous official reports. The Muharram celebration as an inter-communal festival in Mumbai came to an end with this riot. Edwardes, the Commissioner of Police of Bombay, argued that the riot of 1893 broke out as a result of the Hindu Nationalist movement led by Bal Gangadhar Tilak. Edwardes claimed that the movement was initially anti-British, but Tilak widened his movement against Muslims as well (Edwardes 1923, 104-105). The violence between Muslims and Hindus during the month of Muharram became very frequent after the riot. Therefore colonial authorities imposed tight regulations over Muharram. The 1893 riot did not interrupt the Muharram processions, however the riot caused a shift in the regulations. In 1895, the Commissioner of Police announced: "the license will be granted to Mahomednas [Muslims] only" (TOI, Jun 25, 1895: 3).

Mumbai was like a boiling pot and the different mohollas, that signified different ethnic groups, constantly competed with each other; the Muharram processions were an important medium by which the competition was practiced. This competition was particularly manifested by tolis processions during the 5th-10th of Muharram, when each moholla ran their procession through other localities and and fight with the 
bands of rival streets; this 'recalls the free-fighting which used once to take place between the various quarters of Gujarat and Kathiawar towns during the Holi festival' (TOI, Feb 17, 1908:6).

The fast-growing Mumbai intensified the negotiation between the ever increasing diverse groups. During the second half of the 1900s, tension gradually developed between some Sunni and Shi'a communities especially in 1908. Governor of Mumbai initiated a conciliation committee that included 50 influential members of Muslim communities; this unique committee was able to control the tension during Muharram in 1909. Despite the successful initiative in 1909, the conciliation committee was not called in following years. Instead, Edwardes, the Commissioner of Police, introduced new borders for the tolis processions in 1910, which cause anger and riot. Prior to the Muharram of 1912, Edwardes introduced yet another regulation. This regulation stipulated that the number of persons accompanying a procession should not exceed 30 , all tolis processions were totally prohibited, and "the lifting and circulation of tabuts and tazias on tenth night shall be strictly confined to the limits of the respective mohollas in which each tabut or tazia is standing" (TOI, Oct 23, 1911:7).

The police regulations particularly targeted the processions as the source of violence, as Edwardes argued in a lecture: "There is no question of religion or religious fervor here. The tolis are irreligious rascality let loose for five days and nights, to play intolerable mischief in the streets and terrorise the peaceful house-holder" (TOI, Mar 10, 1911: 6). The day after the Ashura of 1912, a short report in Times of India narrates that, 'Friday was the last day of the Mohurram festival and it passed off in Bombay without any hitch whatsoever. No tabut procession took place, as there was no tabut to be taken out so far as the Mahomedan [Muslims] localities of native town were concerned' (TOI, Dec 21, 1912: 9). The reports published in Times of India in years after1912 indicate that the regulation (1912) indirectly stopped the procession; the reports show that the commemoration was limited to the religious service session in Shi'a-Muslim locations. Although the Muharram procession is still known as a Muslims ritual (both Shi'a and Sunni) in India, the procession was later revived in Mumbai as a Shi'i ritual (for more see Masoudi Nejad 2012). Dharavi, however, is an exceptional area in Mumbai, where the procession of Ashura day is dominated by Sunnis.

The riot of 1893 signifies not only a milestone in the history of the Muharram festival in Mumbai, but also the establishment of the Ganpati festival. Edwardes has explained: was an Indian nationalist, journalist, teacher, social reformer, lawyer and an independence activist. He was the first popular leader of the Indian Independence Movement.
'The Hindu-Muhammadan [Muslims] riots of 1893 were directly responsible for the establishment in Western India of the annual public celebrations in honour of the Hindu god Ganpati, which subsequently developed into one of the chief features of the anti-British revolutionary movement in India. The riots left behind them a bitter legacy of sectarian rancour, which Bal Gangadhar Tilak ${ }^{9}$ utilized for broadening his new anti-British movement, by enlisting in its support the ancient Hindu antagonism to Islam' (Edwardes 1923, 104). 
Ganesh or Ganpati is the elephant-headed deity, who is known as the remover of obstacles and the god of auspiciousness. Ganesh was established literarily and iconographically by the fifth century and has been celebrated for centuries in India (Courtright 2005). ${ }^{10}$ Ganesh has been celebrated in a ten-day festival in which temporary images of Ganesh are worshiped in home shrines (Zelliot and Feldhaus 2005, 5699). As Hansen $(2001,29)$ notes, the celebration had become a family-based festival among higher castes during the 19th century; the celebration concluded with the immersion of a small Ganesh idol in the nearby river. The modern history of the Ganpati festival, however, dates back to 1893, when Tilak gave the festival a distinctly political face. Tilak differed from other nationalist leaders in two ways: 'one was his use of Hindu religious symbols as expressions of Indian nationalism, and the other was his acceptance of violence as a legitimate political tool sanctioned by the Hindu tradition' (Embree 2005, 9198). The riot of 1893 provided the immediate cause for the reshaping of the domestic festival of Ganesh into a public manifestation of Hindu culture and the Hindu community (Krishnaswamy 1966, 214).

There is no doubt that Tilak re-invented the Ganpati celebration based on the Muharram festival, which had been the greatest festival of Mumbai. Tilak made the Ganpati festival a largely public affair, making the festival a community-based enterprise. While the immersion of Ganesh used to take place throughout the ten-day festival period, Tilak began having all the immersions take place on the 10 th and final day. Moreover, each mohallah (neighbourhood) arranged the procession together, practising social solidarity among the community, as Muharram was/is organised.

As Edwardes observed, Tilak's objective was to make the procession, in which the god is borne to his final resting-place in the water, as offensive as possible to Muslims by closely imitating the Muharram procession, in which the ta'zyehs and tabuts are immersed in the sea. Edwardes explained:

'Tilak and his party inaugurated a Sarvajanik Ganpati or public Ganpati celebration, providing for the worship of the god in places accessible to the public [...], and arranging that the images of Ganpati should have their males or groups of attendants, like the Musalman [Muslims] tolis attending upon the tabuts'(Edwardes 1923, 104-105).

It is not a coincidence that Tilak initiated the modern Ganpati after the 1893 riot. Muharram was always an opportunity to challenge the British authority. The Hindus participated in Muharram, but they had not been influential enough to make the ritual their own annual Hindu anti-colonial demonstration. Therefore by reinventing the Ganpati festival, Tilak gave the Hindu community their own public ritual with which to challenge both the British authority and Muslim community ${ }^{11}$ (also see Barnouw 1954:81). As Muralidharan explains, the anti-Muslim sentiment was especially obvious in the lyric of songs sung during the celebration (1994:13).

The Muharram ritual was developed in the Middle East, signifying the Shi'a-Sunni division; the ritual was then transmuted and Indianised on

11.

The Muslim community is a minority group who represented the Islamic Mogul Empire that ruled India for a century before the British colonial power. 
the subcontinent, where it is practised as an inter-communal festival intended to maintain a communal harmony between Hindus and Muslims (both Shi'as and Sunnis). However, the 19th century nationalist movement was aimed at delineating social and religious groups. Tilak reinvented the Ganpati celebration and innovatively created a public arena to mobilise Hindus against others. However, such an enterprise has ironically kept references to the Muharram ritual in its DNA, as it is based on the Indian-Muharram ritual. The two communities manifest and celebrate different myths through a community-based procession towards the sea where symbols are immersed. Nevertheless, the immersion has different meanings; it signifies the perpetual status of the martyrs of Karbala, and Hindus conceive it as rebirth of Ganesh.

\section{The riot of 1992 and its aftermath in Dharavi}

In 1992, the far right Hindu group demolished the Babri Masjid, built in 1528, in the northeast of India. In fact, there was a long-lasting dispute between Hindus and Muslims over the site of Babri Masjid (see Van deer Veer 1994, 2-11). The demolition of mosque described as the martyrdom of the mosque by many Muslims; and it sparked angry Muslims to take to the streets all over India in December 1992. One of the most violent confrontations between protestors, police, and Hindus took place in Mumbai and lasted for a couple of months. Within a few days some 200 people, mostly Muslims, were killed and hundreds wounded. During January 1993, Hindu gangs were systematically targeting, looting, and burning Muslim shops, houses and businesses. Shortly, the official death toll exceeded 800, forcing more than 150,000 (mostly Muslims) out of the city. Police forces have been blamed for supporting the violence against Muslims or ignoring it. In response, Muslim gangs affiliated with criminal networks in Mumbai arranged a series of bomb blasts across the city in a single day, targeting bus stations and the city's stock exchange (see Hansen 2001, 121-126). This period left a bitter memory that has changed the relationship between the two communities. When the riot smoke was gone, people were in shock at the level of brutality during this period. As Hansen explained, usually lower classes had been affected by previous riots; however the riot of 1992 severely affected middle classes as well.

People, including Bhau, blame politicians for escalating hatred among communities. Thackeray, the leader of Shiv Sena party, has been particularly blamed for the brutal riot in Mumbai. Bhau explained that people were shocked when the riot had passed, asking why they should hate each other and burn down the houses and shops of others. He added: 'After the incident of Babri Masjid [...] everybody was coerced, Muslims were coerced, Hindus were coerced, [...] but we managed to create a peace' (interviewed April 2010 in Mumbai, Dharavi). During the interview, Bhau harshly criticised elites and argued that the only ones who could solve the problem were the people of Dharavi. He said: 'we managed to create a peace [in Dharavi]. [...] we never called any elite or secular person; we did it in very different manners'. Bhua added: 
"We had to discuss it among ourselves [...] outsiders cannot solve the problem; we are the people who created the problem, let us solve the problem [...] within one year we had a fantastic result... We are not simply giving lectures, seminar[s], we do not believe in that [...] [the] elite class enjoy[s] the problem[s] of poor people [paraphrased]. [...] They enjoy it [at] our cost. They are not worried about our problems, they don't want to solve the problem; in fact they want these problems, then they can have another 10 seminars, so they can fly all over the world. I am very proud of my people. [...] So after one year we celebrated [the conciliation] together [...] with no seminar, nothing, no intellectual[s], no secular [people]. I did not allow any secular [people] to come to Dharavi. I said he's [the secular person] the most dangerous person for the community" (Interviewed, April 2010, Dharavi, Mumbai).

In the committee, they were committed to creating a peace in Dharavi by all means and with the resources that they had. He explained that one of the initiatives was to carry out the Muharram and Ganpati procession throughout the very same route. Knowing that tension always sparks when a Muslim procession passes a temple, or a Hindu procession passes a mosque, I was astonished to hear what Bhau had said and asked: Same? 'Same, and we insisted that' he replied. Bhau explained that some people suggested changing the routes of the processions in Dharavi, but he said:

"We [had to] learn how to cope [with] each other, changing the route will not solve the problem; let us do the same thing. [If] You are changing the route, you are running away from the problem [...] at the time of namaz [Muslims' prayer], Hindus are not allowed to play music; they have to pass [mosques] silently. This is mutual understanding [...] we should continue this. That means we are not afraid of facing [the] problem, let us face the problem and let us try to find some solutions which will create a communal harmony and brotherhood among the community. If we shift the problem to somewhere else the same thing will continue. When you will [have] communal harmony and brotherhood then? (Interviewed, April 2010, Dharavi, Mumbai)

I interviewed Bhau in April, the hottest time in Mumbai, so he was not able to show me the procession route. He introduced me then to Mohammad Ayoub Sheilh, a 39-year old Muslim, who gave me a ride throughout the route, showing me the Hindu temples and mosques that both processions pass and that symbolically link the two communities (figure 2) ${ }^{12}$. The procession route ends at Mahim Bay, a place that is equally important for both Muslim and Hindu communities. The bay is where Muslims immerse their ta'zyehs and Hindus immerse Ganesh every year.

Bhau explained that both the Ganpati and Muharram processions were small events, but they became a major festival after the 1992 incident in Dharavi. Prior to 1992-93, there was only three ta'zyehs [in Dharavi], but now there are about 80 or 90 ta'zyehs'. He added that while tension still occurs during the processions it is something that can be controlled. Now prize are awarded to those who appropriately carry out their procession and question anyone who may make trouble.

12.

I had attached a GPS device to my camera; the metadata of the pictures that I took throughout captures the route 

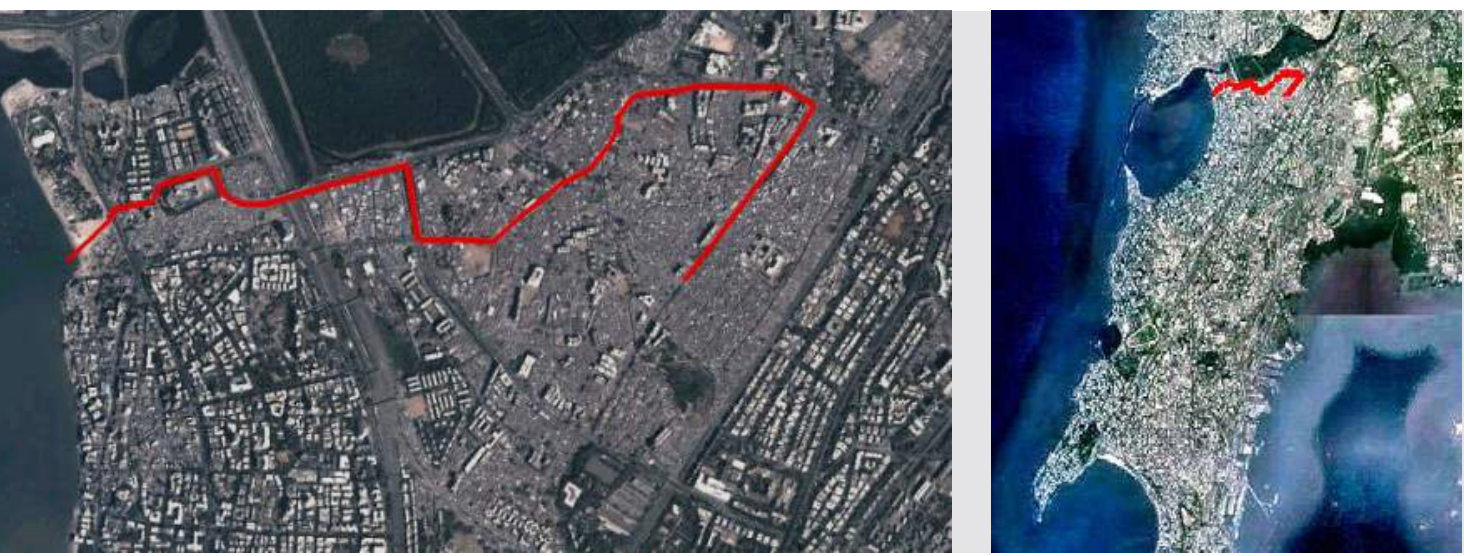

The route of the Ganpati and Muharram processions in Dharavi that ends at Mahim Bay.

13.

The leader of Shiv Sena that was behind the 1992 riot in Mumbai

\section{Religious rituals as a medium for social intimacy}

It is a fact that in the riots of 1893 and 1992-93, far right Hindu-political parties legitimised violence against others by reinventing religious rituals based on the modern paradigm of nationalism. As Van deer Veer et al (1999) show, nationalism has been associated with secularism and relegating religion to a purely private realm, however religion and politics are entwined in complex ways in India and other Asian countries. While India has ever been the land of multiculturalism, the nationalist parties aimed at cleansing the country and called for an ethnically and religiously pure nation. India has usually been associated with Gandhi's non-violence notion, though both Tilak and Thackeray ${ }^{13}$ have religiously glorified violence. Banerjee (2000) argues that the violence erupted in India not simply because of primordial hatred between different religious groups residing in close proximity, but rather violence tends to occur when social, political and ideological factors are manipulated to construct nationalist identities and movements.

While nationalist parties tried to invent Hindu identity through a process of eliminating others during the last century in India, common

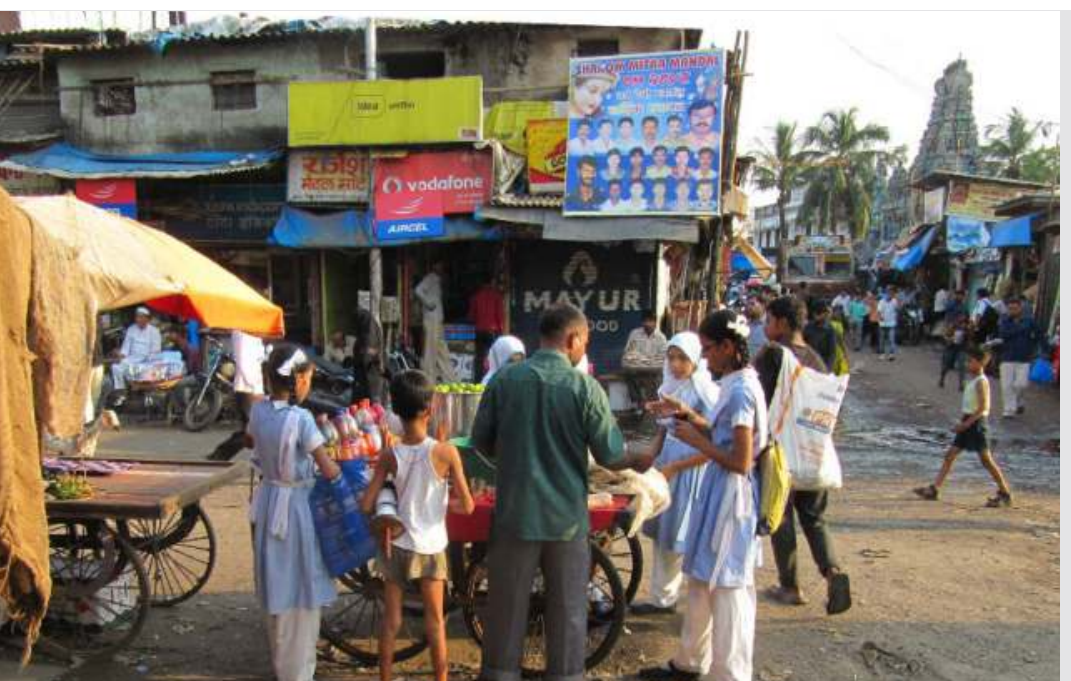

Procession route in Dharavi on a regular day, 2012 Photo: Kosta Mathéy 
people in Dharavi reversed the process, astonishingly by intertwining Muharram and Ganpati processions. By doing so, people of Dharavi have challenged the conventional narration that religious rituals always inflame the tension between communities. Dharavi residents initiated an intimacy between communities based on the paradigm of multiculturalism that has a long background in Indian culture. However the Muharram and Ganpati processions would not be entwined without the genealogical link between the two processions. This link was hidden to nationalist leaders who focused on splitting communities and identities; Tilak did not realise that his invented Ganpati procession based on Muharram would serve to link the two processions; a link that the people of Dharavi used a century later to orchestrate the processions along the same route and to create communal harmony. The two processions are organised along the same route, but they run at different times of the year. The processions pass through several religious places associated with both Hindus and Muslims; therefore they link all places as a single socio-cultural infrastructure. Here the route is a spatial medium by which the two processions are entwined and orchestrated as social practice to establish and maintain social intimacy.

The case of Dharavi reveals that it is not religious rituals that create violence, per se. Religious rituals can inflame sectarianism, but they can also be mediators for communal harmony. The rituals are a medium to manifest division as well as intimacy; the question is which one a community is willing to practise.

\section{References}

Ayoub, M. 1978. Redemptive Suffering in Islam: A Study of the Devotional aspects of 'Āshūrā in Twelver Shīism. Religion and Society 10. The Hague: Mouton.

Banerjee, Sikata. 2000. Warriors in Politics: Hindu Nationalism, Violence, and the Shiv Sena in India. Boulder, Colo: Westview Press.

Birdwood, G. C. M. 1915. Sva. London: Philip Lee Warner.

Barnouw, Victor. 1954. "The Changing Character of a Hindu Festival." American Anthropologist, New Series 56(1):74-86.

Calmard, J. 1996. "The Consolidation of Safavid Shi'ism: Folklore and Popular Religion." In Safavid Persia: The History and Politics of an Islamic Society, ed. Charles Melville, 139-190. Pembroke Persian Papers 4. London: I. B. Tauris.

Calhoun, Craig J. 2002. Dictionary of the Social Sciences. Oxford: Oxford University Press.

Chelkowski, Peter J. 1988. "Diverse Religous Practices." In Shi'ism: Doctrines, Thought, and Spirituality, ed. Seyyed Hossein Nasr, Hamid Dabashi, and Seyyed Vali Reza Nasr, 262-267. Albany: State University of New York Press.

Courtright, Paul B. 1977. Ganeśa and the Ganeśa Festival in Maharashtra: a Study in Hindu Religious Celebration. Ann Arbor ; London: University Microfilms International.
Courtright, Paul B. 2005. “Gaṇeśa.” In Encyclopedia of Religion, ed. Lindsay Jones, 5:32733274. Detroit: Macmillan Reference USA.

Edwardes, S. M. 1923. The Bombay City Police. Oxford: Oxford University Press.

Embree, Ainslie T. 2005. "Tilak, Bal Gangadhar." In Encyclopedia of Religion, ed. Lindsay Jones, 13:9198-9200. Detroit: Macmillan Reference USA.

Fischer, Michael M. J. 1980. Iran: From Religious Dispute to Revolution. Harvard Studies in Cultural Anthropology 3. Cambridge, Mass: Harvard University Press.

Haider, Najam Iftikhar. 2011. The Origins of the Shī'a: Identity, Ritual, and Sacred Space in Eighth-Century Kūfa. Cambridge Studies in Islamic Civilization. New York: Cambridge University Press.

Hansen, Thomas Blom. 2001. Violence in Urban India: Identity Politics, "Mumbai", and the Postcolonial City. Delhi: Permanent Black by arrangement with Princeton University Press.

Krishnaswamy, S. 1966. A Riot in Bombay, August 11, 1893: A Study in Hindu-Muslim Relation in Western India During the Late Nineteenth Century. University of Chicago, Department of History, March. 
Masoudi Nejad, Reza. 2012. "Practising Fractal Shi'i Identities through Muharram Rituals in Mumbai." Diversities 14 (2): 103-17.

Masselos, Jim. 1982. "Changin and Custom in the Format of Bombay Moharram During Nineteenth and Twentieth Centuries." South Asia: Journal of South Asian Studies 5. N.s. 50: 47-67.

Muralidharan, Sukumar. 1994. "Patriotism without People: Milestones in the Evolution of the Hindu Nationalist Ideology." Social Scientist 2(5/6): 3-38.

Newman, Andrew J. 2012. "The Origins of the Shi'a: Identity, Ritual, and Sacred Space in Eighth-Century Kufa (review)." Journal of Shi'a Islamic Studies 5 (2): 195-200.

Korom, Frank J. 1994. "Memory, Innovation, and Emergent Ethnicity: The Creolization of an Indo-Trinidadian Performance." Diaspora: A Journal of Transnational Studies 3 (2): 135-55. doi:10.1353/dsp.1994.0017.

Korom, Frank J. 2003. Hosay Trinidad: Muharram Performances in an Indo-Caribbean Diaspora. University of Pennsylvania Press.

Van deer Veer, Peter. 1994. Religious Nationalism: Hindus and Muslims in India. University of California Press.

Van deer Veer, Peter, and Hartmut Lehmann, eds. 1999. Nation and Religion. Princeton University Press.

Zelliot, Eleanor, and Anne Feldhaus. 2005. "Marathi Religions." In Encyclopedia of Religion, ed. Lindsay Jones, 8:5696-5700. Detroit: Macmillan Reference USA.
References published in the The Times of India (TOI) sorted by the day of original publication

"Spirit of the Indian Press." 1845. The Bombay Times and Journal of Commerce, January 25.

"Hundred Years Ago, From the Times of India October 11, 1855. Muslim and Hindu Festival" 1955. The Times of India, October 11

"A Hundred Years Ago: From The Times of India Monday, 6 January 1879 The Mohurrum." The Times of India, Jan 6, 1979.

“The Mohurrum Festival." 1880. The Times of India, December 14.

"The Mohurrum." 1886. The Times of India, October 11.

"The Police and the Mohurram." 1895. The Times of India, June 25.

Etonensis, 1908. "The Bombay Mohurrum. Stray Scenes." The Times of India, February 17.

"The Mohurrum." 1911. The Times of India, March 10.

“The Bombay Muharram. Revised Rules" 1911. The Times of India, October 23.

"Mohurrum in Bombay." 1912. The Times of India, December 21.

"Muharram, Police Regulations." 1912. The Times of India, November 10. 



\section{Violence and the Enchantment of Everyday Life in Johannesburg: Preliminary Insights ${ }^{1}$}

Obvious Katsaura

This paper outlines some ideas of the author's ongoing postdoc project, sponsored by the Volkswagen Foundation

Previous page:

Figure 1; A group of people from the Shembe Church doing their ceremony. The Shembe church is a mixture of christianity with the Zulu traditions and has over 4 million followers. Source: iStock/ THEGIFT777
Johannesburg is a city well known for high levels of violence and crime (Boisteau 2005; Dirsuweit 2002; Schönteich and Louw 2001). Yet there has been a lack of examination of the role of traditions, beliefs, and spiritualities, however varied, in the mediation or prevention of urban violence and the fear it induces. While contemporary explanations of public violence invoke the idea of a "culture of violence" in South Africa (Von Holdt 2011; Von Holdt 2012d), they rarely, if at all, locate explanations and descriptions within the matrix of beliefs, traditions. and spiritualities. Also, current studies on xenophobic violence (Landau 2010; Landau and Haupt 2007; Landau, Ramjathan-Keogh and Gavatri 2005; Misago 2011; Misago, Landau and Monson 2009), local security initiatives (Benit-Gbaffou 2008a; Benit-Gbaffou 2008b; Bénit-Gbaffou, Fourchard and Wafer 2012), and violent protests or strikes (Alexander 2010; Atkinson 2007; Hough 2009; Von Holdt et al. 2011) do not attempt to adequately understand the potential role of religious practices and mysticism in explaining the genesis and governance of urban violence and crime.

Furthermore, religion is rarely conceptualised as an influence in urbanism $^{2}$, let alone as an institution that plays a key role in the (re)production of urban order or disorder. This is the case notwithstanding the existence of a corpus of literature that examines the role of religion (and ethnicity) in fuelling conflict and enhancing the restoration of order in (post) war situations in Africa and elsewhere (Elbadawi and Sambanis 2000; Ellis and Ter Haar 1998; Marsden 2002; Ranger 1992). The trivialisation of the role of religion, beliefs, traditions, and spiritualities in the making of urban orders or disorders in South Africa is puzzling, especially in a context where even the government of South Africa recognised that a restoration of morality was necessary for crime and violence reduction launching the moral regeneration campaign in the early 2000s (Rauch 
2005; Rauch 2011). Religion and religious leaders also played a key role in post-apartheid attempts at reconciliation in South Africa (Chapman and Bernard 2003). This shows that despite its apparently "modernist" orientation, South Africa still remains a very much enchanted society in which symbols, myths, beliefs, traditions, and spiritualities play a "key role" in the ordering of (urban) social life; this is even officially appreciated at the level of government.

Given the persistence of fear of real or imagined violence in Johannesburg in a context of apparent inadequacy of state efforts to fully maintain law and order, one therefore wonders how people survive and adapt. It is in this context that I examine of the role of traditions (customs), beliefs and spiritualities as social and psychological resources invoked by urban populations in coping with or governing urban violence. Such resources, which are currently marginally appreciated in urban studies literature, enable resilience and flexibility of (African) urbanites in difficult and trying circumstances (Simone and Abouhani 2005). I pursue this line of thought, notwithstanding the fact that in many instances, religion and beliefs, especially fundamentalist versions thereof (Appadurai 2006), account for rebellion, violence, and disorder (Turner 1991).

In this chapter I argue that urban violence and associated uncertainties generate enchanted urbanisms, especially in a context of lack of faith in the state's capacity to resolve these uncertainties and crises. Enchanted urbanism is a concept that describes increased belief in the supernatural, myths, and symbols in the configuration of everyday practices in the city. In this case I argue that despite observed modern or secular inclinations of city life (Goldstein 2009), many urban residents in South Africa [as elsewhere in Africa (Cohen 1969)] remain grounded, fully or partially, in their traditions, spiritualities, and beliefs - invoking their ethnic identities and associated cultural, ritual, and ethno-spiritual practices (Bigger 2009; Judin 2008; Kumar 2007; Stark 1999). While most of such practices are associated with pre-modernity and rurality (Bigger 2009), in the context of South Africa (as elsewhere) it would be a mistake to unduly split the rural from the urban, as urban populations (always) re-invoke traditional practices, rituals, and beliefs in responding to crises (such as violence) and as a way of life (O'Connor 1995). In this case, enchanted urbanism becomes observable in everyday urban commerce and social exchange. Beliefs, traditions (customs), and spiritualities can configure how urban dwellers walk, transact (trade), neighbour, associate, and befriend in contexts marred by fear of violence and crime - of the unpredictable, strange and fearsome. In this case symbols, myths, and customs are invoked in everyday urbanisms, influencing people's relationship with (and in) a city characterised by fear of violence.

For the purpose of this study, I define tradition as long standing practices which could be inherited or bequeathed. ${ }^{3}$ The concept of spirituality here denotes practices or thoughts that have to do with beliefs in deities ${ }^{4}$. Belief is conceptualized as an idea in which some confidence is placed. ${ }^{5}$ While analytical definitions of violence vary, I define it here as the "use of forceful acts motivated by the conscious or unconscious desire to obtain or maintain political, economic, or social power" (MacIliwaine and Moser

02 .

There are recent attempts to analyse the urban impact of religion, although these have mainly focused on "pre-modern" cities and Islam, ignoring other contemporary impacts. See Benson, Amira K., and Alison L. Gascoigne (Eds.). 2007. Cities in the pre-modern Islamic world: Urban impact of religion, state and society. New York: Routledge. Also see AlSayyad, Nezar. 2011. The Fundamentalist City?: Religiosity and the Remaking of Urban Space. New York: Routledge.

03. pass (something) on or leave (something) to someone else by will

See Ibid

05. See Ibid 
06.

The research upon which this chapter taps is funded by the Volkswagen Stiftung under the auspices of a "Postdoctoral Fellowship in the Humanities" in the programme "Knowledge for Tomorrow: Cooperative Research Projects in Sub-Saharahan and North Africa".
2004). I resort to a conceptual continuum that distinguishes between social, political, and economic violence (Moser and Mcllwaine 2001). In this study, although I refer to domestic violence, I am interested in public violence. I focus on collective violence (including strikes and xenophobic violence) and violent crime, while noting that concepts of violence and crime should not be used interchangeably (Moser and McIlwaine 2004; Pillay 2008).

This chapter is premised in theoretical explorations around the concept of enchanted urbanisms, I have invented it, and on preliminary fieldwork thus far conducted under the auspices of a research project that explored the mediatory role of religion, magic, and rituals in contexts of violence and the fear of violence in Johannesburg. ${ }^{6}$ This study is a multi-sited ethnography of Johannesburg and this particular chapter relies of field research done in the Johannesburg inner city neighborhoods of Rosettenville, which is a peri-central neighbourhood, Chiawelo, which is a Township neighbourhood, as well as Sandton, a high income neighbourhood. Below is a discussion of the theoretical frame of reference for this study.

\section{Theoretical positioning}

As a reference point, I benefit from the work of classical social theorists such as Durkheim, Weber, and Marx in my endeavour to understand the role of religion, beliefs, and traditions in urbanised (or industrialised) contexts. Following Durkheimian thought, my analysis invokes the notion of "(re)production of order" or "disorder" (peace, violence, fear) (Bourdieu 1986; Von Holdt 2012a; Von Holdt 2012b; Von Holdt 2012c), analysing the role of traditions, beliefs, and spiritualities in building moral or social orders and acting as "social cement" in urban contexts predisposed to "anomie" and "normlessness" (Durkheim 1975; Turner 1991).

In tandem with the Weberian tradition, I analyse the political and social significance of religious authority and the legitimacy thereof in the making of social and political orders (Kokosalakis 1985; Riis 1998; Turner 1991; Weber 1997). I observe a scenario where there is a re-enchantment or enchantment, rather than simply disenchantment of the world more visible in situations where modernity and urbanity have been accompanied by unresolved social problems such as increasing levels of violence and crime (Bennett 2001; Curry 2012; Jenkins 2000; Lee 2008). In fact, urbanism and modernity, in this context, come with a dialectic of disenchantment and enchantment or re-enchantment, rather than mainly with the former (Jenkins 2000). Thus, social and political stresses emanating from increasing levels of urban violence and uncertainty promote re-invocations of belief systems, traditions, and spiritualities as adaptive and regulatory mechanisms. Thus, I seek here to analyse the re-enchantment of the world in a context of violent modernities and urbanisms.

The explosion of violence and variations in its intensities, repertoires, and responses to it across various urban spaces is Marxianly analysed in terms of differences in material conditions of humans inhabiting those spaces - spaces of disadvantage which Wacquant designate as "territories of urban relegation" (Wacquant 2007) inhabited by "urban outcasts" (Wacquant 2008). Such spaces are more vulnerable to uncertainty as the 
residents cannot purchase protection and a sense of security for themselves. In the same vein, increased religiosity of sections of the population in these troubled spaces can be conceptualised as tantamount to the pacification of the masses (Toshio and Grapard 1996): religion operating as the opium (Marx and Raines 2002; Turner 1991).

Given the institutional gap created by the inadequacies of the state, the governance of violence invites other social institutions and civic collectivities, which then fill this gap. In this case, religion is one of the social institutions that play an important role in the making of urban orders. Religion plays a significant role in shaping the habits (practices and strategies) of urban dwellers as they navigate fearful cities. Not only is religion a matter of concern here, but also non-religious rituals that come to epitomise attempts by urbanites to generate ontological security by enhancing the predictability of life (Dirsuweit 2007), for instance by taking certain temporal or spatial practices and strategies that reduce the risk of violent victimisation in the city (de Certeau 1984). This may range from anything including the creation of walking or driving paths, the generation of mental maps that enhance perceived safe navigation of the city, or the avoidance of certain places during the day or night (Lynch 1960). In this case, I argue that there is an "institutionalisation" and "habitualisation"8 (Berger and Luckmann 1966) of fear, if not of violence itself (Katsaura 2012). The religious practices, everyday rituals, and mind maps of the city thus come to constitute stocks of cultural and social "capital" (Bourdieu 1986), deployed by collectivities and individuals in the negotiation of the urban social world. These stocks of knowledge are not to be ignored in our quest to understand the repertoires, negotiation, and governance of (the fear of) urban violence at local levels - and the associated everyday or periodic interaction rituals (Goffman 1961): violence and counter-violence practices and discourses themselves are public and/or everyday rituals.

Now I turn to the imaginations of Johannesburg, highlighting anecdotes that position the city as a place of fear.

\section{Imagining Johannesburg: Fear as a key signifier}

Johannesburg is generally imagined as a luring and enchanting city in the positive and negative sense. It lures people from all over South Africa, Africa, and the world in search of fortune; yet this lure of fortune doubles as a lure to live in a constant state of anxiety, fear, violence, and crime. It is both the hope for fortune and the fear of violence that is enchanting in Johannesburg. People living in Johannesburg, thus, also generally imagine the city as a space of immense hope, yet of great fear. Consider this statement by one interviewee:

"This is indeed the city of gold. It's a space of opportunity. If you want to make money, Johannesburg is the place to be. In my view, it's a place full of business opportunities and so there is a stampede of people wanting to live in Johannesburg. People hope that if they come to Johannesburg, their lives will become better. Even long back our fathers used to come to Johannesburg to work in the mines [from Zimbabwe]. However, this

07.

Institutionalisation is a concept that describes the habitualisation, patterning, and regularisation of human practices, customs, and behaviours - enhancing the predictability of social life (see Berger and Luckmann 1966).

08.

Habitualisation here refers to the reproducibility of a human action or behaviour with an economy of effort as a result of it being repeated frequently (see Berger and Luckmann 1966). 
is also a violent city. If you live in Johannesburg you have to constantly watch your back. The city is a place of opportunities also for criminals. We have a lot of hardcore criminals also in this city. You must be streetwise." 9

Not only is Johannesburg imagined as a space of opportunity and fear by its residents, but also by people from elsewhere. In conversations with people from Harare, Zimbabwea, a city that has supplied many immigrants to Johannesburg, fear of the city of Johannesburg seems widespread:

"...That place is scary. We are seeing a lot of funerals from that side .... But again, many people from here want to come and live in that city because of the opportunities it offers. Once in that city, though, one needs to be very careful to avoid being killed" 10

Given the facticity of fear of violence in Johannesburg, it is worthwhile to explore the ways in which people cope with this fear. Below I explore two ways in which people respond to fear of violence, which I understand as indicating a ritualisation of everyday life, emanating from people's attempts to generate a sense of safety. I analyse whether, indeed, there has been a theologisation of everyday life as a response to fear of violence and then I proceed to explain how routinisation of everyday practices in the city work as a safety generating mechanism.

\section{Theologisation of everyday life}

Religion plays a significant role in influenceing people's responses to uncertainty and to crisis (Malinowski 1955). It emerged that in Johannesburg as well, religion is a strong reference point and a significant resource deployed by people to contend with living in a city considered to be violence and crime ridden. The city of Johannesburg is itself understood theologically as a space abounding with spirits - bad and good. For those who have come from far off places, there is fear of the bad spirits in the city. One interviewee from Zimbabwe had this to say in a group interview:

"There are spirits in this land. These spirits fight with us strangers. As strangers in this city, we therefore need to worship God so that God protects us in whatever we do. Johannesburg, as I can describe it has three spirits. The first spirit is one of wealth. Those spirits undermine your attempts to make money in this city especially because you will be a foreigner. The spirit doesn't want the wealth from this land to be taken away to other lands. The second spirit is the one of women. This land is full of women who operate as prostitutes - they have mermaid spirits. If you play with them you can lose your finances because they like money. You will risk becoming broke. The third spirit is of violence and criminality. Now this is a very dangerous spirit. You may migrate from your country a good person, but if you are not careful, once you are here, you are worn by this spirit. So, even as we walk in this city, we need to be very careful as the spirit of violence is connected to the spirit of death. To survive all these spirits, you really need God. You need to be prayerful." 11 

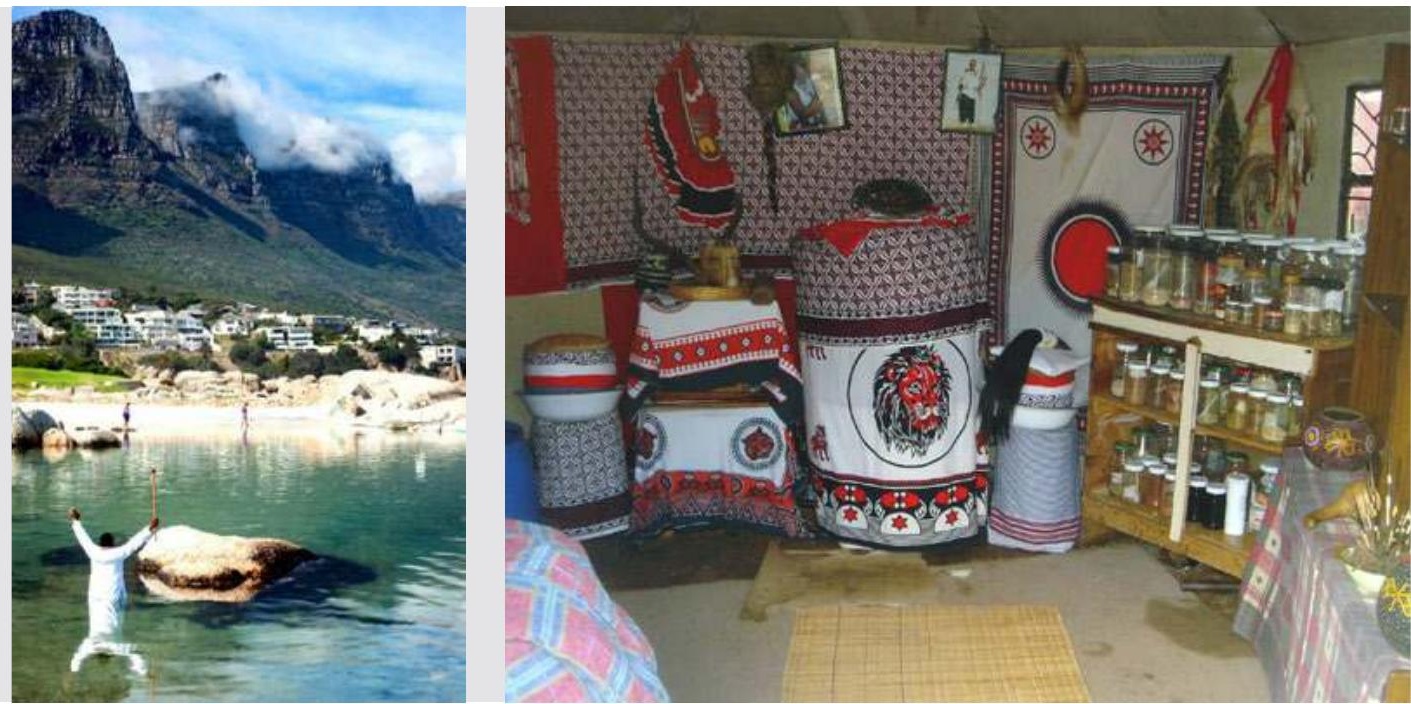

Another participant in this group interview emphasised the importance of prayer in a context of fear of violence:

"Ya, living here is hard. It is God who protects you because anytime when people get into conflict or an argument, its common for them to shoot each other with guns. They do not hesitate to kill. Eh, they do not have respect for life. That is the biggest lesson I have learnt here. So the biggest favour you can do to yourself is to know God. If some one steps on you or offends you, you must quickly say sorry, even if you are not in the wrong. Even if the person scolds you, you must remain quiet. And here, getting mugged is common - here it's worse than back home [Zimbabwe]. You really realise that living here needs divine protection. It's not the same as being at home [Zimbabwe]." 12

The group interview is revealing of the layered nature of fears that affect people living in Johannesburg, particularly those coming from outside South Africa. First, Johannesburg's relatively wealthy economy in Africa is a major attraction for immigrants, who, once in the city, content with the fear of failing to make it in this economy - hence the above reference to the spirits that attempt to withhold wealth from "strangers". Secondly, there is fear of losing money to prostitutes who are equally partaking of the city in search of fortune. Thirdly, violence and criminality is a key factor behind the fearsomeness of Johannesburg. This violence and criminality, because of its frequent lethality, befits the casting of Johannesburg as a necropolis - a city of death (Malaquais 2007). As emerging from this interview, prayer becomes an integral part of survival in this unpredictable city. In an interview, a Zimbabwean man from Chiawelo ${ }^{13}$, stressed the point that every morning he goes to a secluded hill to pray for divine protection and guidance during his daily socio-economic transactions and navigation of the city. This has become a long-standing ritual in his life.

In my own observations of a Pentecostal church in Johannesburg's inner city, various forms of charms are given to congregants to give a

Left:

African pastor standing in the ocean raises a staff his hands while praying and rejoicing over water baptisms performed in the Atlantic Ocean Source:

iStock/ wanderluster

Right:

Interior of a traditional round hut in a township near Johannesburg displaying ritual instruments Photo: Kosta Mathéy

12.

Group Interview, Nyembesi, member of the Johanne Masowe Apostolic Sect who was an immigrant from Zimbabwe, 9 May 2014.

13.

Interview, Marko, Chiawelo, 20 May 2014. 
sense of divine protection. These charms range from anointing oil which they apply on their bodies everyday, white handkerchiefs which they can carry everyday, to stickers bearing pictures of their religious leader (pastor - prophet) which they are encouraged to stick on their cars or doors or any place they deem necessary,.

Interviewing sangomas (traditional healers) in Faraday, in inner city Johannesburg, it emerged that traditional healers also play a key role in guaranteeing spiritual protection from physical attacks by criminals. For example, one traditional healer explained:

"I have muthi [medicine] that I give my clients to protect their houses and cars. For the house, this muthi works like security. When a criminal wants to get in, they suddenly get gripped by fear. I do the same for cars to make criminals fear to even attempt to open the doors of a car to steal the car or to steal things inside the car. They will always feel like the owner will come back before they could even touch the car. If a car is stolen, I can also perform a ritual on the crime spot to make sure that the car is recovered. Many who have come to me have received phone calls indicating the recovery of their cars. I can also use muthi to punish the criminals by inflicting pain on them after they commit crimes - sometimes they then confess their crimes."

The effects of the use of prayers or charms to avert violence and crime or to enhance vengeance, compensation, or recovery for the victims, is worthy of theorisation. The question is not so much on the effectiveness of these charms in dealing with the problems at the level of materiality, but on their pycho-social effects. The significance of charms could simply be in their enhancement of the confidence of the victims of fear and violence, enhancing their ontological security, which is important for their daily life in a city gripped by fear of the unknown.

In spaces of spiritual gatherings within the city of Johannesburg, the fear of violence and crime is also expressed and addressed and there is a constant attempt to invoke divine protection for members of religious congregations. In one of the churches attended, a preacher stated:

"My message today is that we are in a season of injury and we must be prayerful and careful. September, October, November are months of injury. We must pray for protection during this season. People are desperate for money. They want to go home where they come from in December in a big way. People are desperate to buy cars. Let us be vigilant and not be trapped or tricked. We must be watchful, we must be prayerful. There are too many dangers in this season. Criminals are very active. They want to make a financial killing.... The devil wants to take his last chance of the year - a chance to devour people... You must pray for the

Church Sermon Pastor, Pentecostal Church, Johannesburg CBD, 21 September 2013.
Commentaries of people in public realm such as pastors, priests, and prophets on the scourge of violence and crime in Johannesburg lend credence to fear among the populace. If not creating moral panics (Cohen 2002), such comments simply endorse and sensationalise the fears. The content of public prayers also reflects the fear of public violence. Below 
is a an excerpt of a prayer by a pastor in a Pentecostal church in the inner city of Johannesburg, in which he blessed his congregants at the end of a church service saying:

"Armed robbers have no power in your life. Hired killers have no power in your life. Witches and wizards have no power in your life. Premature death shall never be your portion..... In Jesus' name, Amen!" 15

This goes on to show that the violence that is feared, while it is mostly of a physical nature, is also understood as spiritual; hence the mention of armed robbers, witches, and wizards in the same prayer. This is unsurprising in the context of born again Christians who ardently believe in the fundamental connection of the physical to the spiritual and, by extension, the connection between physical and spiritual violence (Chidester 2012; Marshall 2009).

Religion is therefore a key factor of everyday life. The Johannesburg landscape is awash with churches, shrines, mosques, and market places for sangomas. These spaces and the associated institutions play a very significant role in the (re)production of social order in the city. They must be understood as playing a key role in mediating the exigencies of life in Johannesburg, a city in which residents contend with rampant physical violence as well as structural violence meted by an unequal economic and spatial setup that condemns many ordinary men and women to misery and hopelessness. In this case, it is not surprising that religion-various Apostolic and Pentecostal movements- are popular among people occupying social ranks that are considered to be of the poor. This is the category that Wacquant and Bauman have elsewhere respectively referred to as "urban outcasts" and "wasted lives" (Bauman 2004; Wacquant 1993). In the face of helplessness and victimization, these religious entities and associated practices provide a temporary and useful exit from the pains of the world - Marxianly operating somewhat as the opiate of the afflicted.

15.

Church Prayer,

Pastor, Pentecostal Church, Johannesburg CBD, 12 April 2014.

Left:

Ritual face

painting of the Xhosa tribe in the Western Cape. Photo:

Kosta Mathéy

Right:

Xhosa religious practice is distinguished by elaborate and lengthy rituals, initiations, and feasts. Modern rituals typically pertain to matters of illness and psychological wellbeing.

Photo:

Kosta Mathéy
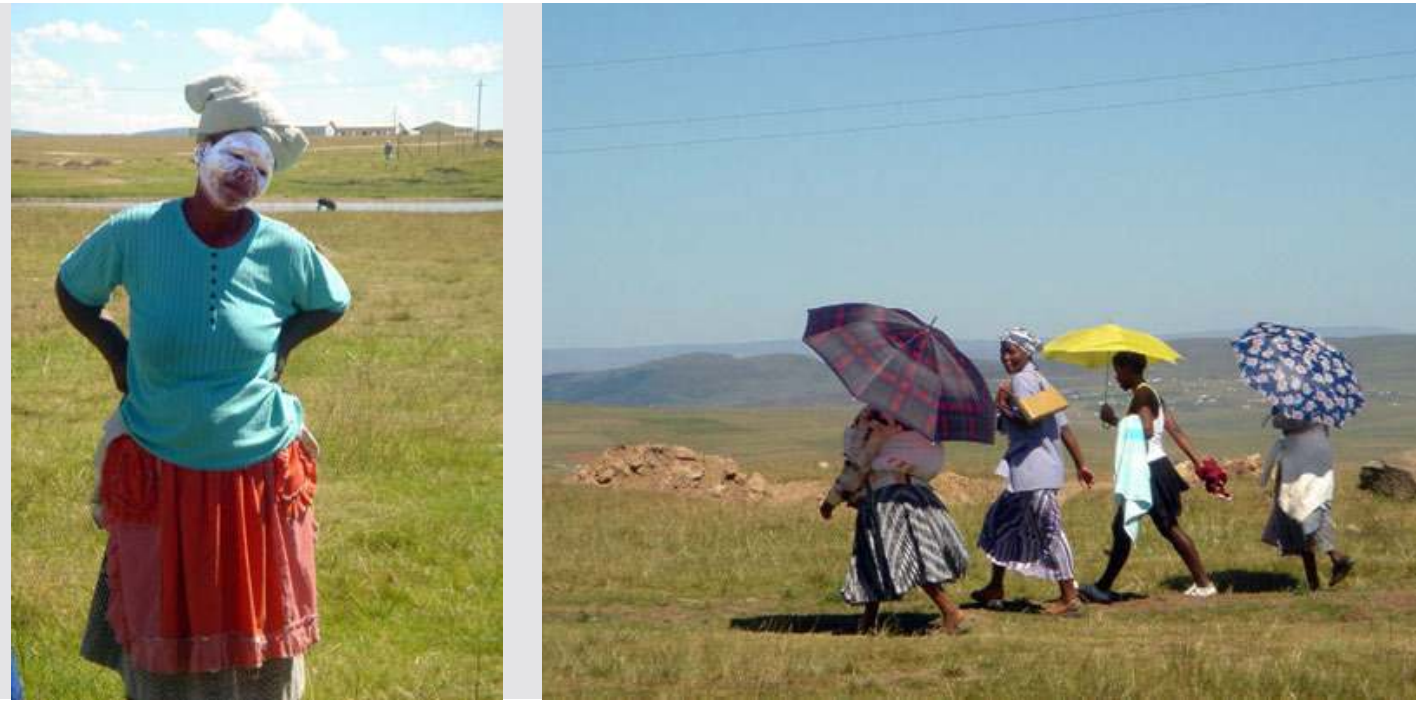
16. Interview, Pindai, Rosettenville, 9 May 2014.

\section{Routinisation of everyday life}

Contexts of fear and uncertainty, as noted by theorists such as Malinowski, Giddens, Bourdieu, and others invoke attempts at routinisation and habitualisation of life to generate a sense of security and predictability (Bourdieu 1977; Giddens 1984; Malinowski 1955). Some refer to this as a kind of ritualisation of life, that is a reduction of sets of repeated behaviours or customs that enhance its predictability (see Burger and Luckmann 1966). It is therefore the case that some individuals in Johannesburg create certain social routines and certain walking paths as a response to the fear of real or imagined violence or crime. Talking of how he manages his life in a context of fear in Johannesburg, an interviewee stated:

"I work in the city centre. It is a very dangerous place. If I make money, I quickly go to a safe place with my money. It's a problem to walk around with money in the city centre. If you take even 100 Rand out off you pocket, if it's seen by criminals, violence will erupt. They will attack you to take your money. Even if I have no money, I make it a point that I leave the city centre before $6 \mathrm{pm}$. By $6 \mathrm{pm}$ I will be at my home because I know that after $6 \mathrm{pm}$, particularly when it gets dark, I will be at greater risk of attack." 16

Although the above tale focuses on the city centre even in residential places individuals generate their mental maps with the aim of enhancing personal safety. Below, a resident of Chiawelo narrated his understanding of the area he lives in:

"You see, when we are in Chiawelo and surrounding areas we have places that we are afraid off, especially a place called White City. We know which areas we do not dare to go into. Although Chiawelo is relatively safe, the moment you cross Chris Hani Road, after those traffic lights from where you came and cross into White City, you must be careful. There are boys who take Nyaope [an addictive drug]. Those Nyaope boys patrol that area to rob people. Two of my friend lost their mobile phones in that area. Its better not to go to those areas after 6pm and if you do go there, it's better to avoid carrying valuables." 17

This story shows that there are both spatial and temporal strategies employed by people to avoid becoming victims of violence and crime. Individuals have got mental maps of the city, as informed by their fears of certain places, which directs their movement and location in the city at specific times. These spatial practices are the everyday strategies and tactics employed by people as they transect and transit through space (de Certeau 1984). They are reflective of residents' structuring of the perceptions (or images) of the city into "recurring elements such as paths (along which movements flow) and edges (which differentiate one part of the urban fabric from another)" (Lynch 1960:98). It is the fear of violence and other urban disorders that configure such images - images about dangerous or safe paths, spaces or neighbourhoods - which culminate in mental maps influencing individuals or social groups' navigation and classification of city spaces. Some spaces of the city are therefore feared, avoided, 
or disowned, while others are claimed and owned by individuals and social groups (as reflected in territorialist discourses and practices).

In richer neighbourhoods, such as Sandton, people adopt other methods of securing their spaces that can also be described as routine and ritualistic. There is a booming private security sector in such neighbourhoods, and some of the mechanics of its operations demand that individuals adopt certain behaviours at all times, in order to enhance their safety. A security guard interviewed in one of Sandton's gated communities explained:

"Here we people rely on private security. You see, there is always a private security vehicle on patrol in the area. We have the tactical response unit, which is heavily armed, always on patrol and on standby to tackle any security challenges. The people here always have a panic button on them. If they press that button, the tactical response unit arrives in just a very few minutes to deal with whatever security threat is there. Most of people here go to bed with the panic button in their possession, in case of any scares. It's normally put by the bedside for quick reaction in the face of any threats." 18

Thus, the use of state of the art security technologies is integral to the securing of everyday life in high-income suburbs of Johannesburg and it has essentially been routinised, if not ritualised. This speaks of obsession with fear, its entrenchment into everyday cosmology, and thus, its enchanting effects. While the obsession with security may seem irrational, one merely needs to observe that cases of violence - namely house robbery - are generally isolated and episodic. This brings to question the objectivity of fears that people have, yet one is tempted to understand the gravity of the subjective fear that grips people's consciousness and sub-consciousness.

Below, I conclude by laying some notes that crystallise the further meanings of narratives and analysis above.

\section{Conclusion}

Johannesburg, thus, can be understood as a city so intriguing because of its wealth, architecture, and not least because of its violence, floating fear, and also its religiosity. Simone (2004) rightly conceptualises Johannesburg as a city of intersecting fragments, of ruins underneath and beyond which a complex network of relations and a sophisticated as well as resilient social infrastructure is discernible. Religion, and various overt and covert ritualistic practices that enable residents to confront violence and fear thereof is a significant component of this social infrastructure. Given its complexity, and the complexities of its ordinary residents, Johannesburg can best be described as an enchanted and enchanting web.

From this study emerge two key conclusions. First is the observation that the context of fear of violence and crime and a cohort of other urban disorders such as unemployment and poverty spur a retreat into the ambit of the divine and spiritual for protection and/or psychological comfort. This scenario that I describe constitutes a theologisation of everyday life - a condition in which people increasingly depend on

Interview, Security Officer, Sandton 23 May 2014. 
an imagined theocratic order in confronting their everyday life and its challenges or opportunities. This theologisation is here conceptualised as a function of uncertainty and lack of faith in the state, especially in contexts of constant threats to humanity, as in the case of high levels of violence and crime. In the context of the narratives provided above, the majority of participants were in fact immigrants whose connection to the government in South Africa was characterised by distrust and fear; government agents such as police officers are themselves considered as some of the main culprits in the meting of violence and injustices on the bodies of immigrants. Its is therefore not surprising that most of them turn to this imagined theocratic order, as opposed to the conventional government as they seek safety, or simply a sense thereof.

While religious rituals and religious institutions play an important role in configuring responses to violence in Johannesburg as discussed above, non-religious rituals are also significant. It is well known, from Malinowski, to Bourdieu to Giddens, that uncertainty and anxiety invoke a search for stability, not only by calling upon higher authority, theocratic or otherwise, in an attempt to institutionalise a sense of predictability and security. Non-religious rituals, in the form of habituated practices and strategies play a significant role in generating a sense of safety and security. These range from patterned ways of walking (and driving) in the city, following pathways of perceived safety, and temporal strategies such as avoiding spaces of the city considered dangerous at night.This chapter opens a minefield of research into the significance of religion, magic, and rituals in the mediation of violence and fear thereof in Johannesburg - a minefield whose exploration is still just at its infancy with possibilities for further debate, if not repudiation of some of the views here presented.

\section{References}

Alexander, Peter. 2010. "Rebellion of the poor: South Africa's service delivery protests-a preliminary analysis." Review of African Political Economy 37(123):25-40.

AlSayyad, Nezar. 2011. The Fundamentalist City?: Religiosity and the Remaking of Urban Space. New York: Routledge.

Appadurai, Arjun. 2006. Fear of small numbers: An essay on the geography of anger. Durham: Duke University Press.

Atkinson, Doreen. 2007. "Taking to the streets: has developmental local government failed in South Africa." State of the nation: South Africa 2007:53-77.

Bauman, Zygmunt. 2004. Wasted Lives: Modernity and its outcasts. Cambridge: Polity Press.

Benit-Gbaffou, Claire. 2008a. "Community Policing and Disputed Norms for Local Social Control in Post-Apartheid Johannesburg." Journal of Southern African Studies 34(1):93109.

Benit-Gbaffou, Claire. 2008b. "Unbundled security services and urban fragmentation in Post-Apartheid Johannesburg." Geoforum 39:1933 - 50.

Bénit-Gbaffou, Claire, Laurent Fourchard, and Alex Wafer. 2012. "Circulation of security local initiatives in space and time: the case of Johannesburg." International journal of urban and regional research 39(6):936-57.

Bennett, Jane. 2001. The enchantment of modern life: attachments, crossings, and ethics. Princeton: Princeton University Press.

Benson, Amira K., and Alison L. Gascoigne (Eds.). 2007. Cities in the pre-modern Islamic world: Urban impact of religion, state and society. New York: Routledge.

Berger, Peter, and Thomas Luckmann. 1966. The social construction of reality; A Treatise in the sociology of knowledge. New York: Penguin

Bigger, Stephen. 2009. "Ethno-spirituality: A Postcolonial Problematic?" Alternation:: Interdisciplinary Journal for the Study of the Arts and Humanities in Southern Africa (9). 
Boisteau, Charlotte. 2005. "Dynamics of exclusion: Violence and security policies in Johannesburg." Pp. 255 - 68 in Public problems - Private solutions?: Globalising cities in the South, edited by Klaus Segbers, Simon Raiser, and Krister Volkmann. Aldershot: Ashgate Publishing Limited.

Bourdieu, Pierre. 1977. Outline of a Theory of Practice. Cambridge: Cambridge University Press.

Bourdieu, Pierre. 1986. "The forms of capital." Pp. 241 - 58 in Handbook of theory of research for sociology of education. Transalated by Richard Nice, Reprinted by permission, edited by Richardson. London: Greenwood Press.

Chapman, Audrey, and Spong Bernard. 2003. Religion \& Reconciliation in South Africa: Voices of religious leaders. Pennsylvania: Templeton Press.

Chidester, David. 2012. Wild religion: tracking the sacred in South Africa. Bekerley: University of California Press.

Cohen, Abner. 1969. Custom and Politics in Urban Africa: A study of Hausa Migrants in Yoruba towns. Berkely: University of California.

Cohen, Stanley. 2002. Folk devils and moral panics: The creation of the mods and rockers. London \& New York: Routledge.

Curry, Patrick. 2012. "Enchantment and modernity." PAN: Philosophy Activism Nature (9):76 89.

de Certeau, Michael. 1984. The practice of everyday life. Berkeley CA: California; University of California Press.

Dirsuweit, Teresa. 2002. "Johannesburg: A fearful City?" Urban Forum 13(3):4 - 19.

Dirsuweit, Teresa. 2007. "Between ontological security and the right difference: Road closures, communitarianism and urban ethics in Johannesburg, South Africa." Autrepart (2):53-71.

Durkheim, Emile. 1975. Emile Durkheim on morality and society. Chicago: University of Chicago Press.

Elbadawi, E, and Nicholas Sambanis. 2000. "Why are there so many civil wars in Africa? Understanding and preventing violent conflict." Journal of African Economies 9(3):244-69.

Ellis, Stephen, and Gerrie Ter Haar. 1998. "Religion and politics in sub-Saharan Africa." The Journal of Modern African Studies 36(2):175201.

Giddens, Anthony. 1984. The Constitution of Society: Outline of the theory of Structuration. London: Polity Press.

Goffman, Erving. 1961. Encounters: Two studies in the sociology of interaction. Middlesex, England: Penguin Books Ltd.

Goldstein, Warren S. 2009. "Secularization Patterns in the Old Paradigm." Sociology of religion 70(2):157-78.

Hough, Mike. 2009. "Violent protest at local government level in South Africa: revolutionary potential?" Scientia Militaria: South African Journal of Military Studies 36(1):1-14.

Jenkins, Richard. 2000. "Disenchantment, enchantment and re-enchantment: Max Weber at the millennium." Max Weber Studies 1(1):11-32.

Judin, Hilton. 2008. "Unsettling Johannesburg: The country in the city." Pp. 121-46. in Other cities, other worlds: Urban imaginaries is a globalising age, edited by Andreas Huyssens. London: Duke University Press.

Katsaura, Obvious. 2012. "Socio-spatial politics of community safety governance in Johannesburg." in School of Architecture and Planning: University of the Witwatersrand.

Kokosalakis, Nikos. 1985. "Legitimation power and religion in modern society." Sociology of Religion 46(4):367-76.

Kumar, P Pratap. 2007. "Urbanism and the" Death of Religion": Strategies of religious manifestation in modern society." Journal for the Study of Religion 20(2):43 - 56.

Landau, Loren B. 2010. "Loving the alien? Citizenship, law, and the future in South Africa's demonic society." African Affairs 109(435):21330 .

Landau, Loren B., and Iriann Haupt. 2007. "Tactical Cosmopolitanism and Idioms of Belonging: Insertion and Self - Exclusion in Johannesburg." in Migration Studies Working Paper Series. Johannesburg: University of the Witwatersrand.

Landau, Loren, K. Ramjathan-Keogh, and S. Gavatri. 2005. "Xenophobia in South Africa and Problems Related to it." in Forced Migration Working Paper Series Johannesburg: Forced Migration Studies Programme, University of the Witwatersrand.

Lee, Raymond LM. 2008. "Modernity, mortality and re-enchantment: The death taboo revisited." Sociology 42(4):745-59.

Lynch, Kevin. 1960. The image of the city. Massachusetts: MIT press.

Maclliwaine, Cathy, and Caroline Moser. 2004. Encounters with violence in Latin America. London: Routlegde.

Malaquais, Dominique. 2007. "Doula/Johannesburg/New York." Pp. 31-52 in Cities in contemporary Africa, edited by Martin Murray and Garth A. Myers. New York: Palgrave Macmillan.

Malinowski, Branislaw. 1955. Magic, Science and Religion. New York: Doubleday \& Co.

Marsden, Peter. 2002. The Taliban: War and Religion in Afghanistan. London: Zed Books.

Marshall, Ruth. 2009. Political spiritualities: the Pentecostal revolution in Nigeria. Chicago: University of Chicago Press.

Marx, Karl, and John C Raines. 2002. Marx on religion. Philadephia: Temple University Press.

Misago, Jean-Pierre. 2011. "Disorder in a changing society: Authority and the micro-politics of violence." in Exorcising the demons from 
within, edited by Loren Landau. Johannesburg: Wits University Press.

Misago, Jean-Pierre, Loren B. Landau, and Tamlyn Monson. 2009. "Towards Tolerance, Law, and Dignity: Addressing Violence against Foreign Nationals in South Africa." Johannesburg: International Organisation for Migration (IOM).

Moser, Caroline, and Cathy McIlwaine. 2001. "Violence in a post-conflict context: Urban poor perceptions from Guatemala." Latin America and Carribean Region; Environmentally and Socially Sustainable Development Sector Management Unit, The World Bank, Washington D.C.

Moser, Caroline, and Cathy McIlwaine. 2004. Encounters with Violence in Latin America: Urban Poor Perceptions from Colombia and Guatemala. New York and London: Routledge.

O'connor, Richard A. 1995. "Indigenous urbanism: class, city and society in Southeast Asia." Journal of Southeast Asian Studies 26(01):30-45.

Pillay, Suren. 2008. "Crime, community and the governance of violence in post-apartheid South Africa." Politikon 35(2):141-58.

Ranger, Terence. 1992. "War, violence and healing in Zimbabwe." Journal of Southern African Studies 18(3):698-707.

Rauch, Janine. 2005. “Crime prevention and morality: The campaign for moral regeneration in South Africa [Electronic Version]."

Rauch, Janine. 2011. Crime Prevention and Morality The Campaign for Moral Regeneration in South Africa. Pretoria: Institute for Security Studies.

Riis, Ole. 1998. "Religion Re-Emerging The Role of Religion in Legitimating Integration and Power in Modern Societies." International Sociology 13(2):249-72.

Schönteich, Martin, and Antoinnete Louw. 2001. "Crime in South Africa: A country and cities profile." Pretoria: Institute for Security Studies.

Simone, AbdouMaliq. 2004b. "People as Infrastructure: Intersecting Fragments in Johannesburg." Public culture 16(3).

Simone, AbdouMaliq, and Abdelghani Abouhani (Eds.). 2005. Urban Africa: Changing Countours of Survival in the City. London and NewYork: CODESRIA Books in association with zed books.

Stark, Rodney. 1999. “Secularization, R.I.P.” Sociology of Religion 60(3):249-73.
Toshio, Kuroda, and Allan Grapard. 1996. "The World of Spirit Pacification: Issues of State and Religion." Japanese journal of religious studies:321-51.

Turner, Bryan S. 1991. Religion and social theory. London: Sage Publications Limited.

Von Holdt, K, M Langa, S Molapo, N Mogapi, K Ngubeni, J Dlamini, and A Kirsten. 2011. "The smoke that calls: Insurgent citizenship, collective violence and the struggle for a place in the new South Africa." Centre for the Study of Violence and Reconciliation, Society, Work and Development Institute, Cape Town and Johannesburg.

Von Holdt, Karl. 2011. "Overview: Insurgent citizenship and collective violence: Analysis of case studies." in The smoke that calls: Insurgent citizenship, collective violence and the struggle for a place in new South Africa, edited by Karl Von Holdt, Malose Langa, Sepetla MalapoKindiza Ngubeni, Jacob Dlamini, and Adele Kirsten. Johannesburg: CSVR and SWOP - Wits University.

Von Holdt, Karl. 2012a. "Bodies of defiance." in Conversations with Bourdieu: The Johannesburg Moment, edited by Michael Burawoy and Karl Von Holdt. Johannesburg: Wits University Press.

Von Holdt, Karl. 2012b. "Bourdieu in South Africa." in Conversations with Bourdieu: The Johannesburg moment, edited by Michael Burawoy and Karl von Holdt. Johannesburg: Wits University Press.

Von Holdt, Karl. 2012c. "Symbolic challenge " in Conversations with Bourdieu: The Johannesburg moment, edited by Michael Burawoy and Karl Von Holdt. Johannesburg: Wits University Press.

Von Holdt, Karl. 2012d. "Violence." in Conversations with Bourdieu: The Johannesburg moment, edited by Michael Burawoy and Karl Von Holdt. Johannesburg: Wits University Press.

Wacquant, Loic. 1993. "Urban Outcasts: Stigma and Division in the Black American Ghetto and the French Urban Periphery." International journal of urban and regional research 17(3):366-83.

Wacquant, Loic. 2008. Urban outcasts: a comparative sociology of advanced marginality. Cambridge: Polity Press.

Wacquant, Loïc. 2007. "Territorial stigmatization in the age of advanced marginality." Thesis Eleven 91(1):66-77.

Weber, Max. 1997. The theory of social and economic organization. New York: Free Press. 

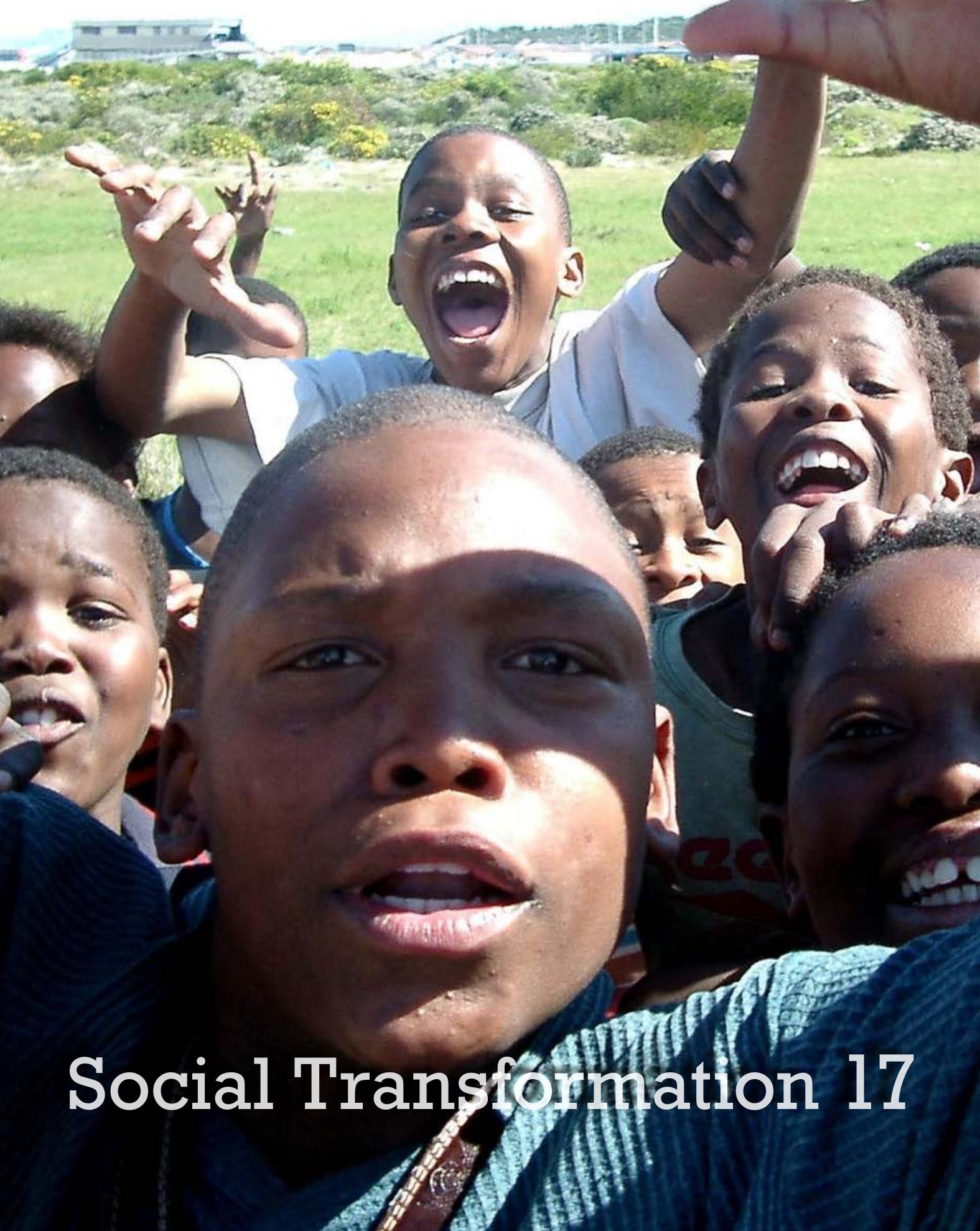


\title{
Embracing the Complexity of Community Safety Challenges \\ The STS Methodology to reduce violence in Khayelitsha and Johannesburg
}

\author{
Barbara Holtmann and Emma Holtmann
}

Women's legal centre complaint

(2013)
Previous page:

Children in

Khayelitsha expecting to get entry to the public

swimming pool which was closed for undisclosed reasons. Photo:

Kosta Mathéy
Crime and violence are severe problems for communities throughout South Africa ${ }^{1}$. While there are many strategies to respond to the threat of crime and to combat crime, criminal justice responses are over-burdened and inadequate. Like many complex problems, unsafety is intractable and does not respond well to linear or simple solutions. This paper regards crime and violence as outcomes of other social and economic ills and aims to embrace the complexity of the challenge at local level by using systems thinking and practice (Holtmann 2014).

Any attempt to address local safety as an inclusively local issue, rather than as an issue that must be addressed from a national perspective, requires an inversion of traditional South African governance models. (See figure one below). In this model, leadership is conceived as a support function for local action, with feedback providing opportunity for leaning, improved policy, and treasury allocation. This encourages community ownership and increases accountability at local level.

\section{The methodology}

The Social Transformation System (STS) offers a process of collective introspection in which it is safe to embrace complexity. It promotes the vision of systemic transformation through collaborative actions, agreement of value attached to thematic interventions, the alignment of strengths, and capacities for the achievement of shared objectives. It allows for participative rapid assessment to benchmark current status and develop and manage action plans.

This methodology has been developed through an iterative process, with exposure to projects in a range of settings and with a range of intended outcomes over some years. Of these, the facilitation of crime prevention strategies or local safety plans for 24 police precincts in the 


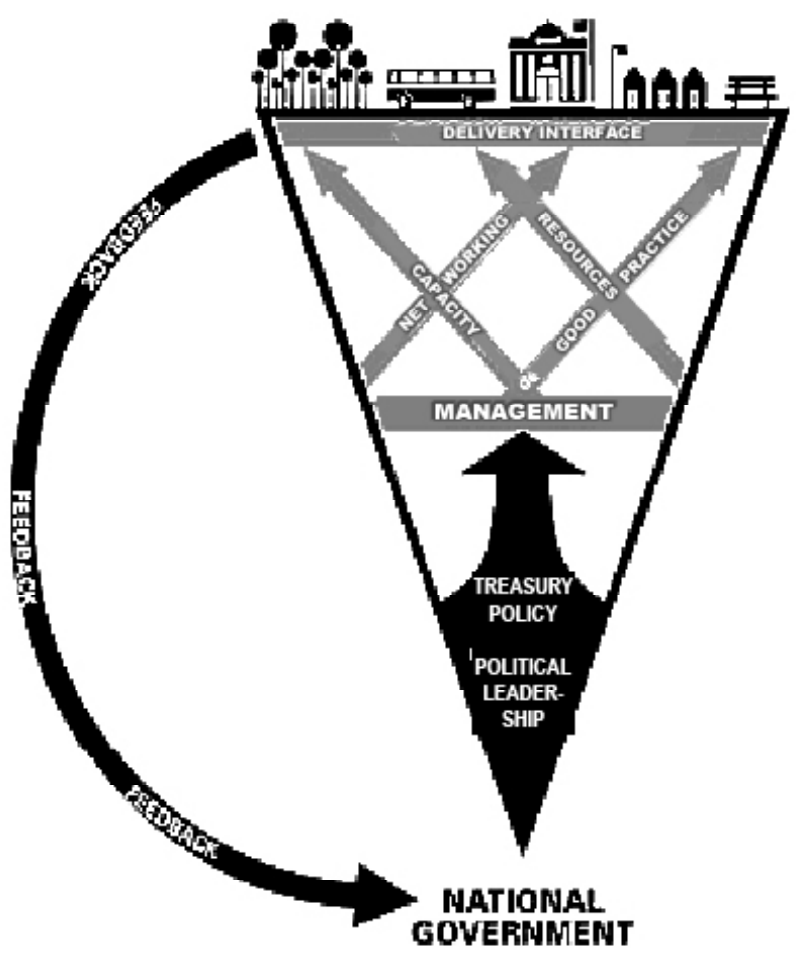

Western Cape was significantly informative, although the plans were never implemented. The plan for Khayelitsha, a township in Cape Town, has recently been revisited as a result of a Commission of Inquiry into policing in Khayelitsha.

Khayelitsha is a predominantly black working-class and poor community situated about thirty-five kilometers from the central business district of Cape Town. The area is barren and windswept and suffers heavy flooding in the winter months. Although the population is not accurately known, it is estimated at about 750,000 inhabitants. Khayelitsha has grown rapidly over nearly 40 years. It is Cape Town's largest township, very densely populated, extremely poor, and with exceptionally high levels of unemployment. There are formal areas with brick homes and electricity, water, sanitation services, and regular refuse removal. However, other residents live in informal structures, commonly referred to as "shacks" or as backyarders ${ }^{2}$, with no access to services. They have poor health, and high levels of unsafety. In a complaint by the Women's Legal Centre, it was stated:

"Community members report that girls and women are frequently beaten and raped whilst walking to and from communal toilets or fetching water from communal taps close to their homes. Domestic abuse [also] poses a threat to the safety of many women within their own homes. Between March 2003 and March 2011 there has been a 9.36\% increase in the number of reported sexual crimes in Khayelitsha" (Women's Legal Centre).
Figure one Governance for Local Development and Active Citizenship

02.

Township backyard shacks have been constructed in the backyards of existing legalized houses with an own plot, when the ban on free movement was lifted for the black population after Apartheid. Those migrants would normally squat on empty land. But when the national elections where celebrated with black participation for the first time. all voters required a formal and legal address, which a backyard dwelling could provide. 


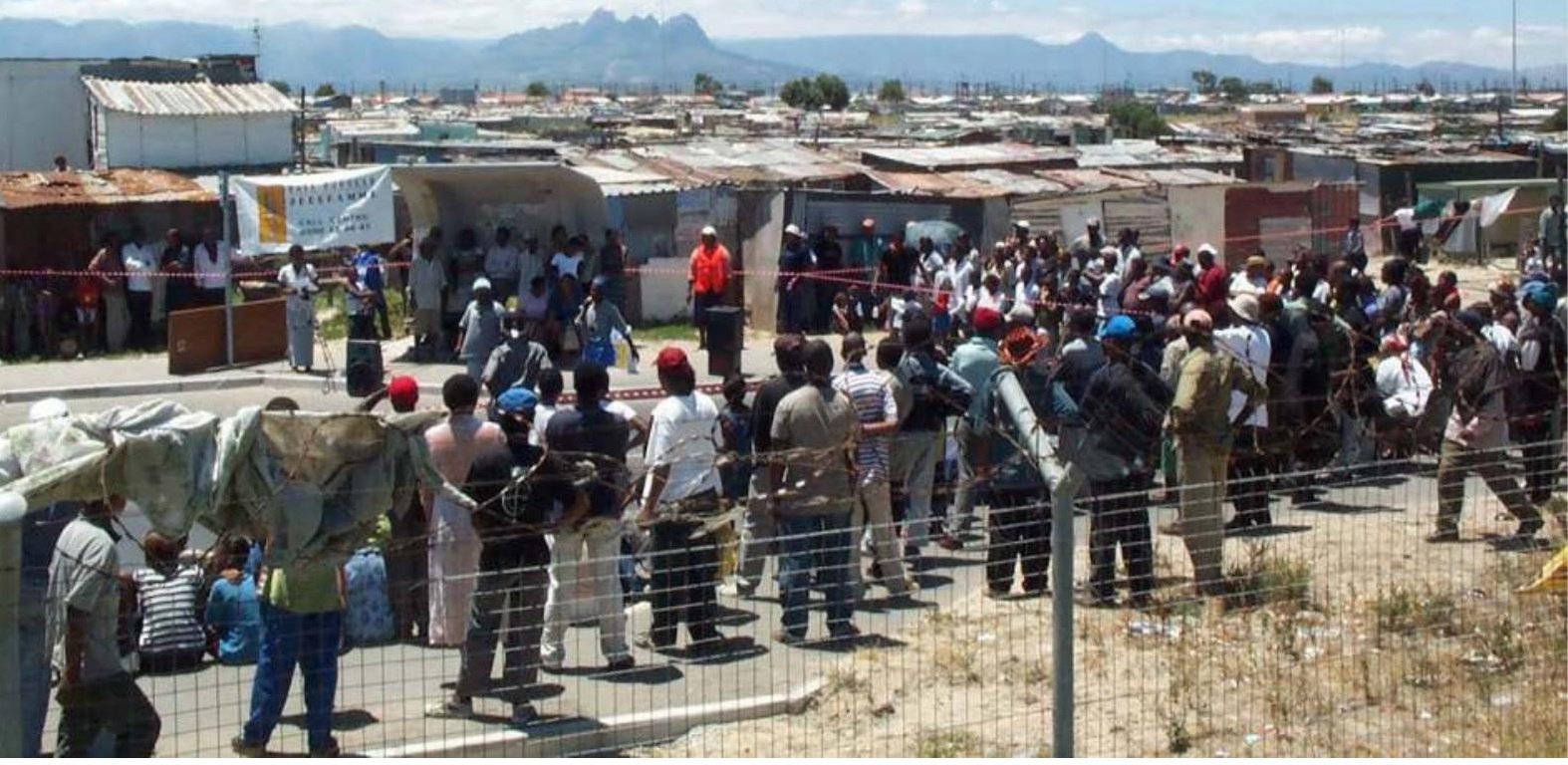

View over The Western Cape Project in Kayelitsha came about as a result of a workKhayelitsha Township, Cape flats.

Photo: K. Mathéy shop towards the end of 2004. ${ }^{3}$ The workshop aimed to explore the role of police in addressing crimes related to social issues. Based on a research model from the Council of Scientific \& Industrial Research (CSIR), Breaking the Cycle of Crime and Violence (Figure 2) included interpersonal crimes associated with alcohol, sexual offences, drug related crimes, and youth involved with gangs.

The image of the cycle that traps so many South African communities visualizes in one snapshot why it's so difficult to enable sustainable com-

03.

This workshop was co-hosted by The International Centre for Prevention of Crime (ICPC), the South African Police Service, and the Council for Scientific and Industrial Research (CSIR) on matters of policing and community safety in preparation for the ICPC Colloquium, held in Oslo (November 2007). munity development (and safety). It does not attempt to describe everything that is relevant or may occur, but rather to provide a systemic view of the complexity. It serves to frame the challenge of community intervention and development as difficult and to guide participants to an understanding of why it is so hard to intervene systemically. The outer circle of the figure above demonstrates how someone who displays antisocial behaviour is the same person as the vulnerable victim of anti-social behavior: the individual is just at a different point in the cycle. In the centre of the circle, and at the centre of the challenge of community development, lies the problem of low trust. South Africa is a society where there are low levels of interpersonal trust, as well as low trust in the criminal and social justice systems. When people do not trust others they are more likely to themselves behave in a way that is untrustworthy, and this deepens divisions. The context for antisocial, criminal, and violent behaviour is described using 6 key, systemic, social, and historical factors in the centre of the circle: these are characteristics of communities in which community development represents a challenge because of issues that include high rates of migrancy, a sense of uselessness, guns and violence, poverty, drugs, and alcohol abuse. The systemic nature of 


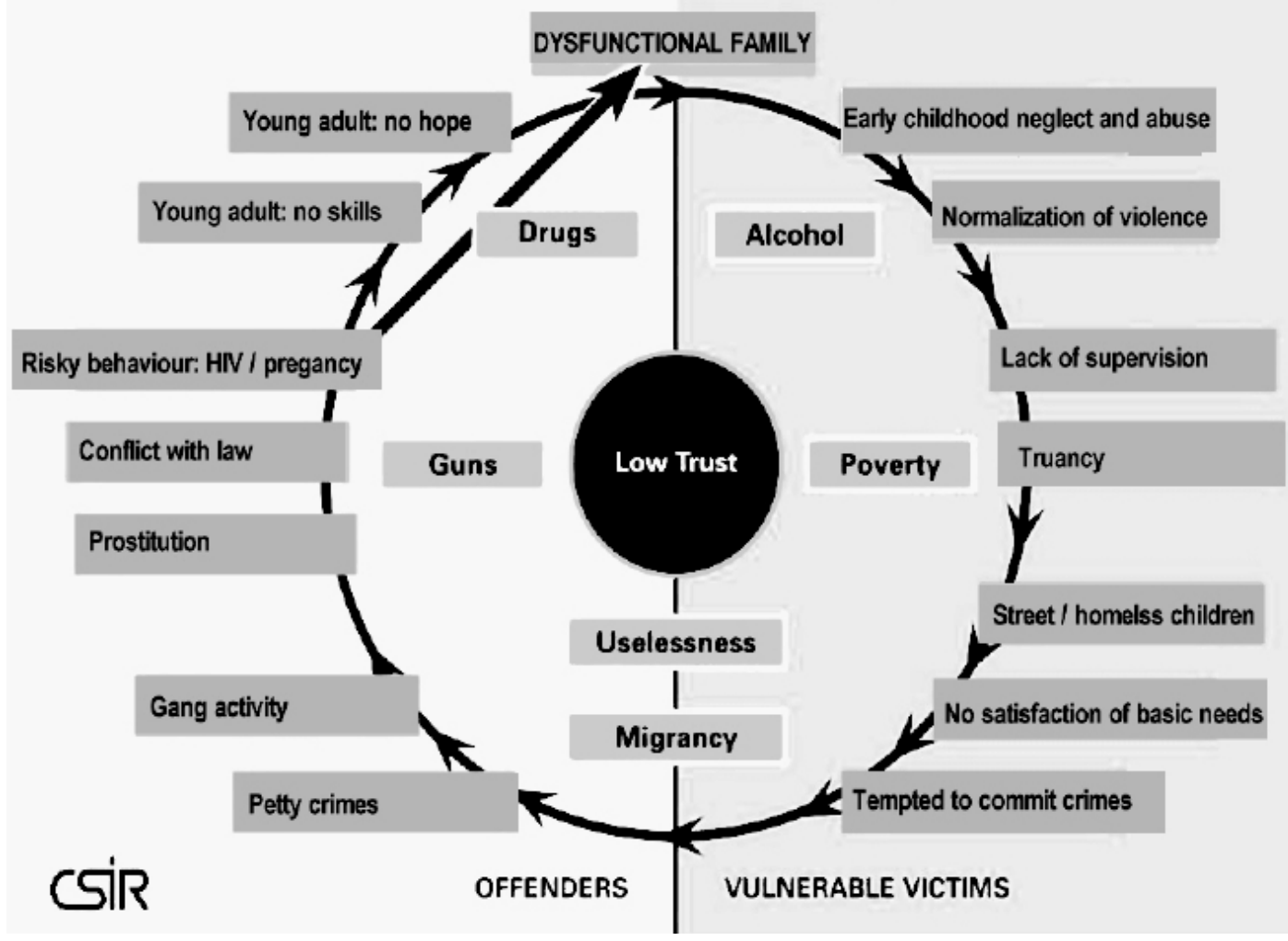

these factors is linked to the policies of the apartheid government, which was designed to serve a small minority of the population. The infrastructure and services established by that government were not intended to Figure 2: Cycle of Crime and Violence uplift and support the needs of the majority and many of the contemporary factors can be traced directly back to the apartheid policy of divide and rule. As a result of these and other oppressors, the life cycle of many children begins with fragile and fragmented families - often as a result of accidental pregnancy. In many instances, male children head households, as the father is absent. They do so however, without adult skills and without resources to nurture the other children for whom they might provide care.

Part of the workshop were field trips designed to explore the environments in which this cycle commonly occurred and facilitated group discussions to identify appropriate roles for police in the prevention and reduction of such crimes. The outcomes of this workshop highlighted the complexity of the challenges facing police in these crimes. Subsequently a research project was initiated to distinguish between police roles and responsibilities, and those of other departments and stakeholders, in order to develop integrated, multi-sector strategies which would address "social crimes" at a local level. The focus of the resulting Safety Plans was to identify and articulate achievable objectives that could be reached by the full Provincial range of stakeholders, who together could make a community safe. These were thus not intended as operational policing plans, but as integrated plans, inclusive of all departments and stakeholders. 


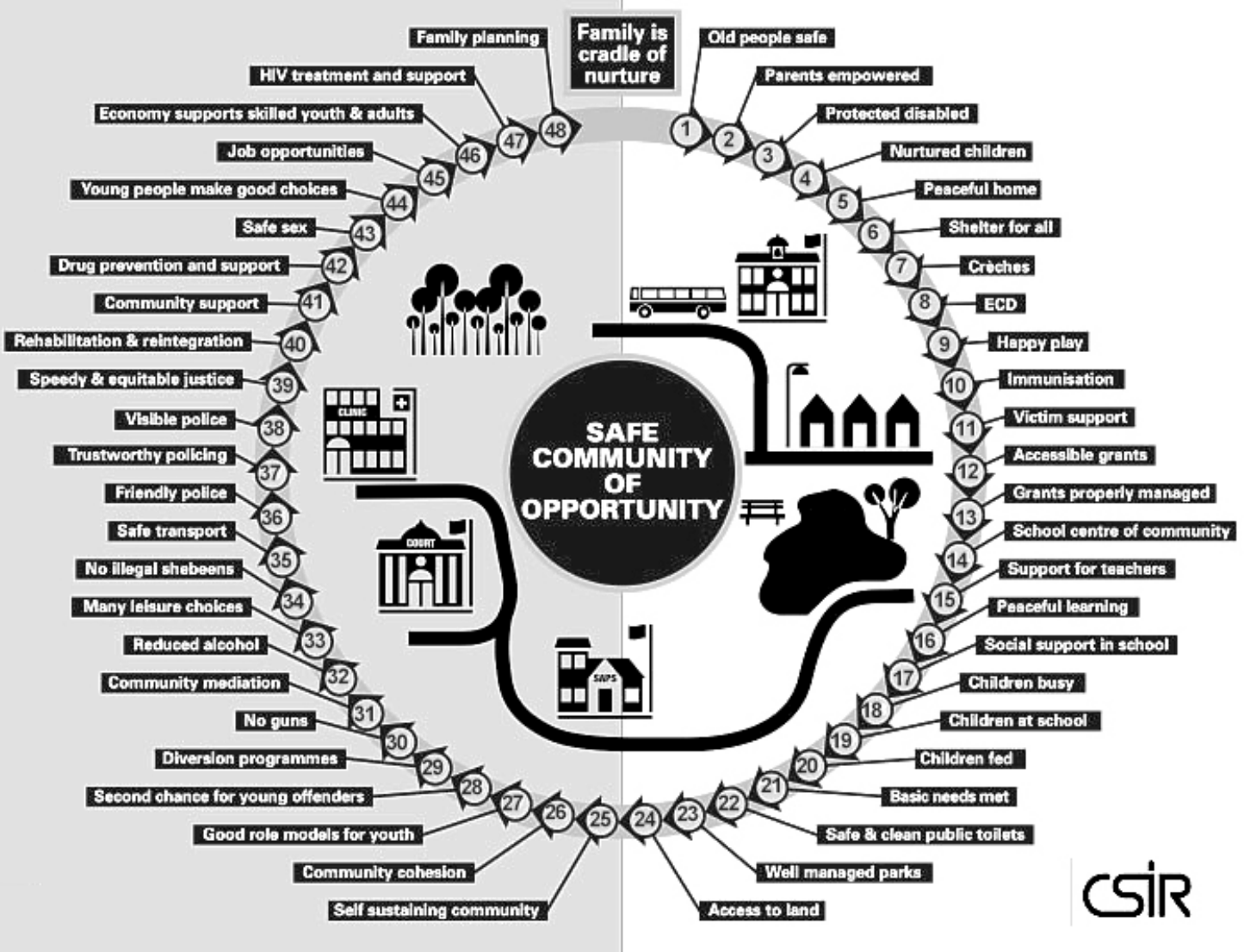

Figure 3: It was also not the intention of the South African Police Service to lead Safe Community of Opportunity implementation of the Safety Plans; it was the intention that such leadership should be sought from within Provincial Government.

The Safety Plans were developed using a combination of literature review, undertaken by a team of experts in different aspects of community safety, and applied a safety lens to (for instance) nutrition, early childhood development, schools, parenting, young people, and families. At the same time, the team undertook consultative workshops in which service providers and community members were asked to respond to the cycle by drawing, in groups, "what it looks like when it's fixed". Theses drawings were then analyzed and taken back to the experts with the question "are these people right? Is this what it looks like when a community is safe?" Based on this process, a model, the Safe Community of Opportunity model, was compiled, representing an inclusive range of elements and outcomes that must be in place for sustainable community safety (Figure 3).

Useful insights that emerged from revisiting the Khayelitsha Safety Plan included:

- Safety Plans should be seen as a tool for all government and not just for the police.

- Safety Plans are not about fighting crime; they are about addressing 
safety concerns and moving towards a vision of a safe place.

- Safety Plans should be formally institutionalized into local government development and planning processes.

- Safety Plans will not succeed without leadership, commitment, and constant communication; information sharing and feedback are likewise fundamental.

- Community engagement is essential.

- Civil society should be seen as an excellent resource.

- Monitoring and Evaluation should be participative, inclusive, and objective in order to incrementally improve implementation from one budget cycle to another.

- Communication about the Safety Plans and of successes as they are achieved will provide vital engagement and motivation for sustaining what are often difficult and complex partnerships.

The Social Transformation System methodology has since been refined and used to develop community-specific models with various transformational objectives for various settings, including both urban communities and rural villages. This allows the Social Transformation System to bring existing research into each new setting, while simultaneously incorporating local knowledge and experience.

The original "cycle of crime and violence" has, with subsequent learning, evolved to become the "cycle of inequality and poverty" (Figure 4), which focuses more on the complexity of local settings and challenges than on a direct response to unsafety. The updated model makes important links between the lack of opportunity, at a local level, and high levels of crime and violence. Many communities experience low levels of support from state service providers and this is reflected in almost continuous service delivery protests and community disruption. The cycle perpetuates with high levels of teenage pregnancy, high rates of school drop-outs and truancy, and young people experiencing low levels of hope for the future.

The STS process is used to:

- Safely embrace the challenge of these complex systemic problems;

- Envision: "what it looks like when it's fixed";

- Align social investment strategy with business visions and objectives;

- Enable everyone to be useful in moving towards a shared vision;

- Promote essential, sustainable collaboration based on mutual need;

- Impart participatory, intuitive bench-marking and impact assessment;

- Manage multi-dimensional, thematic actions'

- Negotiate terms of engagement with delivery partners;

- And maximize return on investment in a transformed system.

The model and methodology encompass an optimistic process to establish "what it looks like when it's fixed". This focuses not solely on the 


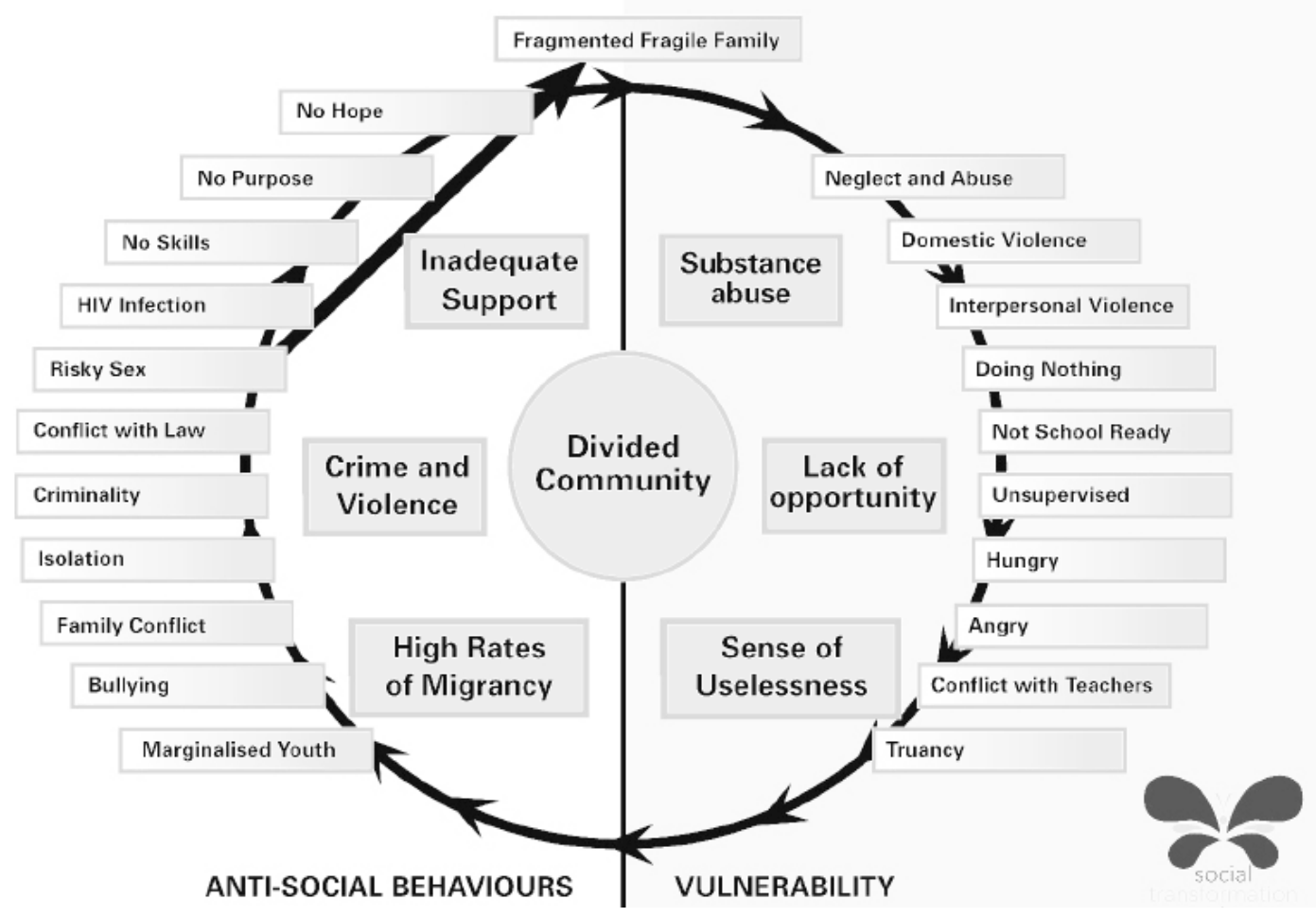

Figure 4: intervention but the intended outcomes, envisaged in the investment (or Cycle of Inequality and Poverty. Copyright: Barbara Holtmann mobilization) of stakeholders. It requires that interventions be tested against outcomes and that there is a possibility that proposed interventions may not prove to be the most appropriate...

This process involves the convening of a workshop or workshops in which an inclusive range of participants deliver a collective vision, alongside individual introspection, to identify the way in which each will contribute to achieving the vision. This vision must be clearly defined and mandate appropriate collaborative partnerships based on mutual benefit, a rapid assessment (based on knowledge in the room), and action plans that focus on shifting the status of the whole towards sustainable resilience. The outcome of the workshop process is a populated model of a "fixed" state or transformed system, clearly articulated as a shared destination towards which -through collaborative effort over an agreed time period- there is a collective commitment.

A software tool supports the process, prompting the capture of the elements of a defined "fixed" state and a rapid assessment of the current status of the system against the "fixed" state.

The elements of each particular vision are verified by embedded research. The model provides the research behind the interdependencies amongst an inclusive range of elements and in this way, verifies elements that emerge through the visioning process. The participants score elements on the basis of pre-researched simple indicators - how close or distant is the achievement of each element. Once all elements are scored, participants agree on a benchmark in the form of an overall score for how 
far the current position is from the fixed state. This becomes the baseline, against which progress will be measured. Participants then identify their individual and partnership roles and functions: identifying leaders, key partners and supporting partners. All then develop action plans. Typically the workshop delivers themed interventions based on pre-determined simple criteria, for instance:

1. Interventions that aim to improve the outcomes that demonstrate the greatest deficit or need (if nothing is done about the biggest problems, they threaten to bring down the overall system; also, ignoring the worst problem areas will be a barrier to real change to the system score).

2. Interventions that build on the outcomes that demonstrate existing promise or progress (this is typically the easiest area in which to score relatively quick and demonstrable wins).

3. Interventions that focus on the outcomes where there is the greatest alignment of interest and strategic objectives.

The methodology relies on respectful interaction amongst participants. All voices are equally valued; regardless of relative power or hierarchical relationships outside of the process, in the workshop all have equal standing. Anomalies in the baseline rapid assessment undertaken in the workshop will quickly emerge - the measurements are systemic and where there is a gap in knowledge the logic of the model will demonstrate it. This often provides the entry point for engagement with absent stakeholders who may not know at the outset why they should participate in the process. Action plans are developed according to a simple template that links all actions to elements of the model. Participants simulate their intentions so that they can anticipate the impact that actions will have on the status of the whole system, rather than against isolated or individual terms of reference. If the simulation doesn't demonstrate impact, then the action plan will not meet the approval of the whole group. In

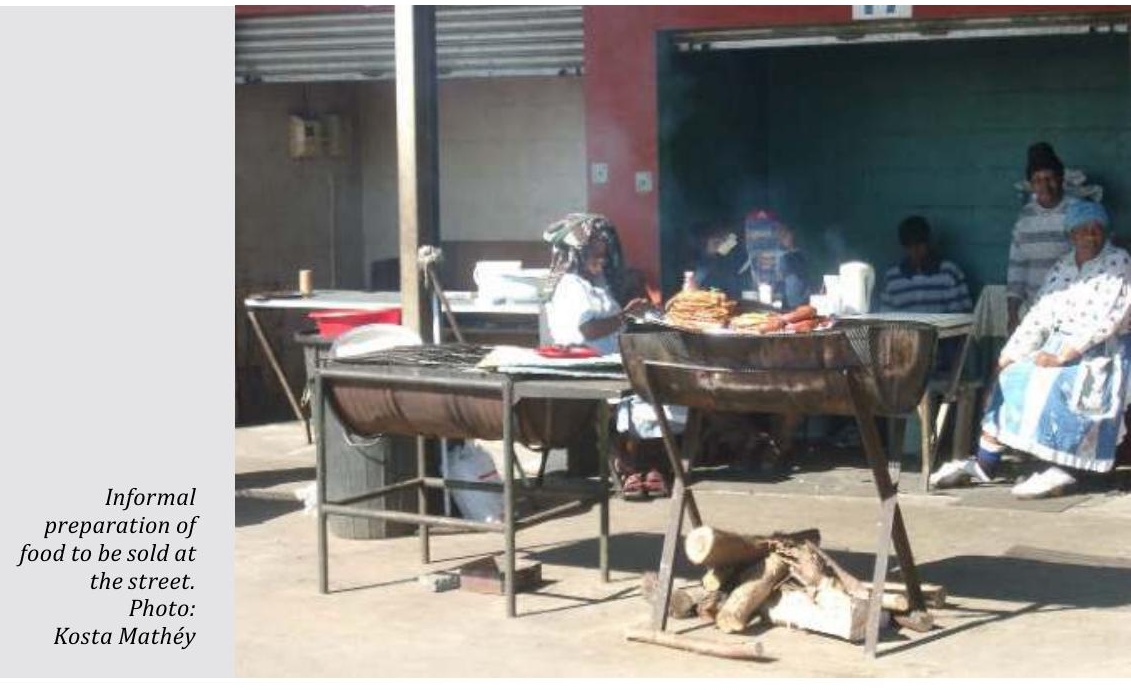


each instance, all participants must agree on the steps, the elements, and the action plans; moreover, they are contracted to play their part. Action plans cannot make promises on behalf of others, only the participants themselves can commit to actions. Thus if stakeholders are missing, the action plan must include the way in which the present stakeholders will achieve the buy-in from the absent ones. All this is framed in terms of individual and collective value, placed on the ability to achieve the consensus driven vision and the elements thereof.

Throughout the process, everyone has a function and all functions have equal value. The "Social Transformation System" delivers practical, pragmatic action plans because it begins with the opportunity to imagine a highly valued outcome and moves quickly into the space of realistic expectation. Furthermore, the system is constrained by what can be contributed by the participants themselves and is thus not elevated by unrealistic expectations of others.

\section{Social transformation system applied in Johannesburg}

In another setting, the methodology demonstrates the power of civil society leadership in local responses to unsafety. Johannesburg attracts migrants from all over South Africa and the rest of Africa. Infrastructure in the inner city, although less than 130 years old, is over-burdened. Developed and evolved as a thriving business hub, the city centre is now home to an estimated 500,000+ people, many undocumented (City of Johannesburg 2011: 18). The population is multi-cultural and multilingual and there is little cohesion amongst immigrants from different countries (Simone 2001; Murray 2008). Locals are often hostile towards immigrants and children experience xenophobia in schools (Osman 2009), with language representing a barrier to education and inclusion. Many formal businesses have moved out of the inner city; much of the business and trade conducted is informal and hard to regulate. Every day over 20,000 minibus taxis bring in at least another 500,000 people from surrounding townships and suburbs. Sanitation and waste management are under significant pressure and the city is congested and hard to navigate. The delivery of safety, social, education, developmental, and health services in the inner city is a severe challenge (City of Johannesburg 2007).

Johannesburg Child Welfare is a South African Non-Profit Organization (NPO) which attempts to respond to the needs of close to 70,000 vulnerable children in and around Johannesburg annually (Johannesburg Child Welfare Annual Report 2012/2013: 8). The organization's social workers facilitate adoptions, foster care, and counseling, relief from violence and poverty, and skills development. Thembalethu, a centre established in 1996 by Johannesburg Child Welfare to deliver skills development programmes to unemployed young women, is situated in the heart of the most degraded and unsafe area of the inner city, Joubert Park. The Old Drill Hall, the dilapidated Heritage Site that houses Thembalethu, is occupied by a loosely connected group of Non-Profit Organizations, delivering developmental child services. The site is situated directly across the road 
and two blocks down from two of the city's biggest and busiest taxi stations and so experiences a high volume of traffic.

The Old Drill Hall site is not an environment conducive to the protection and support of children. The site is dirty, cluttered with litter, smells as a result of the lack of proper waste management, unclean toilets, and the often-unhygienic food preparation by informal traders on the streets outside. The garden has been appropriated by an informal business selling temporary parking, and is often inhabited by intoxicated people or vehicles that hinder access. The buildings themselves suffer as a result of poor management and maintenance and fixtures are broken and walls and floors visibly filthy.

In 2012, Johannesburg Child Welfare commissioned a consultative planning process to build strategies which would address the complexity of the systemic challenges in and around the Old Drill Hall and Thembalethu. Using the 'Social Transformation System' methodology, the collective vision for the inner city was articulated as "what it looks like when it's fixed" (Holtmann 2011) for a "Best Life for Every Child in the Inner City" programme. The programme was systemic and comprised a diverse range of outcomes, including infrastructure, service delivery, a culture of caring for the environment, support networks, safe and reliable transport, regulation and management of informal traders, waste management, safe and clean toilets, and much more.

The immediate recommendation that followed the initial consultative exercise for the programme was the establishment of three themed action forums, grouped according to shared interests and mandates of the diverse network of stakeholders. In a city with very low levels of trust, particularly between civil society and local government, stakeholders revealed a sense of isolation, each struggling alone with similar challenges. Relationships were characterized by blame, defensiveness and resentment. A stakeholder mapping process prompted opportunities for mutual support where partners shared objectives to promote trust. A coordinator was appointed by Jo'burg Child Welfare to facilitate introspective engagements with each stakeholder and explore relationships in order to answer "what do I bring that will take us closer to our vision?" During the 12 months that followed over 60 governments and non-government stakeholders were mapped against the vision and as the database grew, opportunities for short, medium, and long-term interventions presented themselves. From these, interventions were chosen for immediate implementation, such as:

1. The formation of an 'Activities Club' at the Old Drill Hall, for access to sporting and other extracurricular activities, oriented towards inner city youth and their parents. Key partners on this team include NPOs and local government departments;

2. Taxi Drivers as Agents for Social Change forming and exploring mutually respectful relationships between taxi drivers and other road users, with key partners including Taxi Associations and Local and Provincial Government departments; 
3. A Communications Opportunities task team working on messaging and branding for the programme and ensuring that each stakeholder was able to maximise the communications opportunity that the programme represents. This team must respond to the challenges of communicating with a constantly changing, transient local community;

4. An effective referral network for health and wellbeing social service providers in the precinct in order to promote effective access to the full network of social support services on offer in the inner city. Key partners include NPOs and the Local Government;

5. A gardening initiative at the Old Drill Hall providing gardening activities for children as learning and play, as well as generating food and beautifying the space. Key partners include NPOs, occupants of the site, and the local government's parks agency;

6. A management and maintenance committee comprising all the occupants of the site, which allocates roles and responsibilities in respect to maintenance, safety, a code of conduct, and development initiatives at the site;

7. A residential recycling initiative, establishing recycling initiatives in each of the residential buildings in the precinct with property owners, local government waste management, and residents;

8. Precinct Plan: this team is designing a spatial planning vision for the precinct, connecting the Old Drill Hall with St Mary's Cathedral, 5 blocks away and blighted by very similar challenges. Key partners include university architectural and planning practitioners and various local government departments;

9. As the timelines on these projects are long, an 'Island of Optimism' was planned for World Aids Day (December 1, 2013) to celebrate the value of and potential in partnerships. Partners in the programme took part in a neighbourhood event. The day began with a service at the cathedral, followed by a walk through the streets to the Old Drill Hall where there were exhibitions, music, drama and dance performances, and displays of services and projects. This event mobilised over 30 of the government and non-government partners in the programme;

10. Late in 2013 the local government cracked down on traders, removing them from the streets in a way that violated previous agreements (Boundless City 2013; City of Johannesburg undated; Holdsworth 2011). The traders took them to court and were reinstated. This was a setback to the "Best Life" project. In a workshop some of the children who use Thembalethu regularly expressed their fears and resentment of the traders, who contribute to the congestion, disorganization, and unhygienic conditions of the neighbourhood. This conflict of interests is exacerbated by the conflicted relationship between Local Government and the traders; a series of workshops is planned to facilitate mutually respectful navigation of the conflicting needs to find mutually beneficial solutions. 


\section{Lessons learned}

- Integrated implementation requires a significant investment of time and energy from all stakeholders. Sustained and committed leadership are also instrumental. However much time is spent on establishing these relationships, while more will always be required. In an environment where many people are operating outside of the formal grid, are undocumented, and have no formal relationship with the city, trust is possibly the greatest asset in establishing sustainable and impactful collaborations, but it is also the scarcest commodity.

- The transience of too many stakeholders negatively impacts the stability and sustainability of partnerships; there is a need for constant recruitment and induction of new people in the environment.

- The value added by each stakeholder should not be measured in isolation, but rather in terms of the contribution made by connecting one stakeholder to others. No one stakeholder is more important than any other.

- Local government urban management structures bring value in networking the various role players in an urban transformation programme of this nature, since it is their mandate to work with all stakeholders.

- Without a dedicated facilitator, who focuses not only on existing needs but also on recruitment of new partners and on strategic engagements between partners, integrated interventions cannot be sustained. The role of facilitator requires a significant time investment to embrace the complexity of the social setting and the stakeholder network.

- Following this comprehensive approach it is possible to generate integrated and sustainable strategic plans, based on consultative, systemic thinking.

- Integrated planning and interventions benefit all partners, who support one another and who leverage one another's work to create deeper impact.

- Setbacks are part of the package; partners must expect them and try to deal with them in a mutually supportive way rather than apportioning blame.

\section{Community leadership}

Johannesburg Child Welfare demonstrates leadership in children's services as it has embraced the complexity of the challenges confronting vulnerable children in the migrant inner city (United Nations Children's Fund 2012). To build spaces which are conducive to the delivery of services to vulnerable women and children requires the support of a diverse range of partners. It requires programmes that are systemic and responsive to 
the particular challenges posed by an unpredictable migrant environment. While Jo'burg Child Welfare does not have expertise to respond, for instance, to issues of waste management, transport services, informal trade, and spatial design, it cannot ignore these issues as they impact its ability to deliver within its mandate.

Johannesburg Child Welfare values the establishment and maintenance of sustainable and trustworthy partnerships and has demonstrated resilience and commitment to a long-term vision in which there is an opportunity for each child to live his or her best life. To deliver meaningful services to children in complex environments it is necessary to offer opportunities for service delivery to partners whose mandates and expertise impact the lives of vulnerable children in profound and particular ways.

This project demonstrates the value of community leadership in community matters.

\section{References}

Beavon, K. (2004) Johannesburg: the making and shaping of the city. Pretoria: University of South African Press.

Boundless City (2013) Why the current crackdown on informal trade in Johannesburg makes me so angry Retrieved March 18th 2014. http:// www.boundlesscity.com/informalbl.html

City of Johannesburg. (2007) Charter: safety and security Retrieved March 18th 2014. http:// www.joburg.org.za/index.php?option=com_co ntent\&view=article\&id=2099: charter-safetyand-security\&catid=165\&Itemid=124

City of Johannesburg. (2011) Growth and development strategy 2040 Retrieved March 18th 2014. http://www.joburg.org.za/index. php?option=com_content\&id=7343:joburg-gds2040 -strategy\&Itemid=114

City of Johannesburg (undated) The rise and rise of hawking in the city Retrieved March 18th 2014. http://www.joburg.org.za/index. php?option=com_content $\&$ task=view\&id $=134 \&$.

Holdsworth, C. (2011) Johannesburg: the city that once was Retrieved March 18th 2014. http://www.thoughtleader.co.za/candicehold sworth/2013/06/21/johannesburg-thecity-that-once-was/

Holtmann, B (2010) Safe Communities of Opportunity; a Strategy for a Safe South Africa, PhD thesis, Da Vinci Institute for Technology Management.

Holtmann, B (2011) What it Looks Like When it's Fixed Johannesburg: Price Waterhouse Coopers.
Holtmann, B (2014) Report, Khayelitsha Commission

Jones, 0. (1993) Assaulting childhood: children's experiences of migrancy and hostel life in South Africa. Johannesburg: Wits University Press.

Jo'burg Child Welfare (2013) Annual Report.

Kent, L (2014) "We are used to it": explorations of childhood perceptions of danger and safety in living in the Johannesburg Inner City. Unpublished, Masters Thesis, University of Witswatersrand.

Murray, M. (2008). Taming the disorderly city: the spatial landscape of Johannesburg after apartheid. New York: Cornell University Press

Osman, R. (2009) The phenomenon of xenophobia as experienced by immigrant learners in inner city schools of Johannesburg Retrieved March 18th 2014. http://uir.unisa.ac.za/ bitstream/handle/10500/3203/dissertation_ osman_r.pdf?sequence $=1$

Simone, A. (2001) African migration and the remaking of inner city Johannesburg In A Morris \& A Bouillon (Eds) African immigration to South Africa: francophone migrants of the 1990s. Pretoria: Protea Book House

United Nations Children's Fund (2012) The state of the world's children 2012: Children in an urban world. Retrieved 18th March 2014. https://www.unicef.org.au/downloads/publications/SOWC_2012_Main_Report_LoRes_PDF_ EN_Embargoed_12212.aspx

Women's Legal Centre (undated) http://www. khayelitshacommission.org.za/terms-of-reference/women-s-legal-centre-complaint.html 


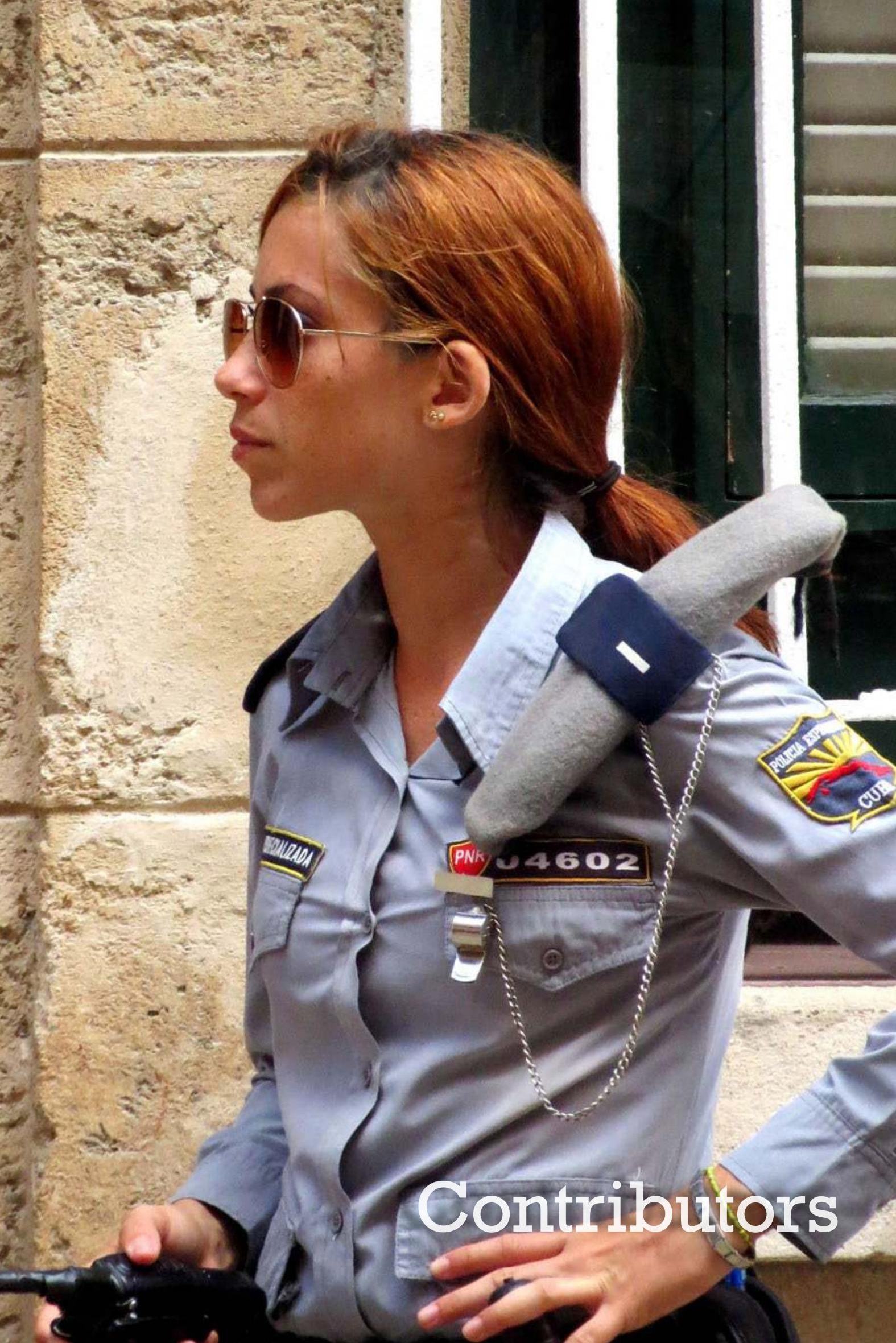




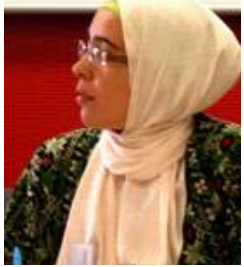

Fatima Mayada Al-Nammari is an Assistant Professor at the University of Petra, Jordan, and an Honorary Research Associate at the University College London. Dr. Al-Nammari is experienced in integrated urban planning and international development, heritage conservation, and urban studies. She has conducted research on urban disaster management and recovery. Her professional and academic experiences span several countries, with the United Nations and other global organizations. Additionally, Dr. Al-Nammari has received several honors and awards, and published and presented in many professional and academic forums.

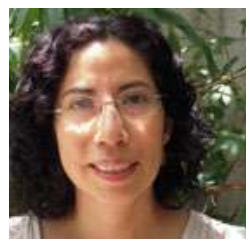

María Antonieta Beltrán is social psychologist, researcher and international consultant. Her interests focus, at one hand, on the different forms of violence experienced by people living in social exclusion and, at the other, on gender identity differences, gender stereotypes and (violent) practices allowed to man and woman in different contexts. Her research work is situated principally in popular neighborhoods in Latin America. She has studied violence and abuse against child ren and woman, violence perpetrated by woman, attitudes towards the use of firearms, social prevention practices directed at youth, and education and work opportunities for excluded young people. Her actual research centers on the relationship between gang members and their female relatives, and on the constructions of gender identity of female gang members in El Salvador. She has been associated with the Institute of Public Opinion (IUDOP) of the José Simeón Cañas (UCA) and the Latin American Faculty of Social Sciences (FLACSO) - El Salvador.

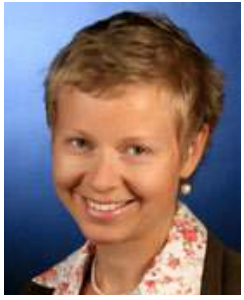

Anne-Kristin Borszik studied sociology, anthropology and German literature at Hamburg University, Catholic University Lisbon and Freie Universität Berlin and graduated in 2004 with a master thesis on political music from Guinea-Bissau. Thereafter, she worked at Friedrich-Ebert-Stiftung and at Fundação Assistência Médica Internacional (AMI), both located in Lisbon. In 2007, she joined a collaborative research project on "Local Strategies of Conflict Management in Guinea-Bissau", funded by Volkswagen Stiftung between 2006 and 2012 and located at Bayreuth University and INEP (Bissau). In 2014, she received her $\mathrm{PhD}$, based on a study of interaction in dispute settlement in eastern Guinea-Bissau

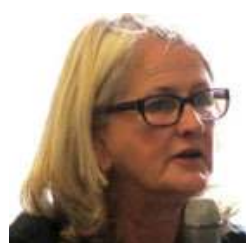

Barbara Holtmann is the developer of a systems model and methodology that enables clarity of purpose where there are many diverse stakeholder views and inputs into a particular setting. This home grown 100\% South African process highlights issues essential to sustainability and provides a platform for more effective planning and goal setting.

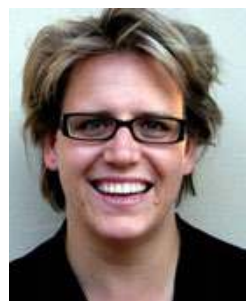

Emma Holtmann holds an MPhil in African Studies and an LLB. Emma practiced as an attorney in Johannesburg before shifting her focus to community safety and development work. She now works with the Social Transformation System (STS), facilitating capacity building, and mentoring users through strategic action planning and implementation processes. Emma has managed the development of a web-based application that supports the vision, stakeholder mapping and management of complex community problem solving and she conducts research to ensure that indicators used for benchmarking and impact assessment are current and reflect relevant empirical works. 
Nicholas Kasang is an urban and regional planner and former project coordinator of the Community Based Urban Violence Prevention Program (U-CARE) at the Global Urban Studies Institute. His work and research focus on the integration of social components into spatial violence prevention initiatives in developing metropolises of Latin America and Africa. Within this focal point, the contemporary situations of the Venezuelan capital, Caracas, and the South African State have received particular attention. Mr. Kasang has collaborated with UN-HABITAT and the GIZ, among others, in appraising and developing violence prevention programs for various international contexts. He has been published in Brazil, Germany, and South Africa.

Obvious Katsaura teaches in the Department of Sociology at University of the Witwatersrand, Johannesburg. His current research interests lie more broadly in Urban and Regional Sociology, with a focus on violence and urban safety, urban politics and governance, religion and African urbanisms, and urban ethnonational diversity. He is currently (2014 - 2016) engaged in postdoctoral research funded by the Volkswagen Foundation; focusing on the mediatory role of religion, magic and ritual in contexts o fear of violence in Johannesburg. Most of his other research has so far focused on the city of Johannesburg, South Africa.

Joanna Kotowski-Ziss is partner of SUM Consult and a social and urban development expert with more than 20 years of experience in 24 different countries in Africa, Latin America, Asia and Europe. Throughout her work Mrs. Kotowski-Ziss has specialized in slum and squatter settlement upgrading, violence prevention, community development, and youth promotion, as well as monitoring and evaluation systems. In Namibia, Eritrea, India, Mexico, Nicaragua, El Salvador, Colombia and Kosovo, she has guided interdisciplinary groups of local experts and conducted large socio-economic surveys. Currently she is part of the consultant team to the violence prevention through
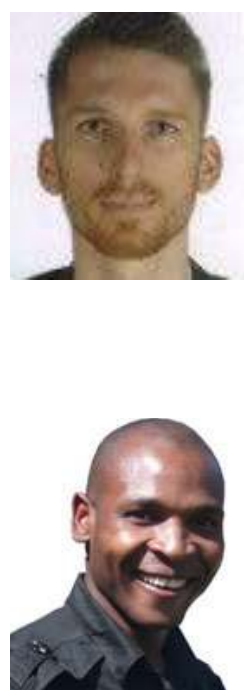
urban upgrading and youth promotion program in Honduras (CONVIVIR).

Veronica Martinez-Solares is the research director at the Governance, Security and Justice initiative in Proyectos Estratégicos Consultoría, funded by the International Development Research Centre, as well as a member of Board of Directors in the International Organization for Victim Assistance. Since 1992, she has worked on criminal justice issues in Mexico. Her extensive experience has led to her invited participation in important international human rights projects. She has been a visiting researcher at the University of Ottawa and the National Policing Improvement Agency (UK), and visiting scholar at the University of Cambridge.

Reza Masoudi Nejad is an Alexander von Humboldt Fellow at Zentrum Moderner Orient (Berlin). He is an urban planner, interested in the interaction between society and space with a focus on the broad idea of ritual. He received his PhD from the University College London (2009) then was a research fellow at the Max Planck Institute for the Study of Religious and Ethnic Diversity (MPI-MMG), Germany (2009-11). His doctoral dissertation, The Rite of Urban Passage, focused on exploring the social dynamics through the spatial transformation of religious processions in Iranian cities since the 1920s. His project at MPI-MMG, Rituals and Socio-Spatial Negotiations in Mega-Cities, was aimed at exploring rituals in public spaces as one of the mediums by which diverse ethnicities practice social division, intimacy, and integration in Mumbai, India.
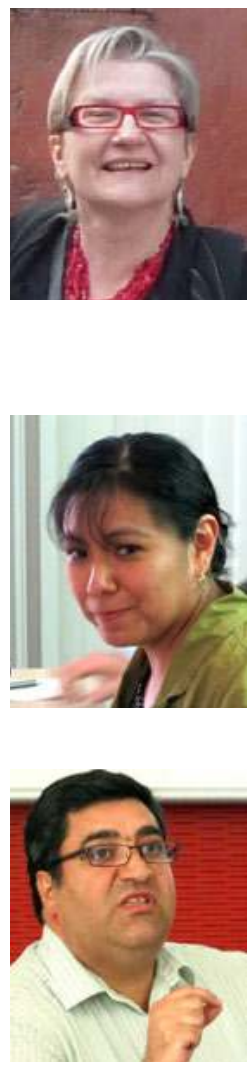


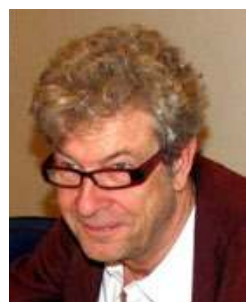

Kosta Mathéy Prof. with PhD in Applied Social Sciences and registered architect in Britain and the Commonwealth was founder of two M.Sc. programs on Urban Development Planning at the University of Technology in Darmstadt, and the Vietnamese German University in Ho Chi Minh City. He also is or has been teaching at Universities in Cuba, Brazil, Colombia, Oman, and Nigeria. He elaborated the concept for the Violence Prevention through Upgrading Program in Khayelitsha, Cape Town and directed the Community Based Urban Violence Prevention research program (U-CARE) 2008-14. Currently he is director of the Global Urban Studies Institute at the International Academy $n$ Berlin. He is author or editor of 7 books and more than 100 articles in edited books and scientific journals.

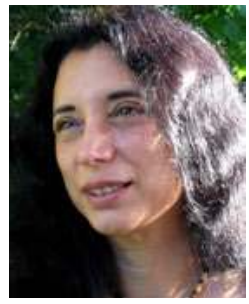

Silvia Matuk is a graduated architect (ENSAPLV- Paris), and completed a second study in sociology and political economy (Sorbonne - Paris 8). She is a researcher and analyst on processes of peace building, after the armed conflict in El Salvador, and other violent urban settings. Since more than 20 years, she has been working as coordinator and consultant to international projects focusing on low cost housing, community-based development programs, ecological and sustainable architecture, and vernacular heritage, in Latin America (in Brazil, Chile, Cuba, Ecuador, México, Peru and Venezuela) as well as in several Chinese provinces, in cooperation with Tianjin University. She is founding Member of GEOdomus International (International Organization for Geo-architecture and Human Habitat) in Barcelona, and GLOBUS (Global Urban Studies Institute) in Berlin. She is co-author of several reports and books, including also Construire pour la paix (UNESCO-NU Habitat II).

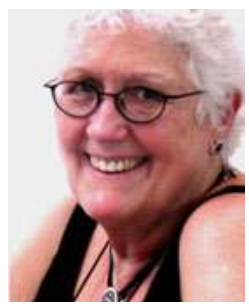

Caroline Moser is an urban social anthropologist and social policy specialist with more than forty years' experience in academic research, teaching and training. She conducted extensive research on urban violence, most recently as the principal investigator of a four city project on 'Understanding the tipping points of urban conflict'. Caroline Moser has worked as a lecturer in academic university departments at the LSE, London and New School, the Development Planning Unit of UCL; in the World Bank, where she researched the impact of structural adjustment on the urban poor; in policy-related research thinktanks, the Overseas Development Institute, London and Brookings Institution, Washington. Until 2012 she was Professor of Urban Development and Director of the Global Urban Research Centre in the University of Manchester.

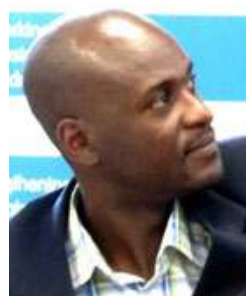

Romanus 0. Opiyo is a lecturer, in the Department of Urban and Regional Planning, University of Nairobi, Kenya. He has been engaged in coordinating undergraduate planning research project since the year 2006. He has published in the area of participatory planning, planning for Information and Communication Technology (ICTs) facilities for informal sector and sustainable planning for informal settlements. Romanus was a beneficiary of the Volkswagen foundation PhD scholarship through U-CARE program. He has been involved in both National and International researches touching in the areas of urban violence, transportation, climate change, environmental planning and issues of urban youth and sports. He has also consulted for both National and International organizations on myriad of issues such as urban and regional security and development challenges. Romanus is a volunteer board member of St. Joseph Technical institute Nyang'oma school for the deaf. 
Carlos Andrés Restrepo, sociologist graduated from the University of Antioquia in Medellin (Colombia). Acts as general coordinator of is member of the Citizen's Round table for Peace in Itagüí. In 2004 he was awarded honorary mention for his graduation thesis in education and sociology and proposed for the title of the youngest City Changer in Itaqüí in the category of social work.

Christophe Sados Touonsi is a lecturer and doctoral candidate at the Université de Yaoundé in Cameroon, Department of Geography. Since 2008 he has been a participating researcher for the Community Based Urban Violence Prevention Program (U-CARE) at the Global Urban Studies Institute (GLOBUS).

Leiman Julieth Sánchez Betancur Student of sanitation engineering at the University of Antioquia, and coordinator of the environmental section of AEQUUS group. Founding member of the environmental research group Aliados con el Planeta at the School of Environment within the Faculty of Engineering, University of Antioquia. She also organizes educational meetings with the youth and children of the neighbourhood (storytelling, spatial problem analysis), and with craftspeople for the knowledge exchange about environmentally save materials. Julieth also is author of essays uniting her political and poetical thoughts on ways to improve the social reality of her neighbourhood and to create better living conditions in the same.

Luz Amparo Sánchez Anthropologist, Antioquia University, Masters Candidate in Contemporary Philosophy, Institute of Philosophy Antioquia University. Researcher Corporación Región, City and territory rights Field Coordinator, for the same institution. Coauthor of various texts and articles published in academic magazines around fear, memory and forced displacement. Coreporter of the investigation: The invisible traces of the war. Forced displacement in District 13 for the National Center of Historic Memory report. National Commission of Reparation and Reconciliation.

Wim Savenije is researcher and lecturer with the department of Social and Political Anthropology at the Facultad Latinoamericana de Ciencias Sociales (FLACSO) in Argentina. His areas of interest are violent youth groups and the transnational street gangs or 'maras' in Central America, the relationship between the security forces and communities with high levels of insecurity, the dynamic relation between marginalization, social exclusion and the incidence of violence, and the possibility of employing social prevention strategies to diminish violence and delinquency at neighbourhood level. The topics of his $\mathrm{PhD}$ are the dynamics of social and auto exclusion fomented by the Mara Salvatrucha (MS-13) and the Eighteen Street Gang (Barrio 18), and student gangs in Central America. He has extensive field experience in the various countries of the region. His current research focuses on 1. the continuing development of the 'maras' and the relationship with the often makeshift security policies in the Central American region; 2 . the efforts of security forces (police and military) to alleviate the insecurity caused by the street gangs in urban neighbourhoods; 3 . how growing up and living in neighbourhoods with high level of insecurity affects the lives of ordinary (no-gang) youths; and 4. how initiatives focusing on the social prevention of violence can influence the lives of youth at risk.
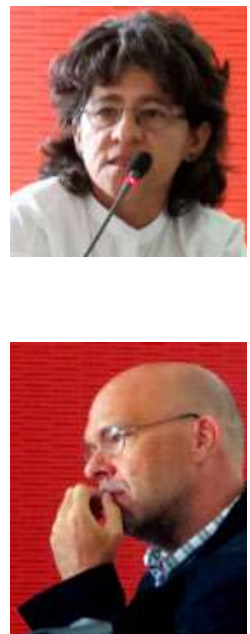


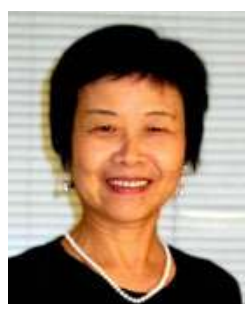

Qin Shao is Professor of History at The College of New Jersey and former fellow at the Radcliffe Institute for Advanced Studies, Harvard University and at the International Research Center on Work and Lifecycle in Global History, Humboldt University. She is the author of Shanghai Gone: Domicide and Defiance in a Chinese Megacity (Rowman \& Littlefield, 2013), Culturing Modernity: the Nantong Model, 1890-1930 (Stanford University Press, 2004), and articles in major international scholarly journals. Shao's research has been awarded other fellowships, including the Woodrow Wilson International Center for Scholars, Washington D.C and the National Endowment for the Humanities. She has presented her research at the University of Oxford and the Harvard Law School, among other institutes. Shao's recent work has focused on the human dimension of rapid urbanization in post- Mao China, especially on such issues as mental health, dignity, property rights, and grass-roots resistance. She is working on a new project about the impact of politically imposed and enforced physical displacement under Mao.

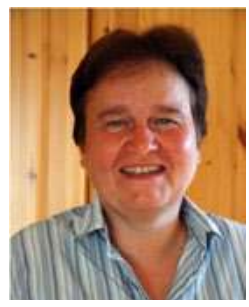

Heidrun Zinecker Habilitation (2004) and PhD (1987) at University of Leipzig, political scientist, since 2008 Professor for International Relations at University of Leipzig, Germany. Research on violence, transition to democracy, peace making and peace building, learning and regionalism. Fieldwork in Honduras, El Salvador, Guatemala, Nicaragua, Costa Rica, Colombia and México. Visiting fellow at Universidad de la Habana, Universidad Nacional Bogotá, St. Antony's College of the University of Oxford, Universidad Complutense Madrid, Universidad Academia de Humanismo Cristiano in Santiago de Chile, University of Texas, University of California in Santa Barbara and Uniwersytet Jagiellonski in Krakow. Among other relevant publications, author of Gewalt im Frieden. Formen und Ursachen der Gewaltkriminalität in Zentralamerika (forthcoming). 

